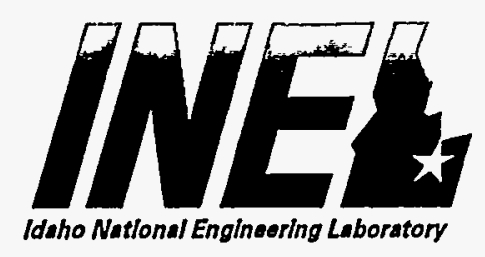

INEL-96/0182

July 1996

Idaho Natlonal Engineering Laboratory

\title{
Conceptual Design Report for the ICPP Spent Nuclear Fuel Dry Storage Project
}

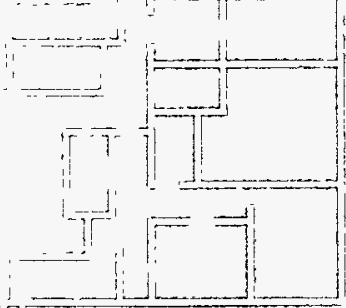

RECENED

AUG 229996

OSTI

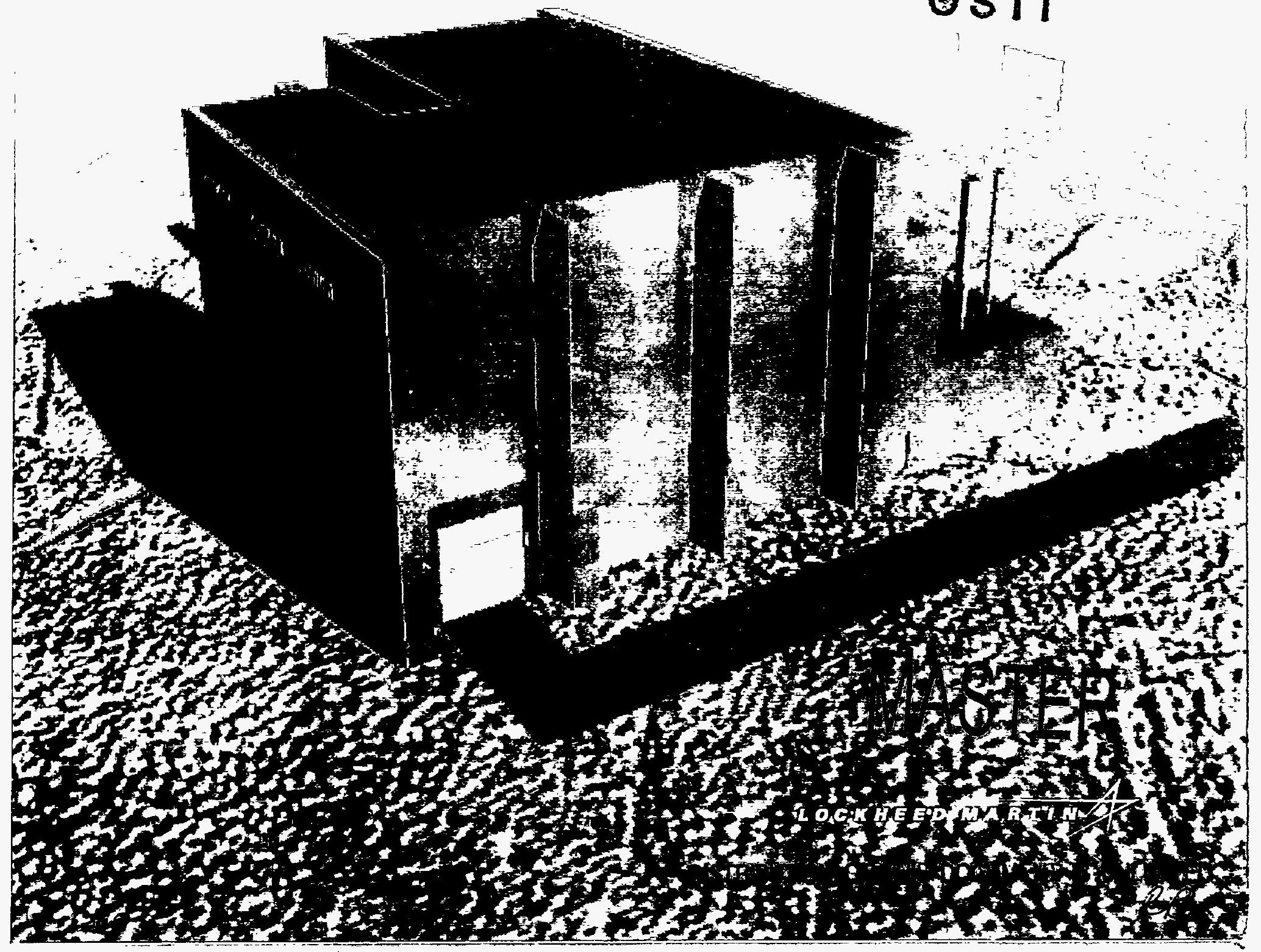




\section{Conceptual Design Report for the ICPP Spent Nuclear Fuel Dry Storage Project}

Published July 1996

Idaho National Engineering Laboratory

INEL Spent Nuclear Fuel Program

Lockheed Martin Idaho Technologies Company

Idaho Falls, Idaho 83415 


\section{DISCLAIMER}

Portions of this document may be illegible in electronic image products. Images are produced from the best available original document. 


\section{DISCLAIMER}

This report was prepared as an account of work sponsored by an agency of the United States Government. Neither the United States Government nor any agency thereof, nor any of their employees, makes any warranty, express or implied, of assumes any legal liability or responsibility for the accuracy, completeness, or usefulness of any information, apparatus, product, or process disclosed, or represents that its use would not infringe privately owned rights. Reference herein to any specific commercial product, process, or service by trade name, trademark, manufacturer, or otherwise does not necessarily constitute or imply its endorsement, recommendation, or favoring by the United States Government or any agency thereof. The views and opinions of authors expressed herein do not necessarily state or refiect those of the United States Government or any agency thereof. 


\begin{abstract}
The conceptual design is presented for a facility to transfer spent nuclear fuel from shipping casks to dry storage containers, and to safely store those containers at the Idaho Chemical Processing Plant at the Idaho National Engineering Laboratory. The spent fuels to be handled at the new facility are identified and the overall design and operating criteria are established. The physical configuration of the facility and the systems used to handle the SNF are described. A detailed cost estimate for the design and construction of the facility is presented.
\end{abstract}




\section{EXECUTIVE SUMMARY}

This report presents the technical approach, schedule, and estimated cost for designing and constructing a facility at the Idaho Chemical Processing Plant (ICPP) that will transfer spent nuclear fuel (SNF) from shipping casks into dry storage containers and provide interim dry storage of the SNF.

The Department of Energy entered into an agreement with the State of Idaho to place SNF into dry storage at the Idaho National Engineering Laboratory (INEL). The facility, as described in this report, is an essential means of implementing that agreement by providing the capability to recieve, transfer, and store selected SNF. The concepts presented in this report will support the initial movement of SNF into dry storage by the commitment date of July 1,2003 . The design life of the facility is several decades, which also supports the agreements related to completion of SNF transfer activities.

Significant design requirements and assumptions are as follows:

- The facility is to be designed in accordance with 10 CFR 72 and the implementing standard ANSI/ANS 57.9

- The facility is to be designed to handle a wide variety of fuel configurations received in an undefined sequence

- The facility is to be used only for handling intact or canned fuel, i.e., all fuel received at the facility will be contained within an intact confinement boundary.

Several alternatives were considered and screened in order to settle on the selected concept. Design options included (1) upgrading and using the Test Area North (TAN) Hot Shop; (2) designing, constructing, and using a new, stand-alone shielded facility; (3) designing, constructing, and using a new, stand-alone, bermed, remote facility; (4) using the FAST pools for wet loading; and (5) using some existing cask handling capability at the FAST facility and performing packaging operations in a new facility added to FAST. On the basis of life cycle cost, compatibility with planned operations at the ICPP, and a conservative approach to initial project planning, a new, stand-alone, shielded facility was selected as the concept to be developed during this design stage.

The concept for the SNF Dry Storage Facility (DSF) includes two structures: a Dry Transfer Cell (DTC) for receiving, transferring, and packaging the SNF; and a Dry Storage System (DSS) for storing the SNF. The DSS includes SNF storage packages, transfer equipment, aboveground storage pad, and shielded storage modules. These are described below.

The DTC contains an Administrative Area, Utility Support Area, Cask Handling Bay, Cask Preparation Area, and Hot Cell.

The Administrative Area contains typical office and support functions.

The Cask Handling Bay includes the equipment and space in which shipping casks are received, unloaded from their transport vehicle, and placed vertically on an electrically driven trolley for transfer 
into the rest of the facility. All subsequent cask operations are performed while the cask remains on the trolley. The Cask Handling Bay is also used for loading filled transfer casks onto the onsite transfer trailer.

A shipping cask is moved into the Cask Preparation Area on the trolley, the outer lids are removed, gas samples are taken from the cask cavity, and preparation is made to move the cask into the Hot Cell for fuel unloading and transfer. The Cask Preparation Area is used to prepare the shipping cask for return to the shipping facility. These operations include inspection and cleaning, replacement of cask lids, and leak testing before shipping. The Cask Preparation Area is also used for welding the lids on the SNF storage canisters after they are loaded in the Hot Cell.

The final part of the DTC is the Hot Cell, a heavily shielded cell into which the shipping cask, still on the trolley, is moved for unloading and transfer. Personnel entry into the Hot Cell is made for final cask preparation, placement of contamination barriers, and equipment maintenance. The fuel is transferred from the shipping cask using a remotely operated crane with a suite of end effectors that can manipulate a wide variety of SNF configurations. The fuel is transferred to one of four lag storage vaults for temporary storage until an appropriate inventory of SNF is accumulated to fill a Dual-Purpose Canister (DPC).

When sufficient fuel is accumulated, a DPC is brought through the Cask Preparation Area (on a trolley and in a vertically oriented transfer cask) and into the Hot Cell. Fuel is transferred from the lag storage vaults into the DPC, while the DPC remains in the transfer cask. When the DPC is full, its shield plug is inserted. The DPC is then moved back through the Cask Preparation Area where the DPC internal cavity is purged and backfilled with inert gas. Two lids are welded in place using an automatic welding machine. The transfer cask with sealed DPC is then moved into the Cask Handling Area.

In the Cask Handling Area, the transfer cask is loaded onto the on-Site transfer trailer, rotated into a horizontal orientation, and towed to the storage area.

In addition to the transfer equipment, the DSS includes a concrete basemat, asphalt driveways, and shielded storage modules. Based on an assessment of a previous study of a preferred storage configuration, the NUHOMS® horizontal dry storage system will be utilized. In this concept, the dry storage canister in the transfer cask is moved into alignment with a storage module that contains a cavity into which the DPC is pushed using a hydraulic ram mounted on the transfer vehicle. A shield door is lowered over the cavity opening and the DPC is in interim storage.

A study was performed to determine the best location for siting the DTC and DSS based on design requirements, land use/zoning/site development, environmental impact, available space, and utilities. The proposed site is southeast of CPP-666 (FAST) and is within the current ICPP plant perimeter fencing.

The Total Estimated Cost (TEC) is approximately $\$ 41 \mathrm{M}$ for the DTC and $\$ 59 \mathrm{M}$ for the DSS. The $\$ 59 \mathrm{M}$ for the DSS includes the cost of DPCs and storgae modules for about half of the SNF that is described in this report. Additional SNF could be accommodated with the procurement of additional 
DPCs and storage modules and the expansion of the storage area. The capability for such expansion is included in the design.

The schedule for this project assumes that it will be a FY 1998 Line Item. Title Design will take approximately 20 months beginning in January 1998, and construction will be performed from January 2000 to January 2002 . Facility operation will start at the end of FY-2002. 


\section{CONTENTS}

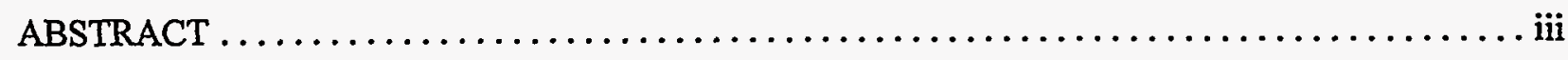

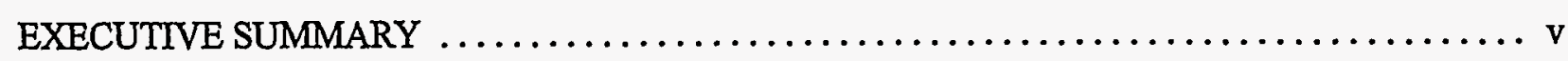

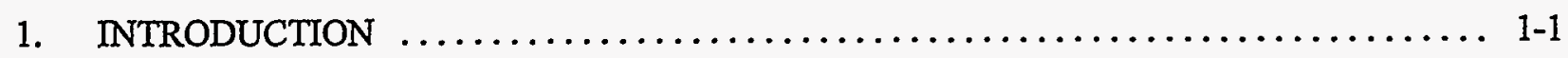

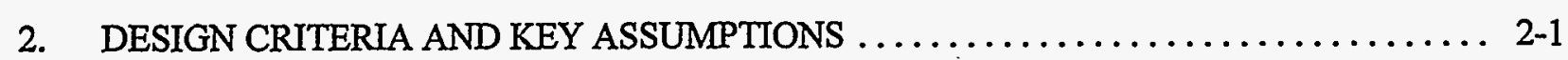

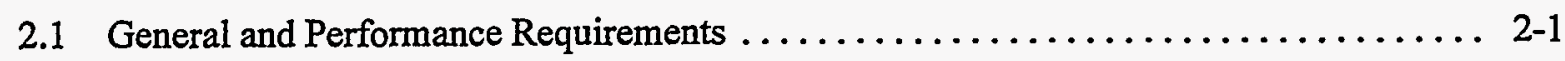

2.2 Safety Requirements $\ldots \ldots \ldots \ldots \ldots \ldots \ldots \ldots \ldots \ldots \ldots \ldots \ldots \ldots \ldots \ldots \ldots \ldots \ldots \ldots \ldots \ldots, 2$

2.3 Environmental Requirements $\ldots \ldots \ldots \ldots \ldots \ldots \ldots \ldots \ldots \ldots \ldots \ldots \ldots \ldots, 2-2$

2.4 Regulatory Requirements $\ldots \ldots \ldots \ldots \ldots \ldots \ldots \ldots \ldots \ldots \ldots \ldots \ldots \ldots \ldots \ldots \ldots \ldots \ldots \ldots \ldots \ldots, 2-3$

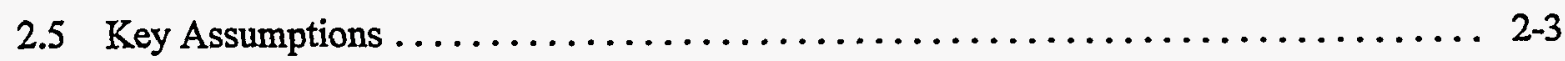

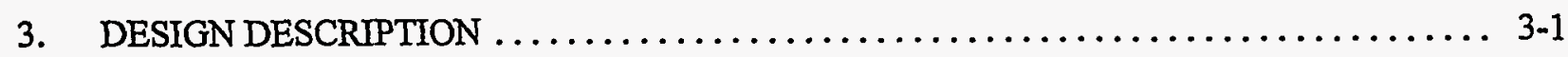

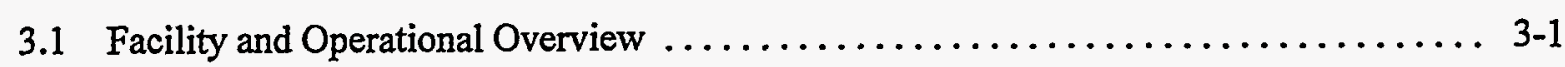

3.1.1 Dry Transfer Cell $\ldots \ldots \ldots \ldots \ldots \ldots \ldots \ldots \ldots \ldots \ldots \ldots \ldots \ldots \ldots \ldots \ldots \ldots \ldots \ldots \ldots \ldots, 1$

3.1.2 DPC Transport ......................................... 3-7

3.1.3 Dry Storage System $\ldots \ldots \ldots \ldots \ldots \ldots \ldots \ldots \ldots \ldots \ldots \ldots \ldots \ldots \ldots \ldots \ldots \ldots \ldots \ldots, 3-7$

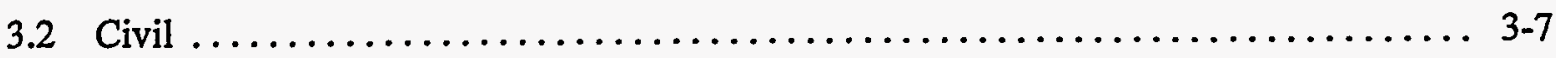

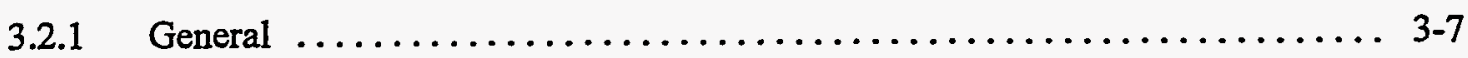

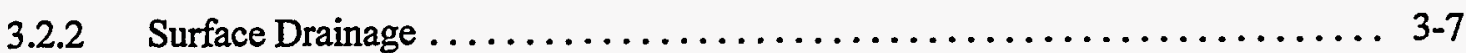

3.2.3 Rock Excavation ..................................... 3-8

3.2.4 Soil Excavation and Shoring $\ldots \ldots \ldots \ldots \ldots \ldots \ldots \ldots \ldots \ldots \ldots \ldots \ldots \ldots \ldots \ldots, 3-8$

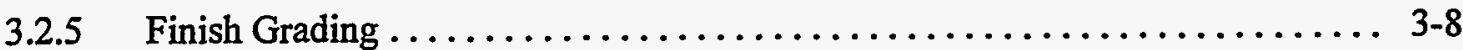

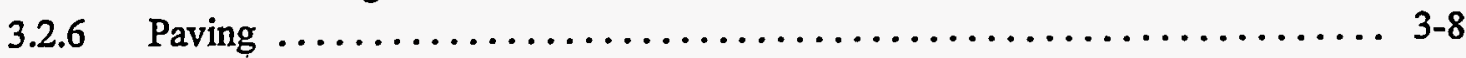

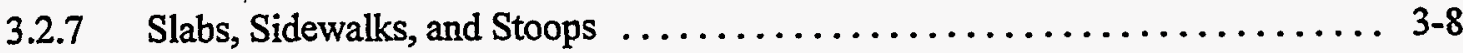

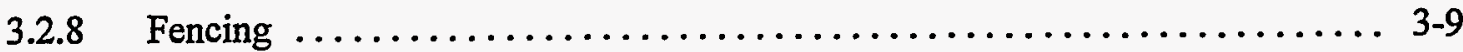

3.2.9 Underground Utilities $\ldots \ldots \ldots \ldots \ldots \ldots \ldots \ldots \ldots \ldots \ldots \ldots \ldots \ldots \ldots \ldots, 3-9$

3.2.10 Site Demolition ..................................... 3

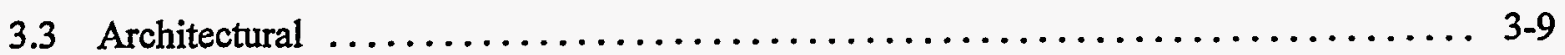

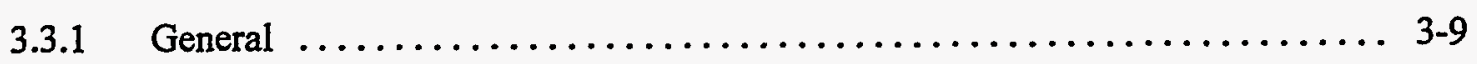

3.3.2 Building Features $\ldots \ldots \ldots \ldots \ldots \ldots \ldots \ldots \ldots \ldots \ldots \ldots \ldots \ldots \ldots \ldots \ldots \ldots \ldots, 13$ 


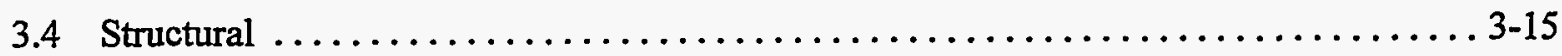

3.4.1 General ............................................. 3-15

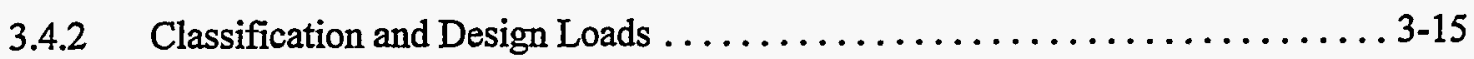

3.4.3 Footings and Foundations $\ldots \ldots \ldots \ldots \ldots \ldots \ldots \ldots \ldots \ldots \ldots \ldots \ldots \ldots \ldots \ldots \ldots \ldots \ldots, 17$

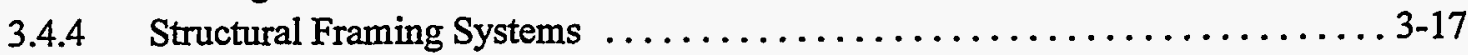

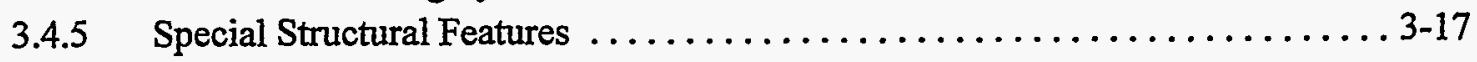

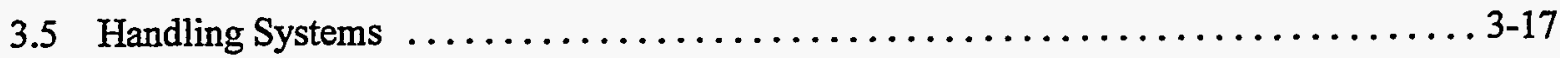

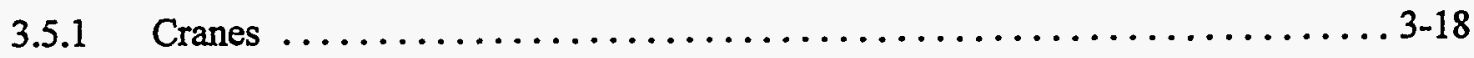

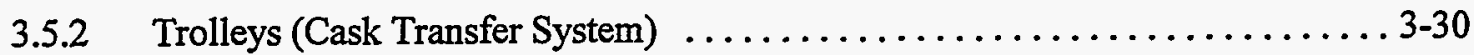

3.5.3 Lifting Fixtures $\ldots \ldots \ldots \ldots \ldots \ldots \ldots \ldots \ldots \ldots \ldots \ldots \ldots \ldots \ldots \ldots \ldots \ldots \ldots \ldots, 31$

3.5.4 Multipurpose Transfer Cask and Transporter ..................... 3-32

3.5.5 Shipping Cask Handling $\ldots \ldots \ldots \ldots \ldots \ldots \ldots \ldots \ldots \ldots \ldots \ldots \ldots \ldots \ldots \ldots, 34$

3.5.6 Cask Work Platforms and Bucket Racks $\ldots \ldots \ldots \ldots \ldots \ldots \ldots \ldots \ldots .3 .34$

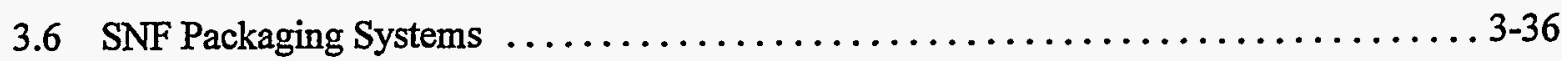

3.6.1 Canning System .................................... 3-36

3.6.2 DPC Welding, Drying, Purging, Inerting, and Sealing ............. 3-40

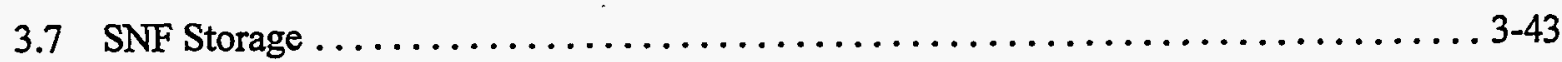

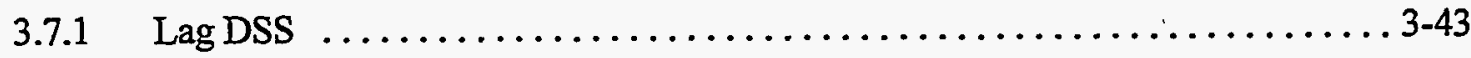

3.7.2 Dry Storage System (DSS) $\ldots \ldots \ldots \ldots \ldots \ldots \ldots \ldots \ldots \ldots \ldots \ldots \ldots \ldots \ldots \ldots, 44$

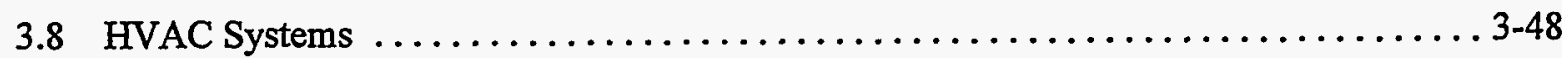

3.8.1 General Description $\ldots \ldots \ldots, \ldots \ldots \ldots \ldots \ldots \ldots \ldots \ldots \ldots \ldots \ldots, 3-48$

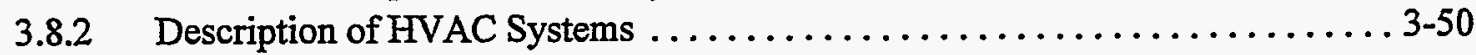

3.9 Mechanical Utilities ...................................... 3-57

3.9.1 Compressed Air ........................................ 3 57

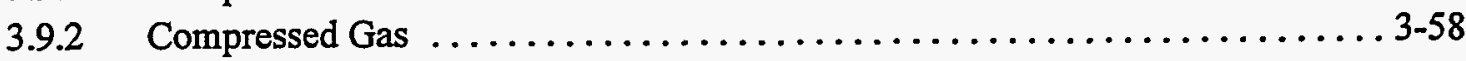

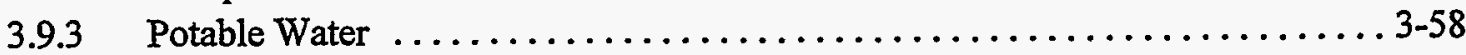

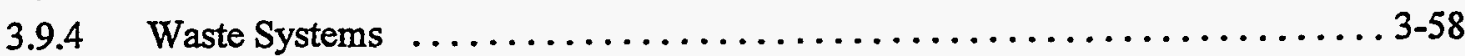

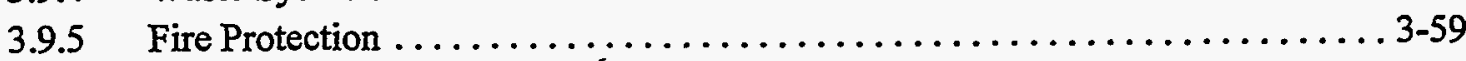

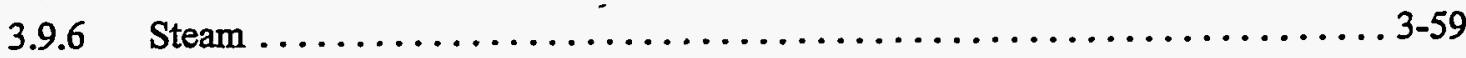

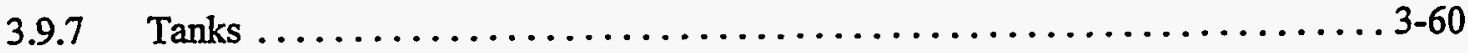

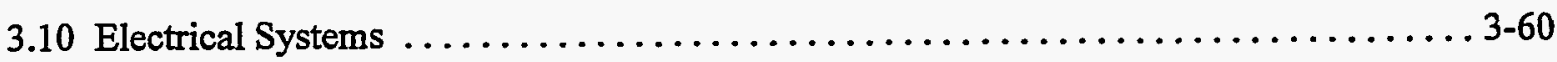




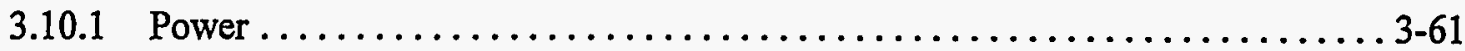

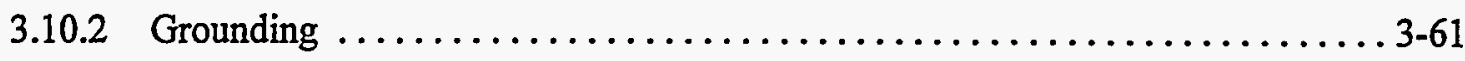

3.10.3 Cathodic Protection .................................... $3-61$

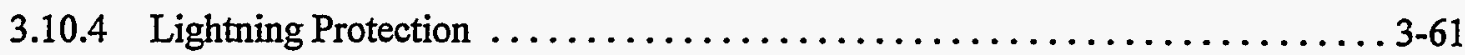

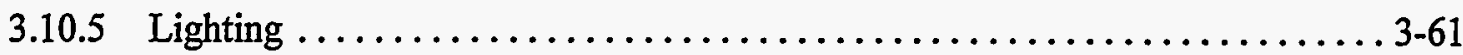

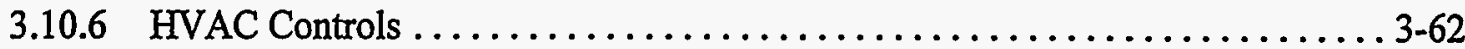

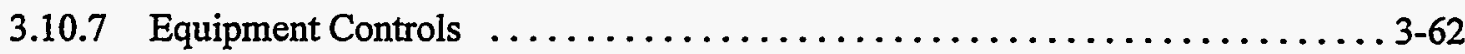

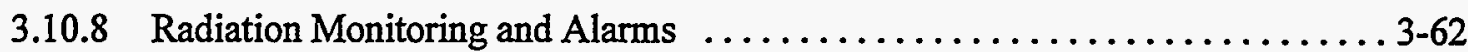

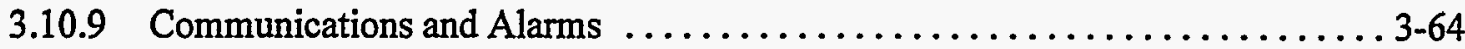

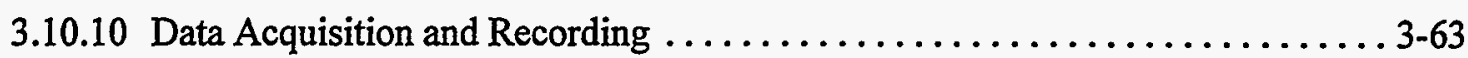

3.10 .11 Security Systems $\ldots \ldots \ldots \ldots \ldots \ldots \ldots \ldots \ldots \ldots \ldots \ldots \ldots \ldots \ldots \ldots \ldots, 6 \ldots \ldots$

4. CODES AND STANDARDS APPLICABLE TO THE SNF DRY STORAGE PROJECT $\ldots . .4$ 4-1

5. PRELIMINARY ACQUISITION STRATEGY FOR THE SNF DRY

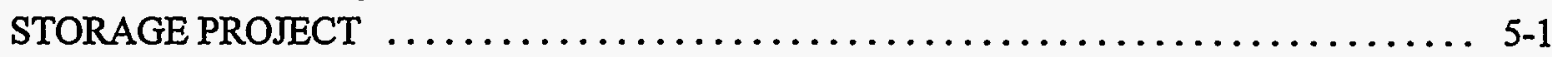

$5.1 \quad$ General $\ldots \ldots \ldots \ldots \ldots \ldots \ldots \ldots \ldots \ldots \ldots \ldots \ldots \ldots \ldots \ldots \ldots \ldots \ldots \ldots \ldots, 5,1$

5.2 Dry Transfer Cell (DTC) $\ldots \ldots \ldots \ldots \ldots \ldots \ldots \ldots \ldots \ldots \ldots \ldots \ldots \ldots \ldots \ldots \ldots \ldots \ldots \ldots \ldots \ldots \ldots, 1$

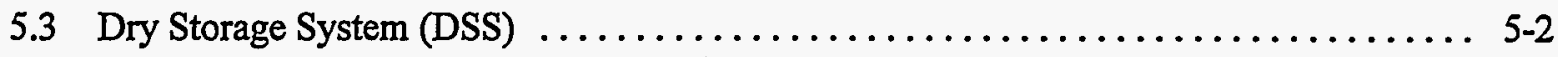

5.4 Site Preparation and Utility Tie-Ins $\ldots \ldots \ldots \ldots \ldots \ldots \ldots \ldots \ldots \ldots \ldots \ldots, 5-2$

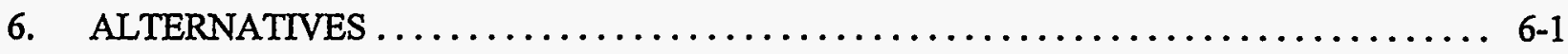

6.1 Introduction $\ldots \ldots \ldots \ldots \ldots \ldots \ldots \ldots \ldots \ldots \ldots \ldots \ldots \ldots \ldots \ldots \ldots \ldots, 6,1$

6.2 Identification and Assessment of Alternatives $\ldots \ldots \ldots \ldots \ldots \ldots \ldots \ldots \ldots, 6-2$

6.2 .1 TAN Hot Shop $\ldots \ldots \ldots \ldots \ldots \ldots \ldots \ldots \ldots \ldots \ldots \ldots \ldots \ldots \ldots \ldots \ldots \ldots, 6,2$

6.2.2 New Stand-Alone, Shielded Facility $\ldots \ldots \ldots \ldots \ldots \ldots \ldots \ldots \ldots \ldots, 6-2$

6.2.3 New Stand-Alone, Bermed, Remote Facility $\ldots \ldots \ldots \ldots \ldots \ldots \ldots \ldots .6 .6 .2$

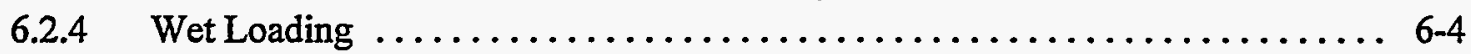

6.2 .5 Use of the FAST Facility $\ldots \ldots \ldots \ldots \ldots \ldots \ldots \ldots \ldots \ldots \ldots \ldots \ldots, 6,4$

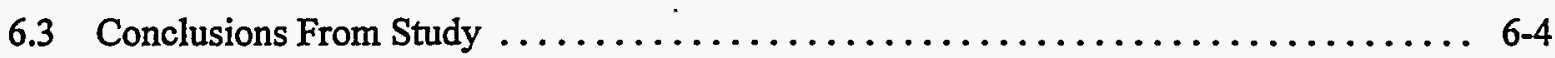

7. UNCERTAINTIES AND RECOMMENDATIONS FOR FURTHER DESIGN

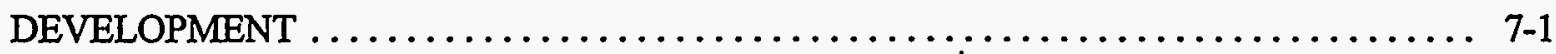

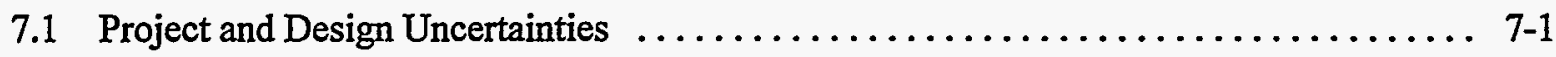

7.1.1 Facility Location and Configuration $\ldots \ldots \ldots \ldots \ldots \ldots \ldots \ldots \ldots \ldots \ldots \ldots \ldots \ldots, 7-1$ 


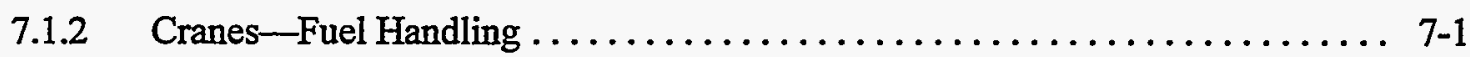

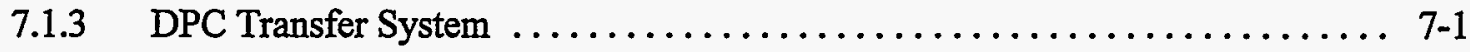

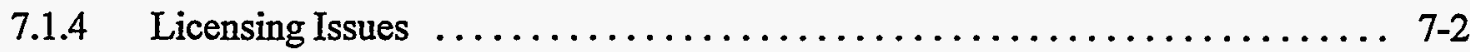

7.1.5 Security Requirements $\ldots \ldots \ldots \ldots \ldots \ldots \ldots \ldots \ldots \ldots \ldots \ldots \ldots \ldots \ldots \ldots \ldots, 2$

7.1.6 Cranes-Cask Handling $\ldots \ldots \ldots \ldots \ldots \ldots \ldots \ldots \ldots \ldots \ldots \ldots \ldots \ldots \ldots \ldots \ldots \ldots \ldots, 2$

7.1.7 Minor Canning of SNF $\ldots \ldots \ldots \ldots \ldots \ldots \ldots \ldots \ldots \ldots \ldots \ldots \ldots \ldots \ldots \ldots \ldots \ldots \ldots \ldots, 2$

7.1 .8 DPC Loading Optimization $\ldots \ldots \ldots \ldots \ldots \ldots \ldots \ldots \ldots \ldots \ldots \ldots \ldots \ldots \ldots \ldots \ldots, 2$

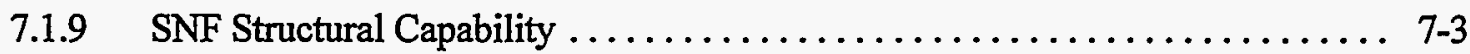

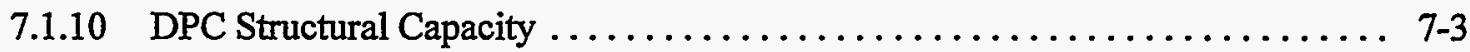

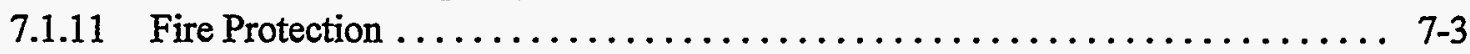

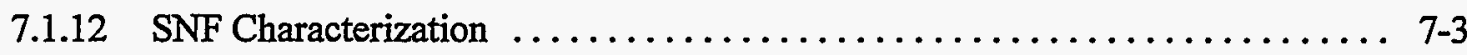

7.1.13 Ventilation System Requirements ........................ 7-4

7.2 Recommendations for Near-term Design Development $\ldots \ldots \ldots \ldots \ldots \ldots \ldots \ldots \ldots$ 7-4

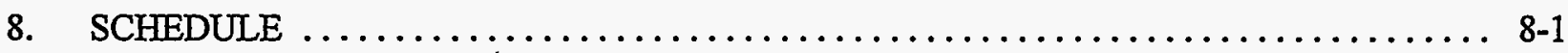

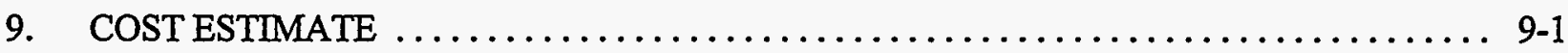

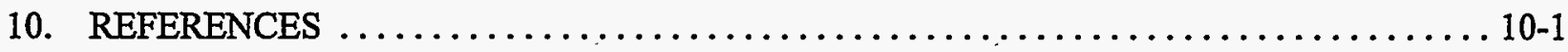

Appendix A-CPP-666 FSA Spent Nuclear Fuel (SNF) Transfers to the

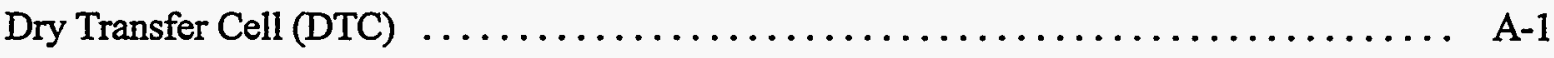

Appendix B-Conceptual Design Criteria for the ICPP Spent Nuclear Fuel Dry Storage

Project $\ldots \ldots \ldots \ldots \ldots \ldots \ldots \ldots \ldots \ldots \ldots \ldots \ldots \ldots \ldots \ldots \ldots \ldots \ldots \ldots \ldots \ldots$, B-1

Appendix C—Project Design Criteria for the Spent Nuclear Fuel Dry Storage Project ........ C-1

Appendix D-ICPP Spent Nuclear Fuel Dry Storage Project (DSP) Dry Fuel Transfer Cell

Facility Siting Study $\ldots \ldots \ldots \ldots \ldots \ldots \ldots \ldots \ldots \ldots \ldots \ldots \ldots \ldots \ldots \ldots \ldots \ldots \ldots \ldots \ldots, 1$

Appendix E-Criticality Safety Scoping Calculations for Selected Fuels in NUHOMS@

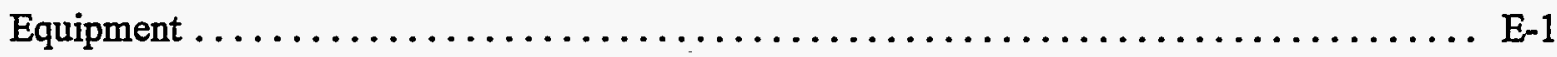

Appendix F-DPC Optimization and Loading Study $\ldots \ldots \ldots \ldots \ldots \ldots \ldots \ldots \ldots \ldots \ldots \ldots \ldots \ldots \ldots \ldots \ldots$

Appendix G-Cost Estimate $\ldots \ldots \ldots \ldots \ldots \ldots \ldots \ldots \ldots \ldots \ldots \ldots \ldots \ldots \ldots \ldots \ldots \ldots \ldots \ldots \ldots, \mathrm{G}-1$

Appendix H—Equipment List Spent Nuclear Fuel Dry Storage Project $\ldots \ldots \ldots \ldots \ldots \ldots \ldots \ldots$ H-1

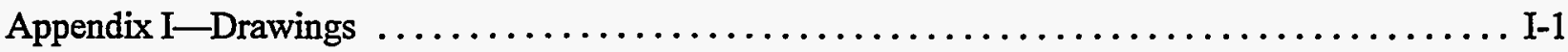




\section{FIGURES}

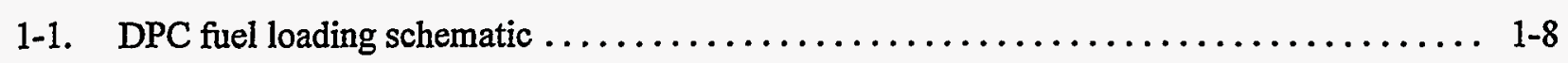

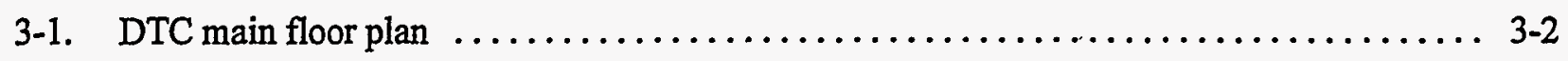

3-2. Block diagram of the flow of equipment and materials through the DSF $\ldots \ldots \ldots \ldots . . .3$

3-3. The Cask Handling Crane is a top-running, double-girder overhead bridge

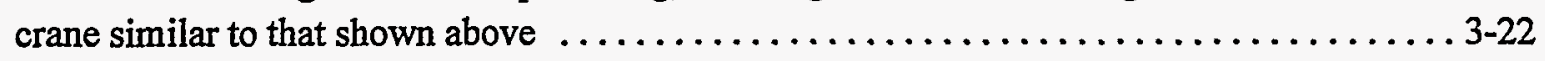

3-4. The Cask Preparation Area Crane will be a NOG-1, Type II underhung monorail

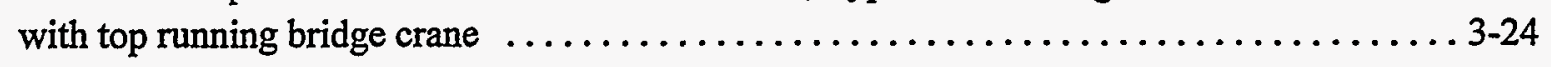

3-5. An anthropomorphic teleoperated manipulator will be located at the

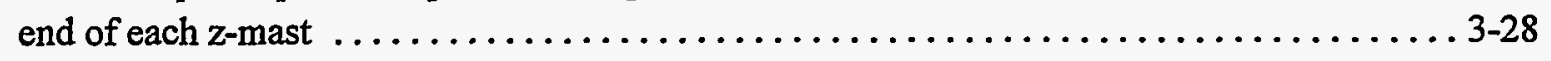

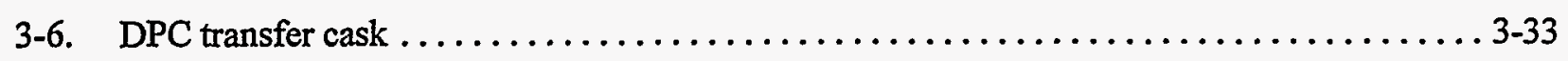

3-7. The onsite DPC transfer cask is mounted on a dedicated transport

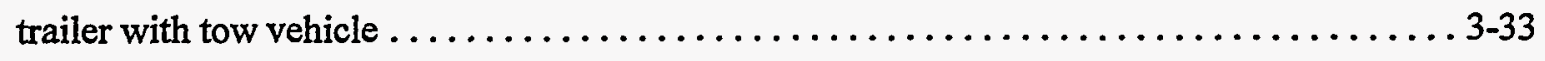

3-8. The onsite DPC transfer cask is designed to interface with the

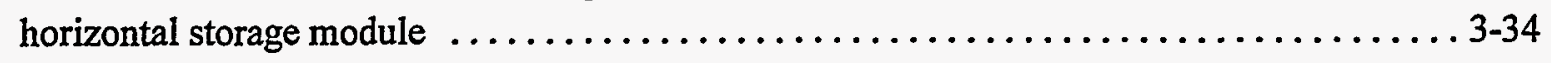

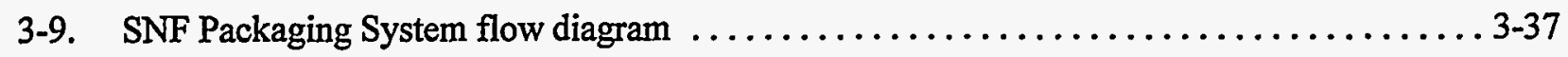

3-10. Can piercing system and operational sequence $\ldots \ldots \ldots \ldots \ldots \ldots \ldots \ldots \ldots \ldots \ldots \ldots$

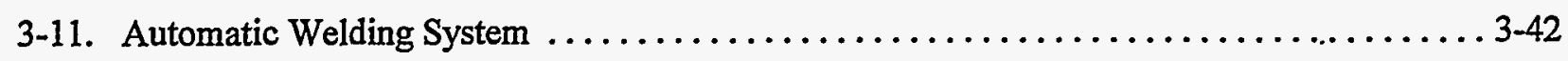

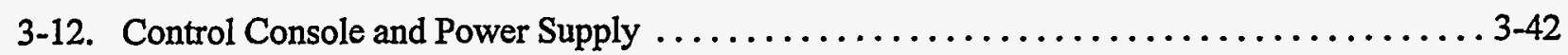

3-13. NUHOMS ${ }^{\circledast}$ horizontal storage module $\ldots \ldots \ldots \ldots \ldots \ldots \ldots \ldots \ldots \ldots \ldots \ldots \ldots \ldots \ldots \ldots$

5-1. Dry Storage Facility acquisition strategy options $\ldots \ldots \ldots \ldots \ldots \ldots \ldots \ldots \ldots \ldots$

6-1. Value Engineering Decision Analysis Matrix $\ldots \ldots \ldots \ldots \ldots \ldots \ldots \ldots \ldots \ldots \ldots$

8-1. Project schedule $\ldots \ldots \ldots \ldots \ldots \ldots \ldots \ldots \ldots \ldots \ldots \ldots \ldots \ldots \ldots \ldots \ldots \ldots \ldots \ldots .2$ 


\section{TABLES}

1-1. SNF to be handled and canned in the DTC $\ldots \ldots \ldots \ldots \ldots \ldots \ldots \ldots \ldots \ldots \ldots \ldots \ldots$

1-2. SNF Dry Storage Project fuel receiving schedule $\ldots \ldots \ldots \ldots \ldots \ldots \ldots \ldots \ldots \ldots \ldots$

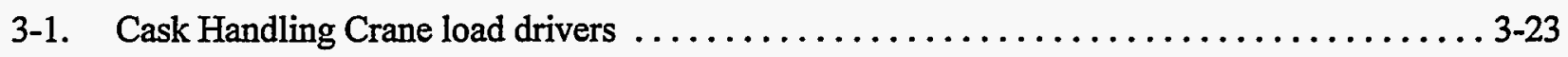

3-2. Load drivers for sizing the Cask Preparation Area crane $\ldots \ldots \ldots \ldots \ldots \ldots \ldots \ldots .24$

3-3. Load drivers for sizing the Fuel Unit Handling Crane z-mast,

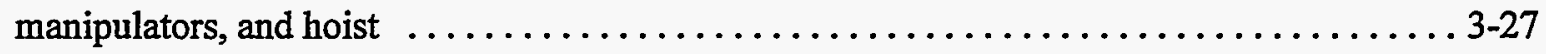

3-4 Fourteen configurations of shipping casks have been identified that may be

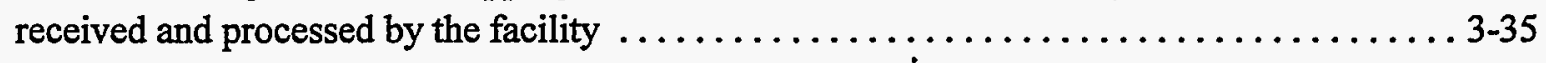

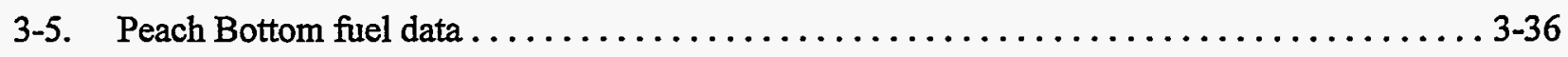

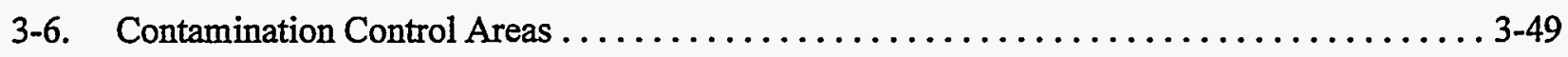

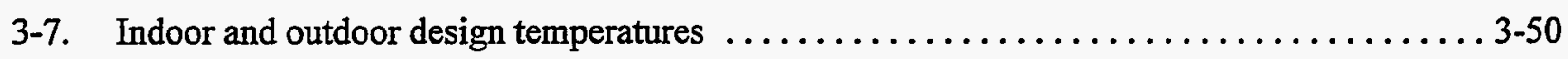

4-1. Draft codes and standards-SNF project-May $29,1996 \ldots \ldots \ldots \ldots \ldots \ldots \ldots \ldots \ldots$.2

9-1. SNF Dry Storage Project cost summary $\ldots \ldots \ldots \ldots \ldots \ldots \ldots \ldots \ldots \ldots \ldots \ldots \ldots \ldots \ldots \ldots \ldots$ 


\section{ACRONYMS}

A-E Architect-Engineer

CAM Constant Air Monitors

CCTV Closed Circuit Television

CMAA Crane Manufacturers Association of America

CMU concrete masonry units

DHB Dry Handling Bucket

DOE Department of Energy

DPC Dual-Purpose Canister

DSC Dry Shielded Canisters

DSF Dry Storage Facility

DSS Dry Storage System

DTC Dry Transfer Cell

ED\&I engineering, design, and inspection

EPA Environmental Protection Agency

FAST Fluorinel Dissolution Process and Fuel Storage

FDP Fluorinel Dissolution Process

FSR Feasibility Study Reports

FSVR Fort St. Vrain Reactor

GFE government-furnished equipment

GMAW gas-metal-arc-welding

HSM horizontal storage module

ICPP Idaho Chemical Processing Plant 
INEL Idaho National Engineering Laboratory

IPDT Integrated Product Development Team

ISFSI Independent Spent Fuel Storage Installation

LAN Local Area Network

LWBR light water breeder reactor

MCC Motor Control Center

OBE Operating Basis Earthquake

OCRWM Office of Civilian Radioactive Waste Management

OPC other project cost

PDC Project Design Criteria

PEP Project Execution Plan

PEW process equipment waste

RAM Radiation Area Monitors

RCRA Resoure Conservation and Recovery Act

SCADA Supervisory Control and Data Acquisition

SNF spent nuclear fuel

SSE Safe Shutdown Earthquake

TAN Test Area North

TEC Total Estimated Cost

TMI Three Mile Island

TPC Total Project Costs

UPS uninterruptable power supply 


\section{Conceptual Design Report for the ICPP Spent Nuclear Fuel Dry Storage Project}

\section{INTRODUCTION}

This Conceptual Design Report presents the conceptual design of a facility to transfer spent nuclear fuel (SNF) from U.S. Department of Energy (DOE) shipping casks into dual-purpose canisters (DPCs) and to place those canisters into dry storage at the Idaho Chemical Processing Plant (ICPP) at the Idaho National Engineering Laboratory (INEL). The facility is referred to as the Dry Storage Facility (DSF) and includes one building, referred to as the Dry Transfer Cell (DTC), in which the SNF is received and transferred into the DPCs and a storage area (the Dry Storage System) for storing the loaded DPCs.

The Department of Energy and the State of Idaho entered into an agreement (see Reference 1 for applicable details) to place INEL SNF into dry storage by 2023. Dry storage of SNF is operationally simpler and less costly than storage in water-filled pools. Also, dry storage facilities can be readily designed for safe storage durations of several decades. This is sufficient time for implementing decisions on final disposition of SNF and is a substantially longer period of time than is practical in many of the storage pools in which SNF is currently stored. The fuel is to be stored in a configuration suitable for off-site shipment as part of an NRC-licensed shipping package, and also suitable for longterm storage in a repository or monitored retrievable storage facility. According to the agreement, placement of selected SNF into dry storage is to start by July 2003. The facility described in this report will be used to package and store some of the DOE spent nuclear fuel that is currently residing in aging or filled storage facilities located at the INEL, other DOE laboratories, universities, and foreign research reactor facilities. The facility concept supports initial operation by 2003 .

The fuel that will be packaged in the DTC and stored in the DSS was selected out of a comprehensive inventory of DOE SNF. A significant criterion for the selection of the fuel was that it be contained in a relatively sound first boundary of stainless steel or zirconium, (either fuel cladding or a "can") that separates the actual fuel material from the handling environment. The selection process was essentially one of elimination with the following SNF eliminated from the full list:

- Naval fuel-it will be managed by other efforts.

- SNF located at the INEL Test Area North (TAN)-this fuel will be packaged using existing equipment in the TAN Hot Shop and is expected to be in dry storage before the new facility is in operation.

- Sodium-bonded fuel一this requires additional treatment before it can be put into interim storage.

- SNF whose primary containment (cladding or can) are significantly degraded-this fuel will require handling in a suitable facility to package it in a sound first containment. 
The resulting SNF to be handled in the Dry Storage Facility is identified and briefly described in Table 1-1. As may be noted by the absence of entries for some of the fuels, additional information will be required to support the identification of the final inventory to be handled. The preliminary schedule for receiving and placing that fuel into storage is presented in Table 1-2. As shown in Table 1-2, the SNF is currently located at the INEL and at facilities throughout the world. It is not expected that the SNF Dry Storage Project will have significant influence on the schedule of shipments from most off-Site locations. However, it is assumed that the shipment of on-Site SNF will be controlled by this project and that campaigns of fuel shipments from ICPP facilities will be scheduled to support efficient operations in the DTC. Appendix A documents a study performed to determine what equipment and processes will be needed to support efficient transfer of fuel from the FAST Facility to the DTC.

A storage concept that is considered highly reliable and cost effective is the placing of the SNF in sealed, shielded containers that are stored on a concrete basemat aboveground. This is an approach being adopted by the commercial nuclear power industry as reactor facility operators consume available space in their water-filled storage pools. In the selected concept, SNF is contained within two independent barriers to prevent the release of any radioactive materials during the life of the storage operation. The SNF, either contained in its intact cladding or in sealed cans is placed in steel DPCs (roughly $5 \mathrm{ft}$ in diameter and $16 \mathrm{ft}$ long). After the SNF is loaded, the canisters are sealed and placed in concrete vaults on a storage basemat. The vaults provide the radiological shielding required to reduce radiation fields to levels that ensure worker safety. The concrete also serves as a barrier to natural phenomena such as tornados and earthquakes. Cooling to dissipate decay heat from the SNF is achieved with natural convection cooling through air flow paths in the shielding vaults.

The arrangement of fuel within the DPCs was analyzed to ensure criticality safety, adequate heat removal capability, and adequate radiation shielding to provide storage through the year 2035 with assurance that the public, storage facility operations personnel, and the environment will all be protected from potential radiological hazards. Figure 1-1 illustrates a workable DPC loading of the specific SNF to be stored. This figure shows the distribution of SNF in the DPCs assuming that different types of fuel are generally not stored in the same DPC. More efficient use of the storage volume could be achieved if fuel types were mixed in some of the DPCs. Additional studies will be performed during later design stages to optimize DPC loading.

The specific configuration of the storage system was selected during the feasibility study documented in Reference 2. While other configurations could be used, the selected NUHOMS ${ }^{\circledR}$ horizontal storage method is considered the most cost effective at this time.

It is intended that the DSF will be licensed by the U.S. Nuclear Regulatory Commission. To this end, the facility will be designed in accordance with the guidance in ANSI/ANS 57.9, Design Criteria for an Independent Spent Fuel Storage Installation (Dry Type), which implements Title 10, "Energy," Code of Federal Regulations, Part 72, "Licensing Requirements for the Independent Storage of Spent Nuclear Fuel and High Level Radioactive Waste" (10 CFR 72). In general, the requirements of these documents have taken precedence over other requirements that have historically been imposed on INEL projects. Additionally, the DPC and its internal packaging must be designed and ultimately licensed for transport and final storage. 
This report comprises ten sections (with the introduction) and several appendices.

Section 2 summarizes the most important design criteria and assumptions used to guide the facility design. No detailed requirements are contained in an appendix.

Section 3 starts with a description of the flow of SNF from receipt to placement into storage. It provides a broad overview of the facility features and capabilities. The remaining parts of Section 3 contain descriptions of the major systems that are contained in the facility. The specific operational requirements, functions, and physical descriptions are discussed.

Section 4 identifies the primary Codes and Standards that are applicable to the various facility systems. As the design becomes more detailed, additional codes and standards will be identified.

Section 5 describes the preliminary acquisition strategy, or the approach to be followed in developing the Title design and proceeding into construction.

Section 6 describes the alternative technical approaches that were considered in selecting the one to be developed in the conceptual design effort. A structured process was used to identify potential alternatives and to evaluate those alternatives against specified criteria to determine which concept was most appropriate for development.

Section 7 identifies a number of uncertainties that were identified during the conceptual design. In general, these uncertainties impart a level of risk to the validity of the design and the accuracy of the cost estimate. Those risks, and a description of actions that could be undertaken to address them are included in this section.

Section 8 is the summary level schedule for the project. It illustrates the sequence and timing of events that will occur to ensure the milestones agreed to by $\mathrm{DOE}$ and the State of Idaho will be met.

Section 9 summarizes the cost estimate and describes the key considerations made in developing the estimate. Details are included in an appendix.

Section 10 lists the primary references used in support of the design and the design criteria.

Several appendices include more detailed design criteria, studies and analyses performed to develop and confirm the design, and preliminary drawings of the facility and major equipment. 
Table 1-1. SNF to be handled and canned in the DTC.

\begin{tabular}{|c|c|c|c|c|c|c|c|c|c|c|c|c|}
\hline SNF Name & $\begin{array}{l}\text { FHU: } \\
2035 \\
\end{array}$ & $\begin{array}{l}\text { Height } \\
\text { (in.) }\end{array}$ & $\begin{array}{l}\text { Width } \\
\text { (in.) }\end{array}$ & $\begin{array}{l}\text { Length } \\
\text { (in.) }\end{array}$ & $\begin{array}{l}\text { DHBb } \\
\text { Length }\end{array}$ & $\begin{array}{l}\text { DHB } \\
\text { Cells }\end{array}$ & $\begin{array}{l}\text { Layers/ } \\
\text { DHBB }\end{array}$ & $\begin{array}{l}\text { FHU/ } \\
\text { DHB }\end{array}$ & DHBs & $\begin{array}{l}\text { FHU per } \\
\text { DPC }\end{array}$ & $\begin{array}{c}\text { NUHOMS }{ }^{\circledR} \text { DPC \& } \\
\text { Loading }\end{array}$ & $\begin{array}{l}\text { No. of } \\
\text { DPCs }\end{array}$ \\
\hline ACRR ELEMENTS & 256 & TBD & TBD & TBD & & & & 0 & TBD & & & 1.00 \\
\hline ACRR EXPERIMENTS & 1 & TBD & TBD & TBD & & & & 0 & TBD & & & * \\
\hline ARKANSAS & 3 & TBD & TBD & TBD & & & & 0 & TBD & & & * \\
\hline CANDU * & 3 & & 5.00 & 168.0 & 1 & NA & 1 & NA & NA & 52 & BWR DPC, 1 layer & 0.00 \\
\hline CANDU * & 3 & TBD & 3.50 & 12.0 & 4 & 7 & 3 & 21 & 1.00 & 1176 & 14-Tube, 12 layers & 0.00 \\
\hline CP-5 CONVERTER CYLINDER & 2 & $\mathrm{TBD}$ & TBD & TBD & & & & 0 & TBD & & & * \\
\hline DRESDEN * & 23 & 4.40 & 4.40 & 135.0 & 1 & 2 & 1 & 2 & 12.00 & 28 & 14-Tube, 1 layer & 0.00 \\
\hline DRESDEN * & 1 & 4.40 & 4.40 & 135.0 & 1 & 2 & 1 & 2 & 1.00 & 28 & 14-Tube, 1 layer & 0.00 \\
\hline DRESDEN * & 4 & 4.40 & 4.40 & 135.0 & 1 & 2 & 1 & 2 & 2.00 & 28 & 14-Tube, 1 layer & 0.00 \\
\hline DRESDEN I REACTOR FUEL & 2 & TBD & TBD & IBD & & & & 0 & IBD & & & * \\
\hline FRR/TRIGA *** & 4940 & 0.00 & 1.48 & 30.00 & 4 & 24 & 1 & 24 & 206.00 & 1344 & 14-Tube, 5 layers & 3.00 \\
\hline FSVR & 744 & 16.32 & 14.17 & 31.22 & NA & NA & NA & NA & NA & 35 & $\begin{array}{l}\text { FSV Basket/special } \\
103^{n} \mathrm{lg} \text { fuel bucket. }\end{array}$ & 21.26 \\
\hline PATHFINDER & 7 & 9.62 & 9.62 & 84.00 & 1.62 & 1 & 1 & 1 & 7.00 & 7 & FSV Basket & 0.62 \\
\hline PBF DRIVER CORE & 60 & & $\begin{array}{l}8.63 \\
.\end{array}$ & 60.00 & 1.25 & 1 & 2 & 2 & 30.00 & 28 & $\begin{array}{l}\text { 14-Tube DPC, } 3 \\
\text { layers }\end{array}$ & 1.71 \\
\hline PULSTAR - BUFFALO & 24 & 3.00 & 3.00 & 28.00 & 5 & 5 & 1 & 5 & 5.00 & 350 & $\begin{array}{l}\text { 14-Tube DPC, } 4 \\
\text { layers }\end{array}$ & 0.07 \\
\hline PULSTAR-N.C. STATE UNIV. & 34 & 2.74 & 3.15 & 37.98 & 1.25 & 5 & 3 & 15 & 3.00 & 263 & 14-Tube, 4 layers & 0.13 \\
\hline PULSTAR-SUNY-BUFFALO & 43 & 2.74 & 3.15 & 38.00 & 1.25 & 5 & 3 & 15 & 3.00 & 263 & 14-Tube, 4 layers & 0.16 \\
\hline SHIPPINGPORT LWBR & 48 & IBD & 25.50 , & 158.0 & NA & NA & 1 & NA & NA & 3 & $\begin{array}{l}\text { Three, } 25.57 \text { in. dia } \\
\text { cans per special DPC } \\
\text { basket }\end{array}$ & 16.00 \\
\hline SHIPPINGPORT PWR-Cl-S4 & 1 & $5.5^{* *}$ & $5.5^{* *}$ & 104.5 & 1.25 & 1 & 1 & 1 & 1.00 & 14 & 14-Tube, 1 layer & 0.06 \\
\hline SHIIPINGPORT PWR-C2-S1 & 19 & 7.38 & 7.38 & 104.5 & 1.25 & 1 & 1 & 1 & 19.00 & 14 & 14-Tube, 1 layer & 1.09 \\
\hline SHIPPLNGPORT PWR-C2-S2 & 20 & 7.38 & 7.38 & 104.5 & 1.25 & 1 & 1 & 1 & 20.00 & 14 & 14-Tube, 1 layer & 1.14 \\
\hline TREAT & 390 & 3.96 & 3.96 & 96.00 & 1.25 & 4 & 1 & 4 & 98.00 & 56 & 14-Tube, 1 layer & 5.57 \\
\hline TRIGA BER-II (GERMANY) & 21 & 3.15 & 2.99 & 36.80 & 4 & 5 & 1 & 5 & 4.20 & 280 & 14-Tube, 4 layers & 0.08 \\
\hline TRIGA CONV. PENN STATE & 241 & TBD & 1.48 & 28.31 & 5 & 24 & 1 & 24 & 10.04 & 1680 & 14-Tube, 5 layers & 0.14 \\
\hline IRIGA CONV/ARRR & 91 & IBD & 1.38 & 28.37 & 5 & 24 & 1 & .24 & 3.79 & 1680 & 14-Tube, 5 layers & 0.05 \\
\hline TRIGA FLIP * & 2 & TBD & 3.80 . & 30.00 & 4 & 4 & 1 & 4 & 0.50 & 224 & $\begin{array}{l}\text { 14-Tube DPC, } 5 \\
\text { layers }\end{array}$ & 0.01 \\
\hline TRIGA FLIP/OSU & 91 & TBD & 1.48 & 28.58 & 5 & 24 & 1 & 24 & 3.79 & 1680 & 14-Tube, 5 layers & 0.05 \\
\hline TRIGA FLIP/TEXAS A \& M & 101 & TBD & 1.48 & 30.00 & 4 & 24 & 1 & 24 & 4.21 & 1344 & 14-Tube, 5 layers & 0.08 \\
\hline IRIGA FLIP/U.OF WI & 101 & IBD & 1.48 & 30.00 & 4 & 24 & 1 & 24 & 4.21 & 1344 & 14-Tube, 5 layers & 0.08 \\
\hline IRIGA FLIP/WASH.STATE UNI & 78 & TBD & 1.48 & 30.00 & 4 & 24 & 1 & 24 & 3.25 & 1344 & 14-Tube, 5 layers & 0.06 \\
\hline TRIGA SST & 296 & TBD & 1.48 & 28.31 & 5 & 24 & 1 & 24 & 12.33 & 1680 & 14-Tube, 5 layers & 0.18 \\
\hline IRIGA UNIV. OF IIIINOIS & 305 & IBD & 1.48 & 28.31 & 5 & 24 & 1 & 24 & 12.71 & 1680 & 14-Tube, 5 layers & 0.18 \\
\hline
\end{tabular}


Table 1-1. (Continued).

\begin{tabular}{|c|c|c|c|c|c|c|c|c|c|c|c|c|}
\hline SNF Name & $\begin{array}{l}\text { FHU } \\
2035 \\
\end{array}$ & $\begin{array}{l}\text { Height } \\
\text { (in.) }\end{array}$ & $\begin{array}{l}\text { Width } \\
\text { (in.) }\end{array}$ & $\begin{array}{l}\text { Length } \\
\text { (in.) }\end{array}$ & $\begin{array}{l}\text { DHB' } \\
\text { Length } \\
\end{array}$ & $\begin{array}{l}\text { DHB } \\
\text { Cells } \\
\end{array}$ & $\begin{array}{c}\text { Layers/ } \\
\text { DHB }\end{array}$ & $\begin{array}{l}\mathrm{FHU} / \\
\mathrm{DHB}\end{array}$ & DHBs & $\begin{array}{l}\text { FHU per } \\
\text { DPC }\end{array}$ & $\begin{array}{l}\text { NUHOMS }{ }^{\circ} \text { DPC \& } \\
\text { Loading }\end{array}$ & $\begin{array}{l}\text { No. of } \\
\text { DPCs }\end{array}$ \\
\hline TRIGA-CORNELL & 165 & IBD & 1.48 & 28.31 & 5 & 24 & 1 & 24 & 6.88 & 1680 & 14-Tube, 5 layers & 0.10 \\
\hline TRIGA-FLIP & 61 & TBD & 1.48 & 30.00 & 4 & 24 & 1 & 24 & 2.54 & 1344 & 14-Tube, 5 layers & 0.05 \\
\hline TRIGA-FLIP/GA & 117 & TBD & 1.48 & 30.00 & 4 & 24 & 1 & 24 & 4.88 & 1344 & 14-Tube, 5 layers & 0.09 \\
\hline TRIGAJAFRRI & 95 & IBD & 1.48 & 28.31 & 5 & 24 & 1 & 24 & 3.96 & 1680 & 14-Tube, 5 layers & 0.06 \\
\hline TRIGA/DOW & 78 & TBD & 1.48 & 28.31 & 5 & 24 & 1 & 24 & 3.25 & 1680 & 14-Tube, 5 layers & 0.05 \\
\hline TRIGA/GA & 155 & TBD & 1.48 & 28.31 & 5 & 24 & 1 & 24 & 6.46 & 1680 & 14-Tube, 5 layers & 0.09 \\
\hline TRIGA/KANSAS STATE UNIV. & 191 & IBD & 1.48 & 28.31 & 5 & 24 & 1 & 24 & 7.96 & 1680 & 14-Tube, 5 layers & 0.11 \\
\hline TRIGAMCCLELLAN AFB & 90 & TBD & 1.48 & 28.31 & 5 & 24 & 1 & 24 & 3.75 & 1680 & 14-Tube, 5 layers & 0.05 \\
\hline TRIGA/OSU & 99 & TBD & 1.48 & 28.31 & 5 & 24 & 1 & 24 & 4.13 & 1680 & 14-Tube, 5 layers & 0.06 \\
\hline TRIGA/REED COLLEGE & 67 & TBD & 1.48 & 28.31 & 5 & 24 & 1 & 24 & 2.79 & 1680 & 14-Tube, 5 layers & 0.04 \\
\hline TRIGATIEXAS A \& M & 85 & TBD & 1.48 & 28.31 & 5 & 24 & 1 & 24 & 3.54 & 1680 & 14-Tube, 5 layers & 0.05 \\
\hline TRIGATIEXAS A \& M & 28 & TBD & 0.00 & 0.00 & 5 & 24 & 1 & 24 & 1.17 & 1680 & 14-Tube, 5 layers & - \\
\hline TRIGA/UNIV, OF ARIZONA & 98 & TBD & 1.47 & 28.47 & 5 & 24 & 1 & 24 & 4.08 & 1680 & 14-Tube, 5 layers & 0.06 \\
\hline TRIGA/UNIV. OF MARYLAND & 186 & TBD & 1.48 & 28.31 & 5 & 24 & 1 & 24 & 7.75 & 1680 & 14-Tube, 5 layers & 0.11 \\
\hline TRIGA/UNIV. OF UTAH & 225 & TBD & 1.48 & 28.31 & 5 & 24 & 1 & 24 & 9.38 & 1680 & 14-Tube, 5 layers & 0.13 \\
\hline TRIGANUNIV. OF WISCONSIN & 127 & TBD & 1.48 & 28.31 & 5 & 24 & 1 & 24 & 5.29 & 1680 & 14-Tube, 5 layers & 0.08 \\
\hline TRIGAUNIV. OF WISCONSIN & 28 & TBD & TBD & TBD & 5 & 24 & 1 & 24 & 1.17 & 1680 & 14-Tube, 5 layers & - \\
\hline TRIGAJUNIV.OF CAL.-IRVINE & 113 & TBD & 1.48 & 28.00 & 5 & 24 & 1 & 24 & 4.71 & 1680 & 14-Tube, 5 layers & 0.07 \\
\hline TRIGA/UNIV.OF TEXAS@AUST. & 158 & TBD & 1.48 & 28.31 & 5 & 24 & 1 & 24 & 6.58 & 1680 & 14-Tube, 5 layers & 0.09 \\
\hline TRIGAVUSGS & 200 & TBD & 1.48 & 28.31 & 5 & 24 & 1 & 24 & 8.33 & 1680 & 14-Tube, 5 layers & 0.12 \\
\hline TRIGAVIA & 56 & TBD & 1.48 & 28.31 & 5 & 24 & 1 & 24 & 2.33 & 1680 & 14-Tube, 5 layers & 0.03 \\
\hline TRIGA/WASH.STATE UNIV. & 327 & TBD & 1.48 & 28.31 & 5 & 24 & 1 & 24 & 13.63 & 1680 & 14-Tube, 5 layers & 0.19 \\
\hline PEACH BOTTOM CORE 1 & 18 & TBD & 3.5 & 144 & 1 & 4 & 1 & 4 & 5.00 & 56 & 14-Tube, 1 layers & 0.32 \\
\hline PEACH BOTTOM CORE I & 796 & TBD & 3.5 & 144 & 1 & 4 & 1 & 4 & 199.00 & 56 & 14-Tube, 1 layers & 14.21 \\
\hline \multirow[t]{2}{*}{ PEACH BOTTOM CORE 2} & 786 & TBD & 3.5 & 126 & 1 & 7 & 1 & 7 & 113.00 & 98 & 14-Tube, 1 layers & 8.00 \\
\hline & & & & & & & & & 899 & & TOTAL & 78.00 \\
\hline $\begin{array}{l}\text { a. FHU: Fuel Handling Unit } \\
\text { b. DHB: Dry Handling Bucket }\end{array}$ & & & & & & & & & & & & \\
\hline
\end{tabular}


Table 1-2. SNF Dry Storage Project fuel receiving schedule.

\begin{tabular}{|c|c|c|c|c|c|c|c|}
\hline SNF Name & Site & Facility & Location & FHU & $\begin{array}{l}\text { Number of } \\
\text { Casks }\end{array}$ & Start Date & $\begin{array}{c}\text { Finish } \\
\text { Date }\end{array}$ \\
\hline FSVR & INEL LITCO & ICPP-603 IFSF & ICPP & 744 & 149 & $1 / 1 / 03$ & $7 / 22 / 03$ \\
\hline PATHFINDER & INEL LITCO & ICPP-603 & UNDERWATER & 7 & 2 & $7 / 22 / 03$ & $11 / 15 / 03$ \\
\hline SHIIPPNGPORT PWR-CI-S4 & INEL LITCO & ICPP-666 & ICPP FAST/4 & 1 & 1 & $11 / 15 / 03$ & $11 / 20 / 03$ \\
\hline SHIPPINGPORT LWBR & INEL LITCO & ICPP-749 SECOND GEN. & ICPP-749 & 48 & 10 & $11 / 18 / 03$ & $11 / 29 / 03$ \\
\hline TREAT & INEL ANI-W & TREAT & ANL-W & 390 & 78 & $12 / 16 / 03$ & $1 / 1 / 04$ \\
\hline SHIIPINGPORT PWR-C2-S1 & INEL LTTCO & ICPP-666 & ICPP FAST $/ 4$ & 19 & 4 & $12 / 2 / 03$ & $12 / 6 / 03$ \\
\hline SHIPPINGPORT PWR-C2-S2 & INEL LITCO & ICPP-666 & ICPP FAST/4 & 20 & 4 & $12 / 9 / 03$ & $12 / 16 / 03$ \\
\hline TRIGA BER-II (GERMANY) & INEL LITCO & ICPP-603 IFSF & ICPP-603 IFSF & 21 & 5 & $9 / 2 / 04$ & $9 / 10 / 04$ \\
\hline TRIGA FLIP & INEL LITCO & ICPP-603 & UNDERWATER & 2 & 1 & $9 / 10 / 04$ & $9 / 12 / 04$ \\
\hline TRIGA SST & INEL LITCO & ICPP-603 & UNDERWATER & 296 & 60 & $9 / 13 / 04$ & $12 / 3 / 05$ \\
\hline PEACH BOTTOM CORE 1 & INEL LITCO & ICPP-603 IFSF & ICPP & 18 & 4 & $12 / 17 / 04$ & $1 / 23 / 05$ \\
\hline IRIGA/AFRRI & NON DOE DOM. & $\begin{array}{l}\text { ARMED FORCES } \\
\text { RADIOBIO.FAC }\end{array}$ & $\begin{array}{l}\text { ARMED FORCES } \\
\text { RADIOBIO.FAC }\end{array}$ & 95 & 19 & $3 / 11 / 06$ & $4 / 7 / 06$ \\
\hline FRR EAST/TRIGA & FRR & $\begin{array}{l}\text { FOREIGN RESEARCH } \\
\text { REACTOR }\end{array}$ & $\begin{array}{l}\text { FOREIGN RESEARCH } \\
\text { REACTOR }\end{array}$ & 4,940 & 988 & $4 / 5 / 06$ & $8 / 1 / 06$ \\
\hline PBF DRIVER CORE & INEL LITCO & PER-620 & REACTOR & 60 & 12 & $12 / 2 / 06$ & $1 / 23 / 08$ \\
\hline PEACH BOTTOM CORE 1 & INEL LITCO & ICPP-749 FIRST GENERATION & ICPP-749 & 796 & 160 & $12 / 3 / 08$ & $8 / 10 / 09$ \\
\hline PEACH BOTTOM CORE 2 & INEL LITCO & ICPP-603 IFSF & ICPP & 786 & 158 & $9 / 1 / 09$ & $8 / 10 / 10$ \\
\hline PULSTAR - BUFFALO & INEL LITCO & ICPP-603 & UNDERWATER & 24 & 5 & 9/9/09 & $9 / 17 / 09$ \\
\hline TRIGAREED COLLEGE & UNIVERSITY & REED REACTOR FACIITY & REED COLLEGE & 67 & 14 & $2 / 22 / 12$ & $4 / 12 / 12$ \\
\hline PULSTAR-SUNY-BUFFALO & UNIVERSITY & STATE UNIV. OF NY-BUFFALO & $\begin{array}{l}\text { STATE UNIV. OF } \\
\text { NY-BUFFALO }\end{array}$ & 43 & 9 & $4 / 12 / 12$ & $6 / 17 / 12$ \\
\hline IRIGA FLIP/IEXAS A \& M & UNIVERSTYY & TEXAS A \& M & TEXAS A \& M & 101 & 21 & $6 / 20 / 12$ & $8 / 18 / 12$ \\
\hline TRIGA/IEXAS A \& M & UNIVERSITY & TEXAS A \& M & TEXAS A \& M & 85 & 17 & $8 / 18 / 12$ & $9 / 16 / 12$ \\
\hline TRIGA-CORNELL & UNIVERSITY & CORNELL UNIVERSITY & CORNELL & 165 & 33 & $2 / 22 / 13$ & $6 / 1 / 13$ \\
\hline TRIGA/IEXAS A \& M & UNIVERSTTY & TEXAS A \& M & TEXAS A \& M & 28 & 6 & $6 / 1 / 13$ & $8 / 1 / 13$ \\
\hline $\begin{array}{l}\text { TRIGAUNNIV.OF } \\
\text { CAL.-IRVINE }\end{array}$ & UNIVERSITY & UNIV. OF CALIF.-IRVINE & $\begin{array}{l}\text { UNIV. OF } \\
\text { CALIF.IRVINE }\end{array}$ & 113 & 23 & $2 / 22 / 14$ & $4 / 15 / 14$ \\
\hline $\begin{array}{l}\text { TRIGAJUNIV.OF } \\
\text { TEXAS@AUST. }\end{array}$ & UNIVERSITY & UNIV. OF TEXAS-AUSTIN & $\begin{array}{l}\text { UNIV. OF } \\
\text { TEXAS-AUSTIN }\end{array}$ & 158 & 32 & $4 / 15 / 14$ & $2 / 21 / 15$ \\
\hline $\begin{array}{l}\text { TRIGA/KANSAS STATE } \\
\text { UNIV. }\end{array}$ & UNIVERSITY & KANSAS STATE UNIVERSITY & $\begin{array}{l}\text { KANSAS STATE } \\
\text { UNIVERSITY }\end{array}$ & 191 & 39 & $7 / 1 / 15$ & $8 / 22 / 15$ \\
\hline IRIGA/UNIV. OF ARIZONA & UNIVERSITY & UNIVERSITY OF ARJZONA & UNIVERSITY OF & 98 & 20 & $8 / 25 / 15$ & $10 / 17 / 15$ \\
\hline $\begin{array}{l}\text { PULSTAR-N.C. STATE } \\
\text { UNIV. }\end{array}$ & UNIVERSITY & N. CAROLINA STATE UNIV. & $\begin{array}{l}\text { N. CAROLINA STATE } \\
\text { UNIV. }\end{array}$ & 34 & 7 & $10 / 20 / 15$ & $11 / 21 / 15$ \\
\hline $\begin{array}{l}\text { TRIGA/UNIV. OF } \\
\text { MARYLAND }\end{array}$ & UNIVERSITY & UNIVERSITY OF MARYLAND & $\begin{array}{l}\text { UNIVERSITY OF } \\
\text { MARYLAND }\end{array}$ & 186 & 38 & $1 / 26 / 16$ & $3 / 31 / 16$ \\
\hline TRIGA CONV. PENN STATE & UNIVERSITY & PENNSYLVANIA STATE UNIV. & $\begin{array}{l}\text { PENNSYLVANIA } \\
\text { STATE UNIV. }\end{array}$ & 241 & 49 & $2 / 2 / 16$ & $3 / 27 / 16$ \\
\hline TRIGA FLIP/OSU & UNIVERSITY & OREGON STATE UNIVERSITY & $\begin{array}{l}\text { OREGON STATE } \\
\text { UNTVERSITY }\end{array}$ & 91 & 19 & $4 / 27 / 16$ & $6 / 16 / 16$ \\
\hline TRIGA UNIV. OF ILLINOIS & UNIVERSTTY & UNIVERSITY OF ILLINOIS & UNIVERSITY OF & 305 & 61 & $2 / 5 / 15$ & $8 / 7 / 16$ \\
\hline TRIGAVOSU & UNIVERSTTY & OREGON STATE UNIVERSITY & $\begin{array}{l}\text { OREGON STATE } \\
\text { UNIVERSITY }\end{array}$ & 99 & 20 & $10 / 7 / 16$ & $11 / 2 / 16$ \\
\hline TRIGA/UNTV. OF UTAFI & UNIVERSITY & UNIVERSITY OF UTAF & UNIVERSTTY OF & 225 & 45 & $1 / 19 / 17$ & $2 / 24 / 17$ \\
\hline $\begin{array}{l}\text { TRIGAJUNIV. OF } \\
\text { WISCONSIN }\end{array}$ & UNIVERSITY & UNIVERSITY OF WISCONSIN & $\begin{array}{l}\text { UNIVERSITY OF } \\
\text { WISCONSIN }\end{array}$ & 127 & 26 & $2 / 1 / 17$ & $3 / 25 / 17$ \\
\hline
\end{tabular}


Table 1-2. (Continued).

\begin{tabular}{|c|c|c|c|c|c|c|c|}
\hline SNF Name & Site & Facility & Location & FHU & $\begin{array}{l}\text { Number of } \\
\text { Casks }\end{array}$ & Start Date & $\begin{array}{c}\text { Finish } \\
\text { Date }\end{array}$ \\
\hline $\begin{array}{l}\text { TRIGA FLIP/WASH.STATE } \\
\text { UNI }\end{array}$ & UNIVERSITY & WASHINGTON STATE UNIV. & $\begin{array}{l}\text { WASHINGTON } \\
\text { STATE UNIV. }\end{array}$ & 78 & 16 & $3 / 14 / 17$ & $4 / 15 / 17$ \\
\hline CANDU & SRS & RBOF & SAVANNAH RIVER & 3 & 1 & $7 / 21 / 17$ & 9/9/17 \\
\hline $\begin{array}{l}\text { DRESDEN I REACTOR } \\
\text { FUEL }\end{array}$ & ORNL & BLDG. 7920 & STORAGE AREAS & 2 & 1 & $2 / 27 / 18$ & $3 / 1 / 18$ \\
\hline $\begin{array}{l}\text { TRIGAUNIV. OF } \\
\text { WISCONSIN }\end{array}$ & UNIVERSITY & UNIVERSITY OF WISCONSIN & $\begin{array}{l}\text { UNIVERSITY OF } \\
\text { WISCONSIN }\end{array}$ & 28 & 6 & $7 / 27 / 18$ & $9 / 22 / 18$ \\
\hline $\begin{array}{l}\text { TRIGA/WASH.STATE } \\
\text { UNIV. }\end{array}$ & UNIVERSITY & WASHINGTON STATE UNIV. & $\begin{array}{l}\text { WASHINGTON } \\
\text { STATE UNIV. }\end{array}$ & 327 & 66 & $3 / 29 / 17$ & $10 / 23 / 18$ \\
\hline TRIGA FLIP/U.OF WI & UNIVERSITY & UNIVERSITY OF WISCONSIN & $\begin{array}{l}\text { UNIVERSITY OF } \\
\text { WISCONSIN }\end{array}$ & 101 & 21 & $9 / 25 / 18$ & $10 / 23 / 18$ \\
\hline TRIGA/DOW & NON DOE DOM. & DOW TRIGA REACTOR & $\begin{array}{l}\text { DOW TRIGA } \\
\text { REACTOR }\end{array}$ & 78 & 16 & $3 / 1 / 18$ & $5 / 1 / 19$ \\
\hline TRYGA-FLIP/GA & NON DOE DOM. & GA TRIGA REACTOR FACILITY & TRIGA REACTOR & 117 & 24 & $5 / 7 / 19$ & $6 / 12 / 19$ \\
\hline TRIGA/GA & NON DOE DOM. & GA TRIGA REACTOR FACKITY & TRIGA REACTOR & 155 & 31 & $5 / 24 / 19$ & $1 / 22 / 20$ \\
\hline TRIGA/VA & NON DOE DOM. & OMAHA VA MEDICAL CENTER & OMAHA VA & 56 & 12 & $2 / 14 / 20$ & $3 / 14 / 20$ \\
\hline TRIGAUUSGS & NON DOE DOM. & USGS FAC. OF DENVER, CO & $\begin{array}{l}\text { DENVER FEDERAL } \\
\text { CENTER }\end{array}$ & 200 & 40 & $3 / 11 / 20$ & $3 / 19 / 20$ \\
\hline TRIGAMCCLELLAN AFB & NON DOE DOM. & SNRS & SNRS & 90 & 18 & $2 / 20 / 20$ & $3 / 28 / 20$ \\
\hline & & & TOTALS & 11,859 & 2,391 & & \\
\hline
\end{tabular}

THE FOLLOWNG UNDETERMINED FUELS HAVE NOT BEEN INCLUDED IN THE SCHEDULE

\begin{tabular}{|c|c|c|c|c|}
\hline ACRR ELEMENTS & $\begin{array}{l}\text { SANDIANAT } \\
\text { LAB }\end{array}$ & ANNULAR CORE RES REACTOR & DRY WELLS & 256 \\
\hline ACRR EXPERIMENTS & $\begin{array}{l}\text { SANDIA NAT } \\
\text { LAB }\end{array}$ & ANNULAR CORE RES REACTOR & DRY WELLS & 1 \\
\hline ARKANSAS & NON DOE DOM. & LYNCHBURG TECH. CTR. & B\&W NESI & 3 \\
\hline CP-5 CONVERTER & ANL-E & CHICAGO PILE 5 & CASK/ROD STORAGE & 2 \\
\hline DRESDEN & SRS & RBOF & $\begin{array}{l}\text { SAVANNAH RIVER } \\
\text { SITE (SRS) }\end{array}$ & 23 \\
\hline DRESDEN & SRS & RBOF & $\begin{array}{l}\text { SAVANNAH RIVER } \\
\text { SITE (SRS) }\end{array}$ & 1 \\
\hline DRESDEN & SRS & RBOF & $\begin{array}{l}\text { SAVANNAH RIVER } \\
\text { SITE (SRS) }\end{array}$ & 4 \\
\hline TRIGA CONVIAARRR & NON DOE DOM. & ARRR & ARRR & 91 \\
\hline TRIGA-FLIP & INEL ANL-W & N-RAD & N-RAD & 61 \\
\hline
\end{tabular}

NOTE: 1. A conservative estimate of (5) FHUs per cask was used.

2. The number of casks was rounded up to the nearest cask in each case. 


\begin{tabular}{|c|c|c|c|}
\hline \multirow{6}{*}{ 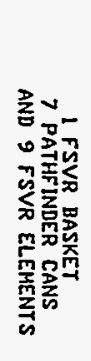 } & PATHFINDER & FSVR & FSVR \\
\hline & PATHFINDER & FSVR & FSVR \\
\hline & PATHFINDER & FSVR & \multirow{5}{*}{. } \\
\hline & PATHFINDER & FSVR & \\
\hline & PATHFINDER & FSVR & \\
\hline & PATHFINDER & FSVR & \\
\hline & PATHFINDER & FSVR & \\
\hline
\end{tabular}

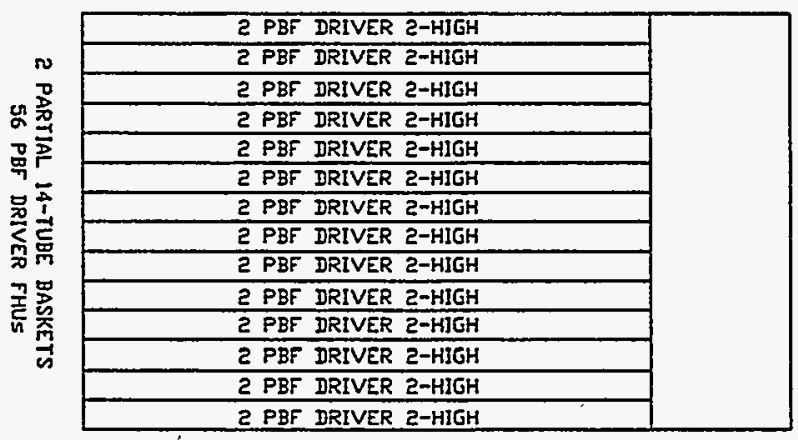

\begin{tabular}{|c|c|c|c|c|}
\hline FSVR & FSVR & FSVR & FSVR & FSVR \\
\hline FSVR & FSVR & FSVR & FSVR & FSVR \\
\hline FSVR & FSVR & FSVR & FSVR & FSVR \\
\hline FSVR & FSVR & FSVR & FSVR & FSVR \\
\hline FSVR & FSVR & FSVR & FSVR & FSVR \\
\hline FSVR & FSVR & FSVR & FSVR & FSVR \\
\hline FSVR & FSVR & FSVR & FSVR & FSVR \\
\hline
\end{tabular}
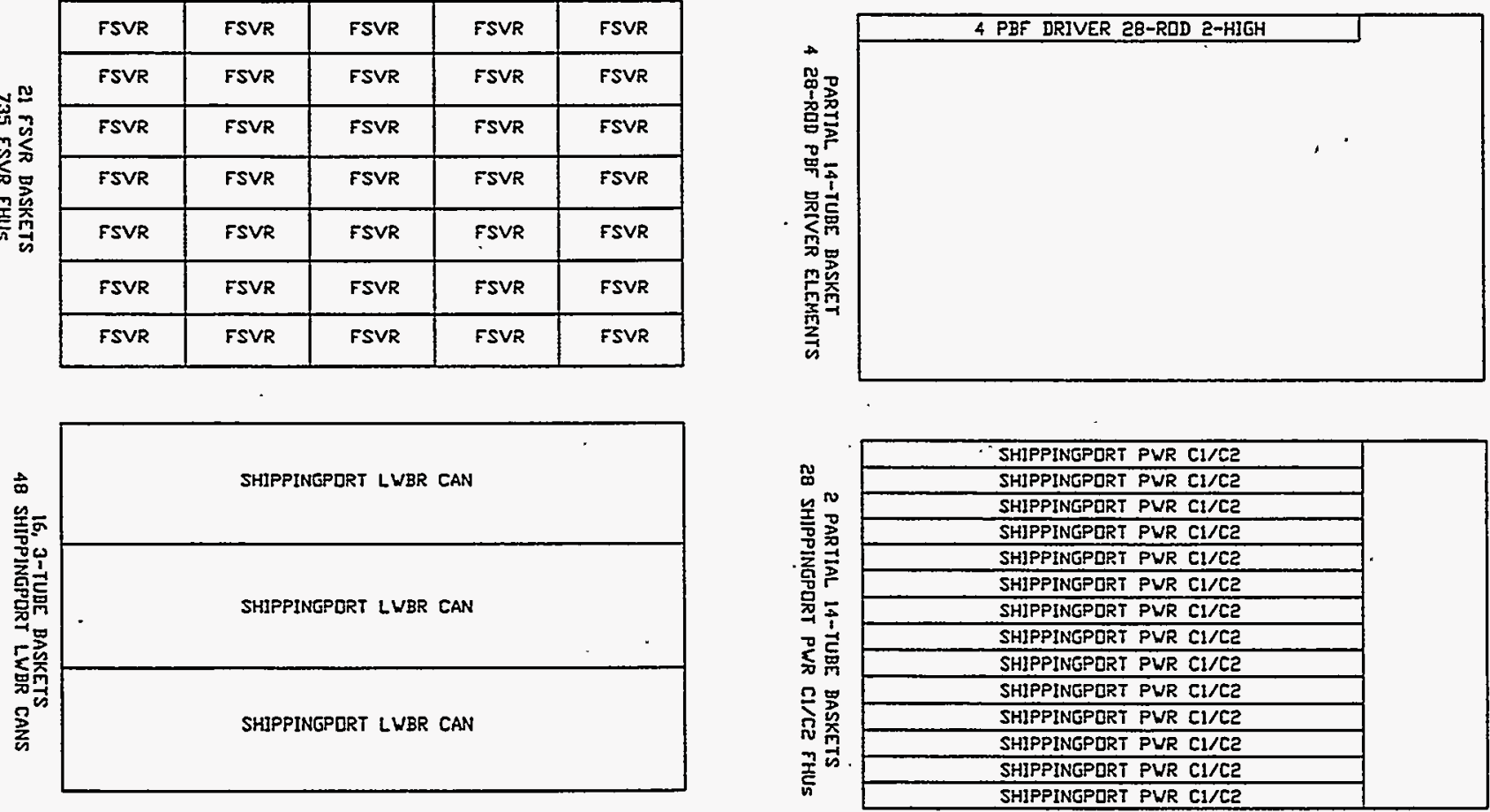

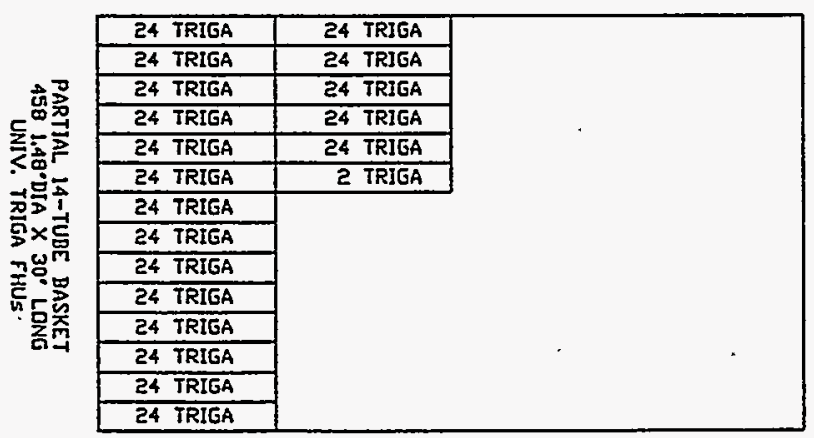

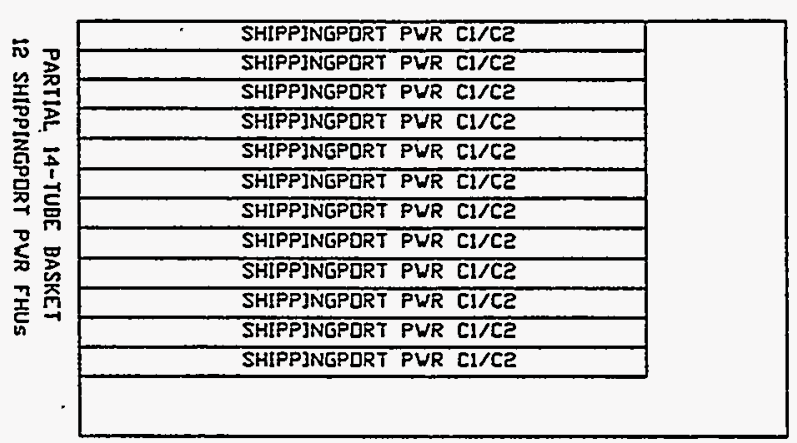

Figure 1-1. DPC fuel loading schematic. 


\begin{tabular}{|c|c|c|c|c|c|}
\hline \multirow{14}{*}{ 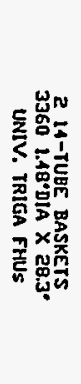 } & 24 TRIGA & 24 TRIGA & 24 TRIGA & 24 TRIGA & 24 TRIGA \\
\hline & 24 TRIGA & 24 TRIGA & 24 TRIGA & 24 JRIGA & 24 TRIGA \\
\hline & 24 IRIGA & 24 TRIGA & 24 TRIGA & 24 JRIGA & 24 TRIGA \\
\hline & 24 JRIGA & 24 TRIGA & 24 TRIGA & 24 TRIGA & 24 TRIGA \\
\hline & 24 TRIGA & 24 TRIGA & 24 TRIGA & 24 TRIGA & 24 TRIGA \\
\hline & 24 TRIGA & 24 TRIGA & 24 TRIGA & 24 TRIGA & 24 TRIGA \\
\hline & 24 TRIGA & 24 TRIGA & 24 TRIGA & 24 TRIGA & 24 TRIGA \\
\hline & 24 TRIGA & 24 TRIGA & 24 TRIGA & 24 TRIGA & 24 TRIGA \\
\hline & 24 TRIGA & 24 TRIGA & 24 TRIGA & 24 TRIGA & 24 TRIGA \\
\hline & 24 TRIGA & E4 TRIGA & 24 TRIGA & 24 TRIGA & Z4 TRIGA \\
\hline & 24 TRIGA & 24 TRIGA & 24 TRIGA & 24 TRIGA & 24 TRIGA \\
\hline & 24 TRIGA & 24 TRIGA & 24 TRIGA & 24 TRIGA & 24 TRIGA \\
\hline & 24 TRIGA & 24 TRIGA & 24 TRIGA & 24 TRIGA & 24 TRIGA \\
\hline & 24 TRIGA & 24 TRIGA & 24 TRJGA & 24 TRIGA & 24 TRIGA \\
\hline
\end{tabular}
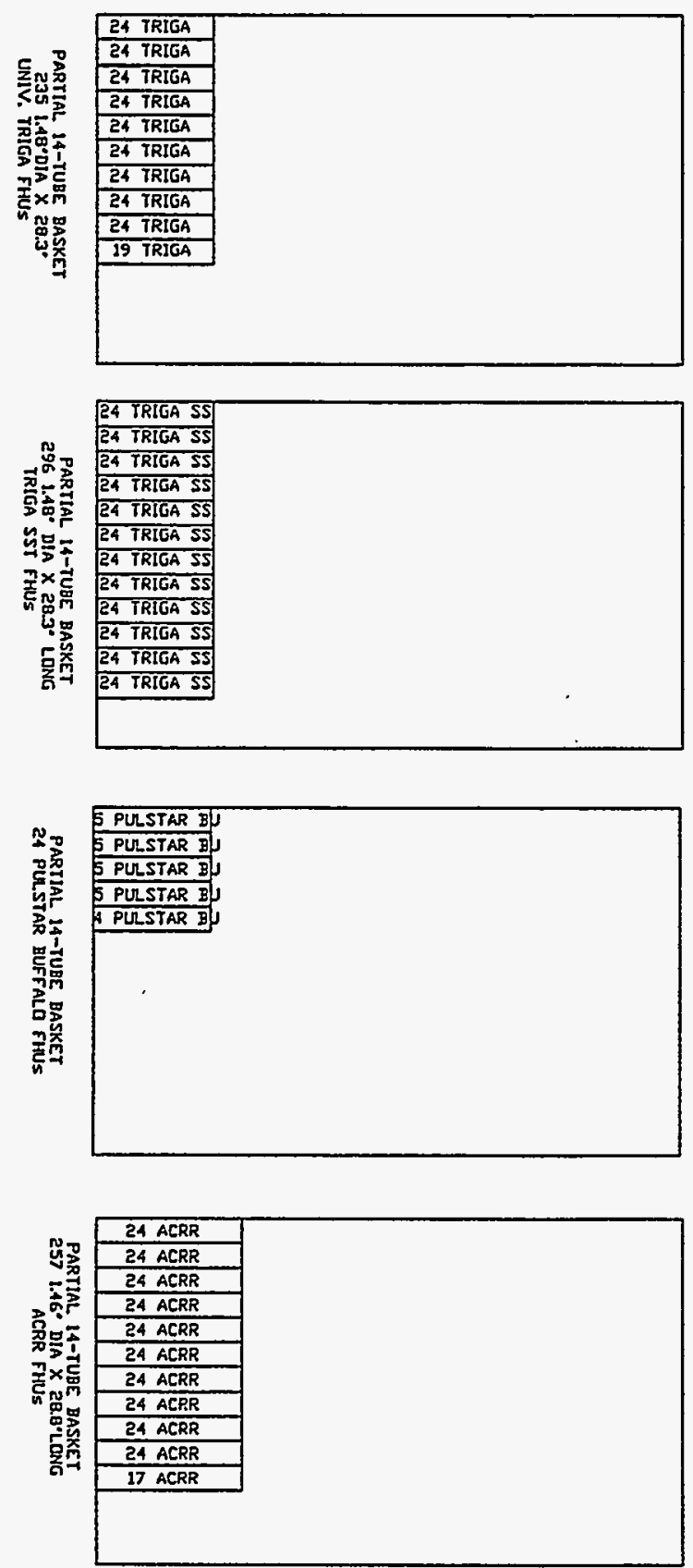

Figure 1-1. (continued).

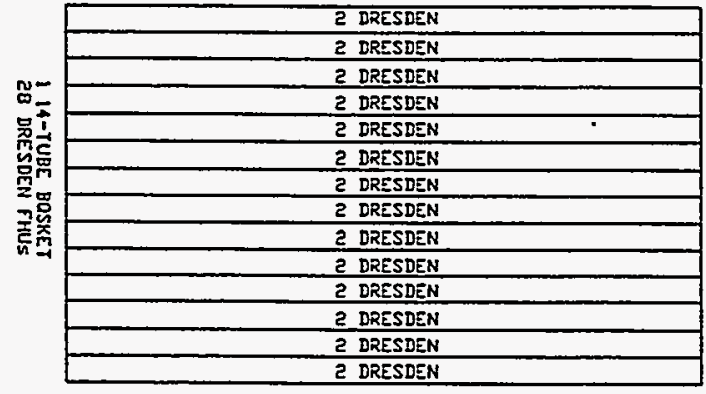

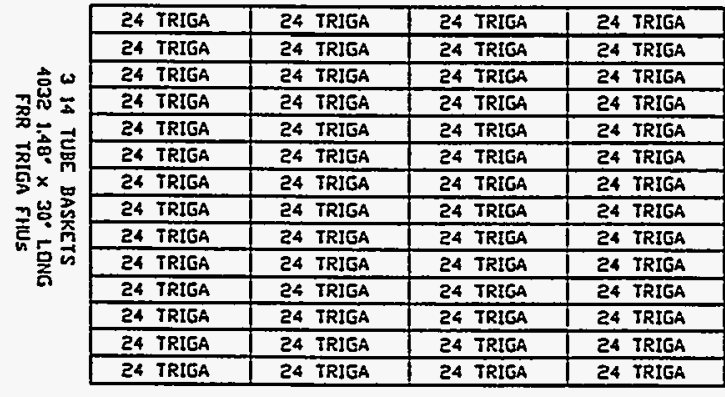
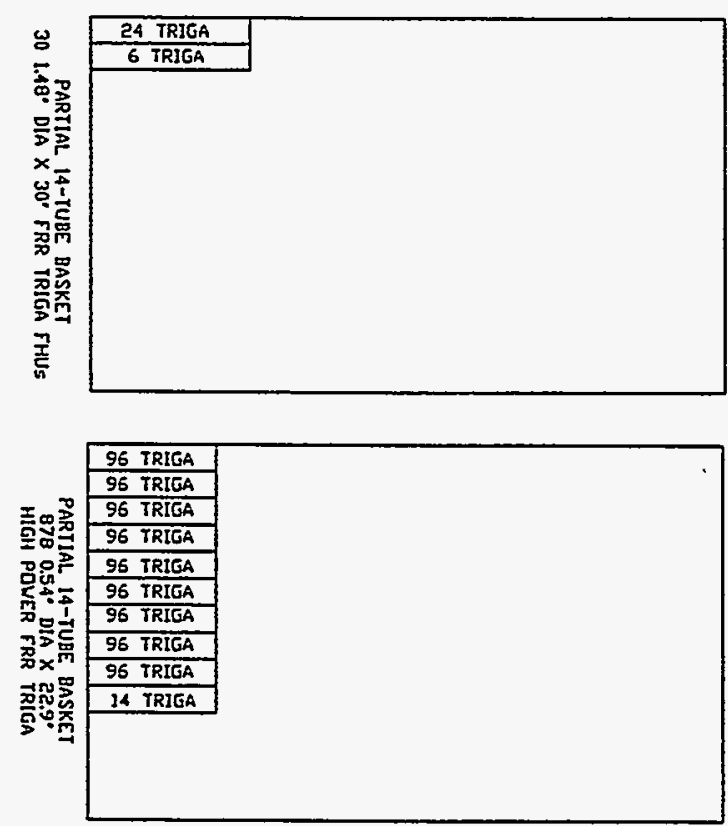

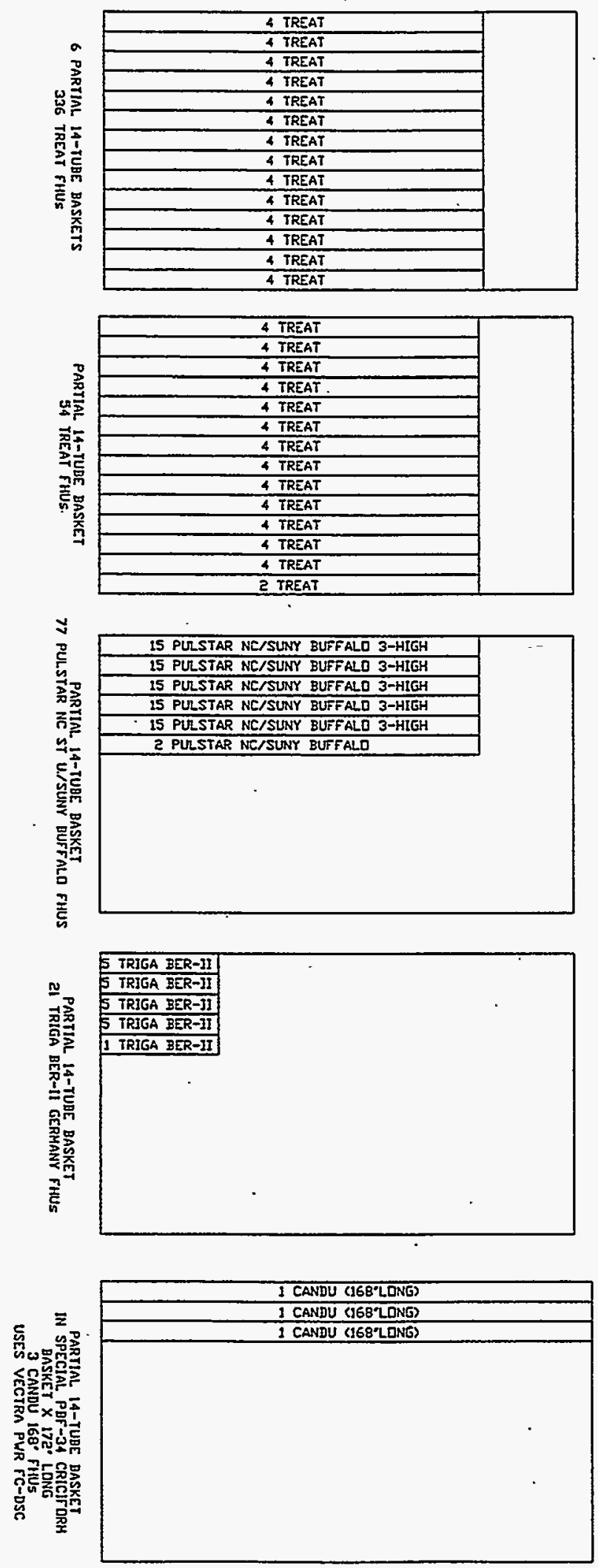

Figure 1-1. (continued).
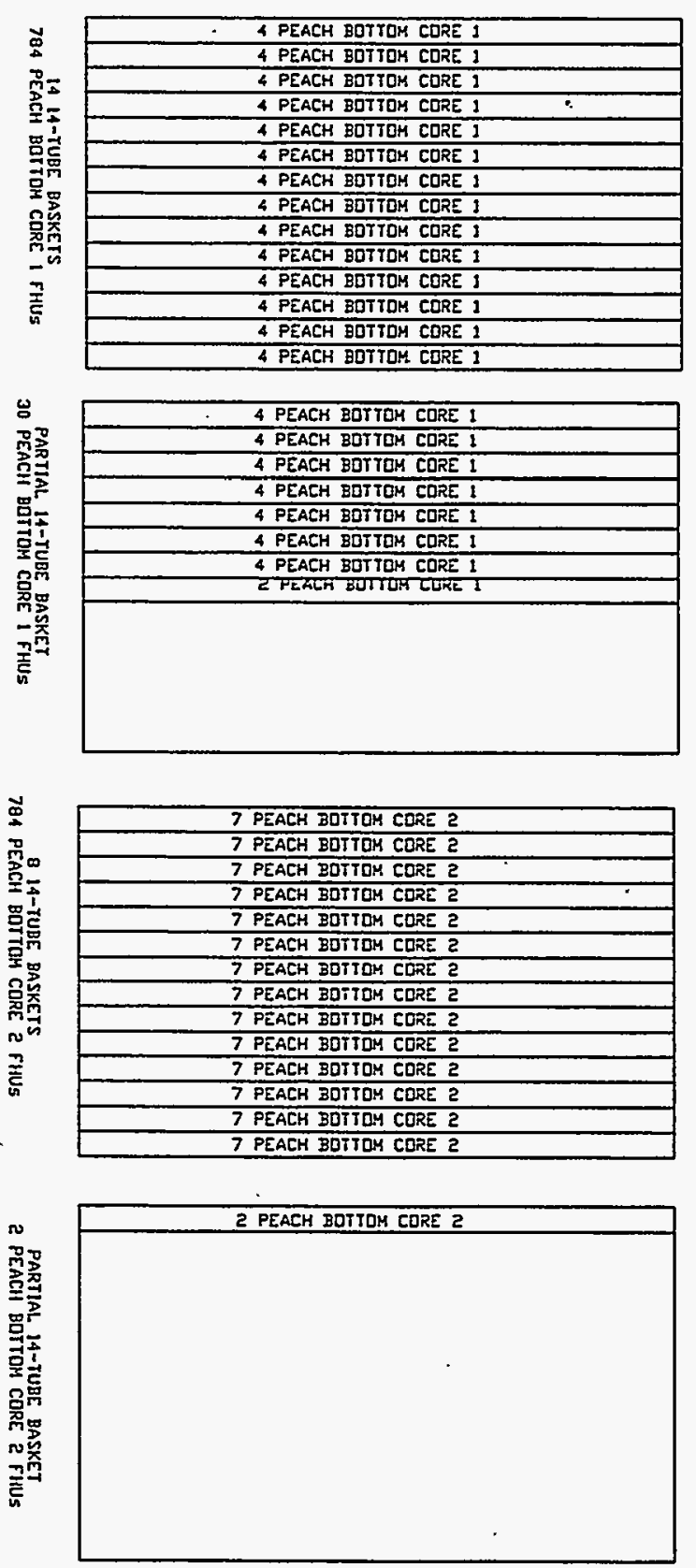


\section{DESIGN CRITERIA AND KEY ASSUMPTIONS}

The Conceptual Design was developed on the basis of the Conceptual Design Criteria (Appendix B) and on a number of Key Assumptions identified during the design effort. The most significant of the Conceptual Design Criteria are summarized in Sections 2.1 through 2.4. The Key Assumptions are included as Section 2.5.

Appendix $\mathrm{C}$ contains the Project Design Criteria which were developed during the Conceptual Design effort. The Project Design Criteria (PDC) provide more detailed requirements than the Conceptual Design Criteria and are based on specific features established during the conceptual design. The PDC are to be used as the design requirements baseline during Title Design.

\subsection{General and Performance Requirements}

The Dry Storage Facility shall consist of a Dry Transfer Cell (DTC) in which SNF is transferred from shipping casks to Dual-Purpose Canisters (DPCs), and a Dry Storage System (DSS) to handle and store DPCs containing SNF.

- A DTC shall transfer SNF from shipping casks to dry storage canisters. The dry storage canisters shall be commercial DPCs, and shall be sealed and inerted for storage.

- A Dry Storage System comprising an outdoor aboveground concrete storage basemat, and suitable shielded, monitored, storage modules shall be provided. Loaded DPCs from the DTC shall be transported and placed into the storage modules on the storage basemat.

- The DTC shall be sized to transfer fuel from a maximum of 12 incoming SNF shipping casks per month, and to fill a maximum of two DPCs per month. The facility shall be designed to operate on a schedule of two 12-hour shifts per day.

- The DTC shall have the capability to perform minor canning processes. These include the packaging of peach bottom fuel elements, either already canned or in bare assemblies, in cans that are sealed to constitute the first of two confinement boundaries required by 10 CFR 72 .

- The conceptual design shall include the Vectra NUHOMS ${ }^{\circledR}$ system for horizontal storage of the DPCs.

- The storage area shall be designed to allow ready expansion throughout its life up to a maximum capacity of 240 DPCs.

- A data management system shall be provided to record the receipt, inventory, transfer, and disposal of all SNF in storage. The records shall include, as a minimum, the name of the fuel shipper, the estimated quantity of radioactive material per item (including special nuclear material in spent fuel), item identification and serial number, storage location, onsite 
movements and locations of each fuel assembly or DPC, and final shipment to an offsite location.

- Design life of the SNF Dry Transfer Cell and equipment shall be 30 years and have maintainable or replaceable life of 60 years.

- Design life of the Dry Storage System shall be 60 years

- The design life of the DPCs shall be 100 years.

\subsection{Safety Requirements}

- Facility design features and physical controls shall ensure occupational exposure is maintained ALARA during normal and off-normal operations.

- Spent fuel handling, packaging, transfer, and storage systems shall be designed to be maintained subcritical under the worst case moderated and reflected conditions, and to ensure that before a nuclear criticality accident is possible, at least two unlikely, independent, and concurrent or sequential changes must occur in the conditions essential to nuclear criticality safety.

- The DPC and its internal basket shall be designed to maintain the fuel cladding below the maximum allowable temperatures. Maximum allowable temperatures $\left(380^{\circ} \mathrm{C}\right.$ for 5 -yearcooled fuel, $340^{\circ} \mathrm{C}$ for 10 -year-cooled fuel must not be exceeded in the Hot Cell lag storage, the MP-187 transfer cask, and in the storage modules at all conditions to which the fuel may be exposed.

- The spent fuel storage package shall be designed to provide adequate heat removal capacity without active cooling systems.

- The fuel handling equipment shall be designed against single failure resulting in dropping the fuel. Designs shall include appropriate redundancy and consider diversity to reduce the possibility of concurrent common-mode failures of redundant items.

- The SNF Dry Storage Facility shall be designed to be able to recover from accidents involving dropping of casks, SNF, SNF baskets/buckets/cans, and DPCs.

\subsection{Environmental Requirements}

- The SNF Dry Storage Facility shall be designed for construction and operation in accordance with the environmental limitations described in DOE/EIS-0203-F, Department of Energy Programmatic Spent Nuclear Fuel Management and Idaho National Engineering Laboratory Environmental Restoration and Waste Management Programs Final Environmental Impact Statement. 


\subsection{Regulatory Requirements}

- The facility shall be licensed by the NRC and shall be designed in accordance with 10 CFR 72 and 10 CFR 73.

- The facility shall be designed in accordance with ANSI/ANS 57.9, Design Criteria for an Independent Spent Fuel Storage Installation (Dry Type).

- The DPC and internal packaging shall be licensed for off-Site shipment in accordance with 10 CFR 71, and long term storage in accordance with 10 CFR 60.

\subsection{Key Assumptions}

The assumptions made during the development of the conceptual design are included below. These assumptions require verification during follow-on design efforts. In some cases, the assumptions may have a strong bearing on the direction of the design; in other cases, the assumptions simply identify important issues that need to be addressed as the design progresses.

- $\quad$ SNF is dry and located in a DOE- or NRC-approved shipping cask when it arrives at the Dry Transfer Cell. Some SNF may require final drying after being placed in the DPC, but there will be no appreciable free water that could be available to spread contamination during handling.

- Approximately two-thirds of the SNF to be handled has intact cladding or is in intact cans, i.e., the SNF cladding or the cans provide the first confinement barrier as defined by NRC 10 CFR 72.122. For this fuel, no additional conditioning, testing, treatment, decanning, or canning is required within the DTC.

- $\quad$ Peach Bottom (PB) SNF that will be placed in approximately 25 DPCs will require minor canning. This will be limited to overpacking the SNF, vacuum drying, purging, inerting and sealing the PB SNF inside a new can. It is assumed that no raw fuel will be exposed to the Hot Cell environment while transferring the PB fuel from the shipping cask to the DPC, lag storage, or canning station.

- The spent nuclear fuel has sufficient identification and records of previous characterization that only in-cell identification of SNF permanent marking is required to comply with DOT and NRC identification requirements for shipment and storage. Such characterization will meet the DOE requirements for "road ready" when properly sealed in DPCs.

- A DPC having an external shell of a standard commercial or DOE canister (e.g., a Vectra NUHOMS ${ }^{\oplus}$ or DOE OCRWM MPC) shall be specified. The internal basket features may be modified to meet the requirements of DOE SNF. 
- No engineered features are required to open the DPCs for the purposes of adding more SNF, performing additional fuel characterization, or verifying the inventory of SNF once the DPC is closed (welded). Any verification actions, and any actions taken to verify that the SNF has not been disturbed, will be part of facility administrative processes.

- The commercially available automatic welding machine for whichever DPC is selected will be used in the DTC.

- Physical security requirements can be met with typical access controls (e.g., card readers and alarmed doors) to the facility. Specific security system capabilities to prevent removal of small quantities of SNF are not required.

Note: The requirements applicable to security systems are continuing to evolve. This is primarily a result of interpretations of existing regulations (10 CFR 73) and an understanding of proposed NRC rules. Where questions concerning the interpretation of 10 CFR 73 arise, guidance has been sought from NUREG-1497.

- Schedules for transferring SNF currently located onsite may be established and adjusted as necessary to support an uninterrupted sequence of filling a DPC by direct transfer from the onsite shipping cask(s). This will eliminate a potential need to temporarily store that fuel in the Hot Cell. 


\section{DESIGN DESCRIPTION}

\subsection{Facility and Operational Overview}

This section describes the functions of the Dry Storage Facility (DSF) and the flow of materials [shipping casks, fuel, Dual-Purpose Canisters (DPCs), transfer casks] through the facility. It also briefly discusses the configurations and capabilities of the various facility systems. Details of the system configurations and capabilities are provided in Sections 3.2 through 3.10.

The DSF includes the necessary equipment to receive, handle, and store spent nuclear fuel. There are two primary parts to the facility: the Dry Transfer Cell (DTC) and the Dry Storage System (DSS). The facility will be located at the ICPP, where the fuel will be stored until moved for final disposition. The DSF is designed to provide versatile fuel-handling capabilities and minimize obsolescence.

\subsubsection{Dry Transfer Cell}

As illustrated in Figure 3-1, the main process areas in the DTC are the Cask Handling Bay, the Cask Preparation Area, the Hot Cell, the Buffer Area, the Utility Support Area and the Administrative Area. The general capabilities and operations that occur in these areas are described below. Figure 3-2 is a block diagram that illustrates the flow of equipment and material through the facility.

3.1.1.1 Fuel Receipt and Preparation. Fuel elements are received at the facility in a variety of shipping casks that are transported by truck/trailer. The casks, some of which are protected by covered shipping skids, are moved into the drive-through truck bay. If necessary, road grime is washed from the shipping packages. The shipping cover and tie-down rigging are removed, and handling trunnions installed if needed. Using a 150-ton overhead crane, personnel upright the cask, lift it from the skid, and place it vertically on an electrically driven trolley. The trolley is used to move the cask from the Cask Handling Bay into the Cask Preparation Area. In the Cask Preparation Area, a gas sample from the cask internal cavity is taken to ensure no abnormal radiological conditions exist that might require special cask/fuel handling operations. The outer lid (if the specific cask has that configuration) is removed with the crane in the Cask Preparation Area and temporarily stored. The inner cask lid bolts are also removed in the Cask Preparation Area to limit the amount of time required for lid removal once the cask is placed in the Hot Cell. The cask is then moved, on the trolley, through shielding doors and into the Hot Cell.

3.1.1.2 Hot Cell Operations. The Hot Cell has an overhead bridge system that includes two fuel-handling manipulators and hoist/hook assemblies that are mounted on separate trolleys but on the same bridge. The Hot Cell also contains four lag storage vaults for temporary storage of SNF. The vaults are used to accommodate the different capacities of the shipping casks and storage canisters.

The cask is moved into position in the Hot Cell and a combination of permanent and disposable contamination barriers are installed. The Hot Cell is then vacated for remote lid removal and fuel transfer. 

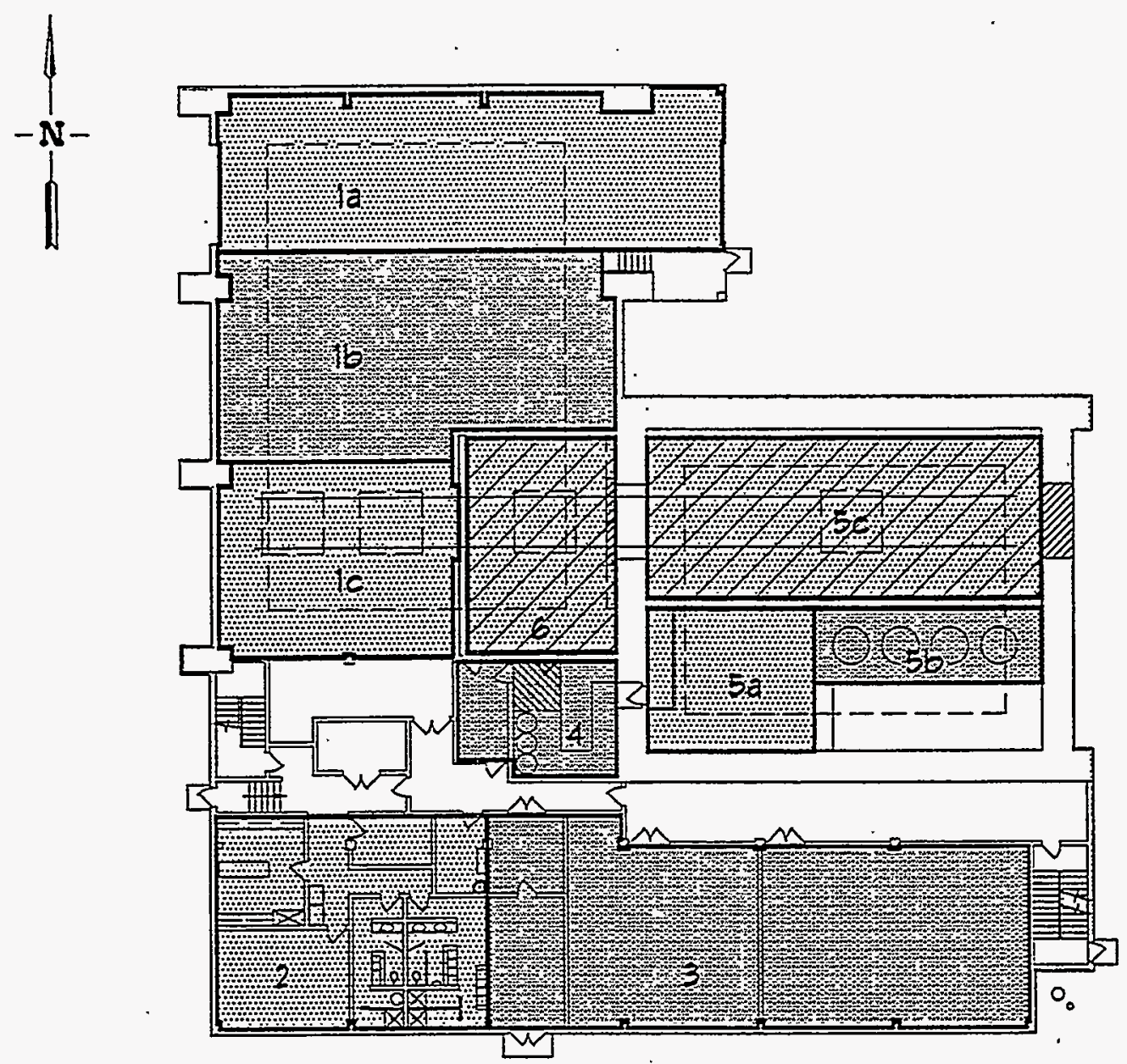

\section{LEGEND}

1.

\section{1:}

ㄴ.

2.

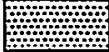

2.

3.
CASK HANDLING BAY

a. TRUCK BAY

b. LAYDOWN AREA

c. CASK STAGING AREA

ADMINISTRATIVE AREA

UTILITY SUPPORT AREA
4.

5.

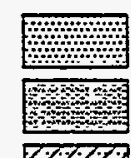

$\% \%$

6. \%
BUFFER AREA

HOT CELL

a. CANNING AREA

b. LAE STORAEE AREA

C. FUEL TRANSFER AREA

CASK PREPARATION AREA

Figure 3-1. DTC main floor plan. 


\section{SHIPPING CASK PROCESS FLOW}

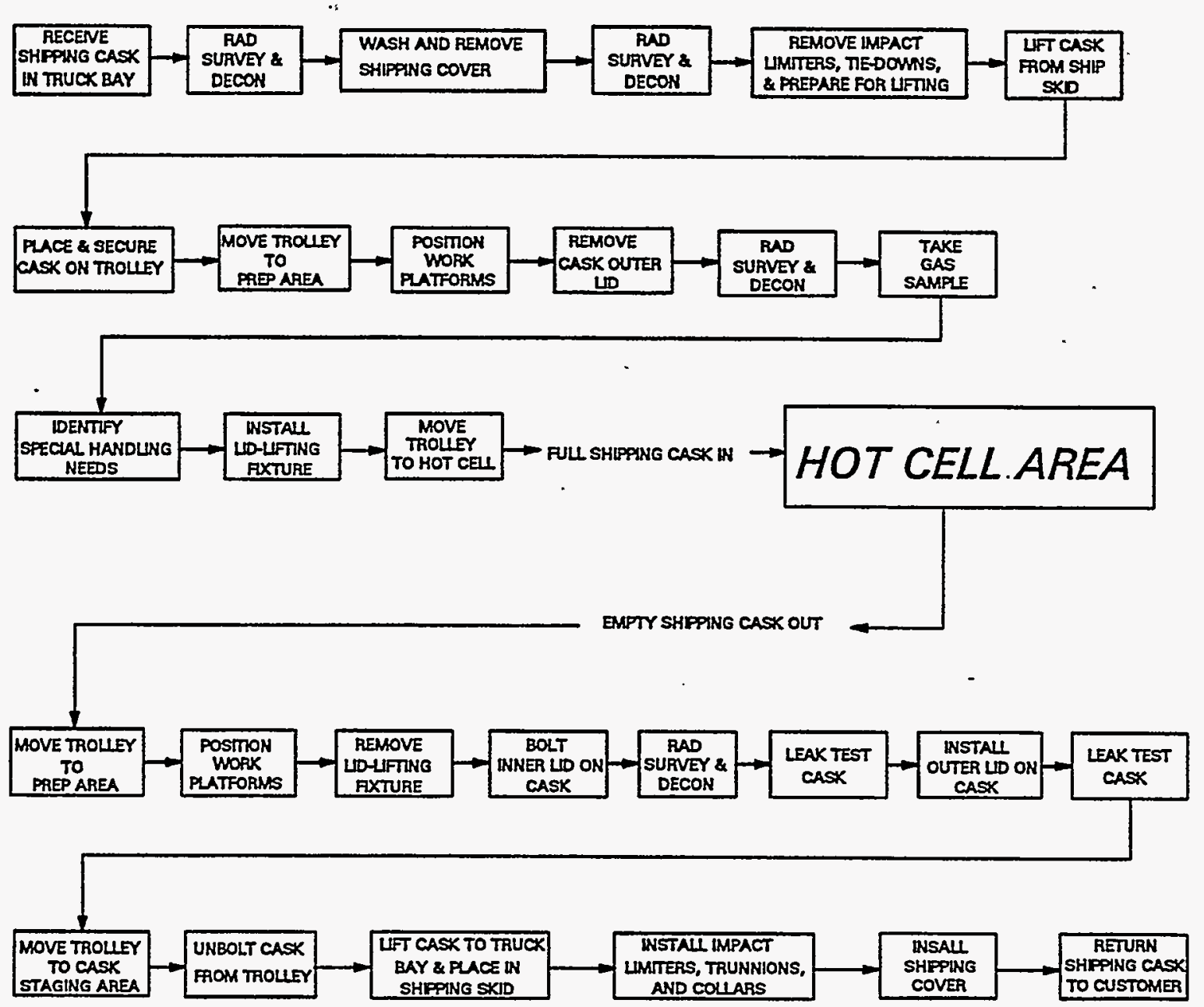

NOTE: Shipping cask trolley and transfer cask trolley travel on the seme tracks.

\section{SNF DRY STORAGE FACIIITY PROCESS FLOW DIAGRAM FIGURE 1 OF 3}

Figure 3-2. Block diagram of the flow of equipment and materials through the DSF. 


\section{HOT CELL PROCESS FLOW}

FOR OFF-SITE FUEL
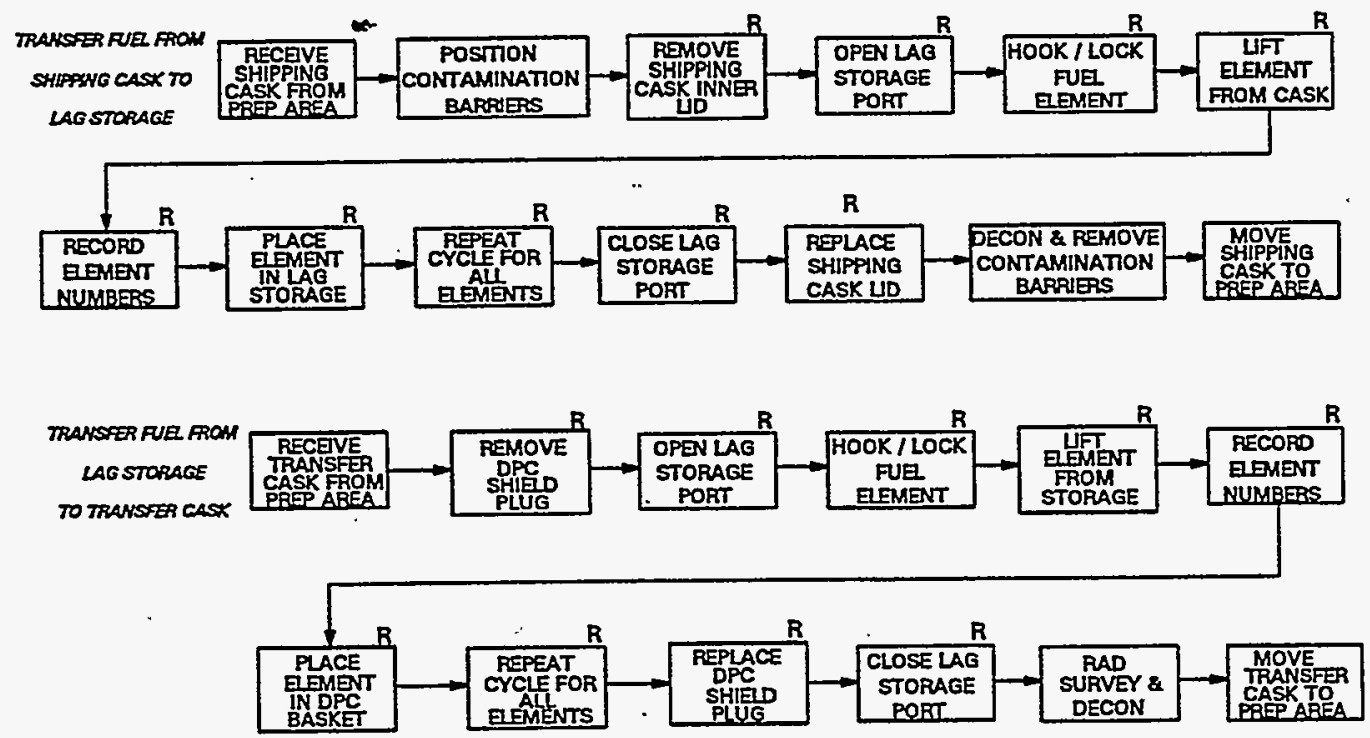

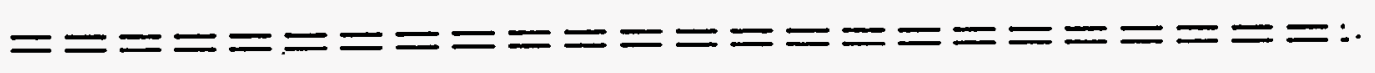

FOR ON-SITE FUEL

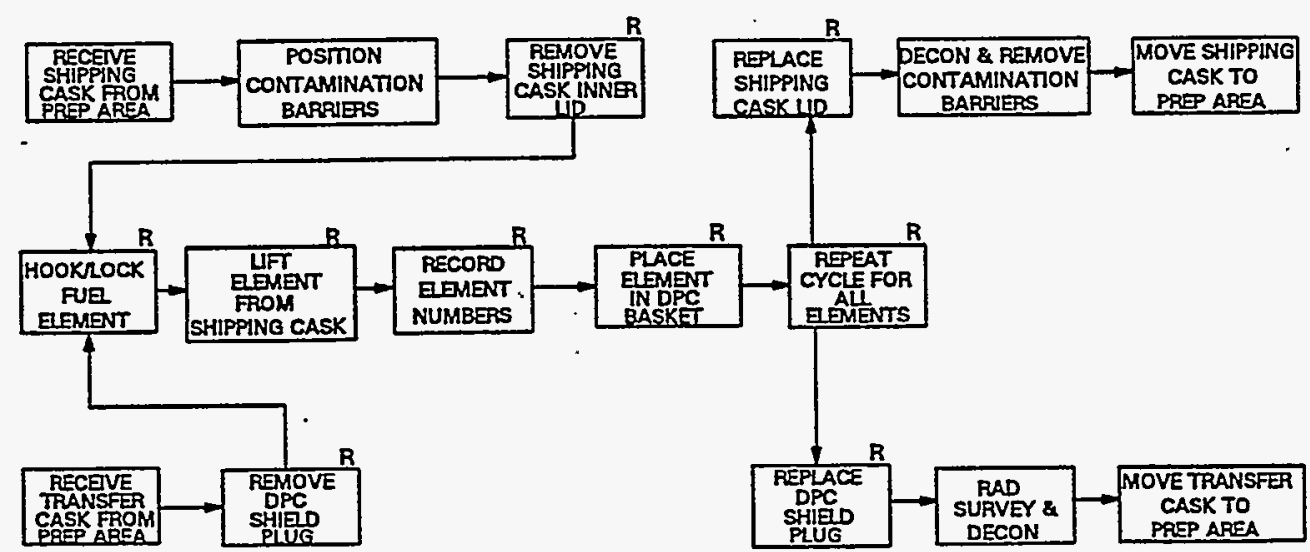

$R=$ REMOTE OPERATION

SNF DRY STORAGE FACIITY PROCESS FLOW DIAGRAM FIGURE 2 OF 3

Figure 3-2. (continued). 


\section{TRANSFER CASK PROCESS FLOW}

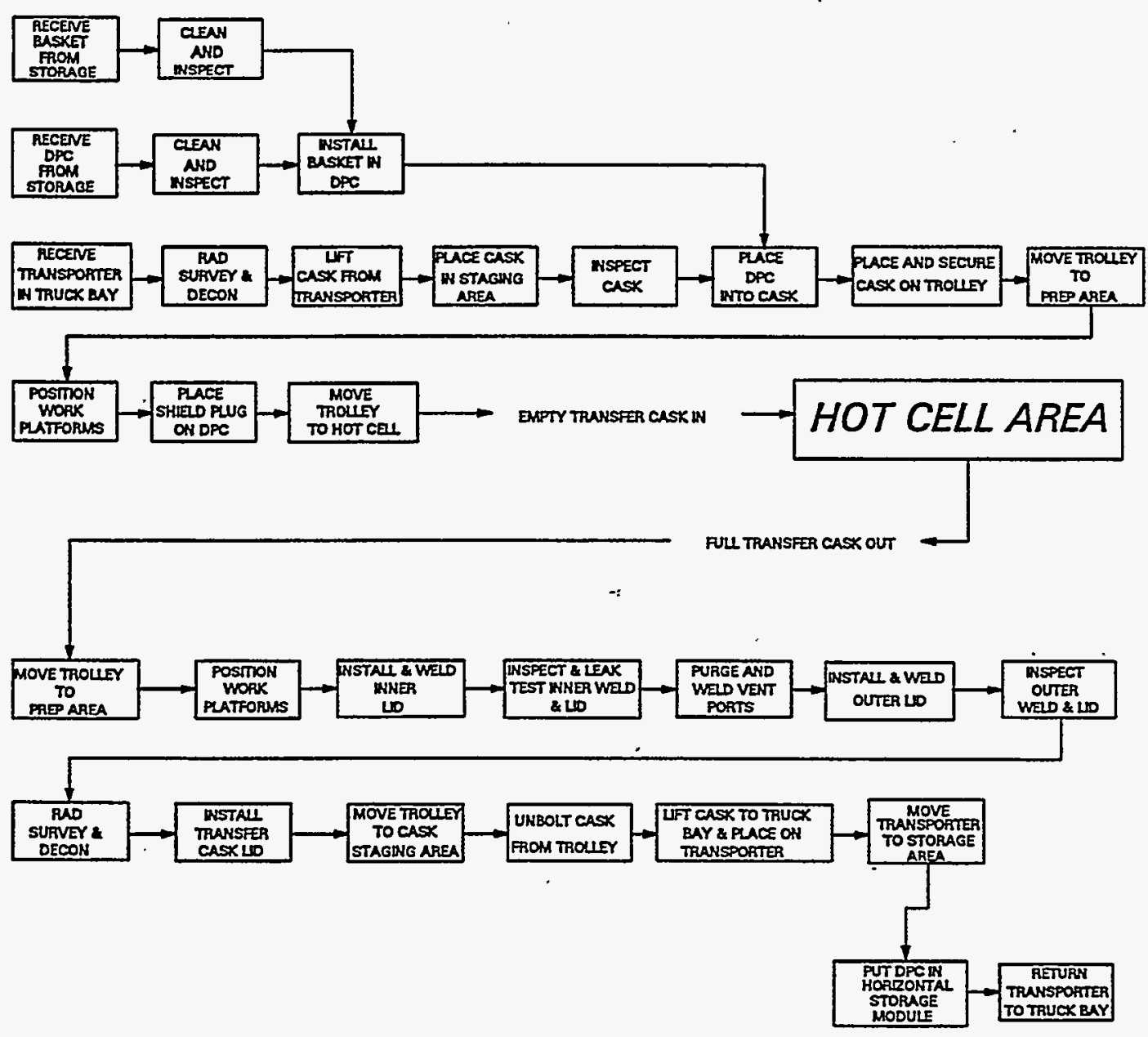

NOTE: Shipping cask trolloy and transfer cask trolloy travel on the samo tracks.

Figure 3-2. (continued). 
Once personnel are out of the Hot Cell, the crane is used to remove the cask lid and place it in a temporary laydown area within the Hot Cell. The lid from a selected lag storage vault is opened, and the fuel transfer crane is used to remove the fuel from the cask.

The fuel may be placed in a lag storage vault, or in a Dry Handling Bucket (DHB) for consolidation with other elements before placement in the vault. The latter sequence is used when handling small fuel cans or single elements that are appropriate for consolidating to minimize the handling efforts required later in the storage sequence. The typical sequence will be to place the fuel cans or rods in a DHB.

As the fuel is removed from the shipping cask, it is visually identified with use of an in-cell camera. This identification is recorded, as is the specific location of that element or can in the DHB.

DHBs are placed in lag storage when they are full or after the last of the fuel is removed from the cask. As in the case of individual elements and cans, the location of the DHB and the identification of its contents are recorded.

When feasible from a fuel shipping schedule standpoint, the DHBs may be placed in the DPC without being first placed in lag storage. This variation on the handling sequence is primarily limited to campaigns of fuel transfers that involve relatively few shipments to fill a DPC and where those shipments originate on-Site.

Once the shipping cask is empty, the lag storage vault and shipping cask lids are replaced. If transfers have been made to a DPC, then its shield plug is put into place. Personnel reenter the hot cell, package any contaminated temporary barrier materials for disposal, survey the cask and trolley to ensure they are clean, decontaminate if necessary, and then move the shipping cask on the trolley back into the Cask Preparation Area.

3.1.1.3 Shipping Cask Return Operations. The empty shipping cask is surveyed and decontaminated if necessary, the lid(s) is rebolted and the seal leak checked. Maintenance on the cask can be performed in the Cask Preparation Area if the trolley is not needed to maintain schedule, or the cask can be moved to the Cask Handling Bay and placed aside for more time-consuming maintenance. After completion of any required maintenance, the shipping cask is placed back on its shipping trailer and returned to the appropriate shipper for the next load. The shipping cask can be temporarily stored on the loading dock if required by shipping logistics.

3.1.1.4 DPC Loading. When sufficient fuel is accumulated in the lag storage vaults to fill a DPC, the receipt and handling of shipping casks is interrupted to load a DPC with the SNF from the lag storage vault(s). The onsite transfer cask is brought into the Truck Bay on its transporter. The cask is upended, removed from the transporter, loaded with a DPC and the canister basket (with loose shield plug set in place), placed on a transfer trolley, and moved into the Hot Cell.

Contamination barriers are placed in position, and the DPC shield plug is set aside.

The Hot Cell is vacated and the lid from the appropriate lag storage vault(s) is opened. The fuel transfer crane is used to move SNF from the lag storage vault to the DPC. As is required for all SNF movements, the location of each element, can, or DHB is tracked and recorded. 
Once the DPC is full, the lag storage vault lid is closed and the DPC shield plug is placed back on the DPC. The Hot Cell is then reentered and the transfer cask is surveyed, decontaminated if necessary, and prepared for moving to the Cask Preparation Area. Occupancy in the Hot Cell is minimized during these operations.

The transfer cask is moved into the Cask Preparation Area and the inner DPC lid is welded, inspected, and repaired if necessary. The DPC is leak checked, weld repaired if necessary, and filled with inert gas. The second DPC lid is put into place, welded, inspected, and repaired if needed. The transfer cask lid is secured to the transfer cask.

The transfer cask is then subjected to a final radiological survey and moved back to the Cask Handling Bay.

\subsubsection{DPC Transport}

Transport of the DPC, in the transfer cask, is performed with a custom trailer and tow vehicie. The transfer cask is moved with the crane from the trolley to the transfer cask trailer, and rotated to the horizontal position. From here the tow vehicle is used to haul the trailer and cask to the outside DSS (NUHOMS ${ }^{\circledR}$ System).

\subsubsection{Dry Storage System}

The DSS consists of a concrete basemat and a number of concrete vaults or modules. The modules are designed for shielding and passive cooling of the DPC, and each module holds a single, horizontally oriented DPC. The loaded, sealed DPC is pushed out of the transfer cask and into its assigned storage module with a hydraulic ram that is part of the transfer trailer. The storage module door is closed and welded. No further handling operations with the fuel and canister are required until the canister is retrieved for final disposition. Monitoring is performed for potential radiological releases, and periodic inspections are made to ensure security regulations are adhered to and that any off-normal conditions (such as obstructed storage module cooling vents) are identified and resolved.

\subsection{Civil}

\subsubsection{General}

The DTC will be located southwest of CPP-666 and the proposed location of the ICPP Interim Storage System project. This location, shown in Drawings T-1 and C-1, provides a convenient site for centralizing fuel transfer operations. This location was selected on the basis of a siting study included as Appendix D.

\subsubsection{Surface Drainage}

Surface drainage for this location is coordinated with the site drainage plan. Site run-off from the facility and DSS is diverted to ditches consistent with current ICPP controls. 


\subsubsection{Rock Excavation}

A soils investigation will be conducted during title design to determine soil properties for design. To the extent practical, the results of prior investigations will also be used. No rock excavation is anticipated at the proposed location.

\subsubsection{Soil Excavation and Shoring}

Initial earthwork consists of clearing and grubbing the site of any vegetation (minimal) and grading areas for the building, parking, access roads, and DSS. Excavation is required for utilities, spread footings and mat foundations.

\subsubsection{Finish Grading}

The finished floor of the facility is at an elevation of $4,918 \mathrm{ft}, 3.5 \mathrm{ft}$ above the truck bay. The floor of the truck bay is approximately $1 \mathrm{ft}$ above the existing grade and the entire area surrounding the building is sloped away to provide adequate drainage from the building to specified drainage paths. The DSS basemat (shown in Drawing C-5) will be constructed by excavating the area down a minimum of $1 \mathrm{ft}$ and then raising the area back up to $3 \mathrm{ft}$ above the existing grade to a finish elevation of $4,916 \mathrm{ft}$. This allows positioning of the storage module inlet vents above the $100-y \mathrm{r}$ flood elevation of $4,917 \mathrm{ft}$.

\subsubsection{Paving}

Asphalt and concrete paving is provided around the building and the access roads. The DSS paving consists of 3-ft-thick concrete basemats supporting the storage modules and 2-ft-thick concrete approach slabs. Asphalt roadways, parking, and turn-arounds are designed and constructed for a minimum vehicle load for an American Association of State Highway and Transportation Officials HS-20 loading. As a minimum, this consists of 4 in. of asphalt on a 6 -in.-thick crushed gravel base. A minimum of 12 in. of pit run gravel underlays the crushed roadbase. Roadways are a minimum of $20 \mathrm{ft}$ wide and provided with compacted gravel shoulders. The basemat, approach slab, and roadways are also designed to include all loads associated with the transfer operations of the NUHOMS ${ }^{\circledR}$ storage modules. Each horizontal storage module (HSM) is approximately 20 - $\mathrm{ft}$ long $\times 9-\mathrm{ft}, 8$-in. wide with a loaded weight of $300,000 \mathrm{lb}$. The NUHOMS ${ }^{\circledR}$ transport trailer has a gross vehicle weight of $258,000 \mathrm{lb}$ and is moved using a conventional road tractor. The trailer weight is uniformly distributed to 16 independently steered, dual-tire axles for a maximum wheel loading of $15,500 \mathrm{lb} / \mathrm{axle}$.

The prime mover axle loads are typically $15,000 \mathrm{lb}$ front; $22,000 \mathrm{lb}$ each on dual rear axles. During the canister transfer operation, the trailer is backed across the reinforced concrete approach slab and raised on four jacks that have a contact area of $1 \mathrm{ft}^{2}$. The loading on the jacks is uniformly distributed during the initial setting. As the canister is transferred to the HSM, the jack feet adjacent to the modules are loaded to a maximum value of $120,000 \mathrm{lb}$.

\subsubsection{Slabs, Sidewalks, and Stoops}

Reinforced concrete sidewalks, door stoops, and approaches are provided to facilitate personnel and vehicle access to the facility. No provisions for the physically handicapped are provided. Building utility and equipment pads are also reinforced concrete and sized to accommodate appropriate loadings. A bollard is provided at each vehicle entrance to the building. 


\subsubsection{Fencing}

Perimeter fencing surrounding the DSS consists of galvanized, pipe supported, 11-gauge steel fabric with 2-in. mesh openings. A $20 \mathrm{ft}$ clear zone will be maintained on each side of the fence. Fencing will be topped by three strands of barbed wire on a single 45-degree arm angled outward. Top rails are continuous along the top edge of the fence fabric. All installed fence hardware is peened or spot welded. The overall fence height, excluding barbed wire, is $8 \mathrm{ft}$. Fencing is grounded.

\subsubsection{Underground Utilities}

Utilities are provided by trenching to the existing location of utility services at ICPP. Pipe routing and connection points with existing ICPP utilities are identified in Drawing C-2. The sanitary sewer connection is located east of ICPP-665, which is approximately $400 \mathrm{ft}$ from the construction site. All other utilities are located in the utility tunnel which is located approximately $100 \mathrm{ft}$ from the construction site. All lines are cathodic protected and the steam line is also insulated. A sanitary sewer is provided by installation of a 8-in. ABS pipe line that will tie into the existing 8-in. sanitary sewer line. Steam will be provided by installation of a 4-in. carbon steel pipeline that will tie into the existing 12-in. high-pressure steam line located in the utility tunnel. Compressed air will be provided by installation of a 2-in. carbon steel pipeline that will tie into the existing 3-in. high-pressure air line located in the utility tunnel. Compressed gas will be provided by bottled gas located in the facility. Potable water will be provided by installation of a 2-in. carbon steel pipe line that will tie into the existing 4-in. potable water line located in the utility tunnel. Service waste will be provided by installation of a 2-in. carbon steel pipe line that will tie into the 4-in. service waste line located in the utility tunnel. During conceptual design, all associated utilities were analyzed for capacity utilization. All existing utilities have excess capacity and will provide the service needed.

\subsubsection{Site Demolition}

Site demolition includes the removal or destruction of several small buildings at the proposed DSS site. The buildings, shown in Drawing C-4, include two pre-engineered, steel-framed structures $25 \mathrm{ft} \times 30 \mathrm{ft}$ and $40 \mathrm{ft} \times 50 \mathrm{ft}$, a wood-framed structure $110 \mathrm{ft} \times 30 \mathrm{ft}$, and a 25 - $\mathrm{ft} \times 50$ - $\mathrm{ft}$ trailer. The latter two are currently scheduled for removal by other projects. All of these structures are single story. In addition, 1,200 linear $\mathrm{ft}$ of 8 - $\mathrm{ft}$ mesh fencing and removable concrete barriers will be removed.

\subsection{Architectural}

\subsubsection{General}

The new Dry Transfer Cell is a four-story structure consisting of approximately $26,000 \mathrm{ft}^{2}$. The building is a rough L-Shaped configuration with dimensions of $155 \mathrm{ft} \times 135 \mathrm{ft}$ and an overall height of $64 \mathrm{ft}$. Building plans, elevations, and sections are shown in Drawings A-1 through A-12.

The various areas within the building are in a controlled environment provided by the HVAC and filtering systems. Different pressures are maintained from area to area by containment barriers and sealable entries. Exposed surfaces of contaminated work areas are decontaminable. The door types and air lock arrangements maintain the pressures for these areas. 
Materials selected for the walls provide durability, low maintenance, shielding, insulation, and decontamination, with appropriate emphasis in these areas depending upon exact location and function within the facility.

The facility design is based upon a UBC occupancy classification for each area. The Administrative Area is Class B, the Cask Handling Bay Class is S-2, and the Hot Cell, Cask Preparation Area, Buffer Area, Operating Galleries, and Utility Support Areas are Class H-7. The UBC construction Type of II-N is used for the Facility.

3.3.1.1 Cask Handling Bay. Approximately $6,400 \mathrm{ft}^{2}$ is provided for washdown, loading, and unloading operations in the Truck Bay, Laydown Area, and Cask Staging Area, as shown on Drawings $A-1$ through $A-4$. This portion of the facility provides receiving and shipping services for the shipping and transfer casks and the DPCs. In addition to this principal function, this area supports minor decontamination and maintenance of transportation packages and provides temporary storage and support for internal handling equipment. A 150-ton cask handling crane with an auxiliary 15-ton hoist is supported over this area to handle the cask transportation package operations. The ground floor of the entire facility is elevated to match the height of the transport vehicle as it is positioned in the Truck Bay.

Truck Bay: This area is long enough for the longest transport package and supports washdown, maintenance, and inspection of the transport vehicle and shipping covers. A system is provided for the washdown of dirt and road grime from the transportation package carrier. An in-line holding tank system has provisions to collect, monitor, and dispose of washdown effluent.

Laydown Area: Space is provided for storing portable personnel barriers, overpacks, impact limiters, and shipping covers. Storage space is provided for special tools, unique to each cask, including lifting yokes and slings and devices necessary for the removal of shipping casks from the transportation vehicle. Storage space is also provided for cask appurtenances that must be removed while the shipping cask is in the loading and unloading cycle. Access is provided to all packages, vehicles, and installed components for purposes of testing, inspection, and maintenance.

Cask Staging Area: Trolley rails begin in this area of the Cask Handling Bay to enable the trolleys to travel into the Cask Preparation Area and the Hot Cell. Space for two trolleys is provided. Demountable work platforms above the trolley system are provided to access the top of the casks as they are inspected, maintained, and moved in and out of the Cask Preparation Area.

3.3.1.2 Cask Preparation Area. Approximately $1,000 \mathrm{ft}^{2}$ is provided for lid removal and installation, welding, gas sampling, and surveying activities of the casks entering and exiting the Hot Cell. In addition to providing space for the casks and working platforms, this area accommodates cask lids, DPC lids, automatic welding equipment, weld inspection equipment, lifting hardware and rigging, and an overhead crane.

Preparation: The preparation area includes a work location of sufficient space to accommodate the largest casks to be processed. The location includes a working area around the various casks at each required work elevation, a laydown area to accommodate cask secondary lids, special tools, and equipment, means for sampling and purging, and access to pressurized air, water, vacuum, and off-gas systems. Storage space is provided for contamination or shielding barriers. 
Maintenance: The maintenance system includes the equipment and areas required to ensure the continuing in-service status of each cask, including such operations as replacement of valves and seals, examination, and exchange of shipping cask internals.

Decontamination: The decontamination wipedown process includes the space and equipment needed for removing minor radioactive contamination from the exterior of the casks, whether loaded or empty.

3.3.1.3 Hot Cell. Approximately 4,500 $\mathrm{ft}^{2}$ is provided for the Hot Cell, which includes the Transfer Area, a Lag Storage Area, and a limited Canning Area. The Hot Cell is for movement of dry SNF from the shipping casks to the DPC, Lag Storage, or Canning Area. It includes shielded and decontaminable walls, floors, and ceilings, and remote handling devices, viewing windows, and closed circuit television monitoring to support removal and insertion of SNF out of shipping casks and into lag storage or DPCs. Interior surfaces of the shielded cell are coated to accommodate decontamination. A Buffer Area is provided next to the Hot Cell for a shielding labyrinth, leading to areas where anti-c clothing can be changed and personnel monitoring devices are located. The hot cell walls are made of 5-ft-thick reinforced concrete.

Canning Area: Canning operations are performed in the area next to the Lag Storage Area. The back side of this area, which has no wall, has a curb to contain expected small amounts of contaminated material that fall from the SNF assemblies as they are handled. An enclosure is also provided over the walkway to the Hot Cell exit passageway. The remote canning operations will be conducted with observation through shielded view windows on the next two floors from the Operating Corridors opposite the Hot Cell wall. The canning equipment anticipated for this area are listed below. For more detailed information, see Section 3.6 and Drawings A-1 through A-3, A-10 and A-11.

- Can Welder and Stand

- Weld Inspection/Test Equipment

- Can Piercing Tool

- Can Drying System

- Gas Sampling/Inerting/Purging Equipment.

Lag Storage Area: Lag storage vaults are provided to hold SNF between shipments when necessary to optimize DPC loading. Concrete shielding is provided around the four lag storage vaults to protect personnel entering the Hot Cell between shipments, the operators outside the cell, and the Cask Preparation Area. The Lag Storage Area consists of four concrete-shielded lag storage vaults with removable (for decon and maintenance) stainless steel sleeves and 14-tube DPC baskets. Cooling for the SNF in the Lag Storage Area is incorporated into the design. The top surface of the Lag Storage Area has storage space for the stepped concrete shield plugs that are removed from the vaults during SNF transfer. The equipment and space anticipated for this area are listed below. For more detailed information see Section 3.7.1.

- Four lag storage vaults with stepped concrete shield plugs 
- Dry Handling Buckets

- Passive cooling for SNF stored in lag storage vaults

- Effluent drain to the floor drain/sump system of the Hot Cell.

Transfer Area: The Transfer Area provides for remote removal of SNF from shipping casks, transfer to and from canning and lag storage, and placement in DPCs. The loading and unloading equipment and features located in this area are listed below. For more detailed information see Section 3.5 of this CDR.

- Fuel handling crane

- Two trolleys

- Lifting fixtures (rigging and handling gear, grapples, slings)

- $\quad$ Rolling Stairway

- Dry Handling Buckets (DHB) and racks/can storage racks

- Laydown area for cask lids.

3.3.1.4 Buffer Area. Approximately $500 \mathrm{ft}^{2}$ is provided for a shielding labyrinth leading from the Hot Cell to the Buffer Area and then to the Anti-C Change Room. Door assemblies are provided separating these areas from each other and maintaining the pressure barriers and shielding requirements necessary to provide clean and safe work conditions.

The Buffer Area provides space for discarded protective clothing used in the Hot Cell and a stepoff pad where contamination can be detected by a personnel contamination monitor. All surfaces in the Buffer Area are decontaminable. The Anti-C Room provides storage of clean Anti-C clothing and space for changing into the clothing.

3.3.1.5 Operating Galleries. Approximately 2,500 $\mathrm{ft}^{2}$ is provided for control and monitoring of remote handling and canning activities. The Operating Galleries are corridors a minimum of $10 \mathrm{ft}$ deep and run the entire length of the Hot Cell on multiple levels as required by viewing angles through the shielding windows and separated from the Hot Cell by a concrete shielded wall. See Drawings A-1 through A-3.

The Operating Galleries provide shielding windows, utilities, and space for crane consoles that will allow remote operations for the cranes inside the Hot Cell. The Operating Galleries have four shielding windows, tool drops, concrete shielded walls, pressure barriers, and future utility rough-ins.

3.3.1.6 Utility Support Areas. Approximately 7,000 $\mathrm{ft}^{2}$ is provided for HEPA Filter, Mechanical, Air Handler, Electrical Panels, uninterruptible power supply (UPS), Communication, Welding, Inert Gases, and Welding Observation Rooms. 
Approximately $1,000 \mathrm{ft}^{2}$ of the Utility Support Areas is provided for the Welding Equipment, Inert Gas storage and control systems, and Welding Observation Rooms located in various rooms and elevations to support facility operations. Equipment space is also provided next to the Cask Preparation Area for welding equipment and gas systems.

3.3.1.7 Crane Maintenance Areas. Approximately $1,100 \mathrm{ft}^{2}$ is provided for the Crane Maintenance Areas. The two Crane Maintenance Areas are located in the south end of the Cask Handling Bay and the west end of the Hot Cell at an approximate elevation of $145 \mathrm{ft}$ and are accessed by a common stair on the west end of the facility. The Crane Maintenance Areas are similar to catwalks in construction with grated floors suspended parallel to the bridge beams. See Drawings A-4, A-10, and A-12.

3.3.1.8 Administrative Areas. Approximately $1,600 \mathrm{ft}^{2}$ is provided for office and support areas for facility personnel. Office space for one supervisor is provided. This office will be provided with lighting, electrical receptacles, local area network, phone, glazed curtain wall for general observation and security, floor and wall coverings and other required furnishings as specified for administrative areas.

Approximately $350 \mathrm{ft}^{2}$ of the administrative area is provided for a Radiation Control and inspection office equipped with cabinetry, inspection and sniffing equipment, electrical receptacles, lighting, and decontaminable wall and floor coverings.

Approximately $400 \mathrm{ft}^{2}$ of the administrative area is provided for a Ready Room with conference furnishings for 8 to 10 people. Space and utilities for a vending machine will be accommodated just outside the Ready Room in the Corridor.

This area also provides space for men's and women's lavatories, showers, lockers, and change facilities, storage, and a janitor's room.

Approximately $3,500 \mathrm{ft}^{2}$ or $13 \%$ of the facility is assigned to stairs and circulation above and beyond the Operating Galleries.

\subsubsection{Building Features}

Building Construction: The floor areas within the facility are concrete slab-on-grade with a perimeter-insulated concrete foundation wall. The suspended floors and lower roof areas are supported by concrete with metal deck over steel bar joist. The suspended roofs over the Cask Handling Bay and the Hot Cell are supported by precast concrete beams, concrete core deck, with a concrete topping as shown on the drawings. Structural steel columns, beams, and joists are used in areas excluding the Hot Cell and the Cask Handling Bay. The latter two areas are constructed of reinforced concrete columns and beams.

Exterior Walls: The outer skin of the exterior walls of the Dry Transfer Cell, shown in Drawings A-6 through A-9, are of metal wall panel (similar to MBCI 26-gauge " $A$ " Panel) over batt insulation, over rigid insulation, meeting the recommended $R$ value of the INEL A/E Standards. The inner substrate wall is made of reinforced concrete, concrete masonry units (CMU), or metal stud with gypsum board. The overall thickness of the exterior walls varies as dictated by the structural, shielding and containment requirements. Glazing occurs in designated areas of the Administrative Area, the clerestory of the Cask Handling Bay, and specified areas of the Operating Galleries for natural daylighting. All glazing for 
these areas are of highly insulated multiple panes integrated at the factory of "Low E" or "High Efficiency" type glazing.

Interior Walls: The interior walls of the Hot Cell are sealed with a decontaminable coating. The CMU walls are painted or sealed with a decontaminable coating where potential contamination areas are to be located. Such potential areas are in the Cask Preparation Area, the Buffer Area, the HEPA Filter Room, and limited Mechanical Areas. The finished gypsum board walls over metal studs, used only in the Administrative Area, receive vinyl wall coverings to lower maintenance and increase life cycle savings.

The floors consist of reinforced concrete slabs on grade. Where washdown or decon activities are to be located, the floors will be sloped to drains, accommodate catch basins, in-line holding tanks, inserts, embedments, isolation/expansion joints, and recesses where required. Recessed floors in the restroom, shower, and locker areas will accommodate grout and tile. Mechanical, Electrical, UPS, Communication, Cask Handling Bay, Equipment, Fan, Stairways, Janitor Room, and Air Handling Rooms have sealed concrete floors. The floors for the Hot Cell, the Cask Preparation Area, the Buffer Area, the Operating Galleries, the HEPA Filter Room, and other supporting areas in the secondary confinement-area with potential radiation contamination have a decontaminable floor covering. Other floors will have a seamless vinyl floor surface. Recessed floor grating systems are provided at the main entry and vestibule.

The ceilings for the Ready Room, Supervisor Office, Rad Con Office, Lobby, and adjacent corridor are $2 \mathrm{ft} \times 2 \mathrm{ft}$ suspended lay-in acoustical tile and T-grid system. Lobby tiles have hold-down clips to prevent displacement when both pairs of entry doors are open and differential pressure occurs. Painted water-resistant gypsum board with vapor barrier ceilings are used in areas of high moisture such as showers, lockers and restrooms. Painted gypsum board are used for vestibule, janitor, observation rooms, and electrical rooms. The remaining areas of the facility are exposed to painted structure as described above.

The roof for the Dry Transfer Cell, shown in Drawing A-5 is a built-up 5-ply roof with the best warranty and life cycle features. This roofing system will be further evaluated in Title Design to ensure original cost and projected maintenance are considered in life cycle costs. The lower roofs are accessed through doors shown on the drawings and the high roof is accessed through a roof hatch from the west stair at the Crane Maintenance Area at $145 \mathrm{ft}$ elevation.

Doors, Windows, and Glazing: Passage doors are flush hollow metal construction with hollow metal frames. Exterior passage and vertical lift doors are insulated and weather sealed. Fire-rated doors have solid mineral cores with appropriate fire-rated labels, and non-rated fire doors have a rigid honeycomb construction core. All locks and cylinders are by the same manufacturer, and all exterior passage doors are secured by card readers. Interior locks are cipher locks with key override for fire protection purposes. All air locks and vestibule doors have glazing (tempered) provided where appropriate. The doors used as pressure/containment barriers receive perimeter seals and automatic door bottoms. All exterior glazing (which is minimal) are insulated with thermally broken frames.

Four Radiation Shielding Windows are installed (as shown on Drawings A-2, A-3, and A-10) at multiple levels, maximizing view angles for observing and controlling remote operations within the Hot Cell. 
Vertical lift doors and bi-parting shield doors are required as noted on the drawings to address various design functions such as insulation, weatherization, containment, pressurization, and radiation shielding. Doors for all $\mathrm{H}-7$ occupancies meet the requirements for areas having area openings to maintain pressure, shielding, and containment barrier separation. ' Special mechanical operator devices and inflatable seals are required in these areas. Door opening space accommodates floor space functions and head room requirements. Standard insulated vertical lift doors with weather seals at the perimeter are used for the entrances to the Truck Bay.

Specialties and Accessories: The facility is equipped with both cabinet and bracket-mounted fire extinguishers throughout. The type of extinguisher, size, and method of mounting are determined by the requirements for the location. Except for the clerestory windows, the exterior windows are equipped with horizontal slat venetian blinds. The Ready Room and Supervisors Office are equipped with dry marker boards. A ceiling mounted, pull-down projection screen is located in the Ready Room. Toilet accessories including dispensers, mirrors, toilet partitions, lockers, benches, cubical and shower curtains and mop racks are included.

Furniture and Equipment: The Ready Room will is provided with wall-mounted cabinetry and cupboards (see Ready Room section for appliances to be installed). A conference table with seating for a minimum of eight people is provided. The Supervisors Office and Rad Con office has the standard GSA furniture compliment.

Signage: A complete signage package is provided for this facility addressing loads, restrictions, gender, Codes, confined spaces, operations, etc.

\subsection{Structural}

\subsubsection{General}

The building is a concrete and steel-framed structure with an interior reinforced concrete hot cell area.

\subsubsection{Classification and Design Loads}

Subpart F, "General Design Criteria ," of 10 CFR 72, presents the general design criteria that are applicable to an ISFSI. USNRC Reg Guide 3.6 identifies ANSI/ANS-57-9-1984 as a recommended guideline for the design of an ISFSI which complies with 10 CFR 72.

All permanent and transient loads that could exist or be developed during normal operation of the facility shall be considered. The following loads are considered:

- Dead Load-Dead load of the structure and attachments including permanent equipment and piping.

a. Areas having quantities of materials in excess of those listed in Table 3-E, UBC that are health hazards as listed in Section 307.1.1, UBC. 
- Live Load-Live loads include snow and rain, operating loads including impact, and vibratory and design transient loads due to operating equipment. Live loads will be determined as required by ANSI/ASCE 7-95, "Minimum Design Loads for Buildings and Other Structures."

- Thermal Loads-Thermal loads occur during operations due to restraint conditions and reaction of the structure from equipment, piping, etc. Thermal loads may be neglected when it is shown that their resultant stresses are secondary and self-limiting in nature and the response of the structure is ductile.

- Lateral Soil Loads-lateral soil pressures and groundwater effects are considered to the extent applicable:

- Snow Load-A ground snow load of at least $35 \mathrm{lb} / \mathrm{ft}^{2}$ will be used in ANSI/ASCE 7-95 calculations. A minimum roof snow load of $30 \mathrm{lb} / \mathrm{ft}^{2}$ is required in all INEL designs.

- Natural Phenomena Loads:

- Seismic: 10 CFR 72 requires that the design earthquake to be considered for the facility are the SSE for a nuclear power plant with a minimum peak horizontal ground motion of $0.10 \mathrm{~g}$ with the appropriate response spectrum as referenced in 10 CFR 100 , Appendix A. The SSE is to be defined by response spectra corresponding to the maximum vibratory accelerations at the elevation of the foundation of the structure. The response spectra are developed from a series of response spectra related to the vibratory motions caused by more than one earthquake. U.S. NRC Reg Guide 1.6 is an acceptable procedure for defining the design response spectra, unless site-specific response spectra data is available. The engineering method used to ensure that the required safety functions are maintained during and after the SSE include the use of a suitable dynamic analysis. 10 CFR 100 requires that the structure to be designed so that if the SSE occurs, specific structures, systems, and components will remain functional. These components are those necessary to ensure; (1) the integrity of the pressure boundary, (2) the capability to shut down the facility and maintain it in a safe condition, and (3) The capability to prevent or mitigate the consequences of accidents that could result in potential offsite exposures.

- Wind Loads: Loads generated by the design basis wind at the 100-yr reoccurrence level per the requirements of ANSI/ASCE 7-95. This requirement is consistent with DOE-1020 standards which are applicable to other INEL structures. Tornado loads shall consider as a minimum ANSI/ANS-2.3.

- Flood: The design flood elevation for the 100 -yr flood is $4,917 \mathrm{ft}$ for this area of the ICPP.

- Off-Normal Operating and Accident Loads-Loads due to a temperature rise resulting from loss of cooling air for an extended period of time or loads resulting from the maximum anticipated heat load are considered, as well as loads due to a drop of a heavy load as 
described in Structural Analysis and Design of Nuclear Plant Facilities, ASCE Manual No. 58.

- Load Combinations-Structures are designed using applicable load combinations and stress limits stipulated in ASCE 7-95, American Institute of Steel Construction, AISC N690, American Concrete Institute, ACI-349.

\subsubsection{Footings and Foundations}

The building foundation is reinforced concrete consisting of individual spread footings for the steel-framed portion of the building. The hot cell and cask handling areas use continuous wall footings, reinforced grade beams and slab-on-grade construction. Footings are extended beyond the recorded frost depth to a minimum depth of $5 \mathrm{ft}$ below grade. The administrative area slab is limited to office area type loads and is constructed of 5-in.-thick reinforced concrete.

\subsubsection{Structural Framing Systems}

Hot Cell-The hot cell area is constructed of 5-ft-thick reinforced concrete walls which extend approximately $64-\mathrm{ft}$ in height. Walls are supported by continuous footings and grade beams. The roof of the hot cell is constructed of prestressed concrete girders with precast hollow core panels spanning between girders. An 8-inch cast-in-place concrete topping complete the roof framing construction.

Cask Handling Bay-The walls of the cask handling bay are 2-ft-thick reinforced concrete with 8-ft $\times 4$ - $\mathrm{ft}$ pilasters spaced at 30 - $\mathrm{ft}$ intervals. The wall system is supported by continuous spread footings and tied together with 6-ft $\times 4-\mathrm{ft}$ grade beams. The roof is designed with 6-ft deep prestressed concrete girders with precast hollow-core panels spanning between girders. An 8-in., cast-in-place concrete topping completes the roof framing construction.

Administrative Areas-The Administrative area and upper floors of the facility are constructed of braced structural steel framing, steel joists, and concrete decking.

\subsubsection{Special Structural Features}

Crane Support Systems-The 150-ton cask handling crane is supported by the 2-ft thick concrete wall and pilasters. The concrete walls provide shear resistance in the north-south direction and resistance in the east-west direction is provided by tying the pilasters together with the opposing pilasters and hot cell wall with 6-ft $\times 4$-ft grade beams and 6-ft deep prestressed concrete girders. The roofs of the hot cell and cask handling bay is designed to transfer the diaphragm forces generated. The crane in the hot cell is supported directly by the 5 -ft thick concrete walls.

\subsection{Handling Systems}

The DTC Handling Systems comprise those systems that are responsible for the physical movement of the fuel from receipt to storage. The primary operating functions of the Handling Systems are:

- Transportation package receiving, unloading and handling 
- Fuel transfer from shipping cask to DPC

- Cask transfer and DPC emplacement into storage

- $\quad$ DPC retrieval and loading into the transportation package.

The handling systems are also required to support other tasks such as cask preparation, fuel canning, decontamination, inspection and characterization, and welding. The primary handling systems or interfaces to the handling system are:

- Cranes

- Cask Handling Crane

- Cask Preparation Area Crane

- Fuel Handling Crane

- $\quad$ Cask Transfer System (Trolleys)

- Multipurpose Transfer Cask and Transporter

- $\quad$ Lifting Fixtures

- $\quad$ Cask Work Platforms

Details of each of these systems are provided in the following sections.

\subsubsection{Cranes}

The design and performance requirements for the cranes in the DTC are provided in ANSI/ANS 57.9. Those requirements are specified by the function of the crane, its location in the process facility, and the importance (from a safety, criticality, and radiological release standpoint) of the lift. Some interpretation of the requirements is necessary to accommodate differences between the facility design and operations assumed in ANSI 57.9 and the design of the DTC as described in this document. The derived requirements specified in the description of the cranes are intended to meet the intent of ANSI 57.9 and the NOG-1 specification which implements most of those requirements.

Because the cost and complexity of single-failure proof cranes are significant factors in the overall design of the DTC, the circumstances that influenced the crane specifications will be discussed here. First, a number of key definitions provide a basis for discussion on how the crane specifications were derived.

The following definitions are from ANSI/ANS 57.9 and ANSI/ASME NOG-1. 


\section{Design Events (From ANSUANS-57.9)}

Design Event I. Design Event I consists of that set of events that are expected to occur regularly or frequently in the course of normal operation of the DTC facility. Examples are the following:

- Transportation package receipt, inspection, unloading, maintenance, and loading

- Preparation of fuel units

- Transfer of spent fuel assembly from DTC to DSS

- Handling of radioactive waste generated during operations

- Insertion of fuel units into or retrieval from storage modules.

Design Event II. Design Event II consists of that set of events that, although not occurring regularly, can be expected to occur with moderate frequency or on the order of one during a calendar year of DTC operation. Examples are the following:

- A loss of external power supply for a limited duration

- A single operator error followed by proper corrective action

- Minor mechanical failure of spent fuel transfer machine during operation

- Failure of any single active component to perform its intended function upon demand

- Spurious operation of certain active components.

Design Event III. Design Event III consists of that set of infrequent events that could reasonably be expected to occur during the lifetime of the DTC. Examples are the following:

- A loss of external power supply for an extended interval

- Major mechanical malfunction involving the spent fuel transfer machine during operation (no loss of shielding but retrieval of fuel required)

- Dropping a fuel unit in a hot-cell area

- Loss of shielding optical oils in a hot-cell viewing window.

Design Event IV. Design Event IV consists of events that are postulated because their consequences may result in the maximum potential impact on the immediate environs. Their consideration establishes a conservative design basis for certain systems that are important to confinement. Typically, this set of events consists of plant-specific design events. 


\section{Crane Types and Other Definitions (From ANSI/ASME NOG-1)}

Type I Crane-A crane that is used to handle a critical load. It shall be designed and constructed so that it will remain in place and support the critical load during and after a seismic event, but does not have to be operational after this event. Single-failure-proof features shall be included so that any credible failure of a single component will not result in the loss of capability to stop and hold the critical load.

Type II Crane-A crane that is not used to handle a critical load. It shall be designed and constructed so that it will remain in place with or without a load during a seismic event; however, the crane need not support the load nor be operational during and after such an event. Single-failure-proof features are not required.

Type III Crane-A crane that is not used to handle a critical load; no seismic considerations are necessary, and no single-failure-proof features are required.

Critical Load-Any lifted load whose uncontrolled movement or release could adversely affect any safety related system when such a system is required for unit safety or could result in potential offsite exposure in excess of the limit determined by the purchaser.

Credible Critical Load-Combinations of lifted loads and plant seismic events which have a probabilities of occurrence equal to or more than $10^{-7}$ times per calendar year at the plant of the crane installation. The critical loads handled by the crane, and their duration of lifts, shall be used in the calculations to determine the credible critical load to be considered for the crane in the crane design load combinations which include seismic loadings. The credible critical load shall be specified by the purchaser.

Single-Failure-Proof Features-Those features which are included in the crane design such that any credible failure of a single component will not result in the loss of capability to stop and hold the critical load within facility acceptable excursion limits.

With these definitions, some key assumptions can be made regarding general and specific design requirements for each of the DTC crane systems.

\section{Assumptions:}

- Since structural and mechanical design criteria are largely driven by earthquake loads, it is necessary to define what earthquakes fall under which Design Events. The Operating Basis Earthquake (OBE) is assumed to be a Design Event III. The Safe Shutdown Earthquake (SSE) is assumed to be a Design Event IV.

- $\quad$ Any cask loaded with SNF shall be considered a critical load. Many of the casks that are to be processed through the DTC are not licensed for over-the-road transport (onsite only). These casks are not rated for a drop. Even those casks that are licensed are drop-rated only with the impact limiters in place. Although it is unlikely that in any drop scenario that an offsite release could occur, a drop could compromise the confinement barriers of the SNF and significantly impact the health and safety of workers in the occupied areas of the DTC. 
- SNF elements handled during remote operations in the hot cell shall not be considered a critical load. The basis for this assumption is twofold: First, the hot cell is designed for remote operations and the consequences of a fuel element drop should not compromise any safety systems, the health and safety of the workers, or result in an offsite release. Second, the fuel handling crane will be designed with sufficient single-failure proof features and system redundancy to recover from equipment failures, off-normal events, and accidents (such as dropping a fuel element).

- Other cranes (regardless of location in the DTC facility) not handling critical loads are not required to be single-failure proof (Type I) cranes. This may appear obvious, but there is some ambiguity between the ANSI/ANS 57.9 and the ANSI/ASME NOG-1 specifications in this regard.

3.5.1.1 Cask Handling Crane. The Cask Handling Crane is a 150/15-ton, top-running, double-girder overhead bridge crane located in the Truck Bay (see Figure 3-3). It is a NOG-1, Type I crane, specified to provide single-failure proof features per the requirements of ANSI/ANS 57.9.

The performance requirements derived from ANSI/ANS 57.9 for the Cask Handling Crane are:

- Provide equipment for off-loading and loading the transportation package for Design Event I

- Provide the capability to load into or remove DPCs from the transfer machine of the DSS for Design Event I

The functional design requirements derived from ANSU/ANS 57.9 for the Cask Handling Crane are:

- The Cask Handling Crane should be designed to accept all of the transportation packages expected to be handled at the DTC.

- The Cask Handling Crane and its support systems shall be designed to withstand all design loadings, including the design phenomena, while remaining in place. The crane may lose its function, but this loss of function shall not result in a loss-of-load incident.

This crane is the major lifting device for handling spent nuclear fuel casks and other heavy equipment in the facility. It is used in conjunction with rigging equipment to load and unload shipping casks and transfer casks from transporters. The 150-ton crane may also be used to load DPCs into the Transfer Casks before fuel transfer. The 15-ton auxiliary hoist is used for lighter-duty work such as removing impact limiters and other rigging equipment. It can also be used for handling smaller casks.

The crane bridge runs on north/south running rails mounted on reinforced concrete walls (see Drawings $\mathrm{A}-4, \mathrm{~A}-10$, and $\mathrm{M}-3$ ). The crane rails are approximately $45 \mathrm{ft}$ high and are $90 \mathrm{ft}$ long. The maximum lift of the crane will be approximately $40 \mathrm{ft}$. The crane ratings are based on the expected loads presented in Table 3-1. The crane is conservatively designed to accommodate future growth and to ensure all possible configurations of casks and rigging do not exceed the rated capacity of the crane. 


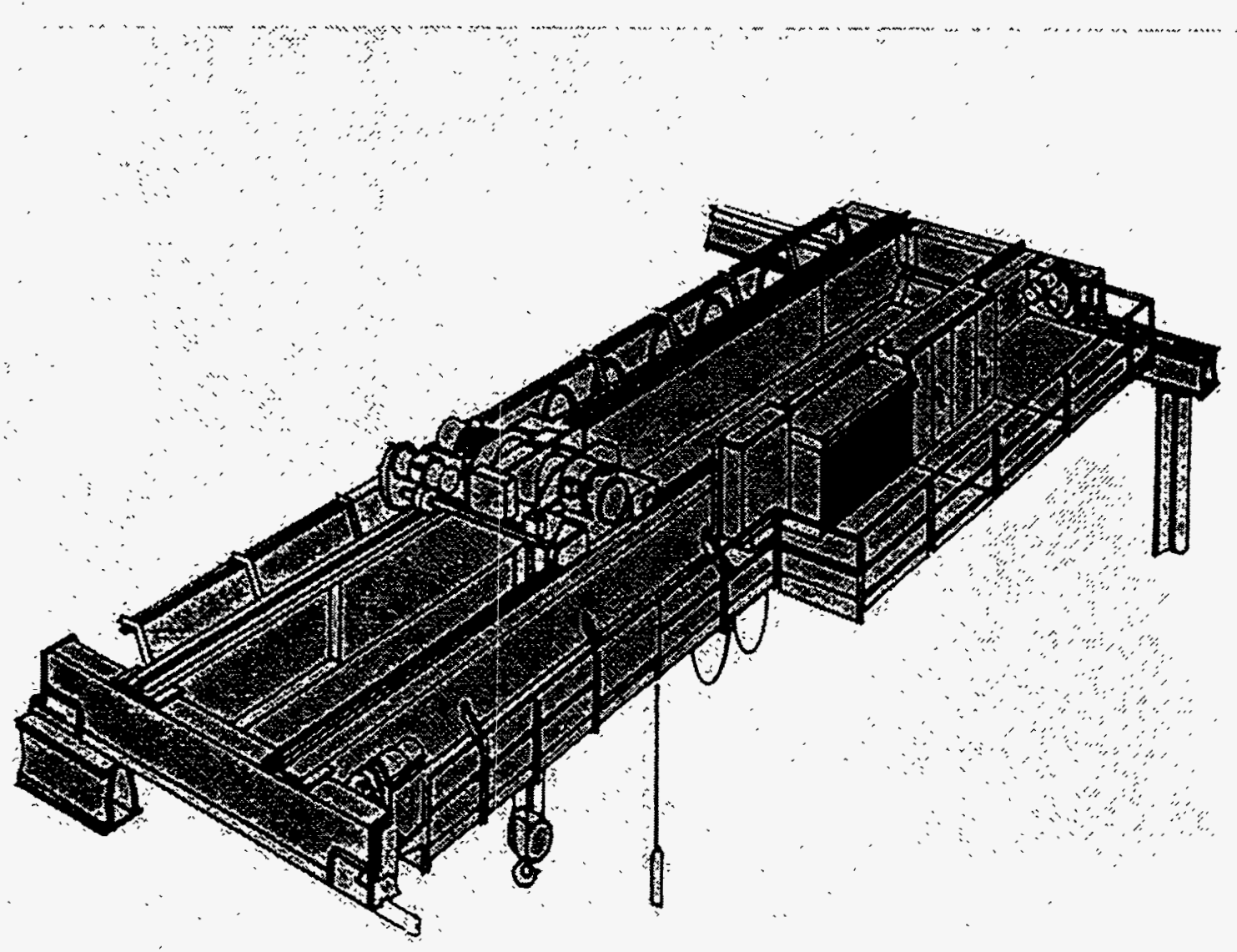

Figure 3-3. The Cask Handling Crane is a top-running, double-girder overhead bridge crane similar to that shown above.

The Cask Handling Crane is not in a radiation area. The operating environment is typical of a continuously occupied modern indoor nuclear facility. The crane is designed to withstand the SSE, while remaining in place. It may lose its function, but this loss of function will not result in a loss-of-load incident.

Single-failure proof features for a Type I crane are included for both the primary (150-ton) and the auxiliary (15-ton) hoist. Electrically controlled dynamic breaking is used.

The crane/bridge trolley drive type shall be an A1 or A-A1, the preferred bridge drive type shall be an $A 4$, and the drive axles will be rotating type. No open gearing shall be permitted.

The crane is controlled via a radio link. A backup pendant control is provided. The crane is to be controlled from the main floor and from the crane maintenance mezzanine. 
Table 3-1. Cask Handling Crane load drivers.

\begin{tabular}{|c|c|}
\hline Capacity & Drivers $^{\mathrm{a}}$ \\
\hline $150 / 15$ ton & $\begin{array}{l}125 \text { tons-Fully Loaded NUHOMS }{ }^{\oplus} \text { MP-187 Cask (approximate) } \\
100 \text { tons-Fully Loaded NUHOMS }{ }^{\oplus} \text { MP-197 Cask (approximate) } \\
8 \text { tons-Impact Limiters (each) }\end{array}$ \\
\hline & $\begin{array}{l}\text { (TN-REG and TN-BRP Casks and Impact Limiters fall within the NUHOMS } \\
\text { envelope) }\end{array}$ \\
\hline
\end{tabular}

a. Does not include the weight of the rigging. All values are rounded up to the nearest ton.

Load weighing devices are provided. Hoist speeds are approximately $5 \mathrm{ft} / \mathrm{min}$ for the 150 -ton hoist and $25 \mathrm{ft} / \mathrm{min}$ for the 15 -ton hoist. The maximum trolley and bridge speed is approximately $50 \mathrm{ft} / \mathrm{min}$.

The avoidance of two-blocking is accomplished by the use of single-failure-proof features that do not rely on any action by the operator. The normal hoist limit switch is supplemented by an independent final hoist limit switch operated by the load block to remove power from the hoist motor and brakes.

Equipment is provided to de-energize the crane power supply in a seismic event. The hoist brakes are capable of holding the credible load during a seismic event.

The crane bridge passes directly over the ceiling of the Cask Preparation Area. A restricted handling path will be implemented so that crane loads and rigging equipment do not interfere with the Cask Preparation Area. The handling path is shown on Drawing A-1.

Light fixtures are provided on the crane bridge to illuminate the area below as the crane moves. A signal system is provided to indicate crane operating status. A flashing warning light is provided on the bridge to indicate that the crane is energized, and an annunciator indicates when the crane is in motion.

3.5.1.2 Cask Preparation Area Crane. The Cask Preparation Area Crane is a 7.5-ton overhead crane illustrated in Figure 3-4. It is a pendant-controlled NOG-1, Type II underhung monorail bridge crane except as noted herein. Technically, the NOG-1 specification covers only top running bridge, multiple girder, overhead and gantry cranes. However, NOG-1 specifies the earthquake structural requirements for the crane as well as the desired quality and inspection criteria. For Type II cranes, the Crane Manufacturers Association of America (CMAA) specifications cover all the other design criteria. For this configuration, CMAA-74 "Specification for Top Running and Under Running Single Girder Electric Traveling Cranes Utilizing Under Running Trolley Hoist" shall apply.

The Cask Preparation Area Crane is used for handling cask outer lids, tools, and other heavy equipment such as the DPC welding machine. The crane ratings are based on the expected loads shown in Table 3-2. 


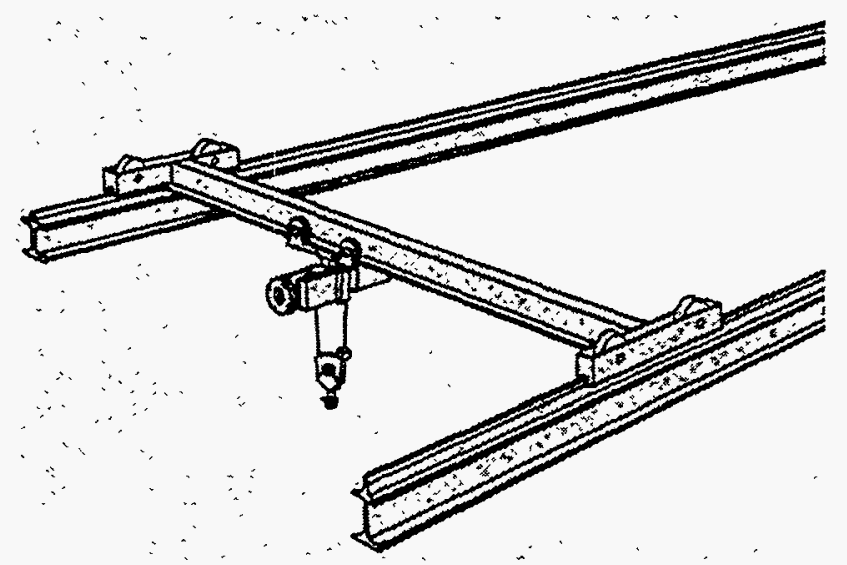

Figure 3-4. The Cask Preparation Area Crane will be a NOG-1, Type II underhung monorail with top running bridge crane. It will utilize a 7.5-ton low headroom hoist with motor geared trolley and bridge.

Table 3-2. Loads used for sizing the Cask Preparation Area crane.

\begin{tabular}{ll}
\hline Capacity & \multicolumn{1}{c}{ Drivers $^{\mathrm{a}}$} \\
\hline \multirow{3}{*}{7.5 ton } & 4 ton-Cask Outer Lid (MP-187 Top Closure) \\
& 3 ton-Cask Outer Lid (MP-197 Top Closure) \\
& 1 ton-DPC Inner Lid \\
& 1 ton-DPC Outer Lid \\
& 2 ton-Welding Machine (Includes Neutron Shield and DSC Inner Lid \\
& Assembly)
\end{tabular}

(TN-REG/TN-BRP do not have inner lids or shield plugs)

a. Does not include the weight of the rigging. All values are rounded up to the nearest ton.

The crane bridge runs on north/south running rails mounted on reinforced concrete walls (see Drawings A-12, M-3, and M-5). The crane rails are $28 \mathrm{ft}$ high and $30 \mathrm{ft}$ long. The maximum lift of the crane will be approximately $26 \mathrm{ft}$. The crane is designed with excess capacity to accommodate future growth and to insure all possible configurations of tools and rigging do not exceed its rated capacity.

The Cask Preparation Area Crane is not in a radiation area. The operating environment is typical of a continuously occupied modern indoor nuclear facility. The crane is designed to withstand a seismic event, while remaining in place, although it is not required to retain the load during the seismic event.

3.5.1.3 Fuel Unit Handling Crane. The Fuel Unit Handling Crane subsystem consists of a single overhead running double-girder bridge crane (see Drawings A-11 and M-4) upon which are mounted two trolleys. Each trolley contains a 2.5-ton capacity telescoping z-mast (so called because the mast only travels in the vertical or ' $z$ ' direction) with a teleoperated manipulator system mounted on the end of 
each mast. Each trolley also incorporates a 15-ton hoist. The fuel handling crane is radio-controlled and designed in accordance with NOG-1 as a Type I crane except as noted herein. This ensures that no single-failure of the handling system will preclude returning the fuel assemblies to their storage locations in the transfer or shipping cask or to lag storage. The crane is designed for both normal operating loads and seismic loads where possible. The electrical system is designed so that the operator can stop and hold a load regardless of the failure of any single component used in normal operations.

The performance requirements derived from ANSIANS 57.9 for the Fuel Unit Handling Crane are as follows:

- Provide remote handling of fuel units for Design Event I and after Design Events II, III, and IV

- $\quad$ Provide the capability for special tooling to handle structurally damaged fuel units subsequent to Design Events II, III, and IV.

The most significant functional design requirements derived from ANSV/ANS 57.9 for the Fuel Unit Handling Crane are as follows:

- When provision for remote maintenance is not made, handling equipment for fuel units and transportation package closure lid(s) shall have sufficient redundancy so that no singlefailure in the handling system will preclude returning unshielded fuel units to shielded storage locations or returning the closure lid(s) to the transportation package.

- Grapples, lifting attachments, and handling equipment for fuel units and transportation package closure lid(s) shall be designed for remote operations, and active lifting components shall be designed to retain their load and fail in a same manner (i.e., in the "latched" state) in the event of loss of actuating power. An independent, remote means shall be provided to disengage any grapple in the cell in the event an active grapple component fails to operate. Grapple operating envelopes shall be designed to be compatible with all interfacing storage and transportation systems.

- Grapples and lifting fixtures for handling fuel units or transportation package closure lid(s) shall be designed to provide positive engagement during a lift, and the grapples and associated controls shall be designed to minimize the potential for inadvertent disengagement. A means shall be provided to indicate that positive engagement has been achieved and to indicate the disengaged position.

- The cranes shall employ redundant limit switches and interlocks to prevent excessive horizontal movement that could affect operation or cause damage to the units being handled, as well as to prevent excessive vertical movement including two blocking. Redundant means of disconnecting power to the cranes shall be available to the operator. The means shall be independent of, and physically separated from, the normal controls, but conveniently located within the planned work area. Redundant means of braking vertical travel shall be provided. Braking of horizontal motion should be provided as necessary to facilitate the required positioning precision. 
- If the possibility exists for fuel units to catch on lips or protrusions during lifting or lowering, the lifting equipment shall have interlocks to sense an unacceptable change (either an increase or a decrease) in hoisting force and automatically stop further travel.

- Remote handling equipment shall be incorporated into the design of the area to permit performance of normal process operations. Particular attention shall be given in the design to methods and equipment required to recover from equipment failures, off-normal events, and accidents.

- Special procedures for handling damaged fuel or damaged fuel units should be anticipated and provisions made in the design.

In addition to the requirements specified in ANSI/ANS 57.9, some of the facility-specific Fuel Unit Handling Crane requirements that must be addressed are the following:

- The Fuel Unit Handling Crane shall be of a flexible design to handle multiple (and often poorly documented) fuel configurations, weights, and attachment (grapple) points. A variety of grapples and other tools for fuel movement shall be provided.

- The system shall accommodate a wide variety of shipping (source) casks.

- The Fuel Unit Handling Crane shall support canning operations.

The design of the Fuel Unit Handling Crane is largely based on the highly successful and proven design used for dry fuel transfer at the INEL Test Area North Hot Shop. Improvements necessary to meet single-failure proof requirements and to provide redundant systems for off-normal events and accident recovery have been added, as well as many basic improvements resulting from the evolution of the hardware.

The following is a general description of the system:

The Fuel Unit Handling Crane uses teleoperated manipulators, a suite of remotely attached tools suspended from the shoulder hook on the z-masts, and/or the 15-ton hoist to grapple fuel assemblies in shipping casks, lift them vertically, and move them to a dry handling bucket. When full, the dry handling bucket is moved with either the z-mast or hoist to either a lag storage location or the DPC. Since the system has a full range of motion in the $\mathrm{X}, \mathrm{Y}$, and $\mathrm{Z}$ directions, it is adaptable to all of the anticipated cask designs. Furthermore, the $\mathrm{z}$-masts and manipulators are sized to provide manipulator access to most of the Hot Cell below their bridge mount. This full range of motion along with the high degree of dexterity inherent in the design of the manipulators reduces the need for additional in-cell manipulators to perform other tasks. Locating the two manipulators with z-masts on separate trolleys on the same bridge allows for both independent and cooperative manipulator operations for maximum system flexibility. The ratings for the lifting components of the Fuel Unit Handling Crane are based on the expected loads listed in Table 3-3.

Redundant mechanical systems and the single-failure proof features of a NOG-1, Type I crane (e.g., extra-limit switches, dual-reeved hoists, redundant brakes) ensure that no single-failure in the handling system preclude returning unshielded fuel units to shielded storage locations or returning the 
Table 3-3. Load drivers for sizing the Fuel Unit Handling Crane z-mast, manipulators, and hoist.

Capacity

Hoists-15 ton

Z-masts-2.5 ton

Manip $1-250 \mathrm{lb}$

Manip 2-250 lb
Drivers $^{\mathbf{a}}$

\author{
15 ton-Lag Storage Plugs \\ 9 ton-BWR/PWR Basket (Qualified for Over-The-Road \\ Transport) \\ 5 ton-DPC Shield Plug (FO or FC) \\ 6 ton-TN-REG/TN-BRP Cask Lid \\ 4 ton-Heavy Fuel Element (Shippingport LWBR)
}

1 ton-Nominally Heavy Element

$100 \mathrm{lb}$ or less-Light Fuel Element

a. Does not include the weight of the rigging. Values are rounded up to the nearest ton.

closure lid(s) to the casks. This includes the use of two trolleys on the bridge. Each trolley is identical and contains a $\mathrm{z}$-mast with manipulator, and hoist. Each trolley is independently capable of performing all of the duties required to perform a fuel transfer or to recover from the failure of the other trolley. The trolleys are designed to engage and push/pull each other in the event of the failure of a trolley drive unit. The bridge has a dual drive system, either of which is capable of moving the bridge in the event of a failure of one of the drive systems.

The z-masts and the manipulators do not meet all requirements of a NOG-1, Type I crane for two reasons. First, it is not practical from a structural standpoint to design the z-masts to withstand seismic loads with the mast in the extended position. However, the z-masts will withstand the seismic loads while in the stowed (fully retracted) position. During any fuel movement, one of the z-masts will be fully retracted so it will survive a seismic event and be available to recover from the potential failure of the other one. All other aspects of the z-mast's design meet NOG-1, Type I requirements for singlefailure proof design. Second, the manipulators are not designed to be single-failure proof. However, they are designed so that the motors will not move under load with the power off. Interlocks on the manipulator prevent inadvertent release of the fuel by locking out the normal release signal when there is a load on the manipulator or grapple. An override capability is provided to allow release when specifically needed. Much of the fuel handling will be performed with grapples meeting the requirements of ANSI/ANS 57.9 suspended from the shoulder hook of the manipulator or from the hoist. The manipulators will primarily be used for rigging, tool handling, removing and installing lid bolts, and other high dexterity tasks. The manipulators will be used for direct fuel handling only when no other means is readily available. 


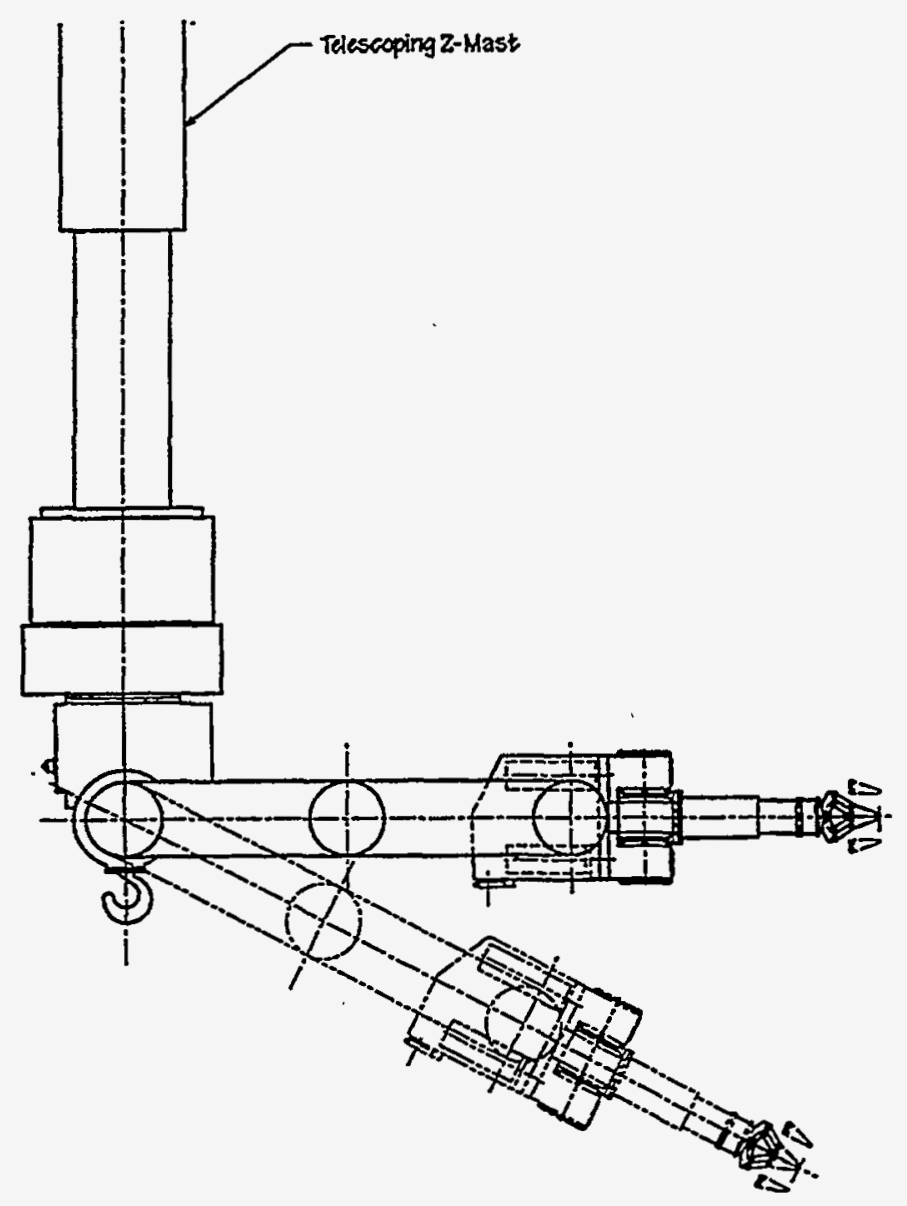

Figure 3-5. An anthropomorphic teleoperated manipulator will be located at the end of each z-mast.

The manipulators are Par 6350 telerobotic manipulators or equivalent (see Figure 3.5-3). The manipulator's configuration is a six-degree-of-freedom anthropomorphic arm that is electrically actuated by the remote master controller. Overall reach of the manipulators is approximately 90 in. Load rating

at any hand orientation is a minimum of $250 \mathrm{lb}$. The manipulators are electrically-driven and mounted on the end of the telescoping $z$-mast. Interchangeable end effectors are provided for each of the two manipulators for maximum operational flexibility. A parallel jaw hand, single hook, dual hook, and a wide variety of tools and accessories can be used with the manipulators. A coupling on the wrist assembly allows these tools to be easily interchanged remotely. Coupling or uncoupling of a hand or accessory is accomplished by straight-line motion of a spring-loaded collar on the wrist. Change fixtures for remote operations will be provided. A tool power receptacle located at the wrist permits use of tools equipped with 115 volt ac/dc universal motors up to $1 / 2$ horsepower.

All wiring is internal and the manipulators are sealed to allow decontamination washdown. Internal motors drive the shoulder pivot, elbow pivot, wrist pivot, and hand. A hook is attached below the shoulder of the manipulator for use with the z-mast to hoist up to 5,000-lb loads. Vertical mast travel is provided using either ballscrew or dual reeved hoists. Vertical mast travel will provide positive drive for mast extension or retraction. If maintenance is required on the manipulators, $z$-masts, or trolleys, the 
bridge will moved to a crane maintenance area. Panels on the manipulators are designed to be easily removed to allow access for repairs.

The crane control system includes robotic control of the bridge, trolley, and three mast axes with the six manipulator axes. A portable controller suitable for operation from multiple viewing windows will provide the operation interaction with the control system. Bridge, trolley, and mast controls are conventional.

The accumulated radiation exposure expected to be seen at the crane bridge is estimated to be approximately $1 \times 10^{5}$ Rad over the 30-year life of the facility. The accumulated radiation exposure expected to be seen at the electro-mechanical manipulator is estimated to be approximately $1 \times 10^{7} \operatorname{Rad}$ over the 30-year life of the facility. Note that the facility life is 30 years with an extension of 30 years possible. If a service life extension is required, equipment will be analyzed for replacement based on actual total exposure. Radiation-hardened optics and electronics for high radiation fields will be utilized. The motor control center for the crane will be located outside the hotcell for ease of maintenance and radiation protection.

Other features and specifications for the Fuel Handling Crane include:

- Single-failure proof features for a Type I crane shall be included for the $z$-mast and the 15-ton hoist. Electrically controlled dynamic braking shall be used.

- The trolley drive type shall be an $\mathrm{Al}$ or $\mathrm{A}-\mathrm{A} 1$, the preferred bridge drive type will be an $A 4$, and the drive axles will be rotating type. No open gearing shall be permitted.

- The crane shall be controlled via a radio link. A backup pendant control shall be provided.

- Load weighing devices shall be provided. Hoist speeds will be approximately $25 \mathrm{ft} / \mathrm{min}$ for the z-mast and $25 \mathrm{ft} / \mathrm{min}$ for the 15-ton hoist. Trolley and bridge speed will be approximately $50 \mathrm{ft} / \mathrm{min}$.

- The avoidance of two-blocking shall be accomplished by the use of single-failure-proof features and do not rely on any action by the operator. The normal hoist limit switch shall be supplemented by an independent final hoist limit switch operated by the load block to remove power from the hoist motor and brakes.

- Equipment shall be provided to de-energize the crane power supply in a seismic event. The hoist brakes will be capable of holding the credible load during a seismic event.

- Light fixtures shall be provided on the crane bridge to illuminate the area below as the crane moves. A signal system shall be provided to indicate crane operating status. A flashing warning light shall be provided on the bridge to indicate that the crane is energized, and an annunciator shall indicate when the crane is in motion.

Pan and tilt camera units with zoom lenses shall be mounted on each of the trolleys to provide wide-area closed-circuit TV monitoring capability for remote operations. Additional cameras shall be placed on the manipulators to provide close views of fuel handling operations. Some cameras may also 
be included on fuel handling grapples to aid the operator in picking the fuel elements and to confirm grapple engagement. Cameras shall supplement direct viewing of operations via the operating gallery window control stations. An audio channel shall be provided from the hot cell to the operating gallery. Microphones in the hot cell shall be connected to adjustable volume speakers in the operating gallery to provide operators with audio feedback during operations. This has been proven to be an effective means of increasing an operator's awareness of the situation in the remote operating area.

\subsubsection{Trolleys (Cask Transfer System)}

The Cask Transfer System includes the trolleys, the rails on which they are mounted, adapters for accommodating different casks, and the attendant control system. The design of the cask transfer system is based on a design prepared by Trans Nuclear Inc., for the DOE Office of Civilian Radioactive Waste Management (OCRWM) for a similar facility.

The trolleys are approximately $11 \mathrm{ft} \times 9.8 \mathrm{ft} \times 3.4 \mathrm{ft}$ and have capacities of 125 tons. They run on rails $9 \mathrm{ft}$ apart that are at or slightly below the floor surface level. The main components of the trolleys are made of painted carbon steel. See Drawing M-14.

The cask adapters include tapered centering guides, bolted to the top plate of the trolley, to guide the cask in place during lowering. These centering guides will resist horizontal loading during a seismic event.

The cask is supported on the trolley by means of trunnion cradles and other fixtures with bolted tiedowns. The trunnion cradles are bolted to the top plate of the trolley. The trunnion cradles and tiedowns and other fixtures are designed to prevent the cask from becoming disengaged during a seismic event. The trolley and cask configurations are shown in Drawings M-12 and M-13.

The trolley is driven through one wheel on each side by a synchronous motor. The variable speed motor provides a trolley speed between $0.7 \mathrm{ft} / \mathrm{min}$ and $10 \mathrm{ft} / \mathrm{min}$. The trolley moves at its selected fast speed for gross positioning and at the slow speed for fine positioning. Limit switches mounted on the rail stop the trolley and ensure that it is positioned properly in the Cask Staging Area, Cask Preparation Area, and the Hot Cell.

The trolley has two braking mechanisms: a service brake and an emergency brake. The service brake is located on the motor drive shaft. The emergency brake is located on the output shaft. Both brakes engage upon loss of electrical power. The emergency brake is automatically engaged as a parking brake when the trolley is not in motion.

Each trolley is locked in place by a locking pin that engages a corresponding hole in the concrete floor in the Cask Staging Area, Cask Preparation Area, and the Hot Cell. This prevents the trolley from sliding along its rails while work is being performed on the cask. The locks prevent damage to equipment or injury to personnel in the event of inadvertent activation of the trolley. The pins are designed to handle the forces resulting from the combined seismic loading and normal operation loads on the locking pin.

Trolley guidance is provided by two sets of lateral rollers on one of the two runway rails. Lateral rollers are used instead of flanged wheels to ensure accurate positioning of the trolleys on its rails. 
Because of the heavy weight of the transfer cask and trolleys, and the need to prevent them from tipping over, a special rail was designed as shown.in Drawing M-14.

A plate mounted beneath each trolley, which runs below the runway rail at each wheel location, prevents the trolleys from tipping over in a seismic event.

Bumper guards are located at the end of each runway rail to prevent damage to the trolleys. A tow ring for attaching a pulling device in the event of a motor failure is mounted on one end of the trolley.

The electrical cables for the motor and sensors on the trolley are run under the floor. The slack in the electrical cables is taken by a winder mounted on the base of the trolley.

Sensors are used to ensure that the Cask Transfer System operates properly. Examples of these sensors are:

- Limit switches on the trolleys (one on the front and one on the back), which stop motion in the event of a collision with the bumper guards. These prevent damage to the equipment.

- Limit switches mounted on the rails, which stop the trolleys at predesignated locations in the Cask Staging Area, Cask Preparation Area, and Hot Cell.

- Switches located in the locking pin housings in the concrete floor, which indicate that the locking pins are fully engaged. These are interlocked with the trolley controls to prevent powering the drive motors when the locking pin is engaged.

All maintenance and repair operations are performed manually. To keep personnel radiation exposures as low as reasonably achievable, trolley repairs and maintenance will normally be performed only when the casks are removed. As a minimum, the casks will be closed before any maintenance or repair is done on the trolleys. A tractor or winch can be used to pull the trolleys if the motors fail.

\subsubsection{Lifting Fixtures}

Lifting yokes are used to remove casks from transporters. The three lifting yokes depicted in Drawings $\mathrm{M}-10$ and $\mathrm{M}-11$ handle all shipping and transfer casks currently identified for use inside the DTC. Each yoke is designed for upending and lifting the variety of shipping and transfer casks. Two of the yokes are open hook designs with parallel lifting arms. The other yoke has closed-hooks, high strength wire rope, and a spreader beam. They are fabricated from high strength carbon steel plate material and are coated with a decontaminable coating. The lifting yokes connect to the hook on the 150-ton overhead crane in the Cask Handling Bay. The yokes are staged on racks for the convenience of attaching the cask handling crane hook. The racks are located on the north wall of the Cask Preparation Area.

Standard lifting and rigging gear are also be used in the facility. Nylon slings, wire rope, eyebolts, and shackles are used in conjunction with the overhead crane to lift the cask transport covers from the transporters and to remove impact limiters. These covers and impact limiters are staged in the Cask Handling Bay for inspection, maintenance, and repairs. Additional standard lifting and handling equipment are staged in the Cask Preparation Area and Hot Cell for lifting and moving cask lids, shield plugs, welding machine, etc. 
The lifting yokes are designed and fabricated in accordance with the ASME B\&PV Code rules for Class 2 component supports (Section III, D Subsection NF, excluding Subsection NCA), NUREG-612 and ANSI-N14.6 requirements for special lifting devices. Utilization of these criteria meets or exceeds the requirements of 10 CFR 72 and ANSI/ANS-57.9 as well as 10 CFR 50. These codes and standards require that the lifting yokes be conservatively designed and need not be specified as single-failureproof. These yokes will be designed with factors of safety of 6 on material yield strength or 10 on material ultimate strength.

\subsubsection{Multipurpose Transfer Cask and Transporter}

The Multipurpose Transfer Cask used in the dry storage system provides shielding and protection from potential hazards during the fuel handling and transfer operations. The transfer cask has a 92.5 in. outside diameter and is 201.5 in. high with a 68 -in. inside diameter by 187 -in.-high inner cavity and a maximum payload capacity of $200,000 \mathrm{lb}$. The transfer cask is designed to meet the requirements of 10 CFR 71 and 10 CFR 72 as a multipurpose cask. As shown in Figure 3-6, the transfer cask is a nonpressure-retaining cylindrical vessel constructed of two concentric cylindrical steel shells, a bolted top cover plate, and a welded bottom end assembly. The annulus formed by the two shells is filled with cast lead for gamma shielding. The transfer cask also includes an outer steel jacket which is filled with hydrogen-rich grout for neutron shielding. The top and bottom assemblies also incorporate neutron shield grout. The transfer cask is designed to provide sufficient shielding to ensure that dose rates are less than $200 \mathrm{mR} / \mathrm{hr}$ at contact for a DPC filled with $24 \mathrm{PWR}$ or $52 \mathrm{BWR}$ commercial fuel assemblies.

The transfer cask is designed to be loaded with SNF in the vertical position and transported (via custom trailer) in the horizontal position. Two lifting trunnions are provided for handling the cask using a lifting yoke and overhead crane. Lower support trunnions are provided on the cask for pivoting the transfer cask from/to the vertical and horizontal positions on the transport trailer.

The tow vehicle, transfer-cask transport trailer, and cask, are shown in Figure 3-7. The transfer cask transport trailer is a dedicated, 8-axle, 32-wheel vehicle used to transport the horizontal cask and DPC over a road leading from the DTC Truck Bay to the basemat. The trailer has a 125-ton payload, is $21 \mathrm{ft}$ long $\times 12 \mathrm{ft}$ wide, and with the heavy haul road tractor, has a turning radius of $8.5 \mathrm{ft}$. Hydraulic jacks at all four corners raise and align the cask with the Horizontal Storage Module (HSM) before the DPC is inserted. The trailer is equipped with a hydraulic ram for pushing the DPC out of the cask and into the HSM. When the DPC is eventually removed from storage, the ram pulls it out of the HSM and back into the transfer cask.

The steps required to place the DPC in the HMS are as follows: The cask with DPC will have been placed on the trailer, lowered to the horizontal position, and the trunnion tie downs will have been installed as part of the DTC cask handling operations. The tow vehicle will be coupled to the trailer and the entire assembly hauled to an empty HSM. The tow vehicle, with the aid of the individual trailer axle steering system, will align the cask with the HSM. This configuration is shown in Figure 3-8. An optical alignment system is used to adjust the trailer corner jacks to align the DPC with the rails in the HSM. The top lid (back end) of the cask is removed, the HSM shield door is opened, and the ram penetration cover plate is removed from the bottom (front end) of the cask. The ram is then extended through the cask penetration port, coupled to the ram grapple ring on the bottom to the DPC, and actuated to push the DPC into the HSM on the guide rails. When the DPC is fully inserted, the ram is withdrawn and the HSM shield door is closed. The cask top cover plate and ram penetration cover plate are replaced, the corner jacks withdrawn, and the trailer and empty cask are towed from the basemat. 


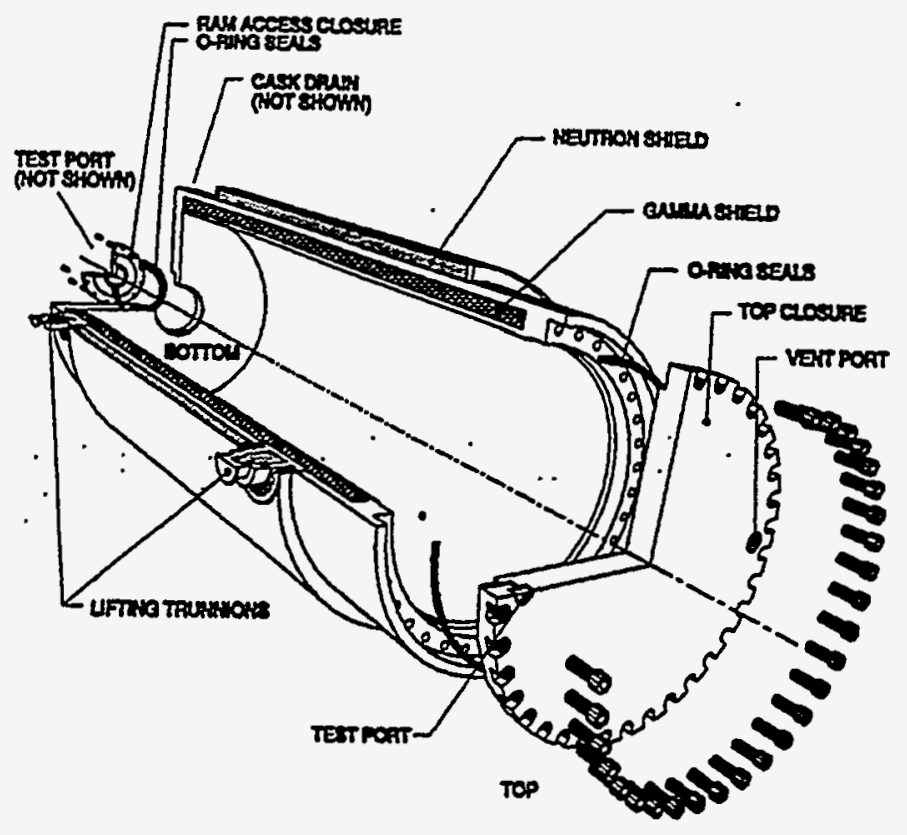

Figure 3-6. DPC transfer cask.

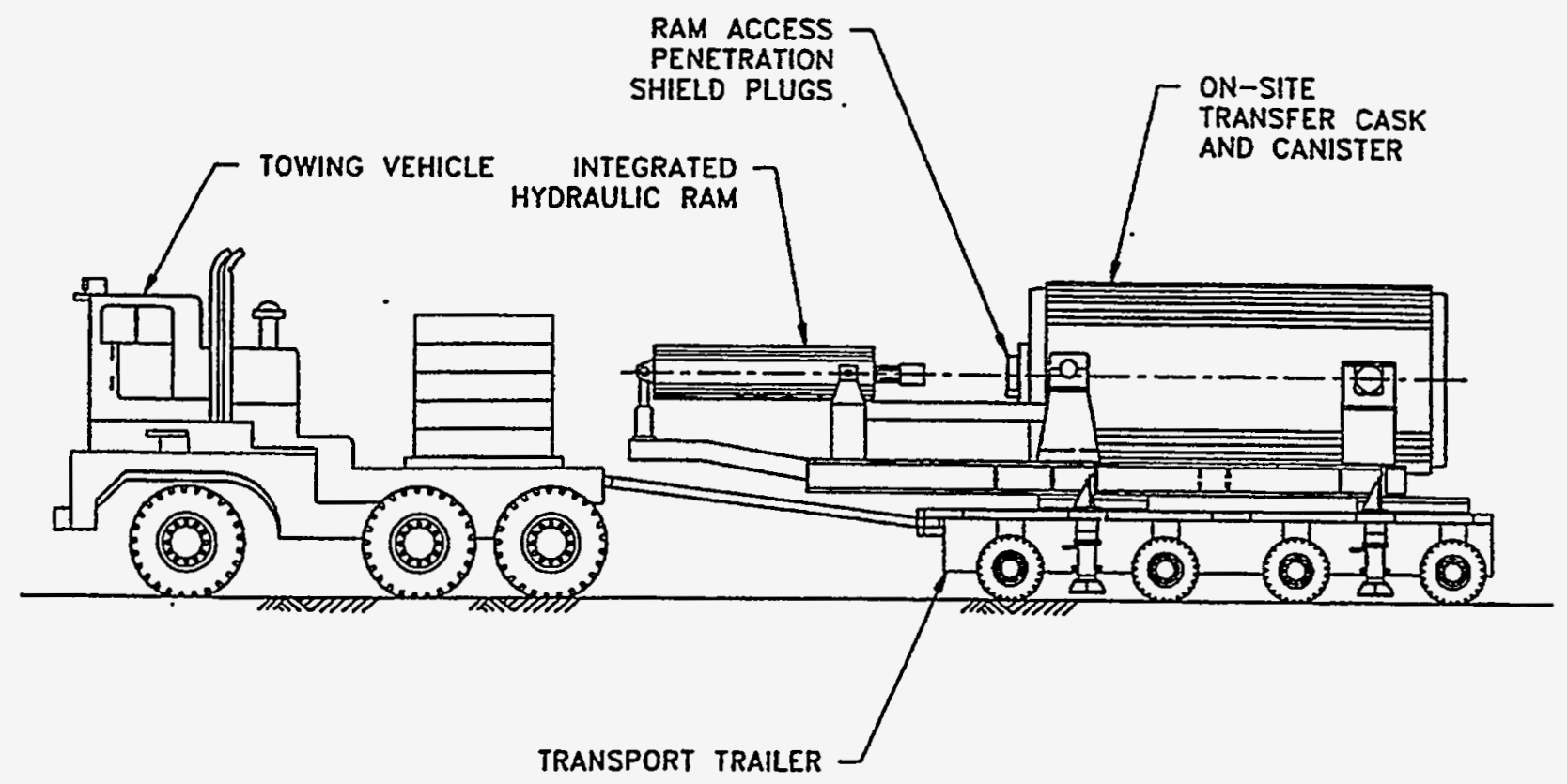

Figure 3-7. The onsite DPC transfer cask is mounted on a dedicated transport trailer with tow vehicle. 


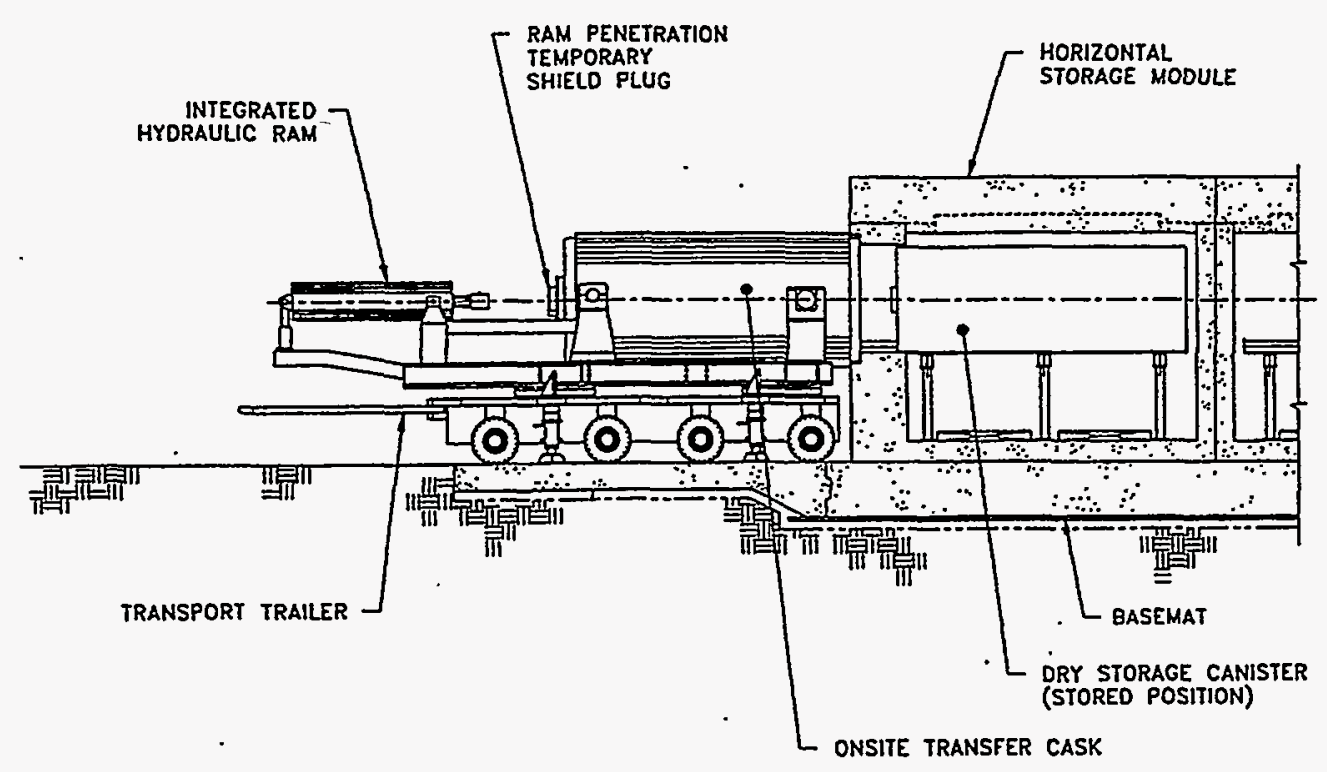

Figure 3-8. The onsite DPC transfer cask is designed to interface with the horizontal storage module.

\subsubsection{Shipping Cask Handling}

SNF shipments will arrive at the DTC in shipping casks transported on tractor-trailers. Drawings M-12 and M-13 show the envelopes and configurations of the 14 casks (mounted on cask transfer trolleys) expected to be used in shipping SNF to the facility. Table 3-4 summarizes the various shipping cask features.

\subsubsection{Cask Work Platforms and Bucket Racks}

The DTC facility is equipped with two fixed overhead work platforms; one is located in the Cask Handling Bay and the other is in the Cask Preparation Area (see Drawing M-8). These work platforms provide a safe and convenient elevated work area for personnel working around the tops of various casks. The platforms are required for regular maintenance and operations. Both work platforms are similar in design and incorporate steel grating with adapter grating sections for different diameter casks. Access to these elevated work areas is by a rolling stairway. This allows for the stairway to be moved out of the way when not in use to free-up valuable floor space for other operations. The work platforms are designed per OSHA and ANSI standards and are fabricated from carbon steel materials covered with a decontaminable coatings. The rolling stairways are commercially available and come in a variety of sizes and configurations to meet the needs of the DTC facility.

The work platform located in the Cask Handling Bay is fabricated with two structural beams as the base structure. The grating is fastened to the beams. This assembly is in two separate sections for ease of handling. The beams locate in different column pockets fabricated in the wall structure of the facility. The pockets are positioned vertically and correlate with various height casks. Three different pocket heights are necessary to access the tops of all the casks entering the facility. The cask handling crane is used to lift each beam and attached grating separately from one pocket to another depending on the height of the cask. The beams and attached grating are also removable and can be placed on a trailer bed and moved out of the facility when not in use. The grating is sized for the largest diameter cask with adapter sections easily positioned with the crane for smaller casks. Handrails and kick plates are features necessary for safety. Some sections of handrail are removable for operations requiring such. The rolling stairway, mentioned above, is used to provide access to the highest elevated position of the work 
Table 3-4. Fourteen configurations of shipping casks have been identified that may be received and processed by the facility.

\begin{tabular}{|c|c|c|c|c|}
\hline $\begin{array}{l}\text { Shipping } \\
\text { cask }\end{array}$ & $\begin{array}{l}\text { Shipping } \\
\text { mode }\end{array}$ & $\begin{array}{c}\text { Outside } \\
\text { dimension }\end{array}$ & $\begin{array}{c}\text { Inside } \\
\text { dimension }\end{array}$ & $\begin{array}{c}\text { Weight } \\
\text { (without impact) }\end{array}$ \\
\hline High Load & Truck & 35-in. sq $\times$ 69-in. high & 13.5-in. sq $\times 51.5$-in. high & $27,250 \mathrm{lb}$ (empty) \\
\hline ATR & Truck & 35-in. dia $\times 74$-in. high & 12.8-in. dia $\times$ 52.5-in. high & $29,000 \mathrm{lb}$ (empty) \\
\hline Ft St Vrain & Truck & 28-in. dia $\times$ 208-in. high & 17.7-in. dia $\times 187.6$-in. high & $47,600 \mathrm{lb}$ (empty) \\
\hline Peach Bottom & Truck & 42.62-in. dia $\times 173.12$-in. high & 26-in. dia $\times 159$-in. high & $62,000 \mathrm{lb}$ (empty) \\
\hline TN-BRP & Transporter & 83.24-in. dia × 190.5-in. high & 64-in. dia $\times 171$-in. high & $197,340 \mathrm{lb}(\max )$ \\
\hline TN-REG & Transporter & 90.25-in. dia × 180-in. high & 71.75-in. dia $\times 163.25$-in. & $209,100 \mathrm{lb}(\max )$ \\
\hline NAC-LWT & Truck & 44.2-in. dia × 199.8-in. high & 13.38-in. dia $\times$ 180.90-in. & $51,200 \mathrm{lb}(\max )$ \\
\hline NLI-1/2 & Truck & 47.13-in. dia × 195.25-in. high & 13.38-in. dia $\times$ 178-in. high & $46,200 \mathrm{lb}(\max )$ \\
\hline GE-2000 & Truck & 38.5-in. dia $\times 71$-in. high & 26.5-in. dia $\times$ 54-in. high & $33,550 \mathrm{lb}(\max )$ \\
\hline IU-04 & Truck & 35.45-in. dia × 96.50-in. high & 31.30-in. dia × 37.80-in. & $45,000 \mathrm{lb}$ (empty) \\
\hline HFEF-6 & Truck & 32.75-in. dia $\times$ 92-in. high & 6-in. dia $\times$ 67.38-in. high & $29,900 \mathrm{lb}$ (empty) \\
\hline NFS 100 & Truck & 70.25-in. dia $\times 128.31$-in. high & 40-in dia $\times 103$-in. high & TBD \\
\hline GA-4 & Truck & TBD & TBD & TBD \\
\hline NRF-Large Cell* & Truck & 81.50-in. dia × 165.50-in. high & 55.50-in. dia $\times 139$-in. high & $220,000 \mathrm{lb}(\max )$ \\
\hline
\end{tabular}

platform. A fixed ladder attached to one beam and grating section is used to access the two lower positions.

The rolling stairway is used throughout the Cask Handling Bay for other operations requiring elevated, but limited, access. These operations include rigging and removal of the cask shipping cover and impact limiters, cask removal from the transporter, cask and DPC maintenance and inspection, and cask positioning on the trolley.

The work platform located in the Cask Preparation Area serves as an elevated work area for numerous required operations. Some of these operations are preparing the cask lid for removal, gas sampling, cask exterior decontamination, welding of DPC lids, weld NDE operations, vacuum drying, and cask cavity inerting. The design of this work platform is similar to the one described above with the exception that this one has folddown grating. This feature is necessary due to limited space available in the Cask Preparation Area. The grating folds up and out of the way to allow for positioning of the cask and trolley. Positioning is accomplished using a locator pin on the trolley base and a corresponding 
sleeved hole in the concrete floor. As the cask is moved on the trolley into the Cask Preparation Area, the trolley is stopped at the proper location and the locating pin is inserted in the hole to ensure exact positioning. The folding grating, sized for the largest diameter cask, is lowered into position around the cask. The handrail is inserted around the outside of the grating, and adapter plates are installed as needed depending on the cask diameter. This platform is accessed using the same rolling stairway described above.

The Hot Cell has no fixed work platform. Most operations in the Hot Cell will be accomplished remotely. Only minor operations require personnel access to the tops of the casks in this area. Therefore, two rolling stairways of different heights are used to access various parts of the casks. These stairways remain in the Hot Cell and will be moved out of the general work area when not in use.

The Hot Cell is equipped with a set of racks for staging Dry Handling Buckets (DHB) for dry fuel transfer operations, and empty fuel cans for canning (see Drawing M-7). The racks are mounted on the east-west running wall of the Lag Storage Area and will be capable of holding up to $21 \mathrm{DHBs}$ or cans. The racks are adjustable to accommodate varying lengths of DHBs and cans. Empty DHBs and cans are staged in the rack prior to fuel transfer operations in the numbers and sizes required for each campaign. The racks will be fabricated from stainless steel or carbon steel covered with a decontaminable coating.

\subsection{SNF Packaging Systems}

\subsubsection{Canning System}

This section describes the processes and equipment required for minor canning of SNF. The term "minor canning" refers to the packaging of relatively intact SNF into sealed cans to provide its first high integrity containment boundary. Only the Peach Bottom fuel (Cores 1 and 2) are considered suitable for the minor canning operations described below. Physical descriptions of the Peach Bottom fuel are provided in Table $3-5$.

Table 3-5. Peach Bottom fuel data.

\begin{tabular}{ccccc}
\hline Fuel name & Unit form & $\begin{array}{c}\text { Weight } \\
(\mathrm{lb})\end{array}$ & $\begin{array}{c}\text { Unit diameter } \\
\text { (in.) }\end{array}$ & $\begin{array}{c}\text { Unit length } \\
\text { (in.) }\end{array}$ \\
\hline Peach Bottom Core 1 & Can & 150 & 4.73 & 158 \\
Peach Bottom Core 2 & Element & 90 & 3.50 & 126 \\
\hline
\end{tabular}

The Peach Bottom fuel is stable but requires canning as a result of degradation of the cans that currently contain some of the fuel, cracked fuel spheres, or other degradation that raises questions concerning the long-term integrity of the containment boundary.

The concept developed for the minor canning operation is based on the assumption that the fuel, in either bare fuel or already-canned configurations, will be placed into new cans without decanning or other significant preparation. 
3.6.1.1 Canning System Overview. As shown in Drawings M-1 and M-6, the canning station area is separated from the rest of the hot cell by a 4-in. high curb and the lag storage vault structure. It is located in the DTC Hot Cell next to the lag storage vaults. This location provides acceptable direct viewing through shielding windows, and leaves the Hot Cell main floor clear for normal fuel transfer and handling operations. All racks and stands are constructed of stainless steel, and the walls and floor in the canning station area are coated to facilitate decontamination. The average canning throughput capacity is two finished cans per day.

The overall sequence of operations is illustrated in Figure 3-9.

3.6.1.2 Can Description. The cans are made of 12-in. diameter, Schedule-10, stainless steel pipe. They have an internal cavity length of 161.50 in. and are similar to the dry handling buckets (DHB) discussed in Section 3.7.2. The can lids, which are ultimately welded to the cans, have a vacuum/pressurization port and are designed so purging, evacuating, leak testing, and back-filling with an inert gas can all be accomplished remotely.

The cans have an internal design pressure of $15 \mathrm{psig}$ and a design temperature of $380^{\circ} \mathrm{C}$.

Support spiders or cruciforms are used to restrain the fuel inside the can. Two such configurations are used: a spider structural support configuration (capable of holding up to seven elements) is used for

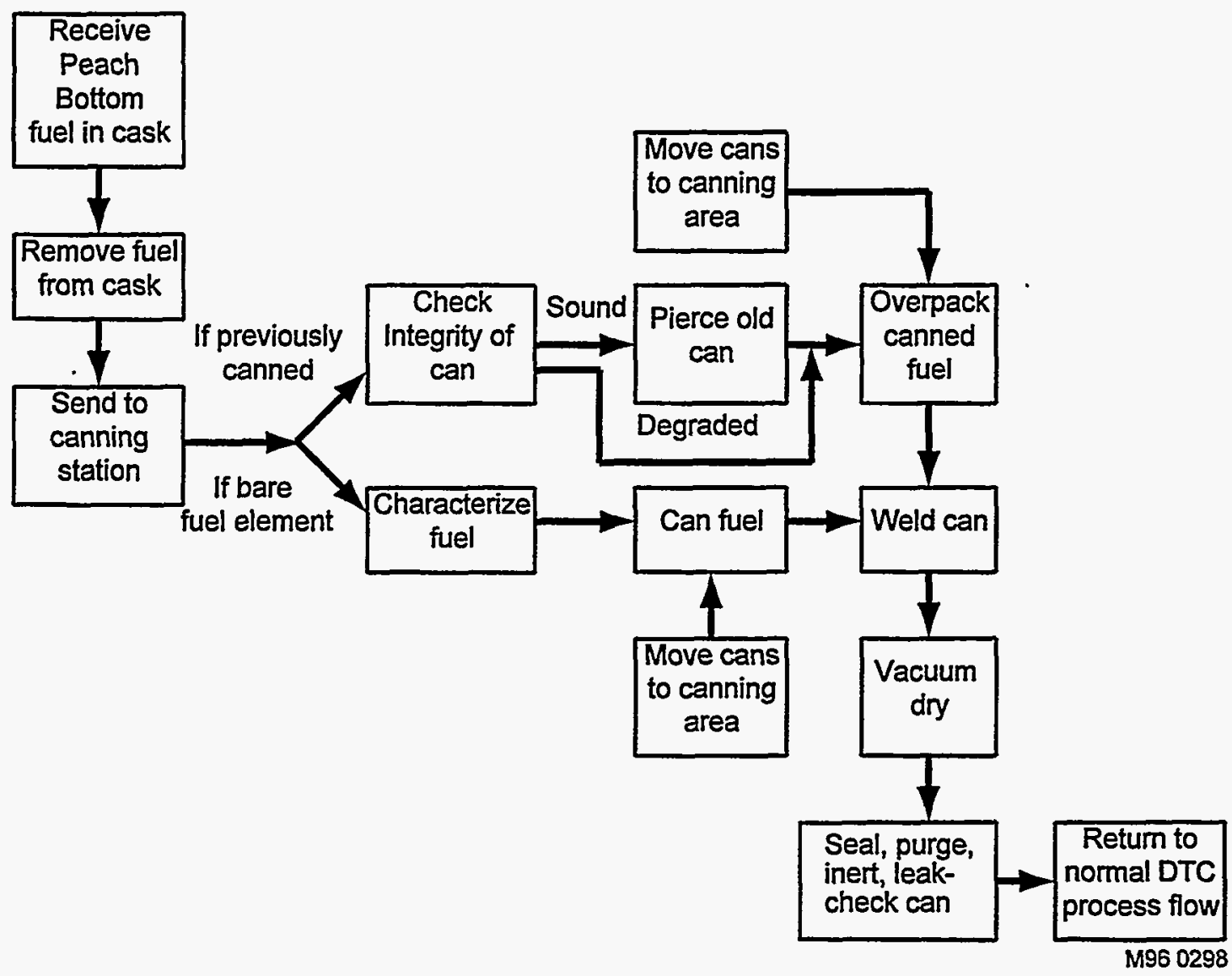

Figure 3-9. SNF Packaging System flow diagram. 
bare fuel elements and a cruciform (four quadrants) structural support configuration is used for previously canned fuels.

3.6.1.3 Canning Station Operations. After the SNF is moved into the Hot Cell and removed from the shipping cask, it is visually checked through the shielded viewing window(s) and by closed circuit television. Visual checks and inspection information will include determining the identity of the fuel unit, whether the fuel unit is intact or broken, whether any corrosion is present, the general condition of the fuel unit, and if the fuel unit requires any special handling.

If the incoming fuel unit is already canned, and if there are no obvious holes in the can wall, it is sent to the can piercing machine. If the fuel unit consists of a bare element, or if the can wall is obviously breached, it is then sent to the can loading station.

The following sequence is typical for Peach Bottom SNF canning operations:

Can Piercing: If the fuel is contained in an old but apparently intact can, it is moved to the can piercing machine. Can piercing is performed to ensure the contents can be dried during vacuum drying operations. The can piercing equipment is pneumatic and is designed to avoid penetrating the fuel inside the can.

The can piercing equipment holds the can in a vertical position without crushing the can. Once the can is secured, the piercing unit produces an opening into the can from the side at the top. As the piercing device is brought into contact with the side of the can, a seal on the end of the collar mates with the can side. A spring behind the collar provides the force to maintain the seal as the penetrating device produces an opening and is backed out. This method does not produce any chips or additional waste requiring disposal and produces a quick and clean penetration into the can.

As the penetration is made, the released gas is captured within the piercing head assembly and piped to a sampling system as shown in Figure 3-10. If the analyzer indicates that the can contains hydrogen, the can is purged with helium until the hydrogen level is low enough to allow safe handling. The gas is released to the DTC ventilation system and exhaust stack following the analysis. See Drawing M-9 for the canning equipment layout and the can piercing machine details.

The stand for the can piercing operation is fastened to the floor at the base and is capable of supporting the hardware with a loaded can in the event of an earthquake.

Can Loading: The can loading station consists of a support stand and a clamping mechanism. The new, empty can is placed on the base and the clamping mechanism is actuated to hold the can in the proper location. Bare fuel elements and pierced or breached cans are moved with the fuel handling crane to the can loading station and lowered into a new can. A lid is retrieved from the can/lid storage rack and placed on the can. The lid is then ready to be welded to the new can.

Like the piercing stand, the stand for the can loading operation is fastened to the floor at the base and is capable of supporting the hardware with a loaded can in the event of an earthquake. See Drawing M-9 for system hardware details and Drawings M-1 and M-6 for equipment layout within the Canning Area. 


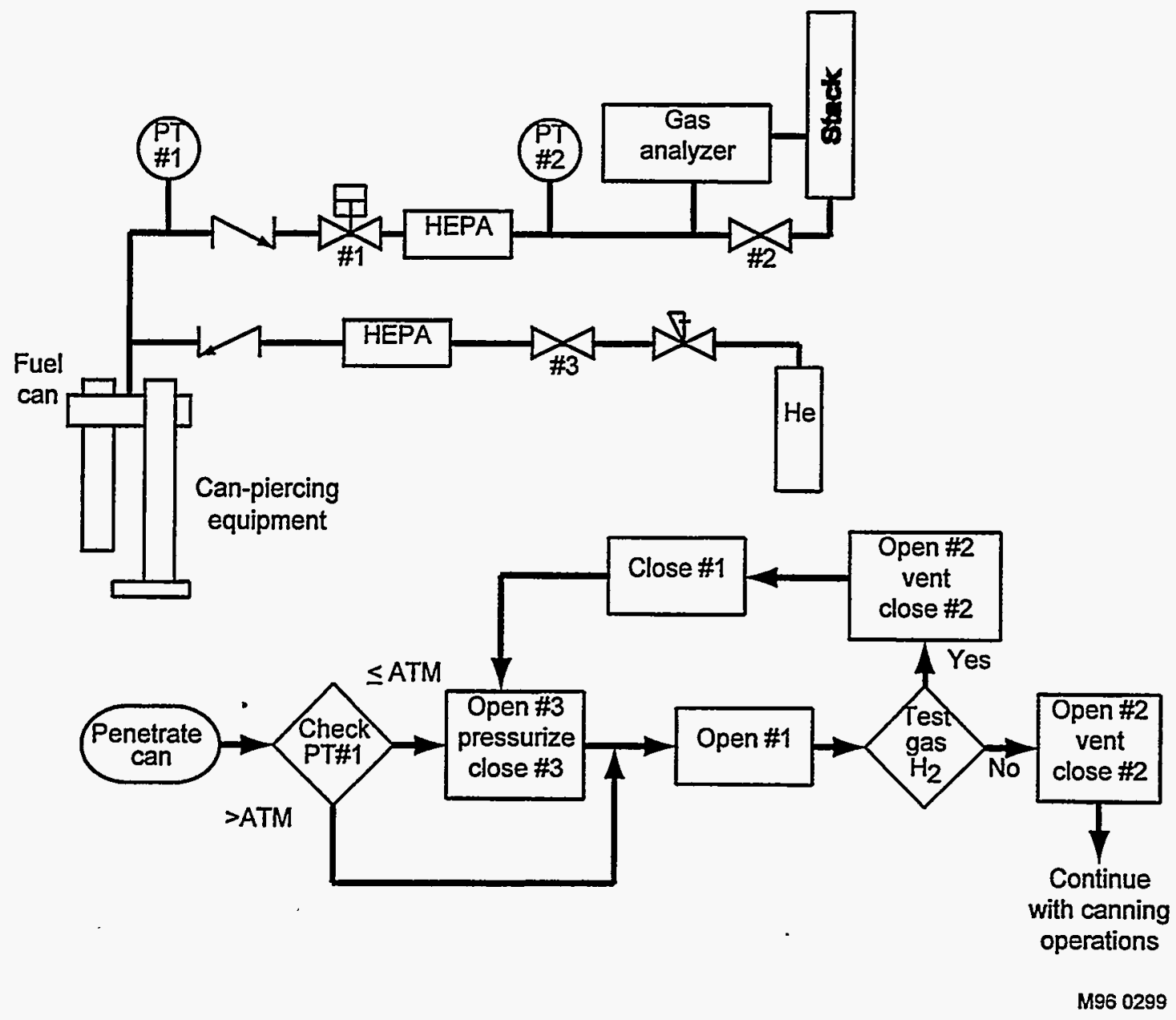

Figure 3-10. Can piercing system and operational sequence.

Can Lid Welding: Once the cans are loaded, they are closed by welding on a lid. A gas-metal-arcwelding (GMAW) process is used, which is a common automatic welding application. The can welding station consists of the support stand (the same stand as used during can loading), a remotely operated welding arm with associated welding machine, gas supply, and a wire wheel. The welding power supply will be a shared unit with the DPC lid welding operations (see Section 3.6.2.1, DPC Automatic Welding System). See Drawing M-9 for the can welding system hardware, and Drawings $M-1, M-5$, and $M-6$ for equipment layout within the canning area.

Fuel Drying: The fuel drying operation (vacuum drying) is performed to remove water that may be present on the fuel or in the old cans. If sealed in the new can, water could support corrosion or potential pressurization resulting from radiolysis. The drying operation is performed in the same stand as the loading and welding. The lid of the can contains a port for attaching to the drying system and to gas supply used for purging, inerting, and pressurizing. The vacuum system is remotely connected to that port and the system is started. The vacuum exhaust is filtered prior.to release into the ventilation system and exhaust stack. Depending on the fuel configuration and condition and on the amount of water present, the drying process may be relatively short (several minutes), or it may take several hours.

To test for dryness, the can is evacuated below the saturation pressure of water and isolated. If the pressure remains constant, the can and its internal contents are dry. If the pressure rises and stabilizes, water is present, in which case the vacuum drying continues. If the pressure continues to rise above the saturation pressure an air leak into the can is present and weld repair is required. 
Can Seal/Purge/Inert/Leak Check: After the fuel has been dried, the can is pressurized with helium and checked for leaks. A sniffer probe attached to the electromechanical manipulator is maneuvered around the can and "sniffs" for helium around the lid weld area. If the can leaks, the weld is repaired and the leak test repeated. During the entire process, the can/lid assembly remains in the same support stand.

Once the integrity of the can weld/seal has been verified, the can is purged and filled with helium at nominally ambient pressure. The can vent/purge port is sealed by remotely welding and the can is ready to be introduced back into the normal process flow. The cans will be moved remotely using the fuel handling crane.

\subsubsection{Canning System Equipment.}

Closed Circuit Television (CCTV): An arrangement of lights and three cameras, specifically dedicated for canning, provide visual access to the canning area and the inside of the can. The cameras are located to allow for viewing of general operations and the specific tasks involved in canning. The cameras have zoom capability and are mounted on pan-and-tilt mechanisms. The CCTVs will aid the operators in can loading and setup processes as well as the various welding, leak checking, and other operational steps that may be in a blind area of the viewing windows. In addition, the system permits close-up viewing of key components, assesses equipment operation, and aids in component failure analysis.

Can/Lid Storage Rack: A stainless steel can/lid storage rack is used to temporarily store the empty cans/lids. The capacity of the rack is five cans and lids.

Fuel and Can Handling Tools: Specialized fuel and can handling tools have been identified for operations within the fuel canning process. These tools are described below:

- Can/Lid Grapple: This grapple is a new tool that will be used to remotely handle the new fuel cans and lids.

- Peach Bottom Can Handling Tool: The Peach Bottom can handling tool is an existing tool used to remotely handle the Peach Bottom Core 1 fuel (fuel in existing cans). Refer to existing LITCO Drawing Number 097984 for details. This tool may need slight modifications to accommodate the proposed canning process.

- Peach Bottom Fuel Handling Tool: The Peach Bottom fuel handling tool is an existing tool used to remotely handle the Peach Bottom Core 2 fuel (bare fuel element). Refer to existing General Atomics Drawing Number 800-156-15005 for details. This tool may need slight modifications to accommodate the proposed canning process.

- Peach Bottom Fuel Handling Tool Grapple: This is a new tool used with the Peach Bottom fuel handling tool to pull the fuel element out of the can.

\subsubsection{DPC Welding, Drying, Purging, Inerting, and Sealing}

After a DPC has been loaded with fuel in the Hot Cell the shield plug is installed, the DPC is surveyed and decontaminated as required, and it is moved on the trolley to the Cask Preparation Area for 
final preparation for storage. The hinged deck plates of the Cask Preparation Area work platform are lowered into place around the cask and the handrails installed.

The operations performed to prepare the DPCs, and the equipment used in those operations are discussed in the following subsections.

3.6.2.1 DPC Automatic Welding System. The canister automatic welding system consists of two major components: the welding machine, shown in Figure 3-11, and the control console and power supply shown in Figure 3-12. The control console and power supply are located in a Weld Observation Area on the second level of the facility next to the Cask Preparation Area as shown on Drawings M-2 and M-5. The welding power supply will be shared with the welding machine for the canning operations as described in Section 3.6.1.

The Weld Observation Area is provided with a viewing window into the Cask Preparation Area where the weld machine resides and welding of DPC lids takes place. The weld machine is connected to the console and power supply with electrical cables and gas and coolant tubing. The welding system is designed to be controlled by a single weld operator from the control console, who views the welding operations through the viewing window and the CCTV system. Another operator is needed to enter the

Cask Preparation Area to observe and perform weld machine setup and removal operations. An intercom system is provided for their communication. Maximum radiation fields at the top of the DPC are expected to be on the order of $300 \mathrm{mR} / \mathrm{hr}$ and the use of the automatic welder is essential for ALARA operations.

The Cask Preparation Area crane lifts the automatic welder, which has been previously attached to the DPC inner lid, to the top of the cask and positions it on the DPC. The lid is then automatically welded in place. The weld is a multiple-pass weld and when completed forms the inner pressure boundary of the DPC that confines any radioactive particles in the DPC cavity. The weld is inspected and repaired if necessary. Upon successful completion of the inspection, the DPC is ready for the vacuum drying process (see the following subsection). At the completion of the drying process, the inner lid weld is helium leak tested. If leaks are not detected, then purging and inerting operations are performed, the inner lid ports are sealed, and the outer DPC lid is welded, using the automatic welder, in much the same way as the inner lid. The outer lid weld also receives an inspection to ensure its integrity.

3.6.2.2 DPC Vacuum Drying/Purging and Inerting. With the inner lid welded to the DPC, the canister is ready for vacuum drying, purging, inerting, and helium leak testing. The vacuum drying process evacuates the DPC cavity and lowers the moisture content to an acceptable level. The vacuum drying system is located inside the Cask Preparation Area. The system includes an air cooled heat exchanger and fan to supplement the vacuum pump's internal oil cooler during helium pump down. The system occupies a $3 \mathrm{ft}$ by $4 \mathrm{ft}$ space on the Cask Preparation Area floor. All controls and instrumentation for the system are mounted in a control console. Operator access is required only at the beginning and end of the evacuation and backfill operations.

The suction line of the vacuum drying system is connected to the DPC vent and siphon ports. A hose is connected from the discharge outlet of the vacuum drying system to the Hot Cell radioactive liquid waste system. A particle filter is located on the suction side of the vacuum drying system. The filter is used to capture any radioactive particles that may be entrained within the gas thereby preventing contamination of the vacuum drying system. A trap and drain in the vacuum discharge line allows any 

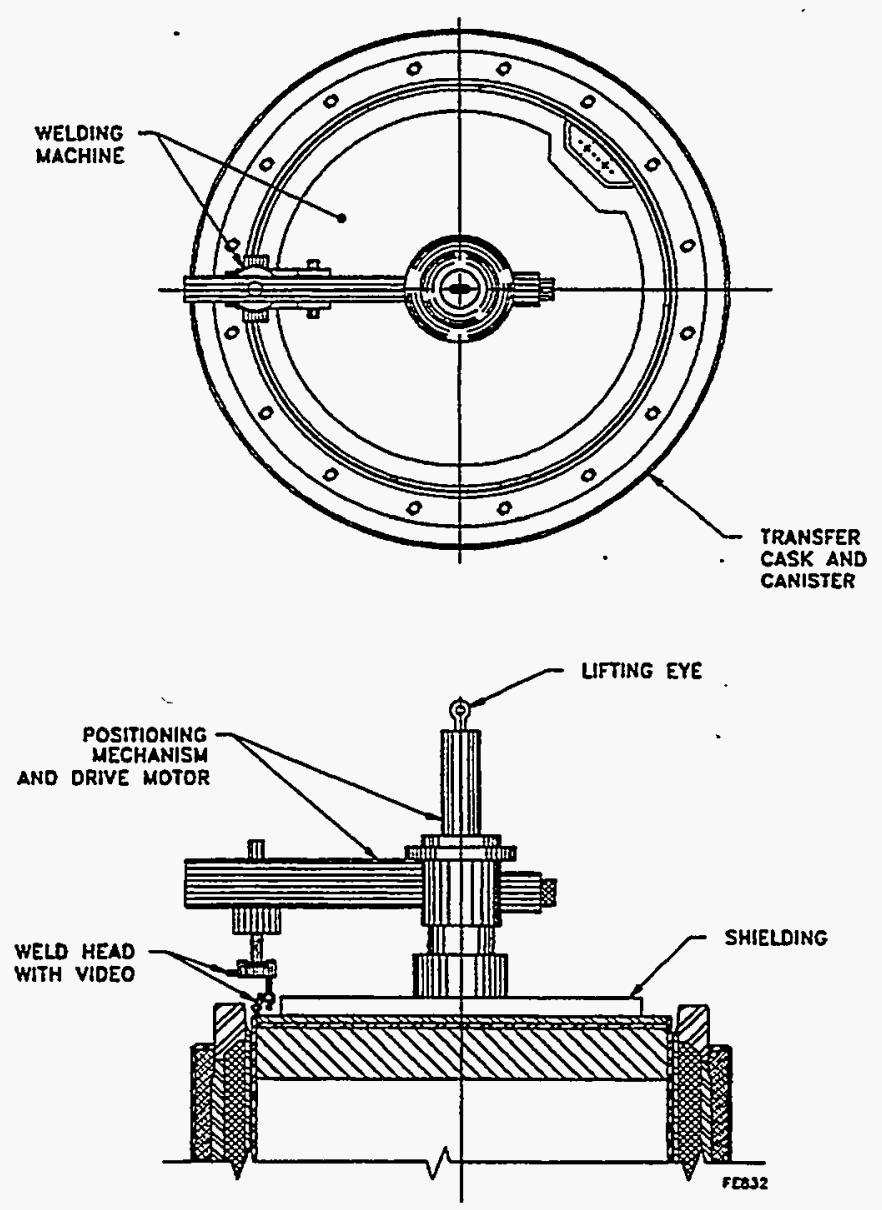

Figure 3-11. Automatic Welding System.

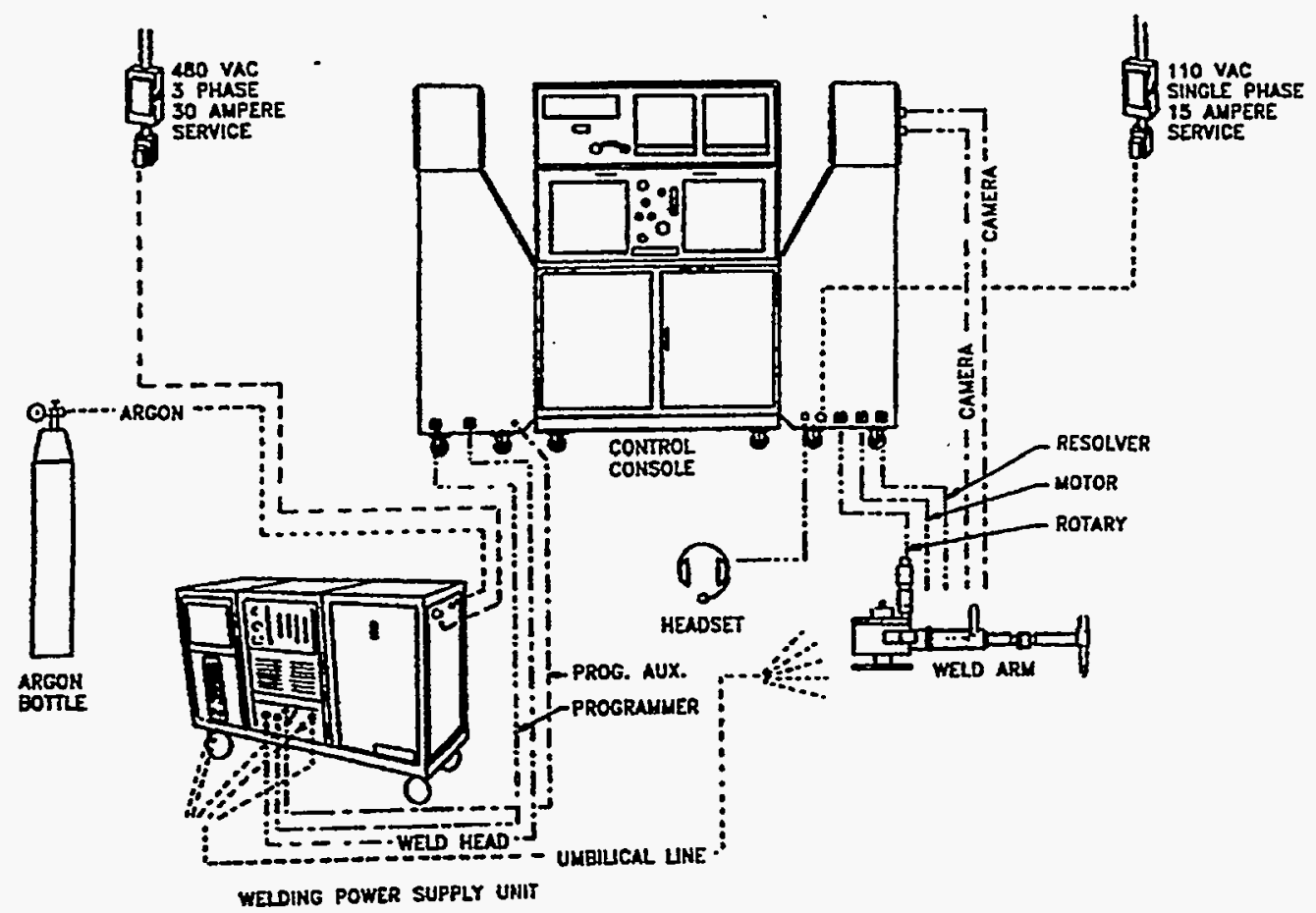

Figure 3-12. Control Console and Power Supply. 
liquid water remaining in the DPC cavity to be routed directly to the waste system. The vacuum drying system is completely closed so that all radioactive material is confined within a controlled system.

Helium is used to purge and inert the cavity of the DPC. Purging and inerting of the cavity atmosphere prepares the fuel for storage. At the completion of the vacuum drying process, the DPC cavity is filled with helium and a leak test is performed to assure that the canister is leaktight. The DPC is pressurized with helium to 22 psia and tested using a helium leak detector. If leak testing fails, repairs are made to the weld and the canister is tested again. The leak detector is mounted on a cart and is located inside the Cask Preparation Area. The cart is approximately $2 \mathrm{ft}$ wide by $3 \mathrm{ft}$ long.

Once the DPC lid welds pass the leak test, the DPC cavity is purged with helium to inert the atmosphere and pressurized to $17 \mathrm{psia}$. The vent and siphon ports are then welded closed and a final leak check performed. The purge and inert gas supply is located on the main level of the DTC in the Cask Staging Area. With the DPC cavity inerted, the outer DPC lid is welded in place following the procedure used for the inner lid.

\subsection{SNF Storage}

\subsubsection{Lag Storage Area}

Four lag storage vaults, shown in Drawings A-1 and A-10, are embedded in an elevated floor of the Hot Cell. A lag storage port is formed by a shielded concrete cavity within the hot cell. The cavity is 72-in. in diameter by 210 -in. deep with a minimum of $3 \mathrm{ft}$ of concrete shielding surrounding it. A 3-ftthick, stepped concrete shield plug provides top shielding and access to the port. A 67.25-in. outside diameter by 167 -in. high by $5 / 8$-in. thick removable stainless steel sleeve is inserted within each port. The sleeve has a large drain port at its bottom plate for draining to a collection tank any water that might enter. The sleeve can be removed for decontamination or maintenance. The 2.38 -in. radial annulus between the lag storage concrete cavity walls and the outside sleeve is used for natural convection cooling of the SNF that will be contained in a 14-tube DPC basket located within the sleeve. A 14-tube DPC basket can be removed from the sleeve for decontamination or placement in a DPC. The standard DPC basket is used in the lag storage port because it affords SNF handling operations identical to those used in loading the DPCs. The lag storage basket accepts various buckets containing fuel that will subsequently be placed in identical baskets within the DPCs.

The concrete shielding will protect personnel in the Cask Preparation Area, Hot Cell, and operating gallery from gamma and neutron radiation. The dose rate at the exterior of the Hot Cell wall in the operating gallery will always be below $0.125 \mathrm{mrem} / \mathrm{hr}$. Calculations also show that the dose rate inside the Hot Cell at the outside of the three-ft thick lag storage walls will also be less than $0.125 \mathrm{mrem} / \mathrm{hr}$ when the lag storage ports are full of fuel.

The lag storage vault stainless steel liners are removable for ease of decontamination. During removal and decontamination, no trolleys or casks would be inside the hot cell. A drain in the bottom of the port prevents inadvertent buildup of decontamination water from moderating fuel within the lag storage vaults (although the fuel in the vaults will be critically safe in the full moderated and reflected condition). Effluent will drain into the hot cell floor drain system and be routed to a collection tank. 
Lag-storage vault lid lifting eyes allow lid removal using the hot cell crane. Normally, only one lag storage port at a time will be open. When removed, the lid of the open port will be placed on or close to the closed lid of another port. Administrative controls will ensure that individuals never enter the hot cell unless all lag storage ports that contain fuel have their lids installed.

The allowable cladding temperatures for stainless- and Zircaloy-clad commercial fuel are $380^{\circ} \mathrm{C}$ and $340^{\circ} \mathrm{C}$ for 5 - and 10-year cooled fuel, respectively. It will be assumed that all of the DOE SNF in the DTC will be subject to the $340^{\circ} \mathrm{C}$ cladding temperature. The lag storage vaults incorporate bottom and top air passages for convection cooling of the outside of the lag storage liner wall. The top passage connects to the Hot Cell exhaust air plenum just south of the lag storage ports. This results in forced cooling of the lag storage ports when the Hot Cell exhaust fans are operating and the exhaust ductwork is not valved out. If the Hot Cell exhaust shuts down the lag storage port cooling will revert to natural convection circulation through the top and bottom cooling passages. The lag storage ports will only be used to temporarily store offsite fuel that arrives in small quantities and cannot be transferred into a DPC without excessive dead time between the next shipment to be placed in that DPC. The large volume fuels in this category are Dresden, offsite TRIGA, Pulstar-Suny-Buffalo, and Pulstar-N.C. State Univ. Only one port is required for all the Dresden fuel and a separate port will be used for the TRIGA. The Pulstar-Suny-Buffalo and Pulstar-N.C. State University fuels can all be placed in four of 14 tubes of the third lag storage 14-tube basket. The fourth lag storage port is a spare.

\subsubsection{Dry Storage System (DSS)}

The DSS consists of an outdoor concrete basemat equipped with lighting and remote area monitors (RAMs), concrete HSMs located on the basemat, and the loaded, sealed, inerted DPCs (including their internal baskets, buckets, cans, and SNF loads). The transfer cask and its transporter and tow vehicle used to deliver and install the DPCs into the HSMs are described in Section 3.5.4. A description of the cask and transporter operations necessary to load the DPC into the HSM is also given in that section. Appendix E contains criticality safety analyses for six candidate fuels that make up approximately $90 \%$ of the total SNF to be loaded in the Dry Transfer Cell. Appendix E describes the configurations of the DPCs loaded into the MP-187 cask, as well as loaded into the HSMs. The results indicate that all $\mathrm{K}_{\text {eff }}$ values for the proposed loadings are less than 0.95 . Initial shielding calculations indicate that the maximum dose rates at the outside of the MP-187 cask and the HSM, for worse-case fuel (FSVR), will be $26.5 \pm 4.8 \mathrm{mrem} / \mathrm{hr}$ and the $0.55 \pm 0.23 \mathrm{mrem} / \mathrm{hr}$ respectively.

3.7.2.1 Basemat. As indicated in Drawing C-1, the basemat is located south of ICPP 665. It is a 3-ft-thick reinforced concrete basemat that is $675 \mathrm{ft}$ long and $276 \mathrm{ft}$ wide. Further structural details of the details of the basemat can be found in Section 3.2.6. It is sized for a maximum of $240 \mathrm{HSMs}$, including 30 for the TMI debris cans, 100 for DTC fuel, and 110 for other TAN fuel and DOE SNF that will be processed in the future canning facility to be built next to the DTC.

3.7.2.2 Horizontal Storage Modules. The modules and basemat are located as shown on Drawings T-1, C-3, and C-5. A typical HSM is shown in Figure 3-13.

The module is a rectangular, thick-walled, precast, reinforced-concrete vault designed to provide $10 \mathrm{mrem} / \mathrm{hr}$ at contact on all accessible vertical walls when loaded with a single DPC containing $52 \mathrm{BWR}$ or $24 \mathrm{PWR}$ commercial fuel elements. Each module is $20 \mathrm{-ft}$ long $\times 15-\mathrm{ft}$ high $\times 9-\mathrm{ft}, 8-1 / 2 \mathrm{in}$. wide. The wall thicknesses are as follows: roof, $3 \mathrm{ft}$; front wall, $2.5 \mathrm{ft}$; side walls, $1.6 \mathrm{ft}$; and back wall, 


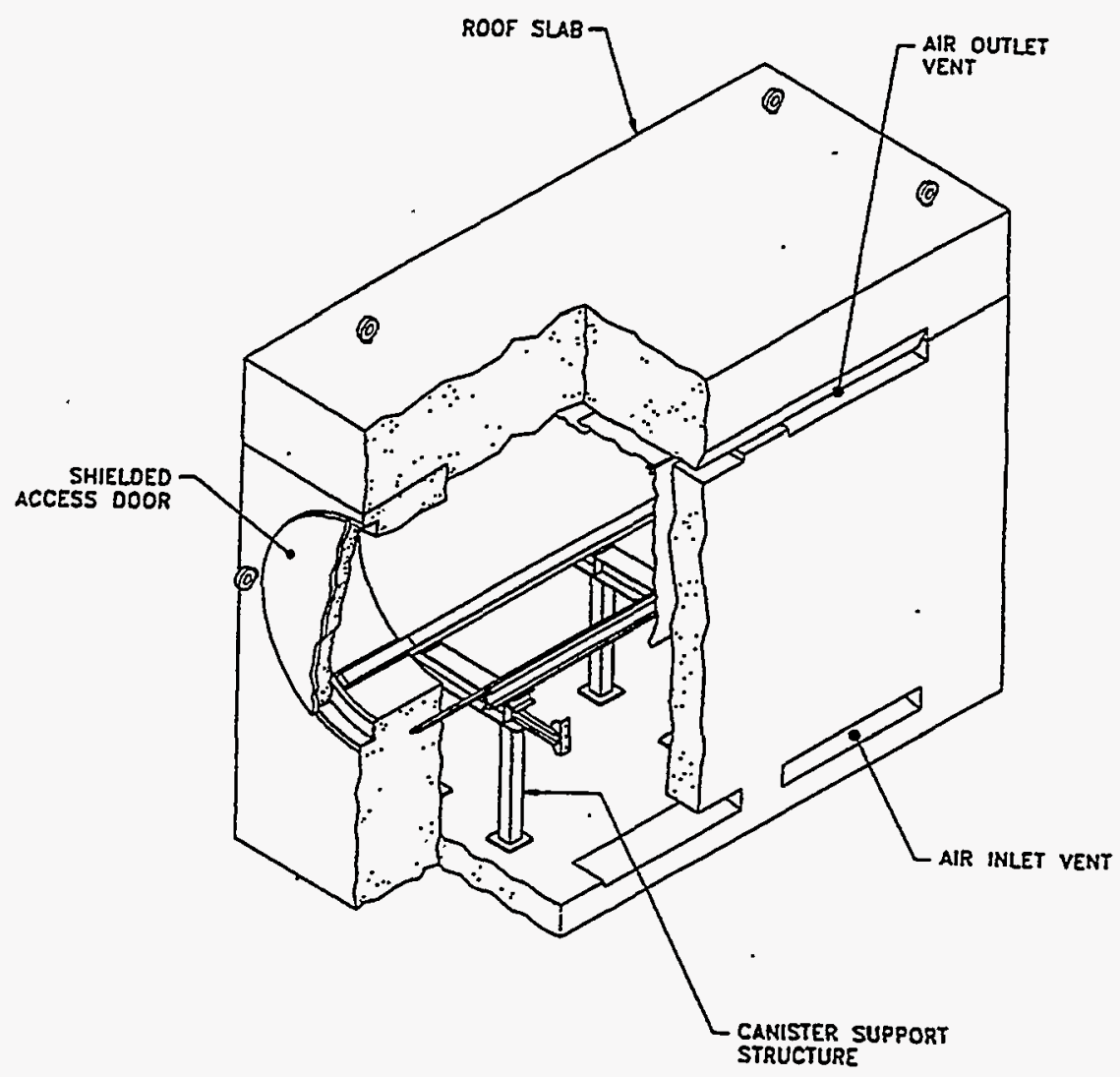

Figure 3-13. NUHOMS ${ }^{\circledast}$ horizontal storage module.

$1 \mathrm{ft}$; floor slab, $1 \mathrm{ft}$. Each module contains a DPC support structure with steel rails to receive and store one DPC in the horizontal position. Each module has a front-shielded door and opening for insertion of the DPC. After the DPC is inserted, the door is closed and welded for physical security purposes. The weight of an HSM with a loaded DPC inside is approximately $300,000 \mathrm{lb}$.

The HSMs are generally placed in double rows on the basemat (see Drawing C-3). The HSMs are placed back-to-back and side-by-side in the rows to reduce the size of the basemat and to reduce the HSM back and side wall thickness since they will face each other and create an exclusion zone between them. The distance between each double row of HSMs is $50 \mathrm{ft}$. This distance is required to maneuver the tow vehicle and transporter with the transfer cask for unloading of DPCs into the HSMs. Each DPC inside an HSM is cooled by a passive, natural-draft convection system in the HSMs. This consists of air inlets and outlets cast into the bottom and top, respectively, of the HSM side walls. A 6-in. gap is maintained between the sides of adjacent modules in the row to allow air to circulate through these vents.

Bird screen mesh is placed over this gap to prevent intrusion. Each module is designed to maintain the fuel cladding of 52 BWR or 24 PWR commercial fuel elements, within a DPC, below the allowable cladding temperature at fuel heat-generation rates of up to $24 \mathrm{~kW}$ per DPC. The modules are designed to withstand seismic accelerations, ambient temperatures, tornados, and floods within ranges that could be incurred at the INEL. The modules at the end of each row require an additional 2- $\mathrm{ft}$ of concrete shielding to achieve a maximum of $10 \mathrm{mrem} / \mathrm{hr}$ all around the double row. The radiation field between adjacent 
modules and above them may be considerably higher than this; however, these are exclusion areas and will not be occupied.

3.7.2.3 Dual-Purpose Canisters. Dual-Purpose Canisters (suitable for storage and shipping) are used for storing the SNF. Each DPC consists of a shell assembly, a removable fuel basket, a top shield plug, and two top cover plates. The DPC shell that will be used for all of the DTC fuel is the NUHOMS ${ }^{\otimes}$ PWR FO-DSC. This DPC was chosen because it can be handled by the NUHOMS ${ }^{\circledR}$ MP-187 cask, transporter, and tow vehicle that will already have been purchased by the Three Mile Island (TMI) Core Debris Canisters Storage Program. This DPC is 186.2 in. long $\times 67.25$ in. outside diameter with a 0.625 -in.-thick wall and an internal cavity length of 167 in. The DPC shell has a permanent bottom shield plug and end plate, a removable top shield plug, and two steel top plates that, when welded to the top of the shell, form a secondary confinement barrier (the primary confinement barrier is formed by the fuel cladding or can for all fuel that will be handled in the DTC). The DPC shell also has integral internal lifting eyes and purge and vent ports. Drawing M-18 shows views of the PWR-FO-DSC with the three baskets that will be used to store all fuel handled in the DTC.

3.7.2.4 DPC Baskets. Each DPC will hold one of three special designs of DPC baskets that in turn hold buckets or cans of SNF. The three special baskets are the Fluor Daniel design (Reference 2) of the 14-Tube basket, the Shippingport LWBR 3-Tube basket, and the Fort St. Vrain (FSVR) 7-tube basket. These three baskets are shown in Drawings $M-15$ and M-16. The baskets are not permanently attached to the shell, and may be lifted in and out by an overhead crane. Neither the standard NUHOMS ${ }^{\circledR}$ BWR nor PWR baskets will be used for any of the DTC fuel.

\subsection{4-Tube Basket-The 14-Tube basket, shown in Drawing M-17, consists of} 22 transverse carbon steel spacer plates evenly spaced along the 167-in. cavity length of the DPC shell. They are held in position by four large tie rods that span the full internal cavity length. A pattern of 14 , 13-in. diameter holes machined in each spacer plate forms 14 "tubes" that span the full basket length. This basket design is similar to that recommended by Fluor Daniel in Reference 3. This basket contains no neutron-absorbing poison material, and is designed to receive 12-in. Schedule-10 pipe buckets and cans described below. These baskets will be used to store all DTC fuel except Shippingport light water boiling water reactor (LWBR), FSVR, and Pathfinder. Approximately 40, 14-Tube baskets will be required for all DTC fuel.

3.7.2.4.2 Shippingport LWBR 3-Tube Basket-The LWBR 3-Tube basket, shown in Drawing $\mathrm{M}-17$, is a special design that will hold only one type of fuel. That fuel consists of the 40 Shippingport LWBR elements currently stored in ICPP 749. Each of these elements is stored in a 25.57-in. outside diameter $\times 158$-in.-long canister. It was decided not to remove the LWBR elements from these cans because the elements have complex shapes that would require many special DPC basket designs. In addition, the LWBR cans contain shock-absorbing material that prevents the element from crushing (if dropped from a height up to $8 \mathrm{in}$.) into a shape that could produce a criticality excursion if it was subsequently exposed to moderating water. Only three of the 25.57-in. LWBR cans will fit in a standard 67.25 in. diameter DPC and therefore the basket has three corresponding "tubes." The basket construction is similar to the 14-Tube style described above, and consists of 22 transverse carbon steel spacer plates evenly spaced along the 167-in. cavity length of the DPC shell. They are held in position by four tie rods that span the full internal cavity length. A pattern of three, evenly spaced 26-in. diameter holes machined in each spacer plate forms the three tubes that span the full basket length. These baskets 
contain no neutron absorbing poison material. Twenty-two 3-Tube baskets will be required for all Shippingport LWBR fuel.

3.7.2.4.3 FSVR 7-Tube Basket-The FSVR 7-Tube basket, shown on Drawing M-17, is a special basket designed to hold 35 bare FSVR hexagonal fuel elements stacked five high in each of seven hexagonal full length tubes. Each hexagonal basket tube is a 3/4-in.-thick SST hexagonal tube with an inside opening that is 16.65 -in. across the corners. One tube is located in the center of the basket, with six more close-packed around it for a total of seven tubes. Besides holding FSVR fuel, each of these baskets, with the use of the Pathfinder bucket described below, will be used to store seven Pathfinder fuel elements currently in ICPP 666 . These baskets contain no neutron-absorbing poison material.

Approximately 16, 7-Tube baskets will be required for all FSVR and Pathfinder fuel.

3.7.2.5 Dry Handling Buckets. Drawings M-15 and M-16 show some details of the buckets. All fuel, except that from FSVR and Shippingport LWBRs and Peach Bottom, will first be placed in buckets within the DTC, before being placed in a DPC basket. All fuel that will be placed in 12-in. Schedule-10 buckets will be, in turn, placed in a 14-Tube basket. As explained above, the Pathfinder fuel will be placed in a 14-in. Schedule-10 bucket that will in turn be placed in an FSVR basket.

3.7.2.5.1 12-in. Schedule-10 SST Buckets-The 12-in. Schedule-10 SST bucket designs are shown on Drawings M-15 and M-16. The buckets allow a small and manageable number of DPC Baskets and SNF items to be handled, while providing efficient SNF fuel packing within the DPCs. The bucket designs do not include poison, but the option to use poison has been maintained. As indicated in the bucket drawing, the 12-in. Schedule-10 buckets consist of one of four lengths of 12-in. Schedule-10 pipe, one of nine styles of cruciforms, and one style of lid. The cruciforms hold and separate the individual fuel elements. Each bucket has a lid that attaches with two 1/2-13 UNC captive screws after the fuel is loaded inside it. Each lid has a lifting-eye for transferring the bucket into the lag storage or into a 14-Tube DPC basket. The buckets are designed in four lengths as shown in the drawing. Eleven different 12-in. Schedule-10 bucket designs are required for all fuel to be handled in the DTC. A Table on Drawing M-16 shows each fuel, along with details of the bucket design and required bucket quantities. Five hundred eighty six 12-in. buckets are required.

3.7.2.5.2 14-in. SST Buckets-All of the Pathfinder fuel rods are stored in seven cans, each of which is too large to be placed in a 12-in. Schedule-10 pipe bucket. Therefore, a special 14-in. Schedule-10 pipe bucket was designed for Pathfinder cans. The Pathfinder bucket is also shown on the bucket drawing. They are 103-in. long including the bolted lid, with a cruciform made of four plates that form a single cell large enough for a single Pathfinder element. This bucket and its lid are similar to the others except that they have a larger diameter that will fit inside a tube of an FSVR 7-Tube basket. As the Table on Drawing M-16 shows, a total of seven 14-in. buckets is required. The 103-in. length of this bucket will allow 14 FSVR elements (two stacked above each bucket in each of the seven FSVR basket tubes) to be stored in the same DPC. Note that all seven Pathfinder fuel cans can be placed in one DPC along with 14 FSVR elements. The single Pathfinder DPC will require a special license that must also include a dual fuel provision if the 14 FSVR elements are loaded in the same DPC with Pathfinder.

3.7.2.6 Dry Storage Cans. The two designs of 12-in. Schedule-10 Cans are also shown on the bucket drawing (M-16). These cans are designed for the Peach Bottom Core 1 and Core 2 fuel that is the only fuel that needs to be canned in the DTC. The cans are 166-in. long and are made of 12-in. Schedule 10 SST pipe similar to the buckets described above. There are two styles of can cruciforms: 
one holds four pre-canned Peach Bottom Core 1 fuel elements from ICPP 749, and the other holds seven bare Peach Bottom Core 2 elements from the ICPP 603 GSA. The cans have a special lid designed to be seal welded to the body to form the primary boundary of the fuel. Each lid is equipped with a quickdisconnect fitting (located in a recess) for venting and purging the can after the fuel is loaded and the lid welded. A small cover is seal-welded over the recess after the can is filled with helium to prevent the quick disconnect fitting from leaking helium through its mechanical seal. The table on the drawing shows a total of 317 cans is required for all Peach Bottom fuel.

3.7.2.7 Dry Handling Bucket and Can Fuel Loading. The various bucket and can fuel loadings are indicated on the bucket drawing (M-16). The cross sections show the various fuel unit cross sections within the bucket cruciforms. The drawing table shows the number of units that are stacked in each cruciform cell, and the total number of fuel units in each bucket or can. A total of 12,000 fuel units will be stored in the buckets and cans.

3.7.2.8 Basket Loading. The basket drawing (M-17) shows the three types of baskets described above. The FSVR basket is used for the FSVR and Pathfinder fuel. The 3-Tube basket is designed for the existing Shippingport LWBR 25.57-in. diameter $\times 158$-in.-long cans. The 14-tube baskets are designed to hold combinations of the four different lengths of 12-in. Schedule-10 buckets and cans discussed above. These combinations are shown in Drawing $M-18$ as either a stack of five 33.2-in.-long buckets, a stack of four 41.5-in.-long buckets, a stack consisting of one 132.8-in-long and one 33.2-in.long bucket, or a single 166-in.-long bucket. Other combinations are possible, but will not completely fill a basket tube, e.g., a stack of three 41.5-in.-long buckets and one 33.2-in.-long bucket. With these combinations of bucket and can loading, efficient loading of different kinds of fuel is possible within the same 14-tube bucket. Appendix $\mathrm{F}$ analyzed the requirements for placing various fuels efficiently in canisters.

No structural analysis was performed as a part of the conceptual design. It is assumed that the 22 spacer-plate baskets will be sufficient to withstand all handling, storage, and shipping loadings, because similar designs have been developed for meeting $10 \mathrm{CFR} 71$ transportation requirements and 10 CFR 72 storage requirements. It is also assumed that suitable bucket cruciform thicknesses (for the cruciform designs shown on Drawing $\mathrm{M}-16$ ) can be established in follow-on design stages, that will adequately support the fuel under loads required to be imposed by 10 CFR 71 and 10 CFR 72 storage requirements.

\subsection{HVAC Systems}

\subsubsection{General Description}

The facility HVAC systems provide temperature conditioning and filtration of supply air and provide pressure control within selected areas of the DTC. The systems also collect exhaust air from contamination control areas, i.e., the Hot Cell, Cask Preparation Area, and Utility Support Rooms, and pass the air through HEPA filters before discharge to the atmosphere. Exhaust systems will maintain the required flowrate of air through the facility, and supply systems will control the flow of air from clean areas to areas of higher potential for contamination.

Heating of supply air will be provided by steam heating equipment. Cooling will be provided by either evaporative cooling or refrigeration equipment. Evaporative cooling was selected for areas where 
ventilation flowrate requiring once-through air dominated over cooling load. Evaporative cooling can provide air at a minimum $65^{\circ} \mathrm{F}$ at the design summer temperature. This applies mainly to the Hot Cell. In other areas, refrigerated cooling equipment was selected due to the dominance of cooling load over ventilation rates and the need to minimize exhaust air and the size of the final HEPA filtration system. Refrigerated systems were assumed to provide cooled air at $55^{\circ} \mathrm{F}$. This allows lower air flowrates than evaporative cooling.

ANSL/ANS 57.9-1992 was used as the primary design document for configuring the HVAC systems and identifying contamination control zones. The HVAC system requirements in ANSI 57.9 are not as stringent as the DOE-ID Architect-Engineer (A-E) Standards, thus resulting in a lower capital and operational cost for the systems than is typical for comparable INEL facilities. The A-E standards were used for guidance when specific direction was not provided in ANSU/ANS 57.9.

3.8.1.1 Contamination Control Concept. Contamination control zones, as defined in ANSI 57.9, were identified as (1) personnel building areas with no potential for airborne radioactivity, (2) main building areas with low potential for airborne radioactive contamination, and (3) process areas with high potential for radioactive contamination. Personnel building areas are identical to Zone IV areas as identified in the DOE-ID A-E Standards. Likewise, main building areas represent Zone I and process areas represent Zone III areas. The area static pressures have been set to ensure that air within the facility flows from areas of low or no contamination potential toward areas of higher contamination potential. Table 3-6 and Drawing HV-1 show the contamination control scheme proposed for the facility.

Table 3-6. Contamination Control Areas.

ANSI 57.9 Contamination

Control Areas

(DOE-ID A-E Std Zones)

Facility Contamination Control Zones

Personnel Building Area

(Zone IV)

Main Building Area (Zone I)

Process Area (Zone III)
Ready Room, Rad Con Office, Restrooms, Electrical Room, UPS Room, Janitorial Room, Supervisor Office, and Communications Room, Supply Air Mechanical Equipment Rooms, Operating Corridors

Cask Preparation Area, Exhaust Fan Room, HEPA Filter Room, Buffer Room

Hot Cell

Since the Hot Cell has the highest potential for contamination, it will have the lowest static pressure and was assigned as a process area. Infiltration into the Hot Cell will flow mainly from the Cask Preparation Area and the Buffer area located between the Hot Cell and the Anti-C change room. All air exhausted from the Hot Cell is HEPA filtered before discharge to the atmosphere. Main building areas for contamination control were assumed to be areas where contamination is not normally present but could be based on the type of operations performed in these areas, such as HEPA filter changeout, outer cask lid removal, cask lid welding, etc. 
3.8.1.2 Facility HVAC System Design Parameters. Design temperatures were selected from the DOE-ID A-E standards and were used as the basis for determining the size of ventilation equipment. The design values are shown in the Table 3-7.

The roof of the facility will have minimum a U-value of $0.045 \mathrm{BTU} / \mathrm{hr}-\mathrm{ft}^{2}-\mathrm{F}$ and the minimum $\mathrm{U}$-value of the exterior walls will be $0.064 \mathrm{BTU} / \mathrm{hr}-\mathrm{ft}^{2}-\mathrm{F}$.

Table 3-7. Indoor and outdoor design temperatures.

\begin{tabular}{lll}
\hline & $\begin{array}{c}\text { Winter } \\
\left({ }^{\circ} \mathrm{F}\right)\end{array}$ & $\begin{array}{c}\text { Summer } \\
\left({ }^{\circ} \mathrm{F}\right)\end{array}$ \\
\hline Outdoor & -14 & $93 \mathrm{DB}$ \\
& & $61 \mathrm{WB}$ \\
Administrative areas & 65 & 72 \\
Hot Cell & 65 & 76 \\
Cask Preparation & 65 & 76 \\
Cask Handling Bay & 65 & 76 \\
All other areas & 65 & 76 \\
\hline
\end{tabular}

\subsubsection{Description of HVAC Systems}

The facility is divided into four main HVAC systems. These are as follows:

1. Cask Handling Bay HVAC System

2. Administrative Area HVAC System

3. Hot Cell and Cask Preparation Area HVAC System

4. Utility Support Area HVAC System.

These four systems were selected mainly on the definition of the contamination control zones and the physical separation of spaces within the facility. Drawings HV-2 through HV-3 show the schematics for each system. Drawings HV-4 through HV-6 show the location of major equipment.

3.8.2.1 Cask Handling Bay HVAC System. For ventilation purposes, the Cask Handling Bay area includes the Truck Bay, Laydown Area, Cask Staging Area, Weld Observation Room, Fan and Air Handler Rooms, and Operating galleries. This area is a main personnel building area for contamination control and is at atmospheric pressure. Heating is provided by AHU-1, which is sized to maintain this area at $65^{\circ} \mathrm{F}$ in the winter and $76^{\circ} \mathrm{F}$ in the summer. Outside air is provided to offset exfiltration losses due to truck exhauster and leakage to the Cask Preparation Area. Truck exhaust snorkels are provided for placement over the truck engine exhaust stacks to eliminate engine exhaust fumes from the area. 
The Cask Handling Bay supply air system is operated as a fixed-volume system with one area operating as a variable air volume system. Conditioned and filtered air is supplied to this area by AHU-1. AHU-1 includes an outside air isolation damper, outside air/return air mixing section, $60 \%$ filter section, steam heating coil section, glycol cooling coil section, and fan section. The approximate fan capacity is $16,000 \mathrm{cfm}$ at $5 \mathrm{in}$. total pressure. At this capacity, the fan needs a $480-\mathrm{V}$, 3-phase, 20-Hp electric motor. The fan capacity is controlled by automatically operated variable position inlet vanes or a variable speed drive to maintain a set pressure in the AHU-1 discharge duct. Supply air ducting provides the means for air distribution throughout the area. Return air ducting is minimum since this AHU is located within the Cask Handling Bay.

The temperature within the Cask Handling Bay spaces is monitored by electronic thermostats located throughout the work area and the data transmitted to the HVAC control system. The control system will then respond with appropriate signals to make adjustments in the area temperature using AHU-1, if required. To prevent overheating or overcooling of the Weld Observation room, this room is provided with a variable air volume box to adjust airflow based on the room temperature.

The heating load was estimated at $260,000 \mathrm{BTU} / \mathrm{hr}$ at the minimum winter design temperature. Heat gains from equipment operating in this area were not factored into the heat load to provide adequate heating when equipment is not operating. In the heating mode, the AHU discharge air temperature will be controlled to approximately $85^{\circ} \mathrm{F}$.

The cooling load was estimated at $290,000 \mathrm{BTU} / \mathrm{hr}$ and included estimates for equipment operation to avoid undersizing of the cooling equipment. The cooling load was the driver for determining air flow requirements. Thus, refrigerated air at $55^{\circ} \mathrm{F}$ was used to reduce the amount of air flow required and the size of air handling equipment. Using evaporative cooled air at $65^{\circ} \mathrm{F}$ would have essentially doubled the amount of air flow required and significantly increased the size of the air handling equipment and ducting. In the cooling mode, the AHU discharge air temperature will be controlled to approximately $55^{\circ} \mathrm{F}$.

Chiller WC-1 uses a 50/50 glycol/water mixture in a closed loop routed to the cooling coil for AHU-1 to provide cool supply air. WC-1 is a 40-ton capacity, water chilling unit with separate air cooled condenser. The condenser/compressor unit is located outdoors. Electrical power required for this unit is estimated at 480-V, 3-phase, 100 amps. This type of system was selected to provide a ground mounted unit accessible by operations and maintenance personnel. As an option, a roof-mounted, direct expansion compressor/air-cooled condenser unit could also be used to provide cooling to AHU-1.

Inlet filter changeout is performed by shutdown of the AHU, since this AHU provides only tempered and conditioned air and does not perform area pressure control functions.

\subsection{Cask Handling Bay HVAC System Supply Air Equipment Energy} Conservation Features-AHU-1 uses approximately 90\% return air during the maximum winter heating season and the maximum summer cooling season. Return air is obtained from the Cask Handling Bay. Return air is mixed with outside air in the AHU mixing section and then passed through the AHU-1 inlet air filters. The mixed air temperature is controlled to approximately $55^{\circ} \mathrm{F}$. Larger proportions of outside air may be used at various times during the year depending on the outside air temperature and the ability to maintain the mixed air at the mixed air temperature setpoint. 


\subsection{Cask Handling Bay HVAC System Supply Air Equipment Safety Features-}

The temperature of the inlet air is monitored to prevent admittance of low temperature air which could frost the inlet filters or freeze an inactive steam coil. Upon detection of low inlet temperature (below $35^{\circ} \mathrm{F}$ ), the return air damper opens to $100 \%$ and the outside air damper closes. Alarms on the facility HVAC control system notify the facility personnel that a low-temperature condition exists.

3.8.2.2 Administrative Area HVAC System. The Administrative Area HVAC System serves the ready room, Rad Con office, restrooms, custodial room, UPS and electrical rooms, communications room, and the supervisor's office. The restrooms receive transfer air from the corridor and are exhausted by toilet exhaust fans. These areas have been assigned as personnel building areas with no potential for contamination. This area is next to the Cask Handling Bay, which is also a personnel building area for contamination control. These areas have been provided with $1.5 \mathrm{cfm} / \mathrm{ft}^{2}$.

The Administration Area HVAC supply air system operates as a variable air volume system. Conditioned and filtered air is supplied to this area by AHU-5. AHU-5 includes an outside air isolation damper, outside air/return air mixing section, $60 \%$ filter section, steam heating coil section, direct expansion cooling coil (7-1/2-ton capacity), and fan section. The approximate fan capacity is $3,000 \mathrm{cfm}$ at 5 in. total pressure. At this capacity, the fan requires a 480-V, 3-phase, 15-Hp electric motor. The fan capacity is controlled by automatically operated variable position inlet vanes or a variable speed drive to maintain a set pressure in the AHU-5 discharge duct.

The temperature within the Administrative Area spaces is monitored by electronic thermostats located throughout the area and the data transmitted to the HVAC control system. The control system * then responds with appropriate signals to the variable air volume boxes to make adjustments in the area temperature. Supply air ducting provides the means for air distribution throughout the area. Return air ducting is routed from the central corridor in the administrative area. The heating load was estimated at $66,000 \mathrm{BTU} / \mathrm{hr}$ at the minimum winter design temperature. Heat gains from equipment operating in this area were not factored into the heat load to provide adequate heating when equipment is not operating. In the heating mode, the AHU discharge air temperature will be controlled to approximately $100^{\circ} \mathrm{F}$.

The cooling load was estimated at 50,000 BTU/hr, and included estimates for equipment operation to avoid undersizing the cooling equipment. The cooling load was the driver for determining air flow requirements. Thus, refrigerated air at $55^{\circ} \mathrm{F}$ was used to reduce the amount of air flow required and the size of air handling equipment. In the cooling mode, the AHU discharge air temperature will be controlled to approximately $55^{\circ} \mathrm{F}$.

AC-2, the compressor/air-cooled condenser unit for AHU-5, requires 7-1/2-ton cooling capacity. Refrigerant piping is routed from AC-2 to the direct expansion coil in AHU-5. Electrical power required for this unit is estimated at $480 \mathrm{~V}, 3$-phase, $22 \mathrm{amp}$. The condenser/compressor unit is located outdoors on the roof directly above the administrative area.

Inlet filter changeout is performed by shutdown of the AHU, since this AHU provides only tempered and conditioned air and does not perform area pressure control functions.

\subsection{Administrative Area HVAC System Supply Air Equipment Energy} Conservation Features-AHU-5 uses approximately 35\% return air during the maximum winter heating season and the maximum summer cooling season. The remainder of the air is exhausted from 
the restrooms and UPS room. Return air is obtained from the central corridor located in the Administrative area. Return air is mixed with outside air in the AHU mixing section and then passes through the AHU-5 inlet air filters. The mixed air temperature or filter inlet air temperature is controlled to approximately $55^{\circ} \mathrm{F}$ using a preheat coil if necessary. Larger proportions of outside air may be used at various times during the year depending on the outside air temperature and the ability to maintain the mixed air at the mixed air temperature setpoint.

\subsection{Administrative Area HVAC System Supply Air Equipment Safety}

Features-The temperature of the inlet air is monitored to prevent admittance of low-temperature air which could frost the inlet filters or freeze an inactive steam coil. Upon detection of low inlet temperature (below $35^{\circ} \mathrm{F}$ ), the return air damper will open to $100 \%$ and the outside air damper will close. Alarms on the facility HVAC control system notify the facility personnel that a low-temperature condition exists.

3.8.2.3 Hot Cell and Cask Preparation Area HVAC System. The Hot Cell and Cask Preparation Area HVAC System controls the ventilation and air conditioning in the Cask Preparation Area, Buffer Area, and the Hot Cell. Two separate exhaust systems are included within this HVAC system. One exhaust system exhausts air from the Cask Preparation and Buffer Areas; and one exhausts from the Hot Cell.

3.8.2.3.1 Cask Preparation Area and Buffer Area-The Cask Preparation Area was designated as a Main Building area (or Zone I area) for contamination control purposes with its static pressure to be controlled at -0.1 in. W.G. below the Cask Handling Bay and the outside environment. The pressure is controlled by maintaining the exhaust air to a set flow and varying the supply air to obtain the desired negative pressure. Air is supplied to this area by AHU-2 and is exhausted through either the Cask Preparation Area Exhaust system or as infiltration air to the Hot Cell and through the Hot Cell exhaust system. AHU-2 is a once-through air system.

The Cask Preparation Area supply air system is operated as a variable volume system to control the air pressure within the area. Conditioned and filtered air is supplied to this area by AHU-2. Supply air ducting provides the means for air distribution throughout the area. Return air ducting is minimum since this AHU is located within this area. Pressure control within this area is performed using an automatically controlled supply air damper. The pressure is measured in this area and transmitted to the facility HVAC control system. Signals are sent from the control system to the automatic damper for pressure adjustment. See also the information with the Hot Cell Supply Air Equipment Description below.

The temperature within the Cask Preparation Area is monitored by electronic thermostats located and the data transmitted to the HVAC control system. Thermostats are located at work height in large open areas. The control system responds with appropriate signals to make adjustments in the area temperature using AHU-2 discharge temperature, if required. Since the Cask Preparation Area is an internal area with no outside exposure, the heating load is taken care of by the Cask Handling Bay system. In the heating mode, the AHU-2 discharge air temperature will be controlled to approximately $68^{\circ} \mathrm{F}$.

In the cooling mode, the AHU discharge air temperature will be controlled to approximately $65^{\circ} \mathrm{F}$. During the summer, AHU-2 will provide cooled air to maintain the Cask Preparation Area temperature at 
$76^{\circ} \mathrm{F}$. Cooling will be provided by an evaporative cooling section within AHU-2. Outside air will be used without evaporative cooling when the outdoor temperature is below $65^{\circ} \mathrm{F}$. Potable water will be used for the evaporative cooling section. Water treatment chemicals will be used in the evaporative cooling sump to control scale and algae buildup.

The Cask Preparation Area is exhausted by the Cask Preparation Area/Utility Support Area Exhaust equipment. This equipment consists of a single bank of final prefilters and HEPA filters, final exhaust fans (one primary and one in standby), and an exhaust stack with monitoring instrumentation. This exhaust equipment is located in the Utility Support Area HEPA Filter Room and Exhaust Fan Room. The exhaust air has a fixed air flowrate of approximately $2,630 \mathrm{cfm}$ to ensure the direction of air flow is from the Cask Handling Bay toward the Hot Cell. See additional information below for the Utility Support Area Exhaust Air System.

3.8.2.3.2 Hot Cell-The Hot Cell Area is a process contamination area (Zone III area) when hot operations are in progress and is controlled to at least -0.6 in. W.G. below atmospheric pressure.

Ventilation air is provided at a minimum rate of 6 air changes per hour or approximately $10 \%$ of the cell volume as required by ERDA 76-21. The pressure is controlled by maintaining a fixed exhaust flow and varying the supply flow to obtain the desired negative pressure. Exhaust air is routed to the Hot Cell exhaust system. The temperature and pressure of the hot cell are monitored and transmitted to the HVAC control system. Control signals are generated by the HVAC control system and sent to HVAC equipment when changes are required to operating parameters.

Supply air for the Hot Cell is provided by AHU-2. The supply air to the Hot Cell is controlled as a variable volume system controlled with the cell static pressure input to the control system. Conditioned and filtered air is supplied to this area by AHU-2. AHU-2 includes an inlet isolation damper, glycol heat recovery coil, $60 \%$ filter section, steam heating coil section, evaporative cooling unit section, and fan section. The approximate fan capacity is $22,830 \mathrm{cfm}$ at 14 in. total pressure at $5,000 \mathrm{ft}$ elevation (52 BHp). At this capacity, the fan requires a 480-V, 3-phase, $60-\mathrm{Hp}$ electric motor. The fan capacity will be controlled by automatically operated variable position inlet vanes or a variable speed drive to maintain a set pressure in the AHU-2 discharge duct.

Supply air ducting carries the supply air into the Hot Cell. Ducting within the Hot Cell distributes the supply air along the upper portion of the cell, and the air flows downward in the cell from the upper levels to the lower portions where the exhaust ducts are located. An automatic isolation damper located at the cell boundary closes if necessary to prevent backflow of air from the Hot Cell. The Hot Cell envelop heat losses due to exterior walls and roof were estimated to be $64,000 \mathrm{BTU} / \mathrm{hr}$ at the minimum winter temperature. However, the heat losses were more than offset by the heat gain (estimated to be $130,000 \mathrm{BTU} / \mathrm{hr}$ ) from lighting and equipment operation. Heat generated by the spent fuel was not factored into the heat gain since the heat from the fuel will generally be pulled directly into the exhaust system.

The total summer cooling load was estimated at 160,000 BTU/hr and included estimates for equipment operation to avoid undersizing of the cooling equipment. The ventilation rate exceeded that necessary for evaporative cooling at the estimated cooling load. In the cooling mode, the AHU-2 discharge air temperature will be controlled to $65^{\circ} \mathrm{F}$. 
Energy conservation features include a glycol heat recovery loop that extracts or rejects heat to the exhaust air from the Hot Cell. The heat recovery coil is sized to obtain a minimum of $32^{\circ} \mathrm{F}$ leaving air temperature during winter temperatures to ensure that the air filter does not get plugged with frost buildup. The heating coil is sized to provide the total amount of heat necessary should the heat recovery system fail to operate. Evaporative cooling was selected because of the significant amount of air required to achieve the air change rate and the normally dry ambient conditions that will allow efficient evaporative cooling. Evaporative cooling will be used whenever the outdoor temperature exceeds $60^{\circ} \mathrm{F}$. At the maximum summer design temperatures, the supply air will be approximately $65^{\circ} \mathrm{F}$, assuming an $85 \%$ efficient evaporation process. At the estimated cooling load for the Hot Cell, the $80 \%$ relative humidity of the supply air will drop to approximately $55 \%$ upon exiting the cell. When outdoor air is below $60^{\circ} \mathrm{F}$, the air will be used directly without evaporative cooling.

AFU-2 is interlocked to prevent its operation when the hot cell exhaust fans are not in operation. After startup of the final exhaust fans, AHU-2 is allowed to start. The facility HVAC control system monitors the air temperature before the heating coil. When and if the temperature drops below $40^{\circ} \mathrm{F}$, an alarm will be initiated at the HVAC control system supervisory monitor indicating a failure of the heat recovery system and the need for immediate attention to prevent possible heating coil freeze-up.

Air within the Hot Cell circulates to the exhaust grilles located next to the lag storage vaults. Ducting routes the exhaust air from the cell to the two exhaust air filter units. The final filters are located upstream of the exhaust fans in the HEPA filter room in the Utility Support Area. Each filter unit consists of a 4-filters-high by 3-filters-wide enclosure with an inlet low-leakage isolation damper for each filter, a 90\% efficiency prefilter, a DOP inlet section, a HEPA filter, a DOP measuring section, and a final low-leakage damper for each filter. Each filter will be a 24-in. $\times 24$-in. size rated for $1,000 \mathrm{cfm}$. Each filter unit requires 24 filters (12 prefilters and 12 HEPA filters).

Two exhaust fans (one in normal operation and one in standby) provide the required exhaust flow from the Hot Cell. Exhaust fans EF-1 and EF-2 are centrifugal fans each rated for high negative pressure capable of providing $20,000 \mathrm{cfm}$ at $16 \mathrm{in}$.W. G. At this capacity and pressure, each fan requires a $480-\mathrm{V}, 3-$ phase electric motor rated for at least $52 \mathrm{BHp}$. Each fan is constructed of the manufacturer's standard materials of construction and is sized to provide $100 \%$ of the exhaust air requirements. The additional fan will be in the standby mode. The fan air flow is controlled by a variable-speed drive or with variable-position inlet vanes. A stack located outside the building will discharge the exhaust air to the environment.

Glycol heat recovery coils located between the final filter unit and the exhaust fan provides for heat collection in the winter and heat rejection in the summer. Collected energy is transferred to the supply air system to offset ambient air heating or cooling needs using a glycol heat recovery system.

The Hot Cell exhaust fans operate continuously to maintain the flow of air into the Hot Cell and contain contamination within the Hot Cell. The Hot Cell exhaust fans are provided with standby power.

3.8.2.4 Utility Support Area HVAC System. The Utility Support Area HVAC System serves the Supply Air Mechanical Equipment Room, the HEPA Filter Room, and the Exhaust Fan Room.

The Supply Air Mechanical Equipment Room is a personnel building zone (Zone IV area) and contains AHU-2 and AHU-3. Supply air to this room is provided by AHU-3. Air flow to this room is 
fixed volume, with some returning to the inlet of AHU-3. The instrument air equipment is also located in this room. This room will be controlled to $65^{\circ} \mathrm{F}$ in the winter and $76^{\circ} \mathrm{F}$ in the summer. Access is provided around each AHU for maintenance work for filter changeout and internal equipment inspection and repair.

Temperature instruments monitor the mixed air temperature to prevent steam coil freezeup. The quantity of outside air will vary depending on the outside air temperature and the cooling and heating requirements of the support area.

The HEPA Filter and Exhaust Fan Rooms are main building areas (Zone I areas) controlled to approximately -0.2 in. W.G. below atmospheric pressure. The supply air for these rooms is provided by AHU-3. The air flow through these rooms is controlled by maintaining a fixed exhaust air flow. The room pressures are controlled by modulating the supply air damper to obtain the desired pressure operating point. The exhaust from these rooms combines with the exhaust from the Cask Preparation Area. The HEPA Filter Room houses the final air filter units for the Hot Cell and for the Cask Preparation Area/Utility Support Area.

The Utility Support Area HVAC supply air system is operated as a fixed volume system for the Supply Air Mechanical Equipment Room and as a variable air volume system for the HEPA Filter and Exhaust Fan Rooms. The supply air fan is controlled to maintain the fan discharge pressure to a set value. Conditioned and filtered air is supplied to these areas by AHU-3. AHU-3 includes an outside air isolation damper, return air damper, inlet air mixing section, $60 \%$ filter section, steam heating coil section, evaporative cooling unit section, and fan section. The fan outputs $3,000 \mathrm{cfm}$ at $5 \mathrm{in}$. total pressure and requires a $480^{\circ} \mathrm{V}, 3-$ phase, $15-\mathrm{Hp}$ electric motor. The fan capacity is controlled by automatically operated variable position inlet vanes or a variable speed drive to maintain a set pressure in the AHU-3 discharge duct. Supply air ducting provides the means for air distribution throughout the area. Return air ducting is minimum since this AHU is located within this area.

The heating load was estimated at $61,000 \mathrm{BTU} / \mathrm{hr}$ at the minimum winter design temperature. Heat gains from equipment operating in this area were not factored into the heat load to provide adequate heating when equipment is not operating. In the heating mode, the AHU discharge air temperature will be controlled to approximately $90^{\circ} \mathrm{F}$.

The cooling load was estimated at $162,000 \mathrm{BTU} / \mathrm{hr}$ and included estimates for equipment operation to avoid undersizing of the cooling equipment. The cooling load was the driver for determining air flow requirements. Thus refrigerated air at $55^{\circ} \mathrm{F}$ was used to reduce the amount of air flow required and the size of air handling equipment and the final HEPA filter unit. AHU-4 provides supplemental cooling to the HEPA Filter and Exhaust Fan rooms using a direct expansion packaged air handling unit rated at 15-ton cooling capacity. AHU-4 includes only a cooling coil. No heating coil is required. The fan for this unit outputs $5,000-7,000 \mathrm{cfm}$ at $0.5 \mathrm{in}$. total pressure with a $480-\mathrm{V}, 3-$ phase, $5-\mathrm{Hp}$ electric motor.

AC-1 is the compressor unit/air cooled condenser for AHU-4. The compressor and air cooled condenser are located outdoors. This unit requires $480-\mathrm{V}, 3$-phase power and use approximately 41 amps. 
AHU-3 uses return air from the Supply Air Mechanical Equipment Room. In addition, AHU-3 uses evaporative cooling during the peak summer cooling season. Direct outside air will be used at other times as long as the mixed air temperature can be maintained at $55^{\circ} \mathrm{F}$.

AHU-3 is interlocked to prevent operation when the Utility Support Area/Cask Preparation Area exhaust fans are not in operation. After startup of the exhaust fans, AHU-3 is allowed to start. The facility HVAC control system monitors the air temperature before the heating coil. If the temperature drops below $40^{\circ} \mathrm{F}$, an alarm is initiated at the HVAC control system supervisory monitor.

Air within the HEPA Filter and Exhaust Fan Rooms flows from supply ducts to exhaust ducts. The final filters are located upstream of the exhaust fans in the HEPA filter room in the Utility Support Area. Each filter unit consists of a 3-filters-high by 2-filters-wide enclosure with an inlet low-leakage isolation damper for each filter, a $90 \%$ efficiency prefilter, a DOP inlet section, a HEPA filter, a DOP measuring section, and a final low-leakage damper for each filter. Each filter is 24-in. $\times 24$-in., rated for 1,000 cfm. The filter unit requires 12 filters ( 6 prefilters and 6 HEPA filters) and is oversized to allow changeout of one filter row containing two filters while the other two rows of filters remain on line.

A set of two exhaust fans (one in normal operation and one in standby) provides the required exhaust flow from the HEPA Filter and Exhaust Fan Rooms. Exhaust fans EF-3 and EF-4 are centrifugal fans each rated for high negative pressure capable of providing $4,800 \mathrm{cfm}$ at $11 \mathrm{in}$. W. G. at 5,000 ft elevation. At this capacity and pressure, each fan requires a $480-\mathrm{V}, 3$-phase electric motor rated for at least $10 \mathrm{BHp}$. Each fan is constructed of the manufacturer's standard materials and is sized to provide $100 \%$ of the exhaust air requirements. The additional fan is in the standby mode. The fan air flow is controlled by a variable speed drive or with variable position inlet vanes. A stack located outside the building discharges the exhaust air to the environment.

\subsection{Mechanical Utilities}

Utilities that must be provided for the ICPP Spent Nuclear Fuel Dry Storage Facility include compressed air, compressed gas, potable water, fire water, high pressure steam, and waste systems. Existing ICPP plant utilities are located in the general area of the proposed facility, and pipe routing and connection points with the existing ICPP utilities are identified in drawing C-2. Waste systems include both service waste and sanitary waste systems. Compressed air, potable water, fire water, high pressure steam, and service waste lines are located in the utility tunnel which is approximately $100 \mathrm{ft}$ from the facility. The tie-in for the sanitary sewer is located approximately $400 \mathrm{ft}$ from the facility. Compressed gas will be provided using bottled gas located in the facility. The proposed utility usage has been analyzed and existing utility capacity is adequate for the proposed life of the facility.

\subsubsection{Compressed Air}

Compressed air is supplied to various locations in the facility from the ICPP underground utilities located in the utility tunnel. A 2-in. carbon steel pipeline will be routed to the new facility. The line enters the building in the mechanical room and is divided into plant air and instrument air in the mechanical room.

3.9.1.1 Plant Air. The plant air lines are copper with sweat fittings. The lines are anticipated to be

$1-1 / 2$ in. in diameter. The locations serviced with plant air include the Cask Handling Bay, Cask 
Preparation Area, and the Hot Cell. Plant air is used to operate pneumatically operated tools associated with cask handling and preparation. All lines are terminated with quick disconnects for flexibility of use.

3.9.1.2 Instrument Air. Instrument air lines are copper with sweat fittings. These lines are also anticipated to be $1-1 / 2$ in. in diameter. Instrument air is used for pneumatically operated HVAC system equipment, and for miscellaneous equipment requiring air for actuators. The air is filtered and dried to a dew point temperature of $-40^{\circ} \mathrm{F}$ using a refrigerated dryer. Pressure regulators are provided at locations as required to reduce air pressure for use by the equipment.

\subsubsection{Compressed Gas}

Various compressed gases are required throughout the facility. Racks containing argon and helium gas cylinders are located in the can welding and inerting equipment room on the third level and in the Cask Staging Area. Argon gas is used for the welding processes and helium is used for pressure testing and inerting operations. Lines are routed from the manifolds to the Cask Handling Bay, Cask Preparation Area and the Canning Area in the Hot Cell.

\subsubsection{Potable Water}

Potable water is supplied from the ICPP underground utilities located in the utility tunnel through a 2-in. carbon steel line. The line enters the building in the mechanical room. The potable water line downstream of the backflow preventer is 2-in. diameter copper pipe with sweat fittings. The largest line in the facility is expected to be the 2-in. diameter, branch line with sizes to be finalized in Title Design.

Equipment and fixtures served include two water closets, one urinal, four sinks, two showers, shower/eyewash facilities, two evaporative coolant units, drinking fountains, and miscellaneous ports located in the Cask Handling Bay, Cask Preparation Area, and Hot Cell area.

A water heater is located in the janitor's closet next to the rest rooms. The unit provides $140^{\circ} \mathrm{F}$ water to the showers and sinks in the rest room and laboratory.

\subsubsection{Waste Systems}

Waste systems for the ICPP Spent Nuclear Fuel Dry Storage Facility include service waste, process equipment waste (PEW), and sanitary waste. Service waste and sanitary waste will be piped from the facility and tied into the existing ICPP utilities. PEW will be collected in a 1,000-gal tank, sampled, and transferred via tanker truck for treatment and storage. The decision to collect and transfer PEW in this manner is based on cost and experience. No PEW lines are located in the vicinity of the facility. From experience at the Site, it is expected that the amount of PEW collected will be minimal. The cost of routing a pipe to the nearest existing PEW line, located in ICPP 666, is expected to be greater than the cost of collection and transfer.

3.9.4.1 Service Waste. The service waste line is connected to the ICPP 4-in. service waste line located in the utility tunnel through a 2-in. carbon steel line that enters the building in the mechanical room. Service waste will be collected and tested before being pumped into the service waste line. Service waste capacity is provided in the Cask Handling Bay, and the Cask Preparation Area. Condensate from the HVAC equipment will also be disposed of using the service waste line. 
3.9.4.2 Sanitary Systems. Sanitary sewer drains are provided at restroom fixtures and drinking fountains served by potable water. Vents are provided and terminate above the facility roof line. A sewer clean out is provided in the sewer main before it leaves the building and elsewhere as required to ensure that all sewer lines are cleanable. The sewer is connected to the existing ICPP system using an 8-in. ABS sewer line. The sewer tie-in connection is located east of ICPP-665. The total pipe length to reach the facility is estimated to be $400 \mathrm{ft}$. One manhole is required in the run for system cleanout capabilities.

\subsubsection{Fire Protection}

Automatic fire protection is provided throughout all areas of this facility with the exception of the Hot Cell. This protection consists of a wet pipe system installed in accordance with National Fire Protection Association codes and standards and Factory Mutual Data Sheets. In addition, fire hydrants are located around the building and inside the dry fuel storage yard in support of manual fire fighting efforts.

Although manual fire extinguishes will be available in the Hot Cell, automatic fire protection is not provided. While no potential criticality issues have yet been identified, automatic water systems present the potential for chemical reaction between water and the graphite fuels. Foam or gaseous systems would not be effective in the large Hot Cell with very high ceiling. When the Hot Cell is in fuel transfer operation, personnel are not present and the combustion loads are very small. No unacceptable consequences of a fire could be identified. When personnel are in the Hot Cell (and combustion loads are higher), the fire extinguishes provide adequate protection.

The automatic sprinkler system is designed based upon an ordinary hazard, group two occupancy as a minimum. Fire suppression, (water spray) is also provided for all HEPA filter systems which have a face area of $16 \mathrm{ft}^{2}$ or larger.

Fire alarms are installed and connected into the Site-wide fire alarm system. The alarms shall detect water flow, heat, and provide supervision for the fire alarm system.

Fire hydrants are arranged to allow access to all exterior areas of the building with a maximum of $300 \mathrm{ft}$ of hose lay. Hydrants located in the storage yard are located at each end of the yard in a manner that allows access to the entire yard.

Some relocation of existing underground fire water mains will be required at the site for the storage basemat.

\subsubsection{Steam}

Steam is supplied to the facility from the ICPP underground utilities located in the utility tunnel through a 4-in. carbon steel line. The line is insulated and cathodic protection is provided. The steam system provides steam at a peak flow of $2,610 \mathrm{lb} /$ hour at $135 \mathrm{psi}$. The steam line enters the building in the mechanical room and is routed from the mechanical room to the fan rooms as needed. Pipe sizes in the building will be identified during Title Design. 


\subsubsection{Tanks}

3.9.7.1 Washdown Water Collection Tank. A storage tank is used to collect washdown water during operations in the Truck Bay. The tank has a capacity of 1,000 gallons. The water collected in the tank will be sampled prior to disposing through the service waste line, or transferring to the ICPP process equipment waste (PEW) system.

3.9.7.2 Process Equipment Waste (PEW) Collection Tank. A 1,000-gal PEW storage tank is located below grade for collection of decontamination water from the Hot Cell, water from the Vacuum Drying System located in the cask preparation area, and water from the fire protection system associated with the HEPA filter banks. The line from the vacuum drying system will include back flow prevention. The tank has sampling and pumping capabilities.

\subsection{Electrical Systems}

\subsubsection{Power}

The DTC facility receives 480-Vac, 800-A, 3-phase commercial power through feeders installed in an underground ductbank from Load Center 3. These terminate in the electrical equipment room at a service entrance-rated Motor Control Center (MCC). The electrical system includes standby power, emergency power, a 277/480-V distribution system, and a 120/208-V distribution system. These subsystems are shown in Drawing E-1 and are discussed below.

Standby power is provided to the DTC facility from the existing Standby Power System at ICPP. Standby power is provided only to the Hot Cell HVAC system exhaust fans and to the Uninterruptible Power Supply (UPS) and is made available through the normal power bus. Controls are provided by the ICPP Utility Control System.

Emergency power is provided by a 80-kVA UPS located in the electrical equipment room. The UPS is dedicated to the fire alarm system, voice paging system, evacuation alarm system, radiation monitoring and alarm system, and the security systems to include the spent fuel DSS perimeter lighting. The UPS has a battery backup sufficient to carry the rated load for 30 minutes.

The 277/480-V distribution system includes one MCC and five distribution panels. The MCC provides power to the HVAC system, cranes, distribution panels, and the spent fuel DSS. The MCC is rated at 277/480-V, 800-A, 3-phase, 4-wire with an 800-A main circuit breaker and ground fault protection. It is located in the electrical equipment room and is equipped with metering. All five distribution panels are 277/480-V, 3-phase, 4-wire panels. Each panel is equipped with a 225-A main breaker and has the capability to supply 42 branch circuits. The panels are located in the Truck Bay, the Cask Handling Bay, the third floor operating corridor, the UPS room, and the Can Welding and Inerting room.

The 120/208-V, 3-phase distribution system is included for receptacles and small power loads. Four panels are included: one panel is equipped with a 150-A main breaker and has the capability for 42 branch circuits. It is powered by a 45-kVA dry-type transformer. Both the transformer and the panel are located in the electrical equipment room. The panel provides power for office lighting and receptacles. Three panels are equipped with a 100-A main breaker and have the capability for 24 branch 
circuits. Each panel is fed by a $25-\mathrm{kVA}$ dry-type transformer. The transformers are located in the electrical equipment room, and of the four panels, one panel is located in the UPS room, two panels in the Electrical Equipment room, and one panel in the Can Welding and Inerting room.

\subsubsection{Grounding}

A perimeter ground loop consisting of \#4/0 bare copper wire and ground rods is included around the facility. The facility steel, water piping, service equipment, distribution equipment, and motor frames are bonded to the ground loop. Equipment grounding is in accordance with the NEC Article 250. Equipment ground wires are included in all conduit runs.

An isolated grounding system is provided that consists of a series of isolated $1 / 4$ in. copper bus bars radially connected via insulated \#2/0 AWG ground conductors to a single point on the facility ground loop. All telecommunications equipment and any Supervisory Control and Data Acquisition (SCADA) systems use the insulated grounding conductors to connect to the isolated ground system.

\subsubsection{Cathodic Protection}

Utility piping is protected through connection to the existing ICPP cathodic protection system. Buried piping is electrically connected to the negative side of the existing rectifier with \#2 AWG cable. Anodes are installed parallel and at the same elevation as the piping. A testing/bonding station is included to periodically monitor the cathodic protection system.

\subsubsection{Lightning Protection}

A lightning protection system meeting the requirements of NFPA 780 will be developed during later design stages. The cost estimate in Section 5 includes an allowance for this system and is based on the costs for comparable protection for other facilities.

\subsubsection{Lighting}

Lighting is designed in accordance with current Illuminating Engineering Society recommendations and uses power-conserving lamps and ballasts. Nonglare fluorescent fixtures are used throughout the facility. Lighting in individual rooms such as offices, breakrooms, and restrooms employs $120-\mathrm{V}$ ballasts. Lighting controls in the offices use two toggle switches to provide three levels of illumination.

Lighting in open areas and equipment rooms uses $277-\mathrm{V}$ ballasts. The $277-\mathrm{V}$ lighting system is controlled by low-voltage switches at each point of entrance and egress of the area. These switches are connected to a programmable lighting control panel mounted in the electrical equipment room.

Emergency and exit lighting are provided at each means of egress. Emergency lighting is provided in all areas and is equipped with 277-V ballasts. This lighting is powered from internal Ni-Cad battery units. Exit lights consist of exit signs powered with $\mathrm{Ni}$-Cad batteries. Three emergency lights will be provided in the Hot Cell. 
High-pressure sodium fixtures are included in the Hot Cell. Twenty 1,000-watt ceiling-mounted fixtures and six 400-watt wall-mounted fixtures are included. Exterior building perimeter lighting are also high-pressure, wall-mounted sodium fixtures with photoelectric controls.

\subsubsection{HVAC Controls}

The HVAC system is controlled from an independent, microprocessor-based system. Temperature, pressure, and operating status information are collected by the system and the output signals generated for control of the HVAC equipment. Local interface units contain the input and output units connected to the central processor. A supervisory computer monitor is provided in the Shift Supervisor's office for reviewing the operating status of the system and making adjustments to control setpoints. A data highway connects the local interface units along with the supervisor's monitor.

\subsubsection{Equipment Controls}

Controls for the facility cranes are supplied by the crane vendor. The controls for cranes in the Hot Cell can be operated either in the cell or from outside any of the cell windows.

Remotely controlled, closed-circuit TV cameras are provided in the Hot Cell for general visual observation, fuel canning operations, fuel inspection, and documentation. Each window is also equipped with a visual inspection station that includes two high-resolution cameras, a monitor, camera controls for pan, tilt, and zoom functions, and recording capability for archival purposes.

A data entry station, used to record and monitor all fuel movements, is co-located with each visual inspection station. A data link permits communications between any of the stations. The data entered through these workstations in conjunction with the video record provide the required historical records for fuels accountability.

The Shift Supervisor's Office is provided with a microprocessor-based system for the collection of alarms from the HVAC system and any other required alarms.

\subsubsection{Radiation Monitoring and Alarms}

Radiation Area Monitors (RAMs) are located in the Truck Bay (1), Cask Preparation Area (1), Cask Staging Area (1), second floor operating corridor (1) third floor operating corridor (2), and the HEPA Filter room (1). All instruments alarm locally and remotely in the RadCon office. Monitor locations are shown on Drawings E-2 through E-4.

Beta/Gamma Constant Air Monitors (CAM) are located in the Truck Bay (1), Cask Preparation Area (1), Cask Staging Area (1), second floor operating corridor (1), third floor operating corridor (2), and the HEPA Filter room. An alpha CAM is located in the inlet duct to the Zone 1 HEPA filter of the HVAC system.

A criticality alarm system is provided in compliance with the criteria of ANSI/ANS 8.3-1986 and ANSI/ANS 57.9-1992. Neutron-sensitive detectors are provided as required by the above standards. These systems provide alarms throughout the facility with a two-tone warbler and flashing red lights. 
Stack monitoring is provided for the detection of radioactive particulates in the air exhaust stream. These instruments comply with the requirements of ANSI-N42.17B-1989. Instruments provide remote readout/alarms in the RadCon Office. An evaluation per ANSI-N13.1-1969 will be performed during Title II design to determine if Iso-kinetic sampling will be required. The current cost estimate is based on providing iso-kinetic sampling for the Hot Cell stack.

Personnel Contamination Monitors are located by the doors between the Anti-C Change Area and the operating corridor and by the door between the Cask Handling Bay and the operating corridor.

Activity Monitors are provided in the washdown water collection tanks and in the PEW collection tank.

The Rad Con Office has a remote alarms monitor, four handheld survey instruments, and a FASTRAK II Dosimetry System (or equal).

Selected instruments (to be determined during Title Design) transmit data to a microprocessorbased system for display, recording, alarm, and trending in the Rad Con Office. The instruments will also be connected to the Radiation, Environmental, and Safety (RE\&S) computer system for remote monitoring. The RE\&S interface is in the utility tunnel.

\subsubsection{Communications and Alarms}

Voice and data telecommunications lines are included throughout the occupied areas of the facility. The new telecommunication service lines are routed in dedicated conduits.

The existing Broadband Local Area Network (LAN) will be made available in the facility. Access ports are provided in all normally occupied offices.

Fire alarm, emergency voice paging, and the evacuation alarm systems are compatible with existing systems at the ICPP. These systems have supervised controls and receive power from the UPS-backed panel. Power and signal wiring runs in separate dedicated raceways.

A device will be installed to record the response of the DTC structure in the event of an earthquake.

\subsubsection{Data Acquisition and Recording}

The data acquisition system is used for material controls and accountability at the DTC facility. The system includes individual PCs located at each window and the supervisor's office all networked to a local server. The system will maintain at least the following information on all fuels received: shipper's name, estimated quantity of radioactive material per item to include special nuclear material in the spent fuel, item identification and seal number, storage location, onsite movements of each fuel assembly, and ultimate storage location. A video record will also be made as each fuel is processed. 


\subsubsection{Security Systems}

The DTC is provided with physical protection systems as required by the proposed 10 CFR 73.51 . Access control to the facility (card readers) are installed on the exterior entrances. Passive Infrared Detectors are located in the Hot Cell. All exterior doors and all doors having direct access to the Hot Cell are alarmed. In addition to these, the doors into the UPS room, the HEPA Filter room, and the Hot Cell exhaust fans are alarmed. All systems interface with the existing Argus security systems. An Argus Field Panel is located in the UPS room, which provides the interface to the Argus host computer located in CPP-1674.

The perimeter of the DSS is illuminated with high-pressure sodium lights placed every $75 \mathrm{ft}$ along the perimeter. The lights are provided UPS power from the DTC facility. The perimeter is also protected by an intrusion detection system which will be either a leaky coaxial cable type (Sentrax) buried underground or a fiber optic sensor mounted to the fence.

All alarms are monitored at the existing ICPP Central Alarm Station and the existing Secondary Alarm Station. 


\section{CODES AND STANDARDS APPLICABLE TO THE SNF DRY STORAGE PROJECT}

Table 4-1 shows the codes and standards applicable to the design of the Dry Storage Facility. The codes and standards are listed as well as the titles and applicable areas. This list is not exhaustive, but covers the main codes and standards that apply. As title design commences and the designs become more detailed, additional codes and standards will be identified. 
Table 4-1. Codes and Standards.

\begin{tabular}{|c|c|c|}
\hline Code/standard & Title & Applies to \\
\hline 10 CFR 20 & Standards for Protection Against Radiation & HVAC, Radiation Protection \\
\hline 10 CFR 50 & Domestic Licensing of Production and Utilization Facilities & Handling \\
\hline 10 CFR 71 & Packaging and Transportation of Radioactive Material & Casks and Transporter \\
\hline 10 CFR 72 & $\begin{array}{l}\text { Licensing Requirements for the Independent Storage of Spent Nuclear Fuel } \\
\text { and High-Level Radioactive Waste }\end{array}$ & \\
\hline Subpart A & General Provisions & Project \\
\hline Subpart B & License Application, Form, and Contents & Project \\
\hline Subpart C & Issuance and Conditions of License & Project \\
\hline Subpart D & Records, Reports, Inspections, and Enforcement & Safeguards/Security \\
\hline Subpart E & Siting Evaluation Factors & Civil \\
\hline Subpart F & General Design Criteria & All Systems \\
\hline Subpart G & Quality Assurance & Quality \\
\hline Subpart $\mathrm{H}$ & Physical Protection & Security \\
\hline Subpart I & Training and Certification of Personnel & Operations, Safety \\
\hline Subpart J & Provision of MRS Information to State Governments and Indian Tribes & Project \\
\hline Subpart K & General License for Storage of Spent Fuel at Power Reactor Sites & Storage Area \\
\hline Subpart L & Approval of Spent Fuel Storage Casks & Casks \\
\hline 10 CFR 73 & Physical Protection of Plants and Materials & $\begin{array}{l}\text { Handling/Rad protection and } \\
\text { security }\end{array}$ \\
\hline 10 CFR 75 & Safeguards on Nuclear Material - Implementation of US/LAEA Agreement & SNF Accountability \\
\hline 10 CFR 435 & $\begin{array}{l}\text { Energy Conservation Voluntary Performance Standards for New Buildings, } \\
\text { Mandatory for Federal Buildings }\end{array}$ & Structural \\
\hline 10 CFR 830 & Nuclear Safety Management & Safety \\
\hline 10 CFR 835 & Occupational Radiation Protection & Radiation Protection \\
\hline $\begin{array}{l}10 \text { CFR } 1021 \\
\text { (also in DOE Order 5440.1D, } \\
40 \text { CFR } 1500-1508 \text {, and } \\
\text { SEN 15-90) }\end{array}$ & NEPA implementing procedures & $\begin{array}{l}\text { Project - EIS has been } \\
\text { approved and ROD issued }\end{array}$ \\
\hline 10 CFR 1022 & Compliance with Floodplain-Wetlands Environmental Review Requirements & Environmental \\
\hline
\end{tabular}


Table 4-1. (continued).

\begin{tabular}{|c|c|c|}
\hline Code/standard & Title & Applies to \\
\hline 10 CFR 1046 & Physical Protection of Security Interests & Security \\
\hline 29 CFR 1910 & Occupational Safety and Health Standards for General Industry & \\
\hline Subpart A & General & Project \\
\hline Subpart B & Adoption and Extension of Established Federal Standards & Project \\
\hline Subpart C & General Safety and Health Provisions & Safety \\
\hline Subpart D & Walking - Working Surfaces & Stairs, platforms, ladders \\
\hline Subpart E & Means of Egress & Architectural, fire protection \\
\hline Subpart G & Occupational Health and Environmental Control & HVAC, noise \\
\hline Subpart H & Hazardous Materials & Compressed gas \\
\hline Subpart I & Personal Protective Equipment & Operations \\
\hline Subpart J & General Environmental Controls & Sanitation, safety \\
\hline Subpart K & Medical and First Aid & Safety \\
\hline Subpart L & Fire Protection & Fire protection, safety \\
\hline Subpart M & Compressed Gas and Compressed Air Equipment & Mechanical Utilities \\
\hline Subpart N & Materials Handling and Storage & Cranes and rigging equip \\
\hline Subpart $O$ & Machinery and Machine Guarding & ?? Canning?? \\
\hline Subpart Q & Welding, Cutting, and Brazing & Welding operations \\
\hline Subpart S & Electrical & Electrical \\
\hline Subpart Z & Toxic and Hazardous Substances & HVAC \\
\hline 29 CFR 1926 & Occupational Safety and Health Regulations for Construction & All systems \\
\hline 40 CFR 50 & National Primary and Secondary Ambient Air Quality Standards & HVAC/HEPA filtration \\
\hline 40 CFR 51 & $\begin{array}{l}\text { Requirements for Preparation, Adoption, and Submittal of Implementation } \\
\text { Plans }\end{array}$ & HVAC/HEPA filtration \\
\hline 40 CFR 52 & Approval and Promulgation of Implementation Plans & HVAC/HEPA filtration \\
\hline 40 CFR 53 & Ambient Air Monitoring Reference and Equivalent Methods & Storage Area, HEPA \\
\hline 40 CFR 58 & Ambient Air Quality Surveillance & Storage Area, HEPA. \\
\hline 40 CFR 260 et seq. & Hazardous Waste Management System: General & $\begin{array}{l}\text { Resource Conservation and } \\
\text { Recovery Act (RCRA) }\end{array}$ \\
\hline
\end{tabular}


Table 4-1. (continued).

\section{Code/standard}

40 CFR 261

40 CFR 262

40 CFR 268.50

40 CFR 300 et seq.

49 CFR 173

Subpart I

American Institute of Steel Construction publication 1989

ANSI/ACI 318-89

ANSI/ACI 349-85

ANSI/AISC N 690-1984

ANSI/ANS 2.3-1983

ANSI/ANS 2.19-1981 (R1990)

ANSI/ANS 8.1-1983 (R1988)
Identification and Listing of Hazardous Waste

Standards Applicable to Generators of Hazardous Waste

Land Disposal Restrictions

National Oil and Hazardous Substances Pollution Contingency Plan

Shippers - General Requirements for Shipments and Packages

Radioactive Materials

Specification for Structural Steel Buildings, Allowable Stress Design and Plastic Design

\section{Building Code Requirements for Reinforced Concrete}

Code Requirements for Nuclear Safety Related Concrete Structures

Specifications for the Design, Fabrication, and Erection of Steel Safety Related Structures for Nuclear Facilities

American National Standard for Estimating Tornado, and Extreme Wind 'Characteristics at Nuclear Power Sites

American National Standard Guidelines for Establishing Site-Related Parameters for Site Selection and Design of an Independent Spent Fuel Storage Installation (Water Pool Type)

American National Standard Nuclear Criticality Safety in Operations with Fissionable Materials Outside Reactors
Applies to

Sample and sample residue

management

Sample and sample residue management

Decontamination water

Operations - MSDS and chemical inventory

Decontamination of external surfaces of transport packages

Steel structures

Structural

Structural design for the facility, especially the confinement areas and storage vaults

Structural design for the facility, especially the confinement areas and storage vaults

Structural

Structural loads even though it is not a water pool type

Criticality analysis/safety 
Table 4-1. (continued).

\begin{tabular}{|c|c|c|}
\hline Code/standard & Title & Applies to \\
\hline ANSI/ANS 8.3-1986 & American National Standard Criticality Accident Alarm System & Criticality analysis/safety \\
\hline ANSI/ANS 8.17-1984 (R1989) & $\begin{array}{l}\text { American National Standard Criticality Safety Criteria for Handling, Storage, } \\
\text { and Transportation of LWR Fuel Outside Reactors }\end{array}$ & Criticality analysis/safety \\
\hline ANSI/ANS 57.9 & $\begin{array}{l}\text { Design Criteria for an Independent Spent Fuel Storage Installation (Dry } \\
\text { Type) }\end{array}$ & All systems \\
\hline ANSI/ANS 57.10-1987 & $\begin{array}{l}\text { American National Standard Design Criteria for Consolidation of LWR Spent } \\
\text { Fuel }\end{array}$ & $\begin{array}{l}\text { Lag storage, HVAC, fire } \\
\text { protection }\end{array}$ \\
\hline ANSI/API 620-1986 & $\begin{array}{l}\text { Rules for Design and Construction of Large, Welded, Low Pressure Storage } \\
\text { Tanks }\end{array}$ & Tanks \\
\hline ANSI/API 650-1988 & Welded Steel Tanks for Oil Storage (for tanks) & Tanks \\
\hline ANSI/ASCE 7-95 & Minimum Design Loads for Buildings and Other Structures & Structural \\
\hline ANSI/ASCE 72-88 & $\begin{array}{l}\text { American National Standard Minimum Design Loads for Buildings and } \\
\text { Other Structures }\end{array}$ & Structural \\
\hline $\begin{array}{l}\text { ANSI/ASME B\&PV Code } \\
\text { Section IX and } \\
\text { Section III or } \\
\text { Section VIII }\end{array}$ & $\begin{array}{l}\text { Welding and Brazing Qualifications } \\
\text { Nuclear Power Plant Components } \\
\text { Pressure Vessels }\end{array}$ & $\begin{array}{l}\text { Welding of sealed containers } \\
\text { and for sealed container } \\
\text { pressure boundaries }\end{array}$ \\
\hline ANSI/ASME B31.3-1990 & Chemical Plant and Petroleum Refinery Piping & Process piping \\
\hline ANSI/ASME N509-1989 & $\begin{array}{l}\text { American National Standard for Nuclear Power Plant Air Cleaning Units and } \\
\text { Components }\end{array}$ & HVAC \\
\hline ANSI/ASME N510-1989 & American National Standard for Testing of Nuclear Air-Cleaning Systems & HVAC \\
\hline ANSI/ASME NOG-1-1989 & $\begin{array}{l}\text { American National Standard Rules for construction of Cranes, Overhead and } \\
\text { Gantry (Top Running Bridge, Multiple Girder) }\end{array}$ & Cranes \\
\hline
\end{tabular}


Table 4-1. (continued).

Code/standard

Title

ANSI/ASME NQA-1-1989

ANSI/AWS D1.1-1990

ANSI B30.2-1990

ANSI B30.11-1993

ANSI/NFPA 10-1990

ANSI/NFPA 12-1989

ANSI/NFPA 12A-1989

à

ANSI/NFPA 12B-1990

ANSI/NFPA 13-1989

ANSI/NFPA 14-1990

ANSI/NFPA 72-1993

ANSI/NFPA 801-1995

ANSI N13.1-1969

ANSI N42.17B-1989

ANSI N14.6-1993
Structural Welding Code - Steel

Overhead and Gantry Cranes (Top Running Bridge, Multiple Girder)

Monorails and Underhung Cranes

American National Standard for Portable Fire Extinguishers

American National Standard for Carbon Dioxide Extinguishing Systems

American National Standard for Fire Extinguishing Systems - Halon 1301

American National Standard for Fire Extinguishing Systems - Halon 1211

American National Standard for Sprinkler Systems

American National Standard for Installation of Standpipe and Hose Systems

American National Standard National Fire Alarm Code

Facilities Handling Radioactive Materials

Guide to Sampling Airborne Radioactive Materials in Nuclear Facilities

Performance Specifications for Health Physics Instrumentation

Occupational Airborne Radioactivity Monitoring Instrumentation

Special Lifting Devices for Shipping Containers weighing 10,000 Pounds $(4500 \mathrm{~kg})$ or More
Applies to

Quality, with special

emphasis in unloading equipment, storage area structures, fuel handling/ transfer, monitoring effluent and direct radiation, and HVAC in contaminated areas.

Storage casks, vaults, cranes

Cranes

Cranes

Fire protection - extinguishers Fire protection - extinguishers Fire protection - extinguishers Fire protection - extinguishers Fire protection - sprinkler systems

Fire protection - standpipe and hoses

Fire protection - smoke detectors

HVAC, fire protection, architectural

Electrical

Electrical

Rigging 
Table 4-1. (continued).

Code/standard

Title

Applies to

ASCE Manual No. 58

ASHRAE 90

Structural Analysis and Design of Nuclear Power Plant Facilities

Structural

American Society of Heating, Refrigerating, and Air-Conditioning, Energy

Efficient Design of New Buildings Except Low-Rise Residential Buildings

CMAA 70

Crane Manufacturers Association of America, Inc., Specification for Electric

Overhead Traveling Cranes

CMAA 74-1987

Specifications for Top Running and Under Running Single Girder Electric

Overhead Traveling Cranes Utilizing Under Running Trolley Hoist

ASCE Manual No. 58

Structural Analysis and Design of Nuclear Power Plant Facilities

ASHRAE 90

American Society of Heating, Refrigerating, and Air-Conditioning, Energy Efficient Design of New Buildings Except Low-Rise Residential Buildings

CMAA 70

CMAA 74-1987

$\mathrm{EPA} / 625 / 7-88 / 003$, PL 101508 , USC $\$ 6901$, and DOE

Orders

\section{ICBO/UBC}

Idaho Code 39-44-1 et seq.

IDAPA 16.01.01000-01999

Crane Manufacturers Association of America, Inc., Specification for Electric

Specifications for Top Running and Under Running Single Girder Electric

Overhead Traveling Cranes Utilizing Under Running Trolley Hoist

Hazardous and Solid Waste Amendment

\section{Uniform Building Code}

Idaho Hazardous Waste Management Act

INEL Transportation Manual

Idaho Administrative Procedures Act - Clean Air Act

INEL Transportation Manual

MIL-F-51068C

Filter: Particulate High Efficiency, Fire Resistant

MIL-F-51079A

Filter Medium: Fire Resistant, High Efficiency

NFPA 70

National Electric Code

NFPA 101

Life Safety Code

NFPA 780

HVAC

Cranes

Cranes

Structural

HVAC

Cranes

Cranes

Decontamination systems/ methods

Structural

HVAC/HEPA filtration

Transport from facility to basemat

HVAC, Fire protection

HVAC, Fire protection

Electrical

Life safety, egress

Electrical 
Table 4-1. (continued).

\begin{tabular}{lll}
\hline \multicolumn{1}{c}{ Code/standard } & \multicolumn{1}{c}{ Title } & \multicolumn{1}{c}{ Applies to } \\
\hline NUREG-0612 & Control of Heavy Loads and Nuclear Power Plants & Cranes and Rigging \\
UFC & Uniform Fire Code & Fire protection \\
USNRC Reg. Guide 1.6 & Design Response Spectra for Seismic Design of Nuclear Power Plants & Structural \\
\hline
\end{tabular}




\section{PRELIMINARY ACQUISITION STRATEGY FOR THE SNF DRY STORAGE PROJECT}

\subsection{General}

This section describes the preliminary acquisition strategy for the SNF Dry Storage Project. The project has been separated into three major construction packages based on schedule requirements, degree of risk, and interfaces:

- Dry Transfer Cell (DTC) -- provides the capability to unload fuel from shipping/transfer casks and to place in dual-purpose canisters (DPCs) for transfer to the Dry Storage System basemat for interim storage in modular dry storage units; also includes work required to obtain an NRC license for the facility.

- Dry Storage System (DSS)-- includes the dry storage canisters, modular dry storage units, and basemat; procurement of the internal basket assemblies used to position fuel into the DPCs; and work required to obtain NRC licenses for each spent nuclear fuel type included in this project scope.

- Site Preparation and Utility Tie-Ins -- includes construction area clearing and grading, basemat area preparation (excavation and backfill with select material), construction fencing, and electrical and utility tie-ins to existing ICPP systems.

The final acquisition strategy for each construction package will be selected in mid FY 1997 and documented in the Project Execution Plan (PEP). Key criteria in this decision process include constructability; value; interface with existing facilities; technical, cost, and schedule risks; and project management control and coordination. Acquisition options have been identified for all three construction packages and are outlined in the following sections.

\subsection{Dry Transfer Cell (DTC)}

Several options have been considered for the DTC facility, including (1) a Design-Build contract, (2) AE design with LITCO serving as the construction manager (i.e., fixed price competitive bid construction), and (3) AE design with LITCO serving as the general contractor for construction. Prior to a final decision on these options, a preliminary design will be prepared by the LITCO Engineering Organization. If determined to be cost effective, an Integrated Product Development Team (IPDT) would then be formed. The IPDT would include several different vendors, engineering companies, and other experts that would work with LITCO and DOE-ID to evaluate the preliminary design of the facility and recommend the best approach for definitive design and construction. At the conclusion of the Preliminary Design or the IPDT effort, a decision on either a Design-Build contract or a Definitive Design AE contract will be made. If the Definitive Design option is chosen, a follow-on decision will be made at the completion of design to determine whether to proceed with the fixed price competitive bid or the LITCO general contractor option. Figure 5-1 shows the decision process for this facility. (Note: The 
Definitive Design can either be done with the LITCO Engineering Organization or be released for competitive bid to the $\mathrm{AE}$ community. That decision will be made at a later date and documented in the PEP.)

Assumptions

- GFE Procurement will be required for some DTC equipment due to long-lead time.

- The Design-Build option would need to include contract clauses defining interfaces, time frame, and scope of the NRC licensing process.

\subsection{Dry Storage System (DSS)}

Two options have been identified for this construction package. The Design-Build contract with Newport News for the Long-Term Storage of TMI-2 Fuel Project contains a provision for additional purchase of horizontal storage. This contract could be extended to purchase internal basket assemblies, DPCs, modular storage vaults, and the basemat for this project. The second option would be to competitively bid a new Design-Build contract.

\section{Assumptions}

- A horizontal storage system will be used since this is the system that was selected for the Long-Term Storage of TMI-2 Project.

- Some of the equipment used for DPC loading on the TMI-2 Project could be reused on this project.

- One INEL dry storage system would be more cost effective and result in lower life cycle costs than maintaining two or more types of dry storage systems.

Issues

- Need to determine if a sole-source justification is required to specify a horizontal storage system. Currently, NUHOMS ${ }^{\circledR}$ is the only supplier of such a system.

\subsection{Site Preparation and Utility Tie-Ins}

Due to plant interface and potential unknown conditions (i.e., underground interferences, plant operations interface, schedule for utility outages to allow for tie-ins, etc.), all electrical and utility tie-ins, as well as site preparation, will be done as a separate construction package. Two acquisition options were identified -- use of LITCO construction forces or competitive fixed price bid. The final decision will be largely based on the complexity of the utility tie-ins and site preparation requirements and the degree of confidence in defining the existing conditions at the ICPP construction site. 


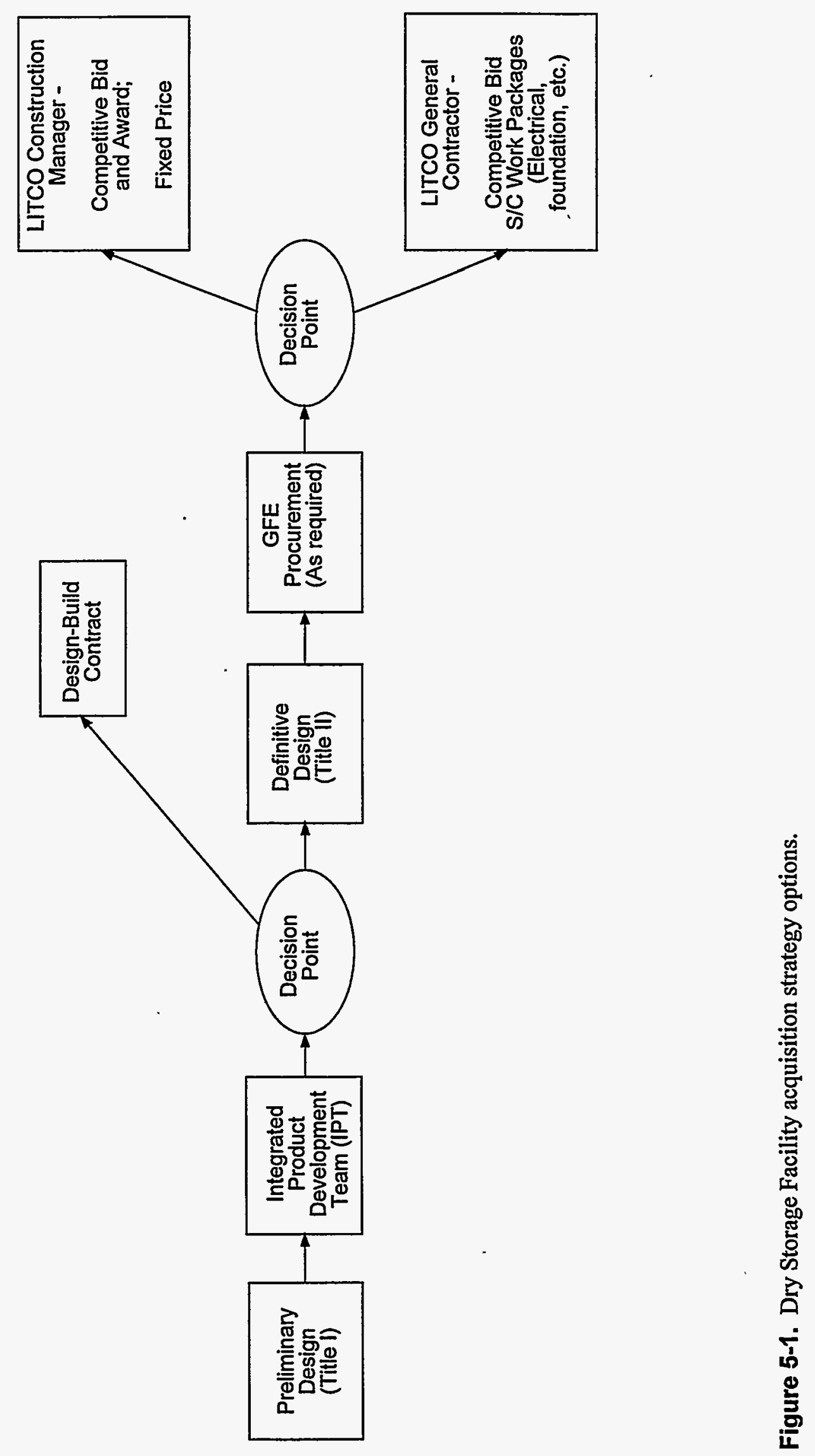




\section{ALTERNATIVES}

\subsection{Introduction}

The Dry Storage Facility includes the DTC and the DSS. The NUHOMS ${ }^{\circledR}$ horizontal storage system concept was established for the conceptual design of the DSS. The concept for the DTC, however, was essentially unrestrained at the beginning of the conceptual design effort. Several alternative approaches were identified and evaluated for that part of the facility. A structured Value Engineering assessment process was used to select the most appropriate concept for development in the conceptual design. The Value Engineering approach included the following sequence: defining the project objectives and essential requirements and criteria; brainstorming to identify potential approaches for meeting those objectives and requirements; assessing the requirements to determine which were essential "go/no-go" (musts) for meeting mission objectives and which could be compared on some scale that measured the degree to which they met objectives; and assigning an importance weighting to those latter criteria.

The alternatives were then evaluated against the weighted criteria. Relative scores were developed for each of the alternatives against each of the criteria, and total scores were developed that indicated the relative degree to which each alternative met the aggregate weighted criteria. The primary rating/selection criteria were: (1) minimize capital investment, (2) minimize life-cycle cost, (3) minimize impacts to existing operational schedules, (4) support ready NRC licensing, (5) minimize environmental issues, (6) minimize transportation complexity, (7) provide flexibility to meet evolving project missions, (8) minimize generation of D\&D waste, and (9) simplify criticality control.

Seven alternatives were identified that appeared to meet the requirements specified for the project. These were: (1) use the Fluorinel Dissolution Process and Fuel Storage (FAST) Facility with support from a new addition and the Fluorinel Dissolution Process (FDP) facility as appropriate, (2) use the Test Area North (TAN) Hot Shop, (3) use a new, stand-alone shielded facility, (4) use a new, stand-alone facility that employs earthen berms and remote operation to provide protection from high radiation sources, (5) use underwater loading sequences to accomplish shielding, (6) use smaller DPCs that could be loaded at the shippers' facilities and be subsequently loaded directly into storage modules at INEL without further packaging, and (7) use modular DPCs that could be loaded into storage modules at INEL without further packaging.

The evaluations of the various alternatives are described below. Additional details concerning the evaluation are contained in Reference 4. The options for alternate configurations of DPCs (small or modular DPCs) were not evaluated against the criteria. These options may be appropriate for consideration as an alternate to a transfer facility, but were judged to be unresponsive to the overall project mission. 


\subsection{Identification and Assessment of Alternatives}

The results of the assessment are summarized in Figure 6-1, with a conclusion that the options met the stated criteria in the following order (best match first): (1) TAN Hot Shop, (2) New, stand-alone shielded facility, (3) new bermed, remote facility, (4) Wet loading, (5) using the FAST and FDP facilities. The results are briefly discussed below, as is the rationale for ultimately choosing the new, shielded, stand-alone facility for development in the conceptual design.

\subsubsection{TAN Hot Shop}

The TAN Hot Shop has been used for years to perform the same operations required for the new mission. It will also be used to load the TMI-2 fuel debris canisters into Dry Shielded Canisters (DSCs), and load the DSCs into a transfer cask in preparation for shipment to ICPP for interim dry storage.

While significant upgrades to TAN infrastructure systems would be needed to support long-term operation, the cost of the facility upgrades were considered to be relatively low, and the overall cost of using the Hot Shop was considered to be the lowest of the identified options. The equipment and systems currently available in the Hot Shop would be adequate to perform the processes of placing the SNF in DPCs and shipping them to the ICPP for placement into dry storage. Remote handling equipment would require relatively little upgrading to be suitable for this activity, although if operation does not begin until 2003, additional upgrades would be anticipated as existing equipment reaches end-of-life.

The conceptual design was not based on the use of TAN because the evaluation team understood that TAN may not be retained as an operating facility through the anticipated life of the SNF Dry Storage Project.

\subsubsection{New Stand-Alone, Shielded Facility}

The description of the new stand-alone, shielded facility is contained in Section 3 of this report and is not repeated here. This facility concept was selected for development in the conceptual design because of its high relative ranking in the order of preference, and because it provides something of a conservative but cost-effective design for accomplishing the defined mission. It can be used as a baseline to compare to other options, particularly those options that require considerations beyond a simple capital cost comparison.

\subsubsection{New Stand-Alone, Bermed, Remote Facility}

This concept includes most of the equipment and features of the new, shielded facility but uses earthen berms for shielding around the fuel handling area, and relies solely on cameras rather than a combination of cameras and direct visual access to control the remote fuel-handling operations. This alternative is somewhat less expensive for the facility, but some utility costs would be higher as a result of placing the facility in a location further removed from existing operations. The primary reason this option was not selected for the conceptual design is that the lack of internal shielding walls would 


\title{
Select Best SNF Dry Storage Facility Option
}

\author{
March 19-20, 1996
}

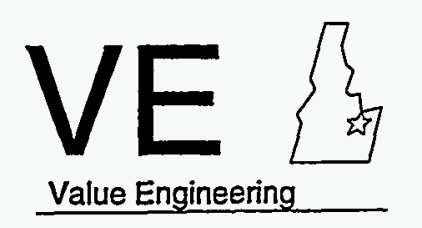

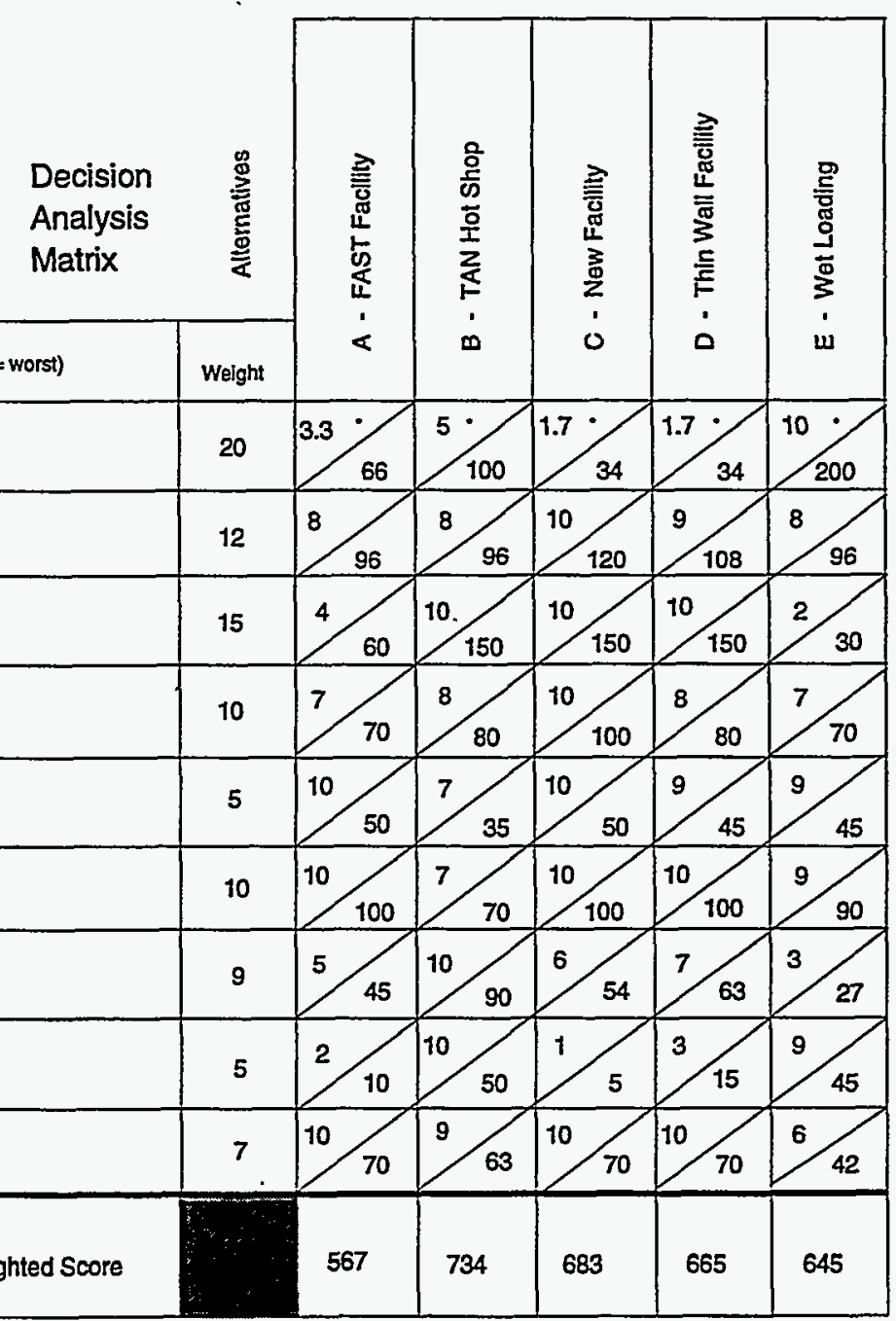

- Ratings were based on the total estimated costs and then distributed across the scale of 10 (best) to 1 (worst).

Figure 6-1. Value Engineering Decision Analysis Matrix. 
prevent concurrent operations at the facility while fuel was being transferred. This would probably limit throughput of the facility to a level that would not meet the projected need.

\subsubsection{Wet Loading}

This concept would use typical underwater handling processes to provide shielding during fuel transfers. The FAST pools would be used. This concept was projected to entail the lowest capital cost, but was not selected because of the probable conflicts with other FAST operations, and because submergence of the graphite fuels (which are chemically reactive with water) would probably require initial canning to prevent exposure to the pool water. This would substantially complicate the overall approach.

\subsubsection{Use of the FAST Facility}

A new hot cell would be added to the FAST facility, but the existing cask receiving area (and crane) would be used for offloading and initial handling of shipping and transfer casks. This would eliminate the need for a new cask handling crane and cask receiving area. While further study is appropriate for this option during later design stages, issues that reduce its attractiveness are the anticipated impacts on other activities scheduled in FAST and the need to keep the FAST facility operational for a longer period than currently planned. FAST is relatively expensive to operate, and it is expected that life-cycle costs would be higher for this option than for the new facility.

\subsection{Conclusions From Study}

As noted above, the alternative selected for development in the conceptual design is the new, stand-alone, shielded facility. At this stage of the project, this is the concept that is most resonsive to the Conceptual Design Criteria (see Appendix A) and is technically most defendable. Further studies will be performed during later design activities to determine if the concept can be modified to reduce cost while still meeting the requirements established and documented in the Project Design Criteria (see Appendix B).

Basing the Conceptual Design on the selected alternative provides a conservative but realistic basis for project planning and future design activities. 


\section{UNCERTAINTIES AND RECOMMENDATIONS FOR FURTHER DESIGN DEVELOPMENT}

A number of issues were identified during the conceptual design effort that require additional investigation before their impact on the facility design and cost can be fully understood. These uncertainties are typical for the initial design stages of a project of this nature. In general, the uncertainties have led to assumptions in the conceptual design that are reflected in the cost estimate.

Where conservative assumptions were made, opportunities exist to reduce the cost of the conceptual facility. Where non-conservative assumptions were made, there is risk that the current conceptual cost estimate understates the true cost of the facility.

The more significant uncertainties are described in Section 7.1. Section 7.2 identifies a number of areas where existing information is sufficient to support near-term additional studies. These are areas that if resolved, can reduce the level of uncertainty in the conceptual design and improve confidence in the correctness of the approach taken and in the corresponding cost estimates. These are recommended for near-term activity.

\subsection{Project and Design Uncertainties}

\subsubsection{Facility Location and Configuration}

As discussed in the previous section, the investigation of alternatives identified options to the location and configuration of the DTC. The conceptual design is based on a conservative approach, i.e., a stand-alone facility. The potential exists that one of the other options, particularly the integration with FAST, would be feasible and would have a lower capital and/or life cycle cost.

\subsubsection{Cranes-Fuel Handling}

The fuel handling crane may not meet the requirements of ANSI/ANS 57.9, simply because the fuel configurations to be handled in the DTC are different from those used as the basis for the commercial standard. Also, the definition of "critical loads" as applied to this facility needs to be accepted by the licensing authority before a defendable position can be established.

\subsubsection{DPC Transfer System}

The assumption has been included in the conceptual design that the transfer cask and transport equipment for moving the loaded DPC from the DTC to the Storage basemat will be provided by the TMI Dry Storage Project. Signifiçant added costs would be incurred if the SNF Dry Storage Project were required to pick up that cost. 


\subsubsection{Licensing Issues}

To minimize the number of DPCs required to package the fuels identified for this effort, some of the DPCs are projected to contain multiple fuel types. Licensing of these mixed-fuel packages by the NRC may be difficult since mixing has traditionally been avoided.

\subsubsection{Security Requirements}

Some uncertainty exists with regard to the physical security system needed. The requirements in 10 CFR 73 can be interpreted as significantly more rigorous than typical security provisions maintained at the NEL. On the other hand, informal discussions with NRC personnel concerning a draft modification to that CFR indicate that it is likely those requirements will be substantially reduced, probably to a level of rigor below that currently required by the DOE at the INEL. The conceptual design is based on using the lower level of rigor expected to be required by the NRC. There is some risk that the proposed modifications will not be codified, and there is also some risk that even if the NRC requirements are modified, DOE requirements may be imposed. Further discussions with DOE and NRC are required to reach a final decision on these requirements.

\subsubsection{Cranes-Cask Handling}

It is assumed for the conceptual design that a crane meeting NOG-1 Type-1 criteria will be required in the Cask Handling Bay. Cranes meeting these criteria are significantly more expensive than those procured to more typical commercial standards. If a justification can be found for a relaxation of the NOG-1 Type-1 requirement, then substantial savings (several hundred thousand dollars) may be achievable.

\subsubsection{Minor Canning of SNF}

The requirement that the capability for minor canning be included in the facility is based on the need to add flexibility, and therefore applicability, for the facility. However, a major assumption upon which the entire approach to DTC fuel transfer is based, is that the Hot Cell will be entered frequently by operations personnel. These entries are made to place and remove contamination control barriers, assemble tools, and to survey and decontaminate the equipment prior to removal from the Hot Cell, and to perform maintenance tasks. This manual approach allows the use of relatively simple remote tools and equipment, thus keeping capital costs lower. If the Hot Cell becomes contaminated as a result of handling degraded fuel, operating costs will increase and personnel exposures to radiation may increase. Additional tools and equipment would probably be needed and the throughput capability of the facility would be impacted, perhaps to the point where the facility becomes the bottleneck to the SNF Dry Storage Project.

\subsubsection{DPC Loading Optimization}

Thermal and shielding calculations are being performed on fuel loading configurations representing approximately $90 \%$ of the fuel to be handled in the SNF Dry Storage Project. The calculations are being made for DTC lag storage, for the DPCs loaded in the MP-187 cask, and for the DPCs loaded in the 
NUHOMS ${ }^{\circledR}$ storage modules. Results of these analyses could require some reduced loading efficiencies in the DPCs, and increase the number of components and DPCs and concrete modules required. This would then be reflected as an increase in the facility cost.

\subsubsection{SNF Structural Capability}

It has been assumed in the conceptual design that the SNF can be handled, stored, and shipped in the horizontal position. There is an uncertainty regarding the capability of the fuel to withstand potential shipping and handling accelerations without damage to the cladding (first containment boundary). The degree to which this will meet applicable criteria is unknown. It is possible that specific support structures would be needed for some of the fuel types to ensure stresses on the fuel cladding remain within the limits of applicable criteria.

\subsubsection{DPC Structural Capacity}

The conceptual design of the DPC baskets is based on a Vectra "road ready" concept that has not yet been licensed. This design includes 22 lateral support plates in the DPC with cutouts forming channels that run the length of the DPC. Structural analyses have not been performed to validate the conceptual design addressed in this report.

While there is some risk that a major redesign might be required, it is anticipated that if changes are needed to meet the structural analyses, they will be minor (e.g., small increases in cruciform thickness) and will not affect the loading efficiency or the cost of the DPC, baskets and buckets.

\subsubsection{Fire Protection}

The Hot Cell does not have egress locations that fully comply with Life Safety regulations. The layout presented in the conceptual design is typical of hot cell designs and is considered fully adequate for the planned operations. This is based on the rationale that multiple exits are required to address the (radiation) hazard in the Hot Cell, and the hazard will be removed (material placed in secure shielded vaults or casks) whenever personnel are in the Hot Cell.

An additional fire safety issue is the lack of automatic fire protection for the Hot Cell. Foam and gaseous protection systems are considered to be ineffective in a room with such a high ceiling and large volume, and water could react chemically with some of the fuel that will be processed. Since the combustion load will be small, and since personnel entry will be administratively controlled, the absence of automatic fire protection systems is considered appropriate.

\subsubsection{SNF Characterization}

The fuel characterization information required by the NRC or DOE prior to licensing for storage or shipment to a repository is not well understood. 10 CFR 72 identifies rather general data needs that are considered achievable through a combination of shipping records (in accordance with 10 CFR 71) and fuel unit identification during fuel handling in the Hot Cell. The conceptual cost estimate is based on this approach. The DOE requirements contained in draft DOE Order 5820.2B are substantially more 
detailed. Obtaining this information might require considerable process development and equipment to assay the fuels that are expected to be received with limited relevant data.

\subsubsection{Ventilation System Requirements}

Another area where DOE and NRC design requirements appear to differ is in the HVAC systems. The NRC requirements are interpreted as being less demanding than those of DOE. The conceptual design is based on the NRC requirements and if the applied interpretation is in error, or if it is determined that DOE requirements are to be applied, additional HEPA filtration will be required with a resultant increase in ventilation system complexity and cost.

\subsection{Recommendations for Near-term Design Development}

The following activities are recommended for near-term action. Completing these will provide the most significant reductions in the uncertainties identified above. These reductions in uncertainty will result in a corresponding increase in the confidence in the estimated facility cost.

- Complete a more detailed analysis of the impacts and cost reduction opportunities associated with interfacing the new facility with the existing FAST Facility. This will require an understanding of the operations that are scheduled at FAST through the period of interest and an assessment of the conflicts that would arise if the new facility were to share the cask handling crane. Requirements applicable to NRC licensing of all or parts of the facility would need to be defined.

- Complete the criticality, thermal, and shielding analyses of the DPC designs for the remainder of the major fuel types. This will provide the justification for the fuel loading planned and estimated in the conceptual design. The shielding calculations may also support reducing the cost of the shield wall surrounding the storage area.

- Perform the structural analyses required to confirm the DPC/basket/bucket designs for use with the six major fuel types identified for this project.

- Perform shielding and structural analyses to confirm the design approach and to identify cost reduction opportunities in the building structure. This would include additional crane and handling equipment definition to better establish the crane rail and building heights and to better define the minimum acceptable load ratings for the cranes.

- $\quad$ Continue the development of the design criteria and bases for the cask handling and fuel handling cranes. Part of this effort may depend on the consequences of a cask/fuel drop event, therefore limited investigation to determine those consequences would be included.

- Conduct a more detailed analysis to determine the applicable security requirements and the potential design and cost impacts of changes in those requirements. This may 
require additional radiological information on the various fuels to be handled and a more in-depth understanding of the regulations (some of which are in draft form).

- Continue the criticality, thermal, shielding, and structural analyses on the remaining $10 \%$ of fuel included in this project. Specifically look at mixing the low volume fuels to improve storage efficiency. 


\section{SCHEDULE}

The project schedule is summarized in Figure 8-1. The most important milestones shown in this figure are:

- $\quad$ Project Validation--June 18, 1996

The Settlement Agreement between the State of Idaho and the U.S. Department of Energy includes the submittal of a request for funding of this effort as a FY-98 line item. Project Validation is a necessary step in that formal request process.

- $\quad$ Start DPC Loading--July 1, 2003

This is the negotiated date for starting the movement of SNF from ICPP storage pools to dry storage.

The other milestones shown in the figure are intermediate objectives important to achieving the goal of starting the transfers by July, 2003 and placing the last of the pool-stored fuel into dry storage by the end of calendar year 2023.

The schedule for receiving various types of fuel during the period of 2003 to 2023 is shown, as is the schedule for procurement of DPCs and storage modules and the construction of the storage pads (basemats). 


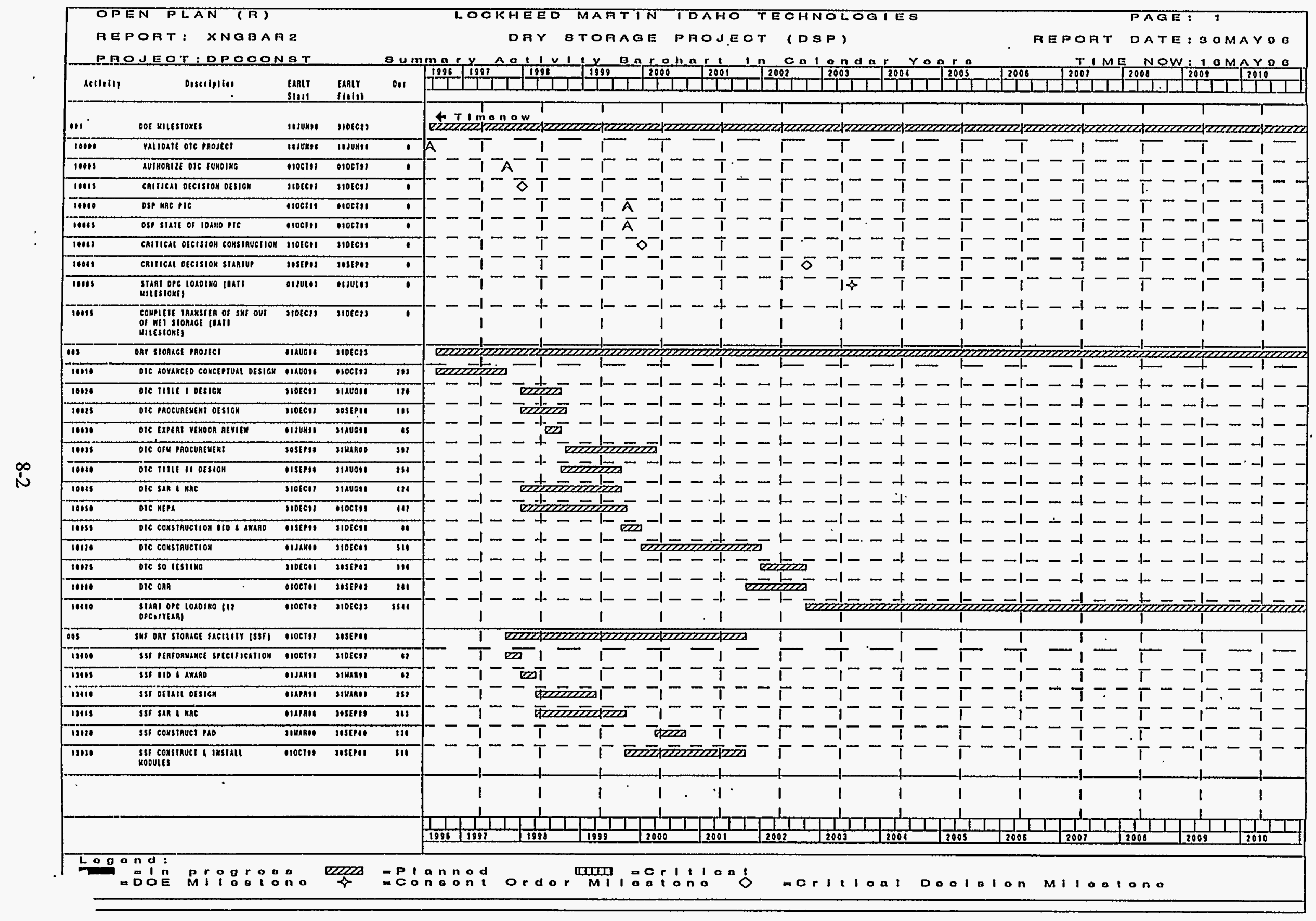

Figure 8-1. Project schedule. 


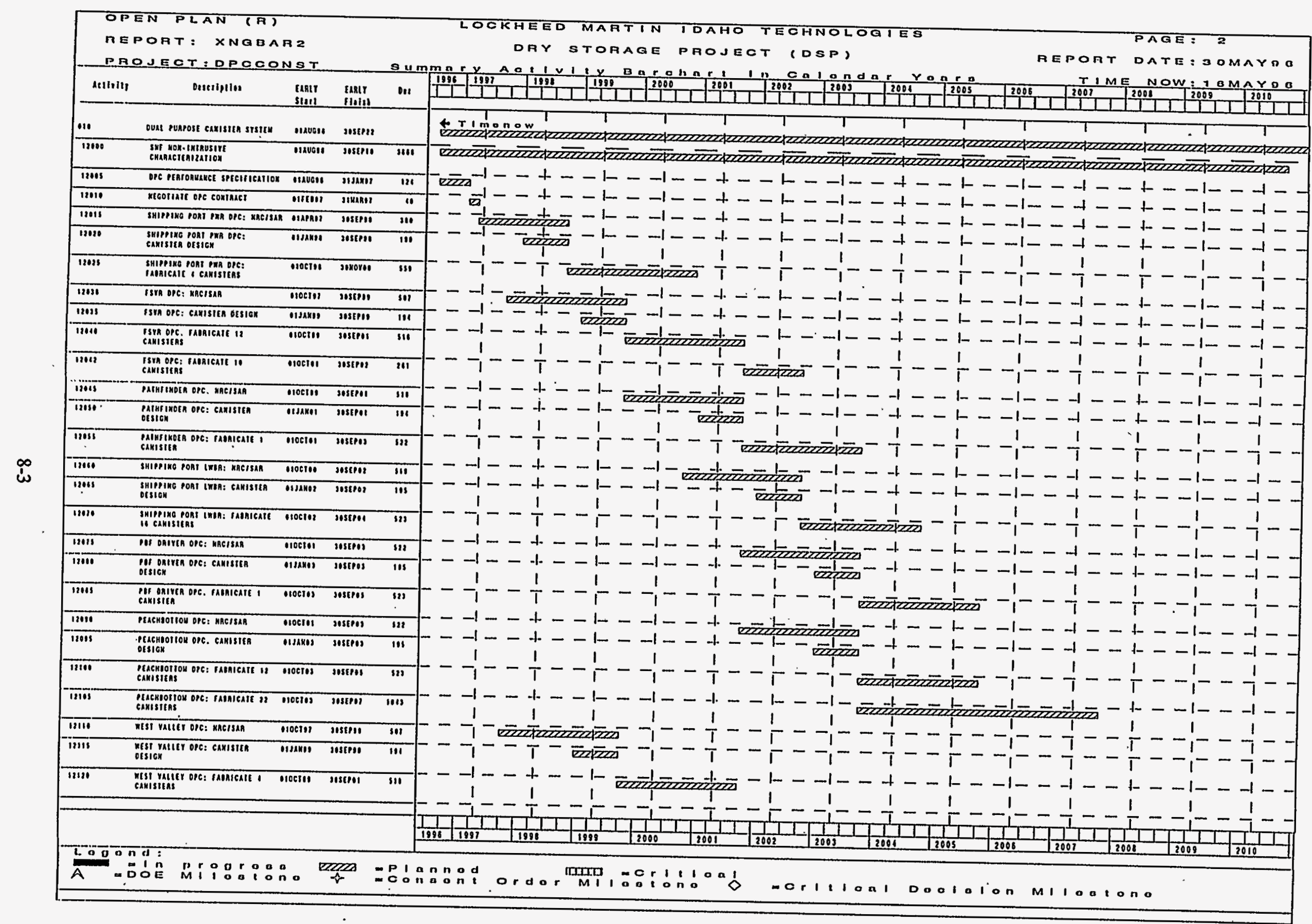

Figure 8-1. (continued). 


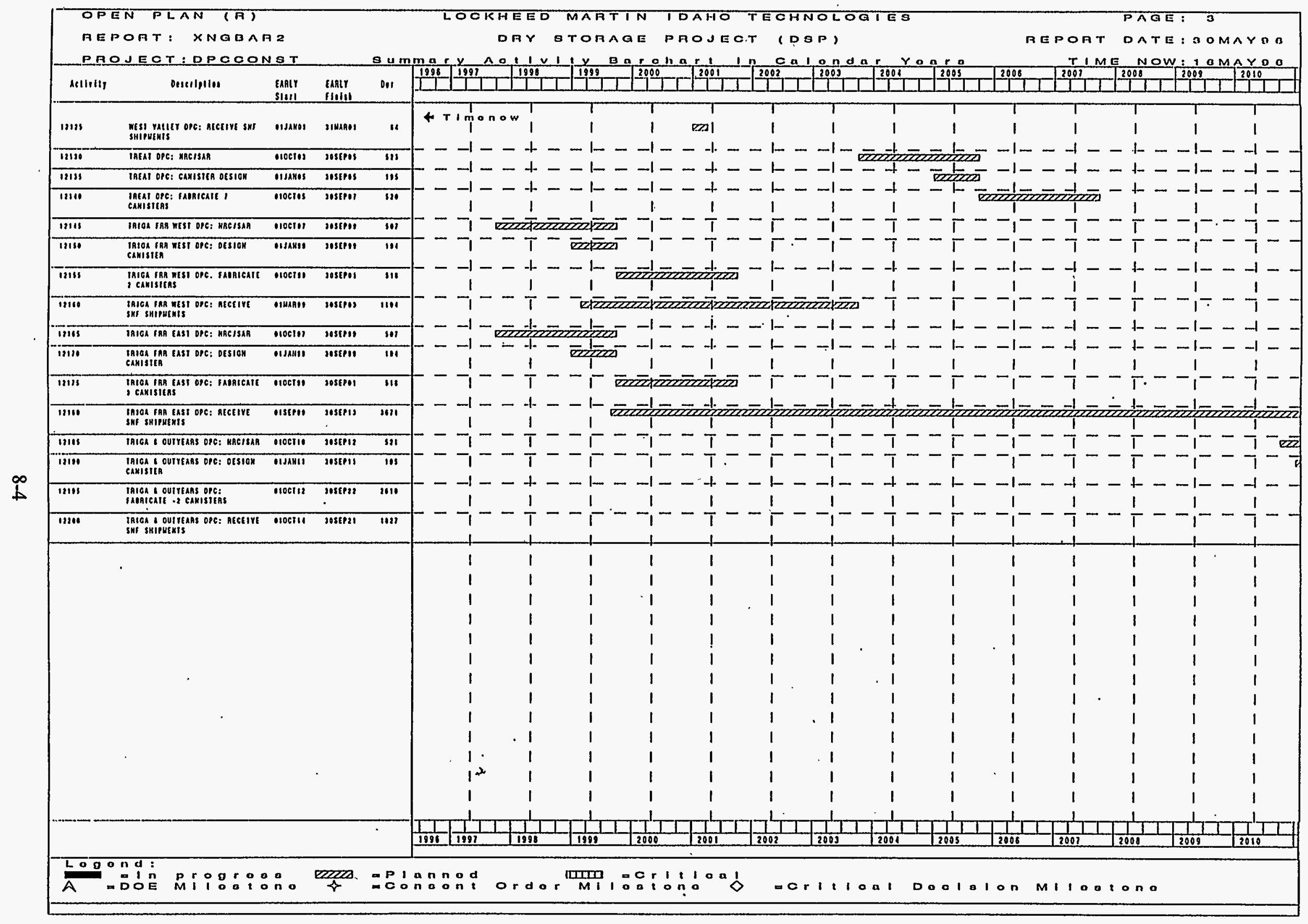

Figure 8-1. (continued). 


\section{COST ESTIMATE}

The Total Estimated Cost (TEC) for the DTC is $\$ 41 \mathrm{M}$. The TEC for the Dry Storage System is $\$ 59 \mathrm{M}$. A breakdown of these costs is provided in Table 9-1 and details of the estimates are provided in Appendix G. It is important to note that the TEC of $\$ 59 \mathrm{M}$ for the DSS does not include storage of all SNF described in this report. This estimate covers 50 DPCs (with baskets and DHBs) which is sufficient for storing SNF received through 2009. To store all of the SNF described in this report would require about 88 DPCs at a total DSS cost of $\$ 134 \mathrm{M}$, including escalation. These costs are in 1996 dollars that have been escalated to the approximate midpoints of each activity; i.e., design and construction.

Conceptual Estimates are required to obtain authorizing legislation and appropriations. The Conceptual Estimate is prepared to aid managers in establishing budgets. All costs relating to TEC for the project are included, including engineering, design, and inspection (ED\&I), construction costs, government-furnished equipment (GFE), project management, construction management, management reserve, contingency, and escalation.

The Conceptual Estimate is based on all the detailed requirements in the CDR including, but not limited to, the design parameters, identified equipment (see Appendix $H$ ) applicable codes, specifications and standards, conceptual design criteria, quality assurance requirements, space requirements, definitions of scope, methods of performance, operations interfaces, and safety requirements.

Other project costs (OPCs) are all other costs related to a project that are not included in the TEC, such as supporting R\&D, preauthorization costs prior to start of Title I design, plant support costs during construction, activation, and start-up. OPC will include, but not be limited to, R\&D; NEPA documentation, project data sheet; CDR; short-form project data sheet; surveying for siting; conceptual design plan; and evaluation of Resource Conservation and Recovery Act (RCRA)/U.S. Environmental Protection Agency (EPA)/State of Idaho permit requirements. OPC has been estimated to be approximately $\$ 5 \mathrm{M}$.

Total Project Costs (TPCs) are all costs specific to a project incurred through the start-up of a facility but prior to the operation of a facility. It comprises TEC and OPC. TPC will include, but not be limited to, design and construction; contingency; economic escalation; Pre-Title I activities; Feasibility Study Reports (FSR); maintenance procedures (to support facility start-up); one-time start-up costs, initial operator training, and commissioning costs and operating procedures (to support facility start-up).

Construction labor rates are based on the prevailing wage rates as determined by the INEL Site Stabilization agreement. The labor values presented in the estimate are based on handbook values that have been adjusted to INEL practices and productivity factors. The labor costs are also based on an adequate supply of skilled workers in the area. Construction material costs are based on handbook values and recent vendor quotes.

It is assumed that the design will be prepared by the INEL A-E organization. This will eliminate additional costs to the design and project management organizations with regards to additional oversight and travel costs to an outside $A-E$, and decrease site and project familiarization time.

It is assumed that the Construction Management will be performed by the INEL Construction Management Organization, taking advantage of the knowledge of site-specific construction practices. The construction subcontractor will be responsible for the first-line inspection activities. The INEL Title III organization will be responsible for concrete and compaction testing, and the overall acceptance of the construction project. 
Table 9-1. SNF Dry Storage Project cost summary.

\begin{tabular}{lrrr}
\hline & \multicolumn{1}{c}{ DTC } & \multicolumn{1}{c}{ DSS } & \multicolumn{1}{c}{ DSF } \\
\hline $\begin{array}{l}\text { Engineering, design, } \\
\text { Inspection }\end{array}$ & $\$ 3,663,000$ & $\$ 378,000$ & $\$ 4,041,000$ \\
Management & $5,820,000$ & $6,880,000$ & $12,700,000$ \\
Construction & $11,995,000$ & $2,682,000$ & $14,677,000$ \\
Gov't furnished equipment & $7,504,000$ & $26,645,000$ & $34,149,000$ \\
Procurement fees & 292,000 & 400,000 & 732,000 \\
G\&A & $1,220,000$ & $1,900,000$ & $3,120,000$ \\
Project contingency & $6,424,000$ & $7,466,000$ & $13,890,000$ \\
Escalation & $4,082,000$ & $12,609,000$ & $16,691,000$ \\
Total estimated cost & $41,000,000$ & $59,000,000$ & $100,000,000$ \\
\hline
\end{tabular}

Escalation is defined as an estimate of the change in price levels over time. The rates used in the preparation of the estimate are based on the DOE-HQ Departmental Price Change Index, FY 1998 Guidance, Anticipated Economic Escalation Rates for General Construction Projects.

Contingency is defined as funds included within an estimate to cover materials, labor, conditions, and risk situations that are an intrinsic part of the intended scope of work, but are not specifically included elsewhere in the estimate due to an uncertainty, either as to the nature, existence, likelihood of occurrence, or magnitude of effect. Contingency funds are included in the project's TEC and shall be considered part of that cost and not extra.

A Contingency Analysis, included in Appendix "X", was prepared to determine the amount of contingency that will be required to complete the project as proposed. Contingency guidelines are established by DOE/FM-50, Cost Estimating Guide, Vol. 6, Cost Guide and are presented in the INEL Cost Estimating Guide.

The contingency is based on the identified assumptions noted during the preparation of the estimate. The incorporation of the assumptions into the estimate could have significant impact on the cost. 


\section{REFERENCES}

1. INEL Spent Nuclear Fuel Program, Mission Need Document for Spent Nuclear Fuel Dry Storage Project, proposed FY-98 Line Item Construction Project, Lockheed Martin Idaho Technologies Company, March 1996.

2. Robert C. Hill et al., Spent Nuclear Fuel Dry Storage Project Feasibility Study, INEL-96/0061, February 1996.

3. Fluor Daniel, Inc., Fuel Canning and Dry Modular Storage Feasibility Study Report, Delivery Order 94-02A, Contract 4353A1, June 1994.

4. A. M. Conner, Summary of the VE Session Held to Determine the Optimum SNF Dry Fuel Transfer Facility, Letter Report AMC-09-96, April 1996. 


\section{Appendix A \\ CPP-666 FSA \\ Spent Nuclear Fuel (SNF) Transfers to the Dry Transfer Cell (DTC)}




$$
\text { A-2 }
$$




\section{Appendix A}

\section{CPP-666 FSA \\ Spent Nuclear Fuel (SNF) \\ Transfers to the Dry Transfer Cell (DTC)}

\section{Conceptual Design}

\section{EXECUTIVE SUMMARY}

The Conceptual Design for the transferring of SNF from CPP-666 FSA to the Dry Transfer Cell (DTC) investigates the loading of spent nuclear fuel (SNF) stored underwater at the Fuel Storage Area (FSA) pools in Building CPP-666 at the Idaho National Engineering Laboratory (INEL) into shipping casks and transferring the casks to the DTC. After receipt of the shipping casks at the DTC, the fuel is transferred into Dual Purpose Canisters (DPCs) in preparation for eventual dry storage.

The Feasibility Study by Fluor Daniel, Inc. evaluated the CPP-666 facility for modifications to allow loading of SNF underwater in the FSA pools into DPCs. The study considered both a base case (minor modifications) and a debottlenecking case (modifications to eliminate interference problems with ongoing operations). The study concluded that in both cases modifications are feasible and loading in DPCs is a viable option.

Since the subject Feasibility Study was completed, additional information about the amounts and types of fuel that must be handled in the FSA for dry storage at the INEL has been received. This information eliminated the need to consider Naval and aluminum fuels. It has now been determined that the Naval and aluminum fuels will be shipped to the Naval Reactors Facility and Savannah River Site, respectively, for preparation for storage. The Feasibility Study concluded that about 120 DPC underwater loadings would be needed to remove the SNF (including the Naval and aluminum fuels) from the FSA pools at CPP-666. With the exclusion of the Naval and Aluminum SNF from the FSA inventory, the remaining Department of Energy (DOE) pristine fuel types considered for loading into DPCs at the FSA number to six. These six fuel types can be loaded into $4 \mathrm{DPCs}$, which is considerably less than the 120 DPC loadings considered in the Fluor Daniel Feasibility Study. This latest information has directed a further evaluation of the need for modifications to CPP-666 as proposed in the Feasibility Study. This Conceptual Design Report (CDR) reevaluates the need for these modifications and investigates transferring SNF (no Naval or aluminum) in shipping casks to the DTC for further handling and loading into DPCs.

This Conceptual Design addresses:

- The types of SNF stored in the CPP-666 FSA pools that would be placed in dry storage under this $\mathrm{CD}$. 
- Loading pristine SNF stored in the CPP-666 FSA pools into shipping casks underwater, removing the loaded casks from the pool, and transferring the cask and fuel to the proposed Dry Fuel Transfer Facility (DTC) for loading into DPCs.

- The shipping casks and fuel loadings that will be required to make the SNF transfers from the CPP-666 FSA pools to the DTC.

- Adjusted cost comparison between concepts presented in the Fluor Daniel Feasibility Study (i.e., loading DPCs with SNF underwater in CPP-666 FSA pools) and item 1.

Considering that modifications to CPP-666 (primarily tooling and equipment for the Base Case) described in the Feasibility Study are same or similar to as those designed into the DTC (with the exception of the crush pads) and the small amount of SNF identified for loading into DPCs, it is proposed that the SNF stored in the FSA pools be loaded into shipping casks and transferred to the DTC for loading into DPCs. This effort will require no modifications to the CPP-666 facility. In addition, existing tooling and shipping casks will be utilized for the fuel loading and transfers. 


\section{CONTENTS}

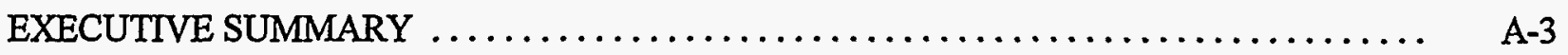

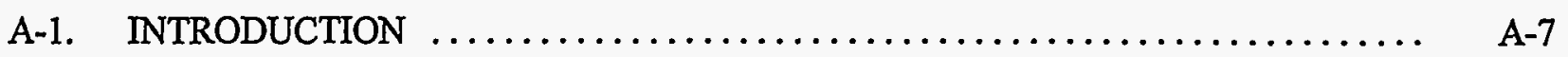

A-2. DESCRIPTION OF CPP-666 FSA FACILITY $\ldots \ldots \ldots \ldots \ldots \ldots \ldots \ldots \ldots \ldots$ A-8

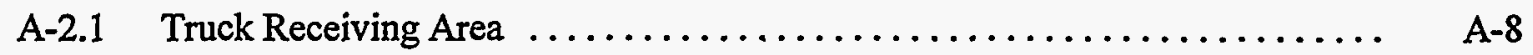

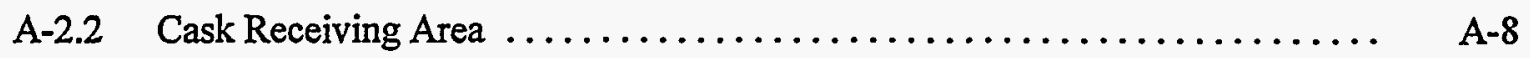

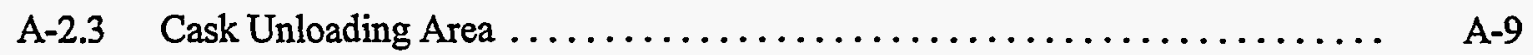

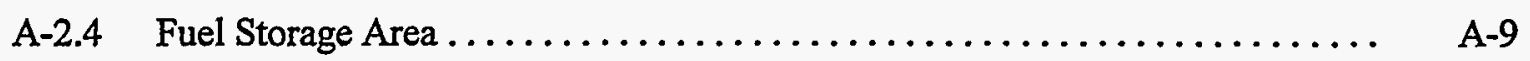

A-3. FSA AND DTC CONFIGURATION AT TIME OF SNF SHIPMENT $\ldots \ldots \ldots \ldots$ A-9

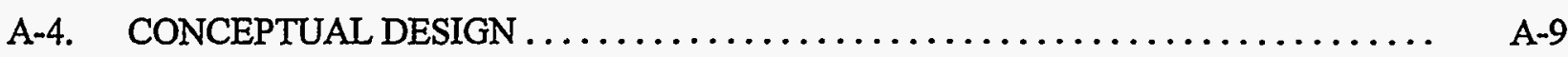

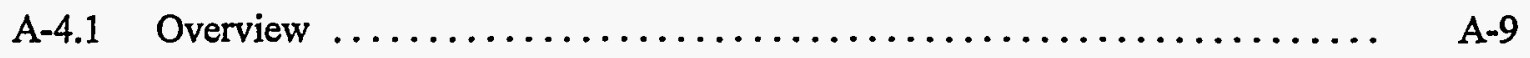

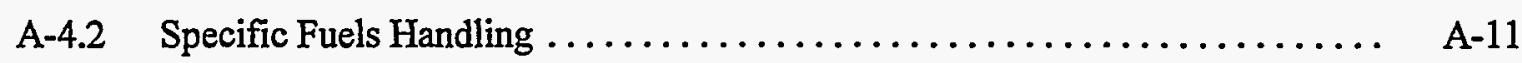

A-4.2.1 Pathfinder $\ldots \ldots \ldots \ldots \ldots \ldots \ldots \ldots \ldots \ldots \ldots \ldots$, A-11

A-4.2.2 Pulstar-Buffalo ................................. A-13

A-4.2.3 Shippingport PWR $\ldots \ldots \ldots \ldots \ldots \ldots \ldots \ldots \ldots \ldots \ldots \ldots$, A-14

A-4.2.4 Triga Flip $\ldots \ldots \ldots \ldots \ldots \ldots \ldots \ldots \ldots \ldots \ldots \ldots \ldots \ldots, \quad$ A-14

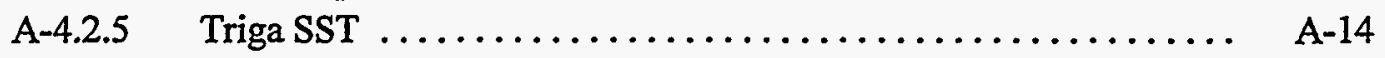

A-4.3 Cask and SNF In-Plant Movements $\ldots \ldots \ldots \ldots \ldots \ldots \ldots \ldots \ldots \ldots \ldots \ldots \ldots \ldots \ldots$

A-4.4 Scheduling $\ldots \ldots \ldots \ldots \ldots \ldots \ldots \ldots \ldots \ldots \ldots \ldots \ldots \ldots \ldots \ldots \ldots \ldots \ldots \ldots, A, 16$

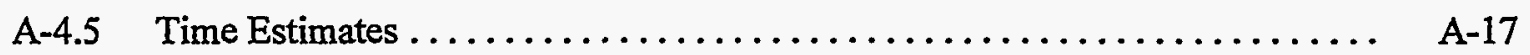

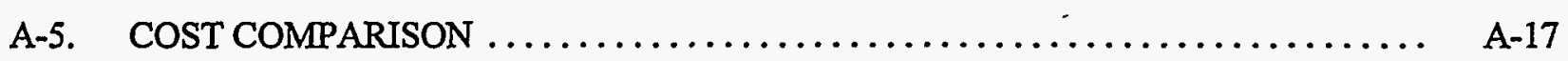

A-6. CONCLUSIONS AND RECOMMENDATIONS $\ldots \ldots \ldots \ldots \ldots \ldots \ldots \ldots \ldots$ A-17

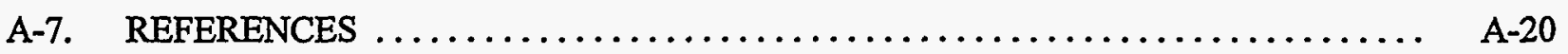

Attachment A-Key Assumptions List $\ldots \ldots \ldots \ldots \ldots \ldots \ldots \ldots \ldots \ldots \ldots \ldots \ldots \ldots \ldots \ldots \ldots \ldots \ldots$, A-21 


\section{FIGURES}

A-1. CPP-666 FSA partial floor plan $\ldots \ldots \ldots \ldots \ldots \ldots \ldots \ldots \ldots \ldots \ldots \ldots \ldots \ldots \ldots \ldots \ldots \ldots$

A-2. CPP- 666 cask and SNF handling plan view $\ldots \ldots \ldots \ldots \ldots \ldots \ldots \ldots \ldots \ldots \ldots \ldots \ldots \ldots$

A-3. CPP-666 cask and SNF handling section view $\ldots \ldots \ldots \ldots \ldots \ldots \ldots \ldots \ldots \ldots \ldots$

A-4. Shipping casks and baskets $\ldots \ldots \ldots \ldots \ldots \ldots \ldots \ldots \ldots \ldots \ldots \ldots \ldots \ldots \ldots \ldots \ldots \ldots$

\section{TABLES}

A-1. $\quad$ CPP-666 FSA SNF inventory $\ldots \ldots \ldots \ldots \ldots \ldots \ldots \ldots \ldots \ldots \ldots \ldots \ldots \ldots \ldots \ldots \ldots \ldots \ldots$

A-2. SNF specific information $\ldots \ldots \ldots \ldots \ldots \ldots \ldots \ldots \ldots \ldots \ldots \ldots \ldots \ldots \ldots \ldots \ldots \ldots \ldots \ldots \ldots \ldots$

A-3. Time estimates to load shipping casks with SNF $\ldots \ldots \ldots \ldots \ldots \ldots \ldots \ldots \ldots \ldots \ldots$ A-18

A-4. Construction direct cost comparison $\ldots \ldots \ldots \ldots \ldots \ldots \ldots \ldots \ldots \ldots \ldots \ldots \ldots \ldots \ldots \ldots$ 


\section{Appendix A \\ CPP-666 FSA \\ Spent Nuclear Fuel (SNF) \\ Transfers to the Dry Transfer Cell (DTC)}

\section{Conceptual Design}

\section{A-1. INTRODUCTION}

The scope of work for this Conceptual Design Report for transferring SNF from CPP-666 FSA to the DTC for loading into DPCs requires the Architect-Engineer (A-E) to develop a conceptual design for the shipping cask that will load and transfer SNF stored at the FSA to the DTC. The SNF inventory considered in this report includes six different Department of Energy (DOE) ${ }^{\mathrm{a}}$ pristine fuel types. These fuels are part of the Baseline SNF Inventory ${ }^{A-1}$ and must be prepared for dry storage and eventual off-site shipment.

The Feasibility Study by Fluor Daniel, Inc. ${ }^{A-2}$ has shown that it is feasible to load SNF stored underwater in the FSA into DPCs. This Study identified methods to accomplish this loading underwater, both for a base case and for a debottlenecking case. The base case investigated minor modifications and equipment to perform the work. The debottlenecking case looked at modifications to minimize interference problems with ongoing operations in the facility. Since the Feasibility Study was completed, additional information about the amounts and types of pristine fuel that must be handled in CPP-666 FSA for dry storage has been received. This information has reduced the amount of SNF to be handled significantly from that reported in the subject Feasibility Study by eliminating the Naval and aluminum fuels. The Naval SNF will be shipped to the Naval Reactors Facility, and the aluminum SNF will be shipped to the Savannah River Site for storage preparation. This CD assumes that no Naval or aluminum fuels will be loaded into DPC at CPP-666. With the elimination of these fuels, it has become necessary to re-evaluate the concepts considered in the subject feasibility study and investigate other options for handling and loading the SNF stored underwater in the FSA. This CD accomplishes these tasks.

Other studies previously completed addressing SNF dry storage in relation to CPP-666 have been reviewed in sufficient detail to complete this Conceptual Design. . $^{\mathrm{A}, \mathrm{A}-4, \mathrm{~A}-5}$

This Conceptual Design addresses the following items:

- The types of SNF stored in the CPP-666 FSA pools that would be placed in dry storage under this CD.

a. For the purpose of this report "pristine" fuel implies fuel where the cladding has not been breached nor has the can or bucket containing the fuel corroded through. 
- Loading pristine SNF stored in the CPP-666 FSA pools into shipping casks underwater, removing the loaded casks from the pool, and transferring the cask and fuel to the proposed Dry Fuel Transfer Facility (DTC) for loading into DPC.

- The shipping casks and fuel loadings that will be required to make the SNF transfers from the CPP-666 FSA pools to the DTC.

- Adjusted cost comparison between concepts presented in the Fluor Daniel Feasibility Study (i.e., loading DPC with SNF underwater in CPP-666 FSA pools) and item $1 .^{\mathrm{b}}$

The assumptions made in the development of this Conceptual Design are listed in Appendix A and relate to spent nuclear fuel inventory, shipping casks, cask inserts, and lifting and handling equipment.

\section{A-2. DESCRIPTION OF CPP-666 FSA FACILITY.}

The FSA in building CPP-666 is used for receipt of SNF, preparation of fuel handling units (FHUs), and underwater storage of FHUs. Normal operations use cask handling crane (CRN-FR-903) and two fuel handling cranes (CRN-FS-901 and -902). A description of the four major areas utilized in this CDR is given below. The operating floor is reference (grade) elevation 0 foot 0 inch (see Figure A-1).

\section{A-2.1 Truck Receiving Area}

The Truck Receiving Area acts as an airlock between the FSA and the environment. There are two access routes into this area from the south end of building CPP-666. Both are serviced with large overhead roll-up doors. Additional roll-up doors between the Truck Receiving Area and the Cask Receiving Area form the airlock. This area has no permanently installed crane.

\section{A-2.2 Cask Receiving Area}

The Cask Receiving Area occupies the south end of the FSA, between the Truck Receiving Area and the unloading pools. The large overhead 130 ton crane services this area. Two decontamination rooms are located in this area. Decontamination Room No. 1 is 17 feet tall and used for shorter casks and Decontamination Room No. 2 is 22 feet tall and used for taller casks. Each room is equipped with front and roof doors for cask placement inside the room with the cask crane. There are walkways and platforms inside the decontamination rooms that allow for personnel access to all areas of the cask. The Decontamination Rooms are supplied with de-ionized water, filtered ventilation, and utility power.

The Cask Receiving Area has stainless steel collection trays on the floor for placement of lifting yokes, casks, and other equipment.

b. The cost estimate presented in the Fluor Daniel, Inc. Feasibility Study ${ }^{A-2}$ included cost for $120 \mathrm{DPC}$ and associated IBA spacers. The adjusted cost reduces the number of DPC to 4 consistent with the amount of SNF to be handled in this $\mathrm{CD}$. This reflects the decision to not handle the Naval and aluminum fuels. 


\section{A-2.3 Cask Unloading Area}

The Cask Unloading Area is a pool area south of Pool No. 1 which is within reach of both the cask handling crane and the fuel handling cranes. It includes two fuel unloading pools where casks are placed for fuel loading/unloading: Unloading Pool No. 1 is 36 feet deep and Unloading Pool No. 2 is 44 feet deep. The bottom of each pool is protected with 1 inch thick steel plate. Lifting yoke storage racks are located on the south wall of the unloading pools. An isolation pool connects each unloading pool. Isolation Pool No. 1 is 31 feet deep and Isolation Pool No. 2 is 41 feet deep.

The Cask Unloading Area also includes the south end of the 31-foot deep transfer channel which connects both Unloading Pools to the storage pools (see Figure A-1).

\section{A-2.4 Fuel Storage Area}

The Fuel Storage Area consists of six pools aligned in the north-south direction and crossconnected by a transfer channel on the east. The SNF is stored in fuel racks in various locations within these six pools. This area is served by the two fuel handling cranes CRN-FS-901 and CRN-FS-902, each with a capacity of 10 tons.

\section{A-3. FSA AND DTC CONFIGURATION AT TIME OF SNF SHIPMENT}

It is assumed that all SNF described in Table A-1 will be temporarily stored at the CPP-666 FSA (in storage racks) by the time this design is implemented. CPP-666 operations of SNF movement, transfer, and shipping will be ongoing for other fuels not described in this report. Facility management and operations will allow and accommodate fuel transfers, loadings, and shipments, as described within this design. All necessary procedures and other documentation will be in place to allow loading and shipping of the SNF described herein. Facility cranes and lifting-and-handling equipment as well as tooling will be available and in usable condition. The DTC will be in operation and ready to receive SNF shipments.

\section{A-4. CONCEPTUAL DESIGN}

\section{A-4.1 Overview}

The purpose of this Conceptual Design is to define the concepts necessary to load SNF stored in the CPP-666 FSA pools into shipping casks and ship the casks to the DTC facility for SNF loading into DPC. This design does not address any part of the DTC facility in relation to loading the SNF identified in this report into DPC.

The SNF stored in the FSA that requires loading into DPC is listed in Table A-1. From the table it is evident that only a small amount of SNF is being considered per the requirements of this design. This CDR is based upon the SNF in Table A-1. As mentioned above, the Fluor Daniel, Inc. Feasibility Study proposed modifications in CPP-666 to handle a much larger amount of SNF than that listed in Table A-1. 
Table A-1. ICPP-666 FSA SNF inventory (expected inventory to be moved from ICPP-666 FSA to the DTC in shipping casks).

\begin{tabular}{|c|c|c|c|c|c|c|c|c|c|c|c|c|}
\hline $\begin{array}{l}\text { Ref. } \\
\text { No. }\end{array}$ & SNF name & FHUs & $\begin{array}{c}\text { Estimated } \\
\text { no. of DPCs }\end{array}$ & Site & Area & Facility ${ }^{\mathfrak{a}}$ & Location & Geometry ${ }^{6}$ & Unit & $\begin{array}{l}\text { Height } \\
\text { (in.) }\end{array}$ & $\begin{array}{l}\text { Width } \\
\text { (in.) }\end{array}$ & $\begin{array}{l}\text { Length } \\
\text { (in.) }\end{array}$ \\
\hline 1 & Pathfinder & 417 & 0.6 & $\begin{array}{c}\text { INEL } \\
\text { LMITCO }\end{array}$ & ICPP & ICPP-603 & $\begin{array}{l}\text { Underwater } \\
\text { Storage Middle }\end{array}$ & Cylinder & Rod & 一 & 0.92 & 79.50 \\
\hline 2 & $\begin{array}{l}\text { Pulstar- } \\
\text { Buffalo }\end{array}$ & 24 & 0.07 & $\begin{array}{c}\text { INEL } \\
\text { LMITCO }\end{array}$ & ICPP & ICPP-603 & $\begin{array}{l}\text { Underwater } \\
\text { Storage South }\end{array}$ & Square & Canister & 3.00 & 3.00 & 35.00 \\
\hline 3 & $\begin{array}{l}\text { Shippingport } \\
\text { PWR-C1-S4 }\end{array}$ & 1 & 0.06 & $\begin{array}{c}\text { INEL } \\
\text { LMITCO }\end{array}$ & ICPP & ICPP-666 & ICPP FAST/4 & Square & Cluster & 5.50 & 5.50 & 104.50 \\
\hline 4 & $\begin{array}{l}\text { Shippingport } \\
\text { PWR-C2-SI }\end{array}$ & 19 & 1.09 & $\begin{array}{c}\text { INEL } \\
\text { LMITCO }\end{array}$ & ICPP & ICPP-666 & ICPP FAST/4 & Square & Cluster & 7.38 & 7.38 & 104.50 \\
\hline 5 & $\begin{array}{l}\text { Shippingport } \\
\text { PWR-C2-S2 }\end{array}$ & 20 & 1.14 & $\begin{array}{c}\text { INEL } \\
\text { LMITCO }\end{array}$ & ICPP & ICPP-666 & ICPP FAST/4 & Square & Cluster & 7.38 & 7.38 & 104.50 \\
\hline 6 & TRIGA Flip & 2 & 0.01 & $\begin{array}{c}\text { INEL } \\
\text { LMITCO }\end{array}$ & ICPP & ICPP-603 & $\begin{array}{l}\text { Underwater } \\
\text { Storage South }\end{array}$ & Cylinder & Canister & - & 3.80 & 30.00 \\
\hline 7 & TRIGA SST & 296 & 0.18 & $\begin{array}{c}\text { INEL } \\
\text { LMITCO }\end{array}$ & ICPP & ICPP.603 & $\begin{array}{l}\text { Underwater } \\
\text { Storage South }\end{array}$ & Cylinder & Element & - & 1.48 & 28.31 \\
\hline
\end{tabular}

a. Fuels that reside in ICPP-603 are to be relocated to ICPP- 666 before the implementation of this design.

b. "Geometry" describes fuel only and does not necessarily describe the configuration of fuel storage. 
Their proposal included much of the same equipment as that designed into the DTC. If the SNF listed in Table A-1 were to be transferred into the DTC for loading into DPC rather than loaded underwater in the FSA into DPC, this would eliminate the need for duplicate equipment in both CPP-666 and the DTC. In addition, heavy shipping casks were considered for the movement of the loaded DPC in the Feasibility Study which required crush pads located in strategic locations to protect the SNF and it's packaging from possible drop accidents. If the SNF is loaded into existing shipping casks in CPP-666 and transferred to the DTC, crush pads are not required.

The proposed method (depicted in Figures A-2 and A-3) looks at loading the SNF at the FSA pools into existing shipping casks underwater; removing the casks from the pools, de-watering the casks, loading the shipping casks containing the SNF on a transporter, and transferring the fuel to the DTC facility. The DTC facility is designed to unload the SNF from the shipping casks, place the fuel into DPC, seal weld the DPC, vacuum dry the fuel, and inert the DPC. The DTC facility will contain all equipment for transferring and handling SNF from shipping casks to DPC.

Some of the fuels identified in Table A-1 are planned to be relocated from CPP-603 to CPP- 666 . These fuels are listed under the column heading "Facility" as ICPP-603. Some of the relocation activities and design work are currently ongoing and the remainder of the work is to be initiated in FY's '98 and '99. It is assumed that when these fuels are relocated, the cask and fuel handling equipment requiring modification and/or redesign, and the existing facility equipment used to relocate the fuel can and will be used to ship the SNF to the DTC. It is therefore further assumed that CPP-666 facility will have available for its operations, during the fuel shipments described in this CDR, all fuel handling tools and equipment that have been or will be used to originally place the SNF in the FSA either through the fuel relocation project or regular shipments.

All documentation and procedures used to place the SNF in the FSA will be used or modified as necessary to perform the work described within this report. It is the intent of this CD to utilize as much equipment and tooling as possible from the initial work to place the fuel in the FSA. This CD does not require any modification to the CPP- 666 facility, nor does this $C D$ identify any new tooling or equipment necessary to perform the required work. In addition, crush pads identified in the Fluor Daniel Report are not required under this design because smaller shipping casks are used to transfer the fuel.

All criticality, thermal, and structural calculations used to support the designs to relocate the CPP-603 fuels and other fuel from other facilities (i.e., Shippingport PWR from NRF) will be used to support this design. No additional calculations are foreseen at this time.

\section{A-4.2 Specific Fuels Handling (Reference Table A-2)}

\section{A-4.2.1 Pathfinder}

Pathfinder SNF is expected to be stored in stainless steel buckets in the storage pools of the FSA in CPP-666 per the CPP-603 Fuel Relocation Project. ${ }^{A-6}$ The bucket design is 9.36 inches square by 84 inches long and can accommodate 62 fuel handling units (FHUs). The referenced project will load the Pathfinder fuel in the buckets prior to shipment to the FSA. The cask used for making the shipments of this fuel from CPP-603 to CPP-666 is a modified HFEF-6 shipping cask (Naval Reactors Facility 
Table A-2. SNF specific information.

CONCEPTUALDEstar

TRAPSTRRRS TOTHBDTC

\begin{tabular}{|c|c|c|c|c|c|c|c|c|c|c|c|}
\hline $\begin{array}{l}\text { KEF: } \\
\text { NO. }\end{array}$ & $\begin{array}{l}\text { SPENT NUCLLAAR FUEI. } \\
\text { TYPE }\end{array}$ & $\begin{array}{l}\text { (a) CASK REQUIRED } \\
\text { FOR SIIIPAENT }\end{array}$ & $\begin{array}{c}\text { INSERTI } \\
\text { BASKETTYPE }\end{array}$ & Fius: & $\begin{array}{l}\text { (b) FIIU'D } \\
\text { CASK }\end{array}$ & $\begin{array}{l}\text { (c) CURRENT } \\
\text { FUEL PACKAGE }\end{array}$ & 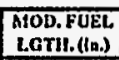 & $\begin{array}{c}\text { CASK INTERNAL } \\
\text { HEIGUI (la.) }\end{array}$ & $\begin{array}{l}\text { (d) CASK } \\
\text { SUIPMENTS } \\
\end{array}$ & $\begin{array}{l}\text { LIFTING YOKE } \\
\text { (0) SIIORT. }\end{array}$ & $\begin{array}{l}\text { LIFTNG YOKE } \\
\text { (K) LONG }\end{array}$ \\
\hline & SATHINDER & HIMPD-6 (MODIHID) & NOT REQUIRID & 417 & 62 & DUCKS: $.963^{\prime \prime} 50 . \times 84^{\prime \prime 20}$ & $\begin{array}{r}70.50 \\
\end{array}$ & $\begin{array}{ll}\text { Mastified } 84.00 \\
\end{array}$ & 7 & CKNY.1:R-PI! & \\
\hline & 2) PUISTAR-BUFARALO & HIIOII LOAD CIIARGER & $3 \times 3$ ARRAY X S1"LO & 24 & 9. & SST CAN-3" SO. $2 \mathrm{~g}^{*} L \mathrm{La}$ & 28.00 & 51.50 & 3 & CRNY-IR-OII & CRNY.1:R.207 \\
\hline & 3 SIIIPPINGPORT PWVR-CI-ST & NIS 100 & (c) $10.1 / 2^{*} S 0 . \times 100^{-1.0}$ & & (i) & CAIT CAGR $10-12^{*} S 0 \times 106^{* L}$ & 100.00 & 103.00 & 00 & CRNY.IR-950.3 & $\begin{array}{l}3 \text { CRNY.S[2807 } \\
\end{array}$ \\
\hline & $\begin{array}{l}4 \\
\text { SIIIPPINGPORT PWR.C2-Si }\end{array}$ & $\frac{105100}{N 1: 5100}$ & (c) $10.122^{*} \times 0 . \times 100^{*} \mathrm{LO}$ & $\frac{79}{19}$ & $\frac{\pi i}{4}$ & 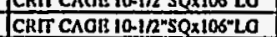 & $\frac{100.00}{100.00}$ & 103.00 & $\frac{100}{.5}$ & \begin{tabular}{|l|l|} 
CRNY.TR-250.3 \\
\end{tabular} & $\begin{array}{l}\text { CRNY.SI:.807 } \\
\text { CRot }\end{array}$ \\
\hline & 5 SIIIPING GPORT PWR.C2-S2 & Nis 100 & (c) $10.1 / 2^{*} \mathrm{~S} 0 . \times 100^{4} 1.0$ & 20 & 4 & 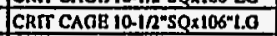 & 100.00 & 103.00 & 5 & CRNY.FR-250.3 & CRNY.SF.807 \\
\hline (8) 6 & 6RIOA FIP & N/A & N/A & & N/A & (ii) SCEP +0 A1.UMI $5^{\circ} \mathrm{OD} \times 36^{\circ} \mathrm{LO}$ & 30,00 & $N / 1$ & NI & N/A & \\
\hline & 7 TRIOA SST & STR CIIARGER & (10) $9.1 R^{*} S O . \times 58^{4} \mathrm{LO}$ & 296 & 20 & (b) SSTCAN $S^{*}$ OD $\times 36^{\circ} \mathrm{LO}$ & 28.37 & 59.00 & 15 & CRNY.TR-911 & CRNY.FR-907 \\
\hline
\end{tabular}

NOTES:

(a) The cask Identiliad In this.column will be used to transler the SNF from the CPP-668 FSA pools to the Dry Transfor Coll Faclity.

(b) This is the totat amount of FHU's the cask can accommedalo por shlpment.

(c) Assumod packago conflguralion in CPP.663 FSA pools

(d) Number of cask shipmonis retars to the number of times the cask will bo loaded and shipped in order to move all the Identlliod fuel.

(o) Insort \#1 is a 10.1/2" square array with 4 compartmonls $100^{\circ}$ long. Insert and cask wore used to ship thls fuol from NAF to CPP.660.

(n) Thls tral will bo combingd wilh 1 of fual Rot. No. 4's shlpments.

(j) Fuel Rof. No. 6. Triga Fillp, is currenlly in aluminum cans thal may be corroded. It has yot to bo doterminod it the DTC lacilly will handlo this fuol.

(h). Each can (aluminum or ssi) contains approximately 5 FHU's

(i) This insert will bo doslgned during the fuol relocallon projoct.

(k) Long Ithing yokes are used for cask IIIIng Into and out of the FSA pools. 
owned/Figure A-4). Cask modifications are required to accommodate the bucket design. The modified cask cavity can accept 1 bucket per shipment and no basket arrangement or other insert is required. The HFEF- 6 cask will be returned to NRF in the unmodified condition when the fuel relocation project is completed. It is assumed that the modified cask components will remain at CPP-666 for use by this project.

It is the intent of this CD to utilize the HFEF-6 cask for shipment of the Pathfinder fuel from CPP-666 to the DTC facility. It is assumed that the cask will be available and in operable condition for use when the shipments take place. The shipment of Pathfinder fuel from CPP-666 to the DTC facility will require that the HFEF- 6 cask be again fitted with the modified components prior to fuel loading and shipping. The fuel will be shipped in the same configuration as determined in the Title II Design document for "CPP-603 Fuel Relocation Project."A-6 All calculations supporting criticality, thermal, and structural contained in the referenced Title II Design document will be utilized as required in shipping the fuel to the DTC.

The Baseline SNF Inventory ${ }^{A-1}$ indicates that there are 417 FHUs of Pathfinder fuel. With 62 FHUs per bucket and 1 bucket per HFEF- 6 cask shipment, 7 shipment will be required to ship the Pathfinder fuel from the FSA to the DTC facility.

\section{A-4.2.2 Pulstar-Buffalo}

Currently, Pulstar-Buffalo SNF resides in stainless steel canisters in the CPP-603 South Basin and is planned to be relocated to CPP-666 FSA. The stainless steel storage canisters measure 3 inches square by 28 inches long and each accommodate 1 FHU. It is assumed that the fuel will remain in these stainless steel canisters during and after the relocation from CPP-603 to CPP-666 FSA.

The Pulstar-Buffalo fuel will be loaded into the high load charger cask prior to shipment from CPP-666 to the DTC. The cask will be fitted with an insert to provide spacing and accommodate multiple canisters per shipment. The insert is a 3 by 3 array measuring 51 inches long and is fabricated from borated stainless steel. The cask and insert are shown in Figure A-4. The cask fitted with the insert will accommodate 9 canisters of Pulstar-Buffalo SNF.

It is assumed that the high load charger cask and the insert will be available and in operable condition for use when the shipments to the DTC take place.

LITCO is preparing to relocate the Pulstar-Buffalo fuel from CPP-603 to CPP-666 prior to placing the fuel in dry storage. This $C D$ assumes that this relocation will be completed before this design is implemented. The relocation effort will require that all criticality, thermal, and structural calculations be performed to show safe handling of the fuel is possible using the insert identified above and the high load charging cask. Upon completion of the relocation of the Pulstar-Buffalo fuel to CPP-666, the shipping of the fuel to the DTC facility will be initiated and completed. This shipment to the DTC will utilize all the same equipment, insert and cask used in the relocation effort. The fuel will be shipped in the same configuration as determined in the relocation effort. All calculations supporting criticality, thermal, and structural used in the relocation effort will be utilized as needed in shipping the fuel to the DTC. 
The Baseline SNF Inventory ${ }^{A-1}$ indicates that there are 24 FHUs of Pulstar-Buffalo fuel. With 9 FHUs per high load charger cask shipment, 3 shipments will be required to ship the Pulstar-Buffalo fuel from the FSA to the DTC facility.

\section{A-4.2.3 Shippingport PWR}

The Shippingport SNF consists of three different types; Shippingport PWR-C1-S4, Shippingport PWR-C2-S1, and Shippingport PWR-C2-S2. This fuel is stored in the fuel storage racks in the FSA building CPP-666. The fuel was received from NRF packaged in a special PWR criticality control spacer arrangement. This fuel was shipped from the Expended Core Facility at NRF in the NFS 100 cask. The details of the shipping are contained in the classified document "NFS-100 Cask SAR."A-7

The special PWR criticality control spacer measures 10-1/2 inches square by about 100 inches long and fits directly inside the cavity of the NFS 100 cask containing insert no. 1 . Insert no. 1 is a 4 compartment array measuring 100 inches long. This insert fits inside the NFS 100 cask and is designed for the special PWR criticality control spacer. The insert allows the cask to accommodate 4 FHUs of Shippingport PWR fuel.

The shipping of this PWR fuel from the FSA to the DTC will be accomplished using the special PWR criticality spacer and the NFS 100 cask. It is assumed that the cask will be available and in usable condition for this shipping effort. This CD will utilize the information contained in the NFS-100 Cask SAR to ship the Shippingport SNF from CPP-666 to the DTC. All the necessary calculations for criticality, thermal, and structural have been completed and approved in the referenced document. No additional tooling or other equipment will be necessary. All tooling and other equipment for this effort will resides at the CPP- 666 facility.

The Baseline SNF Inventory ${ }^{A-1}$ indicates that there are 40 FHUs of Shippingport PWR fuel. With 4 FHUs per NFS 100 cask shipment, 10 shipment will be required to ship the fuel from the FSA to the DTC facility.

\section{A-4.2.4 Triga Flip}

The current configuration of the Triga Flip SNF is not known to any degree of certainty at the time of this CDR. Only 2 or 3 FHUs are stored in the underwater storage South Basin in CPP-603. The fuels may be in either aluminum or stainless steel open-top cans measuring 5 inch O.D. by 36 inch long. The integrity of the can structures and the fuel elements are not known. The DTC may not have the capability of handling this fuel. For these purposes, this fuel is not being considered for DPC loading in this CDR.

\section{A-4.2.5 Triga SST}

At present, the Triga SST SNF resides in stainless steel canisters in the CPP-603 South Basin. The canisters measure about 5 inches O.D. by 36 inches long and contain 5 FHU each. LITCO is preparing to relocate this fuel from CPP-603 to CPP-666 prior to placing it in dry storage. 
The proposed configuration for the relocation of this fuel from CPP-603 to CPP-666 is to repackage the fuel into 9-1/2 inch square by 58 inch long stainless steel buckets and ship the buckets in the STR Charger cask. Approximately 20 FHUs will be loaded into each bucket. The cask cavity will only accept 1 bucket per shipment.

The relocation effort will require that all criticality, thermal, and structural calculations be performed to show safe handling of the fuel is possible using the bucket design and the cask. For the purpose of this CD it is assumed that the fuel will be repackaged as mentioned and the new package will be fully qualified.

Upon completion of the relocation of the Triga fuels to CPP-666, the shipping of the fuel to the DTC facility will be initiated and completed. This shipment to the DTC will utilize all the same equipment and cask used in the relocation project. The fuel will be shipped in the same configuration as determined adequate in the relocation effort. All calculations supporting criticality, thermal, and structural contained in the relocation effort will be utilized as required in shipping the fuel to the DTC.

This design will take the repackaged Triga fuels in the new buckets, load them back into the STR Charger cask underwater, remove the cask from the FSA pool, and ship the cask and fuel from CPP-666 to the DTC. It is assumed that the STR charger cask will be available and in operable condition for use when the shipments to the DTC take place.

The Baseline SNF Inventory ${ }^{A-1}$ indicates that there are 296 FHUs of Triga SST fuel. With 20 FHUs per bucket and 1 bucket per cask shipment, 15 shipments will be required to ship the fuel from the FSA to the DTC facility.

\section{A-4.3 Cask and SNF In-Plant Movements (Reference Figures A-2 and A-3)}

The cask will enter the truck receiving area through the east roll-up door on the transporter. Once inside the truck receiving area, the outside door is closed. The truck receiving area provides an airlock for the FSA facility. In the truck receiving area, road dirt is washed from the transporter and the cask if required. The transporter is then moved through the inner roll-up door into the Cask Receiving and Decontamination Area. The inner door is then closed.

With the cask transporter positioned in the Cask Receiving and Decontamination Area, the cask restraints are removed and the cask is prepared for movement using the cask crane. The cask crane (CRN-FR-903, capacity 130 tons) and short lifting yoke is attached to the cask and the cask is transported to Decontamination Room No. 1. The lifting yoke is removed from the cask trunnions and placed in the lay-down rack.

In the Decontamination Room the cask lid is made pool ready by loosening the lid bolts. The lid bolts are designed with bails for installation and removal underwater using pool reach tools. If the cask

c. Lifting yokes are designed for specific casks and are individually identified in Table A-2. 
is a sealed design (i.e., HFEF-6 and NFS-100) the cavity is filled with water compatible with the FSA pool water. The cavity is filled prior to lowering the cask into the pool to prevent excess bubbling and contamination spray into the air that might occur by sinking the cask and flooding the cavity with pool water. The extra water from the cask added to the FSA pools is acceptable; the pools require about 8000 gallons of makeup water each month. Administrative controls will be utilized to factor the number of shipments and the total amount of water added to the pools in order to keep from adding too much water too quickly. The cask cavity is filled through the cask fill valve located near the top of the cask. The valve accepts a hose fitting and hose for filling. If the cask is not a sealed design (cavity will not hold water as in the STR Charger and High Load Charger) the cask is submerged into the Unloading Pool and it's cavity is naturally filled from the bottom up.

The cask crane and long lifting yoke are used to move the cask from the Decontamination Room onto the Unloading Pool no. 1 floor. With the cask positioned on the floor of the pool, existing "J" and " $L$ " type pool tools are used to remove cask lid bolts and make lifting yoke connections with the cask lid. The lid is removed and staged out of the way. From here, the fuel handling crane is used to move fuel from the fuel storage racks to the cask. With the cask full, the shield lid is placed back on the cask using the cask crane and the long lifting yoke. The lid bolts are tightened using the pool reach tools and the cask is lifted from the pool.

The cask (i.e., STR Charger and High Load Charger) is allowed to drain and drip dry over the unloading pool and then is moved to Decontamination Room 1. If the cask is a sealed design (i.e., HFEF-6 and NFS-100) it's cavity is drained in Decontamination Room 1 rather than over the unloading pool. Draining is accomplished by accessing the drain valve located near the bottom of the cask. The blind flange is removed from the drain valve and a hose is connected to the valve. The valve is opened and the cavity drained. The drain water goes back into the pool. In addition, in the Decontamination Room, the cask exterior can be wiped down and decontaminated.

Next, the lid bolts are tightened in preparation for shipping and the cask is moved from the Decontamination Room to the transporter using the cask crane and the short lifting yoke. The cask is positioned on the transporter and secured in place. The lifting yoke is removed from the cask crane. The doors of the Cask Receiving and Decontamination Area are opened and the transporter is moved out of the Cask Receiving and Decontamination Area into the Truck Receiving Area. The doors of the Cask Receiving and Decontamination Area are then closed. The doors of the Truck Receiving Area are then opened and the transporter is moved out of the building.

\section{A-4.4 Scheduling}

The scheduling of the fuel shipments identified in this $\mathrm{CD}$ will need to be determined as more information is obtained and finalized on the shipment schedule of SNF to the INEL. It is believed that fuel shipments identified in this document can take place anytime an opening presents itself in the operations of CPP-666 and the DTC. The DTC preliminary schedule for operational start-up is September 2003. 
It is recommended to schedule the shipping of all identical fuel during one time block in order to efficiently use the DTC. This would allow direct transfers from the shipping cask to the DPC and would eliminate the need for any lag storage use.

\section{A-4.5 Time Estimates}

Estimates for the " in process" hours for each fuel and associated shipping cask have been compiled in Table A-3. The estimates include all hours for receipt of the shipping cask, loading the fuel, and necessary preparations prior to shipment in CPP-666.

\section{A-5. COST COMPARISON}

A adjusted cost comparison has been completed and summarized in Table A-4. In developing the cost comparison it was necessary to revise costs estimated in the Fluor Daniel Feasibility Study ${ }^{A-2}$ to reflect the loading of 4 DPC rather than the 120 identified in the Study. From the summary it is evident that costs are much less to utilize the DTC and equipment contained therein to accomplish the packaging of the fuels into DPC. No major equipment is needed to transfer fuels from the FSA to the DTC. The only costs related to this CDR are those required to procure the $4 \mathrm{DPC}$.

\section{A-6. CONCLUSIONS AND RECOMMENDATIONS}

This CD has reviewed the option to ship the identified fuels from the FSA to the DTC in shipping casks for eventual loading into DPC. This document has also compared the costs associated with making modifications to the CPP-666 facility to load DPC directly underwater in the FSA to the cost of shipping the fuel to the DTC for loading into DPC. It is obvious, due to the small amount of pristine SNF to be handled, that modifications to CPP- 666 should not be undertaken and that the identified fuels should be loaded into DPC in the DTC.

This design will utilize as much equipment and tooling as possible from the initial work to place the fuel in the FSA. No modifications to the CPP- 666 facility are required, and no new tooling or equipment necessary to perform the required work has been identified.

The DTC will be operational and will be equipped with remote capabilities for dry handling of the SNF. This facility will be fully capable of performing the needed operations to meet the requirements for eventual above ground dry storage of SNF in DPC. Based on the current information, no further effort should be expended in addressing modifications to the CPP- 666 facility.

Much of the relocation of SNF from CPP-603 to CPP-666 has yet to be completed. This CD is based upon this relocation work being completed prior to the implementation of this design. The actual package configuration of the relocation fuels (i.e., Pulstar-Buffalo and Triga) have yet to be finalized. This may have a minor affect on this $\mathrm{CD}$ as described above. Therefore, it is necessary to closely follow the fuel relocation work and make design adjustments as necessary as more information become available. 
Table A-3. Time estimates to load shipping casks with SNF.

CONCEPTUN DESKON

CPP.666FSA SNF.

TRNSFERS TOTHE OTC

FUEL/CASK

\begin{tabular}{|c|c|c|c|c|}
\hline & $\begin{array}{c}\text { PATHFINDER/ } \\
\text { HFEF- } 6\end{array}$ & $\begin{array}{l}\text { PULSTAR-BUFFALO/ } \\
\text { HIGH LOAD CHARGER }\end{array}$ & $\begin{array}{l}\text { SHIPPINGPORTPWPI } \\
\text { NFS-100 }\end{array}$ & $\begin{array}{l}\text { TRIGA SST/ } \\
\text { STRCHARGER }\end{array}$ \\
\hline \multicolumn{5}{|l|}{ OPERATIONS } \\
\hline RECEIVECASK & 1.5 & 1.5 & 1.5 & $\overline{1.5}$ \\
\hline CASK PREPARATIONS & 1.5 & 1.0 & 2.0 & $\overline{1.0}$ \\
\hline OPENCASK & 1.0 & 1.5 & 2.0 & $\overline{1.5}$ \\
\hline TRANSFERFUEL“ & 1.5 & 7.5 & 3.5 & $\overline{1.5}$ \\
\hline CLOSECASK & 2.0 & 1.5 & 2.5 & $\overline{1.5}$ \\
\hline DECONCASK & 2.0 & 2.0 & 3.0 & 2.0 \\
\hline LOAD ON TRUCK & 1.5 & 1.0 & 1.5 & 1.0 \\
\hline${ }^{\star \star}$ SUBTOTAL & 11.0 & 16.0 & 16.0 & 10.0 \\
\hline NO. OF CASK SHIPMENTS & 7 & 3 & 10 & 15 \\
\hline TISTAL IN FACILITY HRS & mang & $m+\cdots, \cdots, \cdots$ & $\therefore \because 160.0$ & 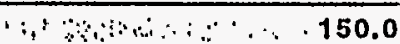 \\
\hline
\end{tabular}

NOTES: RECENECASK = TRANSPORTER BRINGS CASK INTOFACILTY, CASKIS HEMOVED FROM TRALLER AND POSTIONED IN DECONTAMINATON ROOM CASK PREPARATIONS a PREPARE CASK LID FOR REMOVAL UNDERWATER, FILL CAVITY WITH WATER, MOVE CASK TO POOL. FLOOR

OPEN CASK = REMOVE LID BOLTS, LIFT LID FROM CASK, STOWLID

TRANSFER FUEL $=$ TRANSFER FUE FROM STORAGERACK TO FLL CASK

CLOSE CASK = LIFTLID ONTO CASK AND SECURE, RENOVE CASK FROM POOL, DRAN AND DRIP DRY OVER POOL.

DECONCASK = POSTION CASKIN DECONTAMINATION ROOM, DECONEXTERIOR, TORQUELIDBOLTS

LOADONTRUCK $x$ REMOVECASK FROM DECON ROOM AND LOCATE ONTRANSPORTER, SECURECASK

- hours to transfea fuel to fll. 1 cask

-" NPROCESSHOURS FOR 1 CASK 
Table A-4. Construction direct cost comparison.

\begin{tabular}{|c|c|c|c|c|c|c|c|c|c|c|}
\hline \multicolumn{11}{|c|}{ CONSTRUCTION DIRECT COST COMPARISON } \\
\hline Equipment Designallon & \multicolumn{5}{|c|}{$\begin{array}{l}\text { CPP-666 FSA Modifications } \\
\text { To Enable DPC Loading } \\
\text { Fluor Daniel Foaslbility Study }\end{array}$} & \multicolumn{5}{|c|}{$\begin{array}{c}\text { CPP-666 FSA Spent Nuclear Fuel } \\
\text { Transfers to the Dyy Transfer Cell } \\
\text { Conceptual Design }\end{array}$} \\
\hline 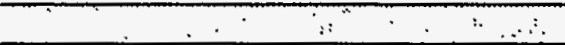 & Qty & Material & Labor & Equlpment & Total & Qty & Malerial & Labor & Equipment & Total \\
\hline DPC - Dual Purpose Canister (Shell) & 4 & 450,000 & 420,000 & & $2,220,000$ & 4 & 450,000 & 420,000 & & $2,220,000$ \\
\hline DPC Shleld Plug & 4 & Inc & Inc & $\ln c$ & & 4 & Inc & Inc & $\ln c$ & \\
\hline IBA - Internal Basket Assembly & 4 & inc & inc & inc & & 4 & Inc & Inc & inc & \\
\hline DPC AutoWelder w/ Console and CCTV & 1 & 650,000 & 1,779 & 150 & 651,929 & 1 & \multicolumn{3}{|c|}{ Included in Dry Transfor Coll } & \\
\hline DPC Leak Test Mass Spectrometer & 1 & Inc & inc & Inc & & 1 & \multicolumn{3}{|c|}{ Included in Dry Transfer Cell } & \\
\hline DPC Vacuum Drying System & 1 & inc & Inc & Inc & & 1 & \multicolumn{3}{|c|}{ Included in Dry Transfer Cell } & \\
\hline DPC DI Water Supply/Draln Hose and Valve & 1 & 1,500 & - & - & 1,500 & NR & & & & \\
\hline DPC Equipment Preparalton Station & 1 & 2,500 & 10,671 & 900 & 14,071 & NA & & & & \\
\hline DPC Fill Pump with Motor ${ }^{\star \star}$ & 1 & 3,532 & 1,423 & 120 & 5,075 & NR & & & & \\
\hline DPC Shleld Plug Lifting Device & 1 & 500 & - & - & 500 & NR & & $\dot{5}$ & & \\
\hline DPC Shleld Plug Retainer & 1 & 10,000 & - & - & 10,000 & NR & & & & \\
\hline DPC Shleld Plug Retainer Fastening Tool & 1 & & & & & NR & & & & \\
\hline Electrical Connectling Equipment ** & 1 & 8,265 & 5,461 & 498 & 14,224 & NR & & & & \\
\hline IBA Spacer Installation Tool & 1 & 1,750 & - & - & 1,750 & 1 & \multicolumn{3}{|c|}{ Included in Dy Transfer Cell } & x \\
\hline IBA Spacers, Pont & 62 & 400 & - & - & 24,800 & AR & \multicolumn{3}{|c|}{ Included In Dry Transfor Cell } & \\
\hline IBA Spacers, Stacking. & 117 & 425 & - & - & 49,640 & $A R$ & \multicolumn{3}{|c|}{ Included In Diy Transfer Cell } & \\
\hline Large Coll Cask In-Pool Crush Pad & 1 & 400,000 & 7,114 & 600 & 407,714 & NA & & & & \\
\hline Lifling Yoke Storage Pan & 1 & 11,435 & 889 & 75 & 12,399 & NR & & & & \\
\hline OTC Crush Pad & 1 & 400,000 & 7,114 & 600 & 407,714 & NA & & & & \\
\hline OTC Crush Pad Lifting Device & 1 & 750 & - & - & 750 & NR & & & & \\
\hline Slings & 1 & 750 & - & - & 750 & 1 & \multicolumn{3}{|c|}{ Included In D ry Transfer Cell } & \\
\hline & & & & & & & & & & \\
\hline Total Cost & & & & & $3,823,000$ & & & & & $2,220,000$ \\
\hline
\end{tabular}

Notes: (a) Labor on DPC is Engineering \& Licensing

(b) Current day costs - No Escalation

(c) Dlrect Costs only - No Overhead and Profit

(d) ** F-D costs that have been re-estimated

(e) $N R=$ Not Requlred $/ A R=$ As Required 


\section{A-7. REFERENCES}

A-1. A. P. Hoskins Letter to W. B. McNaught, APH-14-96, Dry Storage Facility-Dry Transfer Cell Baseline Spent Nuclear Fuel, Dated April 4, 1996

A-2. CPP-666 FSA Modifications to Enable Dual Purpose Canister (DPC) Loading Feasibility Study, Dated April 1996, Prepared by Fluor Daniel, Inc. for DOE.

A-3. Fuel Canning and Dry Modular Storage Feasibility Study (CADMOST Study), Dated June 1994, Prepared by Fluor Daniel, Inc. for DOE.

A-4. Westinghouse Idaho Nuclear Co. (WINCO) ICPP-Process System Description, FAST Facility Fuel Storage Area, Volume XIII, Book 1, Dated August 1987.

A-5. Spent Nuclear Fuel Dry Storage Project Feasibility Study, Dated February 1996, Prepared by Lockheed Idaho Technologies Co. for DOE.

A-6. CPP-603 Fuel Relocation Project, "Pathfinder", Title II Design Package, Dated October 1995, Prepared by Fluor Daniel, Inc. for DOE.

A-7. NFS-100 Cask Safety Analysis Report, ECF, Bettis, Westinghouse Electric Co., Naval Reactors Program, Document No. WAPD-REO "C"-267 "Classified." 


\section{Attachment A}

\section{Key Assumptions List}

The following assumptions have been made in conjunction with this conceptual design.

The shipping casks identified in Table A-2 are available and in usable condition at the time of fuel transfer from CPP-666 to the Dry Transfer Cell Facility. In particular, the HFEF- 6 cask and the NFS- 100 cask are the property of the Naval Reactors Facility, these casks will be available for LITCO to use during this SNF campaign.

The shipping casks identified in Table A-2 are staged at the CPP site. This report does not address transporting shipping cask form another facility (i.e., NRF) to the CPP site.

Transporter/shipping truck and trailer are available and in good usable condition at the time of SNF shipment.

CPP-666 cranes, lifting and handling equipment and facilities identified in this report are available for use and in operable condition at time of SNF shipping.

All SNF identified in Table A-1 is in underwater storage at the CPP-666 FSA pools at the time it is required to be transferred to the DTC. This report does not address the relocation of SNF from CPP-603 or other facility to CPP-666.

Crush pads have not been used during past operations in CPP-666 facility for the casks identified in Table A-2 and will not be necessary for operations described in this Conceptual Design.

HFEF- 6 cask modified components will be available and in usable condition at time of Pathfinder SNF shipping to the Dry Transfer Cell facility. Operations personnel will install the modified cask components prior to SNF loading.

All tooling and equipment existing or fabricated for SNF relocation form CPP-603 to CPP-666 will be available and in operable condition for use during this SNF campaign.

Calculations for criticality, thermal, and structural for specific SNF loading into a shipping cask (identified in Table A-2) have been or will be completed by others. These calculations can be used for the SNF shipping identified in this report.

Operations personnel, trained for SNF fuel transfer and shipping will be made available at CPP-666 to perform the work identified in this report.

The Dry Transfer Cell will be built at the CPP site and be in operation prior to shipping any SNF identified in Table A-1 from CPP-666 pools. 
Fuel identified for relocation from CPP-603 to CPP-666 will be stored at the FSA in it's current proposed configuration, i.e., can, bucket, or cage.

The SNF will not be dried prior to receipt in the DTC. If drying of the SNF is required before loading into DPC, the drying process will take place in the DTC facility. 


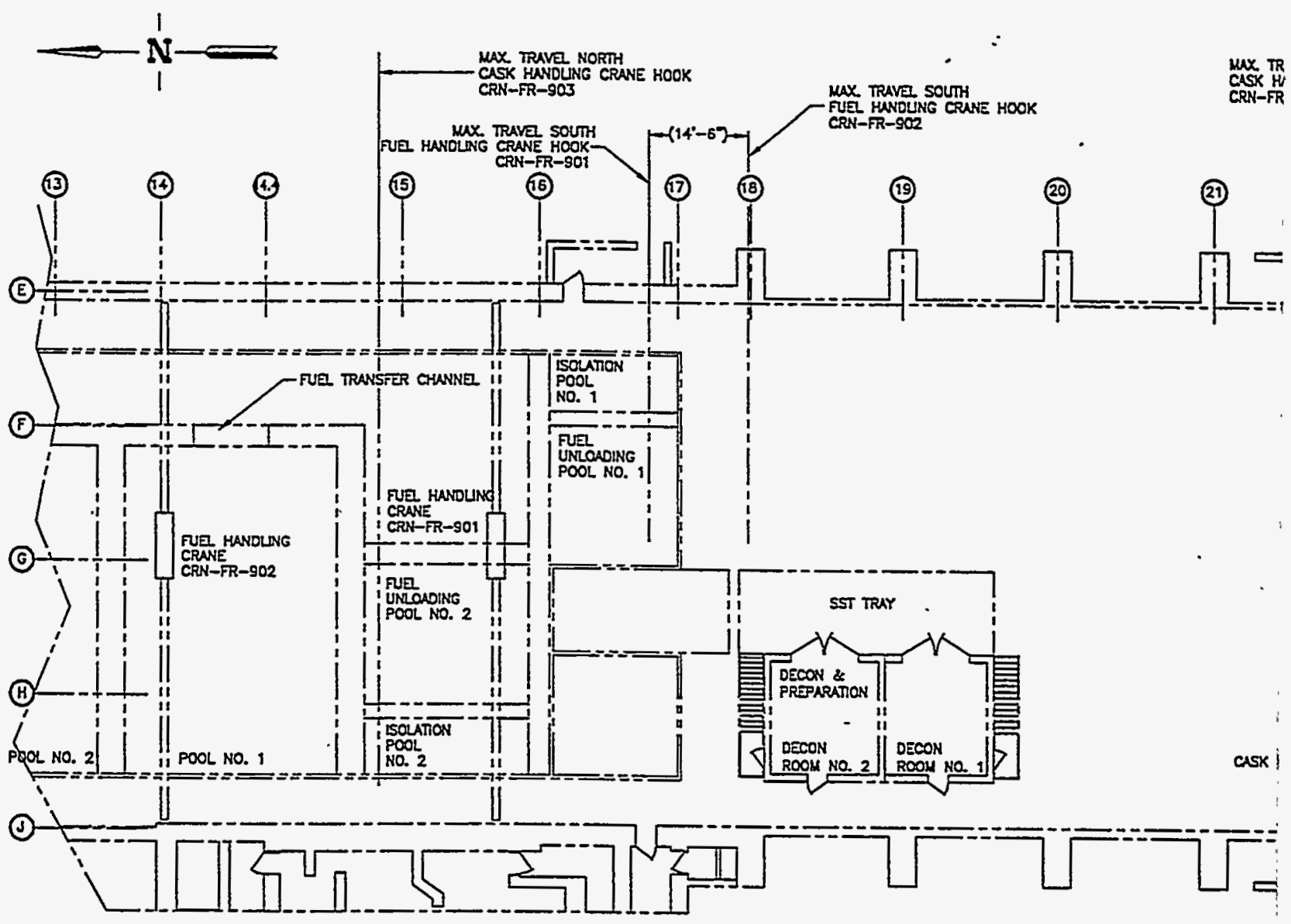

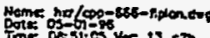

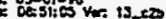

Figure A-1. CPP-666 FSA partial floor plan. 


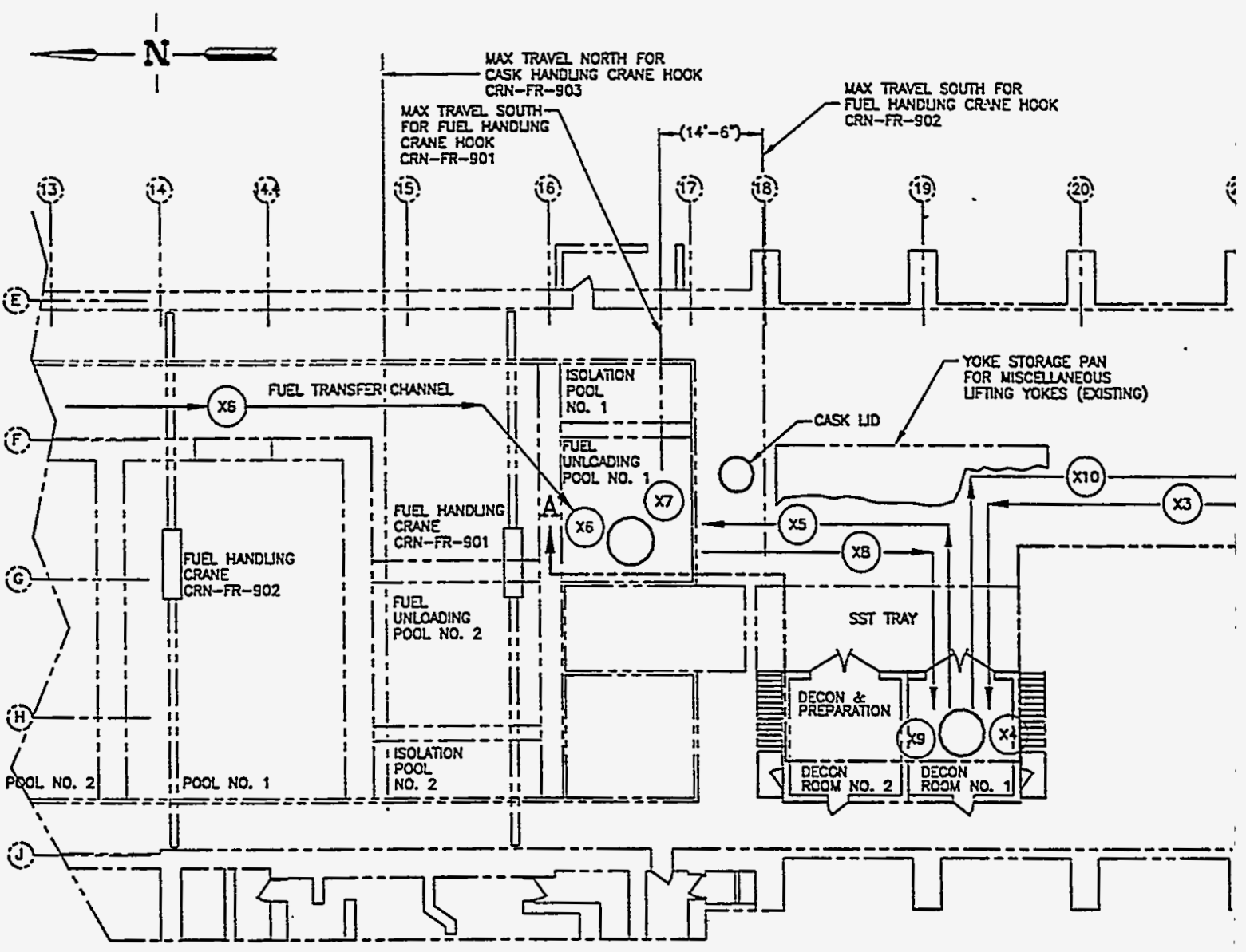

(X1) REDERT EMPTY SHIPPING CASK TO FSA CSKK

P2 REUOVE CASK USING SHORT LFING YOKE

FRON THE TRALIR.

(X3) TRANSPORT SHIPPING CASK FRON THE TRMLER

(x)

(X4) FREP CISK (HFET-6, NFS 100) CAVTT WTH YATER.

X5 TRANSFER CASK TO FUE UNLOADING POOL NO. 1

U

XE) MOVE FHU FROM STORLGE RACK TO CASK.

(x7) LOND SNF WN CASK, NSTRLL CASK LD.

(X8) RENOWE LOADED CASK FROM PCOL RINSE DRIP

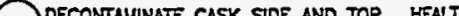

(X9) DECONTAHINMTE CASK SIDE AND TO REESE FOR FUTUE HORK.

X10) TRANSFER LONOED CASK RRON DECON ROOM NO.

X119) SHIP CASK LONDD WTH SNF TO DTC FAEIUTY
GLOSSARY

FHU - FUEL HANDLNG UNT

FSA = TUE STORAGE AREA

SNF = SPENT NUCLEAR TUI

DTC = DRT TRUNSFER CEI
NOTES

1. ROLL-UP DOORS ARE

2. OVERHES CRUNE "Cr CASK HANDUNG IN C

3. CASKS USED ARE NS HIGH LONO CHRG STR CHWRES NFS-100

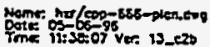

Figure A-2. CPP-666 cask and SNF handling plan view. 


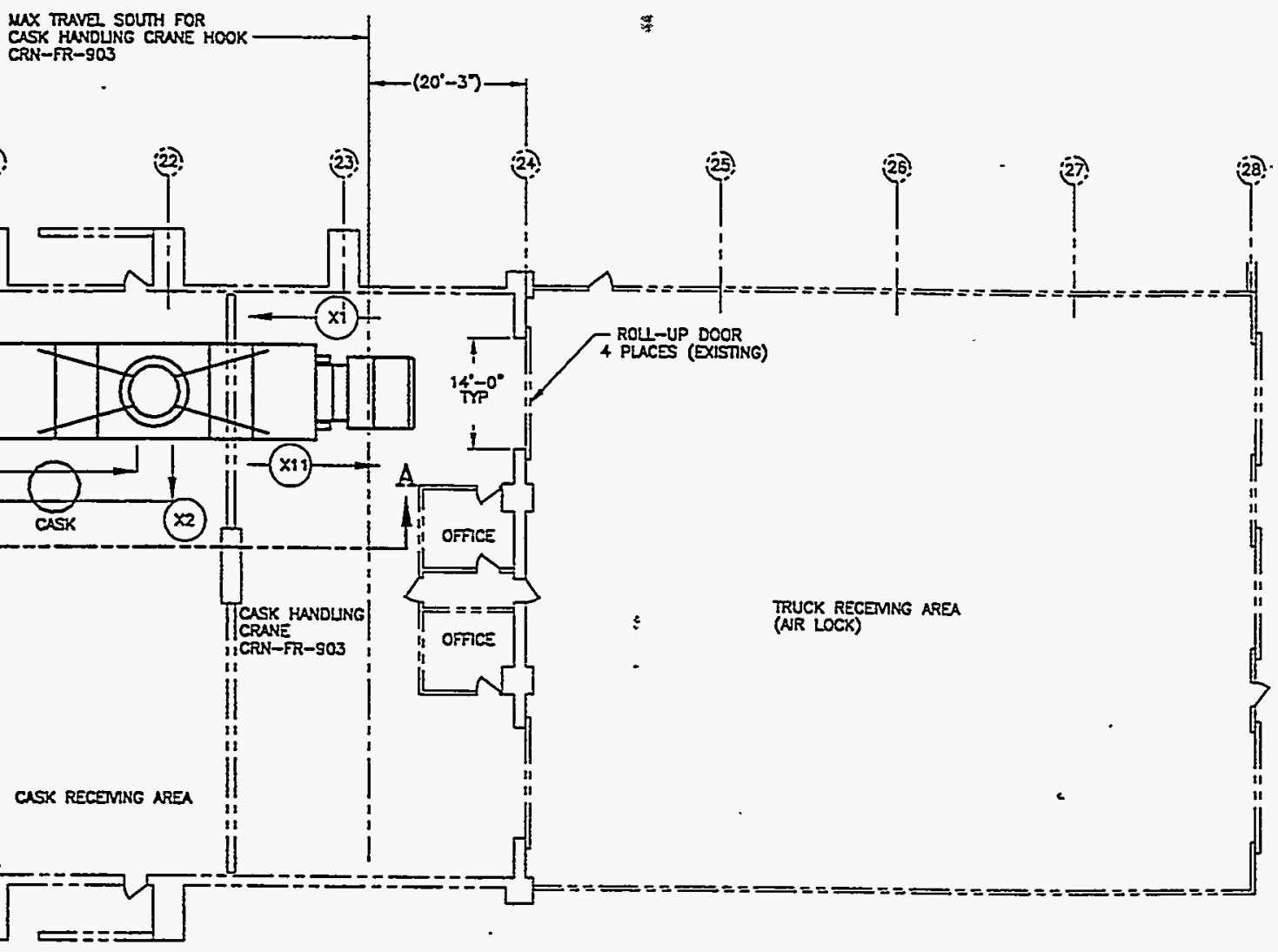




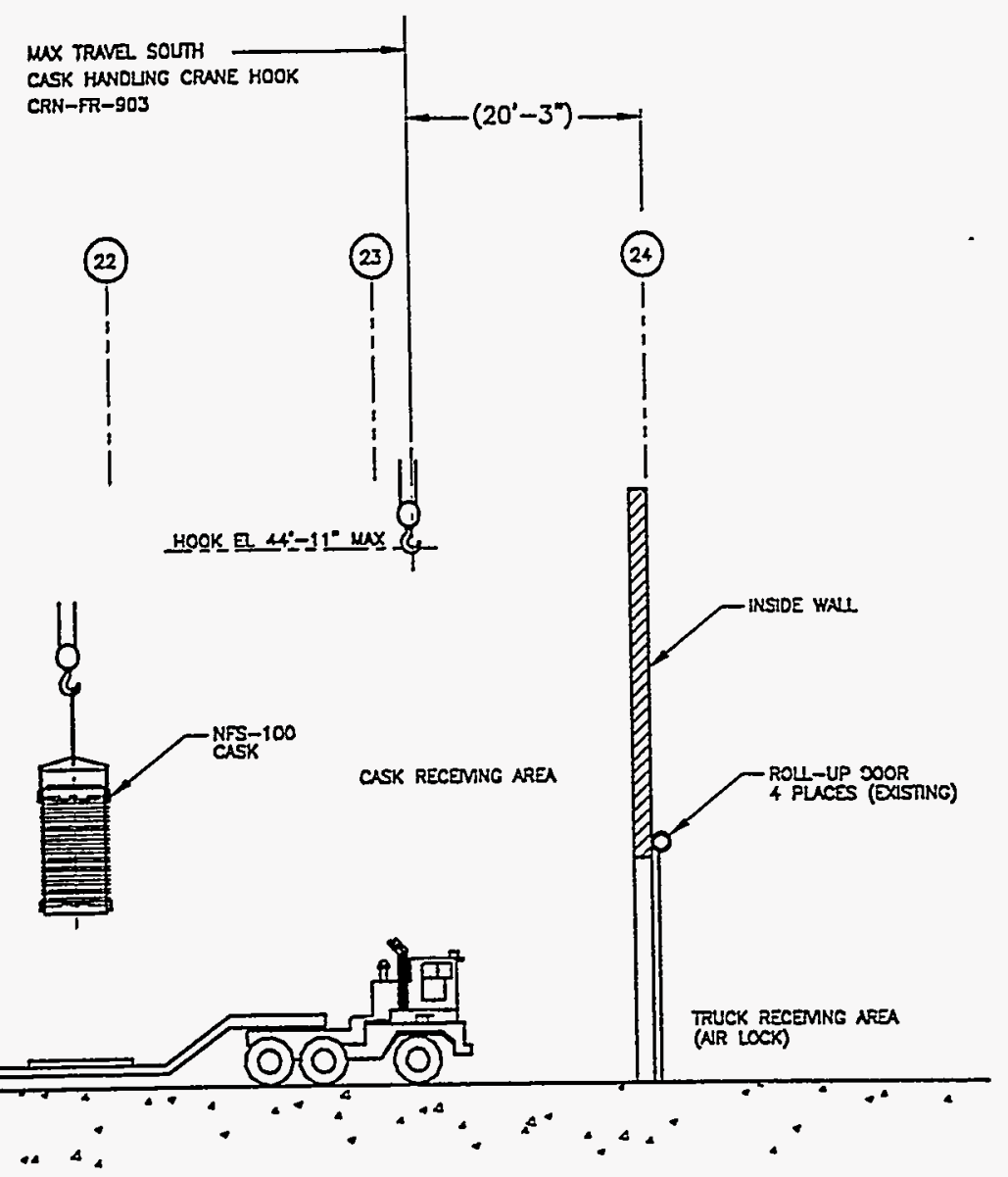



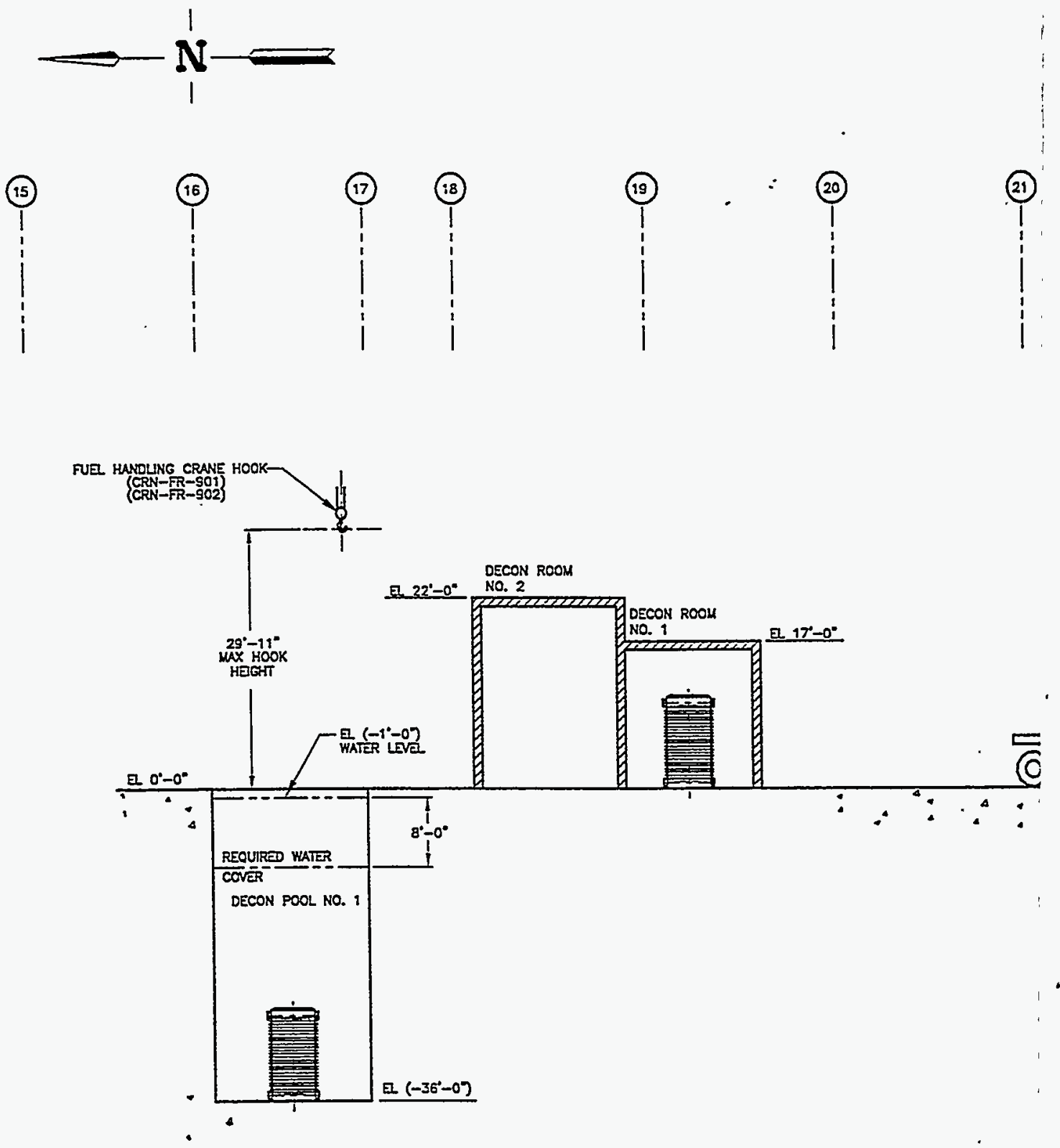

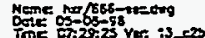

Figure A-3. CPP-666 cask and SNF handling section view. 

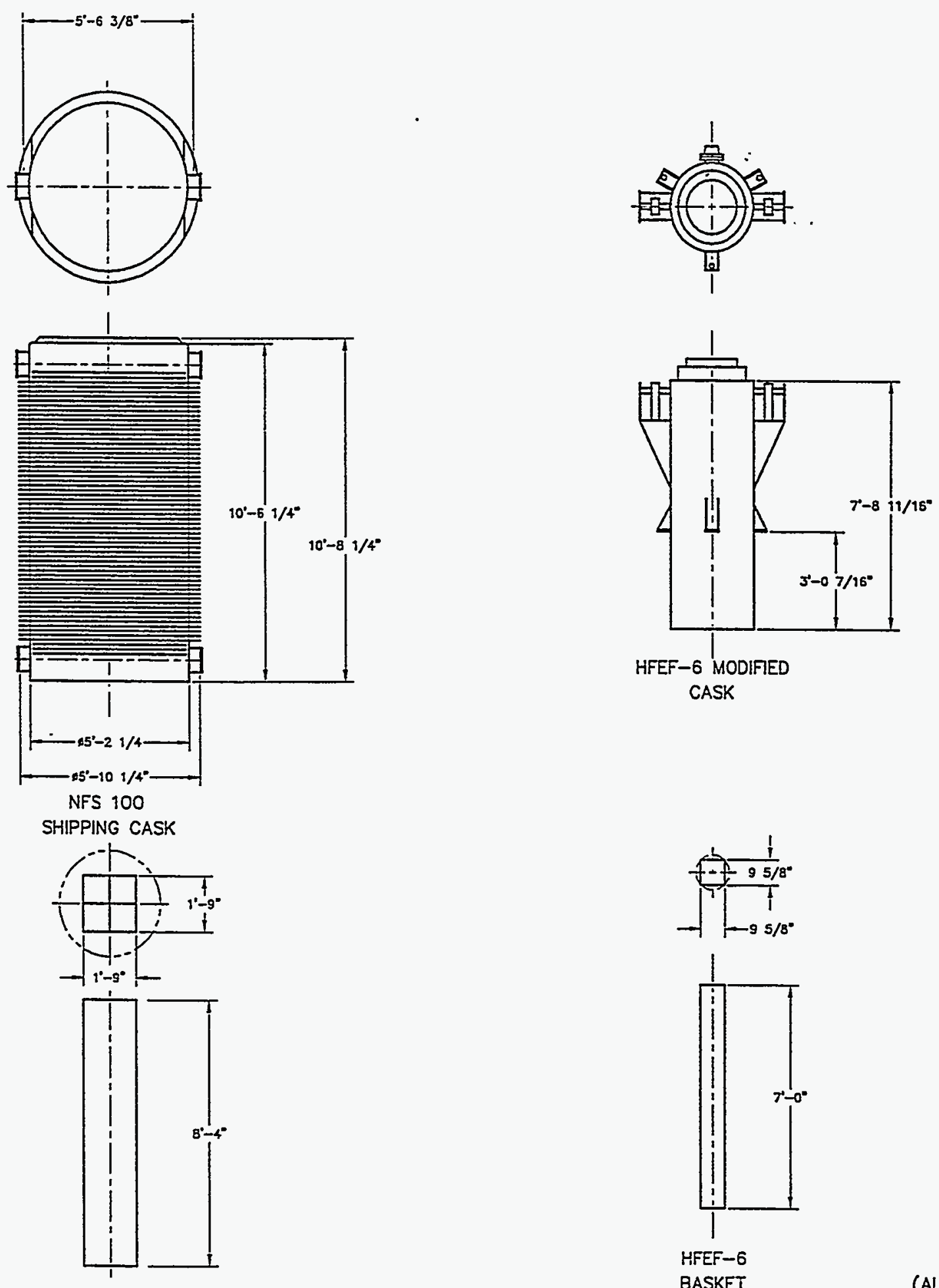

NFS 100

BASKET

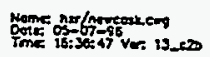

Figure A-4. Shipping casks and baskets. 

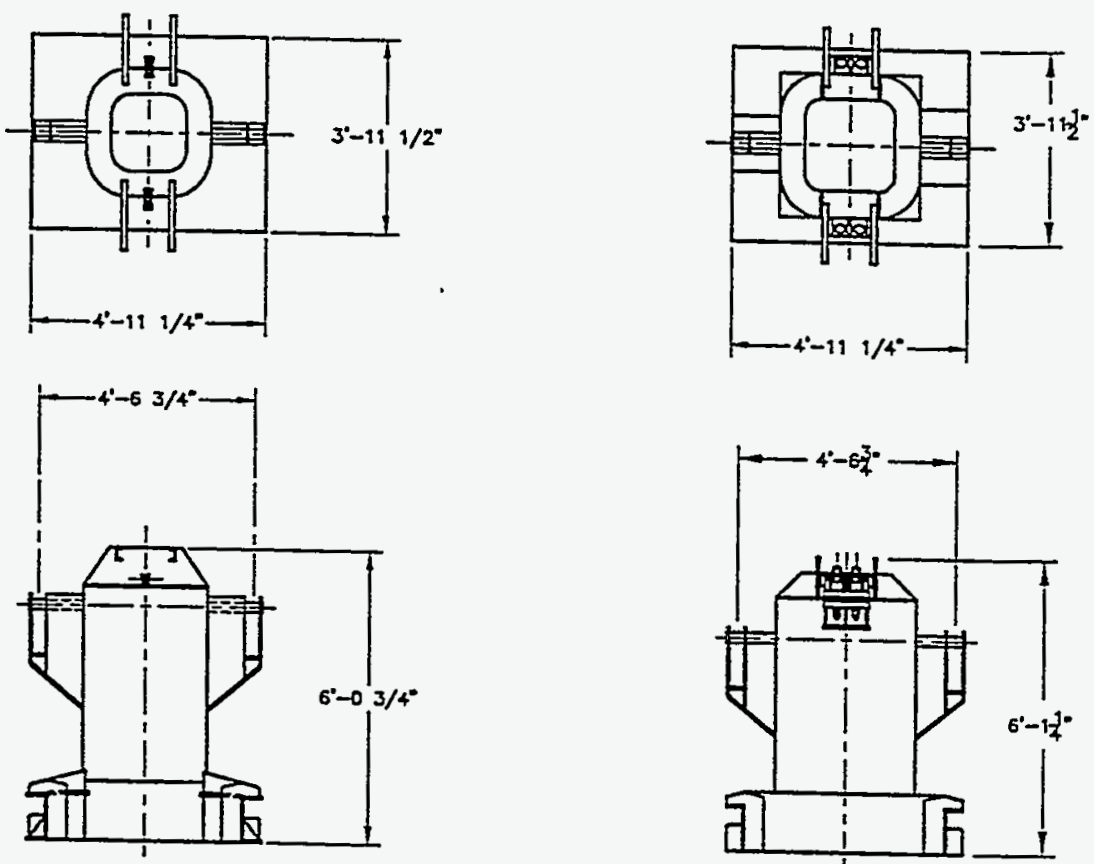

STR

CHARGING CASK

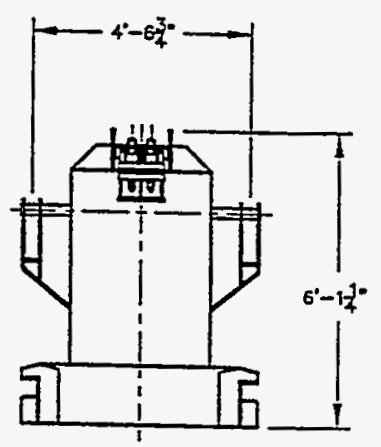

HIGH LOAD

CHARGING CASK
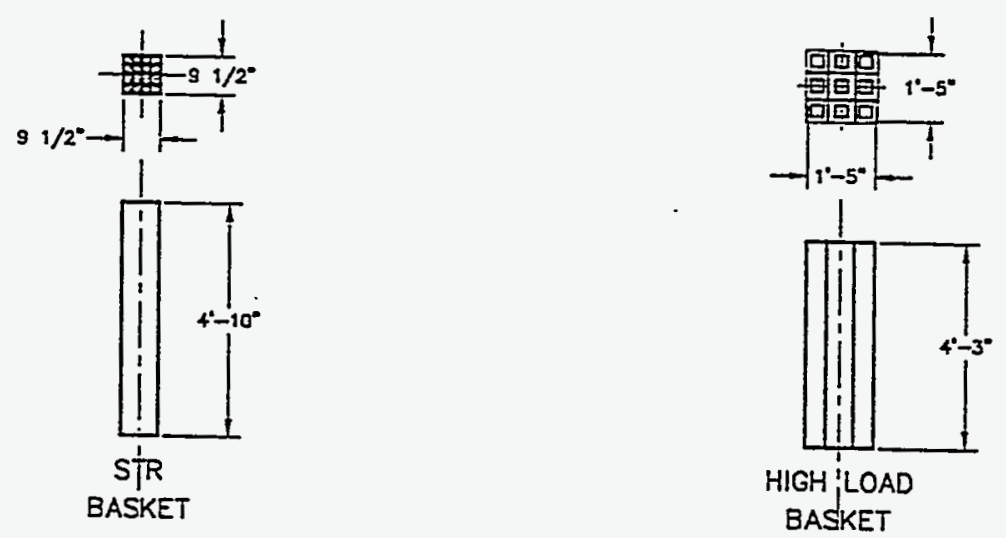

ENSIONS ARE FOR REFERENCE ONLY) 
Appendix B

Conceptual Design Criteria for the ICPP Spent Nuclear Fuel Dry Storage Project 
B-2 


\section{Appendix B}

\section{Conceptual Design Criteria for the ICPP Spent Nuclear Fuel Dry Storage Project}

\section{B-1. INTRODUCTION}

The INEL is committed to packaging existing and future spent nuclear fuel (SNF) and placing the packages in dry storage to comply with the Nuclear Regulatory Commission (NRC) requirements given in 10 CFR 72. The facility to package and store the SNF, an Independent Spent Fuel Storage Installation (ISFSI), is referred to herein as the SNF Dry Storage Facility. It comprises two principal parts: the Dry Transfer Cell, and the Dry Storage System (DSS). The Dry Storage Facility will be licensed by the NRC in accordance with $10 \mathrm{CFR} 72$. In addition, the fuel will be packaged such that it can be readily removed from storage and placed in a dedicated Type B shipping container. That package will be licensed in accordance with Department of Transportation (DOT) 49 CFR 173 and NRC 10 CFR 71.

This facility will receive DOE SNF that is contained in cladding or cans that are sufficiently sound to prevent direct exposure of the fuel material to the handling environment. The facility will be used to package the fuel for storage, place it in interim storage modules, and ultimately transfer the packages to offsite shipping casks. Key assumptions for the SNF Dry Storage Facility are listed in Attachment 1.

\section{B-2. REQUIREMENTS}

\section{B-2.1 General Requirements}

The SNF Dry Storage Facility shall comply with the requirements of ANSI/ANS 57.9.

\section{B-2.2 Operational Requirements}

1. The Dry Transfer Cell (DTC) shall transfer SNF from shipping casks to in-cell lag storage or dry storage canisters. The dry storage canisters shall be commercial dual-purpose canisters (DPCs), and shall be sealed and inerted for storage.

2. The DPCs shall provide one of two confinement barriers for the SNF as required during storage by 10 CFR 72.122 .

3. The DPCs shall have corrosion resistance equal to or greater than that of $\mathbf{3 0 0}$ series stainless steel.

4. The DTC shall have the capability to perform minor canning processes. These include the packaging of fuel elements, either already canned or in intact assemblies, in cans that are sealed to constitute the first of two confinement boundaries required by 10 CFR 72 . 
5. The DTC shall be sized to transfer fuel from a maximum of 12 incoming SNF shipping casks per month (see Table 1 for shipping cask descriptions), and to fill a maximum of two DPCs per month. The facility shall operate on a schedule of two 12-hour shifts per day.

6. Equipment shall be provided for drying, inerting, sealing, and leak checking the DPCs.

7. Equipment shall be provided to sample the gases in the shipping cask internal cavity before opening the cask, and for verifying leak tight conditions before returning the empty cask to the shipper.

8. The equipment within the transfer cell shall have remotely changeable components to handle various types of SNF, SNF baskets, SNF buckets, SNF cans, cask and canister lids and shield plugs, hot-cell lag storage shield plugs, and to perform cell and equipment decontamination.

9. A DSS comprising an outdoor above-ground concrete storage basemat, and suitable shielded, monitored, storage modules shall be provided. Loaded DPCs from the DTC shall be transported and placed into the storage modules on the storage basemat.

10. The DSS shall be designed to allow ready expansion throughout its life up to a maximum capacity of 240 DPCs.

11. Equipment shall include a site transfer cask to transport DPCs from the DTC to the storage basemat and to safely transfer the DPC from the transfer cask to the storage module on the storage basemat.

12. Equipment shall be provided so that the DPCs can be safely retrieved from the storage modules and placed in dedicated offsite shipping casks.

13. Control room, office, change room, and shower facilities shall be minimized to the extent practical for efficient operation.

14. Facility control, process control, and data acquisition systems shall be provided.

\section{B-2.3 Maintenance Requirements}

1. The DTC shall include features to support local maintenance of contaminated equipment. The hot cell shall be designed to be used as a manual contaminated-equipment maintenance area. Normal operation may be suspended during manual maintenance operations. The hot cell shall be capable of being decontaminated.

2. Breathing air facilities within the DTC shall be provided as necessary. 


\section{B-2.4 Design Life Requirements}

1. Design life of the SNF Dry Storage Facility and equipment shall be 30 years and have maintainable or replaceable life of 60 years.

2. The design life of the DPC shall be 100 years.

3. Design life of the Storage Facility shall be 60 years.

\section{B-2.5 Structural Requirements}

1. Structural design shall meet the requirements of ANSI/ANS 57.9.

2. Special features to provide handicapped access within the facility are not required.

\section{B-2.6 Interface Requirements}

1. The DTC shall receive SNF shipments by truck. Delivery by railcar shall not be precluded by the selected site.

2. The DTC shall include equipment to handle, unload, and interface with the MP-187 transfer cask and the shipping casks identified in Table 1. The design should be suitable for adaptation to other, yet-to-be-identified shipping casks whose size and weight are enveloped by those listed above.

3. The DTC handling equipment shall be able to interface and handle all SNF listed in Table 2.

4. The design of the DTC shall be such that ready access and space is assured for a future facility expansion to characterize and treat SNF (treatment may include SNF decanning, sizing, recanning, drying, and inerting).

5. The SNF Dry Storage Facility shall use existing ICPP utilities to the maximum extent supported by sound design and operating considerations.

6. DTC Siting shall be based on: access to existing utilities, use of existing roadways, access to existing security perimeters, and to a lesser extent, proximity to the storage basemat and access to a rail spur.

7. The Storage facility location shall be governed by available ground space at ICPP, integration with the TMI-2 fuel canister storage area, access to road, access to existing utilities, proximity to the DTC, and potential access to rail lines. 


\section{B-2.7 Specific Requirements}

1. The conceptual design shall include the Vectra NUHOMS system for horizontal storage of the DPCs.

\section{B-2.8 Safety Requirements}

\section{B-2.8.1 General}

1. Facility design features and physical controls shall ensure occupational exposure is maintained ALARA during normal and off-normal operations.

2. Personnel radiation exposure levels throughout the SNF Dry Storage Facility shall not exceed $0.125 \mathrm{mr} / \mathrm{hr}$ for continuously-occupied areas.

\section{B-2.8.2 Construction}

1. The design of utility services and distribution systems that are important to safety shall include redundant systems to the extent necessary to maintain, with adequate capacity, the ability to perform safety functions assuming a single failure ${ }^{a}$.

2. The Dry Storage Facility and its systems important to safety ${ }^{b}$ shall be designed to be evaluated by appropriate tests or by other means acceptable to the NRC to demonstrate that they will reasonably maintain confinement of radioactive material under normal, off-normal, and credible accident conditions.

3. Structures, systems, and components important to safety shall be designed and located so that they can continue to perform their safety functions effectively under credible fire and explosion exposure conditions.

4. The design of the Dry Storage Facility shall include provisions to protect against nuclear criticality that might otherwise result from the operation or the failure of fire suppression or decontamination systems.

a. A single failure is an occurrence that results in the loss of capability of a component to perform its intended safety function(s). A multiple failure, i.e., loss of capability of several components, resulting from a single occurrence, is considered to be a single failure. Systems are considered to be designed against an assumed single failure if neither (1) a single failure of any active component (assuming passive components function properly) nor, (2) a single failure of any passive component (assuming active components function properly) results in loss of the system's capability to perform its safety function(s).

b. Structures, systems, and components important to safety mean those features of the Storage Facility whose function is: (1) To maintain the conditions required to store spent fuel safely, (2) To prevent damage to the spent fuel waste container during handling and storage, or (3) To provide reasonable assurance that spent fuel can be received, handled, packaged, stored, and retrieved without undue risk to the health and safety of the public. 
5. Spent fuel handling, packaging, transfer, and storage systems shall be designed to be maintained subcritical under the worst case moderated and reflected conditions, and to ensure that, before a nuclear criticality accident is possible, at least two unlikely, independent, and concurrent or sequential changes must occur in the conditions essential to nuclear criticality safety.

6. The DPC and its internal structures and containers shall be designed to maintain the fuel in a favorable geometry for nuclear criticality safety throughout the operations and life of the system.

7. Each entrance or access point into a high radiation area shall have either a control device that energizes a conspicuous visible or audible alarm signal so that the individual entering the high radiation area and the supervisor of the activity are made aware of the entry; or entryways that are locked, except during periods when access to the areas is required, with positive control over each individual entry.

8. The spent fuel storage package shall be designed to provide adequate heat removal capacity without active cooling systems.

9. The DPC and its internal basket shall be designed to maintain the fuel and fuel cladding below the maximum allowable temperatures. Allowable temperatures $(380 \mathrm{C}$ for 5 -year old zirc or stainless clad fuel, $350 \mathrm{C}$ for 10-year old zirc or stainless clad fuel, $180 \mathrm{C}$ for aluminum clad/canned fuel) must be maintained in the Hot Cell lag storage, the MP-187 transfer cask, and in the storage modules at all ambient temperatures conditions to which the fuel may be exposed.

10. The radiation dose level at one meter from the exterior of the transfer cask (used to transport the loaded DPC to the DSS) shall be less than $200 \mathrm{mR} / \mathrm{hr}$.

11. To limit the size of the radiation area surrounding the DSS, and to maintain reasonable radiation levels during fuel transfers into and out of the storage modules, the radiation dose level at the exterior of any storage module filled with a fuel-bearing DPC(s), shall be less than $200 \mathrm{mR} / \mathrm{hr}$ at contact and less than $10 \mathrm{mR} / \mathrm{hr}$ at 1 meter.

12. SNF that is reactive with water or other chemicals shall be protected from exposure to those materials.

13. The fuel handling equipment shall be designed against single failure* resulting in dropping the fuel. Designs shall include appropriate redundancy and consider diversity to reduce the possibility of concurrent common-mode failures of redundant items.

14. The SNF Dry Storage Facility shall be designed to prevent the dropping of casks, SNF, SNF baskets/buckets/cans, and DPCs under normal and off normal conditions including the design basis accidents (DBAs) that they shall withstand. 
15. The SNF Dry Storage Facility shall be designed to be able to recover from accidents involving dropping of casks, SNF, SNF baskets/buckets/cans, and DPCs.

16. In-cell equipment shall be designed for recovery from all possible conditions to the extent that manned entry into the cell, for maintenance, can be accomplished.

17. If a fuel grapple is supporting the weight of the fuel, the grapple shall be interlocked so that it can not disengage from the crane (or overhead manipulator) or fuel to which it is connected even if the normal control command to do so is inadvertently given. A means of defeating this interlock shall be provided to ensure the grapple can be disengaged at any time even if the full weight of the fuel is on the grapple

\section{B-2.8.3 Operation}

1. Provisions shall be made to enable surveying the external surfaces of the shipping casks for radiation levels and radioactive contamination as soon as practical after receipt of the package, but not later than 3 hours after the package is received at the ICPP if it is received during normal working hours, or not later than 3 hours after the beginning of the next working day if it is received after working hours.

2. Nuclear criticality monitors, constant air monitors, remote area monitors, fire alarm, and emergency voice notification shall be connected with the existing ICPP alarm system.

3. Radiation protection for occupational workers shall be per 10 CFR 835 (Occupational Radiation Protection) and the INEL Radiation Control Manual.

4. Fire protection shall be in accordance with ANSI/ANS-57.9.

\section{B-2.9 Environmental Requirements}

1. Facility emission limits shall be consistent with the INEL Environmental Restoration and Waste Management Programs Final Environmental Impact Statement, DOE/EIS-0203-F.

2. Administrative controls and Best Available Control Technology shall be used to minimize the impacts of air emissions.

3. The facility processes and equipment shall be designed to limit solid waste generation to $115 \mathrm{~m}^{3}$ per year of LLW and $250 \mathrm{~m}^{3}$ per year of industrial (cold) waste.

4. Solid radioactive waste produced by SNF Dry Storage Facility operations shall be packaged in standard RWMC $4 \times 4 \times 8$-ft plywood boxes for contact-handled (CH) LLW or INEL Mark III concrete containers for remote-handled (RH) LLW, and shipped to RWMC for disposal. 
5. Means for measuring the amount and concentrations of radionuclides in effluents during normal operations, and under accident conditions, shall be provided for effluent control systems.

6. DTC warm liquid waste shall be controlled and verified to meet the criteria for existing ICPP handling systems, and shall be transferred to those systems.

7. If all or part of the facility is located outside of existing ICPP fences, the use of new land shall not exceed 551 acres when combined with other storage systems included in DOE/EIS-0203-F.

\section{B-2.10 Safeguards and Security}

1. A data management system shall be provided to keep records showing the receipt, inventory, transfer, and disposal of all SNF in storage. The records shall include, as a minimum, the name of the fuel shipper, the estimated quantity of radioactive material per item (including special nuclear material in spent fuel), item identification and serial number, storage location, on-site movements and locations of each fuel assembly or DPC, and final shipment to an offsite location.

2. Dual records shall be maintained to ensure an off-normal event cannot result in the loss of the sole records of SNF inventories. These records for spent fuel shall be retained for as long as the material is stored, and for a period of five years after the material is disposed of or transferred out of the Storage Facility.

3. Equipment shall be provided to conduct a physical inventory of all spent fuel and high-level radioactive waste in storage at intervals not to exceed 12 months unless otherwise directed by the Commission. A copy of the current inventory shall be retained as a record until the Commission terminates the license.

\section{B-2.11 Quality Assurance Requirements}

1. Quality assurance (QA) requirements for the SNF Dry Storage Facility are identified in ANSI/ANS 57.9, Section 6.15.

\section{B-3 CODES AND STANDARDS}

\section{B-3.1 Code of Federal Regulations}

10 CFR 71 Packaging and Transportation of Radioactive Material

10 CFR 72 Licensing Requirements for the Independent Storage of Spent Nuclear Fuel and High-Level Radioactive Waste 
49 CFR 173 Shippers-General Requirements for Shipments and Packagings

\section{B-3.2 National Codes and Standards}

ANSI/ANS-57.9 Design Criteria for an Independent Spent Fuel

Storage Installation (Dry Type)

\section{B-4. REFERENCES}

INEL Environmental Restoration and Waste Management Programs Final Environmental Impact Statement, DOE/EIS-0203-F. 
Appendix C

Project Design Criteria for the Spent Nuclear Fuel Dry Storage Project 


\section{ABSTRACT}

This document gives the project design criteria for the spent nuclear fuel dry storage proposed design. The primary purpose of the document is to establish the technical baseline for title design. The specific criteria were developed from the conceptual design. 



\section{CONTENTS}

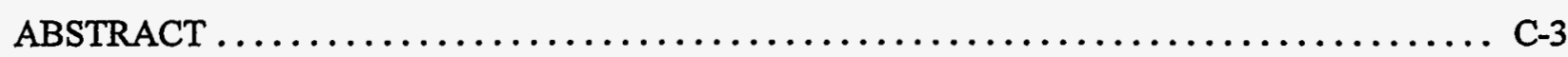

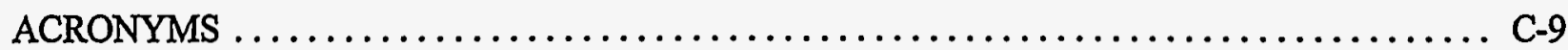

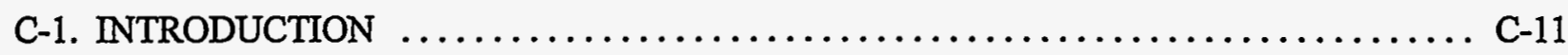

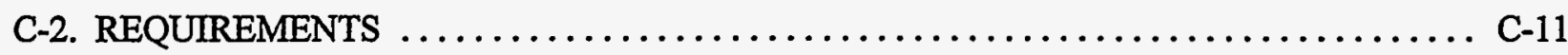

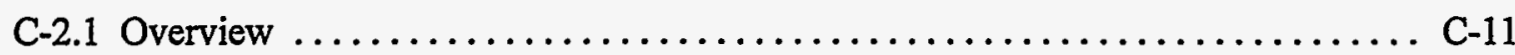

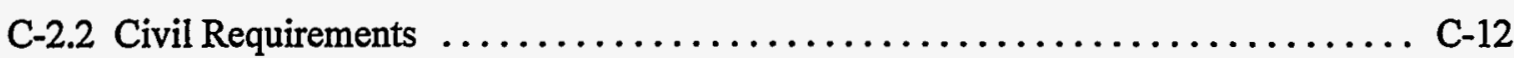

C-2.2.1 General $\ldots \ldots \ldots \ldots \ldots \ldots \ldots \ldots \ldots \ldots \ldots \ldots \ldots \ldots \ldots, \mathrm{C}-12$

C-2.2.2 Surface Drainage $\ldots \ldots \ldots \ldots \ldots \ldots \ldots \ldots \ldots \ldots \ldots \ldots, \mathrm{C}-13$

C-2.2.3 Rock Excavation $\ldots \ldots \ldots \ldots \ldots \ldots \ldots \ldots \ldots \ldots \ldots \ldots, \mathrm{C}-13$

C-2.2.4 Soil Excavation and Shoring $\ldots \ldots \ldots \ldots \ldots \ldots \ldots \ldots \ldots, \mathrm{C}-13$

C-2.2.5 Finish Grading $\ldots \ldots \ldots \ldots \ldots \ldots \ldots \ldots \ldots \ldots \ldots \ldots \ldots \ldots \ldots, \mathrm{C}-13$

C-2.2.6 Paving $\ldots \ldots \ldots \ldots \ldots \ldots \ldots \ldots \ldots \ldots \ldots \ldots \ldots \ldots \ldots \ldots \ldots \ldots \ldots, \mathrm{C}-13$

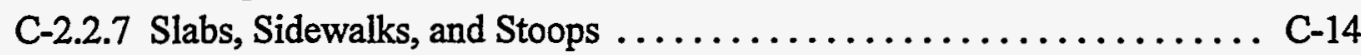

C-2.2.8 Fencing $\ldots \ldots \ldots \ldots \ldots \ldots \ldots \ldots \ldots \ldots \ldots \ldots \ldots \ldots \ldots \ldots, \mathrm{C}-14$

C-2.2.9 Underground Utilities $\ldots \ldots \ldots \ldots \ldots \ldots \ldots \ldots \ldots \ldots \ldots, \mathrm{C}-14$

C-2.2.10 Site Demolition ............................. C-14

C-2.3 Architectural Requirements $\ldots \ldots \ldots \ldots \ldots \ldots \ldots \ldots \ldots \ldots \ldots \ldots \ldots \ldots \ldots \ldots \ldots, C-14$

C-2.3.1 General $\ldots \ldots \ldots \ldots \ldots \ldots \ldots \ldots \ldots \ldots \ldots \ldots \ldots \ldots \ldots, \mathrm{C}-14$

C-2.3.2 Building Features $\ldots \ldots \ldots \ldots \ldots \ldots \ldots \ldots \ldots \ldots \ldots, \mathrm{C}-18$

C-2.4 Structural Requirements $\ldots \ldots \ldots \ldots \ldots \ldots \ldots \ldots \ldots \ldots \ldots \ldots \ldots \ldots \ldots \ldots \ldots \ldots \ldots \ldots, C-18$

C-2.4.1 General ................................... C-18

C-2.4.2 Classification and Design Loads $\ldots \ldots \ldots \ldots \ldots \ldots \ldots \ldots \ldots . . .19$

C-2.4.3 Footings and Foundations .......................... C-19

C-2.4.4 Structural Framing Systems . . . . . . . . . .

C-2.4.5 Special Structural Features $\ldots \ldots \ldots \ldots \ldots \ldots \ldots \ldots \ldots \ldots, \mathrm{C}-20$

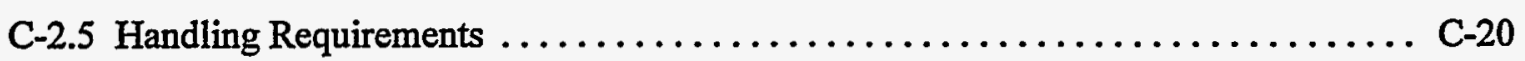

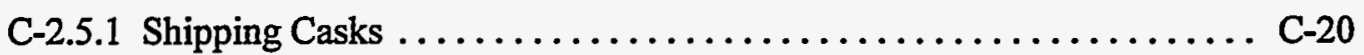

C-2.5.2 Multipurpose Transfer Cask and Transporter .............. C-20

C-2.5.3 Cask Handling Equipment $\ldots \ldots \ldots \ldots \ldots \ldots \ldots \ldots \ldots \ldots, \mathrm{C}-20$

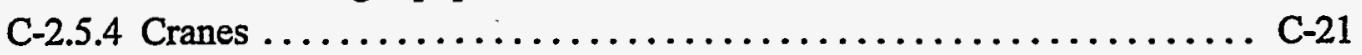

C-2.5.5 Cask Work Platforms . ......................... C-24 
C-2.6.1 Canning System

C-2.7 Storage Area Requirements

C-2.7.1 Basemat and Horizontal Storage Modules .............. C-27

C-2.7.2 Dual Purpose Canisters . ....................... C-28

C-2.7.3 DPC Baskets ............................... C-28

C-2.7.4 Dry Storage Buckets . . . . . . . . . . . . . . . . . . . C-29

C-2.7.5 Dry Storage Cans . ........................ C-29

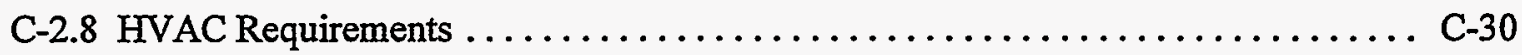

C-2.9 Mechanical Utilities Requirements $\ldots \ldots \ldots \ldots \ldots \ldots \ldots \ldots \ldots \ldots \ldots \ldots \ldots \ldots \ldots \ldots$

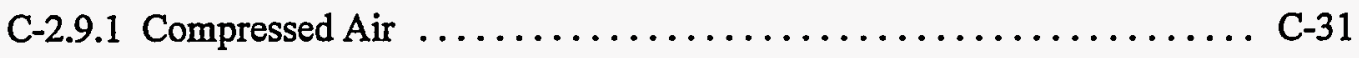

C-2.9.2 Compressed Gas .......................... C-31

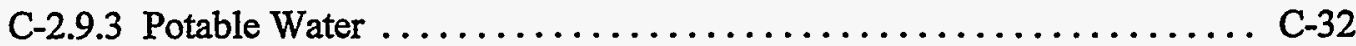

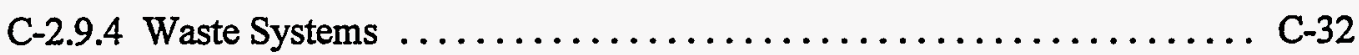

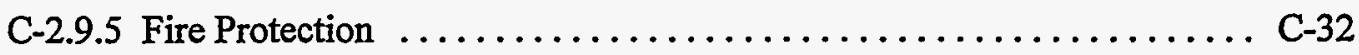

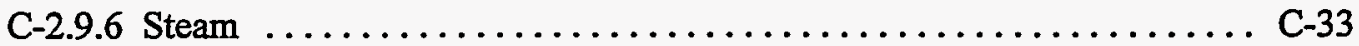

C-2.10 Electrical Requirements $\ldots \ldots \ldots \ldots \ldots \ldots \ldots \ldots \ldots \ldots \ldots \ldots \ldots \ldots \ldots \ldots \ldots \ldots \ldots \ldots$

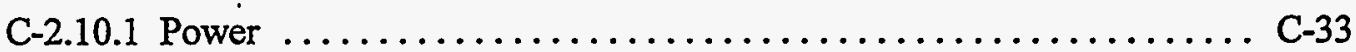

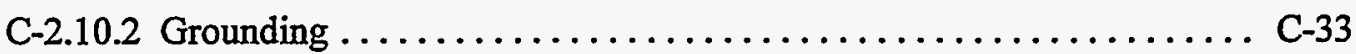

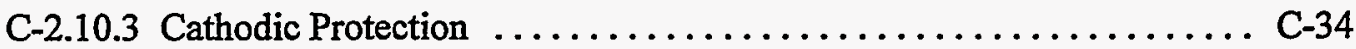

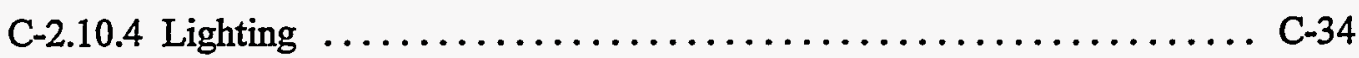

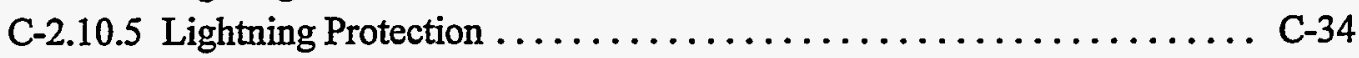

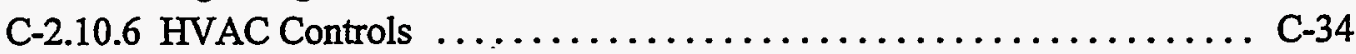

C-2.10.7 Equipment Controls ........................ C-34

C-2.10.8 Radiation Monitoring and Alarms . .................. C-35

C-2.10.9 Communications and Alarms ...................... C-35

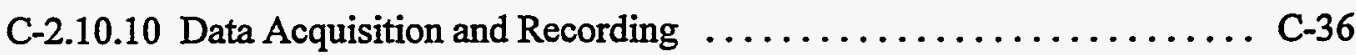

C-2.10.11 Security Systems $\ldots \ldots \ldots \ldots \ldots \ldots \ldots \ldots \ldots \ldots \ldots \ldots \ldots \ldots \ldots \ldots \ldots \ldots$

C-2.11 Design Life Requirements $\ldots \ldots \ldots \ldots \ldots \ldots \ldots \ldots \ldots \ldots \ldots \ldots \ldots \ldots \ldots \ldots \ldots$

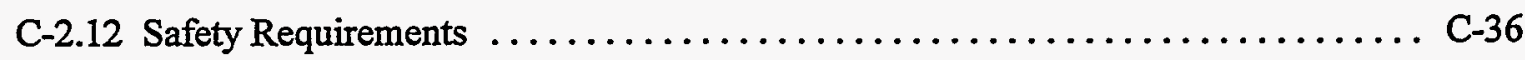

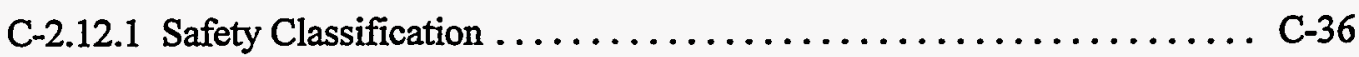

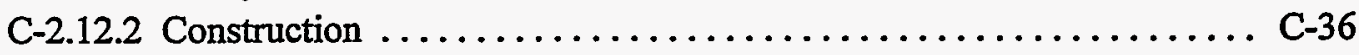

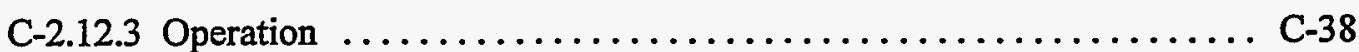




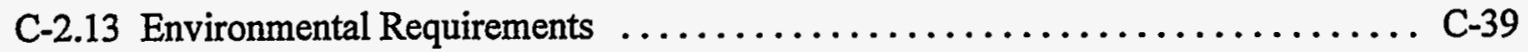

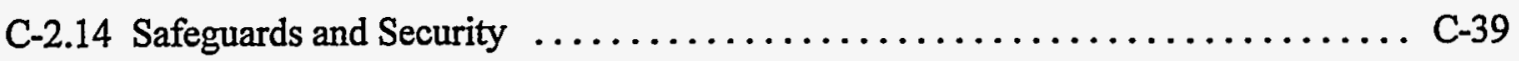

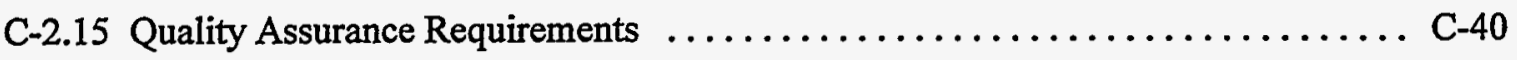

C-3. CODES AND STANDARDS $\ldots \ldots \ldots \ldots \ldots \ldots \ldots \ldots \ldots \ldots \ldots \ldots \ldots \ldots \ldots \ldots \ldots \ldots \ldots \ldots \ldots, 41$

C-3.1 General ....................................... C-41

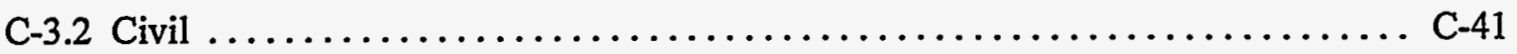

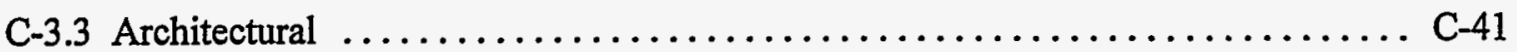

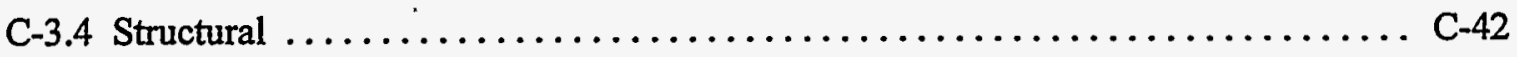

C-3.5 Handling $. \ldots \ldots \ldots \ldots \ldots \ldots \ldots \ldots \ldots \ldots \ldots \ldots \ldots \ldots \ldots \ldots \ldots \ldots \ldots \ldots \ldots, \mathrm{C}-42$

C-3.6 SNF Packaging Systems $\ldots \ldots \ldots \ldots \ldots \ldots \ldots \ldots \ldots \ldots \ldots \ldots \ldots \ldots, \mathrm{C}-43$

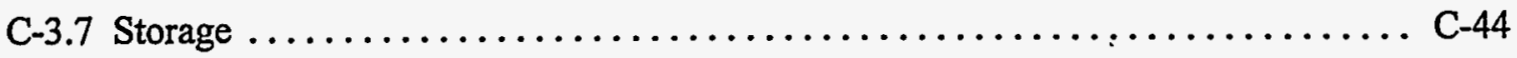

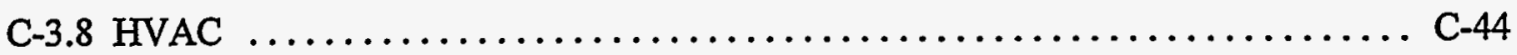

C-3.9 Mechanical Utilities . . . . . . . . . . . . . . . . . . . .

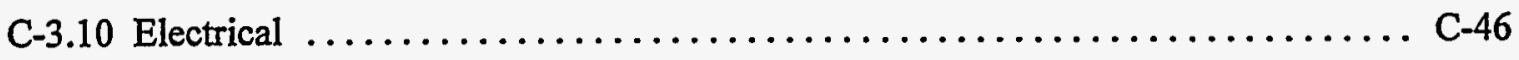

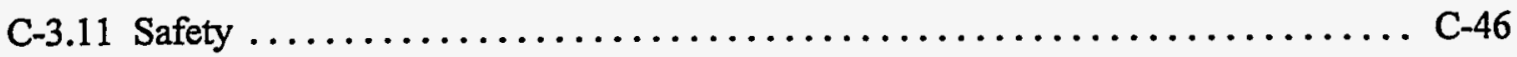

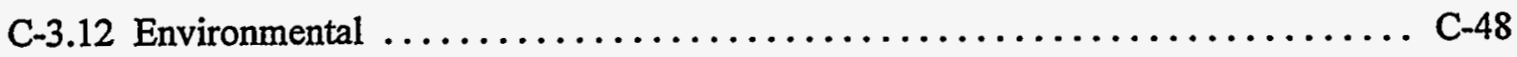

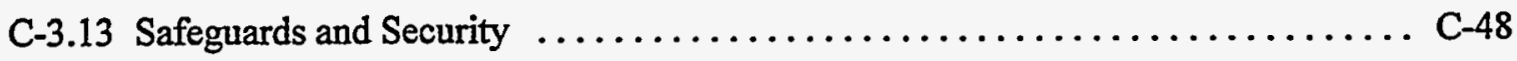

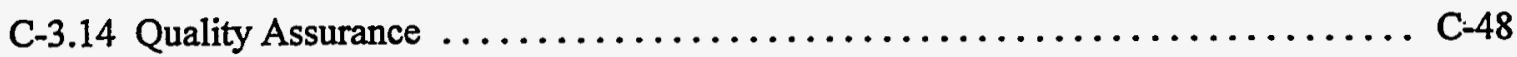


C-8 


\section{ACRONYMS}

CFR Code of Federal Regulations

DOE Department of Energy

DOT Department of Transportation

DSF Dry Storage Facility

DTC Dry Transfer Cell

DPC Dual Purpose Canister

HSM Horizontal Storage Module

ICPP Idaho Chemical Processing Plant

INEL Idaho National Engineering Laboratory

ISFSI Independent Spent Fuel Storage Installation

NRC Nuclear Regulatory Commission

SNF spent nuclear fuel

TMI Three Mile Island

UBC Uniform Building Code

UPS Uninterruptable Power Supply 


\section{Appendix C \\ Project Design Criteria for the \\ Spent Nuclear Fuel Dry Storage Project}

\section{C-1. INTRODUCTION}

The Idaho National Engineering Laboratory (INEL) is committed to packaging existing and future spent nuclear fuel (SNF) and placing the packages in dry storage to comply with the Nuclear Regulatory Commission (NRC) requirements given in 10 Code of Federal Regulations (CFR) 72. The facility to package and store the SNF, an Independent Spent Fuel Storage Installation (ISFSI), is referred to herein as the SNF Dry Storage Facility (DSF). It comprises two principal parts: the Dry Transfer Cell (DTC), and the Storage Area. The DSF will be licensed by the NRC in accordance with 10 CFR 72. In addition, the fuel will be packaged such that it can be readily removed from storage and placed in a dedicated Type B shipping container. That package will be licensed in accordance with Department of Transportation (DOT) 49 CFR 173 and 10 CFR 71.

The DSF will receive Department of Energy (DOE) SNF that is contained in cladding or cans that are sufficiently sound to prevent direct exposure of the fuel material to the handling environment. The facility will be used to package the fuel for storage, place it in interim storage modules, and ultimately transfer the packages to offsite shipping casks.

\section{C-2. REQUIREMENTS}

\section{C-2.1 Overview}

The criteria contained in this document are based on the facility concept that is presented in the SNF Dry Storage Project Conceptual Design Report. As the design is developed further, some of the criteria may become nonapplicable, and others will be identified.

This overview of the concept is provided as an aid in understanding the context in which the criteria are imposed.

The facility will consist of two primary structures: The Dry Transfer Cell (DTC) and the Dry Storage System (DSS).

- The DTC contains four general areas: an Administrative Area, Cask Handling Bay, Cask Preparation Area, and Hot Cell.

The Administrative Area contains typical office and support functions.

The Cask Handling Bay will receive shipping casks, unload them from their transport vehicle, and place them vertically on an electrically driven trolley for transfer into the rest of the 
facility. All cask operations will be performed while the cask remains on the trolley. The Handling Bay will also be used for loading filled transfer casks onto the onsite transfer trailer.

The Cask Preparation Area will receive a shipping cask from the trolley. In the Cask Preparation Area, the outer lids will be removed, gas samples taken from the cask cavity, and preparation made to move the cask into the Hot Cell for fuel unloading. The Cask Preparation Area will also be used to prepare the shipping cask for return to the shipping facility. These operations include inspection and cleaning, replacement of cask lids, and leak testing before shipping.

The Hot Cell is heavily shielded and will receive the shipping cask, still on the trolley, for unloading. Frequent personnel entry into the cell will be made for final cask preparation, placement of contamination barriers, and equipment maintenance. The fuel will be transferred using a remotely operated crane with a suite of end effectors used to grapple a wide variety of SNF configurations. The fuel will typically be transferred to one of four lag storage vaults for temporary storage until an appropriate inventory of SNF is accumulated to fill a Dual-Purpose Canister (DPC).

When sufficient fuel is accumulated, a DPC will be brought through the Preparation Area (on a trolley and in a vertically oriented transfer cask) and into the Hot Cell. Fuel will be transferred from the lag storage vaults into the DPC, while the DPC remains in the transfer cask. The fuel will be placed in the DPCs which, like the lag storage vaults, contain baskets to support the various SNF packages. When the DPC is full, a shield plug will be inserted and the DPC moved on the trolley back to the Cask Preparation Area. In the Cask Preparation Area, the first of two lids will be welded onto the DPC, the internal cavity will be purged and inerted with a gas, and a second lid will be welded in place. The sealed DPC will then be moved out to the Cask Handling Bay.

At the loading dock the DPC and transfer cask will be loaded, in a horizontal position, onto the onsite transfer trailer and towed to the Storage Facility.

- The DSS includes the transfer cask and trailer, a concrete basemat, asphalt driveways, and shielded storage modules. The DSS employs the NUHOMS $®$ horizontal dry storage system. In this concept, the dry storage canister in the transfer cask will be moved into alignment with a storage module that contains a cavity into which the DPC is pushed using a hydraulic ram mounted on the transfer vehicle. A shield door will be lowered over the cavity opening and welded in place.

\section{C-2.2 Civil Requirements}

\section{C-2.2.1 General}

- A suitable site shall be located for the Dry Fuel Transfer Facility at the INEL in the vicinity of the Idaho Chemical Processing Plant (ICPP) 
- $\quad$ Siting shall take into account the Three Mile Island-2 (TMI-2) storage project needs as well

- All civil designs shall be in accordance with 10 CFR 72, Licensing Requirements for the Independent Storage of Spent Nuclear Fuel, Subpart E (Siting Evaluation Factors) and Subpart F (General Design Criteria)

- All civil designs shall meet the requirements of ANSI/ANS 57.9-1992, Design Criteria for an Independent Spent Fuel Storage Installation (Dry Type).

\section{C-2.2.2 Surface Drainage}

- Surface drainage shall be taken into account when the siting location is chosen

- Surface drainage should be consistent with the site drainage plan and current ICPP controls.

\section{C-2.2.3 Rock Excavation}

- A soils investigation shall be conducted to determine soil properties for design.

\section{C-2.2.4 Soil Excavation and Shoring}

- Soil excavation and shoring shall be performed at the chosen site for clearing, grubbing, and grading the site.

\section{C-2.2.5 Finish Grading}

- Finish grading shall be performed and shall properly locate the storage module inlet vents above the 100 yr. flood elevation

- Finish grading shall be performed to allow proper drainage.

\section{C-2.2.6 Paving}

- Paving shall be provided for the storage area, around the building, for parking areas, and for the access roads

- Paving for vehicle traffic areas shall be designed and constructed for a minimum vehicle load for an AASHTO HS-20 loading

- Roadways shall be a minimum of $15 \mathrm{ft}$ wide

- The basemat, approach slab, and roadways shall be designed to include all loads associated with the transfer operations of the storage modules. 


\section{C-2.2.7 Slabs, Sidewalks, and Stoops}

- Sidewalks, door stoops, and approaches shall be provided as needed

- Guard posts shall be provided at all vehicle entrances to the facility.

\section{C-2.2.8 Fencing}

- Fencing shall be provided around the facility

- Fencing shall be grounded

- Fencing shall be a minimum height of $7 \mathrm{ft}$

- Fencing shall be topped with three strands of barbed wire.

\section{C-2.2.9 Underground Utilities}

- Existing underground ICPP utilities shall be extended as necessary to provide necessary services

- Siting shall take into account existing underground utilities.

\section{C-2.2.10 Site Demolition}

- Site demolition may be required, depending on the site location.

\section{C-2.3 Architectural Requirements}

\section{C-2.3.1 General}

- Architectural designs shall be in accordance with 10 CFR 72, Licensing Requirements for the Independent Storage of Spent Nuclear Fuel, Subpart F (General Design Criteria) and Subpart K (General License for Storage of Spent Fuel at Power Reactor Sites)

- Architectural designs shall meet the requirements of ANSI/ANS 57.9-1992, Design Criteria for an Independent Spent Fuel Storage Installation (Dry Type)

- Architectural designs shall be in accordance with 29 CFR 1910, Occupational Safety and Health Standards for General Industry, Subpart D (Walking-Working Surfaces) and Subpart E (Means of Egress). 


\section{C-2.3.1.1 Cask Handling Bay.}

- The Cask Handling Bay shall provide for receipt and shipment of SNF and it's transportation package as well as any associated decontamination, maintenance, and storage activities

- The Cask Handling Bay shall contain a truck bay, laydown area, and cask staging area and shall be sized in accordance with estimated equipment size and the cask shipping schedule

- Cask Handling Bay design shall be based upon a Uniform Building Code (UBC) occupancy classification of Class S-2.

Truck Bay

- The truck bay must interface with the transport trucks

- The truck bay shall support wash down activities of the transport vehicle and shipping covers.

\section{Laydown Area}

- Adequate space shall be provided for storing portable personnel barriers, over-packs, impact limiters shipping covers, shipment of low-level waste, lifting fixtures, special tools, and transportation package appurtenances

Cask Staging Area

- A means shall be provided for cask maintenance and moving transfer carts into and out of the Cask Preparation Area and Hot Cell.

\section{C-2.3.1.2 Cask Preparation Area.}

- Cask Preparation Area design shall be based upon a UBC occupancy classification of Class H-7

- Sufficient space shall be provided for preparation, welding, gas sampling, maintenance, and decontamination activities of the casks (all potential sizes) entering and exiting the Hot Cell. Sizing shall be based on equipment sizes and shipment schedule

- If contamination or shielding barriers are to be used, the Cask Preparation Area shall include storage space for these barriers. 


\section{C-2.3.1.3 Hot Cell.}

- Hot Cell design shall be based upon a UBC occupancy classification of Class H-7.

- Sufficient space shall be provided for transfer of dry SNF from the shipping casks to the DPC casks or Lag Storage and a Canning Ärea.

- The Hot Cell shall include shielded and decontaminable walls, floors and ceilings as appropriate for remote handling devices, viewing windows, and closed circuit television monitoring to permit removal and insertion of fuel units into or out of transportation packages or transfer carts.

- A buffer area shall be required for personnel entering and exiting the cell.

- A work area shall be provided for welding and lid inspection of the transfer cask in the transfer cask bay.

- Sufficient space for a canning area shall be provided, including decontamination activities.

- Shielded view windows shall be provided for remote canning operations and SNF transfer.

- Sufficient space for a transfer system shall be provided.

- A Lag Storage Area shall be provided to hold SNF between shipments when necessary to optimize the final storage package.

- The ports shall provide sufficient shielding to protect personnel from gamma and neutron radiation. The dose rate at the exterior of the Hot Cell wall in the operating gallery shall be below $0.125 \mathrm{mrem} / \mathrm{hr}$. The dose rate in the Hot Cell above the lag storage ports may be at a level of $5 \mathrm{mrem} / \mathrm{hr}$.

- Cooling for the SNF in the Lag Storage Area shall be incorporated into the design. In order to reduce the cooling requirements for fuel within the lag storage ports, the two hottest fuels, Shippingport PWR and FSVR, shall not be placed in lag storage.

- Each Lag Storage port shall have a shield lid. The Lag storage area shall allow for storage space of the shield lids when they are removed.

- The ports shall provide unobstructed draining for any water that might enter the Hot Cell sump.

- The liners shall be decontaminatable.

- Each lag storage port shall have ventilation passages to maintain the fuel clad temperature below $340^{\circ} \mathrm{C}$. 


\section{C-2.3.1.4 Buffer Area.}

- Buffer Area design shall be based upon a UBC occupancy classification of Class H-7

- Facilities for changing anti-c clothing and personnel monitoring (frisking) devices shall be provided adjacent to the cell

- A buffer area shall be provided for a shielding labyrinth leading from the Hot Cell to the . Buffer Area and then to the Anti-C Change Room

- These areas shall be separated from each other and the pressure barriers maintained

- The Buffer Area shall provide space for discarded protective clothing used in the Hot Cell and a step off pad for frisking of contamination by PCM machine

- All surfaces in the Buffer Area shall be decontaminable as well as the floors and walls of the Anti-C room.

\section{C-2.3.1.5 Operating Galleries.}

- Operating Galleries design shall be based upon a UBC occupancy classification of Class H-7

- Operating galleries shall be provided as required by view angles

- Operating galleries shall be separated from the Hot Cell by a concrete shielded wall

- Space and utilities shall be provided to accommodate remote equipment operations.

\section{C-2.3.1.6 Utility Support Areas.}

- Utility Support Areas design shall be based upon a UBC occupancy classification of Class $\mathrm{H}-7$

- Utility support areas shall be provided for the HEPA Filter, mechanical utilities, electrical Panels, UPS, communication systems, and welding operations utilities $-\mathrm{H}-7$ pending.

\section{C-2.3.1.7 Crane Maintenance Areas.}

- Crane maintenance areas shall be provided to support maintenance of all three cranes.

\section{C-2.3.1.8 Administrative Areas.}

- Administrative Area design shall be based upon a UBC occupancy classification of Class B

- Office and support areas shall be provided for facility personnel, including a supervisor 
- Office areas shall be provided with lighting, electrical receptacles, local area network, and phone

- $\quad$ A Ready Room shall be provided for conduct of meetings and work breaks.

- Men's and women's lavatories, showers, lockers, and change facilities shall be provided

- Storage and a janitor's room shall be provided.

\section{C-2.3.2 Building Features}

- All areas within the facility will be in a controlled environment provided by the HVAC and filtering systems (see HVAC requirements-Section 2.8)

- The entire surface area of the contaminated work areas shall be decontaminable

- Devices (such as door types or air lock arrangements) shall maintain pressure barriers for the areas

- Materials selected for the walls shall address durability, low maintenance, shielding, insulation and decontamination.

- The UBC construction Type of II-N shall be used for the Facility

- The walls of the DTC shall meet the recommended R value of the DOE-ID A/E Standards.

- Where wash down or decontamination activities are to be located, the floors shall be sloped to drains that lead to appropriate holding tanks.

\section{C-2.4 Structural Requirements}

\section{C-2.4.1 General}

- Structural designs shall be in accordance with 10 CFR 72, Licensing Requirements for the Independent Storage of Spent Nuclear Fuel, Subpart F (General Design Criteria)

- Structural designs shall meet the requirements of ANSI/ANS 57.9-1992, Design Criteria for an Independent Spent Fuel Storage Installation (Dry Type)

- Structural designs shall be in accordance with ICBO/UBC, the Uniform Building Code

- All designs using reinforced concrete shall meet the requirements of ANSI/ACI 318-89 
- Structural designs shall promote energy conservation in accordance with 10 CFR 435, Energy Conservation Voluntary Performance Standards for New Buildings, Mandatory for Federal Buildings.

\section{C-2.4.2 Classification and Design Loads}

- All permanent and transient loads that could exist or be developed during normal operations of the facility shall be considered in the design of the facility. Loads to be considered shall include: dead, live, thermal, lateral soil, snow, natural phenomena, seismic, wind, flood, offnormal operating and accident loads, and load combinations.

- $\quad$ Design loads shall be determined in accordance with ANSI/ASCE 72-88.

- Live, snow, and wind loads and load combinations shall be determined in accordance with ANSI/ASCE 7-95.

- Seismic loads shall be determined in accordance with 10 CFR 72, 10 CFR 100, and USNRC Reg. Guide 1.6.

- Tornado loads shall be determined in accordance with ANSI/ANS-2.3.

- Off-normal operating and accident loads should be determined in accordance with ASCE Manual No. 58.

- Load combinations shall be designed using applicable load combinations and stress limits stipulated in ANSI/AISC N690 and ANSI/ACI-349.

\section{C-2.4.3 Footings and Foundations}

- Footings and foundations shall be provided as needed

- The Hot Cell and Cask Handling Bay shall be provided with continuous wall footings, reinforced grade beams, and slab on grade construction

- Footings shall be extended below the frost depth.

\section{C-2.4.4 Structural Framing Systems}

- The Hot Cell walls and roof shall be designed consistent with shielding and loading requirements

- The Cask Handling Bay walls and roof shall be designed consistent with shielding and loading requirements. 


\section{C-2.4.5 Special Structural Features}

- The structural design must support the crane systems.

\section{C-2.5 Handling Requirements}

\section{C-2.5.1 Shipping Casks}

- Shipping casks shall be received in the truck bay. Therefore, any transporter shall interface with the truck bay

- $\quad$ Shipping casks must interface with the cask handling equipment (crane, lifting fixtures, etc.). Shippers shall provide any specialized handling equipment (trunnions, etc.) to off-load shipping casks.

\section{C-2.5.2 Multipurpose Transfer Cask and Transporter}

- A Multipurpose Transfer Cask shall be used to provide shielding and protection from potential hazards during the fuel handling and transfer operations.

- The Multipurpose Transfer Cask shall meet the requirements of 10 CFR 71 for onsite transfer and offsite transport and $10 \mathrm{CFR} 72$ for offsite transport.

- The Multipurpose Transfer Cask shall provide sufficient shielding to limit does rates to less than $200 \mathrm{mR} / \mathrm{hr}$ at contact for a DPC filled with 24 PWR or $52 \mathrm{BWR}$ commercial fuel assemblies. Actual shielding will be dependent on the actual fuel in the DPC and will be determined on a case-by-case basis.

- The Multipurpose Transfer Cask must interface with the cask handling equipment (crane, lifting fixtures, etc.).

\section{C-2.5.3 Cask Handling Equipment}

\section{Lifting Fixtures}

- Lifting fixtures shall be provided to remove casks from trailers and railcars.

- The lifting fixtures shall interface with the cranes, casks (shipping and transport), and associated equipment such as cask lids, shield plugs, welding machine, etc.

- The lifting fixtures shall be decontaminable, to the maximum extent possible.

- Standard lifting and rigging gear shall also be provided. 
- The lifting yokes shall be designed and fabricated in accordance with the ASME B\&PV Code rules for Class 2 component supports (Section III, D Subsection NF, excluding Subsection NCA), NUREG-0612 and ANSI-N14.6 requirements for special lifting devices. Utilization of these criteria meets or exceeds the requirements of 10 CFR 72 and ANSI/ANS-57.9 as well as 10 CFR 50.

Cask Transfer System

- A method for transferring casks from the Cask Handling Bay, through the Cask Preparation Area, and into the Hot Cell shall be provided

- The cask transfer system must interface with the various casks

- The cask transfer system must support the SNF shipment schedule

- The transfer system must be fail-safe

- $\quad$ ALARA shall be considered for maintenance of the cask transfer system.

\section{C-2.5.4 Cranes}

- All crane designs shall meet the intent of ANSI 57.9 and the NOG-1 specification which implements those requirements

- All crane designs shall meet the requirements of CMAA 70, Crane Manufacturers Association of America, Inc., Specification for Electric Overhead Traveling Cranes and CMAA 74-1987, Specifications for Top Running and Under Running Single Girder Electric Overhead Traveling Cranes Utilizing Under Running Trolley Hoist

- All cranes shall meet the requirement of NUREG-0612, Control of Heavy Loads and Nuclear Power Plants

- All crane designs shall be in accordance with ANSI B30.2-1990, Overhead and Gantry Cranes (Top Running Bridge, Multiple Girder) and ANSI B30.11-1993, Monorails and Underhung Cranes

- All cranes shall meet the requirements of 29 CFR 1910, Occupational Safety and Health Standards for General Industry, Subpart N, Materials Handling and Storage

- There shall be three cranes provided, including a Cask Handling Crane, a Cask Preparation Area Crane, and a Fuel Handling Crane. 
Cask Handling Crane

- The Cask Handling Crane shall accept transportation packages expected to be handled at the DTC.

- The Cask Handling Crane and its support systems shall be designed to withstand all design loadings, including the design phenomena, while remaining in place. The crane may lose its function, but this loss of function shall not result in a loss-of-load incident.

- Equipment for off-loading and loading of the transportation package for Design Event I shall be provided.

- Lifting devices to handle package heads and package internals for Design Event I and to fail safe for Design Events II and III shall be provided.

- Devices for handling secondary heads, heavy impact tools, or stud tensioners, for Design Event I shall be provided.

- A system for transportation package placement and removal that does not require that the package pass over any other package and that minimizes the passing of one package close to another at the same level for Design Event I shall be provided.

- The capability to receive fuel units from or return fuel units to the fuel handling area for Design Event I shall be provided.

Cask Preparation Area Crane

- The Preparation Booth Crane should be designed to handle secondary heads, heavy impact tools, stud tensioners, DPC welding equipment, and other small loads expected to be handled in the DTC preparation area

- The Preparation Booth Crane shall provide devices for handling secondary heads, heavy impact tools, or stud tensioners, for Design Event I.

Fuel Handling Crane

- Remote handling of fuel units for Design Event I and subsequent to Design Events II, III, and IV shall be provided.

- The capability for special tooling to handle structurally damaged fuel units subsequent to Design Events II, III, and IV shall be provided.

- Materials shall withstand the cumulative effect of radiation exposures anticipated over their design life. 
- Capability for emergency shutdown of the lifting and handling equipment power supply (i.e., manual disconnect) shall be incorporated into the equipment design, independent of and physically separated from the normal controls, but located within the planned work area and readily accessible.

- Handling and process equipment and other support equipment located within the shielded cell shall be designed to function in or be appropriately shielded from the high radiation field produced by unshielded fuel units.

- If provision for remote maintenance is not made, handling equipment for fuel units and transportation package closure lid(s) shall have sufficient redundancy so that no single failure in the handling system will preclude returning unshielded fuel units to shielded storage locations or returning the closure lid(s) to the transportation package.

- Grapples, lifting attachments, and handling equipment for fuel units and transportation package closure lid(s) shall be designed for remote operations, and active lifting components shall be designed to retain their load and fail in a same manner (i.e., in the "latched" state) in the event of loss of actuating power., An independent, remote means shall be provided for disengagement of any grapple in the cell in the event an active grapple component fails to operate. Grapple operating envelopes shall be designed to be compatible with all interfacing storage and transportation systems.

- Grapples and lifting fixtures for handling fuel units or transportation package closure lid(s) shall be designed to provide positive engagement during a lift, and the grapples and associated controls shall be designed to minimize the potential for inadvertent disengagement. A means shall be provided to indicated that positive engagement has been achieved and to indicate the disengaged position.

- Grapples and tools shall be designed to facilitate decontamination, nondestructive testing, maintenance, handling, and storage. Cracks or crevices likely to collect contamination should be avoided.

- Process cranes shall employ redundant limit switches and interlocks to prevent excessive horizontal movement that could affect operation or cause damage to the units being handled, as well as to prevent excessive vertical movement including double blocking. Redundant means of disconnecting power to the cranes shall be available to the operator. The means shall be independent of, and physically separated from, the normal controls, but conveniently located within the planned work area. Redundant means of braking vertical travel shall be provided. Braking of horizontal motion should be provided as necessary to facilitate the required positioning precision.

- If the possibility exists for fuel units to catch on lips or protrusions during lifting or lowering, the lifting equipment shall have interlocks to sense an unacceptable change (either an increase or a decrease) in hoisting force and automatically stop further travel. 
- Remote handling equipment shall be incorporated into the design of the area to permit performance of normal process operations. Particular attention shall be given in the design to methods and equipment required to recover from equipment failures, off-normal events, and accidents.

- Design methods, loadings, and so forth shall be in accordance with section 6.17 of ANSI/ANS 57.9. The handling equipment may lose its function, but functional failure shall not result in a loss of load incident or inability to recover from the failure.

- The special procedures for handling damaged fuel or damaged fuel units should be anticipated and provisions made in the design.

- Safe access to perform necessary testing, inspection, and maintenance shall be provided (e.g., ladders, catwalks, and guard rails).

- Non remote transfer machines shall be automatically annunciated when in motion.

- The Fuel Unit Handling Crane shall be of a flexible design to handle multiple (and often poorly documented) fuel configurations, weights, and attachment (grapple) points. A variety of grapples and other tools for fuel movement shall be provided.

- The system shall accommodate a wide variety of shipping (source) casks.

- The Fuel Unit Handling Crane shall support canning operations

\section{C-2.5.5 Cask Work Platforms}

- The DTC facility shall be equipped with work platforms that shall provide a safe and convenient elevated work area for personnel working around the tops of various casks for regular maintenance and operations in the Cask Handling Bay and Cask Preparation Area

- Access shall be provided to these elevated work areas

- The work platforms shall be designed per OSHA and ANSI standards

- The work platforms shall be decontaminable

- The work platforms shall be designed to interface with all the casks that may be handled in the DTC

- Handrails and kick plates shall be provided

- Some sections of handrail shall be removable for operations requiring such. 


\section{C-2.6 SNF Packaging Systems Requirements}

\section{C-2.6.1 Canning System}

- The canning design shall be in accordance with 10 CFR 72, Licensing Requirements for the Independent Storage of Spent Nuclear Fuel, Subpart F (General Design Criteria).

- The canning design shall meet the requirements of ANSI/ANS 57.9-1992, Design Criteria for an Independent Spent Fuel Storage Installation (Dry Type).

- Canning operations shall provide the Peach Bottom fuel the first or primary containment.

- Canning operations shall not be performed during fuel transfer operations.

- Canning activities shall all be remote operations. The DTC shall be evacuated with no manned entry during canning activities.

- The canning station shall be arranged in such a manner within the hot cell to allow for the full range of motion for the manipulators and other remote devices and still not interfere with other planned activities.

- Appropriate space shall be allocated for the specific canning activities planned. Special consideration shall be given to overhead crane envelopes, electro-mechanical manipulator envelopes, and locations of shielded viewing windows.

- The station throughput capacity shall be on average, two finished cans per day. The station capacity is based on the current operating capacity of the facility.

- Provision shall be made in the canning station area for easy decontamination.

- The walls of the hot cell located at the designated canning station area shall be provided with shielded viewing window(s).

- Quick disconnects for pneumatic, and electrical connections shall allow for remote handling.

- All racks and stands shall be constructed to aid in decontamination operations.

- All maintenance activities to canning hardware and equipment shall be performed manually.

Canning Station Operational Requirements

- Equipment shall be provided to visually verify the fuel and its condition. Precautions will need to be taken during this operation to minimize the spread of contamination. (Note, it is assumed that characterization equipment is already available in the hot cell.) 
- The can piercing equipment shall pierce incoming fuel cans to ensure the contents can be dried during fuel drying operations. Precautions will need to be taken during this operation to minimize the spread of contamination. The can piercing equipment shall hold the can in a vertical position without crushing the can. The can piercing equipment shall cut through the wall of the can without damaging the fuel element inside the can.

To safely vent the pressure and prevent the formation of any explosive mixtures of hydrogen gas from occurring during the can piercing operation. A sampling, vent, and purge operation, in conjunction with the piercing operation, shall occur to sample the gas inside the can, vent any pressure, and purge the can if hydrogen is present.

The stand for the can piercing operation shall be fastened to the floor at the base. The stand for the can piercing operation shall be sufficient to support the hardware with a loaded can in the event of an earthquake.

- A new can/lid storage rack shall temporarily store the empty new cans/lids. Capacity of the rack shall be five cans and lids.

- The can loading equipment shall provide a means to hold a new can securely in place while fuel is loaded into the new can or load already canned fuel (over-packing) into the new cans. Precautions will need to be taken during this operation to minimize the spread of contamination. It is assumed that fuel handling equipment is available for canning operations within the hot cell.

The stand for the can loading operation shall be sufficient to support the hardware with a loaded can in the event of an earthquake.

- The can welding equipment shall weld the lids onto the new cans. Precautions will need to be taken during this operation to minimize the spread of contamination.

The stand for the can welding equipment shall be the same stand used for the can loading operations. The stand for the can welding equipment shall be sufficient to support the hardware with a loaded can in the event of an earthquake.

The fuel drying operation shall be performed to ensure that only dry fuel is sealed inside the can. The drying equipment shall provide a means to dry the fuel (probably using a vacuum type system/operation) inside the hot cell. The vacuum exhaust shall be filtered. (Note, it is assumed that once the fuel is canned, adequate drying, but not necessarily complete drying, will occur in a reasonable length of time.)

- The atmosphere within the cans shall be pressurized with inert gas to minimize corrosion due to oxygen and water vapor.

- Cans shall be helium leak tested in the hot cell to determine that they are properly sealed. 
- Handling equipment such as cranes, electro-mechanical manipulators, grapples, tools, etc. shall be provided inside the cell, as required, to accomplish transfer of items and fuel from station to station and assist canning operations as necessary. (Note, it is assumed that the handling equipment is already available in the hot cell.)

- Fuel and can handling equipment (fuel specific tools, Peach Bottom can handling tool, new can/lid tools, miscellaneous tools, etc.) shall be provided inside the cell, as required, to accomplish transfer of items and fuel units from can to can and assist canning operations as necessary.

- The Closed Circuit Television (CCTV) system (including appropriate lighting), dedicated to the canning area, shall provide viewing capability for operation of the fuel canning equipment. All cameras in the canning area shall have zoom capability and be mounted on a pan-and-tilt mechanism. The system will supplement viewing through the shielded viewing windows.

\section{C-2.7 Storage Area Requirements}

- All storage systems shall be in accordance with 10 CFR 72, Licensing Requirements for the Independent Storage of Spent Nuclear Fuel, Subpart F (General Design Criteria), Subpart K (General License for Storage of Spent Fuel at Power Reactor Sites), and Subpart L (Approval of Spent Fuel Storage Casks)

- $\quad$ All storage systems shall meet the requirements of ANSU/ANS 57.9-1992, Design Criteria for an Independent Spent Fuel Storage Installation (Dry Type) and ANSI/ANS 57.10-1987, Design Criteria for Consolidation of LWR Spent Fuel.

\section{C-2.7.1 Basemat and Horizontal Storage Modules}

- A Storage Area comprising an outdoor above-ground concrete storage basemat and suitable shielded and monitored storage modules shall be provided. Loaded DPCs from the DTC shall be transported and placed into the storage modules on the storage basemat.

- The storage area shall be designed to allow ready expansion throughout its life up to a maximum capacity of 240 Horizontal Storage Modules. The total area shall be minimized, but still allow operations.

- Equipment shall be provided to open and close storage modules.

- The Horizontal Storage Modules shall provide sufficient shielding to limit radiation levels to $10 \mathrm{mR} / \mathrm{hr}$ at contact on all accessible vertical walls when loaded with a single DPC containing 52 BWR or 24 PWR commercial fuel elements.

- The Horizontal Storage Modules shall be of sufficient size to store one DPC (in the horizontal position). 
- The Horizontal Storage Modules shall provide a method for passively cooling the DPCs.

- Each module shall be designed to maintain the fuel cladding below $340^{\circ} \mathrm{C}$.

- The modules shall be designed to withstand seismic accelerations, ambient temperatures, tornadoes, and floods.

- The storage area shall allow for welding operations.

\section{C-2.7.2 Dual Purpose Canisters}

- Canisters shall be provided that are suitable for storing and shipping SNF. As such, the DPCs shall provide a secondary confinement barrier and have lifting eyes, purge ports, and vent ports.

- Only the shorter Vectra PWR-length DPC shall be used.

- The main fuel storage component shall be a DPC shell (Vectra FO-DSC for PWR fuel, Vectra Drawing NUH-05-4004NF, Revision 1). It is a 67.25 in. OD by 186.2 in. long canister with an internal cavity length of $167 \mathrm{in.}$

\section{C-2.7.3 DPC Baskets}

- Neutron absorbing materials shall be used as necessary

- Baskets that are placed within a DPC shall be one of three styles: the Fluor 14-Tube, the Shippingport LWBR 3-tube, or FSVR 7-tube.

14-Tube Basket Requirements

- This basket design shall be designed to receive $12 \mathrm{in.} \mathrm{Schedule-10-pipe} \mathrm{buckets} \mathrm{with}$ cruciforms that may have poison added if necessary.

Shippingport LWBR 3-tube Basket Requirements

- Shall be designed to hold three existing ICPP 749 cans that measure 25.57 In diameter by 158 in. long, and each of which hold a Shippingport LWBR fuel element. 
FSVR 7-tube Basket Requirements

- Shall be designed to hold 35 bare FSVR hexagonal fuel elements stacked 5 high in each of seven hexagonal cells. Each hexagonal basket tube has an inside measurement of 16.65 inches across the corners and is made of 3/4-in. thick stainless steel.

\section{C-2.7.4 Dry Storage Buckets}

- Dry Storage Buckets must interface with DPC baskets

- There shall be two types of dry storage buckets: 12 inch and 14 inch stainless steel buckets

- Dry Storage Buckets shall have cruciforms to hold and separate individual fuel elements

- Dry Storage Buckets shall have lids

- A sufficient number and size of Dry Storage Buckets shall be provided to handle and anticipated fuels.

\section{C-2.7.5 Dry Storage Cans}

- Dry Storage Cans shall be provided for canning the Peach Bottom Core 1 and Core 2 fuel.

- Dry Storage Cans shall have cruciforms to hold and separate individual fuel elements.

- Lids for the Dry Storage Cans shall be provided and shall be welded to the can body.

- A method for venting and purging the Dry Storage Cans, once fuel is loaded and the lid welded, shall be provided.

- The cans shall be capable of sustaining loads during shipping and handling.

- The cans shall meet an internal design pressure of 15 psig. The can shall also meet a design temperature of $380^{\circ} \mathrm{C}$.

- Cans shall allow for standard fabrication methods and procedures. Any handling features on the cans shall not interfere with the transport, loading, sealing, and testing processes.

- The can shall have a vacuum/pressurization port incorporated into its design. Cans shall be designed so that purging, evacuating, leak testing, and back-filling with an inert gas can all be accomplished remotely. 


\section{C-2.8 HVAC Requirements}

- All HVAC systems shall be in accordance with 10 CFR 72, Licensing Requirements for the Independent Storage of Spent Nuclear Fuel, Subpart F (General Design Criteria) and 10 CFR 20, Standards for Protection Against Radiation.

- $\quad$ All HVAC systems shall meet the requirements of ANSI/ANS 57.9-1992, Design Criteria for an Independent Spent Fuel Storage Installation (Dry Type) and ANSI/ANS 57.10-1987, Design Criteria for Consolidation of LWR Spent Fuel.

- $\quad$ HVAC systems shall be in accordance with 29 CFR 1910, Occupational Safety and Health Standards for General Industry, Subpart G (Occupational Health and Environmental Control) and Subpart Z (Toxic and Hazardous Substances).

- The HVAC systems shall meet the air quality requirements addressed in 40 CFR 50-53, and 58.

- The HVAC systems shall be in accordance with ANSI/ASME N509-1989, Nuclear Power Plant Air Cleaning Units and Components and ANSI/ASME N510-1989, Testing of Nuclear Air-Cleaning Systems.

- The HVAC systems shall meet the requirements of Idaho Administrative Procedures Act (IDAPA) 16.01.01000-01999.

- The HVAC systems shall be in accordance with MIL-F-51068C (Filter: Particulate High Efficiency, Fire Resistant) and MIL-F-51079A (Filter Medium: Fire Resistant, High Efficiency).

- The Hot Cell atmospheric pressure shall be controlled during hot operations to $-0.6 \mathrm{~W}$. G. (or lower) below atmospheric pressure.

- Heating loads shall be based on a minimum winter outdoor design temperature of $-14^{\circ} \mathrm{F}$. Cooling loads shall be based on temperatures of $93^{\circ} \mathrm{F}$ dry bulb and $61^{\circ} \mathrm{F}$ wet bulb.

- The HVAC system should maintain a minimum temperature of $65^{\circ} \mathrm{F}$ in the winter and approximately $76^{\circ} \mathrm{F}$ in the summer in the Cask Handling Bay, Cast Preparation Area, and Hot Cell.

- The HVAC system must maintain a minimum temperature of $65^{\circ} \mathrm{F}$ in the winter and approximately $72^{\circ} \mathrm{F}$ in the summer in the Administrative areas.

- Air shall flow from areas of least contamination potential to areas of highest contamination potential.

- The Cask Handling Bay shall normally be maintained at atmospheric pressurè. 
- A method for eliminating truck exhaust fumes from the Cask Handling Bay shall be provided.

- The Cask Preparation Area static pressure shall be controlled to a minimum of $-0.1 \mathrm{in}$. W. G. below the Cask Handling Bay and the outside environment.

- The HVAC system shall collect exhaust air from contamination control areas and pass it through HEPA filters prior to discharge to the atmosphere.

- HVAC design for indoor temperature conditioning shall be based on ASHRAE 90 .

\section{C-2.9 Mechanical Utilities Requirements}

- Mechanical utilities systems shall be in accordance with 10 CFR 72, Licensing Requirements for the Independent Storage of Spent Nuclear Fuel, Subpart F (General Design Criteria)

- Mechanical utilities systems shall meet the requirements of ANSI/ANS 57.9-1992, Design Criteria for an Independent Spent Fuel Storage Installation (Dry Type).

\section{C-2.9.1 Compressed Air}

- The system design for compressed air shall be in accordance with 29 CFR 1910, Occupational Safety and Health Standards for General Industry, Subpart M (Compressed Gas and Compressed Air Equipment)

- Compressed air shall be provided to the facility for plant air and instrument air

- The compressed air line shall be cathodic protected.

- Plant air shall be provided to operate pneumatically operated tools associated with cask handling and preparation in the Cask Handling Bay, Cask Preparation Area, and Hot Cell

- Instrument air shall be used for pneumatically operated HVAC system equipment and other pneumatic operations in the facility.

\section{C-2.9.2 Compressed Gas}

- The system design for compressed gas shall be in accordance with 29 CFR 1910, Occupational Safety and Health Standards for General Industry, Subpart H (Hazardous Materials) and Subpart M (Compressed Gas and Compressed Air Equipment)

- Compressed gas shall be provided to the facility

- Argon compressed gas shall be supplied for welding processes

- Helium compressed gas shall be supplied for pressure testing and inerting operations. 


\section{C-2.9.3 Potable Water}

- Potable water shall be provided to the facility to service water closets, urinal(s), sinks, showers, shower/eyewash facilities, evaporative coolant units, drinking fountains, and miscellaneous ports

- The water line shall be cathodic protected

- A method for heating water to $140^{\circ} \mathrm{F}$ for the showers and sinks shall be provided.

\section{C-2.9.4 Waste Systems}

Liquid Waste

- Liquid waste system(s) shall be provided for in the Cask Handling Bay, Cask Preparation Area, and Hot Cell. Condensate from HVAC equipment shall be disposed of using the liquid waste system

- The liquid system lines shall be cathodic protected

- Liquid waste shall be collected and tested prior to being pumped into the waste line

Sanitary Systems

- The sanitation system design shall be in accordance with 29 CFR 1910, Occupational Safety and Health Standards for General Industry, Subpart J (General Environmental Controls)

- Sanitary sewer drains shall be provided as needed

- Vents shall be provided as needed

- Sewer lines shall be cleanable.

\section{C-2.9.5 Fire Protection}

- $\quad$ Fire water shall be provided

- The fire water line shall be cathodic protected

- $\quad$ Fire protection shall be in accordance with ANSI/ANS-57.9.

- Fire protection systems shall ensure nuclear criticality and suppressant-SNF chemical reactions cannot occur. 


\section{C-2.9.6 Steam}

- Steam shall be provided and routed to the HVAC system as required

- The steam lines shall be cathodic protected

- The steam lines shall be insulated.

\section{C-2.10 Electrical Requirements}

- All electrical systems shall be in accordance with 10 CFR 72, Licensing Requirements for the Independent Storage of Spent Nuclear Fuel, Subpart F

- All electrical systems shall meet the requirements of ANSI/ANS 57.9-1992, Design Criteria for an Independent Spent Fuel Storage Installation (Dry Type)

- Electrical systems shall be in accordance with 29 CFR 1910, Occupational Safety and Health Standards for General Industry, Subpart S (Electrical)

\section{C-2.10.1 Power}

- The electric power system shall be designed to provide emergency electrical supply to essential instrumentation, emergency lighting, emergency communications, and physical security systems.

- Standby power shall be supplied for the Hot Cell HVAC system exhaust fan.

- $\quad$ An Uninterruptable Power Supply (UPS) shall provide emergency power.

- The UPS shall support the Fire Alarm, Voice Paging, HVAC, Radiation Monitoring and Alarm, and security systems. There shall sufficient battery capacity to carry the rated load for a minimum of 30 minutes.

\section{C-2.10.2 Grounding}

- A perimeter ground loop of \#4/0 bare copper and ground rods shall be included around the facility

- The following equipment shall be bonded to the ground loop: facility steel, water piping, service equipment, distribution equipment and motor frames

- Equipment grounding shall be in accordance with NEC Article 250

- An isolated grounding system shall be provided. 


\section{C-2.10.3 Cathodic Protection}

- Utility piping shall be protected through connection to the existing ICPP cathodic protection system

- A testing/bonding station shall be included to periodically monitor the cathodic protection system.

\section{C-2.10.4 Lighting}

- Lighting shall be designed and included in accordance with current Illuminating Engineering Society (IES) recommendations

- Emergency and exit lighting shall be provided at each means of egress

- Hot Cell lighting shall be provided by high-pressure sodium fixtures

- Exterior lighting shall be provided.

\section{C-2.10.5 Lightning Protection}

- A lightning protection system shall be included and shall be designed in accordance with NFPA 780.

\section{C-2.10.6 HVAC Controls}

- A HVAC control system shall be provided. It shall be a smart system that can automatically generate control signals to change HVAC equipment operating parameters based on signal received from various monitors. A computer monitor shall be provided in the Shift Supervisor's office for reviewing the operating status of the system and making adjustments to control setpoints.

- Instrumentation shall be provided to detect and alarm both high and low differential pressure across filters in the HVAC system.

- Instrumentation shall be provided to initiate isolation of the HVAC system filters in the event of fire detection.

\section{C-2.10.7 Equipment Controls}

- Facility control, process control, and data acquisition systems shall be provided.

- Remotely controlled CCTV cameras shall be provided in the Hot Cell for general visual observation, fuel canning operations, fuel inspection, and documentation. 
- Each Hot Cell window shall be equipped with a visual inspection station which shall include two high resolution cameras; a monitor; camera controls for pan, tilt, and zoom functions; and recording capability for archival purposes.

- Instrumentation shall be provided to measure and record the DTC structural response to an earthquake.

- A system shall be provided for the collection of alarms from the HVAC system and other alarms. This shall be located in the Shift Supervisor's office.

\section{C-2.10.8 Radiation Monitoring and Alarms}

- Radiation detection instrumentation shall be provided to warn operating personnel of radiation and airborne radioactivity levels above set limits.

- The RAMs shall alarm locally and remotely in the RadCon office.

- An alpha CAM shall be located in the inlet duct to the Zone 1 HEPA filter for the HVAC system.

- A Criticality Alarm System shall be provided in accordance with ANSI/ANS 8.3-1986.

- Stack monitoring shall be provided for the detection of radioactive particulates in the air exhaust stream. These instruments shall comply with ANSI-N42.17B-1989.

- Provision shall be made in the design for monitoring groundwater in the vicinity of the storage area for radioactive contamination.

- Activity monitors shall be provided in the wash water collected from the Hot Cell.

- Selected instruments (TBD) shall transmit data to a micro-processor based system for display, recording, alarm, and trending in the RadCon Control Office.

\section{C-2.10.9 Communications and Alarms}

- Voice and data telecommunications lines shall be provided throughout the occupied areas of the facility.

- The existing Broadband Local Are Network (LAN) shall be made available in the facility. Access ports shall be provided in all normally occupied offices.

- Fire alarm, emergency voice paging, and evacuation alarm systems shall be compatible with existing systems at ICPP. 


\section{C-2.10.10 Data Acquisition and Recording}

- A data entry station shall be provided to record and monitor all fuel movements. The stations shall be linked for data communications.

\section{C-2.10.11 Security Systems}

- Physical protection of the facility and pad as well as the materials shall be in accordance with 10 CFR 73 and 10 CFR 72, Subpart $H$.

- At least one physical barrier shall be provided between areas accessible to the public and storage. This barrier shall be of sufficient height and strength to hinder unauthorized access. It shall have a $20-\mathrm{ft}$ clear zone on either side and shall be provided with means for the detection of attempts to breach the barrier (intrusion alarm).

- The physical barrier and clear spaces shall be provided with suitable lighting installation as required to provide an illumination of no less than $0.2 \mathrm{fc}$, measured horizontally at ground level.

\section{C-2.11 Design Life Requirements}

- Design life of the SNF Dry Storage Facility and equipment shall be 30 years and have maintainable or replaceable life of 60 years

- The design life of the DPC shall be 100 years

- Design life of the Storage Facility shall be 60 years

\section{C-2.12 Safety Requirements}

\section{C-2.12.1 Safety Classification}

- A safety classification has been determined in accordance with 10 CFR 830 to be a Hazard Class 2.

\section{C-2.12.2 Construction}

- The design of utility services and distribution systems that are important to safety shall include redundant systems to the extent necessary to maintain, with adequate capacity, the ability to perform safety functions assuming a single failure. ${ }^{\mathrm{a}}$

a. A single failure is an occurrence that results in the loss of capability of a component to perform its intended safety function(s). A multiple failure, i.e., loss of capability of several components, resulting from a single occurrence, is considered to be a single failure. Systems are considered to be designed against an assumed single failure if neither (1) a 
- The Dry Storage Facility and its systems important to safety ${ }^{b}$ shall be designed to be evaluated by appropriate tests or by other means acceptable to the NRC to demonstrate that they will reasonably maintain confinement of radioactive material under normal, off-normal, and credible accident conditions.

- Structures, systems, and components important to safety shall be designed and located so that they can continue to perform their safety functions effectively under credible fire and explosion exposure conditions.

- The design of the Dry Storage Facility shall include provisions to protect against nuclear criticality that might otherwise result from the operation or the failure of fire suppression or decontamination systems.

- Spent fuel handling, packaging, transfer, and storage systems shall be designed to be maintained subcritical under the worst case moderated and reflected conditions, and to ensure that, before a nuclear criticality accident is possible, at least two unlikely, independent, and concurrent or sequential changes must occur in the conditions essential to nuclear criticality safety.

- The DPC and its internal structures and containers shall be designed to maintain the fuel in a favorable geometry for nuclear criticality safety throughout the operations and life of the system.

- Each entrance or access point into a high radiation area shall have either a control device that energizes a conspicuous visible or audible alarm signal so that the individual entering the high radiation area and the supervisor of the activity are made aware of the entry; or entryways that are locked, except during periods when access to the areas is required, with positive control over each individual entry.

- SNF that is reactive with water or other chemicals shall be protected from exposure to those materials.

- The SNF Dry Storage Facility shall be designed to prevent the dropping of casks, SNF, SNF baskets/ buckets/cans, and DPCs under normal and off normal conditions including the design basis accidents (DBAs) that they shall withstand.

single failure of any active component (assuming passive components function properly) nor, (2) a single failure of any passive component (assuming active components function properly) results in loss of the system's capability to perform its safety function(s).

b. Structures, systems, and components important to safety mean those features of the Storage Facility whose function is: (1) To maintain the conditions required to store spent fuel safely, (2) To prevent damage to the spent fuel waste container during handling and storage, or (3) To provide reasonable assurance that spent fuel can be received, handled, packaged, stored, and retrieved without undue risk to the health and safety of the public. 
- The SNF Dry Storage Facility shall be designed to be able to recover from accidents involving dropping of casks, SNF, SNF baskets/buckets/cans, and DPCs.

- In-cell equipment shall be designed for recovery from all possible conditions to the extent that manned entry into the cell, for maintenance, can be accomplished.

- If a fuel grapple is supporting the weight of the fuel, the grapple shall be interlocked so that it can not disengage from the crane (or overhead manipulator) or fuel to which it is connected even if the normal control command to do so is inadvertently given. A means of defeating this interlock shall be provided to ensure the grapple can be disengaged at any time even if the full weight of the fuel is on the grapple.

- $\quad$ Fire doors shall be provided as required by DOE-ID-12044, UBC, NFPA-80, and NFPA-101. In addition, all fire doors and frames shall meet all requirements of the Underwriters Laboratories and shall bear the UL or FM label. Fire doors and frames shall be constructed from metal. Structural members, such as steel channels embedded in wall openings, shall not substitute as door frames. All fire doors shall be provided with fitted frames which are anchored to, but separate from, the building structural members. The fire doors shall contain window fitted with UL approved safety glass which is not removable from the outside of the door. Their installation shall meet all of the requirements of NFPA-80 and NFPA-101.

- The facility design shall mitigate natural phenomena hazards. The design shall address common cause effects and interactions for: earthquakes, volcanic events, tornadoes, hurricanes, high winds, floods, excessive rains, excessive snow, ice cover, lightning, and fires. The secondary natural phenomena include drought, fog, frost, high temperatures, low temperatures, landslides, subsidence, surface collapse, uplift, storm surges, and waterspouts. Damage and failure will be considered for systems, structures, and components. In addition, the facility shall have instrumentation or other means to detect and record the occurrence and severity of seismic events.

\section{C-2.12.3 Operation}

- Provisions shall be made to enable surveying the external surfaces of the shipping casks for radiation levels and radioactive contamination as soon as practical after receipt of the package, but not later than 3 hours after the package is received at the ICPP if it is received during normal working hours, or not later than 3 hours after the beginning of the next working day if it is received after working hours

- $\quad$ Radiation protection for occupational workers shall be per 10 CFR 835 (Occupational Radiation Protection) and the INEL Radiation Control Manual

- $\quad$ Fire protection shall be in accordance with ANSI/ANS-57.9

- Facility design features and physical controls shall ensure occupational exposure is maintained ALARA during normal and off-normal operations 
- Personnel radiation exposure levels throughout the SNF Dry Storage Facility shall not exceed $0.125 \mathrm{mr} / \mathrm{hr}$ for continuously-occupied areas.

- The following radiation zones (as described in the DOE-ID AE Standards) shall apply during operations:

Cask Handling Bay-Zone IV

Cask Preparation Area-Zone I

Hot Cell-Zone III

- Safe access will be provided to all packages, vehicles, and installed components for purposes of testing, inspection, and maintenance.

\section{C-2.13 Environmental Requirements}

- Facility emission limits shall be consistent with the INEL Environmental Restoration and Waste Management Programs Final Environmental Impact Statement, DOE/EIS-0203-F

- Administrative controls and Best Available Control Technology shall be used to minimize the impacts of air emissions

- The facility processes and equipment shall be designed to limit solid waste generation to $115 \mathrm{~m}^{3}$ per year of LLW and $250 \mathrm{~m}^{3}$ per year of industrial (cold) waste

- Solid radioactive waste produced by SNF Dry Storage Facility operations shall be packaged in standard RWMC $4 \times 4 \times 8$-ft plywood boxes for contact-handled (CH) LLW or INEL Mark III concrete containers for remote-handled (RH) LLW, and shipped to RWMC for disposal

- Means for measuring the amount and concentrations of radionuclides in effluents during normal operations, and under accident conditions, shall be provided for effluent control systems

- DTC warm liquid waste shall be controlled and verified to meet the criteria for existing ICPP handling systems, and shall be transferred to those systems

- If all or part of the facility is located outside of existing ICPP fences, the use of new land shall not exceed 551 acres when combined with other storage systems included in DOE/EIS-0203-F.

\section{C-2.14 Safeguards and Security}

- A data management system shall be provided to keep records showing the receipt, inventory, transfer, and disposal of all SNF in storage. The records shall include, as a minimum, the 
name of the fuel shipper, the estimated quantity of radioactive material per item (including special nuclear material in spent fuel), item identification and serial number, storage location, onsite movements and locations of each fuel assembly or DPC, and final shipment to an offsite location. The data management system shall meet the requirements of 10 CFR 72 , Licensing Requirements for the Independent Storage of Spent Nuclear Fuel and High-Level Radioactive Waste, Subpart D (Records, Reports, Inspections, and Enforcement).

- Dual records shall be maintained to ensure an off-normal event cannot result in the loss of the sole records of SNF inventories. These records for spent fuel shall be retained for as long as the material is stored, and for a period of five years after the material is disposed of or transferred out of the Storage Facility.

- Equipment shall be provided to conduct a physical inventory of all spent fuel in storage at intervals not to exceed 12 months unless otherwise directed by the Commission. A copy of the current inventory shall be retained as a record until the Commission terminates the license.

- Physical protection of the facility and pad as well as the materials shall be in accordance with 10 CFR 72, Licensing Requirements for the Independent Storage of Spent Nuclear Fuel and High-Level Radioactive Waste, Subpart H (Physical Protection); 10 CFR 73, Physical Protection of Plants and Materials; and 10 CFR 1046, Physical Protection of Security Interests.

\section{C-2.15 Quality Assurance Requirements}

- Quality assurance (QA) requirements for the SNF Dry Storage Facility are identified in ANSI/ANS 57.9, Design Criteria for an Independent Spent Fuel Storage Installation (Dry Type), Section 6.15 and 10 CFR 72, Licensing Requirements for the Independent Storage of Spent Nuclear Fuel, Subpart G (Quality Assurance).

- All purchased items will be restricted to those not suspect/counterfeit, misrepresented, used, or other than represented/advertised in accordance with INEL-95/227, "Guidelines for Identifying Suspect/Counterfeit Material.”

- Records, reports, and inspections shall be done in accordance with 10 CFR 72, Licensing Requirements for the Independent Storage of Spent Nuclear Fuel, Subpart D (Records, Reports, Inspections, and Enforcement).

- Training of personnel shall be performed in accordance with 10 CFR 72, Licensing Requirements for the Independent Storage of Spent Nuclear Fuel, Subpart I (Training and Certification of Personnel). 


\section{C-3. CODES AND STANDARDS}

\section{C-3.1 General}

- 10 CFR 72, Licensing Requirements for the Independent Storage of Spent Nuclear Fuel

- 29 CFR 1910, Occupational Safety and Health Standards for General Industry

- 29 CFR 1926, Occupational Safety and Health Regulations for Construction

- 40 CFR 260 et seq, Hazardous Waste Management System: General

- 40 CFR 261, Identification and Listing of Hazardous Waste

- 40 CFR 262, Standards Applicable to Generators of Hazardous Waste

- $\quad 40$ CFR 268.50, Land Disposal Restrictions

- 40 CFR 300 et seq., National Oil and Hazardous Substances Pollution Contingency Plan .

- $\quad$ ANSI/ANS 57.9, Design Criteria for an Independent Spent Fuel Storage Installation (Dry Type)

\section{C-3.2 Civil}

- 10 CFR 72, Subpart E, Licensing Requirements for the Independent Storage of Spent Nuclear Fuel, Siting Evaluation Factors

- 10 CFR 72, Subpart F, Licensing Requirements for the Independent Storage of Spent Nuclear Fuel, General Design Criteria

\section{C-3.3 Architectural}

- 10 CFR 72, Subpart F, Licensing Requirements for the Independent Storage of Spent Nuclear Fuel, General Design Criteria

- 10 CFR 72, Subpart K, Licensing Requirements for the Independent Storage of Spent Nuclear Fuel, General License for Storage of Spent Fuel at Power Reactor Sites

- 29 CFR 1910, Subpart D, Occupational Safety and Health Standards for General Industry, Walking - Working Surfaces

- 29 CFR 1910, Subpart E, Occupational Safety and Health Standards for General Industry, Means of Egress 
- $\quad$ ICBO/UBC, Uniform Building Code

\section{C-3.4 Structural}

- 10 CFR 72, Subpart F, Licensing Requirements for the Independent Storage of Spent Nuclear Fuel, General Design Criteria

- 10 CFR 100, Reactor Site Criteria

- 10 CFR 435, Energy Conservation Voluntary Performance Standards for New Buildings, Mandatory for Federal Buildings

- $\quad$ ANSI/ACI 318-89, Building Code Requirements for Reinforced Concrete

- $\quad$ ANSI/ACI 349-85, Code Requirements for Nuclear Safety Related Concrete Structures

- $\quad$ ANSI/AISC N 690-1984, Specifications for the Design, Fabrication, and Erection. of Steel Safety Related Structures for Nuclear Facilities

- $\quad$ ANSI/ANS 2.3-1983, American National Standard for Estimating Tornado, and Extreme Wind Characteristics at Nuclear Power Sites

- $\quad$ ANSI/ANS 2.19-1981 (R1990), American National Standard Guidelines for Establishing Site-Related Parameters for Site Selection and Design of an Independent Spent Fuel Storage Installation (Water Pool Type)

- $\quad$ ANSI/ANS 57.9-1992, Design Criteria for an Independent Spent Fuel Storage Installation (Dry Type)

- $\quad$ ANSI/ASCE 7-95, Minimum Design Loads for Buildings and Other Structures

- ANSI/ASCE 72-88, American National Standard Minimum Design Loads for Buildings and Other Structures

- ASCE Manual No. 58, Structural Analysis and Design of Nuclear Power Plant Facilitiēs

- ICBO/UBC, Uniform Building Code

- USNRC Reg. Guide 1.6, Design Response Spectra for Seismic Design of Nuclear Power Plants

\section{C-3.5 Handling}

- 10 CFR 50, Domestic Licensing of Production and Utilization Facilities 
- 10 CFR 71, Packaging and Transportation of Radioactive Material

- 10 CFR 72, Subpart F, Licensing Requirements for the Independent Storage of Spent Nuclear Fuel, General Design Criteria

- 29 CFR 1910, Subpart D, Occupational Safety and Health Standards for General Industry, Walking - Working Surfaces

- 29 CFR 1910, Subpart N, Occupational Safety and Health Standards for General Industry, Materials Handling and Storage

- $\quad$ ANSI/ANS 57.9-1992, Design Criteria for an Independent Spent Fuel Storage Installation (Dry Type)

- ANSI/ASME NOG-1-1989, American National Standard Rules for Construction of Cranes, Overhead and Gantry (Top Running Bridge, Multiple Girder)

- $\quad$ ANSU/AWS D1.1-1990, Structural Welding Code - Steel

- $\quad$ ANSI B30.2-1990, Overhead and Gantry Cranes (Top Running Bridge, Multiple Girder)

- $\quad$ ANSI B30.11-1993, Monorails and Underhung Cranes

- $\quad$ ANSI N14.6-1993, Special Lifting Devices for Shipping Containers Weighing 10,000 Pounds $(4500 \mathrm{~kg})$ of More

- CMAA 70, Crane Manufacturers Association of American, Inc. Specification for Electric Overhead Traveling Cranes

- CMAA 74-1987, Specifications for Top Running and Under Running Single Girder Electric Overhead Traveling Cranes Utilizing Under Running Trolley Hoist

- INEL Transportation Manual

- NUREG-0612, Control of Heavy Loads and Nuclear Power Plants

\section{C-3.6 SNF Packaging Systems}

- 10 CFR 72, Subpart F, Licensing Requirements for the Independent Storage of Spent Nuclear Fuel, General Design Criteria

- $\quad$ ANSI/ANS 57.9-1992, Design Criteria for an Independent Spent Fuel Storage Installation (Dry Type) 


\section{C-3.7 Storage}

- 10 CFR 71, Packaging and Transportation of Radioactive Material

- 10 CFR 72, Subpart F, Licensing Requirements for the Independent Storage of Spent Nuclear Fuel, General Design Criteria

- 10 CFR 72, Subpart K, Licensing Requirements for the Independent Storage of Spent Nuclear Fuel, General License for Storage of Spent Fuel at Power Reactor Sites

- 10 CFR 72, Subpart L, Licensing Requirements for the Independent Storage of Spent Nuclear Fuel, Approval of Spent Fuel Storage Casks

- 40 CFR 53, Ambient Air Monitoring Reference and Equivalent Methods

- $\quad 40$ CFR 58, Ambient Air Quality Surveillance

- $\quad$ ANSI/ANS 57.9-1992, Design Criteria for an Independent Spent Fuel Storage Installation (Dry Type)

- $\quad$ ANSI/ANS 57.10-1987, American National Standard Design Criteria for Consolidation of LWR Spent Fuel

- $\quad$ ANSI/AWS D1.1-1990, Structural Welding Code—Steel

\section{C-3.8 HVAC}

- 10 CFR 20, Standards for Protection Against Radiation

- 10 CFR 72, Subpart F, Licensing Requirements for the Independent Storage of Spent Nuclear Fuel, General Design Criteria

- 29 CFR 1910, Subpart G, Occupational Safety and Health Standards for General Industry, Occupational Health and Environmental Control

- 29 CFR 1910, Subpart Z, Occupational Safety and Health Standards for General Industry, Toxic and Hazardous Substances

- $\quad 40$ CFR 50, National Primary and Secondary Ambient Air Quality Standards

- 40 CFR 51, Requirements for Preparation, Adoption, and Submittal of Implementation Plans

- 40 CFR 52, Approval and Promulgation of Implementation Plans 
- $\quad 40$ CFR 53, Ambient Air Monitoring Reference and Equivalent Methods

- $\quad 40$ CFR 58, Ambient Air Quality Surveillance

- ANSI/ANS 57.9-1992, Design Criteria for an Independent Spent Fuel Storage Installation (Dry . Type)

- ANSI/ANS 57.10-1987, American National Standard Design Criteria for Consolidation of LWR Spent Fuel

- ANSI/ASME N509-1989, American National Standard for Nuclear Power Plant Air Cleaning Units and Components

- ANSI/ASME N510-1989, American National Standard for Testing of Nuclear Air-Cleaning Systems

- ASHRAE 90, American Society of Heating, Refrigerating, and Air-Conditioning, Energy Efficient Design of New Buildings Except Low-Rise Residential Buildings.

- IDAPA 16.01.01000-01999, Idaho Administrative Procedures Act, Clean Air Act

- MIL-F-51068C, Filter: Particulate High Efficiency, Fire Resistant

- MIL-F-51079A, Filter Medium: Fire Resistant, High Efficiency

\section{C-3.9 Mechanical Utilities}

- 10 CFR 72, Subpart F, Licensing Requirements for the Independent Storage of Spent Nuclear Fuel, General Design Criteria

- 29 CFR 1910, Subpart H, Occupational Safety and Health Standards for General Industry, Hazardous Materials

- 29 CFR 1910, Subpart J, Occupational Safety and Health Standards for General Industry, General Environmental Controls

- 29 CFR 1910, Subpart M, Occupational Safety and Health Standards for General Industry, Compressed Gas and Compressed Air Equipment

- $\quad$ ANSU/ANS 57.9-1992, Design Criteria for an Independent Spent Fuel Storage Installation (Dry Type)

- ANSU/API 620-1986, Rules for Design and Construction of Large, Welded, Low Pressure Storage Tanks 
- $\quad$ ANSI/API 650-1988, Welded Steel Tanks for Oil Storage (for tanks)

- $\quad$ ANSI/ASME B31.3-1990, Chemical Plant and Petroleum Refinery Piping.

\section{C-3.10 Electrical}

- 10 CFR 72, Subpart F, Licensing Requirements for the Independent Storage of Spent Nuclear Fuel, General Design Criteria

- 10 CFR 72, Subpart H, Licensing Requirements for the Independent Storage of Spent Nuclear Fuel, Physical Protection

- 10 CFR 73, Physical Protection of Plants and Materials

- 29 CFR 1910, Subpart S, Occupational Safety and Health Standards for General Industry, Electrical

- ANSI/ANS 8.3-1986, American National Standard Criticality Accident Alarm System

- $\quad$ ANSI/ANS 57.9-1992, Design Criteria for an Independent Spent Fuel Storage Installation (Dry Type)

- $\quad$ ANSI-N13.1-1969 (R 1983), Guide to Sampling Airborne Radioactive Materials in Nuclear Facilities

- $\quad$ NEC Article 250, Grounding

- NFPA-70, National Electric Code, 1996

- $\quad$ NFPA 780, Lightning Protection Code, 1996

- $\quad$ ANSI-N42.17B-1989 (R 1994), Performance Specifications for Health Physics Instrumentation-Occupational Airborne Radioactivity Monitoring Instrumentation.

\section{C-3.11 Safety}

- 10 CFR 20, Standards for Protection Against Radiation

- 10 CFR 72, Subpart F, Licensing Requirements for the Independent Storage of Spent Nuclear Fuel, General Design Criteria

- 10 CFR 72, Subpart I, Licensing Requirements for the Independent Storage of Spent Nuclear Fuel, Training and Certification of Personnel

- 10 CFR 73, Physical Protection of Plants and Materials 
- 10 CFR 830, Nuclear Safety Management

- 10 CFR 835, Occupational Radiation Protection

- 29 CFR 1910, Subpart C, Occupational Safety and Health Standards for General Industry, General Safety and Health Provisions

- 29 CFR 1910, Subpart E, Occupational Safety and Health Standards for General Industry, Means of Egress

- 29 CFR 1910, Subpart G, Occupational Safety and Health Standards for General Industry, Occupational Health and Environmental Control

- 29 CFR 1910, Subpart I, Occupational Safety and Health Standards for General Industry, Personal Protective Equipment

- 29 CFR 1910, Subpart J, Occupational Safety and Health Standards for General Industry, General Environmental Controls

- 29 CFR 1910, Subpart K, Occupational Safety and Health Standards for General Industry, Medical and First Aid

- 29 CFR 1910, Subpart L, Occupational Safety and Health Standards for General Industry, Fire Protection

- $\quad$ ANSI/ANS 8.1-1983, American National Standard Nuclear Criticality Safety in Operations with Fissionable Materials Outside Reactors

- ANSI/ANS 8.3-1986, American National Standard Criticality Accident Alarm System

- $\quad$ ANSI/ANS 8.17-1984 (R1989), American National Standard Criticality Safety Criteria for Handling, Storage, and Transportation of LWR Fuel Outside Reactors.

- ANSI/ANS 57.9-1992, Design Criteria for an Independent Spent Fuel Storage Installation (Dry Type)

- $\quad$ ANSI/ANS 57.10-1987, American National Standard Design Criteria for Consolidation of LWR Spent Fuel

- $\quad$ MII-F-51068C, Filter: Particulate High Efficiency, Fire Resistant

- ML-F-51079A, Filter Medium: Fire Resistant, High Efficiency

- $\quad$ NFPA 101, Life Safety Code 
- UFC, Uniform Fire Code

\section{C-3.12 Environmental}

- 10 CFR 1021, NEPA Implementing Procedures

- 10 CFR 1022, Compliance with Floodplain-Wetlands Environmental Review Requirements

\section{C-3.13 Safeguards and Security}

- 10 CFR 72, Subpart D, Licensing Requirements for the Independent Storage of Spent Nuclear Fuel; Records, Reports, Inspections, and Enforcement

- 10 CFR 72, Subpart H, Licensing Requirements for the Independent Storage of Spent Nuclear Fuel, Physical Protection

- 10 CFR 73, Physical Protection of Plants and Materials

- 10 CFR 75, Safeguards on Nuclear Material - Implementation of US/LAEA Agreement

- 10 CFR 1046, Physical Protection of Security Interests

- $\quad$ ANSI/ANS 57.9-1992, Design Criteria for an Independent Spent Fuel Storage Installation (Dry Type)

\section{C-3.14 Quality Assurance}

- 10 CFR 72, Subpart D, Licensing Requirements for the Independent Storage of Spent Nuclear Fuel, Records, Reports, Inspections, and Enforcement

- 10 CFR 72, Subpart G, Licensing Requirements for the Independent Storage of Spent Nuclear Fuel, Quality Assurance

- 10 CFR 72, Subpart I, Licensing Requirements for the Independent Storage of Spent Nuclear Fuel, Training and Certification of Personnel

- $\quad$ ANSU/ANS 57.9-1992, Design Criteria for an Independent Spent Fuel Storage Installation (Dry Type)

- $\quad$ ANSI/ASME NQA-1-1989, American National Standard Quality Assurance Program Requirements for Nuclear Power Plants 
Appendix D

\section{ICPP Spent Nuclear Fuel Dry Storage Project \\ Siting Study}


D-2 


\section{Appendix D \\ ICPP Spent Nuclear Fuel Dry Storage Project Siting Study}

\section{D-1. INTRODUCTION}

A study was performed to determine the best available location for siting the new Spent Nuclear Fuel (SNF) Dry Storage Facility. This facility will package existing and future SNF in a dual-purpose canister (DPC) and store temporarily on-Site. The facility will comprise a fuel transfer building (the Dry Transfer Cell [DTC]) and an aboveground storage area for storing the DPCs in precast concrete storage modules (the Dry Storage System [DSS]). Section D-2 reports the investigation of potential sites for the DTC. Section D-3 reports the investigation of potential sites for the DSS.

\section{D-2. DTC FACILITY SITING STUDY}

The Idaho National Engineering Laboratory (INEL) is committed to packaging existing and future spent nuclear fuel and placing the packages in dry storage, complying with 10 CFR 72. The SNF Dry Storage Facility will be designed to meet the requirements of the U.S. Nuclear Regulatory Commission (NRC) and associated regulatory guides, codes, and standards applicable to SNF storage. This facility will receive DOE SNF in good condition with no fuel cladding breaches, transfer the fuel to dual-purpose canisters (DPCs), and transfer the DPCs to interim storage modules on-Site. Ultimately, the SNF will be transported for final disposition off-Site.

The DTC will support cask maintenance, inspection, and transfer operations 24 hours a day. The facility will be sized to process 12 incoming SNF shipping casks per month.

\section{D-2.1 DTC Facility Objectives}

The facility objectives identified for this project are as follows:

- Provide transportation package (shipping cask) receiving, inspection, handling, and unloading

- Be able to decontaminate, perform minor maintenance, and temporarily store the transportation package

- Provide fuel unit verification

- Be able to transfer fuel unit from shipping buckets to storage buckets, and transfer storage buckets to lag storage

- Be able to transfer fuel unit and storage buckets to DPCs

- $\quad$ Be able to prepare DPCs for transfer to interim storage modules. 


\section{D-2.2. DTC Siting Criteria}

\section{D-2.2.1 Basic Facility Criteria}

The DTC will occupy approximately $10,700 \mathrm{ft}^{2}$ and be constructed of concrete and structural steel. Paved entrances and vehicle staging/parking areas shall be provided.

\section{D-2.2.2 Primary Facility Criteria}

D-2.2.2.1 Location. The DTC should be central to the areas it will support. Shipments to the facility will be made from off-Site and INEL facilities including Power Burst Facility (PBF), Test Area North (TAN), Argonne National Laboratory (ANL)-West, and from within the Idaho Chemical Processing Plant (ICPP) facility such as CPP-666, CPP-749, and the Independent Spent Fuel Storage Facility. OffSite shipments will be received from locations throughout the country. Shipments will be made mostly by truck, but rail shipments could also be expected in the future. The recommended site location should be close to existing facilities that can provide support services such as bus transportation, cafeteria, crafts/maintenance, fuel supply, and emergency response. Roadways should be of suitable design and construction to accommodate heavy truck traffic throughout the year.

D-2.2.2.2 Land Use/Zoning/Site Development. The location of the DTC should not conflict with past or future land use activities. Candidate sites must be located in areas zoned, or consistent with the handling and storage of spent nuclear fuel. An ideal site would require little site demolition and be relatively free of underground utility interferences. The floor height of the facility will be approximately $4 \mathrm{ft}$ above the surrounding grade, therefore the existing elevation of the proposed area should be at least $4,913 \mathrm{ft}$ to provide a floor elevation above the 100 -year flood height of $4,917 \mathrm{ft}$.

D-2.2.2.3 Environmental Impact. The DTC should be located in such a manner as to minimize negative environmental impacts. It is desirable to locate the facility within the ICPP plant boundaries to avoid undisturbed areas. Environmentally controlled or disturbed areas should be avoided.

D-2 2.2.4 Space. The DTC will occupy approximately $10,700 \mathrm{ft}^{2}$. Sufficient space for vehicle staging and parking should also be provided. Site selection should also consider space provisions for future expansion of this facility or an adjacent facility for repackaging and transferring damaged fuel units.

D-2.2.2.5 Utilities. The DTC should be located near existing facilities that can provide the following:

Water: (Both potable and fire) shall be, as a minimum, an 8-in. main, and provide 1,000 gpm. Potable water shall be supplied at $60 \mathrm{gpm}$ minimum.

Sanitary Sewer: An 8-in. sewer main connection is required as a minimum.

Service Waste: A service waste line with capacity for a 2-in. line connection is required.

Steam: A 12 -in. steam main with sufficient pressure for a 4-in. line connection.

Electrical Power/Telephone/Communications: 


\section{D-2.3 Alternate Sites Selected for Study}

The location of this facility at the INEL has been selected at the ICPP to consolidate fuel handling operations. The specific location at ICPP will be recommended by this study.

Preliminary screening of the available sites within the plant boundaries based solely on building size and transportation requirements for shipping and receiving limits the location to the southern end of the plant. Two sites in this vicinity have been selected for evaluation (see Figure D-1). The two sites are as follows:

- $\quad$ Site 1: Area south of the CPP-749 storage yard and east of CPP-603

- $\quad$ Site 2: Area Southeast of CPP-666.

\section{D-2.3.1 Site \#1 South of CPP-749}

D-2.3.1.1 Location. This location provides direct access to the plant perimeter road (Willow/Evergreen) which allows access to the west vehicle gate through an area of the plant with very little traffic. An existing rail spur cuts through the site for fuel shipments to CPP-603, which could be utilized for shipments to the DTC. Support services required for the facility and personnel are available within the ICPP.

D-2.3.1.2 Land Use/Zoning/Site Development. This area is next to CPP-603 (pool Storage) and CPP-749 Dry Fuel Storage area (underground). The area is free of existing structures and utilities that might interfere with new construction. The existing ground elevation of the area is approximately 4,914 ft. The plant perimeter road that accesses this location will require significant upgrading to accommodate the heavy truck traffic.

D-2.3.1.3 Environmental Impact. Currently there are two Environmentally Controlled Areas (ECAs 17-A, 17-B) within the proposed site. Contaminated soil excavated near CPP-603 was stored temporarily in these locations. These areas are listed as "No Action" sites and construction within the areas is not anticipated to be restricted, however there are required permits and risks assumed when excavating in these zones and it is highly desired to avoid these areas. The area south of the railroad tracks contains an additional environmentally controlled area (ECA 3). 


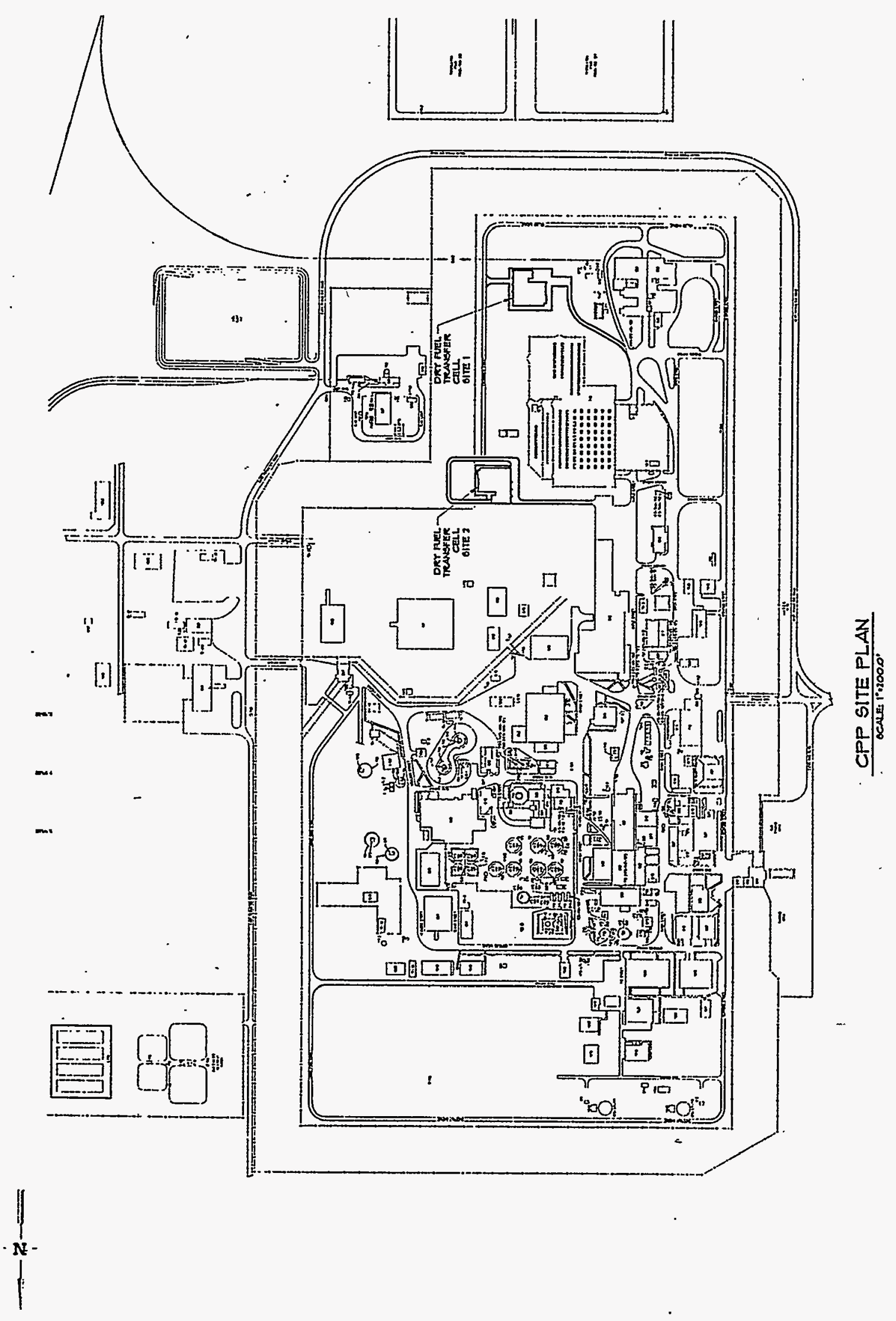

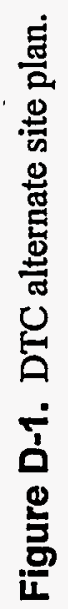


D-2.3.1.4 Space. This location has sufficient space for the DTC and a future expansion if required. Approximately $90,000 \mathrm{ft}^{2}$ is available between the CPP-749 storage yard and the existing railroad tracks.

D-2.3.1.5 Utilities. Utility connections are available from existing ICPP sources. The steam plant utility tunnel provides the majority of the utility connections, approximately $700 \mathrm{ft}$ from the proposed site. This area of the plant has few existing utilities and it is expected that the costs of extending the plant systems to this site will be significant.

Water: A 12-in. firewater main is available in the utility tunnel located. Approximately $1,900 \mathrm{ft}$ of 8 -in. ductile iron pipe would be required for the connection and building loop. A 4-in. potable water line (carbon steel) and a 3-in. potable water line (concrete lined) are available in the utility tunnel. Approximately $700 \mathrm{ft}$ of pipe would be required for the connection.

Sanitary Sewer: The nearest sewer main connection is located just east of CPP-665. Approximately $1300 \mathrm{ft}$ of 8 -in. pipe and 4 manholes would be required to tie into the existing 8 -in. main. The installation of at least one lift station is expected.

Service Waste: A 4-in. carbon steel service waste line is available in the utility tunnel. Approximately $700 \mathrm{ft}$ of carbon steel pipe is required.

Steam: A 12-in. high pressure steam line is located in the utility tunnel. Approximately $700 \mathrm{ft}$ of 4 -in. carbon steel pipe is required.

Electrical Power: Electrical power is available at load center \#4 requiring approximately $500 \mathrm{ft}$ of underground duct bank and conduit.

Telephone/Communications: Available nearby from an existing manhole. Approximately $500 \mathrm{ft}$ of duct bank and conduit required.

\section{D-2.3.2 Site \#2 Southeast of CPP-666}

D-2.3.2.1 Location. This location provides excellent access for shipments and personnel from CPP666. Shipments from off-Site are assumed would use the same routes that currently are used for fuel shipments to CPP-666. This site is closer to the plant support facilities such as cafeteria, bus service, medical etc. Fuel handling personnel and equipment could be readily shared between CPP- 666 and the new facility.

D-2.3.2.2 Land Use/Zoning/Site Development. This area is currently not in use and is separated from the remainder of the plant by the security perimeter established for the FPR construction project. This security fence is no longer in service and can be removed. Locating the facility in this area would be consistent with existing planning efforts to consolidate fuel handling operations. An access road would need to be constructed from CPP-666 and to the new facility. The location of the facility will need to consider avoiding underground utilities located in the vicinity.

D-2.3.2.3 Environmental Impact. There are no existing ECAs within this location. The use of this site would have little adverse effect on the local environment since the adjacent area is already used for a 
similar function. The greatest impact would result from the increased traffic to the area due to the fuel shipments.

D-2.3.2.4 Space. This site has sufficient available space for the proposed facility as well as a future expansion or an additional adjacent facility. Expansion to the south would be limited by the existing utility tunnel.

D-2.3.2.5 Utilities. Utility connections are available from existing plant sources. The steam plant utility tunnel provides the majority of the utility connections.

Water: A 12-in. firewater main is available in the utility tunnel located approximately $100 \mathrm{ft}$ from the proposed site. Approximately $800 \mathrm{ft}$ of 8 -in. pipe would be required for the connection and building loop. A 4-in. potable water line (carbon steel) and a 3-in. potable water line (concrete lined) is also available in the utility tunnel. Approximately $100 \mathrm{ft}$ of pipe would be required for the connection.

Sanitary Sewer: The nearest sewer main connection is located just east of CPP-665. Approximately $350 \mathrm{ft}$ of 8 -in. pipe and 1 manhole would be required to tie into the existing 8 -in. main.

Service Waste: A 4-in. carbon steel service waste line is available in the utility tunnel. Approximately $100 \mathrm{ft}$ of carbon steel pipe is required.

Steam: A 12-in. high pressure steam line is located in the utility tunnel. Approximately $100 \mathrm{ft}$ of carbon steel pipe is required.

Electrical Power: $150 \mathrm{Ft}$ of duct bank is required to access a manhole near CPP-665. Existing conduits are available to connect to Power Control Center \#3 (approximately $300 \mathrm{ft}$ ).

Telephone/Communications: Available nearby from an existing manhole. Approximately $300 \mathrm{ft}$ of duct bank is required.

\section{D-2.4 Preliminary Site Recommendation}

\section{D-2.4.1 General}

Each alternate site was evaluated against the siting criteria in the previous section. The results of this evaluation are summarized in the following tables. Each table rates the alternate sites against a specific criterion and its overall importance to the facility function. 


\section{D-2.4.2 Rating Values}

The scale used for evaluating the criteria were established as follows:

Importance Factor: 1 Least Important, good idea but not driven by criteria.

5 Most Important, critical to mission or significant cost impact.

Site Rating: $\quad 0 \quad$ Fails Criteria Requirements

1 Poor, meets criteria, significant costs, risks or unknowns. Substantial site work, demolition required. Inconvenient or inconsistent usage of site.

2 Average, meets criteria, some risks or unknowns. Normal level of site work, demolition or prep work. Some minor inconvenience or inconsistencies.

3 Good, meets criteria, little cost or inconvenience risk involved.

4 Excellent, Exceeds criteria, provides substantial cost savings, convenience, or flexibility. Ideal usage.

\section{D-2.4.3 Rating Tables}

\section{D-2.4.3.1 Location:}

\begin{tabular}{|c|c|c|c|c|c|}
\hline \multirow[b]{2}{*}{ Criterion Description } & \multirow{2}{*}{$\begin{array}{c}\text { Importance } \\
\text { Factor }\end{array}$} & \multicolumn{2}{|c|}{ Site 1 South of CPP-749 } & \multicolumn{2}{|c|}{ Site 2 East of CPP- 666} \\
\hline & & Rating & Score & Rating & Score \\
\hline Vehicle Access & 5 & 3 & 15 & 3 & 15 \\
\hline Rail Access & 3 & 4 & 12 & 1 & 3 \\
\hline Support Services & 3 & 3 & 9 & 3 & 9 \\
\hline Operations Support & 3 & 3 & 9 & 4 & 12 \\
\hline Storage Access & 4 & 4 & 16 & 4 & 16 \\
\hline Personnel Access & 1 & 2 & 2 & 3 & 3 \\
\hline Total Rating & & & 63 & & 58 \\
\hline
\end{tabular}




\section{D-2.4.3.2 Current Land Use}

\begin{tabular}{|c|c|c|c|c|c|}
\hline \multirow[b]{2}{*}{ Criterion Description } & Importance & \multicolumn{2}{|c|}{ S Site 1 South of CPP-749 } & \multicolumn{2}{|c|}{ Site 2 East of CPP- 666} \\
\hline & Factor & Rating & Score & Rating & Score \\
\hline $\begin{array}{l}\text { Consistent with fuel } \\
\text { handling operations }\end{array}$ & 4 & 4 & 16 & 4 & 16 \\
\hline $\begin{array}{l}\text { Required Site } \\
\text { Development }\end{array}$ & 3 & 1 & 3 & 2 & 6 \\
\hline Total Rating & & & 19 & & 22 \\
\hline
\end{tabular}

\section{D-2.4.3.3 Environmental Impact}

\begin{tabular}{|c|c|c|c|c|c|}
\hline \multirow[b]{2}{*}{ Criterion Description } & \multirow{2}{*}{$\begin{array}{l}\text { Importance } \\
\text { Factor }\end{array}$} & \multicolumn{2}{|c|}{ Site 1 South of CPP-749 } & \multicolumn{2}{|c|}{ Site 2 East of CPP- 666} \\
\hline & & Rating & Score & Rating & Score \\
\hline No negative impacts & 5 & 3 & 15 & 3 & 15 \\
\hline $\begin{array}{l}\text { Environmentally } \\
\text { controlled areas }\end{array}$ & 4 & 1 & 4 & 4 & 16 \\
\hline Total Rating & & & 19 & & 31 \\
\hline
\end{tabular}

\section{D-2.4.3.4 Space Requirements}

\begin{tabular}{|c|c|c|c|c|c|}
\hline \multirow[b]{2}{*}{ Criterion Description } & Importance & \multicolumn{2}{|c|}{ Site 1 South of CPP-749 } & \multicolumn{2}{|c|}{ Site 2 East of CPP- 666} \\
\hline & Factor & Rating & Score & Rating & Score \\
\hline Available area & 5 & 4 & 20 & 4 & 20 \\
\hline Future expansion area & 4 & 4 & 16 & 4 & 16 \\
\hline Total Rating & & & 36 & & 36 \\
\hline
\end{tabular}


D-2.4.3.5 Utilities (See attached cost comparison sheet)

\begin{tabular}{|c|c|c|c|c|}
\hline \multirow[b]{2}{*}{ Criterion Description } & \multicolumn{2}{|c|}{ Site 1 South of CPP-749 } & \multicolumn{2}{|l|}{ Site 2 East of CPP- 666} \\
\hline & Material & Cost & Material & Cost \\
\hline Water & $\begin{array}{l}1,900 \mathrm{ft} 8 \text {-in. ductile iron } \\
\text { pipe } 700 \mathrm{ft} 2 \text {-in. carbon steel } \\
\text { pipe }\end{array}$ & $\begin{array}{l}\$ 58,140 \\
\$ 7,455\end{array}$ & $\begin{array}{l}800 \mathrm{ft} 8 \text {-in. ductile iron pipe } \\
100 \mathrm{ft} 2 \text {-in. carbon steel pipe }\end{array}$ & $\begin{array}{l}\$ 40,650 \\
\$ 2,913\end{array}$ \\
\hline Sanitary Sewer & $\begin{array}{l}1,300 \mathrm{ft} 4 \text {-in. conc. pipe } \\
4 \text { manholes, two lift stations }\end{array}$ & $\$ 72,982$ & $\begin{array}{l}350 \mathrm{ft} \text { 4-in. conc. pipe } \\
1 \text { manhole }\end{array}$ & $\$ 16,111$ \\
\hline Power & $850 \mathrm{ft} \mathrm{duct} \mathrm{bank/conduit}$ & $\$ 116,578$ & $600 \mathrm{ft}$ duct bank/conduit & $\$ 80,826$ \\
\hline $\begin{array}{l}\text { Telephone } \\
\text { Communications }\end{array}$ & $850 \mathrm{ft}$ duct bank/conduit & $\$ 16,578$ & $600 \mathrm{ft}$ duct bank/conduit & $\$ 37,652$ \\
\hline Steam/ Condensate & $\begin{array}{l}700 \mathrm{ft} \mathrm{4-in.} \mathrm{carbon} \mathrm{steel} \mathrm{pipe} \\
700 \mathrm{ft} 2 \text {-in. carbon steel pipe }\end{array}$ & $\overline{\$ 15,596}$ & $\begin{array}{l}100 \mathrm{ft} 4 \text {-in. carbon steel pipe } \\
100 \mathrm{ft} \text { 2-in. carbon steel pipe }\end{array}$ & $\$ 3,768$ \\
\hline Service waste & $700 \mathrm{ft}$ 2-in. carbon steel pipe & $\$ 7,245$ & $100 \mathrm{ft} 2$-in. carbon steel pipe & $\$ 2,883$ \\
\hline High Pres. Air & $700 \mathrm{ft} 2$-in. & $\$ 7.245$ & $100 \mathrm{ft} 2$-in. & $\$ 727$ \\
\hline Trenching/ Backfill & $\begin{array}{l}\text { Excavation, sand bed, } \\
\text { asphalt patching, backfill, } \\
\text { cathodic protection }\end{array}$ & $\$ 342,475$ & $\begin{array}{l}\text { Excavation, sand bed, } \\
\text { asphalt patching, backfill, } \\
\text { cathodic protection }\end{array}$ & $\$ 119,049$ \\
\hline Total & & $\$ 644,293$ & & $\$ 304,578$ \\
\hline Importance Factor (5) & Rating 1 & 5 & Rating 3 & 15 \\
\hline
\end{tabular}


UTIUTY COST COMPARISON SUMMARY

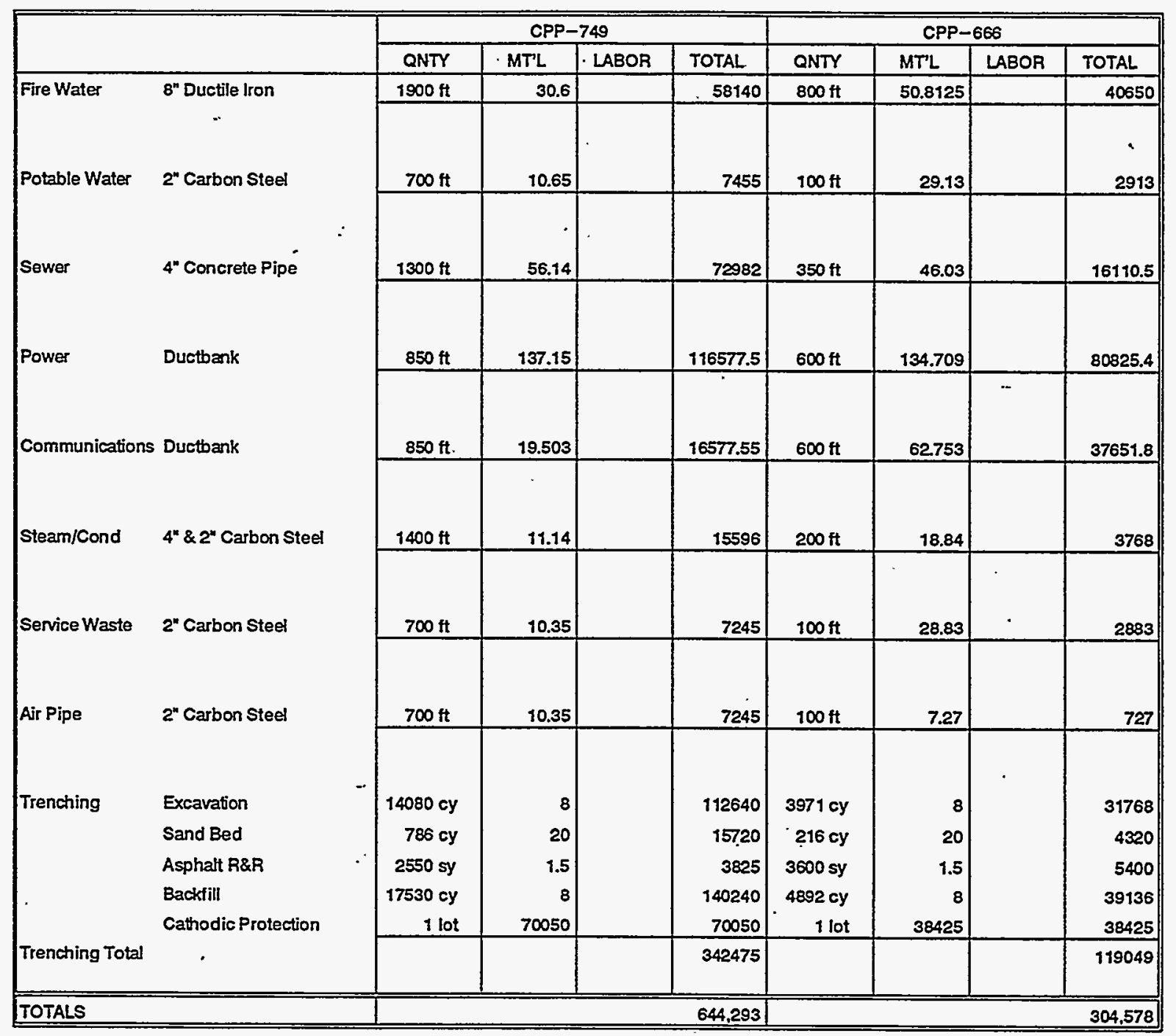

\section{NOTES}

1. The costs shown are drect construction costs only. Indrects (30\%), Procurement (1.5\%) and G\&A (30\%) have not been included.

2. Contingency ( $20 \%$ overall) and Management Reserve (10\% already included in Contingency) have not been included.

3. It is assumed that rock will not be encountered during excavation activities.

4. It is assumed that radiological contamination will not be encountered during excavation activities.

5. Allowances for hand excavation (around underground obstructions) have not been included.

6. It is assumed that the soil removed during excavation may be used for backfill, and additional/import backfill materials will not be required.

7. The cost shown for the ar pipe is based on he placement in the water trench.

8. The cost for the water pipes is based on separate trenches, however, it may be determined that the pipes may be placed in the same trench

9. The power and communication costs shown for CPP -749 are based on all cables being pulled through the same duct bank. Power and communication routes to CPP -666 require separate duct banks.

10. The costs shown for the sewer pipe and the service waste pipe are based on a placement distance of ' 10 ' from the water pipes. If it is necessary that the lines are placed closer together, or if the lines should cross, concrete encasement of the sewer and service waste lines will be required.

11. If plastic/PVC pipe could be used for any of the systems in leu of carbon steel, cathodic protection would not be required.

12. Unit costs per fineal foot for piping are a function of the total footage of pipe and fittings; relatively small units of pipe may have a large number of fittings and a resulting high cost per foot as compared to larger runs of larger pipe.

Figure D-2. Utility cost comparison summary. 


\section{D-2.5 Site Selection}

Based on Total Rating score

\begin{tabular}{lcc}
\hline Criterion & Site 1 South of CPP-749 & Site 2 East of CPP-666 \\
\hline Location & 63 & 58 \\
Land Use & 19 & 22 \\
Environmental & 19 & 31 \\
Space Requirements & 36 & 36 \\
Utilities & 5 & 15 \\
Total Rating & 142 & 162 \\
\hline
\end{tabular}

\section{D-2.6 Recommendation}

The recommended site for the DTC based on the criteria and evaluation results presented in this study is Site 2 east of CPP-666. This site provides very good access from CPP-666 and incoming shipments from exterior sources, with less required plant upgrades. This location centralizes fuel transfer/handling operations to two adjacent facilities. This site will provide convenient personnel access and is closer to the plant support facilities. A significant savings in utility installation costs can be made at this location. Approximately $\$ 339,715$ in direct costs can be saved by constructing at Site 2 . The greatest disadvantage of Site 2 is no existing provisions for rail shipments, which if considered, will offset the savings in utility costs.

The primary disadvantages of Site 1 is the substantial utility and road upgrades required. This location would also require excavation into environmentally controlled areas (for both the site and duct bank run), which should be avoided if possible. 


\section{D-3. DRY STORAGE SYSTEM SITING STUDY}

The DSS will receive and store dry storage canisters in aboveground concrete vaults. This study evaluated two potential locations for the DSS at the ICPP.

The DSS will consist of an outdoor, aboveground concrete pad with commercial vault-type concrete storage modules. Approximately 100 horizontal storage modules will be required for the DSS. The design of the storage area should also include provisions for other storage projects presently in the design or planning stage. Proper coordination of the design and location of the storage area will benefit all related projects by centralizing the storage area, loading and unloading equipment, and monitoring requirements. This study will assume that a centralized area will be used for the storage of approximately 240 storage modules to accommodate all projected storage requirements.

\section{D-3.1 DSS Objectives}

The objectives identified for the DSS are as follows:

- Provide vault-type storage system

- Monitor stored fuels and storage areas

- Confine the storage container

- $\quad$ Provide physical protection

- Be able to insert and retrieve canisters

- Be able to inspect storage vaults.

\section{D-3.2 Facility Siting Criteria}

\section{D-3.2.1 Basic Facility Criteria}

The DSS will provide a secured, monitored, aboveground storage area for interim storage of dry spent fuels prior to final off-Site disposal.

\section{D-3.2.2 Primary Facility Criteria}

D-3.2.2.1 Location. The location of the facility should allow convenient access by shipping vehicles without impacting the operation of the ICPP. Roadways should be of suitable design and construction to accommodate heavy truck traffic throughout the year. A road width of $32 \mathrm{ft}$ consisting of 20 - $\mathrm{ft}$-wide asphalt with compacted gravel shoulders is a minimum recommendation. The maximum wheel loads from the transport trailer are $15.5 \mathrm{kips}$ per axle (16 axles total) and for the tractor $15 \mathrm{kips}$ (front axle) and 22 kips (rear dual axles). Shipments will be made to the storage area from the new DTC, CPP-666 (FAST) and potentially from TAN. Shipments from the storage area will all be made to an off-Site 
location, therefore it is desirable to locate the site near an existing exterior gate to provide direct access. The proposed area should be somewhat isolated from normal plant vehicle and pedestrian traffic.

D-3.2.2.2 Land Use/Zoning/Site Development. The location of the DSS should not conflict with past or future land use activities. Candidate sites must be located in areas zoned, or consistent with the handling and storage of spent nuclear fuel. It is desirable to locate the storage area site to avoid flooding above the elevation of the module inlet vents ( $1 \mathrm{ft}$ above basemat) for abnormal conditions and above the bottom of the canisters ( $+5 \mathrm{ft} 8 \mathrm{in}$.) for extreme conditions. The elevation of the 100 -year flood at the ICPP is 4,917 ft, which would be considered an extreme condition. Assuming a 3-ft-thick subbase and basemat as a minimum, the required site ground elevation should be at least $4,914 \mathrm{ft}$. An ideal site would require very little site demolition and be relatively free of underground utility interferences.

D-3.2.2.3 Environmental Impact. The DSS should be located in such a manner as to minimize negative environmental impacts. It is desirable to locate the facility within the ICPP plant boundaries to avoid undisturbed areas. Environmentally controlled or disturbed areas should be avoided.

D-3.2.2.4 Space. The site selected for the DSS should be sized not only for the units identified for the DSF project, but should also include all other projected storage units of this type. A total area of $176,500 \mathrm{ft}^{2}$ will be required for 240 storage units. The location should also allow sufficient area to allow a convenient organized storage layout. A rectangular or square configuration is the most desirable.

D-3.2.2.5 Utilities. The DSS shall be located near existing facilities that can provide the following utility demands:

Electrical Power

Telephone/Communications

Security Alarms

\section{D-3.3 Alternate Sites Selected for Study}

Preliminary screening of the available sites at the ICPP based on the area required and transportation requirements limits the location to the southern end of the plant. Two sites were selected within the plant boundaries, and for comparison, two locations outside of the existing fence (see Figure D-3). The sites selected for the study are as follows:

Site \# 1 Area south of CPP-691 (FPR)

Site \# 2 South of CPP-749

Site \# 3 Outside of the plant boundary (two sites identified). 


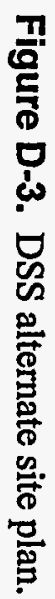

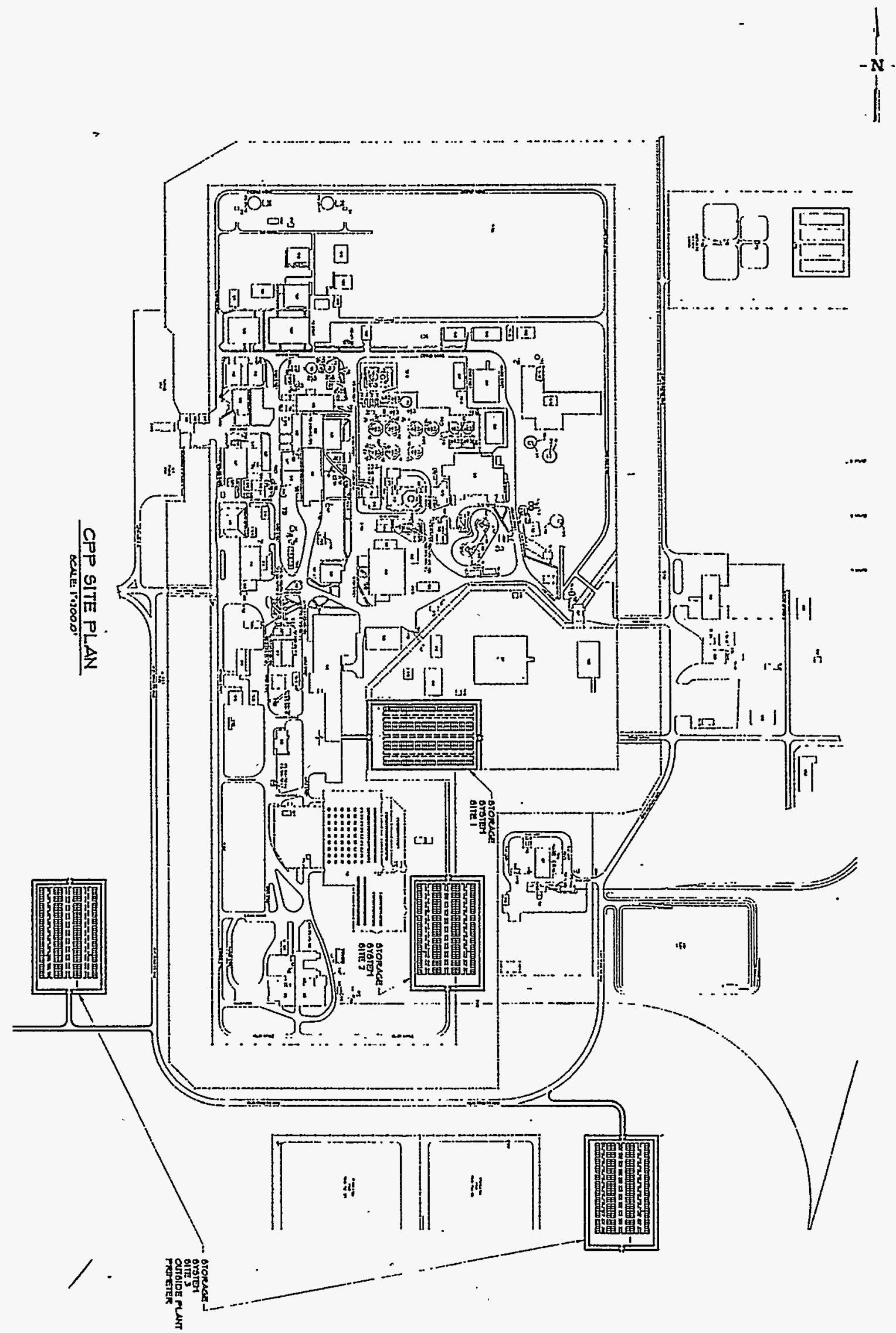




\section{D-3.3.1 Site 1 South of CPP-691 (FPR)}

D-3.3.1.1 Location. This site is within the current plant perimeter fencing and a portion of this fencing could be utilized for the new storage area secured perimeter. This location would provide good access from both the new DTC and CPP 666. The existing FPR gate could be used for shipping units off-Site directly out of the plant. This location is isolated from the populated areas of the plant and would provide an ideal secured area.

D-3.3.1.2 Land Use/Zoning/Site Development. The area currently is used for warehousing and storage for much of the FPR support facilities and materials. Use of this site would require the dismantling or demolition of several steel buildings currently unoccupied or used for storage and the removal of several trailers. The relocation of the trailers is currently underway. It might be possible to use one of the existing buildings for storage of the transport vehicle, or equipment. There currently is an existing underground firewater line through this area which might require relocating depending upon the final site layout. The existing ground elevation of the area is approximately $4,913 \mathrm{ft}$. Three $\mathrm{ft}$ of fill will be required to attain the base elevation required for the 100-year flood.

D-3.3.1.3 Environmental Impact. There are no environmentally controlled areas in this vicinity and . no other limiting environmental restrictions.

D-3.3.1.4 Space. This site has sufficient area for locating the proposed 240 units and could support a much larger facility while maintaining adequate isolation space from nearby facilities.

D-3.3.1.5 Utilities. Electrical power is available nearby at a Load Center 3, approximately $300 \mathrm{ft}$ from the proposed storage area.

\section{D-3.3.2 Site 2 East and South of CPP-749}

D-3.3.2.1 Location. This site is within the current plant security perimeter and would provide good access from the DTC and CPP-666. Off-Site shipments made from the storage area could not be made directly out of the plant unless a new gate is constructed. The alternative shipment routes would be via the plant perimeter road and out the east gate or FPR gate. This area is isolated from the populated areas of the plant.

D-3.3.2.2 Land Use/Zoning/Site Development. This area is next to CPP-603 (pool Storage) and CPP-749 Dry Fuel Storage area (underground). The FAST Facility (pool storage) is also nearby. The area is free of existing structures and utilities that might interfere with new construction. The plant perimeter road and tunnel crossings will need upgrading to accommodate the heavy truck traffic. The existing ground level of the area is approximately $4,914 \mathrm{ft}$. Two $\mathrm{ft}$ of fill will be required at this location to raise the modules above the 100 -year flood elevation.

D-3.3.2.3 Environmental Impact. Currently there are two ECAs (17-A, 17-B) next to the proposed site. Contaminated soil excavated near CPP-603 was stored temporarily in these locations. These areas are listed as "No Action" sites and construction within the areas should not be restricted; however, there are required permits and risks assumed when excavating in these zones and it is highly desirable to avoid 
these areas. The area south of the railroad tracks contains an additional ECA (ECA 3). These areas might be encountered during the installation of the site utilities and limit the usable area.

D-3.3.2.4 Space. This site has available area for locating the proposed 240 units but would require encroaching across Evergreen Avenue and into the current security perimeter. Approximately $90,000 \mathrm{ft}^{2}$ of area is available between the CPP-749 storage yard and the existing railroad tracks. The area south of the railroad tracks contains an additional ECA (ECA 3). Access to the CPP-749 could also be restricted depending upon the size of the storage area.

D-3.3.2.5 Utilities. Electrical power is available at load center \#4. Approximately $500 \mathrm{ft}$ of underground duct bank and conduit is required. Telephone and communications are available nearby from an existing manhole. Approximately $500 \mathrm{ft}$ of duct bank and conduit are required.

\section{D-3.3.3 Site 3 Outside of the plant boundaries}

D-3.3.3.1 Location. There are several possible locations outside of the plant perimeter fence that could be used for the storage area. For evaluation purposes, assume the area east of the percolation ponds and an area west of CPP-603, outside of the West Perimeter Road. Each of these sites would provide an isolated area with good road access. Shipments from the storage area could be made without impacting plant operations.

D-3.3.3.2 Land Use/Zoning/Environmental Impact. These areas are currently undisturbed sagebrush. Siting the storage area outside of the plant would increase the occupied land area of the plant and INEL, which is desirable to avoid.

D-3.3.3.3 Space. The areas outside of the plant have the greatest available space and flexibility for expansion at the ICPP.

D-3.3.3.4 Utilities. Electrical power at either proposed location should be readily available from the new plant power upgrade currently in design. 


\section{D-3.4 Preliminary Site Recommendation}

\section{D-3.4.1 General}

Each alternate site was evaluated against the siting criteria in the previous section. The results of this evaluation are summarized in the following tables. Each table rates the alternate sites against a specific criterion and its overall importance to the facility function.

\section{D-3.4.2 Rating Values}

The scale used for evaluating the criteria were established as follows:

Importance Factor:

1 Least Important, good idea, not driven by criteria

5 Most Important, critical to mission or significant cost impact.

Site Rating:

$0 \quad$ Fails Criteria Requirements

1 Poor, meets criteria, significant costs, risks or unknowns. Substantial site work, demolition required. Inconvenient or inconsistent usage of site.

2 Average, meets criteria, some risks or unknowns. Normal level of site work, demolition or prep work. Some minor inconvenience or inconsistencies.

3 Good, meets criteria, little cost, inconvenience, or risk involved.

4 Excellent, Exceeds criteria, provides substantial cost savings, convenience, or flexibility. Ideal usage. 
D-3.4.3 Rating Tables

D-3.4.3.1 Location:

\begin{tabular}{|c|c|c|c|c|c|c|c|}
\hline \multirow[b]{2}{*}{ Criterion Description } & \multirow{2}{*}{$\begin{array}{l}\text { Importance } \\
\text { Factor }\end{array}$} & \multicolumn{2}{|c|}{$\begin{array}{l}\text { Site } 1 \text { South of } \\
\text { CPP-691 (FPR) }\end{array}$} & \multicolumn{2}{|c|}{$\begin{array}{l}\text { Site } 2 \text { East of } \\
\text { CPP-749 }\end{array}$} & \multicolumn{2}{|c|}{$\begin{array}{c}\text { Site } 3 \text { Outside } \\
\text { Plant } \\
\end{array}$} \\
\hline & & Rating & Score & Rating & Score & Rating & Score \\
\hline Vehicle access & 4 & 3 & 12 & 2 & 8 & 2 & 8 \\
\hline Off-Site shipping access & 4 & 4 & 16 & 2 & $\dot{8}$ & 4 & 16 \\
\hline $\begin{array}{l}\text { Isolation from } \\
\text { operations/personnel }\end{array}$ & 3 & 3 & 9 & 3 & 9 & 4 & 12 \\
\hline $\begin{array}{l}\text { Existing security } \\
\text { provisions }\end{array}$ & 2 & 3 & 6 & 2 & 4 & 0 & 0 \\
\hline Total rating & & & 43 & & 29 & & 36 \\
\hline
\end{tabular}

\section{D-3.4.3.2 Current Land Use/Site Development}

\begin{tabular}{|c|c|c|c|c|c|c|c|}
\hline \multirow[b]{2}{*}{ Criterion Description } & \multirow{2}{*}{$\begin{array}{l}\text { Importance } \\
\text { Factor }\end{array}$} & \multicolumn{2}{|c|}{$\begin{array}{l}\text { Site } 1 \text { South of } \\
\text { CPP-691 (FPR) }\end{array}$} & \multicolumn{2}{|c|}{$\begin{array}{c}\text { Site } 2 \text { East of } \\
\text { CPP-749 } \\
\end{array}$} & \multicolumn{2}{|c|}{$\begin{array}{c}\text { Site } 3 \text { Outside } \\
\text { Plant } \\
\end{array}$} \\
\hline & & Rating & Score & Rating & Score & Rating & Score \\
\hline $\begin{array}{l}\text { Consistent with fuel } \\
\text { storage operations }\end{array}$ & 4 & 2 & 8 & 4 & 16 & 2 & 8 \\
\hline $\begin{array}{l}\text { Required site } \\
\text { development }\end{array}$ & 3 & 2 & 6 & 3 & 9 & 3 & 9 \\
\hline Utilities interference & 2 & 2 & 4 & 4 & 8 & 4 & 8 \\
\hline $\begin{array}{l}\text { Within developed plant } \\
\text { boundaries }\end{array}$ & $: 3$ & 3 & 9 & 3 & 9 & 0 & 0 \\
\hline Total rating & & & 24 & & 42 & & 25 \\
\hline
\end{tabular}




\section{D-3.4.3.3 Environmental Impact}

\begin{tabular}{lccccccc}
\hline & & $\begin{array}{c}\text { Site 1 South of } \\
\text { CPP-691 (FPR) }\end{array}$ & $\begin{array}{c}\text { Site 2 East of } \\
\text { CPP-749 }\end{array}$ & $\begin{array}{c}\text { Site 3 Outside } \\
\text { Plant }\end{array}$ \\
\cline { 2 - 8 } Criterion Description & $\begin{array}{c}\text { Importance } \\
\text { Factor }\end{array}$ & Rating & Score & Rating & Score & Rating & Score \\
\hline No negative impacts & 5 & 3 & 15 & 3 & 15 & 1 & 5 \\
$\begin{array}{l}\text { Environmentally } \\
\text { controlled areras }\end{array}$ & 4 & 3 & 11 & 1 & 4 & 3 & 12 \\
\begin{tabular}{l} 
Total rating \\
\hline
\end{tabular} & & & & & & & \\
\hline
\end{tabular}

\section{D-3.4.3.4 Space Requirements}

\begin{tabular}{lccccccc}
\hline & & $\begin{array}{c}\text { Site 1 South of } \\
\text { CPP-691 (FPR) }\end{array}$ & $\begin{array}{c}\text { Site 2 East of } \\
\text { CPP-749 }\end{array}$ & $\begin{array}{c}\text { Site 3 Outside } \\
\text { Plant }\end{array}$ \\
\cline { 2 - 8 } Criterion Description & $\begin{array}{c}\text { Importance } \\
\text { Factor }\end{array}$ & Rating & Score & Rating & Score & Rating & Score \\
\hline Available area & 5 & 3 & 15 & 3 & 15 & 3 & 15 \\
$\begin{array}{l}\text { Additional area for } \\
\begin{array}{l}\text { expansion and design } \\
\text { flexibility }\end{array}\end{array}$ & 1 & 3 & 3 & 2 & 2 & 4 & 4 \\
Total rating & & & & & & & \\
\hline
\end{tabular}

\section{D-3.5 Site Selection}

Based on Total Rating score

\begin{tabular}{lccc}
\hline \multicolumn{1}{c}{ Criterion } & $\begin{array}{c}\text { Site 1 South of } \\
\text { CPP-691 (FPR) }\end{array}$ & $\begin{array}{c}\text { Site 2 East } \\
\text { of CPP-749 }\end{array}$ & $\begin{array}{c}\text { Site 3 Outside of } \\
\text { Plant }\end{array}$ \\
\hline Location & 43 & 29 & 36 \\
Land Use & 24 & 42 & 25 \\
Environmental & 27 & 19 & 17 \\
Space requirements & 18 & 17 & 19 \\
Utilities & & & \\
Total rating & 112 & 107 & 97 \\
\hline
\end{tabular}




\section{D-3.6 Recommendation}

The recommended site for the storage facility based on the criteria and evaluation results of this study is Site 1 south of CPP-691 (FPR) over Site 2 by a very narrow margin. The two sites are within the current plant perimeter and very similar with respect to available area, environmental impacts, isolation, and security provisions. The main advantage of Site 1 is better vehicle/shipping access, less upgrades or modifications to the plant, and no risks encountered by encroaching into existing ECAs. The existing FPR gate and perimeter fencing can be utilized as much as possible and road upgrades can be kept to a minimum. Site \#2 does not currently allow shipments directly out of the plant and would require a new gate and a complete upgrade of the perimeter road system. 


\section{Appendix E}

\section{Criticality Safety Scoping Calculations for Selected Fuels in NUHOMS $\otimes$ Equipment}




\section{E-2}


Date: June 6,1996

To:

From:

Subject:

\author{
Leroy C. Lewis \\ Daryl A. Lopez
}

Valerie L. Putman Labsir ơ Putman
MS 3114

MS 3765

MS 3458
$6-3295$

$6-9020$

$6-9529$

\section{CRITICALITY SAFETY SCOPING CALCULATIONS FOR SELECTED FUELS IN NUHOMS ${ }^{\circledR}$ EQUIPMENT - VLP-06-96}

\section{INTRODUCTION}

Strategies for Department of Energy (DOE) spent nuclear fuel interim storage include use of a road-ready package with containers suitable for interim storage, intra-site transfers, transport to a permanent storage location, and final storage. The Standardized Nuclear Horizontal Modular Storage (NUHOMS) System and its associated equipment are designed for just such a strategy with spent commercial nuclear fuel. However, much of DOE's spent nuclear fuel is more highly enriched and it is more doubtful that credit will be permitted for fuel burnup and/or fixed neutron absorbers with DOE fuels.

At your request, Idaho National Engineering Laboratory (INEL) Criticality Safety personnel completed criticality safety scoping calculations for the following DOE fuels in NUHOMS equipment to assist in determining the number of containers needed and identifying possible basket design constraints:

- Fort St. Vrain (FSV) elements in the proposed FSV Dual Purpose Canister (DPC),

- Pathfinder Superheater elements in bucket BU-FS-910 in the proposed FSV DPC,

- Power Burst Facility (PBF) Driver Core assemblies in the NUHOMS 24P Dry Shielded Canister (DSC), which is also a DPC, and proposed 14-Tube DPC,

- Shippingport Light Water Breeder Reactor (LWBR) Canisters in the proposed LWBR DPC,

- Shippingport Pressurized Water Reactor (PWR) Core 2 Seed 1 (C2-S1) and Core 2 Seed 2 (C2-S2) assemblies in the NUHOMS 24P DSC, poison-modified NUHOMS 24P DSC, and proposed 14-Tube DPC,

- TREAT fuel in the NUHOMS 52B DSC, which is aiso a DPC, and proposed 14-Tube DPC, and

- TRIGA fuel rods in the proposed 14-Tube DPC.

Conclusions, design constraints, and scoping calculation limitations are described in this cover letter. Equipment, fuel, and fuel specific calculations are described in the attachment. 
Leroy C. Lewis and Daryl A. Lopez

Page 2 of 5

VLP-06-96

June 6, 1996

\section{SUMMARY}

Scoping calculations indicate these fuels will be critically safe in DPCs if specified constraints are satisfied. To envelope many hypothesized storage, handling, and transport conditions, calculations address optimum water moderation within a DPC, three full reflection conditions for a single DPC (water, concrete for storage vaults and wells, and stainless steel for transfer and shipping casks), and interaction between identical DPCs. However, several items are not addressed in this study. For example, models assume fuel and DPC equipment remain intact. Unaddressed items are listed at the end of this summary.

\section{General Constraints}

- The DPC, including associated buckets, tubes, and guide sleeves, and contained fuel must maintain their structural integrity.

- NUHOMS 24P and 52B DSC guide sleeve location and maximum cross-sectional inner-area are within design tolerances indicated by vendor literature (references $1,2,3$, and 4 of attachment).

- Assuming the pipes are sufficiently sturdy, the maximum inner diameter of tubes or buckets in the 14-Tube DPC is within design tolerances of nominal 12 in. schedule 10 pipe and the tube or bucket positions are near described locations in the DPC (Figure 4, page 7 of attachment).

\section{Constraints for FSV Elements in FSV DPC}

- FSV elements are limited to a maximum five elements stacked in each of seven FSV DPC guide sleeves, for 35 elements per DPC. This limit is the DPC physical capacity.

- Each FSV DPC guide sleeve wall must be made from at least $\frac{3}{4}$ in. thick stainless steel.

- Separation distances for FSV DPCs should be re-evaluated when lag storage designs and calculation method validations are available, if there are any further plans to place FSV elements in lag storage.

\section{Constraints for Pathfinder Superheater Elements in FSV DPC}

- Pathfinder Superheater elements in bucket BU-FS-910 are limited to a maximum 64 elements per bucket. This limit exceeds the planned loading of 62 elements per bucket.

- Pathfinder buckets, BU-FS-910, are limited to a maximum two buckets stacked in each of seven FSV DPC guide sleeves, for 14 buckets per DPC. This limit might exceed the DPC physical capacity and does exceed the anticipated total of seven buckets. 
Leroy C. Lewis and Daryl A. Lopez

Page 3 of 5

VLP-06-96

June 6, 1996

\section{Constraints for PBF Assemblies or Loose Rods in 14-Tube DPC or 24P DSC}

- PBF fuel is limited to a maximum 63 fuel rods per tier, with or without assembly canisters, and three tiers per 14-Tube DPC tube, for a total 2646 fuel rods per DPC. This limit exceeds the DPC physical capacity for fuel assemblies but not for loose rods.

- PBF fuel is limited to a maximum 63 fuel rods per tier, with or without assembly canisters, and three tiers per NUHOMS 24P DSC guide sleeve, for 4536 fuel rods per DSC. This limit exceeds the DSC physical capacity for fuel assemblies but not for loose rods.

- If loose rods are loaded or if assembly aluminum canisters could be compromised, physical barriers between tiers should be considered.

\section{Constraints for Shippingport LWBR Containers in LWBR DPC}

- Calculations for LWBR Canisters in the LWBR DPC are required before a loading limit can be determined. However, criticality safety calculations are on hold due to questions with ${ }^{233} U$ data in nuclide cross section libraries and with permission to take some credit for burnup.

\section{Constraints for Shippingport PWR Core 2 Assemblies in 14-Tube DPC}

- Shippingport PWR C2-S1 and -S2 assemblies are limited to one per tube or bucket in a 14-Tube DPC, for a total 14 assemblies per DPC. This limit is the DPC physical capacity.

- Shippingport PWR assemblies are relatively centered within the tubes or buckets.

\section{Constraints for TREAT Fuel in 14-Tube DPC or 52B DSC}

- TREAT fuel must not exceed the internal volume of buckets or tubes in the 14-Tube DPC. This limit exceeds the DPC physical capacity with the proposed four-compartment TREAT Bucket.

- TREAT fuel cans are limited to five cans stacked per guide sleeve in a 52B DSC, with or without fixed neutron absorber, for a total 260 cans per DSC. This limit exceeds the 52B DSC physical capacity.

- One fuel element is equivalent to one fuel can for criticality calculation purposes.

\section{Constraints for Al- and SS-Clad TRIGA Elements in 14-Tube DPC}

- Standard, pseudo-standard, ACPR, FLIP, and similar TRIGA elements are limited to a maximum one elèment per TRIGA Bucket compartment, 24 compartments per bucket, five buckets stacked per tube, in the proposed 14-Tube DPC, for a maximum 70 buckets or 1680 elements per.DPC. This loading is the DPC physical capacity with this bucket design. 
Leroy C. Lewis and Daryl A. Lopez

Page 4 of 5

VLP-06-96

June 6, 1996

- Elements must be verified to conform to the following generic description: initially stainless steel, Incoloy, or aluminum clad, outer diameter between 1.3 and 1.8 in., nominal 15 in. maximum active fuel length, $165 \mathrm{~g}{ }^{235} \mathrm{U}$ per element maximum at beginning-of-life (BOL), $\mathrm{U}$ Zr-hydride fuel matrix, and without exotic materials which are significantly better moderators than water or hydride. Verification is necessary because there are a wide variety of elements identified with the TRIGA name, some of which might not be enveloped by fuel models here.

- Instrumented elements and fuel follower control elements for these fuel types are acceptable.

- Declad elements are acceptable if they maintain clad fuel geometry.

- One rod of a TRIGA 4-rod cluster counts as one standard TRIGA element.

- These elements may be intermixed within DPCs, tubes, and buckets.

- TRIGA Bucket outer walls must be made from nominal 12 in. schedule 10 stainless steel pipe. Smaller diameters and/or thicker walls are acceptable.

- TRIGA Bucket compartment walls are made from nominal $\frac{1}{8}$ in. thick stainless steel. Thicker walls are acceptable.

\section{Constraints for Small-Diameter TRIGA Elements in 14-Tube DPC}

- Although not recommended because of its inefficiency, small-diameter TRIGA elements may be loaded in the same manner as pseudo-standard TRIGA elements (maximum one element per TRIGA Bucket compartment, 24 compartments per bucket, five buckets stacked per tube in the proposed 14-Tube DPC). If this strategy is selected each small diameter element counts as one pseudo-standard element.

- Otherwise, small-diameter TRIGA elements are limited to a maximum four elements per TRIGA Bucket compartment, 24 compartments per bucket, five buckets stacked per tube in the proposed 14-Tube DPC, for a maximum 6720 elements per DPC.

- Small-diameter TRIGA elements must be verified to conform to the following generic description: initially stainless steel, aluminum, or Incoloy clad, nominal 0.54 in. maximum outer diameter, nominal 22 in. maximum active fuel length, $55 \mathrm{~g}{ }^{235} \mathrm{U}$ maximum per element at beginning-of-life, U-Zr-hydride fuel matrix, and without exotic materials which are significantly better moderators than water or hydride. Verification is necessary because descriptions for some TRIGA fuels, such as high-powered TRIGA, had to be assumed and therefore might not be enveloped by fuel models here.

- Instrumented elements and fuel follower control elements for these fuel types are acceptable. 
Leroy C. Lewis and Daryl A. Lopez

Page 5 of 5

VLP-06-96

June 6, 1996

- Declad elements are acceptable if they maintain clad fuel geometry.

- TRIGA Bucket outer walls must be made from nominal 12 in. schedule 10 stainless steel pipe. Smaller diameters and/or thicker walls are acceptable.

- TRIGA Bucket compartment walls must be made from nominal $\frac{1}{8}$ in. thick stainless steel. Thicker walls are acceptable.

- Intermixing small-diameter elements, at more than one element per compartment, with regular diameter elements in the same bucket or DPC should not be allowed without further evaluation. The intended loading is probably safe, but intermixing increases the probability that small and regular diameter elements would be put in the same compartment, an abnormal condition not addressed in this scoping study.

\section{Items Not Addressed}

Scoping calculations do not address several items which should eventually be addressed through criticality safety evaluations, safety analysis, and/or loading limits, including:

- Effects of uncertainties such as design tolerances in manufacturing DPCs and some fuels,

- Calculation method validation,

- Mixing fuel types within one DPC,

- Loss of fuel, tube, bucket, sleeve, and/or DPC structural integrity, especially hypothesized rubblized end-of-life conditions for the final storage facility,

- Use of carbon steel rather than stainless steel where credit for steel was needed to demonstrate criticality safety, although this substitution should not have a significant adverse effect, and

- BER-TRIGA fuel.

VLP

Attachment

$\begin{array}{llll}\text { cc: } & \text { Soon Sam Kim } & \text { MS } 3458 & 6-7634 \\ \text { Mark N. Neeley } & \text { MS 3458 } & 6-7635 \\ \text { Charles E. Stuart } & \text { MS 3458 } & 6-9489 \\ \text { J. Todd Taylor } & \text { MS 3458 } & 6-9656\end{array}$


Attachment

June 6, 1996

VLP-06-96

Page 1

\section{TABLE OF CONTENTS}

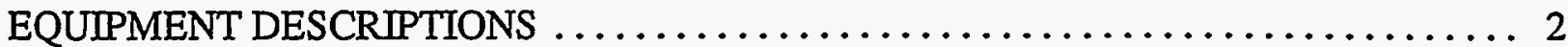

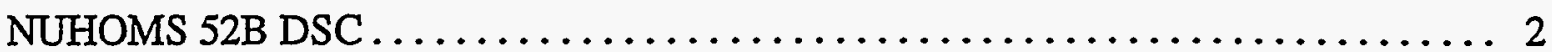

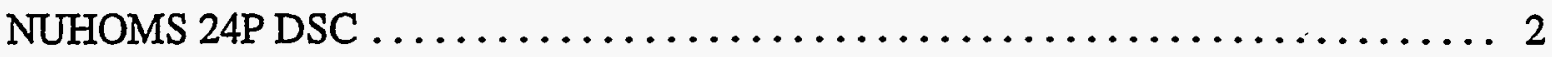

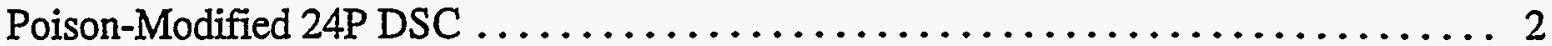

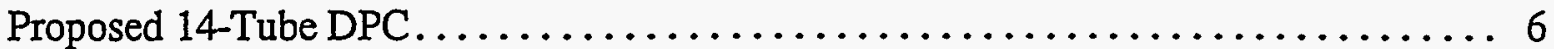

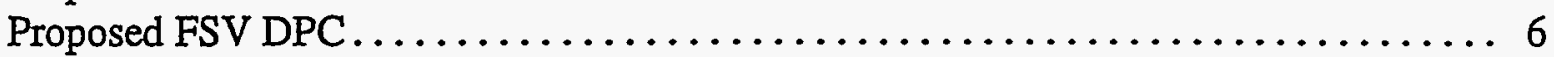

Proposed LWBR DPC . . . . . . . . . . . . . . . . . . . . . . . . 6

Dry Storage Vaults, Wells, and Arrays . . . . . . . . . . . . . . . . . . . 6

Shipping and Transfer Casks. . . . . . . . . . . . . . . . . . . . . 11

FORT ST. VRAIN (FSV) FUEL, STORAGE, and TRANSPORT . . . . . . . . . 12

PATHFINDER SUPERHEATER FUEL, STORAGE, and TRANSPORT . . . . . . 18

POWER BURST FACILITY (PBF) FUEL, STORAGE, and TRANSPORT . . . . . . . 22

SHIPPINGPORT LWBR FUEL, STORAGE, and TRANSPORT ............. 29

SHIPPINGPORT PWR FUEL, STORAGE, and TRANSPORT . . . . . . . . . . 30

TREAT FUEL, STORAGE, and TRANSPORT $\ldots \ldots \ldots \ldots \ldots \ldots \ldots \ldots \ldots \ldots$

TRIGA FUEL, STORAGE, and TRANSPORT................... 43

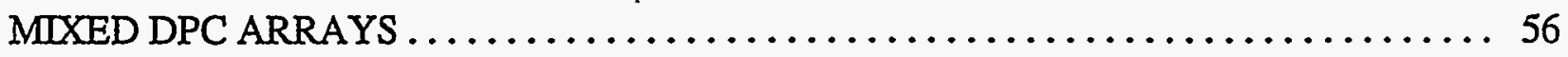

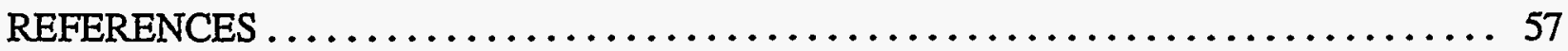


Attachment

June 6, 1996

VLP-06-96

Page 2 of 58

\section{EOUIPMENT DESCRIPTIONS}

\section{NUHOMS 52B DSC}

For purposes of this study the NUHOMS 52B DSC includes canister shell, 52 guide sleeves, neutron poison plates between any two guide sleeves within the shell, and basket structure (spacer discs, etc.) for positioning sleeves and plates. The shell is nominally a $67 \frac{1}{4}$ in. outer diameter, circular cylinder with a $\frac{5}{8}$ in. thick stainless steel wall. Guide sleeves are square cylinders with a nominal 6 in. interior width and an approximate 177 in. usable length. Between each guide sleeve pair there is a nominal $6.3 \mathrm{in}$. wide, 0.1345 in. thick neutron absorber sheet with $75 \mathrm{wt} \%$ boron. Figure 1 shows the 52B DSC model developed by Mark Neeley which assumes DSC metals are stainless steel, modelled as either moderator or SS304, and which neglects fixed neutron absorbers. The 52B DSC is described in more detail in vendor literature. ${ }^{1,2,3}$

\section{NUHOMS 24P DSC}

For purposes of this study the NUHOMS 24P DSC includes canister shell, 24 guide sleeves, and basket structure for positioning sleeves. The DSC does not include fixed neutron poisons. The shell is nominally a $67 \frac{1}{4}$ in. outer diameter, circular cylinder with a $\frac{5}{8}$ in. thick stainless steel wall. Guide sleeves are square cylinders in two sizes, both with slightly more than 9 in. outside width and with approximately 173 in. usable length. Figure 2 shows the 24P DSC model developed by Chuck Stuart, which assumes DSC metals are stainless steel, modelled as moderator or SS304. The DSC basket includes thick steel end pieces which were neglected for consistency between various canisters models. This should have negligible effect on conclusions because most fuels are essentially infinite length in a fully loaded DSC. Fuel-specific calculations with infinite $(20 \mathrm{~cm}$ or more) steel reflectors envelope actual end-piece thicknesses. The 24P DSC is described in more detail in vendor literature. ${ }^{2,3,4}$,

\section{Poison-Modified 24P DSC}

One DSC design, similar to the 24P DSC, includes neutron poison (absorber) either in or between guide sleeves. Material, thickness, and location strategy for poison plates in the 52B DSC were used to model a poison-modified 24P DSC because we did not have sufficient design information. Figure 3 shows the poison-modified 24P DSC model developed by Chuck Stuart. This model is identical to the 24P DSC model (Figure 2, page 4) except for poison plates. Use of this poisoned DSC was investigated as requested but its use is not recommended because the Nuclear Regulatory Commission has not yet ruled on the issue of fixed poisons with highly enriched fuels. 
Attachment

June 6, 1996

VLP-06-96

Page 3 of 58

poison plate: nominal 6.3 in. (16

$\mathrm{cm}$ ) wide; 0.1345 in.

$(0.3416 \mathrm{~cm})$ thick $75 \mathrm{wt} \%$ boron

modelled as moderator; same
length as DSC shell

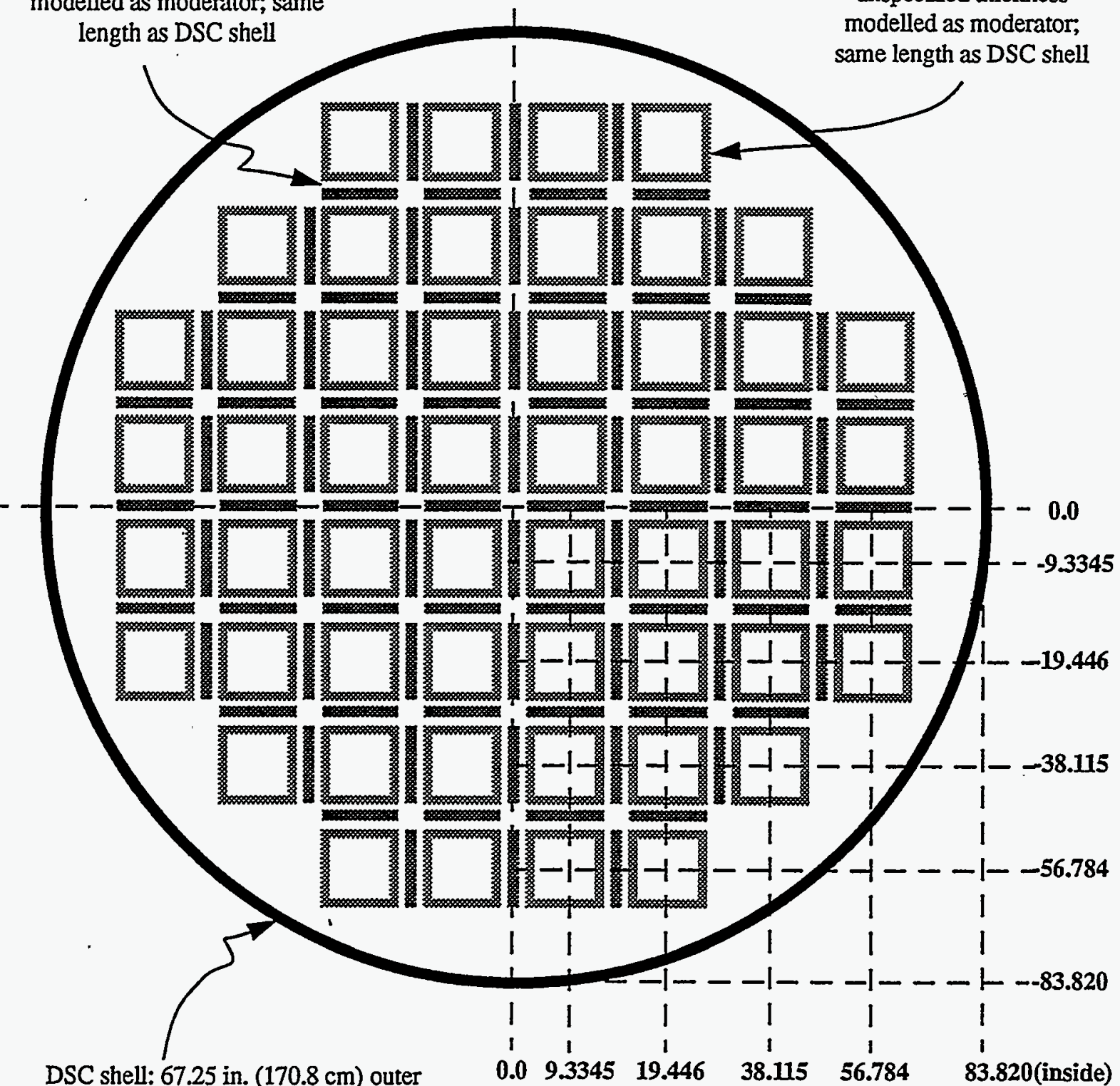

DSC shell: 67.25 in. $(170.8 \mathrm{~cm})$ outer

$\begin{array}{lll}0.0 & 9.3345 \quad 19.446\end{array}$

$38.115 \quad 56.784$

83.820(inside)

diameter, $0.625 \mathrm{in}$. $(1.5875 \mathrm{~cm})$ thick steel

modelled as moderator or SS304; length

all unlabeled dimensions in $\mathrm{cm}$

guide sleeve: nominal 6 in

$(15.24 \mathrm{~cm})$ inner width;

unspecified thickness

modelled as moderator;

varied to match modelled fuel stack height,

177 in. $(449.58 \mathrm{~cm})$ maximum

Figure 1 NUHOMS 52B DSC Model 
Attachment

June 6, 1996

VLP-06-96

Page 4 of 58

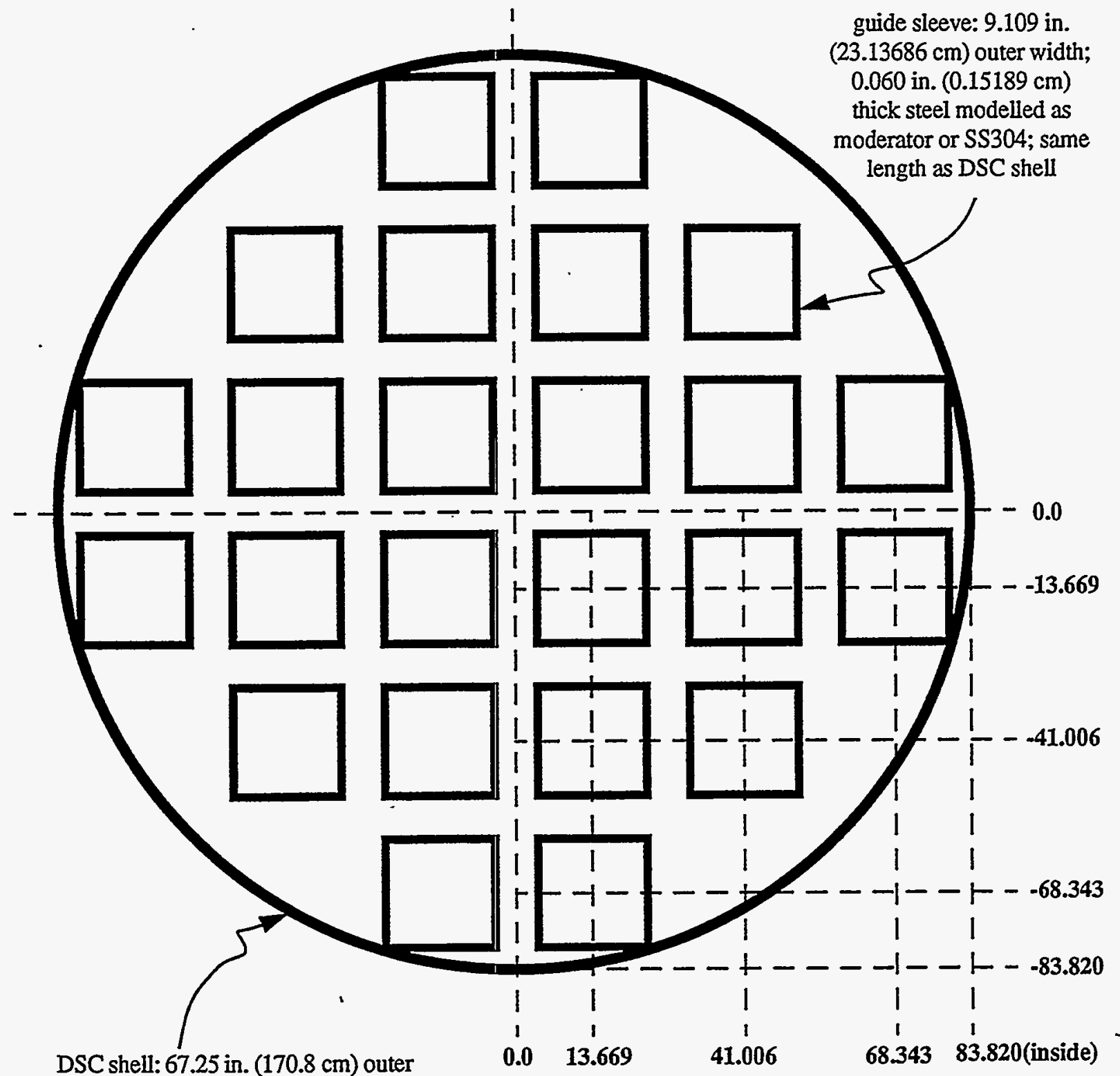

diameter, 0.625 in. $(1.5875 \mathrm{~cm})$ thick

steel modelled as moderator or

SS304; length varied to match

modelled fuel stack height, 187 in.

$(474.98 \mathrm{~cm})$ maximum

all unlabeled dimensions in $\mathrm{cm}$ 
Attachment

June 6, 1996

VLP-06-96

Page 5 of 58

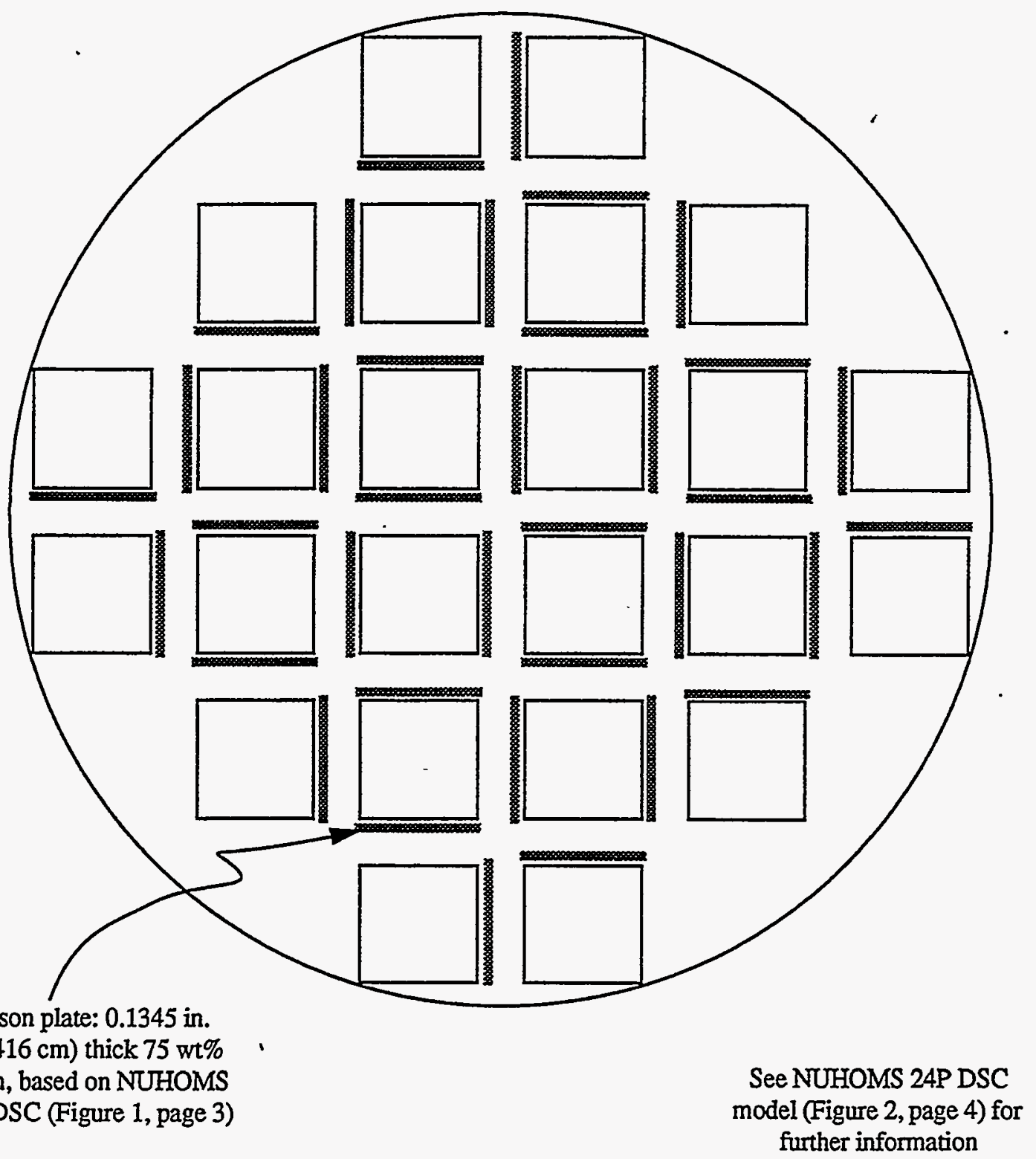

Figure 3 Poison-Modified 24P DSC Model 
Attachment

June 6, 1996

VLP-06-96

Page 6 of 58

\section{Proposed 14-Tube DPC}

For purposes of this study the proposed 14-Tube DPC includes canister shell (assumed to be the 24P DSC shell), 14 tubes or bucket-openings (analogous to guide sleeves in the 24P DSC), and basket structure for positioning tubes or buckets. 5 The DPC does not include fixed neutron absorbers. Figure 4 shows the 14-Tube DPC model developed by Chuck Stuart. Buckets or bucket stacks are considered to be DPC tubes, assumed to be made from 12 in. schedule 10 pipe. Additional bucket structural material is described as necessary with fuel-specific calculations. All materials are assumed to be stainless steel, modelled as moderator or SS304.

\section{Proposed FSV DPC}

For purposes of this study the proposed FSV DPC includes canister shell (assumed to be the 24P DSC shell), seven hexagonal guide sleeves (analogous to guide sleeves in the 24P DSC), and basket structure for positioning sleeves. 5 The DPC does not include fixed neutron absorbers. Figure 5 shows the FSV canister model developed by Soon Sam Kim. Materials are assumed to be stainless steel, modelled as moderator, SS316, or SS304. Guide sleeves are assumed to be butted against each other.

\section{Proposed LWBR DPC}

For purposes of this study the proposed LWBR DPC includes canister shell (assumed to be the 24P DSC shell), guide opening(s) for Shippingport LWBR Storage Canisters (analogous to guide

sleeves in the 24P DSC), and basket structure for positioning LWBR Storage Canisters. ${ }^{5}$ The DPC does not include fixed neutron absorbers. Depending on criticality safety and thermal limitations, there will be one to three openings for LWBR Canisters. Figure 6 shows the three-opening LWBR DPC model developed by Valerie Putman. All materials are assumed to be stainless steel, modelled as moderator or SS304.

\section{Dry Storage Vaults, Wells, and Arrays}

Several dry storage designs exist. Most designs involve a thick concrete cuboid with interior steel structure to hold one DPC and with a thick steel or lead-and-steal door. Such vaults provide near neutronic-isolation between DPCs in adjacent vaults. For a single DPC, these designs are enveloped by modelling a tight-fitting, thick concrete reflector around all sides of a DPC, as shown in Figure 7, to envelope worst-case concrete reflection. For an array of DPCs, a square-pitch twodimensional infinite array with varying concrete divider thicknesses are modelled, as shown in Figure 8, to identify minimum thicknesses needed to isolate DPCs. Figures are included with fuelspecific calculations which use other models. 


\section{Attachment}

June 6, 1996

VLP-06-96

Page 7 of 58

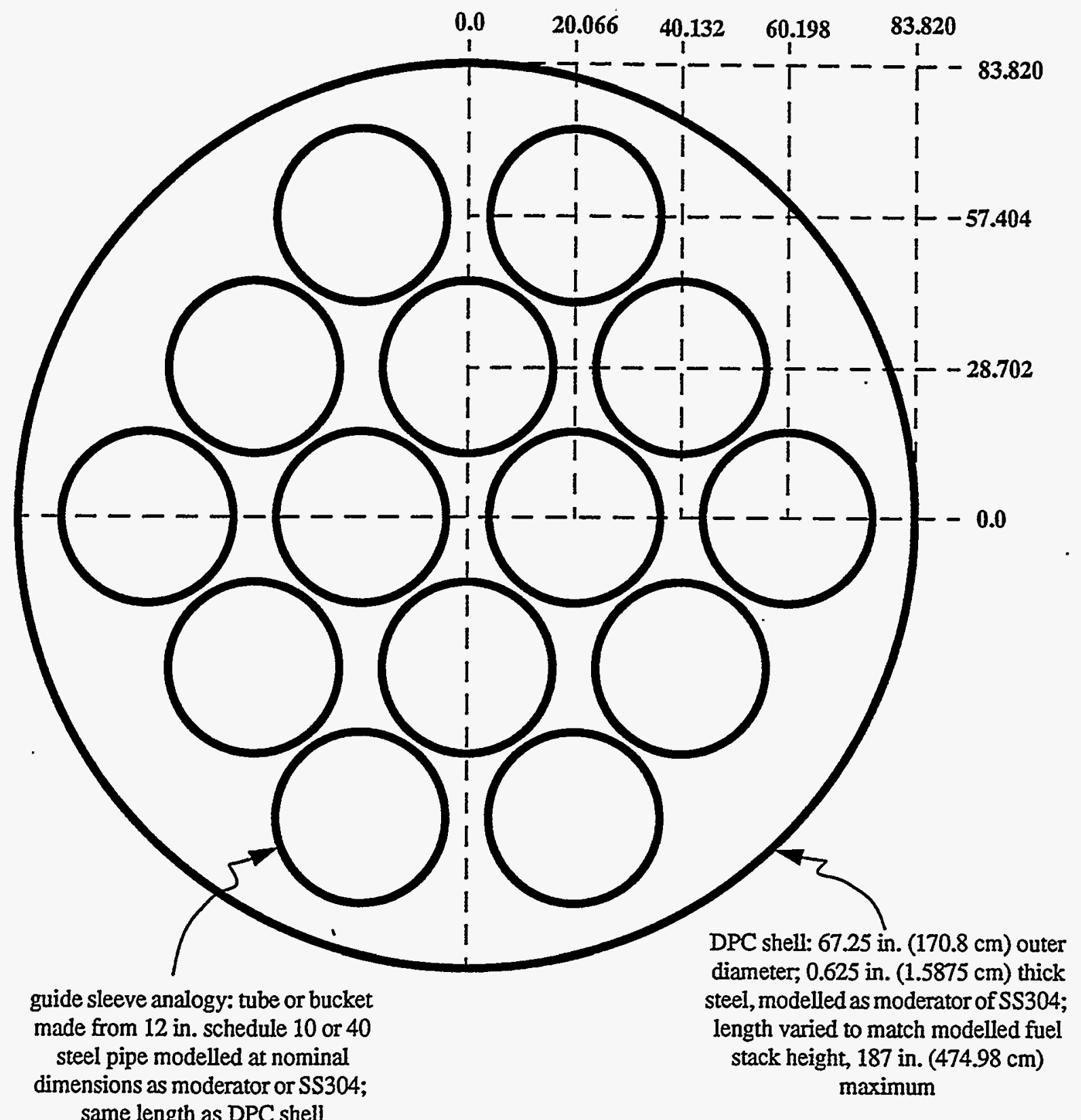

all unlabeled dimensions in $\mathrm{cm}$

Figure 4 Proposed 14-Tube DPC Model 
Attachment

June 6, 1996

VLP-06-96

Page 8 of 58

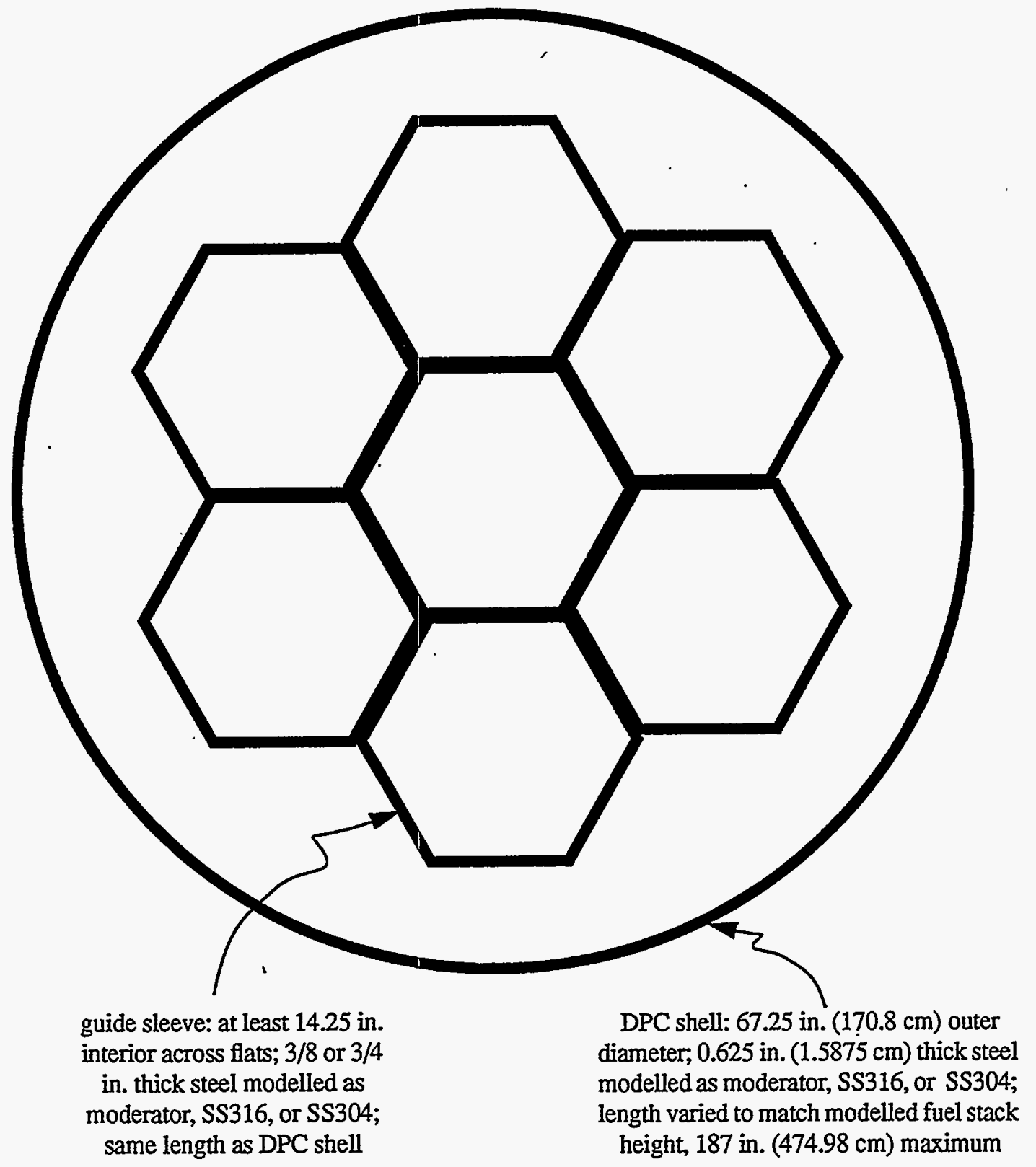

Figure 5 Proposed FSV DPC Model 
-Attachment

June 6, 1996

VLP-06-96

Page 9 of 58

guide sleeve analogy: canister opening in horizontal steel plates, at least 25.5 in. $(64.77 \mathrm{~cm})$ outer diameter, same length as DPC shell

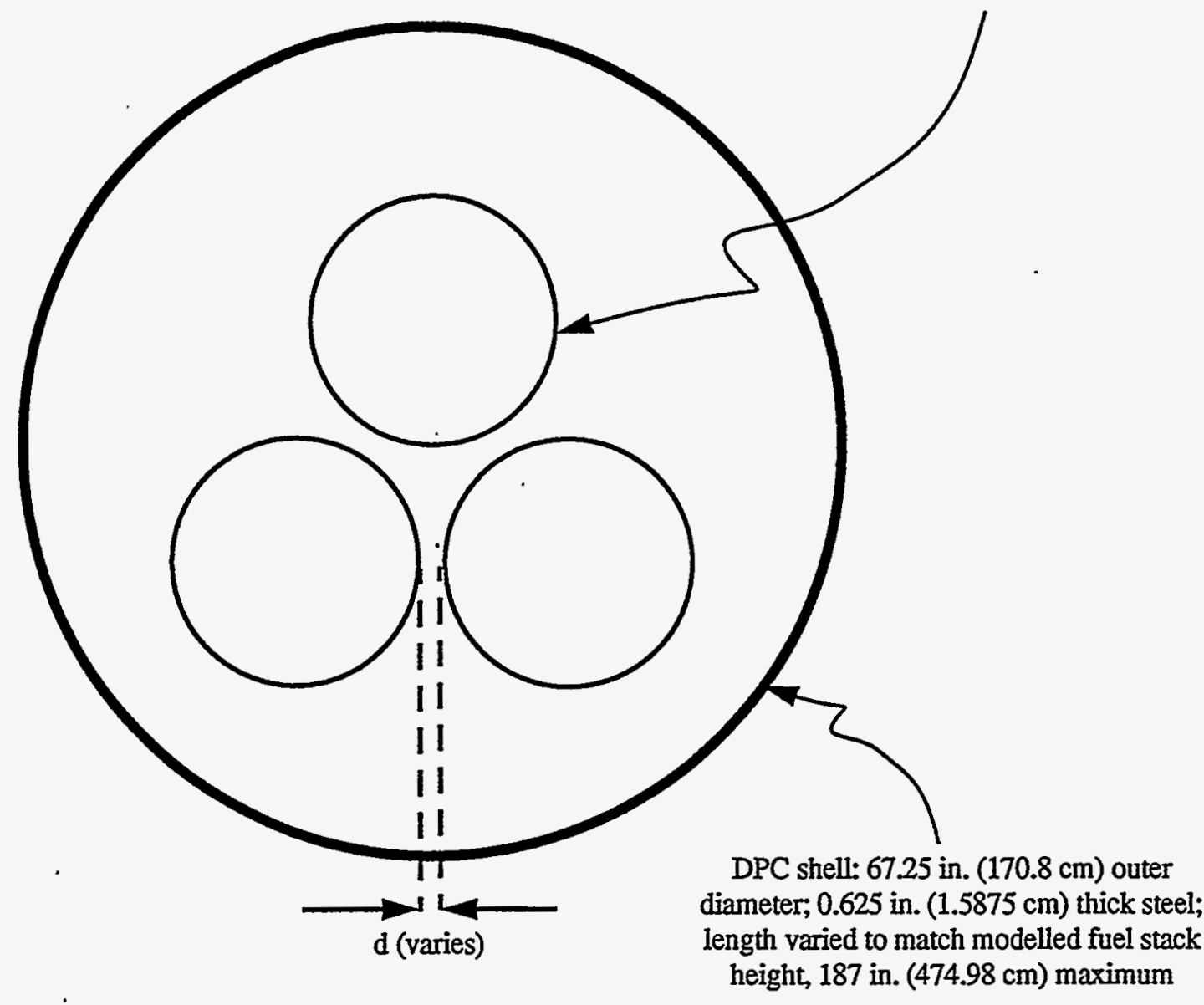

Figure 6 Proposed LWBR DPC Model 
Attachment

June 6, 1996

VLP-06-96

Page 10 of 58

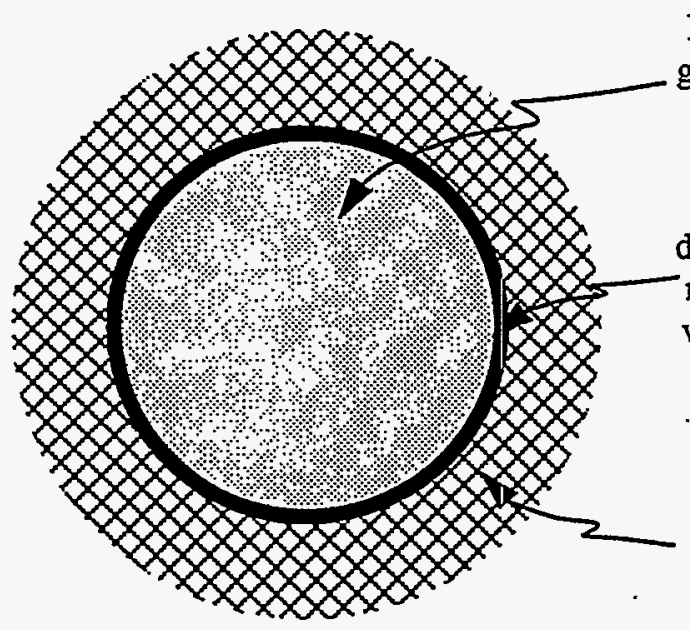

Moderated fuel array, with or without guide sleeves, buckets, etc. See figures of fuel-specific models.

DPC shell: 67.25 in. $(170.8 \mathrm{~cm})$ outer diameter, 0.625 in. $(1.5875 \mathrm{~cm})$ thick steel modelled as moderator or SS304; length varied to match fuel stack height, 187 in.

$(474.98 \mathrm{~cm})$ maximum

Concrete reflector: regular or ICPP concrete, 30 to $63 \mathrm{~cm}$ thick, tight fitting to envelope single DCP in storage vault, well, or hot cell

Figure 7 Single Concrete-Reflected DPC Model for Generic Vault Conditions

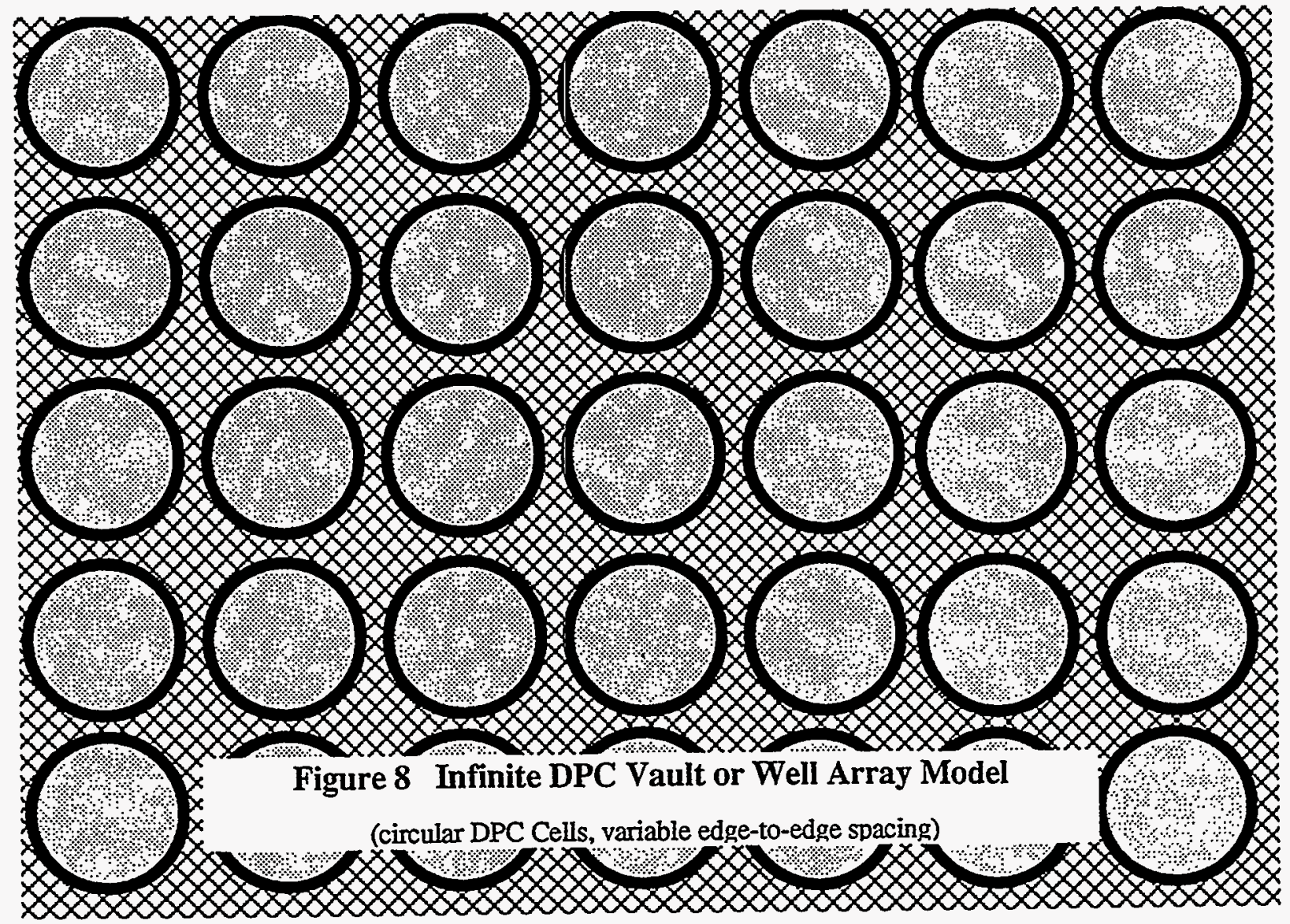


Attachment

June 6, 1996

VLP-06-96

Page 11 of 58

\section{Shipping and Transfer Casks}

Various NUHOMS casks are available for moving DPCs. Casks vary in length, wall thickness, and types of shielding. Models of thick, tight fitting steel reflectors should envelope or approximate reflector effects for most of these casks. Figures are included with fuel-specific calculations which use different cask reflector models. These other models are based on a combination of the NUHOMS's Multi-Purpose Cask (MP-187) and On-Site Transfer Cask. ${ }^{2,3}$

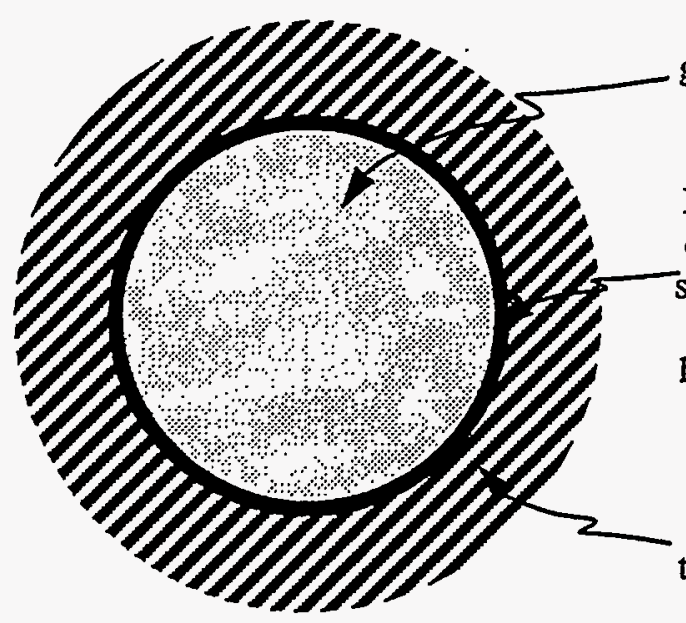

Moderated fuel array, with or without guide sleeves, buckets, etc. See figures of fuel-specific models.

DPC shell: 67.25 in. $(170.8 \mathrm{~cm})$ outer diameter, $0.625 \mathrm{in}$. $(1.5875 \mathrm{~cm})$ thick steel modelled as moderator or SS304;

length varied to match fuel stack height, 187 in. $(474.98 \mathrm{~cm})$ maximum

SS304 reflector: 20 to $63 \mathrm{~cm}$ thick, tight fitting to envelope single DPC in transfer or transport cask

Figure 9 Model of Single Steel-Reflected DPC for Generic Cask Conditions 
Attachment

June 6, 1996

VLP-06-96

Page 12 of 58

\section{FORT ST. VRAIN (FSV) FUEL. STORAGE, AND TRANSPORT}

FSV fuel elements are graphite blocks containing a triangular-pitched array of cylindrical fuel rods, poison rods, and coolant channels. Each element measures approximately 31.22 in. $(79.2 \mathrm{~cm})$ axially and $14.09 \mathrm{in} .(35.8 \mathrm{~cm})$ across the flats of a hexagonal radial surface $(8.23 \mathrm{in}$. or $20.9 \mathrm{~cm}$ side length for each sides). Elements are described more completely in reactor characterization reports. ${ }^{6}$

FSV fuel elements will physically fit only in the proposed FSV and LWBR DPCs, but more efficient packing is expected in the FSV DPC. It should be possible to stack five FSV elements per guide sleeve for a total 35 elements per DPC. Higher stacks and side-by-side configurations will not fit within a guide sleeve. Twenty-one and one-quarter FSV DPCs would be needed for the 744 FSV elements at the INEL.

Soon Sam Kim performed FSV scoping calculations using the geometry of a fuel model developed by Brian Palmer, with nuclide densities developed by Ken Woods and MCNP software. ${ }^{7,8,9}$ In all cases listed here, scoping calculations model a stack of five elements centered in each guide sleeve, with no vertical spacing between elements. For these calculations spacing between guide sleeves was fixed at $0.00 \mathrm{~cm}$. Spacing between elements within a tier was investigated by varying guide sleeve diameter. Figure 10 shows the basic model.

Preliminary calculations address positioning elements within guide sleeves, guide sleeve thickness, optimum moderation, and four reflector conditions (water, concrete, steel, and the OnSite Transfer Cask). Results indicate the system is most reactive when gaps between guide sleeve and fuel element are minimized. For a $\frac{3}{8}$ in. sleeve thickness, at least $2 \mathrm{~cm}$ between fuel and sleeve is required to ensure the system $\mathrm{k}_{\text {eff }}$ does not exceed 0.95 . If this sleeve thickness were used, a minimum $5.9 \mathrm{~cm}$ spacing, including guide sleeve walls, is required between elements in a tier. Table 1 summarizes results for this design, with varying moderator and reflector conditions.

Table 2 summarizes additional calculations, performed with a $\frac{3}{4}$ in. sleeve thickness and no gap between fuel and sleeve. In this model there is approximately $15 \frac{3}{4} \mathrm{in} .(40 \mathrm{~cm})$ between outer radial surface of fuel and DPC outer surface. To provide comparison information, Table 2 includes a case with the NUHOMS On-Site Transfer Cask, shown in Figure 11. This model should be similar to the road-ready NUHOMS MP-187 Cask for criticality safety purposes. 
Attachment

June 6, 1996

VLP-06-96

Page 13 of 58

DSC shell: 67.25 in. $(170.8 \mathrm{~cm})$ outer diameter, 0.625 in. (1.5875

$\mathrm{cm})$ thick SS304; 141.72 in.

guide sleeve: cross-section size

$(360 \mathrm{~cm})$ interior length

varied, 15.67 in. $(39.81 \mathrm{~cm})$ across

flats corresponds to $0 \mathrm{~cm}$ spacing between FSV fuel element and wall;

$3 / 8$ or $3 / 4$ in. thick SS304;

$141.72 \mathrm{in} .(360 \mathrm{~cm})$ interior length

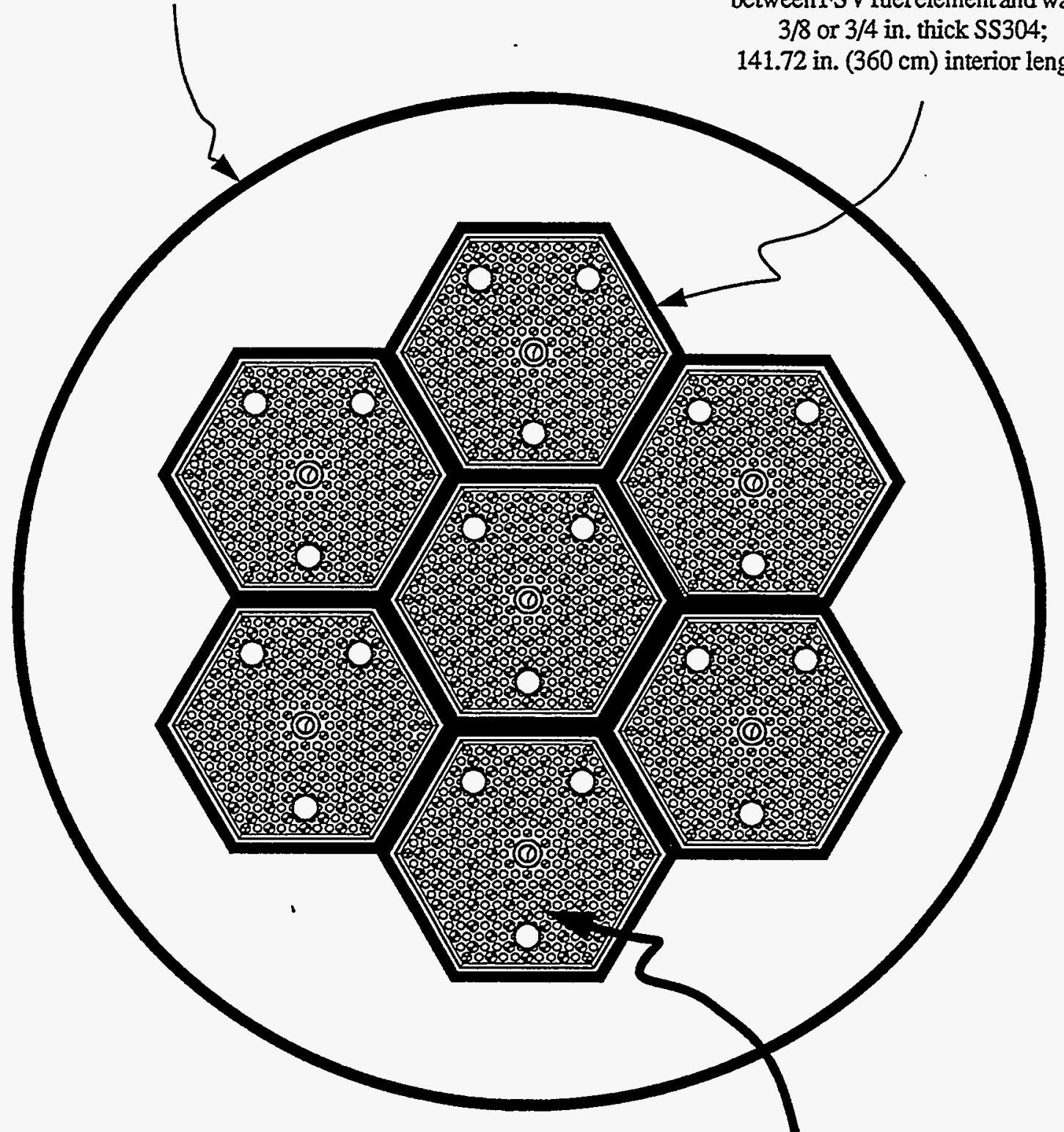

FSV element: 31.22 in. $(79.2 \mathrm{~cm})$ axially and $14.09 \mathrm{in}$.

$(35.8 \mathrm{~cm})$ across the flats of the hexagonal radial surface (8.23 in. or $20.9 \mathrm{~cm}$ side length for each of the six sides) [5 element stack per sleeve]

Figure 10 Model of FSV Fuel in Proposed FSV DSC 
Attachment

June 6, 1996

VLP-06-96

Page 14 of 58

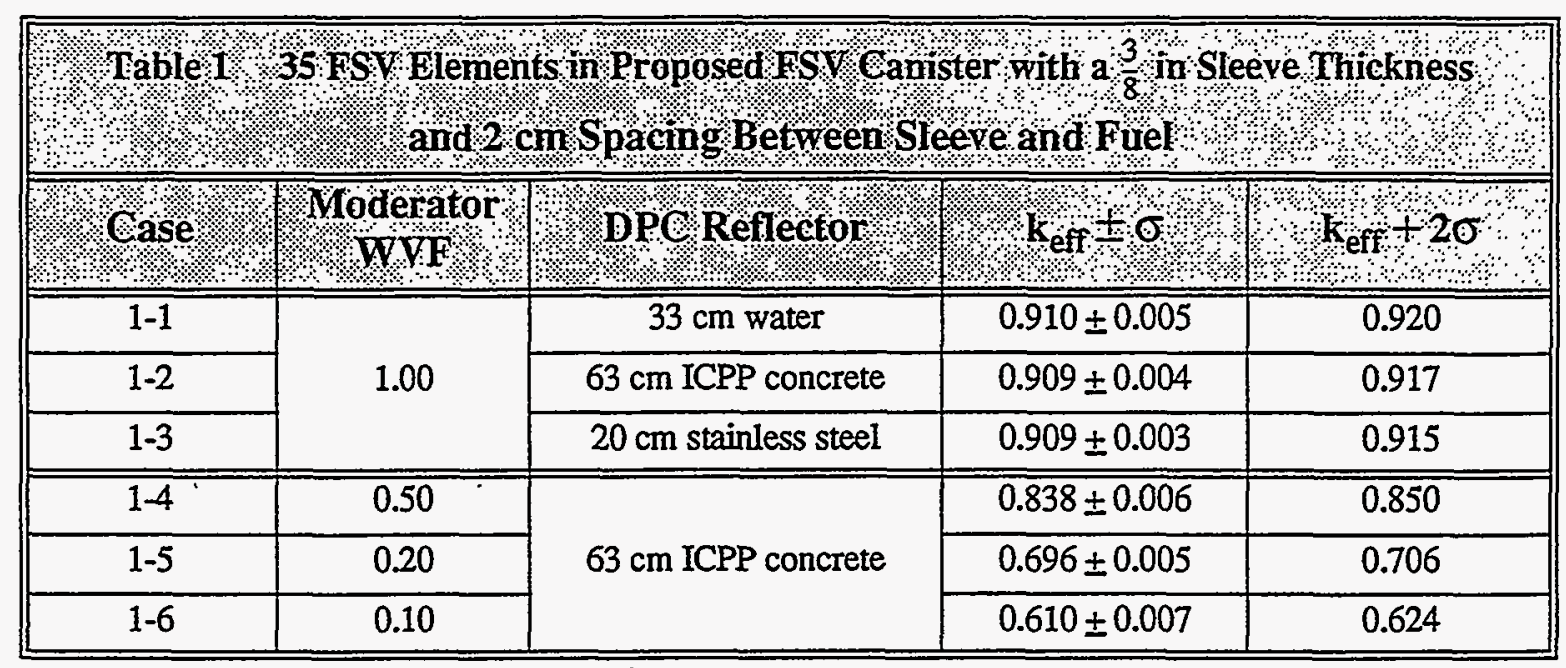

Table2 $35 \mathrm{FSY}$ Elements in proposed rSP Canister witha 3 in Sleeve Thickness and $0 \mathrm{~cm}$ Spacing Befween Sleeveandfuel

\begin{tabular}{|c|c|c|c|c|}
\hline Gase. & Moderator & SPOReflector: & $8 \mathrm{k}_{\text {ef }}-6$ & $\mathrm{~K}$ eff +20 \\
\hline $2-1$ & \multirow{4}{*}{$\begin{array}{l}\text { full density } \\
\text { water }\end{array}$} & $33 \mathrm{~cm}$ full density water & $0.932 \pm 0.005$ & 0.942 \\
\hline $2-2$ & & $63 \mathrm{~cm}$ ICPP concrete & $0.926 \pm 0.005$ & 0.936 \\
\hline $2-3$ & & $20 \mathrm{~cm}$ stainless steel & $0.933 \pm 0.003$ & 0.939 \\
\hline $2-3 a$ & & $\begin{array}{l}\text { cask (Figure } 11 \text {, page } 15 \text { ) } \\
\text { surrounded by } 33 \mathrm{~cm} \text { full density } \\
\text { water }\end{array}$ & $0.930 \pm 0.004$ & 0.938 \\
\hline $2-4$ & void & $63 \mathrm{~cm}$ ICPP concrete & $0.434 \pm 0.007$ & 0.448 \\
\hline
\end{tabular}


Attachment

June 6, 1996

VLP-06-96

Page 15 of 58

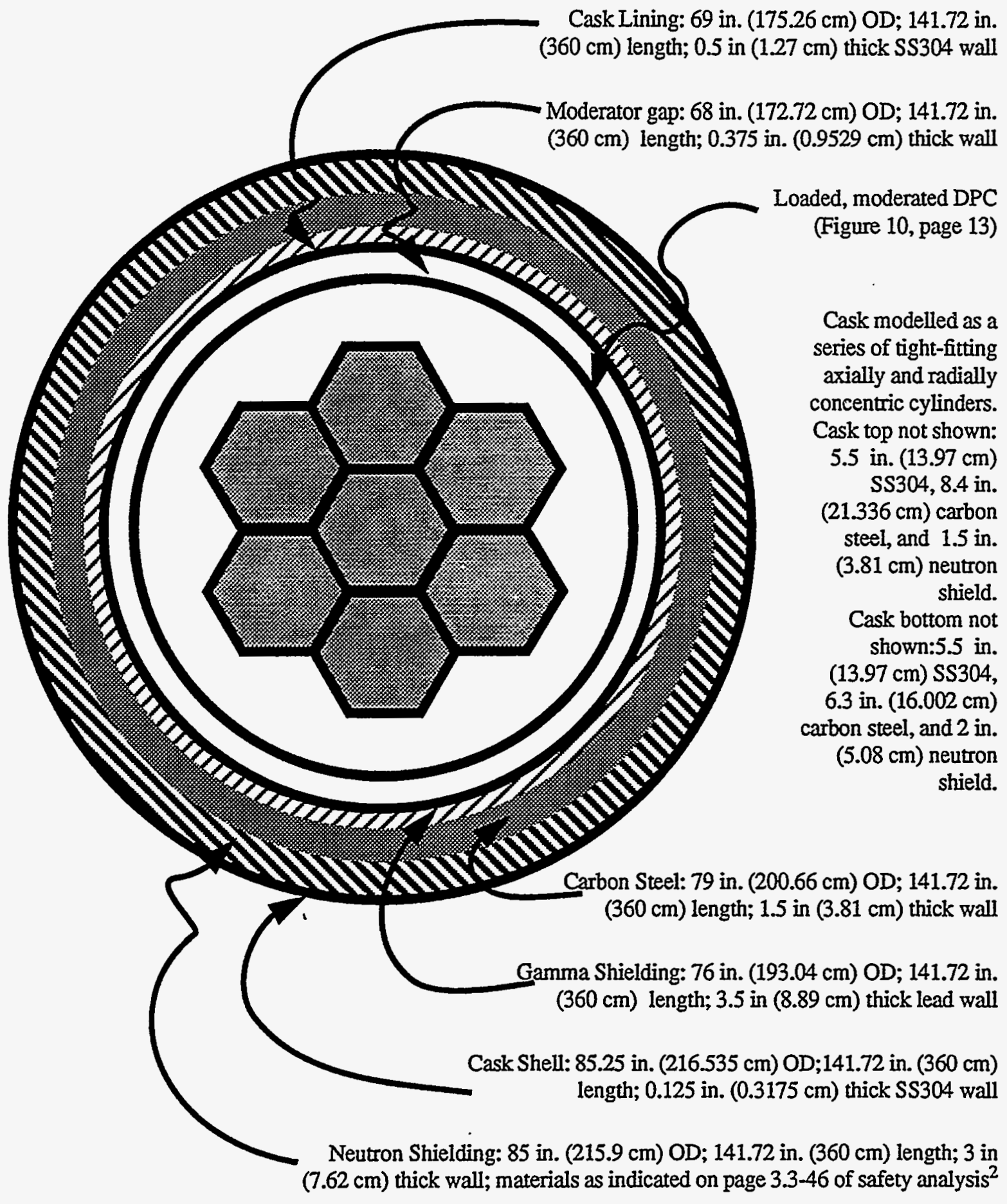

Figure 11 Model of Cask-Reflected FSV Fuel in Proposed FSV DPC 
Attachment

June 6, 1996

VLP-06-96

Page 16 of 58

Table 3 summarizes calculations to determine necessary concrete thicknesses to isolate DPCs in lag storage, using the model shown in Figure 12. Results indicate that, although there is an approximate $1 \%$ increase in $\mathrm{k}_{\text {eff }}$ for an array compared to a single concrete reflected DPC, concrete thickness between DPCs does not affect array $\mathrm{k}_{\mathrm{eff}} \mathrm{s}$. The $15 \frac{3}{4}$ in. $(40 \mathrm{~cm})$ between fuel and DPC wall is much more significant than distance between DPCs.

\begin{tabular}{|c|c|c|c|}
\hline \multicolumn{4}{|c|}{ 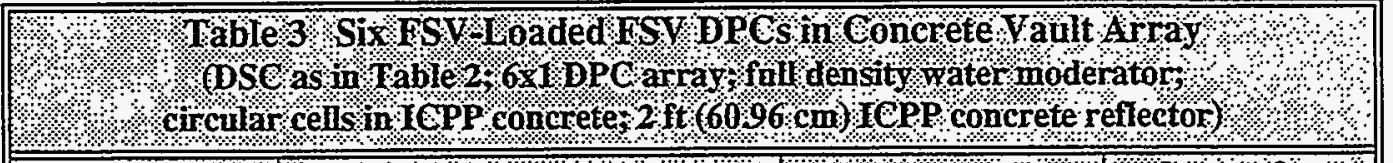 } \\
\hline$\%$ oase & \%०PO Edge fo Adge & \% Keff $-\%$ & $\mathrm{~K}_{\mathrm{eff}}+2 \sigma$ \\
\hline $3-1$ & $30.48 \mathrm{~cm}(1.00 \mathrm{ft})$ & $0.939 \pm 0.004$ & 0.947 \\
\hline $3-2$ & $0.00 \mathrm{~cm}(0.00 \mathrm{ft})$ & $0.939 \pm 0.004$ & 0.947 \\
\hline
\end{tabular}

Results indicate:

- Optimum moderation occurs with full density water, for this model. This conclusion is not affected by horizontal spacing between elements, probably because the primary moderator is graphite in the elements.

- The proposed DPC will be critically safe $\left(k_{\text {eff }} \leq 0.95\right)$, in isolation, fully loaded with FSV elements if canister and elements maintain their structural integrity and guide sleeves satisfy the following requirement.

- Minimum guide sleeve wall thickness must be a nominal $\frac{3}{4}$ in.

- Concrete thickness between DPCs in lag storage will not significantly affect array $\mathrm{k}_{\text {eff }} \mathrm{s}$. However, array $\mathrm{k}_{\text {eff }} \mathrm{s}$ are essentially 0.95 and, therefore, caution should be used in applying these results. 
Attachment

June 6, 1996

VLP-06-96

Page 17 of 58

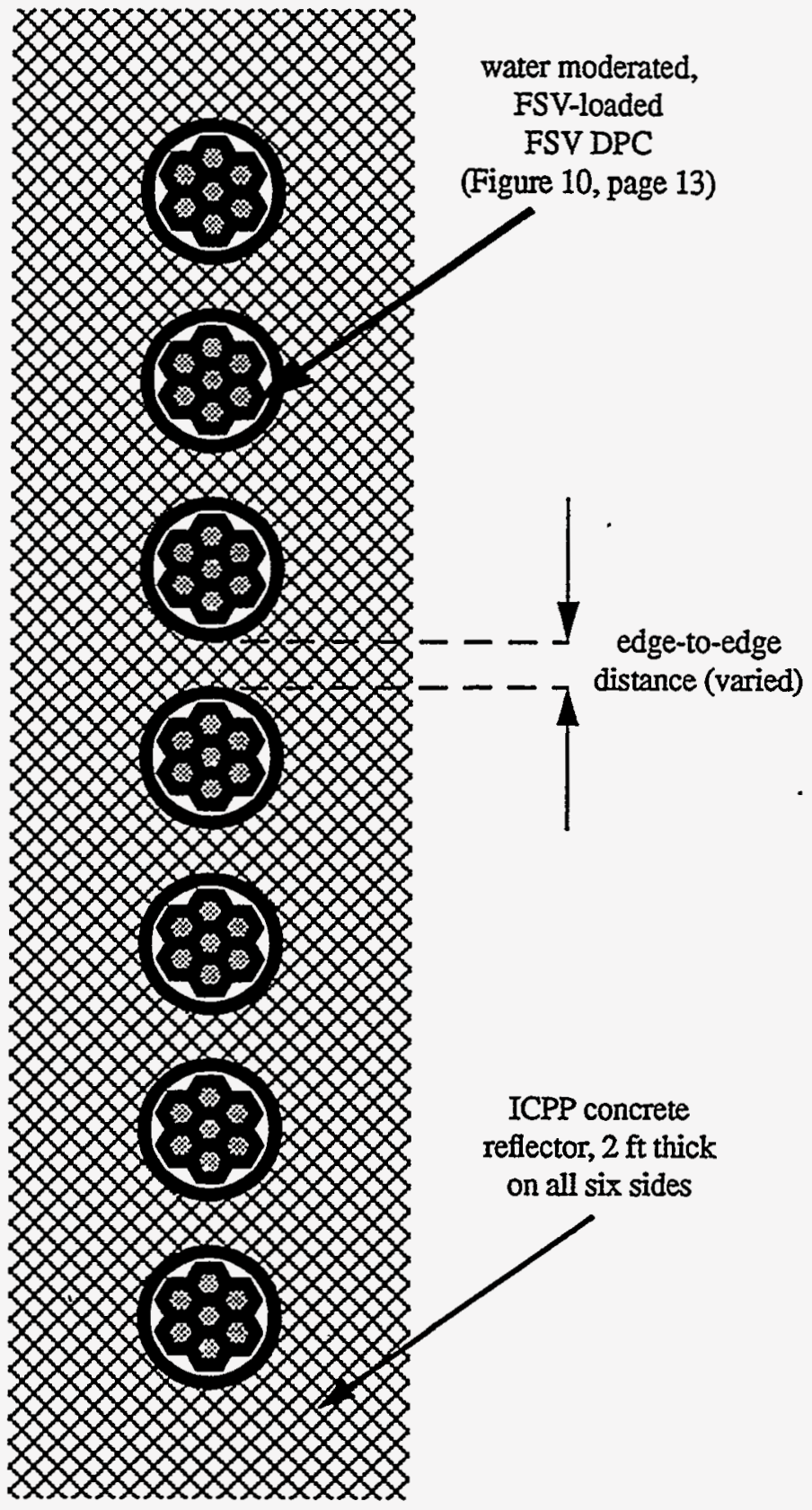

Figure 12 Model of FSV-Loaded FSV DSCs in Lag Storage 
Attachment

June 6, 1996

VLP-06-96

Page 18 of 58

\section{PATHFINDER SUPERHEATER FUEL. STORAGE, AND TRANSPORT}

Pathfinder Superheater elements are a stainless steel clad annular fuel containing $93.5 \%$ enriched $\mathrm{UO}_{2}$ measuring approximately $79.5 \mathrm{in.}(202 \mathrm{~cm})$ in length by $0.839 \mathrm{in.}(2.131 \mathrm{~cm})$ in outer diameter of fueled portion. There are 417 elements at the INEL, 6 unirradiated and 411 irradiated. Elements are to be packaged in BU-SF-910 buckets, which are $9.63 \times 9.63 \times 84$ in. $(24.46 \times 24.46$ x $213.4 \mathrm{~cm}$ ), at a maximum 62 elements per bucket for a total seven buckets. Pathfinder Power Plant reports and INEL evaluations provide further descriptions. ${ }^{10,11,12,13}$

Pathfinder buckets are too large to fit in any DPCs except the proposed FSV and LWBR DPCs. More efficient loadings should be possible in the FSV DPC (Figure 5, page 8). It should be physically possible to stack two buckets per guide sleeve but not possible to insert two buckets side-by-side in one sleeve. ${ }^{5}$ One-half DPC will be needed for elements currently at the INEL.

Mark Neeley performed Pathfinder Bucket scoping calculations using an element model developed by Deborah Henrikson and the KENO V.a criticality code of SCALE 4 software. ${ }^{13,14}$ Figure 13 shows the basic model. The model includes an $8 \times 8$ array of elements ( 64 total elements) in each bucket and stacks two buckets in each guide sleeve, with no vertical spacing between buckets. Guide sleeves were represented with square, rather than hexagonal, radial cross-sections, providing closer reflection of fuel in cases which include guide sleeve steel. Figure 14 shows the vault model used for concrete-reflected cases. The vault model is based on the NUHOMS Horizontal Storage Module with interior dimensions reduced to provide close reflection.

Table 4 summarizes calculations addressing optimum moderation, guide sleeve thickness and location, and three reflector conditions. Including BU-FS-910 steel would produce lower $\mathrm{k}_{\text {eff }} \mathrm{s}$ than listed. Table 5 summarizes calculations to determine isolation criteria for arrays of Pathfinderloaded DPCs.

Results indicate:

- Optimum moderation occurs with full density water for a fully loaded FSV DPC. This conclusion is not affected by spacing between buckets.

- The FSV DPC will be critically safe $\left(k_{\text {eff }} \leq 0.95\right)$ fully loaded with Pathfinder buckets if the canister, buckets, and elements maintain their structural integrity.

- Pathfinder fuel in BU-FS-910 in on DPC is essentially isolated from fuel in an adjacent identical DPC if guide sleeves are butted against each other. 
Attachment

June 6, 1996

VLP-06-96

Page 19 of 58

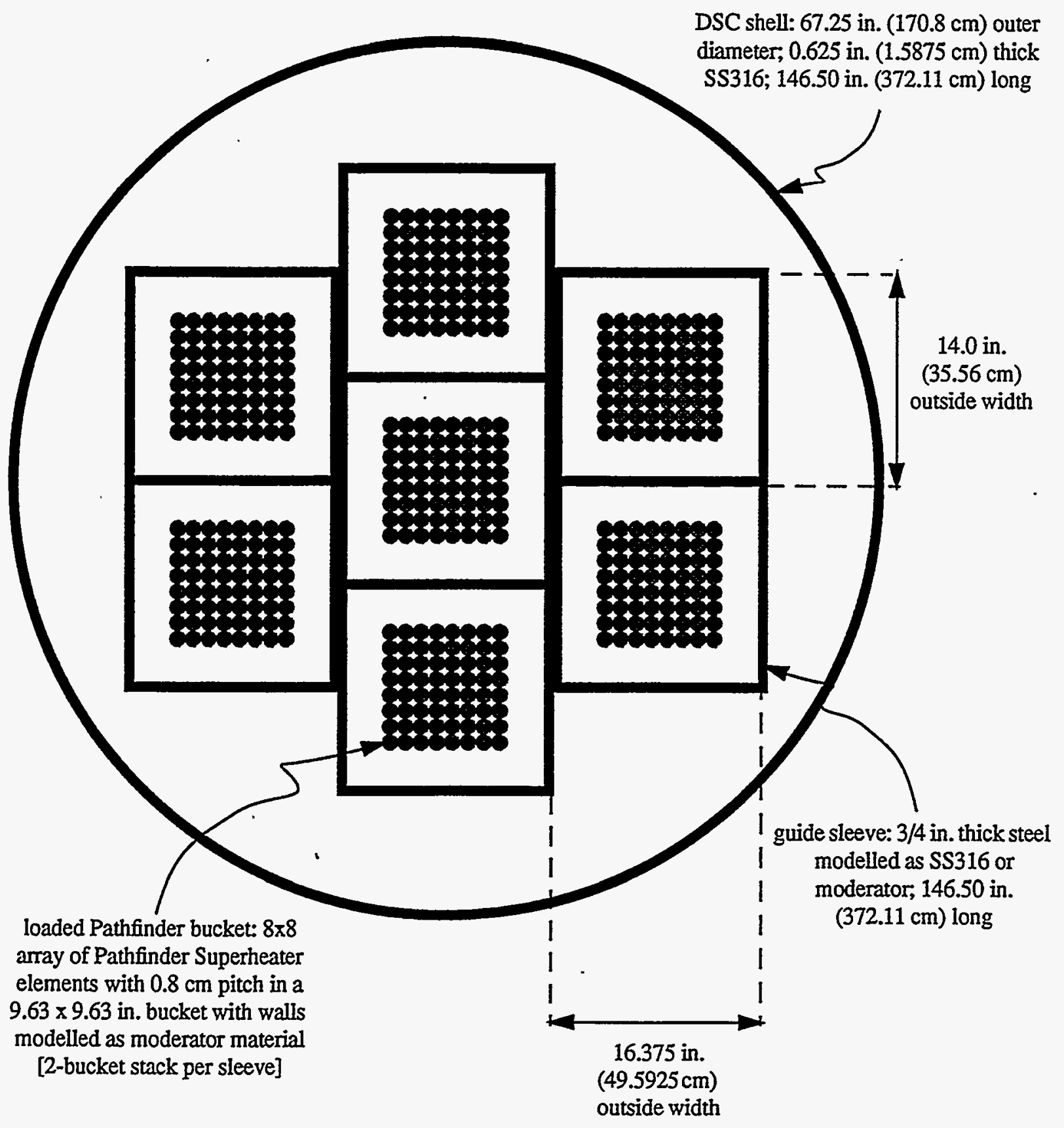

Figure 13 Model of Pathfinder Bucket in FSV DSC 
Attachment

June 6, 1996

VLP-06-96

Page 20 of 58

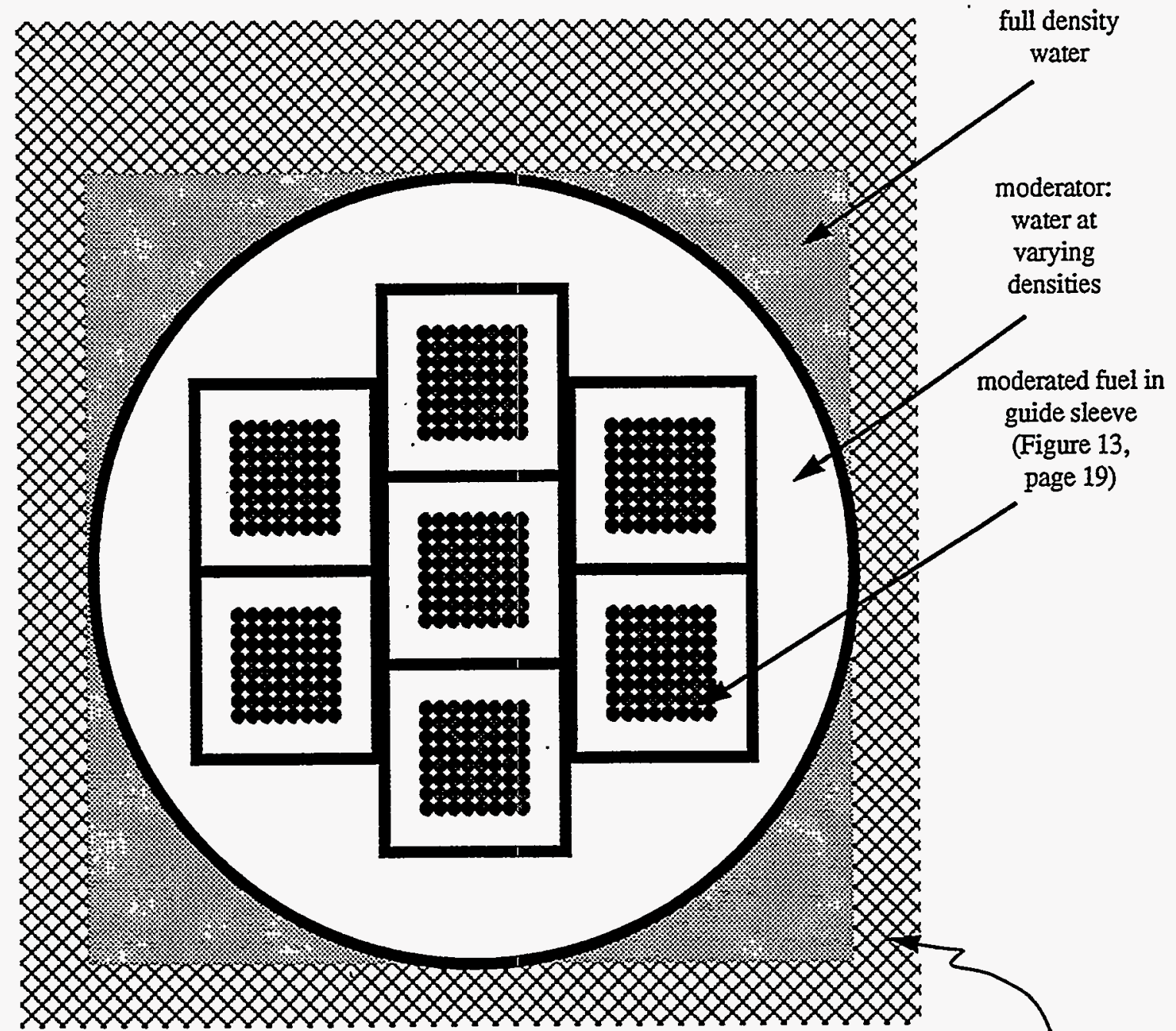

vault: regular concrete, $1.6 \mathrm{ft}(48.76 \mathrm{~cm})$ thick sides (right and left), $1 \mathrm{ft}(30.48 \mathrm{~cm})$ thick back (into paper) and floor (bottom), $3 \mathrm{ft}(91.44 \mathrm{~cm}$ ) thick roof (top), and $2.5 \mathrm{ft}$ (76.2 cm thick) front (out of paper)

Figure 14 - Model of Concrete-Vault Reflected DSC of Pathfinder Fuel 
Attachment

June 6, 1996

VLP-06-96

Page 21 of 58

\begin{tabular}{|c|c|c|c|c|c|}
\hline \multicolumn{2}{|c|}{ किTable 4} & \multicolumn{4}{|c|}{ Fourteen Pathfinder Buckets in an FSV DPC } \\
\hline Case & Reflector & Addifional Description & Moderator & $\mathrm{K}_{\mathrm{eff}} \pm \sigma$ & $\mathrm{Keff}_{2}$ \\
\hline path010 & \multirow{7}{*}{$\begin{array}{l}\text { vault (Figure 14, } \\
\text { page 20) }\end{array}$} & \multirow{7}{*}{$\begin{array}{l}\text { sleeve and bucket modelled as } \\
\text { moderator, } 8.08 \text { in. edge-to- } \\
\text { edge spacing between sleeves }\end{array}$} & 1.00 & $0.896 \pm 0.002$ & 0.900 \\
\hline path013 & & & 0.90 & $0.861 \pm 0.002$ & 0.865 \\
\hline path014 & & & 0.75 & $0.818 \pm 0.002$ & 0.822 \\
\hline path15 & & & 0.50 & $0.743 \pm 0.002$ & 0.747 \\
\hline path16 & & & 0.25 & $0.736 \pm 0.002$ & 0.740 \\
\hline path17 & & & 0.10 & $0.618 \pm 0.002$ & 0.622 \\
\hline path18 & & & 0.00 & $0.207 \pm 0.001$ & 0.209 \\
\hline path011 & \multirow{6}{*}{ as above } & \multirow{6}{*}{$\begin{array}{l}\text { sleeve and bucket modelled as } \\
\text { moderator, } 0.00 \text { in. edge-to- } \\
\text { edge spacing between sleeves }\end{array}$} & 1.00 & $0.941 \pm 0.002$ & $\overline{0.945}$ \\
\hline path019 & & & 0.90 & $0.935 \pm 0.002$ & 0.939 \\
\hline path020 & & & 0.75 & $0.928 \pm 0.002$ & $\overline{0.932}$ \\
\hline path021 & & & 0.50 & $0.939 \pm 0.002$ & 0.943 \\
\hline path022 & & & 0.25 & $0.887 \pm 0.002$ & 0.891 \\
\hline path023 & & & 0.10 & $0.604 \pm 0.002$ & 0.608 \\
\hline$\overline{\text { path034 }}$ & as above & \multirow{3}{*}{$\begin{array}{l}\text { bucket modelled as } \\
\text { moderator, sleeves modelled } \\
\text { as SS304, } 0.00 \text { in. edge-to- } \\
\text { edge spacing between sleeves }\end{array}$} & \multirow{3}{*}{0.90} & $0.882 \pm 0.002$ & $\overline{\overline{0.886}}$ \\
\hline path035 & $\begin{array}{l}30 \mathrm{~cm} \text { full } \\
\text { density water }\end{array}$ & & & $0.887 \pm 0.002$ & 0.891 \\
\hline path036 & $30 \mathrm{~cm} \mathrm{SS304}$ & & & $0.876 \pm 0.002$ & 0.880 \\
\hline
\end{tabular}

\begin{tabular}{|c|c|c|c|c|}
\hline Case & ४DPCReflector & Number of DPCs: & $k_{\text {eff }} \pm \sigma$ & $K_{\text {eff }}=2 \sigma$ \\
\hline path011 & $\begin{array}{l}\text { flooded, tight-fitting, regular } \\
\text { concrete vault (Figure 14, } \\
\text { page 20) }\end{array}$ & 1 & $0.941 \pm 0.002$ & 0.945 \\
\hline path041 & $\begin{array}{l}\text { identical DPCs in a square pitch } \\
\text { array, } 0.00 \text { in edge-to-edge } \\
\text { spacing between DPCs, full. } \\
\text { density water between DPCs }\end{array}$ & infinite & $0.938 \pm 0.002$ & 0.942 \\
\hline
\end{tabular}


Attachment

June 6, 1996

VLP-06-96

Page 22 of 58

\section{POWER BURST FACILITY (PBF) FUEL, STORAGE, AND TRANSPORT}

PBF Driver Core assemblies are arrays of $18.5 \%$ enriched uranium-zirconium steel-clad fuel, aluminum, and/or stainless-steel rods in aluminum canisters with spacer biades, as described in

Section 4.2 of the System Design Description. ${ }^{15}$ Of the 72 assemblies at PBF, 36 contain only fuel rods, 24 contain a mixture of fuel and non-fuel rods, and 12 contain only non-fuel rods. There are six assembly canister designs, for arrays ranging from 31 to 62 rods, with the 62 -fuel-rod design as the largest and mostreactive assembly. However, 49-fuel-rod assemblies are the most common. All assemblies are $60 \mathrm{in}$. long but width varies with canister design.

If the NUHOMS 24P DSC is used, it will be possible to stack PBF fuel assemblies two high in each guide sleeve. Although the sleeve internal width is barely larger than the largest unirradiated assembly, it might be possible to fit two of the smallest assemblies side-by-side in a sleeve. ${ }^{2,3,4}$ Assuming one assembly per tier and that large irradiated assemblies will fit, approximately $1 \frac{1}{4} 24 \mathrm{P}$ DSCs will be needed for the 60 PBF Driver Core fuel assemblies.

Valerie Putman performed PBF scoping calculations using assembly models developed by Virginia Dean and using the KENO V.a criticality code of SCALE 4 software. ${ }^{16,14}$ All fuel assembly designs are enveloped by her 63-rod model: a 7x9 array of fuel rods in a rectangular aluminum canister, neglecting canister parts above and below the active fuel region. Calculations model a stack of three assemblies centered in each guide sleeve, exceeding the DPC design length, to envelope elongated DPC shell designs and hypothetical fuel handling errors. Figure 15 shows the basic model and Figure 16 shows the DSC in an On-Site Transfer Cask.

Table 6 summarizes results for intact, 63-rod fuel assemblies in the 24P DSC for a variety of water moderator densities and three reflector conditions. To provide comparative information regarding a more realistic loading of the DSC, a few calculations were also performed using Virginia Dean's 49-rod canister model. ${ }^{16}$ This model is similar to the 63-rod model except that fuel rods are arranged in a $7 \times 7$ array and canister volume is reduced accordingly. Table 7 compares $49-$ and $63-$ rod-assembly results.

Table 8 summarizes results for loose fuel rods, to envelope two small side-by-side assemblies, hypothetical cases of canister failure, and hypothetical designs which include repackaging fuel rods. The loose-rod model is the 63-rod assembly model with water moderator in place of the aluminum canister.

Table 9 summarizes calculations to determine design criteria for 24P DPC arrays. The calculations model 63 loose fuel rods per tier per guide sleeve. 
Attachment

June 6, 1996

VLP-06-96

Page 23 of 58

guide sleeve: 9.109 in.

$(23.13686 \mathrm{~cm})$ outer width;

DSC shell: 67.25 in. $(170.8 \mathrm{~cm})$

0.060 in. $(0.15189 \mathrm{~cm})$ thick

outer diameter, 0.625 in. $(1.5875 \mathrm{~cm})$

SS304; 108 in. $(274.32 \mathrm{~cm})$

thick SS304; 108 in. $(274.32 \mathrm{~cm})$

interior length

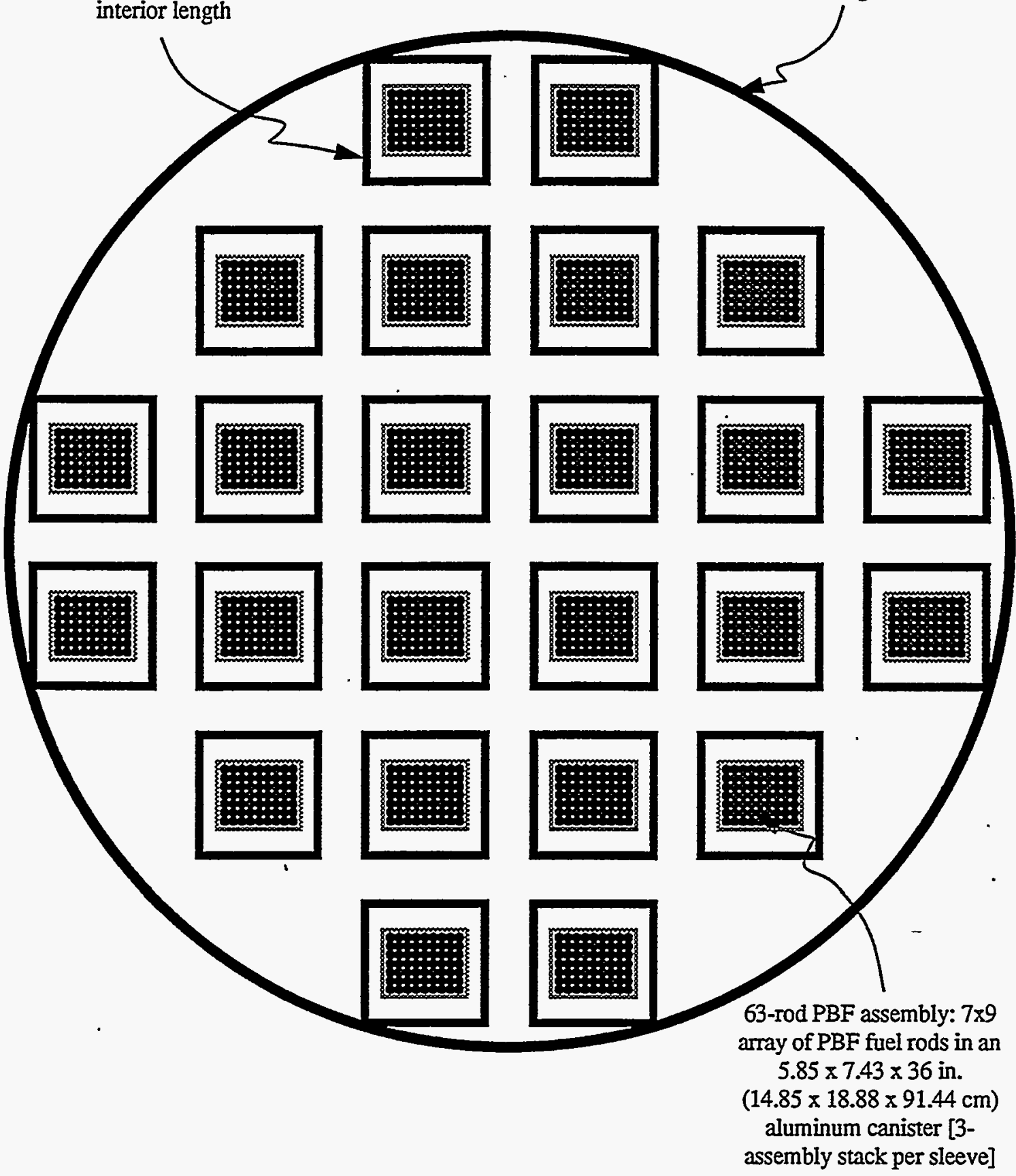

Figure 15 Model of PBF Assemblies in 24P DSC 
Attachment

June 6, 1996

VLP-06-96

Page 24 of 58

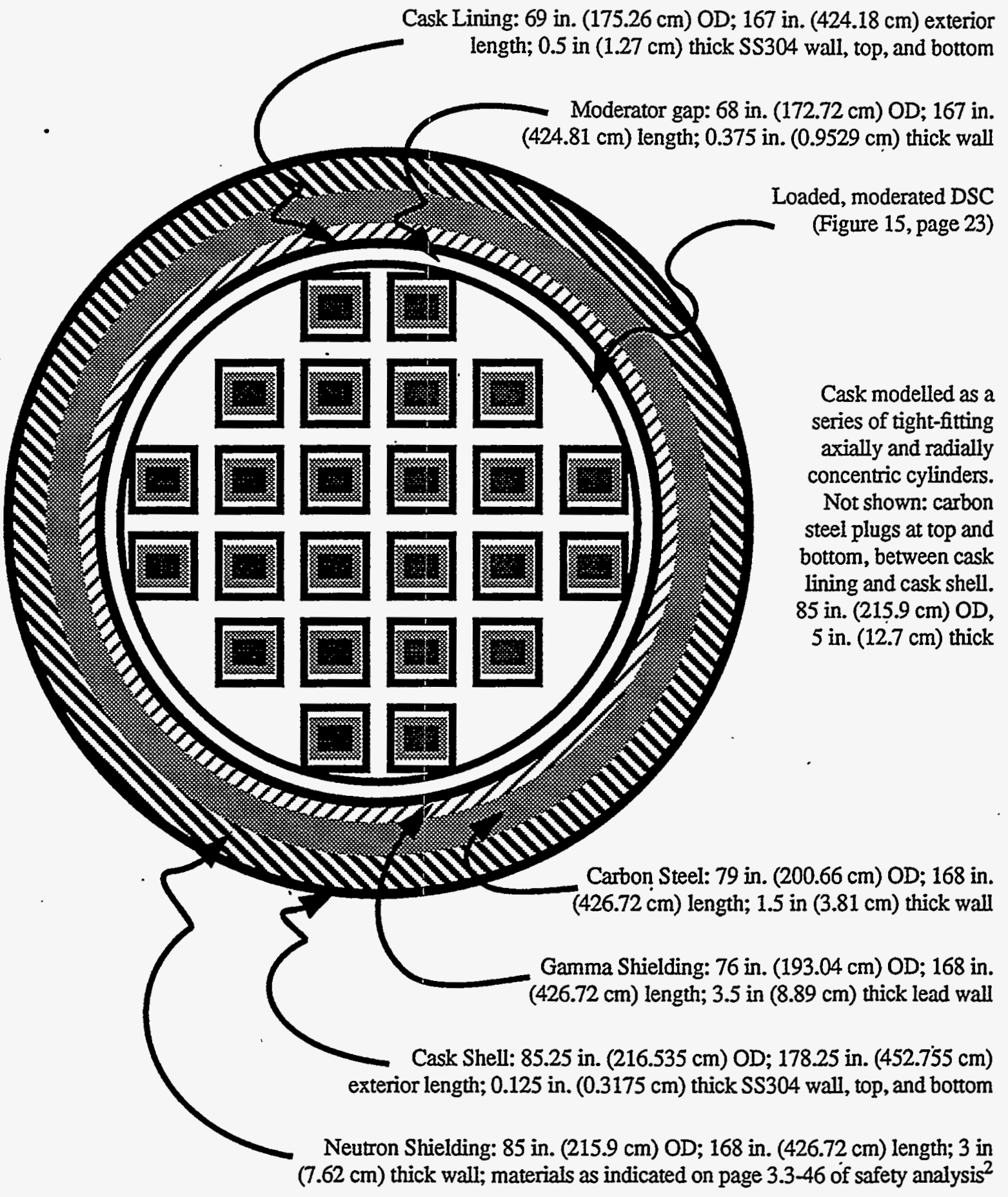

Figure 16 Model of Cask-Reflected 24P DSC of PBF Assemblies 
Attachment

June 6, 1996

VLP-06-96

Page 25 of 58

\begin{tabular}{|c|c|c|c|c|}
\hline \multicolumn{5}{|c|}{ 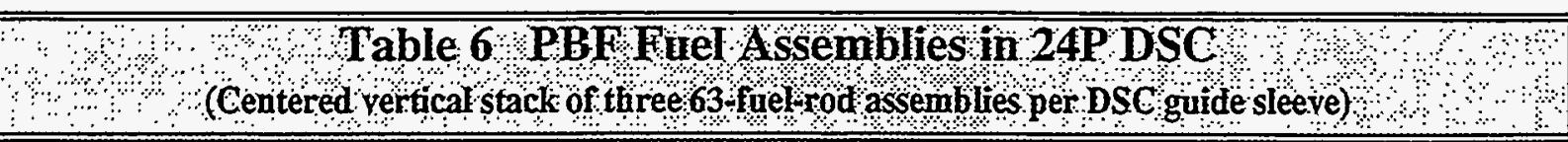 } \\
\hline क Case & $\begin{array}{l}\text { DSC } \\
\text { Reflector }\end{array}$ & Moderator & $\mathrm{k}_{\mathrm{eff}}+1 / \mathrm{l}$ & $\mathrm{k}_{\text {eff }}+2 \sigma$ \\
\hline 63rod.24P.100H2O.H2O & \multirow{8}{*}{$\begin{array}{l}31 \mathrm{~cm} \text { full } \\
\text { density water }\end{array}$} & 1.00 & $0.665 \pm 0.001$ & 0.667 \\
\hline 63rod.24P.075H2O.H2O & & 0.75 & $0.684 \pm 0.001$ & 0.686 \\
\hline 63rod.24P.050H2O.H2O & & 0.50 & $0.745 \pm 0.001$ & 0.747 \\
\hline 63rod.24P.025H2O.H2O & & 0.25 & $0.823 \pm 0.001$ & 0.825 \\
\hline 63rod.24P.010H2O.H2O & & 0.10 & $0.701 \pm 0.001$ & 0.703 \\
\hline 63rod.24P.005H2O.H2O & & 0.05 & $0.542 \pm 0.001$ & 0.544 \\
\hline 63rod.24P.001H2O.H2O & & 0.01 & $0.357 \pm 0.001$ & 0.359 \\
\hline 63rod.24P.000H2O.H2O & & 0.00 & $0.318 \pm 0.001$ & 0.320 \\
\hline 63rod.24P.100H2O.concrete.1 & $\begin{array}{l}31 \mathrm{~cm} \text { ICPP } \\
\text { concrete }\end{array}$ & 1.00 & $0.666 \pm 0.001$ & 0.668 \\
\hline 63rod.24P.100H2O.concrete & \multirow{8}{*}{$\begin{array}{l}62 \mathrm{~cm} \mathrm{ICPP} \\
\text { concrete }\end{array}$} & 1.00 & $0.663 \pm 0.001$ & 0.665 \\
\hline 63rod.24P.075H2O.concrete & & 0.75 & $0.684 \pm 0.001$ & 0.686 \\
\hline 63rod.24P.050H2O.concrete & & 0.50 & $0.746 \pm 0.001$ & 0.748 \\
\hline 63rod.24P.025H2O.concrete & & 0.25 & $0.832 \pm 0.001$ & 0.834 \\
\hline 63rod.24P.010H2O.concrete & & 0.10 & $0.667 \pm 0.001$ & 0.669 \\
\hline 63rod.24P.005H2O.concrete & & 0.05 & $0.613 \pm 0.002$ & 0.617 \\
\hline 63rod.24P.001F2O.concrete & & 0.01 & $0.424 \pm 0.003$ & 0.430 \\
\hline 63rod.24P.000H2O.concrete & & 0.00 & $0.365 \pm 0.003$ & 0.371 \\
\hline 63rod.24P.025H2O.SS , & $\overline{31 \mathrm{~cm} \mathrm{SS304}}$ & 0.25 & $0.843 \pm 0.001$ & 0.845 \\
\hline 63rod.24P.100H2O.cask & \multirow{5}{*}{$\begin{array}{l}\text { cask } \\
\text { (Figure 16, } \\
\text { page 24) }\end{array}$} & 1.00 & $0.665 \pm 0.001$ & 0.667 \\
\hline 63rod.24P.075H2O.cask & & 0.75 & $0.683 \pm 0.001$ & 0.685 \\
\hline 63rod.24P.050H2O.cask & & 0.50 & $0.749 \pm 0.001$ & 0.751 \\
\hline 63rod.24P.025H2O.caks & & 0.25 & $0.836 \pm 0.001$ & 0.838 \\
\hline 63rod.24P.001H2O.cask & & 0.01 & $0.281 \pm 0.001$ & 0.283 \\
\hline
\end{tabular}


Attachment

June 6, 1996

VLP-06-96

Page 26 of 58

\begin{tabular}{|c|c|c|c|c|}
\hline \multicolumn{5}{|c|}{ 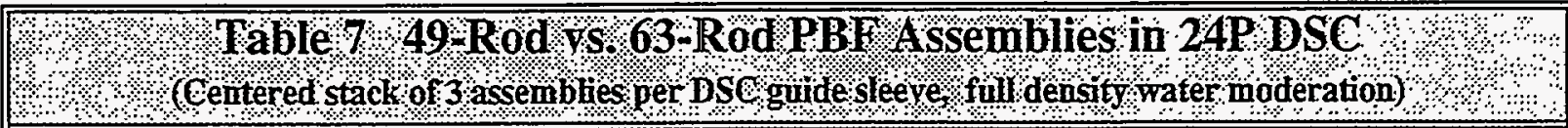 } \\
\hline ४ै. & Reflector & perversolsods & सeftol & $\mathrm{K}_{\mathrm{eff}} \mathrm{z}^{2}$ \\
\hline 49rod.24P.100H2O.H2O & \multirow{2}{*}{$\begin{array}{l}31 \mathrm{~cm} \text { thick, } \\
\text { full density } \\
\text { water }\end{array}$} & $49(7 \times 7)$ & $0.579 \pm 0.001$ & 0.581 \\
\hline 63rod.24P.10OH2O.H2O & & $63(7 \times 9)$ & $0.665 \pm 0.001$ & 0.667 \\
\hline 49rod.24P.100H2O.concrete.1 & \multirow{2}{*}{$\begin{array}{l}31 \mathrm{~cm} \text { thick } \\
\text { ICPP concrete }\end{array}$} & $49(7 \times 7)$ & $0.583 \pm 0.001$ & 0.585 \\
\hline 63rod.24P.100H2O.concrete.1 & & $63(7 \times 9)$ & $0.666 \pm 0.001$ & 0.668 \\
\hline 49rod.24P.100H2O.concrete & \multirow{2}{*}{$\begin{array}{l}62 \mathrm{~cm} \text { thick } \\
\text { concrete }\end{array}$} & $49(7 \times 7)$ & $0.580 \pm 0.001$ & 0.582 \\
\hline 49rod.24P.100H2O.concrete & & $63(7 \times 9)$ & $0.663 \pm 0.001$ & 0.665 \\
\hline
\end{tabular}

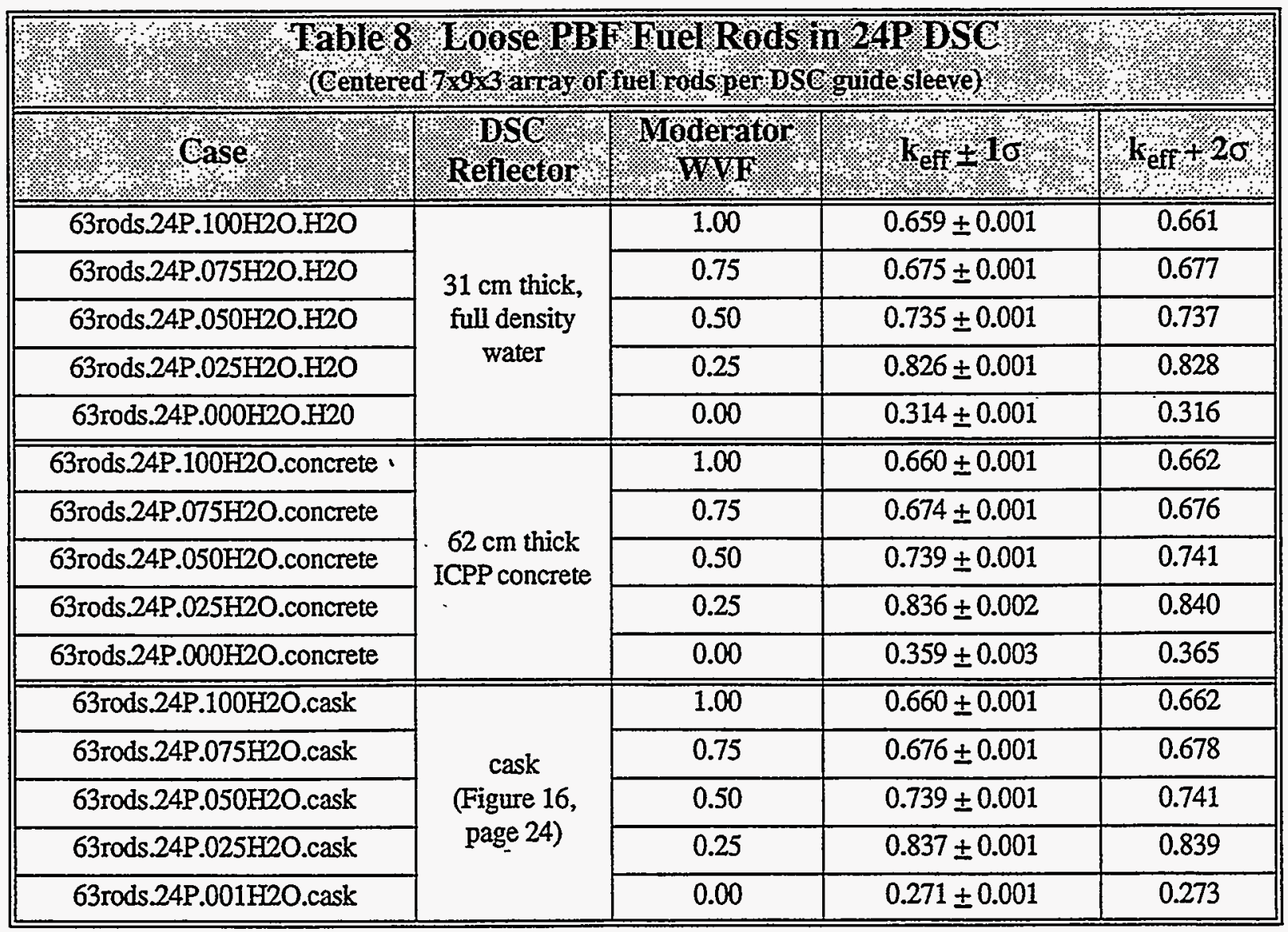


Attachment

June 6, 1996

VLP-06-96

Page 27 of 58

\begin{tabular}{|c|c|c|c|c|c|c|}
\hline \multicolumn{7}{|c|}{ 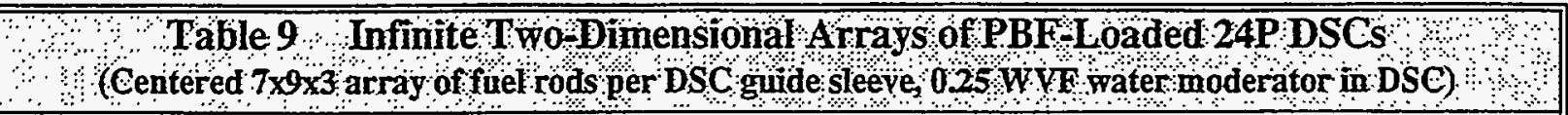 } \\
\hline Plos Case & $\begin{array}{l}\text { DSO } \\
\text { Shelly } \\
\text { Material }\end{array}$ & $\begin{array}{l}\text { Material } \\
\text { Betureen } \\
\text { Dses }\end{array}$ & Edget & $\frac{\mathrm{C}}{\mathrm{C} \text { (inge }}$ & से & सefo \\
\hline 63rods.24P-.025H2O.inf.00conc & moderator & & 0.00 & 0 & $0.866 \pm 0.001$ & 0.868 \\
\hline 63rods.24P.025H2O.inf.00conc & \multirow{3}{*}{ SS304 } & \multirow{3}{*}{$\begin{array}{l}\text { ICPP } \\
\text { concrete }\end{array}$} & 0.00 & $\overline{0}$ & $0.852 \pm 0.001$ & 0.854 \\
\hline 63rods.24P.025H2O.inf.03conc & & & 7.62 & 3 & $0.845 \pm 0.001$ & 0.847 \\
\hline 63rods.24P.025H2O.inf.06conc & & & $\overline{15.24}$ & 6 & $0.840 \pm 0.001$ & 0.842 \\
\hline 63rods.24P.025H2O.inf.025H2O & \multirow{2}{*}{ SS304 } & $\begin{array}{l}0.25 \mathrm{WVF} \\
\text { water }\end{array}$ & \multirow{2}{*}{0.00} & & $0.842 \pm 0.001$ & 0.844 \\
\hline 63rods.24P.025H2O.inf.100H2O & & $\begin{array}{l}\text { full density } \\
\text { water }\end{array}$ & & & $0.835 \pm 0.001$ & 0.839 \\
\hline
\end{tabular}

PBF assemblies will also fit, in two-assembly-height stacks, in the proposed 14-Tube and FSV DPCs. ${ }^{5}$ Loading is not as efficient as with the 24P DSC, requiring about $2 \frac{1}{10}$ 14-Tube DPCs for the 60 assemblies which contain fuel rods. However, scoping calculations address the 14-Tube DPC because the 14-Tube DPC was recently selected for reasons other than criticality safety. Table 10 and Table 11 summarize 14-Tube DPC results for 63 rods per tier, per tube. Optimum moderation, three reflector conditions, effects of tube or bucket wall, and optimum DPC separation are addressed. Results are similar to results for the 24P DSC except that no credit is needed for tube or bucket wall material and that each case has a lower $\mathrm{k}_{\text {eff. }}$. This comparison is expected because the 14-Tube DPC contains significantly less fuel.

PBF fuel assemblies and loose fuel rods are critically safe $\left(k_{\text {eff }} \leq 0.95\right)$ in the $24 \mathrm{PDSC}$ or in the 14-Tube DPC at optimum moderation with concrete, water, or steel reflection, for 63 fuel rods maximum per tier in a guide sleeve or tube and three tiers maximum per guide sleeve or tube, if fuel rod, DPC, and DPC basket structural integrity is maintained. Although DPCs interact, infinite arrays are critically safe, with or without concrete dividers.

Most calculated $\mathrm{k}_{\text {eff }}$ values are so low that they should be considered as indicative of low reactivity but not as absolute, or realistic values. Qualitative comparisons between listed values are valid for PBF fuel (for example, fuel assemblies are less reactive than optimized loose fuel rods) but PBF $\mathrm{k}_{\text {eff }}$ values are not directly comparable to $\mathrm{k}_{\text {eff }} \mathrm{s}$ for other fuels. 
Attachment

June 6, 1996

VLP-06-96

Page 28 of 58

\begin{tabular}{|c|c|c|c|c|c|}
\hline \multicolumn{6}{|c|}{ 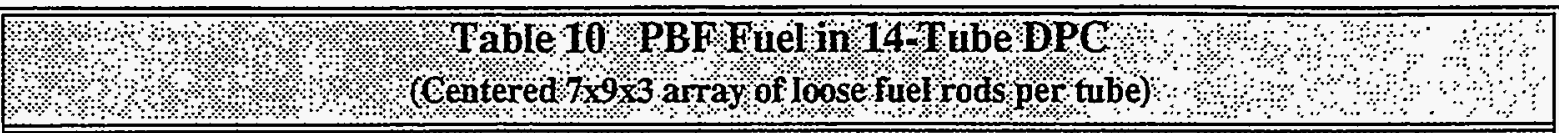 } \\
\hline Qase, & Whibe & Reflector & Woderat & 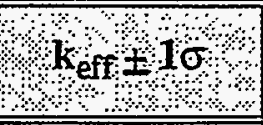 & $\mathrm{k}_{\mathrm{eff}}+20$ \\
\hline 63rods. $14 \mathrm{~T}-.050 \mathrm{H} 2 \mathrm{O}$. 20 & \multirow{3}{*}{ moderator } & \multirow{3}{*}{$\begin{array}{l}31 \mathrm{~cm} \text { thick, } \\
\text { full density } \\
\text { water }\end{array}$} & 0.50 & $0.605 \pm 0.001$ & 0.607 \\
\hline 63 rods.14T-.025H2OF2O & & & 0.25 & $0.768 \pm 0.001$ & 0.770 \\
\hline $63 \mathrm{rods} .14 \mathrm{~T}-.000 \mathrm{H} 2 \mathrm{O} . \mathrm{H} 2 \mathrm{O}$ & & & 0.00 & $0.261 \pm 0.001$ & 0.263 \\
\hline 63 rods.14T-.100H2O.concrete & \multirow{5}{*}{ moderator } & \multirow{5}{*}{$\begin{array}{l}62 \mathrm{~cm} \text { thick } \\
\text { ICPP } \\
\text { concrete }\end{array}$} & 1.00 & $0.593 \pm 0.001$ & 0.595 \\
\hline 63rods.14T-.075H2O.concrete & & & 0.75 & $0.568 \pm 0.001$ & 0.570 \\
\hline 63 rods.14T-.050H20.concrete & & & 0.50 & $0.604 \pm 0.001$ & 0.606 \\
\hline 63 rods. $14 \mathrm{~T}-.025 \mathrm{H} 20.00 \mathrm{ncrete}$ & & & 0.25 & $0.775 \pm 0.002$ & 0.779 \\
\hline 63rods.14T-.000E2O.concrete & & & 0.00 & $0.304 \pm 0.003$ & 0.310 \\
\hline 63rods.14T.100H2O.concrete & \multirow{5}{*}{ SS304 } & \multirow{5}{*}{$\begin{array}{l}62 \mathrm{~cm} \text { thick } \\
\text { ICPP } \\
\text { concrete }\end{array}$} & 1.00 & $0.581 \pm 0.001$ & 0.583 \\
\hline 63rods.14T.075H2O.concrete & & & 0.75 & $0.532 \pm 0.001$ & 0.536 \\
\hline 63rods.14T.050H2O.concrete & & & 0.50 & $0.510 \pm 0.001$ & 0.512 \\
\hline 63rods.14T.025H2O.concrete & & & 0.25 & $0.556 \pm 0.001$ & 0.558 \\
\hline 63rods.14T.000H2O.concrete & & & 0.00 & $0.257 \pm 0.002$ & 0.261 \\
\hline 63 rods.14T-.050H2O.SS304 & \multirow{3}{*}{ moderator } & \multirow{3}{*}{$\begin{array}{c}31 \mathrm{~cm} \text { thick } \\
\text { SS304 }\end{array}$} & 0.50 & $0.605 \pm 0.001$ & 0.607 \\
\hline 63rods.14T-.025H2O.SS304 & & & 0.25 & $0.780 \pm 0.001$ & 0.782 \\
\hline $63 \mathrm{rods} .14 \mathrm{~T}-.000 \mathrm{H} 20.5 S 304$ & & & 0.00 & $0.215 \pm 0.001$ & 0.217 \\
\hline
\end{tabular}

\begin{tabular}{|c|c|c|c|c|c|c|}
\hline \multicolumn{7}{|c|}{ 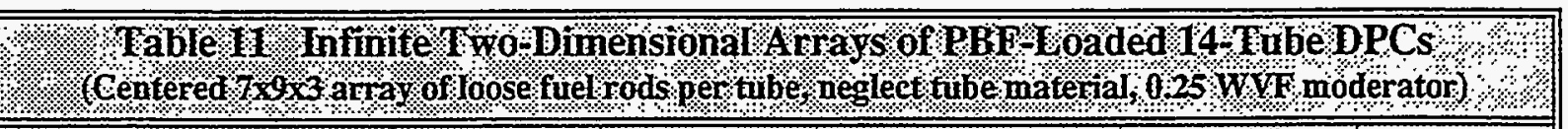 } \\
\hline 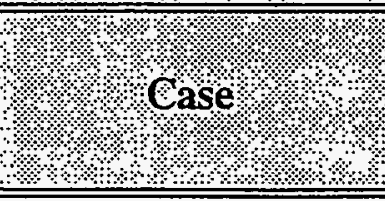 & Mape & $\begin{array}{l}\text { Material } \\
\text { Between } \\
\text { BPPs }\end{array}$ & $\frac{\sqrt{\text { Edge }}}{\text { (cm) }}$ & Edge & $\begin{array}{l}\text { मे } \\
\text { eff } \\
\text { मी }\end{array}$ & Keff \\
\hline 63 rods.14T-.025H2O.inf.00eonc & moderator & $\begin{array}{c}\text { ICPP } \\
\text { concrete }\end{array}$ & 0.00 & 0 & $0.797 \pm 0.001$ & 0.799 \\
\hline 63rods.14T-025H2O.inf.00conce & \multirow{3}{*}{ SS304 } & \multirow{3}{*}{$\begin{array}{l}\text { ICPP } \\
\text { concrete }\end{array}$} & 0.00 & 0 & $0.788 \pm 0.001$ & 0.790 \\
\hline 63rods.14T-.025H2O.inf.03cone & & & 15.24 & 6 & $0.778 \pm 0.001$ & 0.780 \\
\hline 63rods.14T-025H2O.inf.06cone & & & 30.48 & 12 & $0.779 \pm 0.001$ & 0.781 \\
\hline 63 rods.14T-.025H20.inf.00water & moderator & $\begin{array}{l}\text { full density } \\
\text { water }\end{array}$ & 0.00 & 0 & $0.781 \pm 0.001$ & 0.783 \\
\hline 63rods.14T-.025H20.inf.00 water & SS304 & $\begin{array}{c}\text { full density } \\
\text { water }\end{array}$ & 000 & 0 & $0.774 \pm 0.001$ & 0.776 \\
\hline
\end{tabular}


Attachment

June 6, 1996

VLP-06-96

Page 29 of 58

\section{SHIPPINGPORT LWBR FUEL. STORAGE. AND TRANSPORT}

Most Shippingport LWBR fuel at the INEL was partially disassembled and is stored in large canisters with restraining devices and crush pads to assist in maintaining fuel integrity. The need for restraining devices and crush pads indicate this fuel might not be sufficiently sturdy for transport without reinforcement. This indication is especially important because previous calculations indicate that one LWBR Canister could be critical if the undermoderated fuel material is dispersed more than intended and some water, not necessarily enough to fill the LWBR Canister, is added. ${ }^{17}$

Each canister contains one blanket module, seed module, or tightly packed loading of miscellaneous rods and pieces. Miscellaneous rods and pieces are doubly contained, in smalldiameter containers in the LWBR canister. These rods and pieces are remains of fuel removed from blanket and seed modules for analysis. Current plans are to avoid repackaging fuel by loading existing LWBR Canisters into DPCs.

LWBR Canisters are too large to fit in any DPC except the LWBR DPC (Figure 6, page 9). ${ }^{5}$ Up to three LWBR Canisters will physically fit in a DPC shell but scoping calculations will define canister number and location. LWBR Canisters are too long to stack in a DPC with the lid closed but stacking hypothetically could occur during handling.

Valerie Putman started LWBR scoping calculations updating canister models developed at the INEL and using the KENO V.a criticality code of SCALE 4 software. ${ }^{17,18,14}$ Carrently modelled, intact fuel includes an end-of-life (EOL) Blanket III Module, a beginning-of-life (BOL) Seed Module, and end-of-life 32 in. long loose rods and pieces in a standard LWBR canister, neglecting material above and below the fueled region.

We identified significant questions with fuel models and neutron cross-section libraries, which will delay calculation completion. Criticality safety evaluations to date use estimated end-of-life data. Estimated, rather than guaranteed, end-of-life values are not currently permitted at INEL for criticality safety calculations if beginning-of-life is more reactive. It is doubtful that end-of-life values will be permitted by the Nuclear Regulatory Commission when it is time to license the DPCs for transport. In addition, newer ${ }^{233} \mathrm{U}$ data in cross section libraries significantly increase calculated $\mathrm{k}_{\mathrm{eff}} \mathrm{s}$, although neither old nor newer data are well validated. The cumulative effect of updating seed module models produces unacceptably high $\mathrm{k}_{\mathrm{eff}} \mathrm{s}$, known to be significantly higher than is possible. These higher values do not allow us to qualify one seed module per DPC. Work is proceeding to resolve the questions, which also affect current fuel storage. Once funding is identified, an estimated 20 weeks are needed. 
Attachment

June 6, 1996

VLP-06-96

Page 30 of 58

\section{SHIPPINGPORT PWR FUEL, STORAGE, AND TRANSPORT}

Shippingport PWR assemblies are zircaloy clad, approximately $91 \%$ enriched uranium, plate fuel. Each assembly is $7.38 \mathrm{in} .(18.7452 \mathrm{~cm})$ square in cross section with an approximate 97 in. $(246.38 \mathrm{~cm})$ active fuel length. Figure 17 shows a simplified cross-section of a Core 2 Seed 2 assembly. Further descriptions are included in storage evaluations. ${ }^{19}$

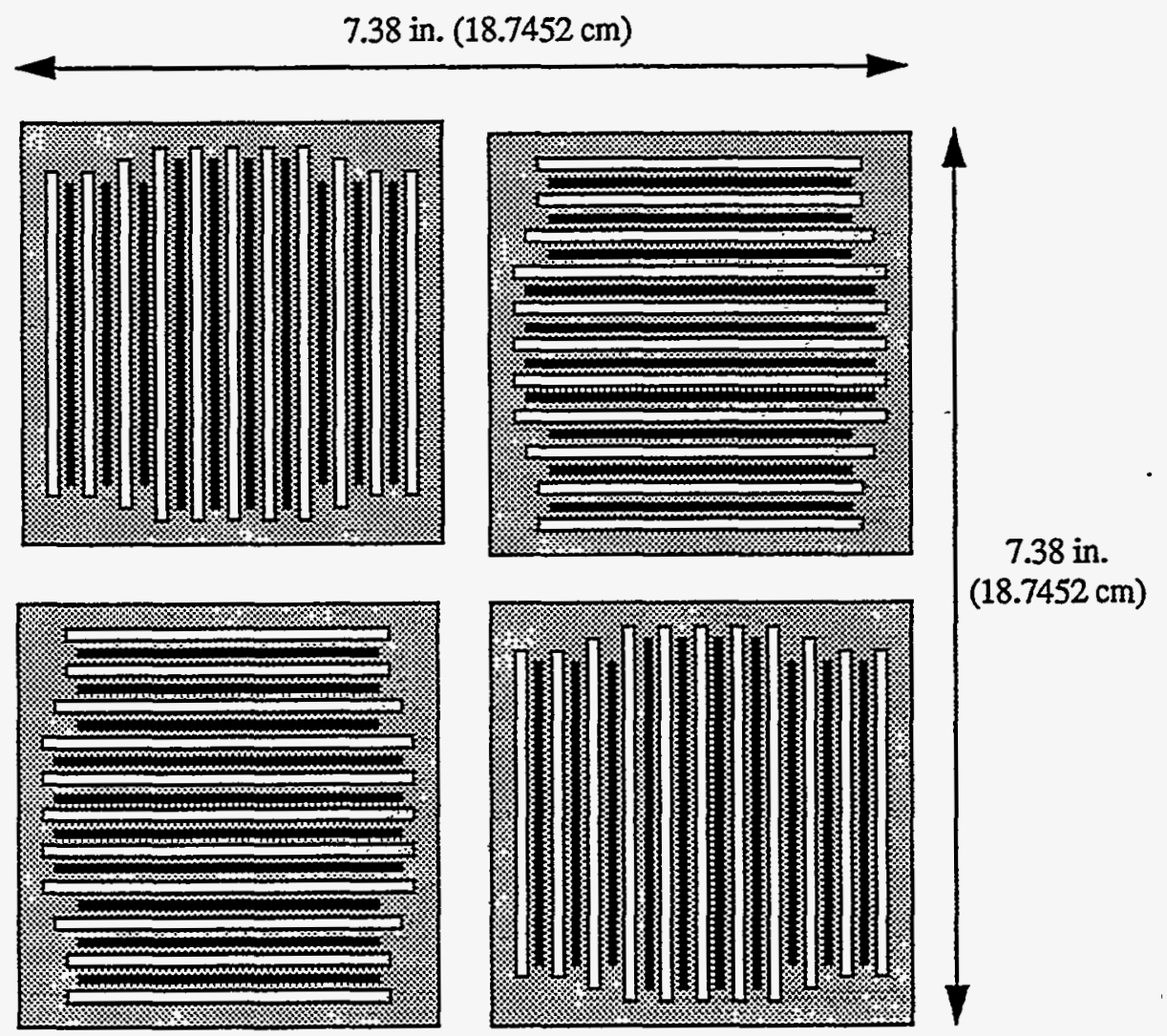

Figure 17 Shippingport PWR Core 2 Seed 2 Subassembly Cross Section

Shippingport PWR assemblies will physically fit one per 24P DSC guide sleeve, one per 14-Tube DPC tube, possibly two per FSV DPC guide sleeve, and possibly three per LWBR DPC canister opening. ${ }^{5}$ It should not be possible to stack assemblies within a DPC although a stack of two assemblies, without DPC lid, can be hypothesized as a handling error. 
Attachment

June 6, 1996

VLP-06-96

Page 31 of 58

Chuck Stuart performed Shippingport PWR scoping calculations using the Core 2 Seed 2 assembly model developed by Deborah Henrikson and the KENO V.a criticality code of SCALE 4 software. ${ }^{19,14}$ This very detailed, discrete fuel model envelopes Core 2 Seed 1 assemblies and most Core 1 assemblies for criticality safety purposes. Guaranteed end-of-life fuel data is used, unlike beginning-of-life-no-poison fuel models used for most fuels.

Table 12 summarizes results for assemblies centered in the DPC volume, taking no credit for basket designs. As expected, configurations of one assembly and one stack of assemblies are critically safe but configurations involving side-by-side assemblies are critical. We should avoid any basket design which physically permits side-by-side assemblies in an unpoisoned bucket, tube, or sleeve.

\begin{tabular}{|c|c|c|c|c|c|c|}
\hline \multicolumn{7}{|c|}{ 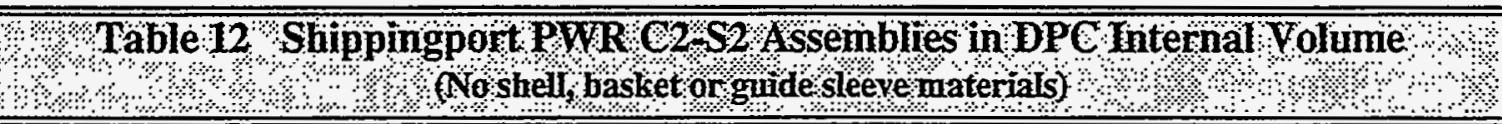 } \\
\hline Case. & opd & $\begin{array}{l}\text { Pof } \\
\text { Tiers } \\
\text { ? }\end{array}$ & $\begin{array}{l}\text { H } 1 \text { of } \\
\text { Assembles } \\
\text { pertier }\end{array}$ & $\begin{array}{l}\text { Spacing } \\
\text { within } \\
\text { frer } \\
(\mathrm{cm})\end{array}$ & 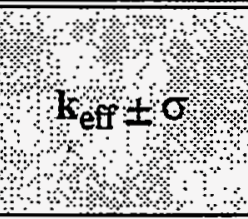 & eff \\
\hline pwr01 & \multirow{4}{*}{ water } & \multirow{2}{*}{1} & 1 & -- & $0.889 \pm 0.003$ & 0.895 \\
\hline pwr02 & & & 2 & 0.0 & $1.064 \pm 0.003$ & 1.070 \\
\hline pwr05 & & \multirow[t]{2}{*}{0} & 1 & -- & $0.888 \pm 0.003$ & 0.894 \\
\hline pwr06 & & & 2 & 0.0 & $1.065 \pm 0.003$ & 1.071 \\
\hline pwr03 & \multirow{4}{*}{ concrete } & \multirow[t]{2}{*}{1} & 1 & - & $0.887 \pm 0.003$ & 0.893 \\
\hline pwr04 & & & 2 & 0.0 & $1.060 \pm 0.003$ & 1.066 \\
\hline pwr07 & & & 1 & - & $0.890 \pm 0.003$ & 0.896 \\
\hline pwr08 & & & 2 & 0.0 & $1.064 \pm 0.003$ & 1.070 \\
\hline
\end{tabular}

Table 13 summarizes calculations for fuel in the 24P DSC (Figure 2, page 4) and the poisonmodified 24P DSC (Figure 3, page 5), addressing effects of various materials, loading configurations (Figure 18, page 32), and reflector conditions. With the exception of one 12assembly configuration (Figure 18b, page 32), results are unacceptable. ${ }^{2}$ The 24P DSC was rejected because a safer, more efficient packing should be achievable with different designs. However, results for assembly stacking are applicable to other designs (specifically, for larger arrays, array $\mathrm{k}_{\text {eff }}$ increases about $1 \%$ if units are stacked assemblies rather than single assemblies).

a. The results are critically unsafe $\left(k_{\text {eff }}>0.95\right)$ or uncomfortably close to $k_{\text {eff }}=0.95$ for unvalidated calculations with very detailed discrete fuel models. 
- Attachment

June 6, 1996

VLP-06-96

Page 32 of 58

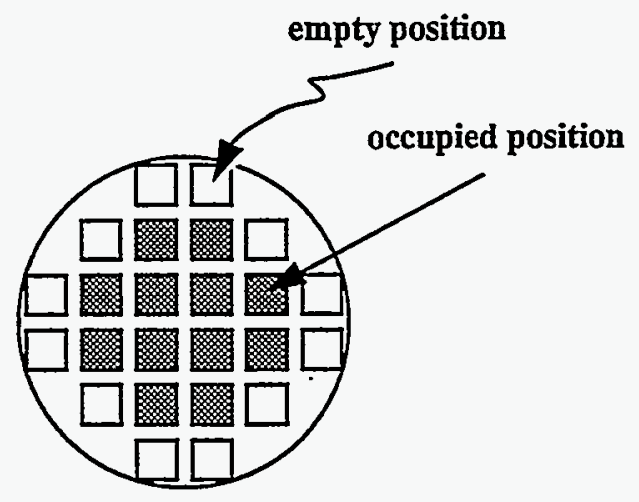

Figure 18a

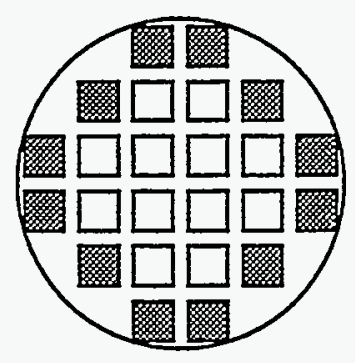

Figure 18b

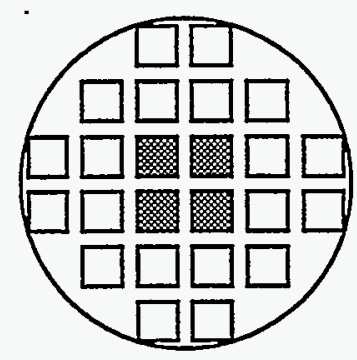

Figure 18c

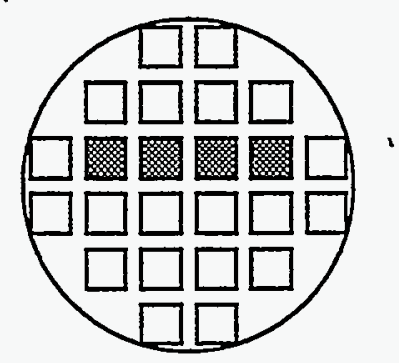

Figure 18d

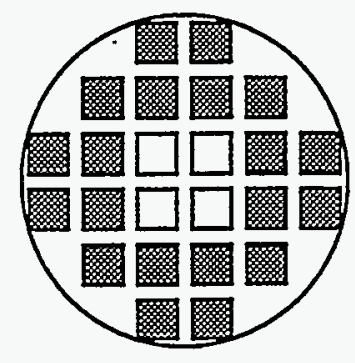

Figure 18e

Figure 18 Loading Configurations Modelled for Shippingport PWR Assemblies in 24P DSC 
Attachment

June 6, 1996

VLP-06-96

Page 33 of 58

\begin{tabular}{|c|c|c|c|c|c|c|}
\hline 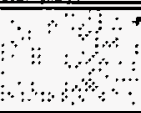 & Table $13 \mathrm{~S}$ & $\begin{array}{l}\text { ppingport PMR } \\
\text { (fullden }\end{array}$ & $\begin{array}{r}2-52 A \\
\text { sitymates }\end{array}$ & Sembliesin N & HOMS $24 P$ & \begin{tabular}{l}
$\mathrm{SC}$ \\
\hdashline
\end{tabular} \\
\hline Case & 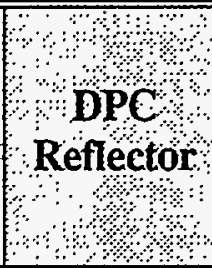 & $\begin{array}{c}\text { mol } \\
\text { Number of } \\
\text { Occupied } \\
\text { Güde Sleeves } \\
\text { }\end{array}$ & $\begin{array}{l}\text { \# of } \\
\text { Tiers } \\
\text { per } \\
\text { Guide } \\
\text { Sleeve. }\end{array}$ & $\begin{array}{l}\text { मे } \\
\text { Additional } \\
\text { Bescription } \\
\text { के }\end{array}$ & $\begin{array}{ll}\mathrm{k}_{\text {eff }}+\mathrm{\sigma} \\
\mathrm{k} \\
\mathrm{k}\end{array}$ & 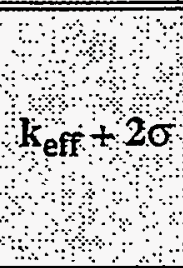 \\
\hline cask01 & 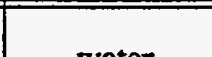 & 94 & 1 & no DSC wall & $1.045 \pm 0.003$ & 1.051 \\
\hline cask02 & waul & 27 & 1 & with DSC wall & $1.042 \pm 0.003$ & 1.048 \\
\hline cask03 & & & & no DSC wall, & $1.049 \pm 0.003$ & 1.055 \\
\hline cask04 & regular & & & with DSC wall & $1.052 \pm 0.003$ & 1.058 \\
\hline cask05 & concrete & 24 & 1 & $\begin{array}{l}\text { no DSC wall, } \\
\text { thicker guide } \\
\text { sleeve wall }\end{array}$ & $1.022 \pm 0.003$ & 1.028 \\
\hline cask06 & & $\begin{array}{l}12 \text { (Figure } 18 a, \\
\text { page } 32 \text { ) }\end{array}$ & & & $1.021 \pm 0.003$ & 1.027 \\
\hline cask07 & regular & $\begin{array}{c}12 \text { (Figure } 18 b, \\
\text { page } 32 \text { ) }\end{array}$ & 1 & חDSC wall & $0.917 \pm 0.003$ & 0.923 \\
\hline cask08 & concrete & $\begin{array}{l}4 \text { (Figure } 18 \mathrm{c} \\
\text { page } 32 \text { ) }\end{array}$ & & no usc wall & $0.972 \pm 0.003$ & 0.978 \\
\hline cask09 & & $\begin{array}{l}4 \text { (Figure 18d, } \\
\text { page 32) }\end{array}$ & & & $0.945 \pm 0.003$ & 0.951 \\
\hline cask10 & & $\begin{array}{c}12 \text { (Figure } 18 b, \\
\text { page } 32 \text { ) }\end{array}$ & & & $0.924 \pm 0.003$ & 0.930 \\
\hline cask11 & $\begin{array}{l}\text { regular } \\
\text { concrete }\end{array}$ & $\begin{array}{l}4 \text { (Figure 18d, } \\
\text { 'page 32) }\end{array}$ & 2 & no DSC wall & $0.944 \pm 0.003$ & 0.950 \\
\hline cask12 & & 24 & & & $1.044 \pm 0.003$ & 1.050 \\
\hline cask13 & & 24 & 1 & poison- & $0.984 \pm 0.003$ & 0.990 \\
\hline cask14 & $\begin{array}{l}\text { regular } \\
\text { concrete }\end{array}$ & $\begin{array}{l}20 \text { (Figure } 18 \mathrm{e}, \\
\text { page 32) }\end{array}$ & 1 & $\begin{array}{l}\text { modified DSC } \\
\text { (Figure 3, }\end{array}$ & $0.942 \pm 0.003$ & 0.948 \\
\hline cask15 & & $\begin{array}{c}20 \text { (Figure } 18 \mathrm{e}, \\
\text { page 32) }\end{array}$ & 2 & $\begin{array}{c}\text { page 5), no DSC } \\
\text { wall }\end{array}$ & $0.954 \pm 0.003$ & 0.960 \\
\hline
\end{tabular}


Attachment

June 6, 1996

VLP-06-96

Page 34 of 58

Table 14 summarizes results for assemblies in the proposed 14-Tube DPC (Figure 4, page 7), addressing effects of DPC shell, DPC tube or bucket, optimum moderation, and three reflector conditions. Calculations model one assembly centered in each tube, for a total 14 assemblies per DPC, with nominal pipe diameters and wall thicknesses for each tube.

Results indicate that assemblies are essentially isolated from each other in this configuration. Assemblies are far enough from the DPC wall that there is no significant difference in effects of common, strong reflectors. Shippingport PWR Core 2 assemblies are critically safe $\left(k_{\text {eff }} \leq 0.95\right)$ in the 14-Tube DPC for all conditions considered, if:

- Assemblies are centered or nearly centered within the tubes or buckets,

- Tubes or buckets are sized and positioned as planned, and

- Assemblies, DPC, and DPC baskets maintain their structural integrity.

\begin{tabular}{|c|c|c|c|c|c|}
\hline & 14. & port PWR & 62.52 \&ssembles in prof & osed14. Iube & DPC.\%?. \\
\hline 4 Case? & Woderator & Reflector & Additional bescription & $\mathrm{k}_{\mathrm{eff}} \pm 0$ & $\mathrm{keff}+2 \%$ \\
\hline cask16 & 1.00 & & & $0.911 \pm 0.003$ & 0.917 \\
\hline cask16b & 0.50 & $\begin{array}{l}\text { Iegular } \\
\text { concrete }\end{array}$ & $\begin{array}{l}12 \text { in. Schedule } 40 \text { SSSO4 pipe } \\
\text { tubes, no DPC shell wall }\end{array}$ & $0.767 \pm 0.003$ & 0.773 \\
\hline cask16c & 0.25 & & & $0.736 \pm 0.003$ & 0.742 \\
\hline cask17 & 1.00 & & & $0.913 \pm 0.003$ & 0.919 \\
\hline cask17e & 0.90 & & & $0.885 \pm 0.003$ & 0.891 \\
\hline cask17a & 0.75 & & & $0.833 \pm 0.003$ & 0.839 \\
\hline cask17f & 0.60 & & & $0.807 \pm 0.003$ & 0.813 \\
\hline cask17b & 0.50 & & & $0.798 \pm 0.003$ & 0.804 \\
\hline cask $17 \mathrm{~g}$ & 0.40 & regular & 12 in. schedule 10 SS304 pipe & $0.793 \pm 0.003$ & 0.799 \\
\hline cask17h & 0.30 & & & $0.802 \pm 0.003$ & 0.808 \\
\hline cask17c & 0.25 & & & $0.813 \pm 0.003$ & 0.819 \\
\hline cask17i & 0.20 & & & $0.812 \pm 0.003$ & 0.818 \\
\hline cask $17 \mathrm{j}$ & 0.15 & & & $0.802 \pm 0.003$ & 0.808 \\
\hline cask17d & 0.00 & & & $0.619 \pm 0.002$ & 0.623 \\
\hline cask17-ss & 100 & SS304 & 12 in. schedule 10 SS304 pipe & $0.912 \pm 0.003$ & 0.918 \\
\hline cask17-H2O & 1.00 & water & tubes, no DPC shell wall & $0.912 \pm 0.003$ & 0.918 \\
\hline cask18-H2O & -1.00 & water & $\begin{array}{c}12 \text { in. schedule } 10 \text { SS304 pipe } \\
\text { tubes, with DPC shell wall }\end{array}$ & $0.913 \pm 0.003$ & 0.919 \\
\hline
\end{tabular}


Attachment

June 6, 1996

VLP-06-96

Page 35 of 58

Table 15 summarizes additional results, originally requested to determine minimum acceptable separation between DPCs in lag storage. Results indicate fuel in one14-Tube DPC is essentially isolated from fuel in an identical adjacent DPC. No additional design constraints are needed to ensure critically safe storage for arrays of these PWR-loaded DPCs.

\begin{tabular}{|c|c|c|c|c|c|c|}
\hline \multicolumn{7}{|c|}{ 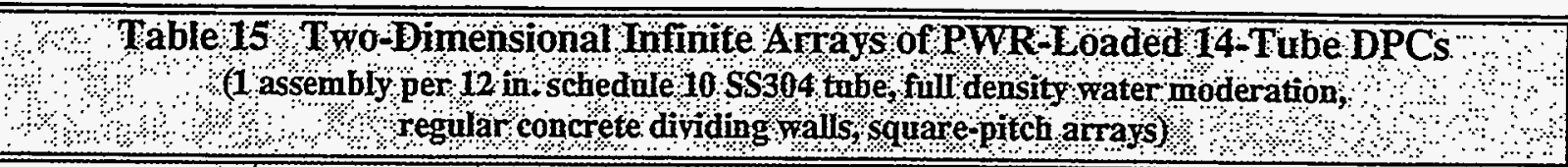 } \\
\hline दase? & DPCshel & $\begin{array}{l}\text { PPCoell } \\
\text { Seross }\end{array}$ & $\begin{array}{l}\text { DPCEdg } \\
\text { Dीp }\end{array}$ & 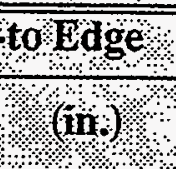 & अ & eft \\
\hline cask97-00wall & moderator & square & 0.00 & 0 & $0.914 \pm 0.003$ & 0.920 \\
\hline cask99-00wall & \multirow{4}{*}{ SS304 } & \multirow{4}{*}{ square } & 0.00 & 0 & $0.913 \pm 0.003$ & 0.919 \\
\hline cask99-06wall & & & 15.24 & 6 & $0.911 \pm 0.003$ & 0.917 \\
\hline cask99-12wall & & & 30.48 & 12 & $0.906 \pm 0.003$ & 0.912 \\
\hline cask99-18wall & & & 45.72 & 18 & $0.915 \pm 0.003$ & 0.921 \\
\hline cask98-06wall & \multirow{4}{*}{ SS304 } & \multirow{4}{*}{ circular } & $\overline{15.24}$ & 6 & $0.910 \pm 0.003$ & 0.916 \\
\hline cask98-12wall & & & 30.48 & 12 & $0.906 \pm 0.003$ & 0.912 \\
\hline cask $98-18$ wall & & & 45.72 & 18 & $0.915 \pm 0.003$ & 0.921 \\
\hline cask98-24wall & & & 60.96 & 24 & $0.912 \pm 0.003$ & 0.918 \\
\hline
\end{tabular}


Attachment

June 6, 1996

VLP-06-96

Page 36 of 58

\section{TREAT FUEL, STORAGE, AND TRANSPORT}

The INEL TREAT reactor is in-service although not currently operating. Available data consists primarily of a summary reactor description obtained before the reactor achieved initial criticality. ${ }^{20}$ Each element contains a nominal $38 \mathrm{~g}$ uranium at beginning-of-life as $93.1 \%$ enriched in ${ }^{235} \mathrm{U}$, $0.248 \mathrm{wt} \% \mathrm{U}_{3} \mathrm{O}_{8}$ uniformly dispersed in graphite (calculated $3.42 \mathrm{~g} \mathrm{U} / l$ snd $3.18 \mathrm{~g}^{235} \mathrm{U} / \mathrm{l}$ ). Fuel is made into nominal $3.8 \times 3.8 \times 8$ in. blocks, stacked six high, and clad in nominal 0.025 in. thick zircaloy-3 for each element. The fuel element is a squarish right cylinder (Figure 19a, page 37), nominally $3.96 \times 3.96 \times 107.25$ in., with aluminum-clad reflector regions and irregularly shaped end-pieces above and below active fuel. Descriptions indicate it might be relatively easy to disassemble elements into fuel cans, reflector cans, and end pieces. Figure $19 \mathrm{~b}$ shows the fuel model developed by Mark Neeley. The element is modelled as beginning-of-life fuel over the fuel can, neglecting can ends.

Mark Neeley and Valerie Putman performed calculations using the above fuel model with the KENO V.a criticality code of SCALE 4 software. ${ }^{20,14}$ Calculations model five stacked fuel cans per guide sleeve or bucket compartment in case of element disassembly and to envelope handling errors. Fuel-can stacks envelope intact elements and do not adversely affect packing efficiency for intact elements.

TREAT fuel elements fit in the NUHOMS 52B DSC (Figure 1, page 3) which was initially considered. It should not be possible to insert more than one intact element or one stack of three cans per guide sleeve, for a total 52 elements or 156 fuel cans per 52B DSC. Table 16 and Table 17 respectively summarize results for TREAT fuel in the 52B DSC, neglecting neutron absorber plates and guide sleeve material.

However, TREAT fuel elements will physically fit in all DPCs and, therefore, a more efficient design proposal, with the 14-Tube DPC (Figure 4, page 7), is used for most calculations. ${ }^{5}$ With this design TREAT elements would be loaded one intact element per compartment, four compartments per TREAT Bucket, one bucket per tube in the 14-Tube DPC, for a total 56 elements per DPC. Alternatively, a stack of three TREAT fuel cans can be loaded into each compartment for a total 168 cans per DPC. These loadings are the physical capacity for this bucket design. Figure 20 shows the basic model. Table 18 and Table 19 respectively summarize results for TREAT fuel in one 14-Tube DPC and in a two-dimensional infinite array of 14-Tube DPCs.

Table 20 summarizes results of calculations which take little or no credit for DPC basket design or fuel can structure, performed because previous calculations produced such low $\mathrm{k}_{\mathrm{eff}} \mathrm{s}$. 
Attachment

June 6, 1996

VLP-06-96

Page 37 of 58

fuel can: $3.96 \times 3.96 \times 48.125$ in.

$(10.058 \times 10.058 \times 122.2375 \mathrm{~cm})$

outside dimensions, with comers cut off

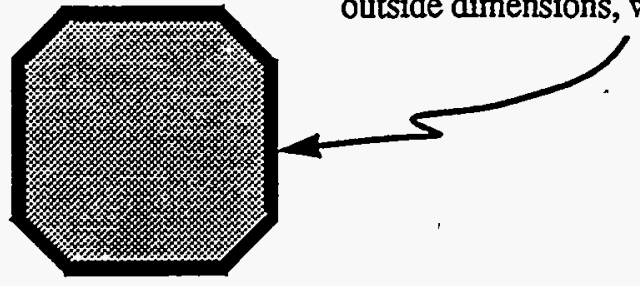

Figure 19a Actual

Fuel: $38 \mathrm{~g} \mathrm{U}$ in $\mathrm{U}_{3} \mathrm{O}_{8}-\mathrm{C}$ matrix,

$3.759 \times 3.759 \times 48$ in.

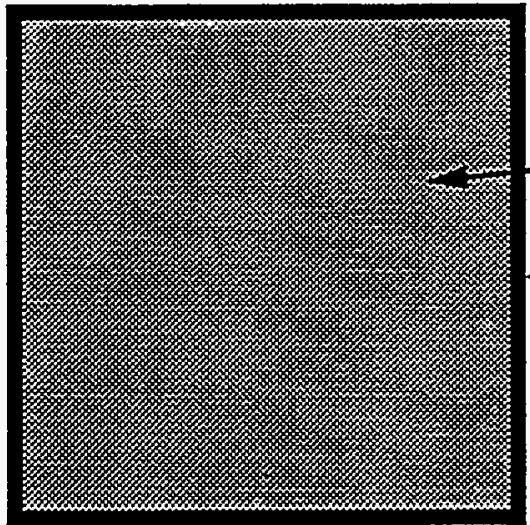

$(9.549 \times 9.549 \times 121.92 \mathrm{~cm})$

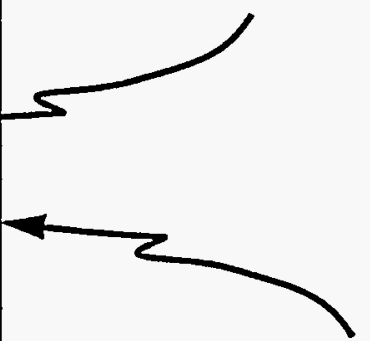

Clad: $\mathrm{Zr}, 0.025 \mathrm{in} .(0.0635 \mathrm{~cm})$ thick, $3.869 \times 3.869 \times 48$ in.

$(9.828 \times 9.828 \times 121.92 \mathrm{~cm})$

inside dimensions

Figure 19b Model

Figure 19 TREAT Fuel Can 
Attachment

June 6, 1996

VLP-06-96

Page 38 of 58

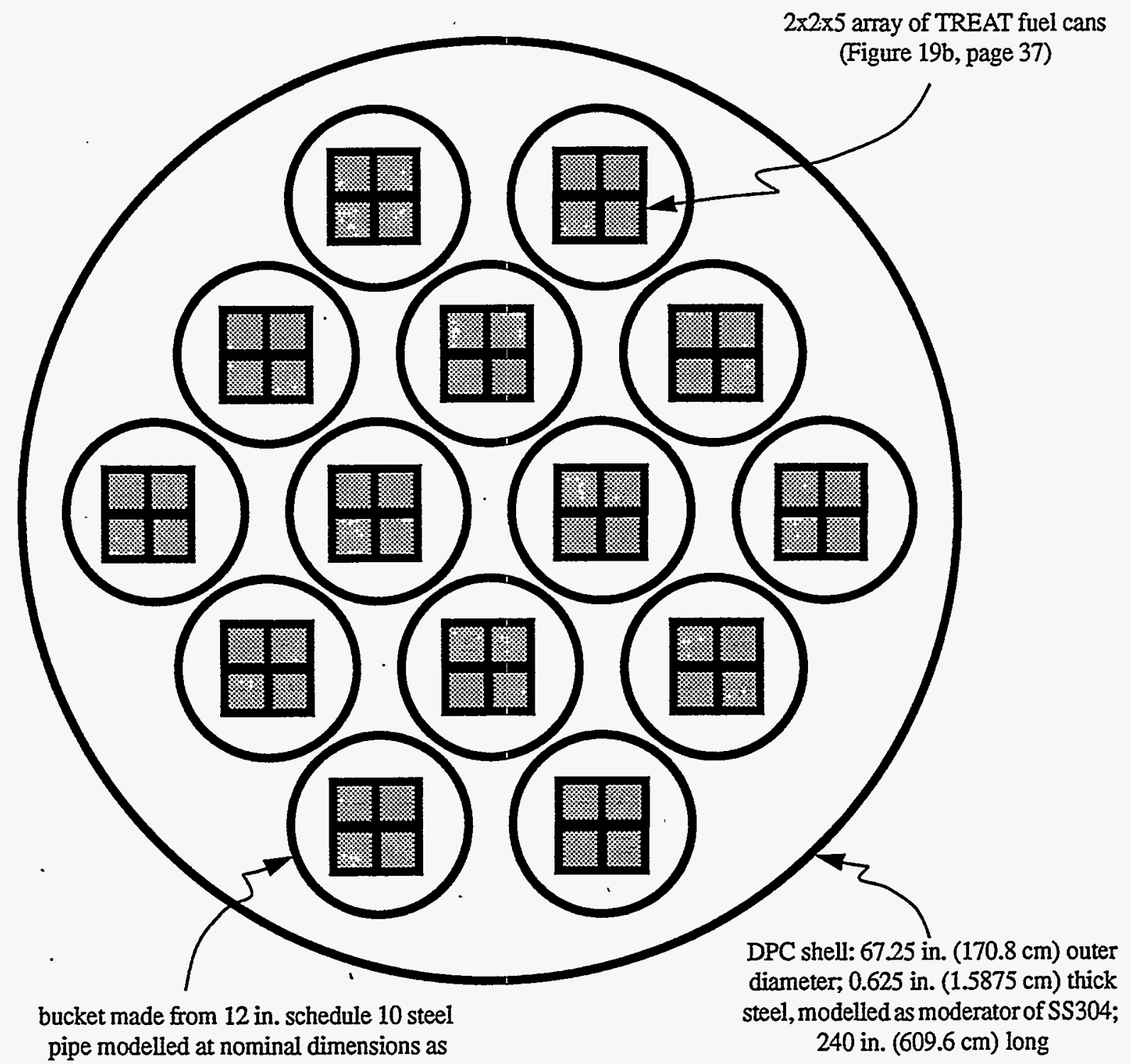

moderator or SS304 (Figure 4, page 7

specifies locations); 240 in. $(609.6 \mathrm{~cm})$

long; cruciform divider walls neglected

Figure 20 Model of TREAT-Loaded 14-Tube DPC 
Attachment

June 6, 1996

VLP-06-96

Page 39 of 58

\begin{tabular}{|c|c|c|c|c|}
\hline $\begin{array}{l}\text { Tab } \\
\text { a }\end{array}$ & 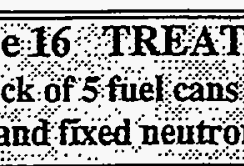 & $\begin{array}{l}\text { Eoaded } 52 \\
\text { reach guide } \\
\text { absorber mo }\end{array}$ & $\begin{array}{l}\mathrm{SC} \text {. } \\
\text { ve } \text { ed as moderatoro }^{-}\end{array}$ & मा \\
\hline Pै। case & Reflector & $\begin{array}{l}\text { Moderator } \\
\text { WVT? }\end{array}$ & $\mathrm{k}_{\mathrm{eft}}+0$ & $\mathrm{k}_{\mathrm{eff}}+2 \sigma$ \\
\hline TREAT014 & \multirow{8}{*}{$\begin{array}{l}62 \mathrm{~cm} \text { thick } \\
\text { ICPP } \\
\text { concrete }\end{array}$} & 1.00 & $0.145 \pm 0.001$ & 0.147 \\
\hline TREAT013 & & 0.75 & $0.181 \pm 0.001$ & 0.183 \\
\hline TREAT012 & & 0.50 & $0.244 \pm 0.001$ & 0.246 \\
\hline TREAT011 & & 0.25 & $0.367 \pm 0.001$ & 0.369 \\
\hline TREAT010 & & 0.15 & $0.425 \pm 0.001$ & 0.427 \\
\hline TREAT008 & & 0.10 & $0.426 \pm 0.001$ & 0.428 \\
\hline TREAT009 & & 0.05 & $0.356 \pm 0.002$ & 0.360 \\
\hline TREAT015 & & 0.00 & $0.114 \pm 0.001$ & 0.116 \\
\hline
\end{tabular}

\begin{tabular}{|c|c|c|c|c|c|}
\hline \multicolumn{6}{|c|}{ 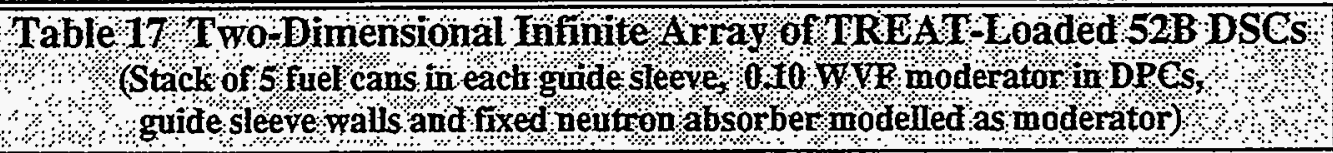 } \\
\hline Case & $\begin{array}{l}\text { DSCSbell } \\
\text { Material }\end{array}$ & $\frac{\text { DSCed }}{\text { (ca) }}$ & $\frac{\text { to edge }}{(6,1)}$ & $\mathrm{k}_{\mathrm{ef}}=\sigma$ & $\mathrm{K}_{\mathrm{eft}}+2 \mathrm{O}$ \\
\hline TREAT016 & \multirow{3}{*}{ SS304 } & 0.00 & 0 & $0.458 \pm 0.001$ & 0.460 \\
\hline TREAT017 & & 15.24 & 6 & $0.438 \pm 0.001$ & 0.440 \\
\hline TREAT018 & & 30.48 & 12 & $0.428 \pm 0.001$ & 0.430 \\
\hline
\end{tabular}


Attachment

June 6, 1996

VLP-06-96

Page 40 of 58

\begin{tabular}{|c|c|c|c|c|c|}
\hline \multicolumn{6}{|c|}{ 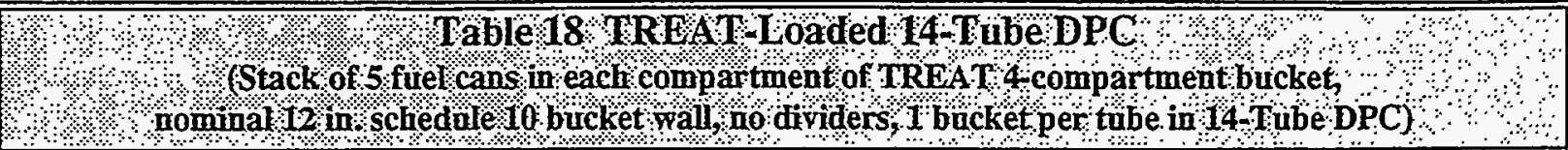 } \\
\hline + & $\begin{array}{l}\text { Bircket: } \\
\text { Watil } \\
\text { Material }\end{array}$ & Reflector & Moderator & + & $\mathrm{k}_{\mathrm{eff}}+2 \sigma$ \\
\hline TREAT.14T-.100WVF.H20 & \multirow{6}{*}{ SS304 } & \multirow{6}{*}{$\begin{array}{c}31 \mathrm{~cm} \\
\text { thick full } \\
\text { density } \\
\text { water }\end{array}$} & 1.00 & $0.182 \pm 0.001$ & 0.184 \\
\hline TREAT.14T-.075WVF.H20 & & & 0.75 & $0.180 \pm 0.001$ & 0.182 \\
\hline TREAT.14T-.050WVF.H20 & & & 0.50 & $0.182 \pm 0.001$ & 0.184 \\
\hline TREAT.14T-.025WVE.H20 & & & 0.25 & $0.192 \pm 0.001$ & 0.194 \\
\hline TREAT.14T-.010WVF.H20 & & & 0.10 & $0.165 \pm 0.001$ & 0.167 \\
\hline TREAT.14T-.000WVF.H20 & & & 0.00 & $0.069 \pm 0.001$ & 0.071 \\
\hline TREAT.14T-.100WVF.conc & \multirow{8}{*}{ SS304 } & \multirow{8}{*}{$\begin{array}{c}62 \mathrm{~cm} \\
\text { thickICPP } \\
\text { concrete }\end{array}$} & 1.00 & $0.182 \pm 0.001$ & 0.184 \\
\hline TREAT.14T-.075WVF.conc & & & 0.75 & $0.178 \pm 0.001$ & 0.180 \\
\hline TREAT.14T-.050WVF.conc & & & 0.50 & $0.181 \pm 0.001$ & 0.183 \\
\hline TREAT.14T-.025WVF.conc & & & 0.25 & $0.193 \pm 0.001$ & 0.195 \\
\hline TREAT.14T-.015WVF.conc & & & 0.15 & $0.185 \pm 0.001$ & 0.187 \\
\hline TREAT.14T-.010WVF.conc & & & 0.10 & $0.176 \pm 0.001$ & 0.178 \\
\hline TREAT.14T-.005WVF.conc & & & 0.05 & $0.147 \pm 0.001$ & 0.149 \\
\hline TREAT.14T-.000WVF.conc & & & 0.00 & $0.084 \pm 0.001$ & 0.086 \\
\hline TREAT.14T--.050WVF.conc & \multirow{5}{*}{ moderator } & \multirow{5}{*}{$\begin{array}{c}62 \mathrm{~cm} \\
\text { thickICPP } \\
\text { concrete }\end{array}$} & 0.50 & $0.275 \pm 0.001$ & 0.277 \\
\hline TREAT.14T--.025WVF.conc & & & 0.25 & $0.399 \pm 0.001$ & 0.401 \\
\hline TREAT.14T-.015WVF.conc & & & 0.15 & $0.456 \pm 0.001$ & 0.458 \\
\hline TREAT.14T-.010WVF.conc & & & 0.10 & $0.457 \pm 0.002$ & 0.461 \\
\hline TREAT.14T--.005WVF.conc & & & 0.05 & $0.379 \pm 0.002$ & 0.383 \\
\hline TREAT.14T-.100WVF.SS304 & \multirow{6}{*}{ SS304 } & \multirow{6}{*}{$\begin{array}{l}31 \mathrm{~cm} \\
\text { thick } \\
S S 304\end{array}$} & 1.00 & $0.183 \pm 0.001$ & 0.185 \\
\hline TREAT.14T-.075WVF.SS304 & & & 0.75 & $0.179 \pm 0.001$ & 0.181 \\
\hline TREAT.14T-.050WVF.SS304 & & & 0.50 & $0.182 \pm 0.001$ & 0.183 \\
\hline TREAT.14T-.025WVF.SS304 & & & 0.25 & $0.193 \pm 0.001$ & 0.195 \\
\hline TREAT.14T-.010WVF.SS304 & & & 0.10 & $0.183 \pm 0.001$ & 0.185 \\
\hline TREAT.14T-.000WVF.SS304 & & & 0.00 & $0.096 \pm 0.001$ & 0.098 \\
\hline
\end{tabular}


Attachment

June 6, 1996

VLP-06-96

Page 41 of 58

\begin{tabular}{|c|c|c|c|c|c|}
\hline \multicolumn{6}{|c|}{ 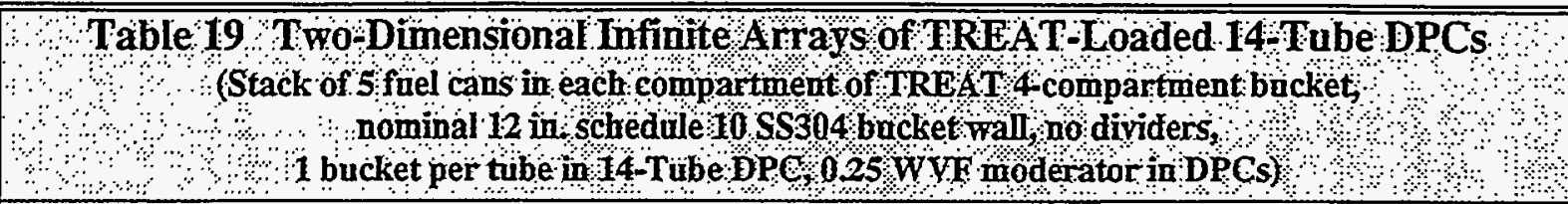 } \\
\hline & DPCShell & PPCedg & tódge & & \\
\hline সै४ & Material & $(\mathrm{cm})$ & (in) & & \\
\hline TREAT.14T-025WVF.inf.00conc & \multirow{3}{*}{ SS304 } & 0.00 & $\overline{0}$ & $0.195 \pm 0.001$ & 0.197 \\
\hline TREAT.14T-.025WVF.inf.06conc & & 15.24 & 6 & $0.192 \pm 0.001$ & 0.194 \\
\hline TREAT.14T-.025WVF.inf.12conc & & 30.48 & 12 & $0.192 \pm 0.001$ & 0.194 \\
\hline TREAT.-14T-.025WVF.inf.00conc & \multirow{3}{*}{ moderator } & $\overline{0.00}$ & 0 & $0.197 \pm 0.001$ & 0.199 \\
\hline TREAT.-14T-.025WVF.inf.06conc & & 15.24 & 6 & $0.194 \pm 0.001$ & 0.196 \\
\hline TREAT.-14T-.025WVF.inf.12conc & & 30.48 & 12 & $0.192 \pm 0.001$ & $\overline{0.194}$ \\
\hline
\end{tabular}

\begin{tabular}{|c|c|c|c|c|c|}
\hline अै। & gable 20 & DPCof $\mathrm{TR}$ & Thuel with Gifte ors & ueture & \%४। \\
\hline Case? & Reflector & Moderator & Additionalovescription & $\mathrm{k}_{\mathrm{eff}}+\sigma$ & $\mathrm{K}_{\mathrm{eft}}+2 \%$ \\
\hline TREAT020 & $\begin{array}{l}\text { identical } \\
\text { DPCs, no } \\
\text { spacing } \\
\text { between }\end{array}$ & not applicable & $\begin{array}{l}\text { fuel matrix homogenized } \\
\text { throughout DPC shell; DPC } \\
\text { array like Case TREAT016 } \\
\text { (Table 17, page 39) }\end{array}$ & $1.226 \pm 0.002$ & 1.23 \\
\hline TREAT019 & $\begin{array}{l}\text { identical } \\
\text { DPCs, no } \\
\text { spacing } \\
\text { between }\end{array}$ & 0.10 & $\begin{array}{c}188 \text { elements per DPC } \\
\text { practically filling DPC volume; } \\
\text { DPC array like Case } \\
\text { TREAT020 above }\end{array}$ & $1.182+0.003$ & 1.19 \\
\hline TREAT021 & concrete & 0.10 & $\begin{array}{l}188 \text { elements in one DPC } \\
\text { practically filling DPC volume }\end{array}$ & $1.170+0.002$ & 1.17 \\
\hline $\begin{array}{l}\text { TREAT+.14T-- } \\
\text {.050WVF.conc }\end{array}$ & & 0.50 & & $0.637 \pm 0.002$ & 0.641 \\
\hline $\begin{array}{l}\text { TREAT+.14T- } \\
.025 W V F . c o n c\end{array}$ & & 0.25 & $\begin{array}{l}\text { fuel matrix homogenized } \\
\text { throughout buckets; bucket }\end{array}$ & $0.810 \pm 0.002$ & 0.814 \\
\hline $\begin{array}{l}\text { TREAT+.14T-- } \\
.010 W V F . c o n c\end{array}$ & $\begin{array}{l}62 \mathrm{~cm} \text { thick } \\
\text { ICPP } \\
\text { concrete }\end{array}$ & 0.15 & $\begin{array}{l}\text { walls modelled as moderator, } \\
\text { no dividers (see cases beginning }\end{array}$ & $0.860+0.002$ & 0.864 \\
\hline $\begin{array}{l}\text { TREAT+.14T- } \\
.010 \text { WVF.cone }\end{array}$ & & 0.10 & $\begin{array}{c}\text { with TREAT.14T-- (Table 18, } \\
\text { page 40)) }\end{array}$ & $0.848 \pm 0.003$ & 0.854 \\
\hline $\begin{array}{l}\text { TREAT+.14T-- } \\
\text {.005WVF.conc }\end{array}$ & & 0.05 & & $0.760+0.003$ & 0.766 \\
\hline
\end{tabular}


Attachment

June 6, 1996

VLP-06-96

Page 42 of 58

Calculated $\mathrm{k}_{\text {eff }} \mathrm{s}$ are very low when some credit is taken for DPC basket structure, fuel size, and fuel clad. This result is expected for such low concentration fuel. However, calculated $\mathrm{k}_{\mathrm{eff}} \mathrm{s}$ are very high when no credit is taken for fuel structure or fuel can placement. Results indicate:

- TREAT fuel is critically safe $\left(\mathrm{k}_{\text {eff }} \leq 0.95\right)$ in the 52B DSC, one element or a stack of five fuel cans per guide sleeve, at optimum moderation for full water, concrete, or steel reflection.

- TREAT fuel is critically safe in the 14-Tube DPC, with the number of elements or fuel cans per tube maximized, at optimum moderation for full water, concrete, or steel reflection.

- Although TREAT-loaded DPCs interact slightly, infinite arrays are critically safe, with or without concrete dividers.

In cases which include DSC guide sleeves or DPC TREAT Buckets with fuel can structure, the calculated $\mathrm{k}_{\text {eff }} \mathrm{s}$ are so low that they should be considered as indicative of low reactivity but not as absolute, or realistic values. Qualitative comparisons between listed values are valid for TREAT fuel but TREAT $k_{\text {eff }}$ values are not directly comparable to $k_{\text {eff }} s$ for other fuels. 
Attachment

June 6, 1996

VLP-06-96

Page 43 of 58

\section{TRIGA FUEL, STORAGE, AND TRANSPORT}

Table 21 summarizes TRIGA fuels addressed in these scoping calculations, which include all but one fuel identified with the TRIGA acronym. In some cases, particularly high-powered (93\% enriched) elements, much of the description is assumed based on other TRIGA fuels. The fuel not addressed is BER-TRIGA, which was not identified as a candidate for this study.

TRIGA fuel is a uranium-zirconium hydride of varying enrichments, uranium-to-zirconium ratios, and zirconium-to-hydrogen ratios, shaped as annular or cylindrical pellets stacked in rods.

(Available data conflict regarding fuel meat shape and possible presence of a central zirconium rod but manufacturer's descriptions indicate an annular shape is usually necessary to evenly distribute hydride.) Fuel elements have varying diameters and clad materials, with miscellaneous end pieces, including graphite, at one or both ends of the fueled region. In most cases nominal fuel parameter values are known but the manufacturer considers additional data proprietary, and has not yet shared that information with us. Table 21 summarizes available and assumed data for the active fuel regions. Where sources provide conflicting data, the more conservative values are listed. ${ }^{21,22}$ Although cladding is indicated, a few declad elements exist.

TRIGA fuel elements physically fit in all DPCs and, therefore, a more specific design proposal is used. With this design, most TRIGA fuel would be loaded into a 24 compartment bucket, sized to stack five buckets per tube position in the 14-Tube DPC. For fuel elements with at least a $1 \frac{1}{4}$ in. diameter, it should not be possible to insert more than one element per compartment, limiting a DPC to 1680 elements. Figure 21 shows the basic model of a TRIGA Bucket with this loading. Although the small-diameter elements are longer, it is hypothetically possible to load five or six small-diameter (Incoloy-clad) elements per bucket compartment. Figure 22 illustrates a worstcase model of nine declad small-diameter elements per compartment, as an example of models used to determine a maximum safe loading with this bucket design.

Mark Neeley and Valerie Putman performed calculations using fuel models developed by Valerie Putman, with the KENO V.a criticality code of SCALE 4 software ${ }^{21,22,14}$ Clad material is neglected to envelope effects of manufacturing uncertainties (tolerances) and to envelope declad elements. Figure 23 and Table 22 summarize fuel models. Each model uses beginning-of-life fuel and neglects material outside the active fuel region (fuel cladding, end reflector and poison pieces, etc.). Beginning-of-life fuel should be more reactive than end-of-life fuel because TRIGA reactors are typically operated in burst or pulse mode, which means there should be little fuel burnup. 
Attachment

June 6, 1996

VLP-06-96

Page 44 of 58

\begin{tabular}{|c|c|c|c|c|c|c|}
\hline $4 ., 4.4$, rable & 21. IRI & PA Aetive Fue & RegionDes & seriptions & 22,24 & मिन \\
\hline ' & अ. B & $61855 \%$ & BOSOI & $\mathrm{H}$ to Zr & Outer & \\
\hline General PRISA & Mass: & Enrichment: & $\begin{array}{l}\text { matiel } \\
\text { matrix } \\
\text { \%w\% }\end{array}$ & $\begin{array}{l}\text { Atom } \\
\text { Ratio }\end{array}$ & Diameter & $\begin{array}{r}\text { Length } \\
\text { (in) } \\
\text { (in) }\end{array}$ \\
\hline & & Aluminun & Clad & & & \\
\hline $\begin{array}{l}\text { Standard (instrumented and } \\
\text { normal) }\end{array}$ & 36 & 20.0 & 8 & 1.0 & 1.41 & 14 or 15 \\
\hline 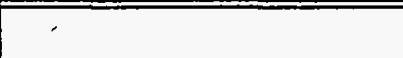 & & Stainless St & el Clad & & & \\
\hline $\begin{array}{c}\text { Standard before } 1965 \text { (plain } \\
\text { \& streamline, instrumented \& } \\
\text { normal) }\end{array}$ & 39 & 20.0 & 8.0 & 1.0 & 1.435 & 15 \\
\hline $\begin{array}{c}\text { Standard after } 1964 \text { (plain \& } \\
\text { streamline, instrumented \& } \\
\text { nomal) }\end{array}$ & 39 & 20.0 & 8.5 to 9.0 & 1.7 & 1.435 & 15 \\
\hline $\begin{array}{l}\text { Standard Fuel Follower } \\
\text { Control Elements }\end{array}$ & 38 & 20.0 & 8.5 & 1.6 & $<1.355$ & 15 \\
\hline $\begin{array}{l}1 \text { rod of 4-Rod Cluster } \\
\text { (instrumented \& normal) }\end{array}$ & [39] & {$[20.0]$} & {$[9.0]$} & {$[1.7]$} & 1.37 & 15 \\
\hline Pseudo-Standard $^{c}$ & 54 & 20.0 & 12 & 1.7 & [1.435] & 15 \\
\hline $\begin{array}{c}\text { Annular Core Pulsed Reactor } \\
\text { (ACPR) (instrumented \& } \\
\text { normal) }\end{array}$ & 54 & 20.0 & 12 & 1.7 & 1.40 & 15 \\
\hline $\begin{array}{c}\text { ACPR Fuel Follower Control } \\
\text { Element }\end{array}$ & 54 & {$[20.0]$} & [12] & 1.6 & {$[1.40]$} & 14.25 \\
\hline $\begin{array}{l}\text { Fuel Life Improvement } \\
\text { Program (FLIP) }\end{array}$ & 137 & 70.0 & 8.5 & 1.6 & {$[1.435]$} & [15] \\
\hline FLIP-LEU-I & 101 & 20.0 & 20.0 & 1.6 & {$[1.435]$} & [15] \\
\hline FLIP-LEU-II & 1,65 & 20.0 & 30.0 & 1.6 & [1.435] & {$[15]$} \\
\hline $\begin{array}{l}\text { FLIP-LEU Fuel Follower } \\
\text { Control Elements }\end{array}$ & 97 & 20.0 & 20.0 & 1.6 & $<1.355$ & 15 \\
\hline & & Incoloy 80 & 0 Clad & & & \\
\hline $\begin{array}{c}\text { Standard (instrumented \& } \\
\text { normal) }\end{array}$ & 55 & 20 & 45 & 1.6 & 0.51 & 22.0 \\
\hline High-Powered ${ }^{\mathrm{d}}$ & 41.36 & 93.15 & [45] & [1.6] & {$[0.51]$} & {$[22.0]$} \\
\hline
\end{tabular}

a Nominal values with brackets $(\square)$ around assumed or deduced values. Unless otherwise noted, fuel pellets are annular with an 0.225 in. inner diameter, usually with a zirconium rod inside the annulus. Seven fuel types have instrumented element designs, all of which are enveloped by the non-instrumented design.

b The fuel pellet is cylindrical rather than annular for aluminum clad elements with a 14-in. active fuel length.

c Type name used at INEL. Pseudo-standard TRIGA is most probably ACPR TRIGA fuel.

d Where data is not available, this fuel type is assumed to be similar to standard Incoloy clad fuel, which is used in the same country (Romania). 
Attachment

June 6, 1996

VLP-06-96

Page 45 of 58

all unlabeled dimensions in $\mathrm{cm}$

wall: 15 or 22 in. long,

12-in. schedule 10

pipe, modelled as

moderator or SS304

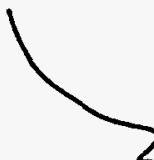

divider: nominal $\frac{1}{8}$ in. thick steel

modeled as moderator or $\$ \$ 304$

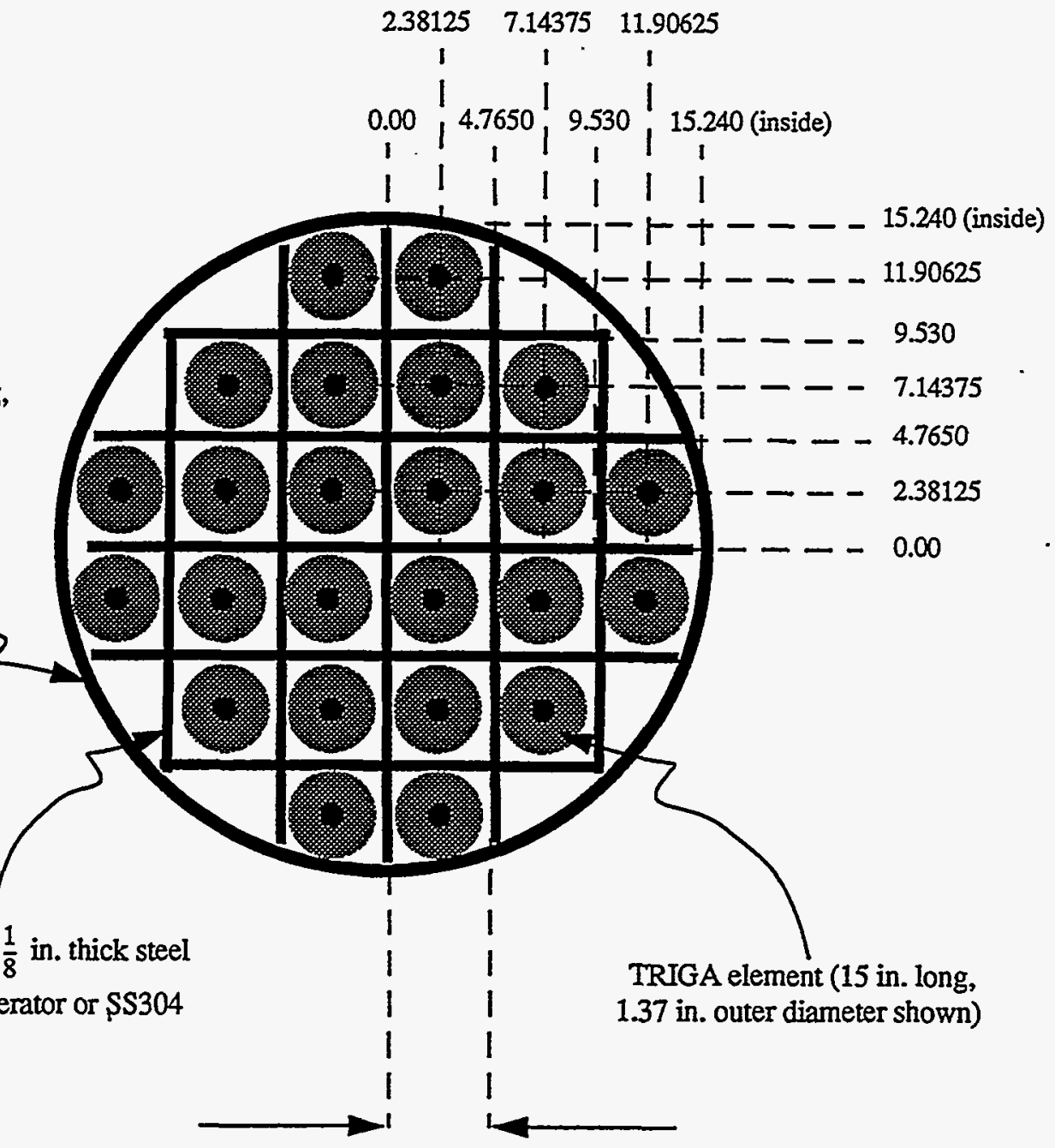

$1 \frac{7}{8}$ in. typical inside width, modelled as

$1 \frac{5}{8}$ in. for modelling convenience

Figure 21 Proposed TRIGA Bucket with Regular-Diameter TRIGA Elements 
Attachment

June 6, 1996

VLP-06-96

Page 46 of 58

variable-size array (maximum $3 \times 3$ )

of 0.51 in. outer diameter, 22 in.

long TRIGA elements

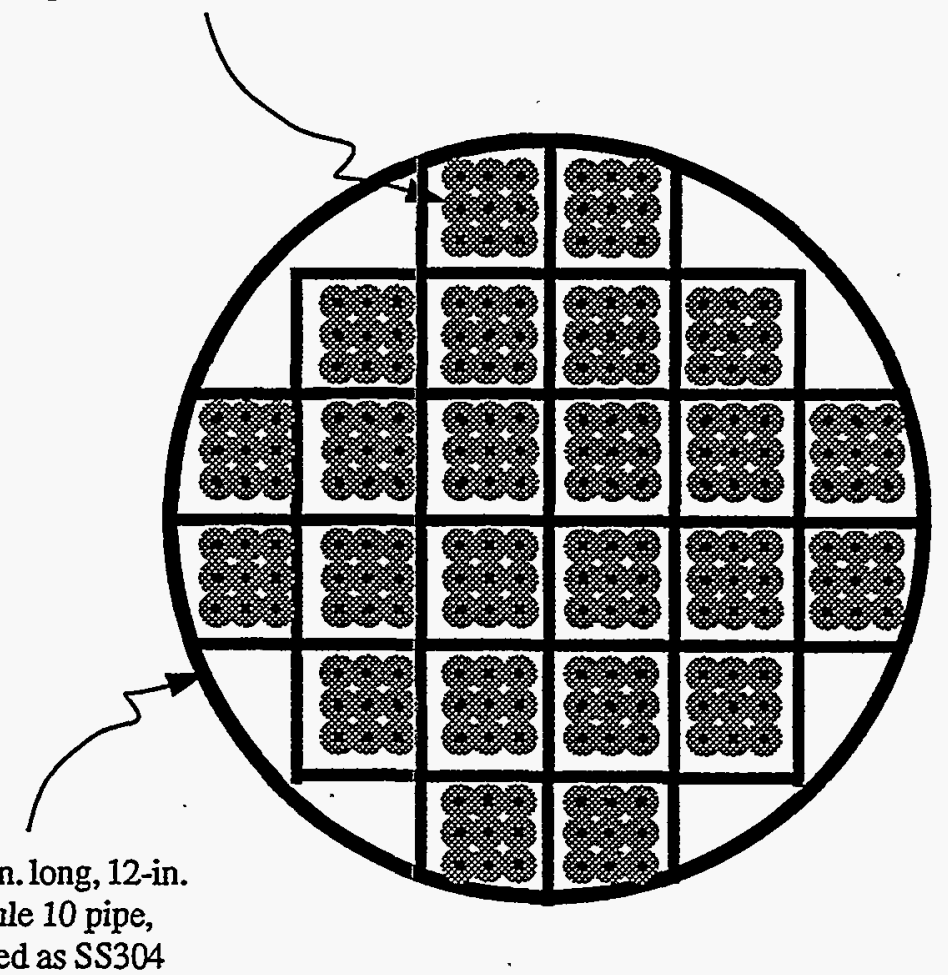

See bucket loaded with regular diameter TRIGA (Figure 21, page 45) for additional information 
Attachment

June 6, 1996

VLP-06-96

Page 47 of 58

Internal rod: 0.225 in.

$(0.5715 \mathrm{~cm})$ diameter; full length, modelled as $\mathrm{Zr}$ or moderator
Fuel Annulus: model parameters specified in Table 22; clad neglected

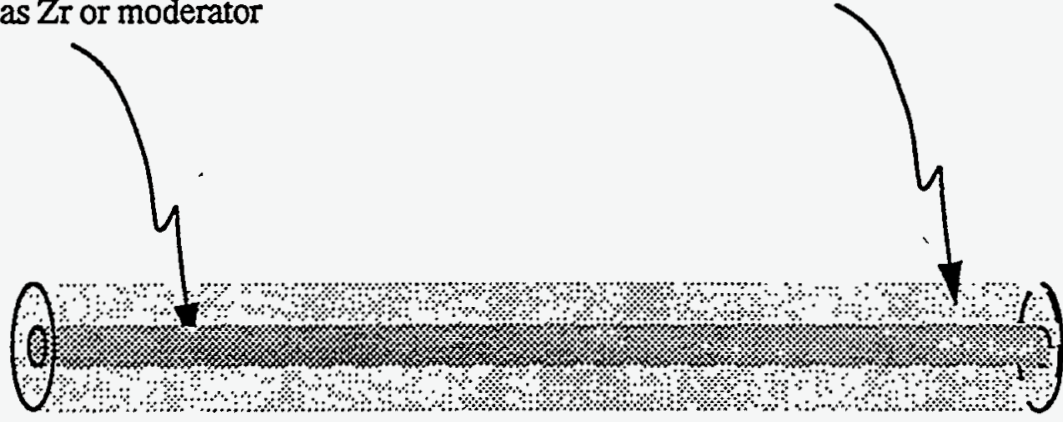

Figure 23 Model of TRIGA Fuel Element

\begin{tabular}{|c|c|c|c|c|c|c|c|c|}
\hline \multicolumn{9}{|l|}{, } \\
\hline \multirow{2}{*}{ sparameter } & ब & बMó & Identifil & TRRIAA & wherexis & indicated & below & +: \\
\hline & मि & $4^{6}$ & $\mathrm{P}^{\mathrm{s} d}$ & $\mathrm{AP}^{\mathrm{P}}$ & $3^{2} \%$ & मी & $\mathrm{lt}^{\mathrm{g}}$ & $\mathrm{Ad}^{\mathrm{h}}$ \\
\hline Outer Diameter (in.) & 1.478 & 1.37 & 1.37 & 1.37 & 1.37 & 1.37 & 0.51 & 0.51 \\
\hline $\begin{array}{l}\text { Fuel Annulus Inner } \\
\text { Diameter (in.) }\end{array}$ & 0.225 & 0.225 & 0.225 & 0.225 & 0.225 & 0.225 & 0.225 & 0.225 \\
\hline Length & 15 & 15 & 15 & 15 & 15 & 15 & 22 & 22 \\
\hline Enrichment (wt\%) & 20 & 20 & 20 & 20 & 70 & 20 & 20 & 93.15 \\
\hline $\mathrm{BOL}^{235} \mathrm{U}(\mathrm{g})$ & 39 & 39 & 54 & 54 & 137 & 165 & 55 & 41.36 \\
\hline $\begin{array}{l}\text { BOL Uranium Content } \\
\text { (wt\%) }\end{array}$ & 9 & 9 & 9 & 12 & 8.5 & 30 & 45 & 45 \\
\hline $\mathrm{H}: \mathrm{Zr}$ atom ratio & 1.7 & 1.7 & 1.7 & 1.7 & 1.6 & 1.6 & 1.6 & 1.6 \\
\hline Cladding & none & none & none & none & none & none & none & none \\
\hline
\end{tabular}

a These models include a central $\mathrm{Zr}$ rod. Models with moderator in place of the $\mathrm{Zr}$ rod are distinguished by adding a hyphen (-) to the end of the identifier (for example, TRIGA- and TRIGAA-).

b Model to investigate effects of fuel annulus diameter (compare results of TRIGA- and TRIGA4).

c Model to investigate effects of uranium wt\% in fuel meat (compare results of TRIGAP and IRIGAA).

d Calculation results indicate one element of this model envelopes one element of any of these clad and declad TRIGA fuel types except the FLIP types. This model is selected for all standard TRIGA.

e Model of declad FLIP.

f Model of declad FLIP-LEU-II, which envelopes FLIP-LEU-I. This model is selected for all TRIGA-FLIP.

g Model of declad standard Incoloy-800 clad TRIGA, selected for all small-diameter TRIGA elements.

h Model of assumed declad high-powered TRIGA. 
Attachment.

June 6, 1996

VLP-06-96

Page 48 of 58

Table 23 compares results for various fuel models. All loadings of one element per TRIGA bucket compartment, except FLIP fuels, are enveloped by the TRIGAP-model, selected as the basic fuel model for standard TRIGA calculations. With this model it is important to note that each rod of a four-rod cluster is considered to be a single element. TRIGA7-and TRIGAI-, respectively, are the models selected for FLIP and small-diameter elements. These models envelope declad elements of their respective element types if fuel meat is intact.

Table 24 and Table 25 summarize results for 14-Tube DPCs with TRIGA Buckets, loaded to capacity with TRIGAP - (worst case pseudo-standard) elements. Calculations address optimum moderation and three reflector conditions for single DPCs and DPC separation for two dimensional infinite arrays of identical DPCs. Results indicate that it is necessary to take credit for steel in bucket outer walls to ensure criticality safety for optimally moderated, full reflection conditions. Infinite two dimensional array calculations indicate that fuel in one 14-Tube DPC is essentially isolated from fuel in an adjacent 14-Tube DPC. At one element per compartment, these results envelope all subject TRIGA element types except FLIP (Table 21, page 44).

Table 26 and Table 27 summarize results for 14-Tube DPCs with TRIGA Buckets, loaded to capacity with TRIGA7- (worst-case FLIP) elements. Calculations address optimum moderation and three reflector conditions for single DPCs and DPC separation for two dimensional infinite arrays of identical DPCs. Results indicate that it is necessary to take credit for steel in bucket walls and dividers to ensure criticality safety for optimally moderated, full reflection conditions. Results for FLIP fuel with steel dividers show trends similar to standard fuel without steel dividers, except that FLIP fuel is more reactive. The highest $\mathrm{k}_{\mathrm{eff}}, 0.945$ for the optimum moderated steel reflected case, is acceptable for these unvalidated calculations because fuel models are very conservative and it is doubtful that FLIP fuel is declad. This case might deserve special attention when a final bucket design is approved.

Table 28 and Table 29 summarize results for 14-Tube DPC with TRIGA Buckets, loaded with identical arrays of TRIGAI- (worst case Incoloy clad, small diameter) elements centered in each compartment. Calculations address element array size, optimum moderation, and two reflector conditions for single DPCs; and DPC separation for two dimensional infinite arrays of identical DPCs. Calculations take credit for steel in bucket walls and dividers because the goal is to determine a maximum loading and because this steel is required for criticality safety with FLIP elements:

Calculation assumptions and results indicate:

- Optimum moderation occurs at about $0.10 \mathrm{WVF}$ for one element centered per compartment and varies for arrays of small-diameter elements in each compartment.

- One rod of a TRIGA 4-rod cluster should be counted as one standard element. 
Attachment

June 6, 1996

VLP-06-96

Page 49 of 58

\begin{tabular}{|c|c|c|c|c|}
\hline \multicolumn{5}{|c|}{ 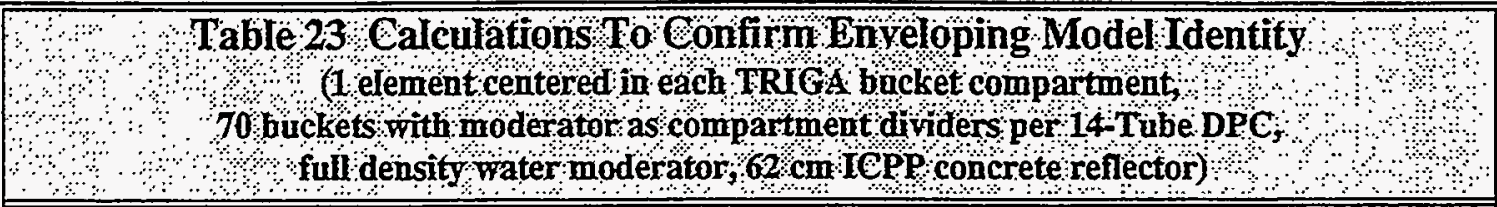 } \\
\hline $\begin{array}{l}\text { Element's } \\
\text { Central Rod } \\
\text { Materian } \\
\text { On }\end{array}$ & 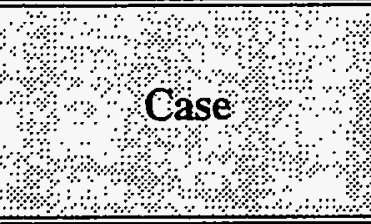 & $\begin{array}{l}\text { Fuelyoudel, } \\
\text { (Figure } 23, \text {, } \\
\text { Table } 22,4 \text { page } 47 \text { ) }\end{array}$ & $\mathrm{k}_{\mathrm{eff}}+\mathrm{\sigma}_{\mathrm{o}}$ & +efo \\
\hline \multirow{8}{*}{$\mathrm{Zr}$} & TRIGA-100WVF.vault & TRIGA- & $0.709 \pm 0.002$ & 0.713 \\
\hline & TRIGA4.100WVF.vauit & TRIGA4 & $0.715 \pm 0.002$ & 0.719 \\
\hline & TRIGAP.100WVF.vault & TRIGAP & $0.823 \pm 0.002$ & 0.827 \\
\hline & TRIGAA.100WVF.vault & TRIGAA & $0.798 \pm 0.002$ & 0.802 \\
\hline & TRIGA7.100WVF.vault & TRIGA7 & $1.011 \pm 0.003$ & 1.017 \\
\hline & TRIGAL.100WVF.vault & TRIGAI & $1.005 \pm 0.003$ & 1.011 \\
\hline & TRIGAI.100WVF.vault & TRIGAI & $0.572 \pm 0.002$ & 0.576 \\
\hline & TRIGAH.100WVF.vault & TRIGAH & $0.514 \pm 0.002$ & 0.518 \\
\hline \multirow{8}{*}{ moderator } & TRIGA--.100WVF.vault & TRIGA- & $0.712 \pm 0.002$ & 0.716 \\
\hline & TRIGA4-100WVF.vault & TRIGA4- & $0.724 \pm 0.003$ & 0.730 \\
\hline & TRIGAP-.100WVF.vault & TRIGAP- & $0.821 \pm 0.002$ & 0.825 \\
\hline & TRIGAA-.100WVF.vault & TRIGAA- & $0.806 \pm 0.002$ & 0.810 \\
\hline & TRIGA7-.100WVF.vault & TRIGA7- & $1.011 \pm 0.003$ & 1.017 \\
\hline & TRIGALr.100WVF.vault & TRIGAL- & $1.007 \pm 0.003$ & 1.013 \\
\hline & TRIGAI-.100WVE.vault & TRIGAI- & $0.583 \pm 0.002$ & 0.587 \\
\hline & TRIGAH-.100WVF.vault & TRIGAH- & $0.521 \pm 0.002$ & 0.525 \\
\hline
\end{tabular}


Attachment

June 6; 1996

VLP-06-96

Page 50 of 58

\begin{tabular}{|c|c|c|c|c|c|}
\hline ४ै. & $\begin{array}{l}\text { ble } 24 \\
\text { hentered Most } \\
\text { ? }\end{array}$ & $\begin{array}{l}\text { TRIGAFu } \\
\text { chbucket col } \\
\text { tstackedin }\end{array}$ & 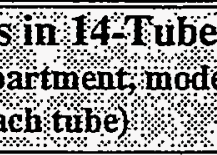 & PC & lers \\
\hline Pै। & $\begin{array}{l}\text { Bücket } \\
\text { Wall } \\
\text { Matertal }\end{array}$ & Reflector & Moderator & से & से \\
\hline TRIGAP-14T-.050WVF.water & \multirow{3}{*}{ SS304 } & \multirow{3}{*}{$\begin{array}{l}31 \mathrm{~cm} \text { thick } \\
\text { full density } \\
\text { water }\end{array}$} & 0.50 & $0.862 \pm 0.002$ & 0.866 \\
\hline TRIGAP-14T-.025WVF.water & & & 0.25 & $0.901 \pm 0.002$ & 0.905 \\
\hline TRIGAP-.14T-000WVE.water & & & 0.00 & $0.736 \pm 0.002$ & 0.740 \\
\hline TRIGAP-.14T-.100WVF.valt & \multirow{5}{*}{ moderator } & \multirow{5}{*}{$\begin{array}{l}62 \mathrm{~cm} \text { thick } \\
\text { ICPP } \\
\text { concrete }\end{array}$} & 1.00 & $0.851 \pm 0.002$ & 0.855 \\
\hline TRIGAP-14T-.075WVF.vault & & & 0.75 & $0.892 \pm 0.002$ & 0.896 \\
\hline TRIGAP-.14T--050WVF.vault & & & 0.50 & $0.975 \pm 0.002$ & 0.979 \\
\hline TRIGAP-.14T-.025WVF.vault & & & 0.25 & $1.105 \pm 0.003$ & 1.111 \\
\hline TRIGAP-14T-.000WVF.vauit & & & 0.00 & $0.903 \pm 0.005$ & 0.913 \\
\hline TRIGAP-.14T-.100WVF.vault & \multirow{6}{*}{ SS304 } & \multirow{6}{*}{$\begin{array}{l}62 \mathrm{~cm} \text { thick } \\
\text { ICPP } \\
\text { concrete }\end{array}$} & 1.00 & $0.821 \pm 0.002$ & 0.825 \\
\hline TRIGAP-14T-.075WVF.vault & & & 0.75 & $0.842 \pm 0.002$ & 0.846 \\
\hline TRIGAP-.14T-.050WVF.vault & & & 0.50 & $0.863 \pm 0.002$ & 0.867 \\
\hline TRIGAP-.14T-.025WVF.vault & & & 0.25 & $0.900 \pm 0.003$ & 0.906 \\
\hline TRIGAP-.14T-.010WVF.vault & & & 0.10 & $0.900 \pm 0.003$ & 0.906 \\
\hline TRIGAP-14T-.000WVF.vault & & & 0.00 & $0.818 \pm 0.004$ & 0.826 \\
\hline TRIGAP-14T-050WVF.SS304 & \multirow{6}{*}{ SS304 } & \multirow{6}{*}{$\begin{array}{l}31 \mathrm{~cm} \text { thick } \\
\text { SS304 }\end{array}$} & 0.50 & $0.861 \pm 0.003$ & 0.867 \\
\hline TRIGAP-14T-025WVF.SS304 & & & 0.25 & $0.904 \pm 0.002$ & 0.908 \\
\hline TRUGAP-14T-015WVF.SS304 & & & 0.15 & $0.923 \pm 0.003$ & 0.929 \\
\hline TRIGAP-14T-010WVV.SS304 & & & 0.10 & $0.926 \pm 0.002$ & 0.930 \\
\hline TRIGAP-14T-005WVE.SS304 & & & 0.05 & $0.915 \pm 0.003$ & 0.921 \\
\hline TRIGAP-.14T-.000WVF.SS304 & & & 0.00 & $0.877 \pm 0.004$ & 0.885 \\
\hline
\end{tabular}


Attachment

June 6, 1996

VLP-06-96

Page 51 of 58

\begin{tabular}{|c|c|c|c|c|c|c|}
\hline \multicolumn{7}{|c|}{ 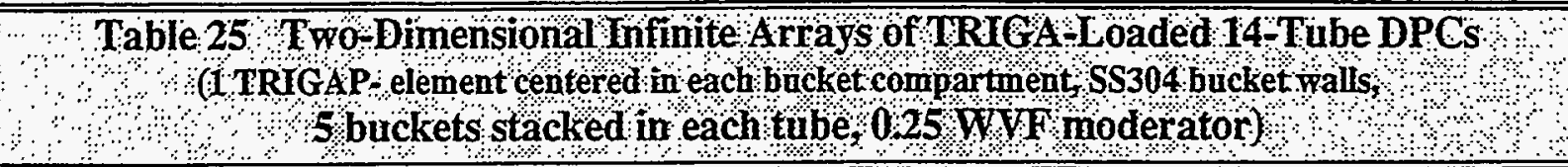 } \\
\hline 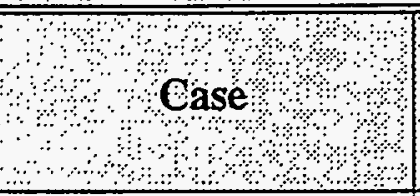 & $\begin{array}{l}\text { Bpeे? } \\
\text { Shell, } \\
\text { Material }\end{array}$ & $\begin{array}{l}\text { Material } \\
\text { Between: } \\
\text { DPलs! }\end{array}$ & Edget & (inge & eff & aff $2 \sigma$ \\
\hline TRIGAP-..14T-.025WVF.inf.06conc & moderator & $\begin{array}{c}\text { ICPP } \\
\text { concrete }\end{array}$ & 15.24 & 6 & $0.911 \pm 0.002$ & 0.915 \\
\hline TRIGAP-14T-.025WVF.inf.00conc & \multirow{3}{*}{ SS304 } & \multirow{3}{*}{$\begin{array}{c}\text { ICPP } \\
\text { concrete }\end{array}$} & 0.00 & $\overline{0}$ & $0.905 \pm 0.002$ & 0.909 \\
\hline TRIGAP-.14T-.025WVF.inf.06conc & & & 15.24 & 6 & $0.907 \pm 0.002$ & 0.911 \\
\hline TRIGAP-.14T-025WVF.inf.12conc & & & 30.48 & 12 & $0.905 \pm 0.002$ & 0.909 \\
\hline TRIGAP-.-14T-025WVF.inf.06water & moderator & $\begin{array}{l}\text { full density } \\
\text { water }\end{array}$ & 15.24 & 6 & $0.897 \pm 0.002$ & 0.901 \\
\hline TRIGAP-.14T- .025 WVF.inf.00 water & \multirow{2}{*}{ SS304 } & \multirow{2}{*}{$\begin{array}{l}\text { full density } \\
\text { water }\end{array}$} & 0.00 & 0 & $0.891 \pm 0.003$ & 0.897 \\
\hline TRIGAP..14T-.025WVF.inf.06water & & & 15.24 & 6 & $0.896+0.002$ & 0.900 \\
\hline
\end{tabular}


Attachment

June 6, 1996

VLP-06-96

Page 52 of 58

\begin{tabular}{|c|c|c|c|c|c|}
\hline H. & $\begin{array}{l}6 \% \text { TREA } \\
\text { 69-elemen } \\
304 \text { bucket }\end{array}$ & $\begin{array}{l}\text { MPFuels } \\
\text { entereding } \\
\text { Is, s bucket }\end{array}$ & $\begin{array}{l}\text { Single } \\
\text { Shick } \\
\text { stackedinea }\end{array}$ & $\begin{array}{l}\text { Qibe:DPC } \\
\text { partment, } \\
\text { tube) }\end{array}$ & मnन \\
\hline 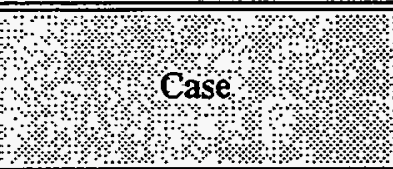 & $\begin{array}{l}\text { Bucket } \\
\text { Dupder } \\
\text { Matertal }\end{array}$ & 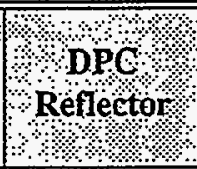 & Moderator & אै। & मn' \\
\hline TRIGA7-.14T.050WVF. water & & $31 \mathrm{~cm}$ & 0.50 & $0.836 \pm 0.003$ & 0.842 \\
\hline TRIGA7-.14T.025WVF, water & SS304 & thick full & 0.25 & $0.886 \pm 0.002$ & 0.890 \\
\hline TRIGAP-.14T.000WVF. water & & water & 0.00 & $0.726 \pm 0.002$ & 0.730 \\
\hline TRIGA7-.14T-.100WVF.vault & moderator & $\begin{array}{c}62 \mathrm{~cm} \\
\text { thick ICPP } \\
\text { concrete }\end{array}$ & 1.00 & $1.011 \pm 0.003$ & 1.017 \\
\hline TRIGA7-14T.100WVF.vault & & & 1.00 & $0.804 \pm 0.003$ & 0.810 \\
\hline TRIGA7-.14T.075WVF.vault & & & 0.75 & $0.804 \pm 0.003$ & 0.810 \\
\hline TRIGA7-14T.050WVF.vault & & $62 \mathrm{~cm}$ & 0.50 & $0.837 \pm 0.003$ & 0.843 \\
\hline TRIGA7-.14T.025WVF.vault & 3. & & 0.25 & $0.895 \pm 0.003$ & 0.901 \\
\hline TRIGA7-14T.010WVF.vault & & & 0.10 & $0.916 \pm 0.004$ & 0.924 \\
\hline TRIGA7-14T.000WVE.vault & & & 0.00 & $0.829 \pm 0.004$ & 0.837 \\
\hline TRIGA7-.14T.050WVF.SS304 & & & 0.50 & $0.835 \pm 0.002$ & 0.839 \\
\hline TRIGA7-.14T.025WVF.SS304 & & & 0.25 & $0.902 \pm 0.002$ & 0.906 \\
\hline TRIGA7-14T.015WVF.SS304 & & $31 \mathrm{~cm}$ & 0.15 & $0.930+0.003$ & 0.936 \\
\hline TRIGA7-.14T.010WVF.SS304 & S.DJU4 & SS304 & 0.10 & $0.935 \pm 0.005$ & 0.945 \\
\hline TRIGA7-.14T.005WVF.SS304 & & & 0.05 & $0.935+0.003$ & 0.941 \\
\hline TRIGA7-14T.000WVF.SS304 & & & 0.00 & $0.900 \pm 0.004$ & 0.908 \\
\hline
\end{tabular}


Attachment

June 6, 1996

VLP-06-96

Page 53 of 58

\begin{tabular}{|c|c|c|c|c|c|c|c|}
\hline Case $\mathrm{s}$ & Moderato & DPCSheil & $\begin{array}{l}\text { Materal } \\
\text { Betreen }\end{array}$ & Edger & Edge & $\mathrm{k}_{\mathrm{eff}} \pm 1 \sigma$ & $\mathrm{k}_{\text {eff }}+2$ \\
\hline m०ै। & & Material & DPES & $(\mathrm{cm})$ & (iiv) & & \\
\hline $\begin{array}{l}\text { TRRGA7-:- } \\
\text { 14T.025WVFinfococone }\end{array}$ & 0.25 & moderator & $\begin{array}{l}\text { ICPP } \\
\text { concrete }\end{array}$ & 0.00 & 0 & $0.900 \pm 0.002$ & 0.904 \\
\hline TRIGA7-.14T.010WVF.inf.00conc & \multirow{3}{*}{0.10} & \multirow{3}{*}{ SS304 } & \multirow{3}{*}{$\begin{array}{l}\text { ICPP } \\
\text { concrete }\end{array}$} & 0.00 & $\overline{0}$ & $0.903 \pm 0.002$ & 0.907 \\
\hline TRIGA7..14T.010WVF.inf.06conc & & & & 15.24 & 6 & $0.918 \pm 0.002$ & 0.922 \\
\hline TRIGA7-.14T.010WVF.inf.1200ne & & & & 30.48 & 12 & $0.911 \pm 0.002$ & 0.915 \\
\hline TRIGA7-.14T.025WVF.inf.00cone & \multirow{3}{*}{0.25} & \multirow{3}{*}{ SS304 } & \multirow{3}{*}{$\begin{array}{l}\text { ICPP } \\
\text { concrete }\end{array}$} & 0.00 & 0 & $0.897 \pm 0.003$ & 0.903 \\
\hline TRIGA7-.14T.025WVF.inf.06cone & & & & 15.24 & 6 & $0.901 \pm 0.002$ & 0.905 \\
\hline TRIGA7-.14T.025WVF.inf.12cone & & & & 30.48 & 12 & $0.896 \pm 0.003$ & 0.902 \\
\hline $\begin{array}{l}\text { TRIGA7.; } \\
\text { 14T.025WVFF.inf.00water }\end{array}$ & 0.25 & moderator & $\begin{array}{c}\text { full } \\
\text { density } \\
\text { water }\end{array}$ & 0.00 & 0 & $0.893 \pm 0.003$ & 0.899 \\
\hline $\begin{array}{l}\text { TRIGA7- } \\
.14 \mathrm{~T} .025 \mathrm{WVF} \text {.inf.00 water }\end{array}$ & 0.25 & SS304 & $\begin{array}{c}\text { full } \\
\text { density } \\
\text { water }\end{array}$ & 0.00 & 0 & $0.889 \pm 0.003$ & 0.895 \\
\hline
\end{tabular}

\begin{tabular}{|c|c|c|c|c|c|}
\hline Table 28 small & of & kiders 5 bu & ackedin & $\mathrm{bet}$ ? & \\
\hline 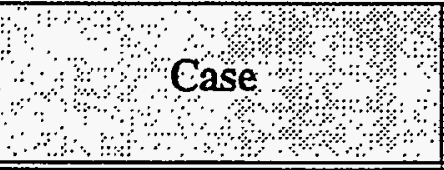 & $\begin{array}{l}\text { R日PC } \\
\text { Reflector }\end{array}$ & $\begin{array}{l}\text { Number of } \\
\text { Elements per } \\
\text { Compartment }\end{array}$ & Moderatog & $\mathrm{r}_{\mathrm{eff}}+\mathrm{O}$ & $\mathrm{e}_{\mathrm{ef}}+2$ \\
\hline TRIGAI-2.14T.100WVF.vault & \multirow{8}{*}{$\begin{array}{l}62 \mathrm{~cm} \text { thick } \\
\text { ICPP } \\
\text { concrete }\end{array}$} & \multirow{8}{*}{$\begin{array}{c}2 \\
(2 \times 1)\end{array}$} & 1.00 & $0.593 \pm 0.02$ & 0.597 \\
\hline TRIGAI-2.14T.075WVF.vault & & & 0.75 & $0.597 \pm 0.002$ & 0.601 \\
\hline TRIGAI-2.14T.050WVF.vault & & & 0.50 & $0.613 \pm 0.002$ & 0.617 \\
\hline TRIGAI-2.14T.025WVF.vault & & & 0.25 & $0.630 \pm 0.003$ & 0.636 \\
\hline TRIGAI-2.14T.015WVF.vault & & & 0.15 & $0.611 \pm 0.003$ & 0.617 \\
\hline TRIGAI-2.14T.010WVF.vault & & & 0.10 & $0.581 \pm 0.002$ & 0.585 \\
\hline TRIGAI-2.14T.005WVF.vault & & & 0.05 & $0.500 \pm 0.003$ & 0.506 \\
\hline TRIGAI-2.14T.000WVF.vault & & & 0.00 & $0.331 \pm 0.003$ & 0.337 \\
\hline
\end{tabular}


Attachment

June 6, 1996

VLP-06-96

Page 54 of 58

\begin{tabular}{|c|c|c|c|c|c|}
\hline \multicolumn{6}{|c|}{ 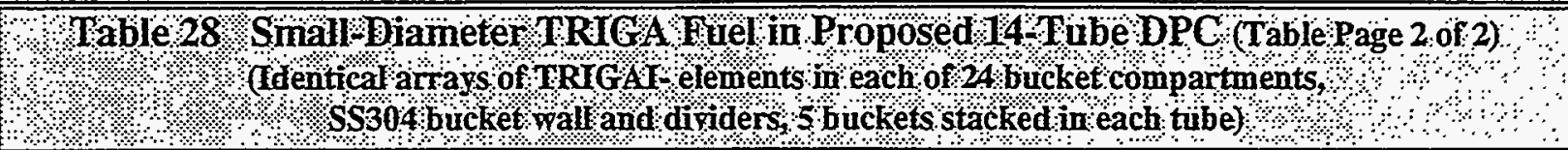 } \\
\hline (2) & Reflector: & $\begin{array}{l}\text { Nümiber of } \\
\text { Elementspers } \\
\text { Compartment }\end{array}$ & Moderator & & $\mathrm{k}_{\mathrm{eff}}+2 \sigma$ \\
\hline TRIGAI-4.14T.100WVF.vault & \multirow{8}{*}{$\begin{array}{l}62 \mathrm{~cm} \text { thick } \\
\text { ICPP } \\
\text { concrete }\end{array}$} & \multirow{8}{*}{$\begin{array}{c}4 \\
(2 \times 2)\end{array}$} & 1.00 & $0.793 \pm 0.002$ & 0.797 \\
\hline TRIGAI-4.14T.075WVF.vault & & & 0.75 & $0.786 \pm 0.002$ & 0.790 \\
\hline TRIGAI-4.14T.050WVF.vault & & & 0.50 & $0.801 \pm 0.002$ & 0.805 \\
\hline TRIGAI-4.14T.025WVF.vault & & & 0.25 & $0.834 \pm 0.002$ & 0.838 \\
\hline TRIGAI-4.14T.015WVF.vault & & & 0.15 & $0.822 \pm 0.002$ & 0.826 \\
\hline TRIGAI-4.14T.010WVF.vault & & & 0.10 & $0.787 \pm 0.002$ & 0.791 \\
\hline TRIGAI-4.14T.005WVF.vault & & & 0.05 & $0.721 \pm 0.002$ & 0.725 \\
\hline TRIGAI-4.14T.000WVF.vault & & & 0.00 & $0.569 \pm 0.002$ & 0.573 \\
\hline TRIGAI-4.14T.025WVF.SS304 & $\begin{array}{l}31 \mathrm{~cm} \text { thick } \\
\text { SS304 }\end{array}$ & $\begin{array}{c}4 \\
(2 \times 2)\end{array}$ & 0.25 & $0.838+0.002$ & 0.842 \\
\hline TRIGAI-5.14T.100WVF.vault & \multirow{10}{*}{$\begin{array}{l}62 \mathrm{~cm} \text { thick } \\
\text { ICPP } \\
\text { concrete }\end{array}$} & \multirow{10}{*}{$\begin{array}{c}5 \\
(2-1-2)\end{array}$} & 1.00 & $0.959 \pm 0.002$ & 0.963 \\
\hline TRIGAI-5.14T.095WVF.vault & & & 0.95 & $0.948 \pm 0.003$ & 0.954 \\
\hline TRIGAI-5.14T.085WVF.vault & & & 0.85 & $0.941 \pm 0.003$ & 0.947 \\
\hline TRIGAI-5.14T.075WVF.vault & & & 0.75 & $0.933 \pm 0.002$ & 0.937 \\
\hline TRIGAI-5.14T.050WVF.vauit & & & 0.50 & $0.932 \pm 0.002$ & 0.936 \\
\hline TRIGAI-5.14T.025WVF.vault & & & 0.25 & $0.941 \pm 0.002$ & 0.945 \\
\hline TRIGAI-5.14T.015WVF.vault & & & 0.15 & $0.917 \pm 0.002$ & 0.921 \\
\hline TRIGAI-5.14T.010WVF.vault & & & 0.10 & $0.878 \pm 0.002$ & 0.882 \\
\hline TRIGAI-5.14T.005WVF.vault & & & 0.05 & $0.802 \pm 0.002$ & 0.806 \\
\hline TRIGAI-5.14T.000WVF.vault & & & 0.00 & $0.656 \pm 0.002$ & 0.660 \\
\hline TRIGAI-6.14T.100WVF.vault & \multirow{8}{*}{$\begin{array}{l}62 \mathrm{~cm} \text { thick } \\
\text { ICPP } \\
\text { concrete }\end{array}$} & \multirow{8}{*}{$\begin{array}{c}6 \\
(2 \times 3)\end{array}$} & 1.00 & $0.906 \pm 0.002$ & 0.910 \\
\hline TRIGAI-6.14T.075WVF.vault & & & 0.75 & $0.904 \pm 0.002$ & 0.908 \\
\hline TRIGAI-6.14T.050WVF.vault & & & 0.50 & $0.917 \pm 0.003$ & 0.923 \\
\hline TRIGAI-6.14T.025WVF.vault & & & 0.25 & $0.956 \pm 0.003$ & 0.962 \\
\hline TRIGAI-6.14T.015WVF.vault & & & 0.15 & $0.946 \pm 0.002$ & 0.950 \\
\hline TRIGAI-6.14T.010WVF.vault & & & 0.10 & $0.916 \pm 0.002$ & 0.920 \\
\hline TRIGAI-6.14T.005WVF.vault & & & 0.05 & $0.857 \pm 0.002$ & 0.861 \\
\hline TRIGAI-6.14T.000WVF.vault & & & 0.00 & $0.740 \pm 0.002$ & $0.744^{\prime}$ \\
\hline $\begin{array}{c}\text { TRIGAI-9.14T.100WVF.vault } \\
.\end{array}$ & $\begin{array}{l}62 \mathrm{~cm} \text { thick } \\
\text { ICPP } \\
\text { concrete }\end{array}$ & $9(3 \times 3)$ & 1.00 & $1.008 \pm 0.003$ & 1.014 \\
\hline
\end{tabular}


Attachment

June 6, 1996

VLP-06-96

Page 55 of 58

\begin{tabular}{|c|c|c|c|c|c|}
\hline 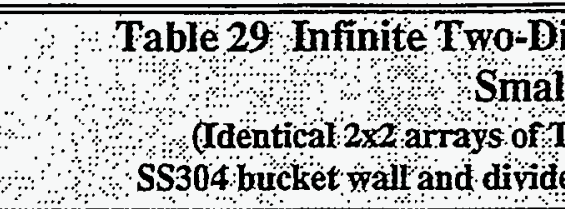 & 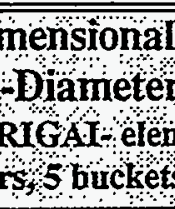 & $\begin{array}{l}\text { Arrays } \\
\text { TRIGA } \\
\text { entsunea } \\
\text { stacked }\end{array}$ & $\begin{array}{l}4 \text { Tuk } \\
\text { ement } \\
\text { f24 b }\end{array}$ & PCSToa & (tor) \\
\hline 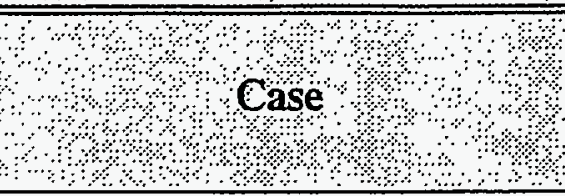 & $\begin{array}{l}\text { Material } \\
\text { Between } \\
\text { ppes }\end{array}$ & $\begin{array}{l}\text { pol } \\
\text { (cdge-t } \\
\text { (cil) }\end{array}$ & $\frac{\text { Fige }}{\text { (n) }}$ & $\mathrm{K}_{\mathrm{eft}}+\mathrm{\sigma}$ & सef? \\
\hline TRIGAI-4.14T.025WVF.inf.00conc & \multirow{3}{*}{$\begin{array}{c}\text { ICPP } \\
\text { concrete }\end{array}$} & 0.00 & 0 & $0.829 \pm 0.002$ & 0.833 \\
\hline TRIGAI-4.14T.025WVF.inf.06conc & & 15.24 & 6 & $0.828 \pm 0.002$ & 0.832 \\
\hline TRIGAI-4.14T.025WVF.inf.12conc & & 30.48 & 12 & $0.829 \pm 0.003$ & 0.834 \\
\hline
\end{tabular}

- Intact TRIGA fuel will be critically-safe $\left(\mathrm{k}_{\text {eff }} \leq 0.95\right)$ at one element per TRIGA Bucket compartment for all addressed conditions, if the bucket is constructed as indicated below and if the elements satisfy one of the descriptions in Table 21.

- Intact, small-diameter TRIGA fuel will be critically-safe ( $\left.k_{\text {eff }} \leq 0.95\right)$ at four elements per TRIGA Bucket compartment for all addressed conditions, if the bucket is constructed as indicated below and if the elements satisfy one of the last two descriptions in Table 21.

- TRIGA Bucket walls must be constructed from nominal $12 \mathrm{in}$. schedule 10 stainless steel pipe. Smaller diameters and/or thicker walls are acceptable.

- TRIGA Bucket dividers must be constructed from nominal $\frac{1}{8}$ in. thick stainless steel for a maximum 24 compartments per bucket. Thicker divider walls are acceptable.

- TRIGA fuel in one DPC is essentially isolated from TRIGA fuel in an adjacent identical DPC, with or without concrete dividers.

- BER-TRIGA fuel is not addressed. 
Attachment

June 6, 1996

VLP-06-96

Page 56 of 58

\section{MIXED DPC ARRAYS}

Storage operations can be simplified when differently loaded DPCs can be mixed in an array. Although these calculations do not model such arrays, results for arrays of identical DPCs indicate, in most cases, fuel within one DPC is neutronically isolated, or nearly isolated, from fuel in an adjacent DPC. Where interaction appears to be more than $1 \sigma, \mathrm{k}_{\text {eff }} \mathrm{s}$ are relatively low.

Based on experience with different fuel arrays elsewhere, mixed DPC arrays should be critically safe because:

- If water reflected, optimally moderated DPC $\mathrm{k}_{\mathrm{eff}} \mathrm{s}$ are near but do not exceed 0.95 , interaction between different DPCs should be no greater than interaction in an array of worst case, identical DPCs.

- If water reflected, optimally moderated DPC $\mathrm{k}_{\mathrm{eff}} \mathrm{s}$ are low (significantly less than 0.95), interaction between different DPCs is insufficient to raise the array $k_{\text {eff }}$ above 0.95 . 
Attachment

June 6, 1996

VLP-06-96

Page 57 of 58

\section{REFERENCES}

1 "NUHOMS ${ }^{\circledR}-52 B$ Dry Shielded Canister," Vectra Technical Bulletin (Seattle, Washington: Vectra Technologies, Inc., no date).

2 NUH-003 (Rev. 2), Safety Analysis Report for the Standardized NUHOMS ${ }^{\circledR}$ Horizontal Modular Storage System for Irradiated Nuclear Fuel, Vol. I, Vectra Technologies, Inc., Seattle, Washington (November 1993).

3 NUH-05-151 (Rev. 1), Safety Analysis Report for the NUHOMS ${ }^{\circledR}-M P 187$ Multi-Purpose Cask, Vectra Technologies, Inc., Seattle, Washington (February 1995).

4 "NUHOMS $^{\circledR}$-24P Dry Shielded Canister," Vectra Technical Bulletin (Seattle, Washington: Vectra Technologies, Inc., no date).

5 Project 020825 TBA (Draft), Daryl A. Lopez, "Criticality, Thermal, and Shielding Analysis of DTC Fuel," MC\&IE Department Task Baseline Agreement (Idaho Falls, Idaho: Lockheed Idaho Technologies Company, April 9 and 30, 1996).

6 Gulf-GA-D12455, W. W. Hudritsch, W. J. Scheffel, and O. M. Stansfield, Preirradiation Characterization of Material for the Fort St. Vrain HTGR Core Surveillance Program, Gulf General Atomic (March 1973).

7 CSS-92-021, Brian [M.] Palmer, "Criticality Safety Issues Associated with the Burial of Highly Enriched Nuclear Fuel in a Geologic Repository" (Idaho Falls, Idaho: Westinghouse Idaho Nuclear Company, Inc., December 1992).

8 INEL-96/096, Kenneth B. Woods, "Criticality Safety Evaluation for Mixed Canisters of Fuels in the Irradiated Fuel Storage Facility" (Idaho Falls, Idaho: Lockheed Idaho Technologies Company, April 1996).

9 LA-12625-M, J[udith] F. Briesmeister (editor), MCNP - A General Monte Carlo N-Particle Transport Code, Los Alamos National Laboratory, Los Alamos, New Mexico (November 1993).

10 ACNP-63016, "Pathfinder Atomic Power Plant Technical Progress Report: January 1963 March 1963" (Allis-Chalmers Manufacturing Company, June 1963).

11 ACNP-65599, P. S. Lacey, et. al., "Pathfinder Atomic Power Plant Boiler Core and Full Core Critical Experiments" (Allis-Chalmers Manufacturing Company, August 1966).

12 ACNP-65531, "Pathfinder Atomic Power Plant Technical Progress Report: April 1964 - June 1964" (Allis-Chalmers Manufacturing Company, April 1965). 
Attachment

June 6, 1996

VLP-06-96

Page 58 of 58

13 INEL-95/228 (Rev. 1), D[eborah] J. Henrikson, "Criticality Safety Evaluation for Pathfinder in Divided Buckets, Revision 1" (Idaho Falls, Idaho: Lockheed Idaho Technologies Company, February 1996).

14 CCC-545 (version 4.0), SCALE4, A Modular Code System for Performing Standardized Computer Analyses for Licensing Evaluation, RSIC Computer Code Collection, Oak Ridge National Laboratory, Oak Ridge, Tennessee (1993).

15 SDD 4.2, M. J. Mortenson, "Reactor Core System," PBF System Design Description (Idaho Falls, Idaho: EG\&G Idaho, Inc., approved March 1976).

16 NRRT-N-91-015, V[irginia] F. Dean, "Criticality Safety Analysis of the PBF Temporary Underwater Fuel Storage Racks with Reduced Cadmium" (Idaho Falls, Idaho: EG\&G Idaho, Inc., April 1991).

17 Fast-7-84, E[dwin] Fast letter to R[obert] E. Wilson, "CSE for LWBR Vault Storage" (Idaho Falls, Idaho: Westinghouse Idaho Nuclear Company, Inc., March 6, 1984.)

18 Fast-30-86, E[dwin] Fast letter to G[erald] T. Paulson, "Vault Storage of LWBR Type Loose Rods and Cut Pieces" (Idaho Falls, Idaho: Westinghouse Idaho Nuclear Company, Inc., December 22, 1986).

19 DXH-02-94, D[eborah] J. Henrikson letter to B[rian] M. Palmer, "Shippingport PWR Geologic Disposal" (Idaho Falls, Idaho: Westinghouse Idaho Nuclear Company, Inc., April 5, 1994).

20 "Research, Test and Experimental Reactors," Directory of Nuclear Reactors, Vol. II, International Atomic Energy Agency, Vienna, Austria (1959): pp. 243-248.

21 GA-C18542, N. Tomsio, "Characterization of TRIGA Fuel" (San Diego, California: GA Technologies, Inc., October 1986).

22 WINCO-1215, B[rian] M. Palmer, "Unclassified Fuels inthe CPP-603 Fuel Storage Basins" (Idaho Falls, Idaho: Westinghouse Idaho Nuclear Company, Inc., March 1994). 


\section{Appendix F}

\section{DPC Optimization and Loading Study}




\section{F-2}




\section{Appendix F \\ DPC Optimization and Loading Study}

The fuel to be processed in the DTC is given in Table F-1. The following criteria were used to determine the design for DPC baskets and canisters to handle the fuel in Table 1:

- Use the Vectra PWR FO-DSC or FC-DSC style DPC (Vectra drawing NUH-05-4004NF) if possible so the MP-187 cask and its handling equipment (to be purchased for the TMI core debris canisters storage project) may also be used for the DTC system.

- If PWR FO-DSC or FC-DSC style DPCs can be used, avoid specifying standard NUHOMS 52-B DPCs (BWR DPC) and baskets because they cannot be placed in the MP-187 cask (the BWR DPC would require that a new OS-197 cask system be purchased).

- Store SNF in the smallest number of DPCs practical (because the per-canister cost for future transportation, handling, and ultimate disposal is expected to be very high).

- Avoid using borated neutron absorbing material in the storage baskets and buckets if possible, but use it if necessary to increase the loading efficiency and decrease the number of DPCs.

- Limit the number of different DPC basket designs to reduce design, fabrication, setup, and tooling/inspection charges.

- Limit the number of different bucket and welded-can designs to reduce design, fabrication, setup, and tooling/inspection charges.

- Place each level of FHU in a separate basket or bucket cell to avoid binding or "jackstrawing" FHUs with one another.

Based on these criteria, the following storage items were specified or designed for the DTC storage canister system :

1. DPC:

a. The Vectra PWR FO-DSC

2. Baskets:

a. A 14-Tube basket $(14,13$-in. diameter round tubes) derived from previous concept work done by the Fluor Daniel Inc., for the INEL aluminum-clad fuel.

b. A 7-Tube basket (with hexagonal tubes) designed specifically for the 744 FSVR fuel blocks. This is also used for the Pathfinder FHUUs in special 14-in. diameter buckets. 
c. A 3-Tube basket (three, 26-in. diameter round tubes) designed specifically for the 48, 25.5in. diameter canisters currently stored in ICPP 749 that each contain a Shippingport LWBR FHU.

3. Buckets:

a. 12-in. Schedule-10 SST buckets (for use in the 14-tube basket)

Thirteen different buckets (comprising four different lengths and nine different cruciform designs) are used for all fuel in Table F-1 except Peach Bottom, Shippingport LWBR, FSVR, and Pathfinder.

b. 14-in. Schedule-10 SST buckets (for use in the 7-tube FSVR basket)

One bucket style is used for the Pathfinder FHUs. The bucket is 103 in. long and has a square, single-cell cruciform used to store Pathfinder FHUs in the 7-tube FSVR basket. Two FSVR fuel blocks can be stacked above each Pathfinder bucket in each basket cell.

\section{12-in. Schedule-10 SST Cans}

a. Two buckets styles (both 166-in. long and using two of the nine cruciform styles from 3-a above) are used for canning the Peach Bottom fuel in the DTC canning/welding station.

\section{Results}

The above criteria have been met. The NUHOMS PWR FO-DSC has been specified for all fuel because all three baskets will fit into it. Therefore, the OS-197 cask does not have to be purchased. The basket and bucket designs were held to a minimum while loading as efficiently as possible. The number of different baskets has been limited to three, the number of buckets to 14 , and the number of cans to two. The bucket lengths have been designed to allow efficient stacking of different mixes of fuel in the same DPC (for small-volume fuel or partial loads left over after loading large-volume fuels in multiDPCs). The total number of DPCs for all fuel in Table F-1 has been held to less than 80 . Preliminary criticality analyses done on approximately $90 \%$ of the fuel in Table F-1 show that none of that fuel will require the addition of neutron-absorbing poison. With this design, each FHU is contained in its own cell so that no jackstrawing or binding can occur.

Thermal and shielding calculations are being run on fuel loading configurations representing approximately $90 \%$ of the fuel in Table F-1. The calculations are being run for DTC lag storage, for the DPCs loaded in the MP-187 cask, and for the DPCs loaded in the NUHOMS ${ }^{\circledast}$ precast concrete storage modules. Results of those analyses could require some reduced loading efficiency, and increase the number of components and DPCs required.

In addition, structural analyses have yet to be done on these configurations. It is anticipated that if changes are needed to meet the structural analyses, they will be minor (e.g., small increases in cruciform thickness) and will not affect the loading efficiency. Also, to achieve the number of DPCs postulated, 
NRC licenses must be obtained for all DPC loadings, including those having mixes of different kinds of fuel in the same DPC.

Table F-1. Fuel to be processed in the DTC.

\begin{tabular}{|c|c|c|c|c|c|c|c|c|c|c|c|c|}
\hline SNF_NAME & $\begin{array}{l}\text { FHU } \\
2035 \\
\end{array}$ & $\begin{array}{l}\text { HEIGHT } \\
\text { (iin) }\end{array}$ & $\begin{array}{l}\text { WIDTH } \\
\text { (in) }\end{array}$ & LEN.(in) & $\begin{array}{c}\text { DHB } \\
\text { LENGTH }\end{array}$ & $\begin{array}{l}\text { DHB } \\
\text { CEUS }\end{array}$ & $\begin{array}{l}\text { LAYERSI } \\
\text { DHB }\end{array}$ & FHUIDHB & DHBS & $\begin{array}{l}\text { FHU PER } \\
\text { DPC }\end{array}$ & $\begin{array}{c}\text { NUHOMS DPC \& } \\
\text { LOADING }\end{array}$ & $\begin{array}{l}\text { NO. OF } \\
\text { DPCS }\end{array}$ \\
\hline ACRRELEMENTS & 256 & 0.00 & 0.00 & 0.00 & & & & NA & NA & & & 1.00 \\
\hline ACRR EXPERIMENTS & 1 & 0.00 & 0.00 & 0.00 & & & & NA & NA & & & - \\
\hline ARKANSAS & 3 & 0.00 & 0.00 & 0.00 & & & & NA & NA & & & - \\
\hline CANDU * & 3 & & 5.00 & 168.0 & 1 & NA & 1 & NA & NA & 52 & BWR DPC, 1 layer & 0.06 \\
\hline CANDU: & 3 & 0.00 & 3.50 & 120 & 4 & 7 & 3 & 21 & 1.00 & 1176 & 14Tube, 12 layers & 0.00 \\
\hline CP.5 CONVERTER CYLNDER & 2 & 0.00 & 0.00 & 0.0 & & & & NA & NA & & & - \\
\hline DRESDEN * & 23 & 4.40 & 4.40 & 135.0 & 1 & 2 & 1 & 2 & 12.00 & 28 & 14-Tube, 1 layer & 0.82 \\
\hline DRESDEN * & 1 & 4.40 & 4.40 & 135.0 & 1 & 2 & 1 & 2 & 1.00 & 28 & 14-Tube, 1 layer & 0.04 \\
\hline DRESDEN" & 4 & 4.40 & 4.40 & $\{35.0$ & 1 & 2 & 1 & 2 & 200 & 28 & 14Tube, 1 layer & 0.14 \\
\hline DRESDEN I REACTOR FUEL & 2 & 0.00 & 0.00 & 0.00 & & & & NA & NA & & & - \\
\hline FRR/RRGA "m & 4940 & 0.00 & 1.48 & 30.00 & 4 & 24 & 1 & 24 & 206.00 & 1344 & 14Tube, 5 layers & 3.68 \\
\hline FSVR & 744 & 16.32 & 14.17 & 31.22 & NA & NA & NA & NA & NA & 35 & FSV Basket/special & 21.26 \\
\hline PATHFINDER & 7 & 9.62 & 9.62 & 84.00 & 1.62 & 1 & 1 & 1 & 7.00 & 7 & FSV Basket & 0.62 \\
\hline PBF DRVER CORE & 60 & & 8.63 & 60.00 & 1.25 & 1 & 2 & 2 & 30.00 & 28 & 14-Tube DPC, 3 & 1.71 \\
\hline PULSTAR - BUFFALO & 24 & 3.00 & 3.00 & 28.00 & 5 & 5 & 1 & 5 & 5.00 & 350 & 14Tube DPC, 4 & 0.07 \\
\hline PULSTAR-N.C. STATE UNIV. & 34 & 274 & 3.15 & 37.98 & 1.25 & 5 & 3 & 15 & 3.00 & 263 & 14Tube, 4 layers & 0.13 \\
\hline PULSTAR-SUNY-BUFFALO & 43 & 274 & 3.15 & 38.00 & 1.25 & 5 & 3 & 15 & 3.00 & 263 & 14-Tube, 4 layers & 0.16 \\
\hline SHIPPINGPORT LWBR & 48 & 0.00 & 25.50 & 158.0 & NA & $\mathrm{NA}$ & 1 & NA & NA & 3 & Three, 25.57 in. dia & 16.00 \\
\hline SHIPPINGPORT PWR-C1-S4 & 1 & $5.5^{\mathrm{m}}$ & $5.5^{* *}$ & 104.5 & 1.25 & 1 & 1 & 1 & 1.00 & 14 & 14-Tube, 1 layer & 0.06 \\
\hline SHIPPINGPORT PWR-C2-S1 & 19 & 7.38 & 7.38 & 104.5 & 1.25 & 1 & 1 & 1 & 19.00 & 14 & 14Tube, 1 layer & 1.09 \\
\hline SHIPPINGPORT PWR-C2-S2 & 20 & 7.38 & 7.38 & 104.5 & 1.25 & 1 & 1 & 1 & 20.00 & 14 & 14-Tube, 1 layer & 1.14 \\
\hline TREAT & 390 & 3.96 & 3.96 & 96.00 & 1.25 & 4 & 1 & 4 & 98.00 & 56 & 14-Tube, 1 layer & 5.57 \\
\hline TRIGA BER. (GERMANY) & 21 & 3.15 & 2.99 & 36.80 & 4 & 5 & 1 & 5 & 4.20 & 280 & 14Tube, 4 layers & 0.08 \\
\hline TRIGA CONV. PENN STATE & 241 & 0.00 & 1.48 & 28.31 & 5 & 24 & 1 & 24 & 10.04 & 1680 & 14Tube, 5 layers & 0.14 \\
\hline TRIGA CONWJARRR & 91 & 0.00 & 1.38 & 28.37 & 5 & 24 & 1 & 24 & 3.79 & 1680 & 14-Tube, 5 layers & 0.05 \\
\hline TRIGAFLP * & 2 & 0.00 & 3.80 & 30.00 & 4 & 4 & 1 & 4 & 0.50 & 224 & 14Tube DPC, 5 & 0.01 \\
\hline TRIGAFUPIOSU & 91 & 0.00 & 1.48 & 28.58 & 5 & 24 & 1 & 24 & 3.79 & 1680 & 14-Tube, 5 layers & 0.05 \\
\hline TRIGAFLIPTEXASA\&M & 101 & 0.00 & 1.48 & 30.00 & 4 & 24 & 1 & 24 & 4.21 & 1344 & 14-Tube, 5 layers & 0.08 \\
\hline TRGGAFLPNU.OFWI & 101 & 0.00 & 1.48 & 30.00 & 4 & 24 & 1 & 24 & 4.21 & 1344 & 14Tube, 5 layers & 0.08 \\
\hline TRGA FLPWASH.STATE UNI & 78 & 0.00 & 1.48 & 30.00 & 4 & 24 & 1 & 24 & 3.25 & 1344 & 14-Tube, 5 layers & 0.06 \\
\hline TRIGA SST & 296 & 0.00 & 1.48 & 28.31 & 5 & 24 & 1 & 24 & 1233 & 1680 & 14-Tube, 5 layers & 0.18 \\
\hline
\end{tabular}


Table F-1. (Continued).

\begin{tabular}{|c|c|c|c|c|c|c|c|c|c|c|c|c|}
\hline SNF_NAME & $\begin{array}{l}\text { FHU } \\
2035 \\
\end{array}$ & $\begin{array}{l}\text { HEIGHT } \\
\text { (in) }\end{array}$ & $\begin{array}{l}\text { WDTH } \\
\text { (in) }\end{array}$ & LEN. (in) & $\begin{array}{c}\text { DHB } \\
\text { LENGTH }\end{array}$ & $\begin{array}{c}\text { DHB } \\
\text { CELLS } \\
\end{array}$ & $\begin{array}{c}\text { LAYERSI } \\
\text { DHB }\end{array}$ & FHUIDHB & DHBS & $\begin{array}{c}\text { FHUPER } \\
\text { DPC } \\
\end{array}$ & $\begin{array}{c}\text { NUHOMS DPC \& } \\
\text { LOADING }\end{array}$ & $\begin{array}{l}\text { NO.OF } \\
\text { DPCS }\end{array}$ \\
\hline TRIGA UNIV. OF ILUNOIS & 305 & 0.00 & 1.48 & 28.31 & 5 & 24 & 1 & 24 & 1271 & 1680 & 14-Tube, 5 layers & 0.18 \\
\hline TRIGA-CORNELL & 165 & 0.00 & 1.48 & 28.31 & $\mathbf{5}$ & 24 & 1 & 24 & 6.88 & 1680 & 14-Tube, 5 layers & 0.10 \\
\hline TRIGA-FLIP & 61 & 0.00 & 1.48 & 30.00 & 4 & 24 & 1 & 24 & 254 & 1344 & 14-Tube, 5 layers & 0.05 \\
\hline TRIGA-FUP/GA & 117 & 0.00 & 1.48 & 30.00 & 4 & 24 & 1 & 24 & 4.88 & 1344 & 14Tube, 5 layers & 0.09 \\
\hline TRIGAAFRRI & 95 & 0.00 & 1.48 & 28.31 & 5 & 24 & 1 & 24 & 3.96 & 1680 & 14-Tube, 5 layers & 0.06 \\
\hline TRIGADOW & 78 & 0.00 & 1.48 & 28.31 & 5 & 24 & 1 & 24 & 3.25 & 1680 & 14-Tube, 5 layers & 0.05 \\
\hline TRIGAGA & 155 & 0.00 & 1.48 & 28.31 & 5 & 24 & 1 & 24 & 6.46 & 1680 & 14-Tube, 5 layers & 0.09 \\
\hline TRIGAKANSAS STATE UNIV. & 191 & 0.00 & 1.48 & 28.31 & 5 & 24 & 1 & 24 & 7.96 & 1680 & 14-Tube, 5 layers & 0.11 \\
\hline TRGAMCCLELLAN AFB & 90 & 0.00 & 1.48 & 28.31 & 5 & 24 & 1 & 24 & 3.75 & 1680 & 14-Tube, 5 layers & 0.05 \\
\hline TRIGANOSU & 99 & 0.00 & 1.48 & 28.31 & 5 & 24 & 1 & 24 & 4.13 & 1680 & 14-Tube, 5 layers & 0.06 \\
\hline TRIGAREED COLLEGE & 67 & 0.00 & 1.48 & 28.31 & 5 & 24 & 1 & 24 & 2.79 & 1680 & 14-Tube, 5 layers & 0.04 \\
\hline TRIGATIEXAS A\& M & 85 & 0.00 & 1.48 & 28.31 & 5 & 24 & 1 & 24 & 3.54 & 1680 & 14-Tube, 5 layers & 0.05 \\
\hline TRIGAMTEXASA\&M & 28 & 0.00 & 0.00 & 0.00 & 5 & 24 & 1 & 24 & 1.17 & 1680 & 14Tube, 5 layers & - \\
\hline TRIGANNIV. OF ARIZONA & 98 & 0.00 & 1.47 & 28.47 & 5 & 24 & 1 & 24 & 4.08 & 1680 & 14-Tube, 5 layers & 0.06 \\
\hline TRIGAUUNIV. OF MARYLAND & 186 & 0.00 & 1.48 & 28.31 & 5 & 24 & 1 & 24 & 7.75 & 1680 & 14-Tube, 5 layers & 0.11 \\
\hline TRIGANUNN. OF UTAH & 225 & 0.00 & 1.48 & 28.31 & 5 & 24 & 1 & 24 & 9.38 & 1680 & 14-Tube, 5 layers & 0.13 \\
\hline TRIGANUNIV. OF WISCONSIN & 127 & 0.00 & 1.48 & 28.31 & 5 & 24 & 1 & 24 & 5.29 & 1680 & 14-Tube, 5 layers & 0.08 \\
\hline TRIGAUNIV. OF WISCONSIN & 28 & 0.00 & & 0.00 & 5 & 24 & 1 & 24 & 1.17 & 1680 & 14-Tube, 5 layers & - \\
\hline TRIGANUNIV.OF CAL_IRVINE & 113 & 0.00 & 1.48 & 28.00 & 5 & 24 & 1 & 24 & 4.71 & 1680 & 14Tube, 5 layers & 0.07 \\
\hline TRIGANUNN.OF & 158 & 0.00 & 1.48 & 28.31 & $\mathbf{5}$ & 24 & 1 & 24 & 6.58 & 1680 & 14Tube, 5 layers & 0.09 \\
\hline TRIGANUSGS & 200 & 0.00 & 1.48 & 28.31 & 5 & 24 & 1 & 24 & 8.33 & 1680 & 14-Tube, 5 layers & 0.12 \\
\hline TRIGANA & 56 & 0.00 & 1.48 & 28.31 & 5 & 24 & 1 & 24 & 2.33 & 1680 & 14-Tube, 5 layers & 0.03 \\
\hline TRIGAWASH.STATE UNIV. & 327 & 0.00 & 1.48 & 28.31 & 5 & 24 & 1 & 24 & 13.63 & 1680 & 14-Tube, 5 layers & 0.19 \\
\hline PEACH BOTTOM CORE 1 & 18 & 0.00 & 3.5 & 144 & 1 & 4 & 1 & 4 & 5.00 & 56 & 14-Tube, 1 layers & 0.32 \\
\hline PEACH BOTTOM CORE 1 & 796 & 0.00 & 3.5 & 144 & 1 & 4 & 1 & 4 & 199.00 & 56 & 14Tube, 1 layers & 14.21 \\
\hline \multirow[t]{2}{*}{ PEACH BOTTOM CORE 2} & 786 & 0.00 & 3.5 & 126 & 1 & 7 & 1 & 7 & 113.00 & 98 & 14-Tube, 1 layers & 8.02 \\
\hline & & & & & & & & & 899 & & TOTAL & 78.63 \\
\hline
\end{tabular}




\section{Appendix G}

\section{Cost Estimate Summary}


Rev01-96

$\begin{array}{ll}\text { Project } & \text { SNF DRY STORAGE PROJECT } \\ \text { Requester } & \text { INE/ICPP }\end{array}$

Unescalated
ENGINEERING, DESIGN AND INSPECTION

Title I and II Design

Title III Inspection

\section{MANAGEMENT}

Project Management

Construction Management

\section{CONSTRUCTION}

Div 1 General Requirements

Div 2 Sitework

Div 3 Concrete

Div 4 Masonry

Div 5 Metals

Div 6 Wood and Plastics

Div 7 Moisture Protection

Div 8 Doors and Windows

Div 9 ' Finishes

Div 10 Specialties

Div 11 Equipment

Div 12 Furnishings

Div 13 Special Construction

Div 14 Conveying Systems

Div 15 Mechanical

Div 16 Electrical

GOVT FURNISHED EQUIPMENT

PROCUREMENT FEES

G\&A

SUBTOTAL

PROJECT CONTINGENCY

Management Reserve

Contingency

TOTAL ESCALATION

$\begin{array}{ll}\text { Type of Est } & \text { Conceptual } \\ \text { File No } & 2314-8 \\ \text { Prep'd By } & \text { S.M. Bradford }\end{array}$

Escalation

$\begin{array}{r}3,357,000 \\ \hline 684,000 \\ \hline\end{array}$

- $10 \%$ of Cosstruction $\operatorname{Cos} 820 d$ GFE 276,000 114,000

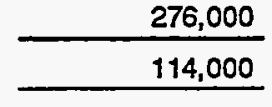

$\begin{array}{r}11,211,000 \\ \hline 1,489,000 \\ \hline\end{array}$

$\begin{array}{r}2,331,000 \\ \hline 221,000 \\ \hline\end{array}$

$\begin{array}{r}\hline 625,000 \\ \hline 1,582,000 \\ \hline 4,315,000 \\ \hline 426,000 \\ \hline 891,000 \\ \hline 117,000 \\ \hline 388,000 \\ \hline 310,000 \\ \hline 30,000 \\ \hline 1,486,000 \\ \hline 11,000 \\ \hline 622,000 \\ \hline 2,009,000 \\ \hline 1,969,000 \\ \hline\end{array}$

$34,149,000$

734,000

$3,120,000$

$\begin{array}{r}98,000 \\ \hline 260,000 \\ \hline 677,000 \\ \hline 66,000 \\ \hline 133,000 \\ \hline 17,000 \\ \hline 58,000 \\ \hline 46,000 \\ \hline 4,000 \\ \hline 222,000 \\ \hline 2,000 \\ \hline 93,000 \\ \hline 300,000 \\ \hline 304,000 \\ \hline 9,338,000 \\ \hline 180,000 \\ \hline 691,000 \\ \hline\end{array}$

Date

Chk'd By

Appr'd By

Totals

$4,431,000$

$15,252,000$

$17,061,000$

$43,487,000$

914,000

$3,811,000$

$84,956,000$

$15,044,000$

$5,248,000$

$8,516,000$
$1,280,000$

$18 \%$ of Subcotal

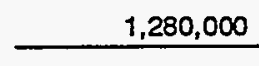

$16,711,000$

TOTAL ESTIMATED COST: 
Rev 01-96

Project

SNF DRY STORAGE PROJECT DRY TRANSFER CELL

Requester R. C. HILL

Unescalated

ENGINEERING, DESIGN AND INSPECTION

Title I and II Design

Title III Inspection

\section{MANAGEMENT}

Project Management

Construction Management

\section{CONSTRUCTION}

Div 1 General Requirements

Div 2 Sitework

Div 3 Concrete

Div 4 Masonry

Div 5 Metals

Div 6 Wood and Plastics

Div 7 Moisture Protection

Div 8 Doors and Windows

Div 9 Finishes

Div 10 Specialties

Div 11 Equipment

Div 12 Furnishings

Div 13 Special Construction

Div 14 Conveying Systems

Div 15 Mechanical

Div 16 Electrical

GOV'T FUANISHED EQUIPMENT

PROCUREMENT FEES

G\&A

SUBTOTAL

PROJECT CONTINGENCY

Management Reserve

Contingency

TOTAL ESCALATION

\begin{tabular}{|c|c|}
\hline Type of Est & Conceptual \\
\hline File No & $2314-8$ \\
\hline Prep'd By & S.M. Bradford \\
\hline & Escalation \\
\hline $18 \%$ of Construttio & Cost and GFE \\
\hline & 246,000 \\
\hline & 76,000 \\
\hline
\end{tabular}

Date

$06 / 17 / 96$

Chk'd By

Appr'd By

Totals

$3,985,000$

$\begin{array}{r}3,153,000 \\ \hline 510,000 \\ \hline\end{array}$

$4,481,000$

$1,339,000$

545,000

200,000

$13,787,000$

\begin{tabular}{|c|c|}
\hline 449,000 & 67,000 \\
\hline 674,000 & 101,000 \\
\hline $3,080,000$ & 461,000 \\
\hline 322,000 & 48,000 \\
\hline 891,000 & 133,000 \\
\hline 117,000 & 17,000 \\
\hline 388,000 & 58,000 \\
\hline 310,000 & 46,000 \\
\hline 30,000 & 4,000 \\
\hline $1,486,000$ & 222,000 \\
\hline 11,000 & 2,000 \\
\hline 622,000 & 93,000 \\
\hline $2,009,000$ & 300,000 \\
\hline $1,606,000$ & 240,000 \\
\hline $7,504,000$ & 748,000 \\
\hline 292,000 & 44,000 \\
\hline $1,220,000$ & 122,000 \\
\hline
\end{tabular}

$8,252,000$

336,000

$1,342,000$

$34,267,000$

$6,733,000$
$20 \%$ ofSubbotal

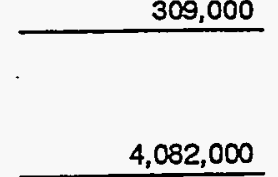

TOTAL ESTIMATED COST:
$\$ 41,000,000$ 
Projoct

SNF DRY STORAGE PROJECT DRY TRANSFERCELLL

Location INEL/ICPP
Requester R.C.HLL

Type of Est. Conceptual Source (E) Eng. Est.

$M$ Vendor

(P) Pur. Order

(H) Handbook Ref.

\begin{tabular}{|c|c|c|c|c|c|c|c|c|c|c|c|}
\hline $\begin{array}{l}\text { ACCT. } \\
\text { No. }\end{array}$ & DESCAPTION & $\begin{array}{l}E, V, \\
P, H \\
\end{array}$ & $\begin{array}{l}\text { MAT'L } \\
\text { UNIT } \\
\end{array}$ & $\begin{array}{c}\text { MAT'LUT. } \\
\text { COST }\end{array}$ & $\begin{array}{c}\text { UNIT LAB. } \\
\text { HAS } \\
\end{array}$ & $\begin{array}{c}\text { TOTAL } \\
\text { LAB. HRS. }\end{array}$ & $\begin{array}{l}\text { LABOR } \\
\text { RATE } \\
\end{array}$ & $\begin{array}{l}\text { LABOR } \\
\text { COST } \\
\end{array}$ & $\begin{array}{l}\text { MAT'L } \\
\text { COST } \\
\end{array}$ & $\begin{array}{l}\text { OH\&P } \\
\text { COST } \\
\end{array}$ & $\begin{array}{l}\text { TOTAL } \\
\text { COST } \\
\end{array}$ \\
\hline \multirow[t]{7}{*}{ DIV 1} & GENERALREQUIREMENTS & & & & & & & & & & \\
\hline & Supervision / Project Management - 1 FTE & & 27 mnths & & 173 & 4,671 & 40.00 & 186,840 & & 56,052 & 242,892 \\
\hline & Safety Supervision - .25 FTE & & 27 mnths & & 43 & 1,168 & 40.00 & 46,710 & & 14,013 & 60,723 \\
\hline & Training & & $30 \mathrm{ea}$ & & 60 & 1,800 & 40.00 & 72,000 & & 21,600 & 93,600 \\
\hline & Construction Fence & & $4,000 \mathrm{ft}$ & 10 & complete & & & & 40,000 & 12,000 & 52,000 \\
\hline & & & & & & & & & & & \\
\hline & TOTALDIV 1 - GENERAL REQUIREMENTS & & & & & 7,639 & & 305,550 & 40,000 & 103,665 & 449.215 \\
\hline & & & & & & & & & & & \\
\hline \multirow[t]{3}{*}{ DIV 2} & SITEWORK & & & & & & & & & & \\
\hline & Clear and Grub & & 105,500 sf & 0.4 & 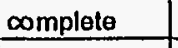 & & & & 42,200 & 12,660 & 54,860 \\
\hline & BuildUp Area - Pit Run & & $4,000 \mathrm{cy}$ & 17 & Complete & & & & 68,000 & 20,400 & 88.400 \\
\hline \multirow[t]{5}{*}{$\dot{.}$} & 6"Crushed Gravel Subbase & & $870 \mathrm{cy}$ & 35 & Complete & & & & 30,450 & 9,135 & 39,585 \\
\hline & Asphatt $-4^{\prime \prime}-24,000$ SF & & 580 bns & 60 & Complete & & & & 34,800 & 10,440 & 45,240 \\
\hline & Building Excavalion / Badxfill & & $4,200 \mathrm{cy}$ & 16 & Complete & & & & 67,200 & 20,160 & 87,360 \\
\hline & Trench Excavation and Backfill & & $6,500 \mathrm{cy}$ & 20.3 & Complete & & & & 131,950 & 39,585 & 171,535 \\
\hline & & & & & & & & & . & & \\
\hline & FroWater Pipe - includes Hydrants, PIVs, otc & & $1,200 \mathrm{ft}$ & 40 & complele & & & & 48,000 & 14,400 & 62,400 \\
\hline & Potable Water Pipe - 2"CS w/Valving & & $100 \mathrm{ft}$ & 29.13 & Complete & & & & 2,913 & 874 & 3,787 \\
\hline & Sewer Pipe - 8" ABS w/ 1 Manhole & & $400 \mathrm{ft}$ & 46.03 & complete & & & & 18,412 & 5,524 & 23,936 \\
\hline & Service Waste $-2^{\prime \prime}$ CS & & $100 \mathrm{ft}$ & 28.83 & complete & & & & 2,883 & 865 & 3,748 \\
\hline & Stoam Piping $-2^{\prime \prime} \mathrm{CS}$ w/Valving & & $100 \mathrm{ft}$ & 19.84 & $\infty$ mplete & & & & 1,984 & 595 & 2,579 \\
\hline & High Pressure Air Plpe $-2^{n} \mathrm{CS}$ & & $100 \mathrm{ft}$ & 7.27 & complete & & & & 727 & 218 & 945 \\
\hline & Remove Existing Security Fence & & $1,200 \mathrm{ft}$ & 17 & complete & & & & 20,400 & 6,120 & 26,520 \\
\hline & & & & & & & & & & & \\
\hline & Mob and Demob & & $1 \mathrm{bt}$ & & & & & & & 61,089 & 61,089 \\
\hline & Storm Water Pollution Prevention Plan & & $1 \mathrm{bt}$ & 500 & 40 & 40 & 35.00 & 1.400 & 500 & 570 & 2,470 \\
\hline & & & & & & & & & & & \\
\hline & & & & & & & & & & & \\
\hline & TOTALDIV 2 - SITEWORK & & & & & & & 1.400 & 470,419 & 202,635 & 674,454 \\
\hline
\end{tabular}

File No. 2314-B Date 06/14/96

Prop'd By S.M. Bradford 
Project

SNF DRY STORAGE PROJECT DRY TRANSFERCELL.

\begin{tabular}{|c|c|c|c|c|c|c|c|c|c|c|c|}
\hline $\begin{array}{l}\text { ACCT. } \\
\text { No. }\end{array}$ & DESCAPTION & $\begin{array}{l}\text { E.V. } \\
\text { P.H }\end{array}$ & $\begin{array}{l}\text { MAT'L } \\
\text { UNIT }\end{array}$ & $\begin{array}{c}\text { MAT'LUT. } \\
\text { COST } \\
\end{array}$ & $\begin{array}{c}\text { UNIT LAB. } \\
\text { HRS } \\
\end{array}$ & $\begin{array}{c}\text { TOTAL } \\
\text { LAB. HRS. }\end{array}$ & $\begin{array}{l}\text { LABOR } \\
\text { RATE }\end{array}$ & $\begin{array}{l}\text { LABOR } \\
\text { COST }\end{array}$ & $\begin{array}{l}\text { MAT'L } \\
\text { COST } \\
\end{array}$ & $\begin{array}{l}\text { OH\&P } \\
\text { COST } \\
\end{array}$ & $\begin{array}{l}\text { TOTAL } \\
\text { COST }\end{array}$ \\
\hline \multirow[t]{28}{*}{ DIV 3} & CONCRETE & & & & & & & & & & \\
\hline & Footings / Foundation / Grade Beams & & $1,034 \mathrm{cy}$ & 65 & 0.4 & 414 & 32.67 & 13,512 & 67,210 & 24,217 & 104,939 \\
\hline & Reinforcing & & $96,295 \mathrm{lb}$ & 0.2 & 0.008 & 578 & 32.67 & 18,876 & 19,259 & 11,440 & 49,575 \\
\hline & Formwork & & 9,984 sf & 0.45 & 0.05 & 499 & 32.67 & 16,309 & 4,493 & 6,240 & 27,042 \\
\hline & & & & & & & & & & & \\
\hline & Slabs / Pads & & 739 cy & 65 & 0.495 & 366 & 32.67 & 11,951 & 48,035 & 17,996 & 77,982 \\
\hline & Mechanically Place & & $739 \mathrm{cy}$ & 25 & - & & & & 18,475 & 5,543 & 24,018 \\
\hline & & & & & & & & & & & \\
\hline & Hot Cell & & $4,388 \mathrm{cy}$ & 65 & & & & & 285,220 & 85,566 & 370,786 \\
\hline & Snap Ties and Grout Holes & & 20,744 sf & 1.5 & 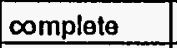 & & & & 31,116 & 9,335 & 40,451 \\
\hline & Reinforcing & & $279,105 \mathrm{lb}$ & 0.2 & 0.008 & 2,233 & 32.67 & 72,947 & 55,821 & 38,630 & 167,398 \\
\hline & Formwork & & $41,488 \mathrm{sf}$ & 0.66 & 0.087 & 3,609 & 32.67 & 117,921 & 27,382 & 43,591 & 188,894 \\
\hline & Mechanically Place & & $4,388 \mathrm{cy}$ & 51 & 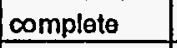 & & & & 223,788 & 67,136 & 290,924 \\
\hline & Aoof Dedks & & $273 \mathrm{cy}$ & 65 & 0.704 & 192 & 32.67 & 6,279 & 17.745 & 7,207 & 31.231 \\
\hline & Roinforcing & & $15,038 \mathrm{lb}$ & 0.2 & 0.008 & 120 & 32.67 & 3,930 & 3,008 & 2,081 & 9,019 \\
\hline & Formwork & & 11,034 sf & 0.45 & 0.18 & 1,986 & 32.67 & 64,887 & 4,965 & 20,956 & 90,807 \\
\hline & Mechanically Place & & 273 cy & 25 & $\infty$ mplete & & & & 6,825 & 2,048 & 8,873 \\
\hline & & & & & & & & & & & \\
\hline & 2nd, 3rd, 4th Floor Decks & & $96 \mathrm{cy}$ & 65 & 0.704 & 68 & 32.67 & 2,208 & 6,240 & 2,534 & 10,982 \\
\hline & Reinforcing & & $9,212 \mathrm{lb}$ & 0.2 & 0.007 & 64 & 32.67 & 2,107 & 1,842 & 1,185 & 5,134 \\
\hline & Mechanically Place & & $96 \mathrm{cy}$ & 25 & $\infty$ mplete & & & & 2,400 & 720 & 3,120 \\
\hline & & & & & & & & & & & \\
\hline & Columns & & $64 \mathrm{cy}$ & 65 & 1.806 & 116 & 32.67 & 3,776 & 4,160 & 2,381 & 10,317 \\
\hline & Reinforcing & & $53,191 \mathrm{lb}$ & 0.2 & 0.008 & 426 & 32.67 & 13,902 & 10,638 & 7,362 & 31,902 \\
\hline & Formwork & & $7,128 \mathrm{sf}$ & 0.68 & $\begin{array}{r}0.087 \\
\end{array}$ & 620 & 32.67 & 20,260 & $\mathbf{4 . 7 0 4}$ & 7.489 & 32,454 \\
\hline & Mechanically Place & & $64 \mathrm{cy}$ & 25 & 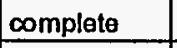 & & & & 1,600 & 480 & 2,080 \\
\hline & & & & & & & 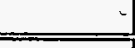 & & & & \\
\hline & SUBTOTAL CONCAETE THIS PAGE & & & & & 11.715 & & 382,736 & 859,081 & 372,545 & $1,614,362$ \\
\hline
\end{tabular}


Project

SNF DRY STORAGE PROJECT

DRY TRANSFERCELL

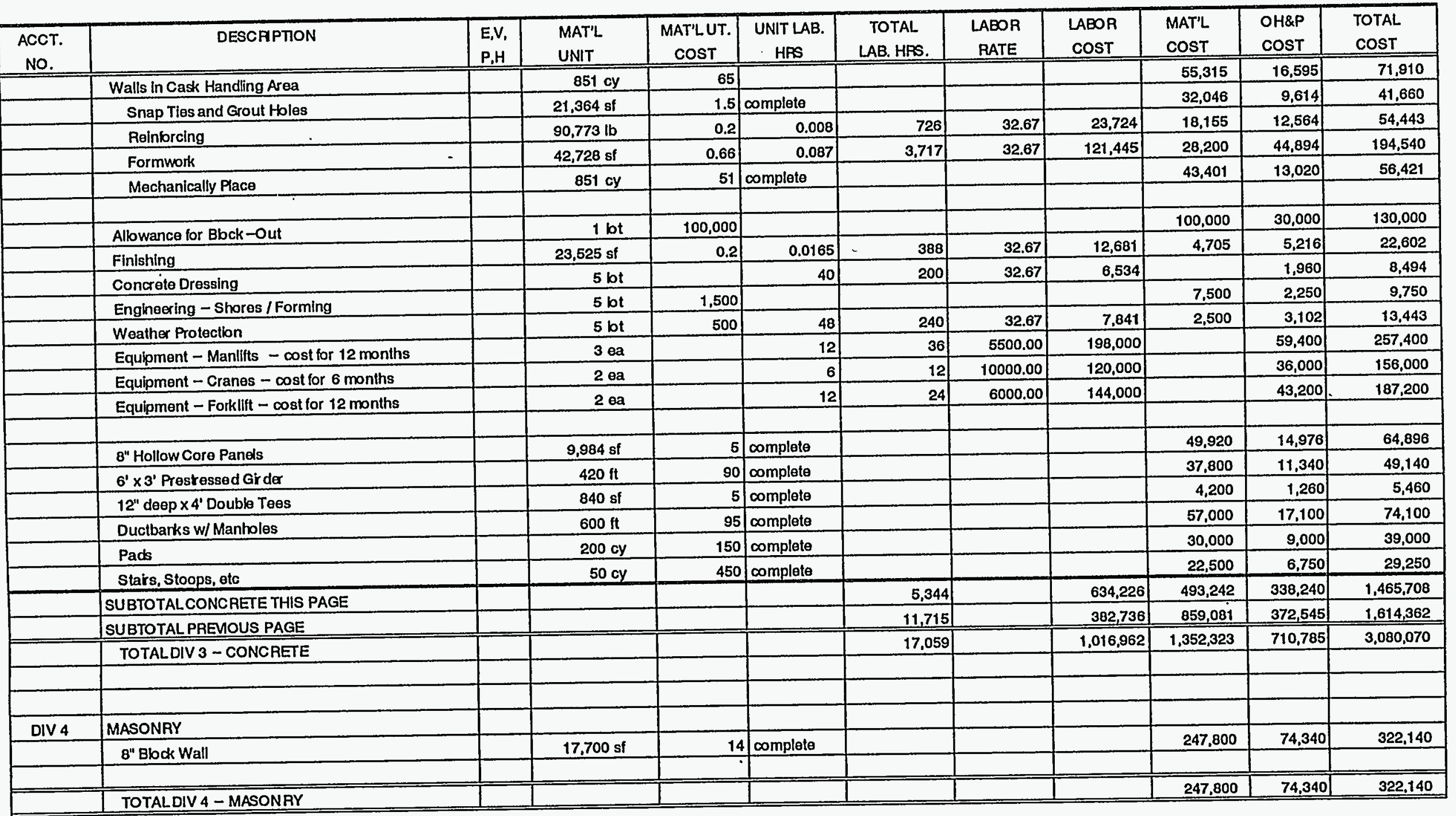


Projact

SNF DRY STORAGE PROJECT DRYTRANSFERCELL

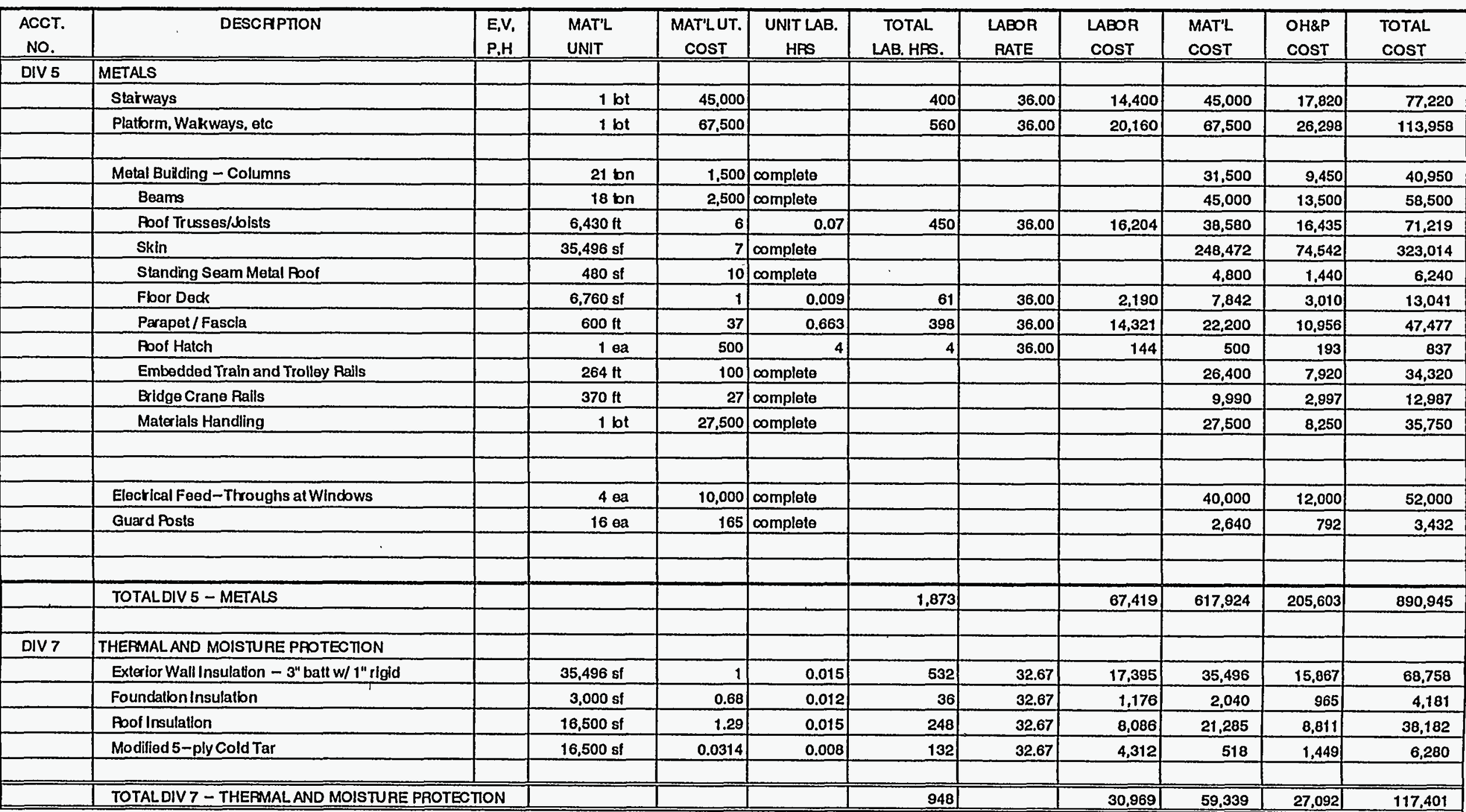




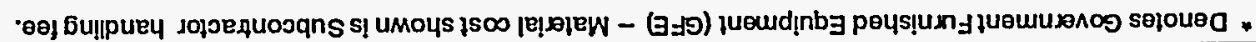

\begin{tabular}{|c|c|c|c|c|c|c|c|c|c|c|c|}
\hline 29L'60E & $88 b^{\prime} 1 L$ & 281.122 & $960^{\circ} \mathrm{LI}$ & & EZs & & & & & S3HSINIJ-6 ^IOTYIOI & \\
\hline & & & & & & & & & & & \\
\hline & & & & & & & & & & & $\cdot$ \\
\hline$\angle 16^{\prime} I$ & 266 & $002^{\prime} 1$ & $\square \angle 2$ & $\angle 9^{\circ} Z \varepsilon$ & 8 & 61.0 & 02 & Ks 09 & & pedso & \\
\hline $81 b^{\prime} 1$ & $\angle Z \varepsilon$ & 999 & seb & $\angle 9^{\prime} 2 \varepsilon$ & E1 & $8 \varepsilon 0^{\circ} 0$ & SL8'L & IS OSE & & 6ujlooly I Ku!n ssejurees & \\
\hline S9E'E & $\angle L L$ & $219^{\prime} !$ & $\angle \angle 6$ & $\angle 9^{\circ} Z \varepsilon$ & $0 \varepsilon$ & $\varepsilon 20^{\circ} 0$ & $t Z^{\prime \prime}$ & Is $00 \varepsilon^{\prime} \mathrm{l}$ & & 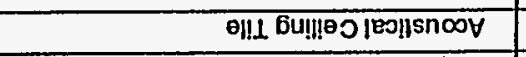 & \\
\hline $160^{\prime} \mathrm{s}$ & SLL'L & osz'z & $999^{\prime} !$ & $\angle 9^{\prime} Z \varepsilon$ & 19 & $\angle 10^{\circ} 0$ & SL'O & jS $000^{\prime} \varepsilon$ & & Bu!lonos $\|$ EMIKu!n & \\
\hline 2E9'9 & $00 \varepsilon^{\prime} 1$ & 008'ट & 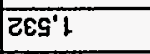 & $\angle 9^{\prime} Z E$ & $\angle b$ & $\angle 90^{\circ} 0$ & $b$ & \$S 002 & $\cdot$ & ө\|IL $\| E M$ opueso & \\
\hline $9 \varepsilon L^{\circ} O L$ & $8 \angle t^{\prime} Z$ & $696^{\prime} b$ & $06 Z^{\prime} \varepsilon$ & $\angle 9^{\circ} Z \varepsilon$ & 101 & \begin{tabular}{|l|l}
$8 \varepsilon 0^{\circ} 0$ & 5 \\
\end{tabular} & $\overline{S L 8^{\prime} L}$ & is 0s9'z & & 6u!log & \\
\hline $00 L^{\prime} b Z$ & OOL'S & $000^{\prime} 61$ & & & & 비비떠 & I & Is $000^{\circ} 61$ & & ojosuojpejees & \\
\hline $000^{\prime} L Z Z$ & $000^{\prime} 19$ & $000^{\prime} 0 \angle t$ & & & & 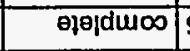 & 9 & $15000^{\prime}+\varepsilon$ & & kxod $\exists-\mu \mid e_{d}$ & \\
\hline $00 s^{\prime} 61$ & $00 g^{\prime} t$ & $000^{\circ} \mathrm{St}$ & & & & 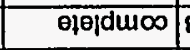 & $\varepsilon^{\circ} 0$ & is $000^{\prime} 0 \mathrm{~s}$ & & 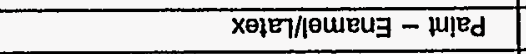 & \\
\hline $80 b^{\prime} 2$ & 9SS & 086 & $z L \varepsilon^{\prime} l$ & $\angle 9^{\circ} \mathrm{ZE}$ & $2 b$ & $120^{\circ} 0$ & $b Z^{\prime \prime 0}$ & Is 000'z & & 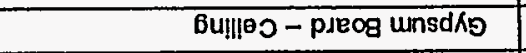 & \\
\hline $6 \angle b^{\prime} 8$ & $\angle \mathrm{SG} \mathbf{C}^{\prime} \mathrm{I}$ & $896 '$ & tss't & $\angle 9^{\prime} Z \varepsilon$ & $6 \varepsilon 1$ & $\angle 10^{\circ} 0$ & 620 & $1500 Z^{\prime} 8$ & & s\|leM-pdeog unsdks & \\
\hline $86 L^{\prime} Z$ & 669 & 089 & 89s'1 & $\angle 9^{\circ} \mathrm{ZE}$ & 80 & $t 20^{\circ} 0$ & 620 & is 000'2 & & Bu!!IOO - spnis $|E| \theta W$, $8 / \mathrm{s} \varepsilon$ & $\cdot$ \\
\hline$\varepsilon Z L^{\prime} Z$ & 829 & 299 & $82 b^{\prime} 1$ & $\angle 9^{\circ} 2 \varepsilon$ & to & $610^{\circ} 0$ & $62^{\prime} 0$ & Is 008'2 & & 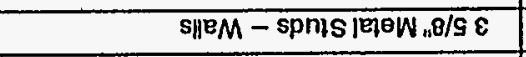 & \\
\hline & & & & & & & & & - & SgHSINIS & $6 \wedge 10$ \\
\hline & & & & & & & & & & & \\
\hline S9l'88E & $\angle \angle S^{\prime} 68$ & BL8'ELZ & $0 \angle L^{\prime} \forall Z$ & & $8 S L$ & & & & & SMOONIM ONY SHOOd-8N107 $\forall 101$ & \\
\hline$\varepsilon 6 z^{\prime} 8$ & 616.1 & $896^{\prime} t$ & $\left|I t^{\prime}\right|$ & $\angle 9^{\prime} Z \varepsilon$ & $\varepsilon b$ & $8 !$ & $20 Z$ & $e \theta \forall z$ & & SMOpu!M & \\
\hline $886^{\prime} 9 \mathrm{pl}$ & $026^{\prime} \varepsilon \varepsilon$ & $000^{\prime} 001$ & $890^{\prime} \varepsilon$ & $\angle 9^{\circ} Z \varepsilon$ & $00 t$ & 001 & $000^{\prime} \mathrm{se}$ & EQt & & 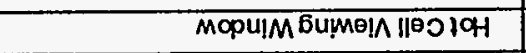 & * \\
\hline$\angle L \theta^{\prime} b Z$ & $1 L L ' S$ & $000^{\circ} 91$ & $9 \varepsilon L^{\prime} \varepsilon$ & $\angle 9^{\prime} Z E$ & 96 & 21 & $000^{\prime} z$ & eo 8 & & $\angle \times 9-1$ - 2 uuos $\theta d$ & \\
\hline $81 \varepsilon^{\prime} 81$ & $\angle 2 z^{\prime} t$ & $000^{\circ} \mathrm{Zl}$ & $160^{\prime} \mathrm{Z}$ & $\angle 9^{\prime} Z \varepsilon$ & 09 & 91 & $000^{\prime} \varepsilon$ & E日 & & 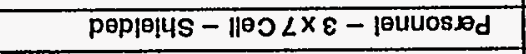 & \\
\hline$\angle D G^{\prime} B L$ & $08 z^{\prime} t$ & $000^{\prime}+1$ & $\angle 9 Z^{\prime} \varepsilon$ & $\angle 9^{\prime} Z \varepsilon$ & 001 & $S$ & oss & ee 08 & & 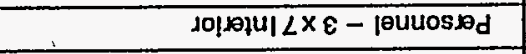 & \\
\hline $190^{\prime} \mathrm{EL}$ & $\not 10^{\prime} \varepsilon$ & 0 OSZ'B $^{\prime}$ & $\angle 6 L^{\prime} L$ & $\angle 9^{\prime} Z \varepsilon$ & SS & 9 & 09 & EO II & & 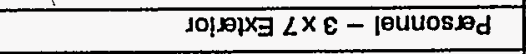 & \\
\hline $000^{\prime} 0 \varepsilon_{1}$ & $000^{\prime} 0 \varepsilon$ & $000^{\prime} 001$ & & & & 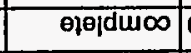 & $000^{\prime} 001$ & EQ I & & peplel4s - 02 $\times 91-1000 \| \theta 0$ & \\
\hline 09ع'6 & $091^{\prime} 2$ & $00 Z^{\prime} L$ & & & & 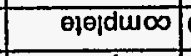 & $00 z^{\prime} L$ & EO I & & $02 \times 91-1000 d n-110$ & \\
\hline $0 z L^{\prime} 81$ & OzE't & $00 t^{\prime}+1$ & & & & 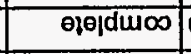 & $\overline{002 ' L}$ & 802 & & $91 \times 91-1000 \times n] \perp$ & \\
\hline & & & & & & & & & & SMOONIM ONV SHOOO & $8 \wedge 10$ \\
\hline 1500 & 1500 & 1500 & ISO0 & IIVY & SHH 9V7 & SUH & 1500 & LINn & $\begin{array}{l}H^{\prime} d \\
\Lambda^{\prime} \exists\end{array}$ & NOLdHOS & $\begin{array}{l}\text { ON } \\
100 Y\end{array}$ \\
\hline \multirow[t]{3}{*}{ 7Ұ1OL. } & d8HO & $7,1 \forall W$ & 40087 & yoart & TVIOL & gVIINn & $\ln 7,18 \mathrm{~W}$ & 1.IVW & $n g$ & Nothatase & \\
\hline & & & & & & & & & & $77 \exists O 4 \exists \triangle S N V Y \perp A Y O$ & \\
\hline & & & & & & & & & & 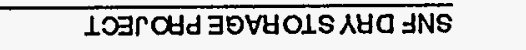 & pollold \\
\hline
\end{tabular}


Page 6 of 17

Project SNF DRY STORAGE PROJECT DRY TRANSFERCELL.

\begin{tabular}{|c|c|c|c|c|c|c|c|c|c|c|c|}
\hline $\begin{array}{l}\text { ACCT. } \\
\text { NO. }\end{array}$ & DESCRPTION & $\begin{array}{l}E, V, \\
P, H \\
\end{array}$ & $\begin{array}{l}\text { MAT'L } \\
\text { UNIT }\end{array}$ & $\begin{array}{c}\text { MAT'LUT. } \\
\text { COST }\end{array}$ & $\begin{array}{c}\text { UNIT LAB. } \\
\text { HRS }\end{array}$ & $\begin{array}{c}\text { TOTAL. } \\
\text { LAB. HRS. }\end{array}$ & $\begin{array}{l}\text { LABOR } \\
\text { RATE }\end{array}$ & $\begin{array}{l}\text { LABOR } \\
\text { COST }\end{array}$ & $\begin{array}{l}\text { MAT'L } \\
\text { COST }\end{array}$ & $\begin{array}{l}\text { OH\&P } \\
\text { COST }\end{array}$ & $\begin{array}{l}\text { TOTAL } \\
\text { COST }\end{array}$ \\
\hline \multirow[t]{11}{*}{ DIV 10} & SPECIALTIES & & & & & & & & & & \\
\hline & Counters/Cabinets & & $15 \mathrm{tt}$ & 135 & Complete & & & & 2,025 & 608 & 2,633 \\
\hline & Restroom Accessorles & & $2 \mathrm{bt}$ & 7,000 & -omplete & & & & 14,000 & 4,200 & 18,200 \\
\hline & Dimensional Lelters and Numbers & & $14 \mathrm{ea}$ & 113 & 1 & 14 & 32.67 & 457 & 1,582 & 612 & 2,651 \\
\hline & Poom Signs & & 25 ea & 25 & 0.5 & 13 & 32.67 & 408 & 625 & 310 & 1,343 \\
\hline & Fre Extinguisher Cabinets & & 402 & 140 & 2 & 8 & 32.67 & 261 & 560 & 246 & 1.068 \\
\hline & Projection Screen & & $1 \mathrm{ea}$ & 1849 & 2 & 2 & 32.67 & 65 & 1,849 & 574 & 2,489 \\
\hline & Dry Marker Board & & 2 ea & 615 & 1.5 & 3 & 32.67 & 98 & 1,230 & 398 & 1,726 \\
\hline & & & & & & & & & & & \\
\hline & & & & & & & & & & & \\
\hline & TOTALDIV 10 - SPECIALTIES & & & & & 40 & & 1,290 & 21,871 & 6.948 & 30.110 \\
\hline & & & & & & & & & & & \\
\hline \multirow[t]{7}{*}{ DIV 12} & FURNISHINGS & & & & & & & & & & \\
\hline & Window Blinds & & 2 ea & 140 & 0.5 & 1 & 32.67 & 33 & 280 & 94 & 406 \\
\hline & Office Furnilure & & $2 \mathrm{ea}$ & 3,000 & 1 & 2 & 32.67 & 65 & 6,000 & 1,820 & 7,885 \\
\hline & Break Room Furniture & & 1 bt & 2,000 & 3 & 3 & 32.67 & 98 & 2,000 & 629 & 2,727 \\
\hline & & & & & & & & & & & \\
\hline & & & & & & & & & & & \\
\hline & TOTALDIV 12 - FUANISHNGS & & & & & 6 & & 196 & 8,280 & 2,543 & 11,019 \\
\hline & & & & & & & & & & & \\
\hline & & & & & & & & & & & \\
\hline & & & & & & & & & & & \\
\hline & & & & & & & & & & & \\
\hline & & & & & & & & & & & \\
\hline & & & & & & & & & & & \\
\hline & & & & & & & & & & & \\
\hline & & & & & & & & & & & \\
\hline & & $\cdot$ & & & & & & & & & \\
\hline & & & & & & & & & & & \\
\hline & & & & & & & & & & & \\
\hline
\end{tabular}


Projoct

SNF DRY STORAGE PROJECT DRY TRANSFERCELL

\begin{tabular}{|c|c|c|c|c|c|c|c|c|c|c|c|}
\hline $\begin{array}{l}\text { ACCT. } \\
\text { No. } \\
\end{array}$ & DESCAPTION & $\begin{array}{l}E, V, \\
P, H \\
\end{array}$ & $\begin{array}{l}\text { MAT'L } \\
\text { UNIT } \\
\end{array}$ & $\begin{array}{c}\text { MAT'LUT. } \\
\text { COST }\end{array}$ & $\begin{array}{c}\text { UNIT LAB. } \\
\text { HRS }\end{array}$ & $\begin{array}{c}\text { TOTAL } \\
\text { LAB. HRS. }\end{array}$ & $\begin{array}{l}\text { LABOR } \\
\text { RATE } \\
\end{array}$ & $\begin{array}{l}\text { LABOR } \\
\text { COST } \\
\end{array}$ & $\begin{array}{l}\text { MAT'L } \\
\text { COST } \\
\end{array}$ & $\begin{array}{l}\text { OH\&P } \\
\text { COST } \\
\end{array}$ & $\begin{array}{l}\text { TOTAL } \\
\text { COST } \\
\end{array}$ \\
\hline \multirow[t]{14}{*}{ DIV 11} & EQUIPMENT & & & & & & & & & & \\
\hline & Cask Transfer Trolleys & & 2 ea & 250,000 & $\infty$ mplete & & & & 500,000 & 150,000 & 650,000 \\
\hline & Cask Handling Bay Work Platform & & $1 \mathrm{ea}$ & 10,000 & $\infty$ mplete & & & & 10,000 & 3,000 & 13,000 \\
\hline & Preparation Booth Work Platform & & $1 \mathrm{ea}$ & 25,000 & $\infty$ mplete & & & & 25,000 & 7,500 & 32,500 \\
\hline & & & & & & & & & & & \\
\hline & Lag Storage Vaults & & $4 \mathrm{ea}$ & 100,000 & Domplete & & & & 400,000 & 120,000 & 520,000 \\
\hline & & & & & & & & & & & \\
\hline & & & & & & & & & & & \\
\hline & Strage Stands & & 2 bt & 20,000 & complete & & & & 40,000 & 12,000 & 52,000 \\
\hline & Lifting Yokes & & $3 \mathrm{ea}$ & 7.500 & 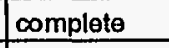 & & & & 22,500 & 6,750 & 29.250 \\
\hline & Misc Tooling & & $1 \mathrm{bt}$ & 75,000 & 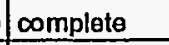 & & & & 75,000 & 22,500 & 97,500 \\
\hline & Fuel Handling Grapples & & 2 bt & 20,000 & complete & & & & 40,000 & 12,000 & 52,000 \\
\hline & Canning Handling Tool & & 3 ea & 9,500 & 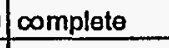 & & & & 28,500 & 8,550 & 37,050 \\
\hline & Cask Access Stainways & & 2 ea & 1,000 & $\infty$ mplete & & & & 2,000 & 600 & 2,600 \\
\hline & & & & & & & & & & & \\
\hline & & & & & & & & & & & \\
\hline & & & & & & & & & & & \\
\hline & & & & & & & & & & & \\
\hline & & & & & & & & & & & \\
\hline & & & & & & & & & & & \\
\hline & TOTALDIV 11 - EQUIPMENT & & & & & & & & $1,143,000$ & 342,900 & $1,485,900$ \\
\hline & & & & & & & & & & & \\
\hline & & & & & & & & & & & \\
\hline DIV 14 & CONVEYNG SYSTEMS & & & & & & & & & & \\
\hline$\star$ & $150 / 15$ Ton Bridge Crane & & 1 ea & 135,000 & & 1,000 & 40.00 & 40,000 & 135,000 & 17,500 & 192,500 \\
\hline 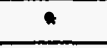 & 7.5 Ton Bridge Crane & & 1 ea & 5,500 & & 120 & 40.00 & 4,800 & 5,500 & 1,030 & 11,330 \\
\hline$\star$ & Fuel Handing Crane - includes 3 Trolleys, & & & & & & & & & & \\
\hline & Z-Masts, Manipulabrs, Conłols, atc & & $1 \mathrm{ea}$ & 300,000 & & 2,000 & 40.00 & 80,000 & 300,000 & 38,000 & 418,000 \\
\hline & & & & & & & & & & & \\
\hline 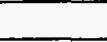 & TOTALDIV 14 - CONVEYNG SYSTEMS & & & & & & & 124,800 & 440,500 & 56.530 & 621.830 \\
\hline
\end{tabular}

- Denotes Government Furnished Equipment (GFE) - Material cost shown is Subcontractor handling fee 
Date 06/14/96 Prep'd ByT. E. Sivill

Project SNF DRY STORAGEPROJECT DRY TRANSFERCELL

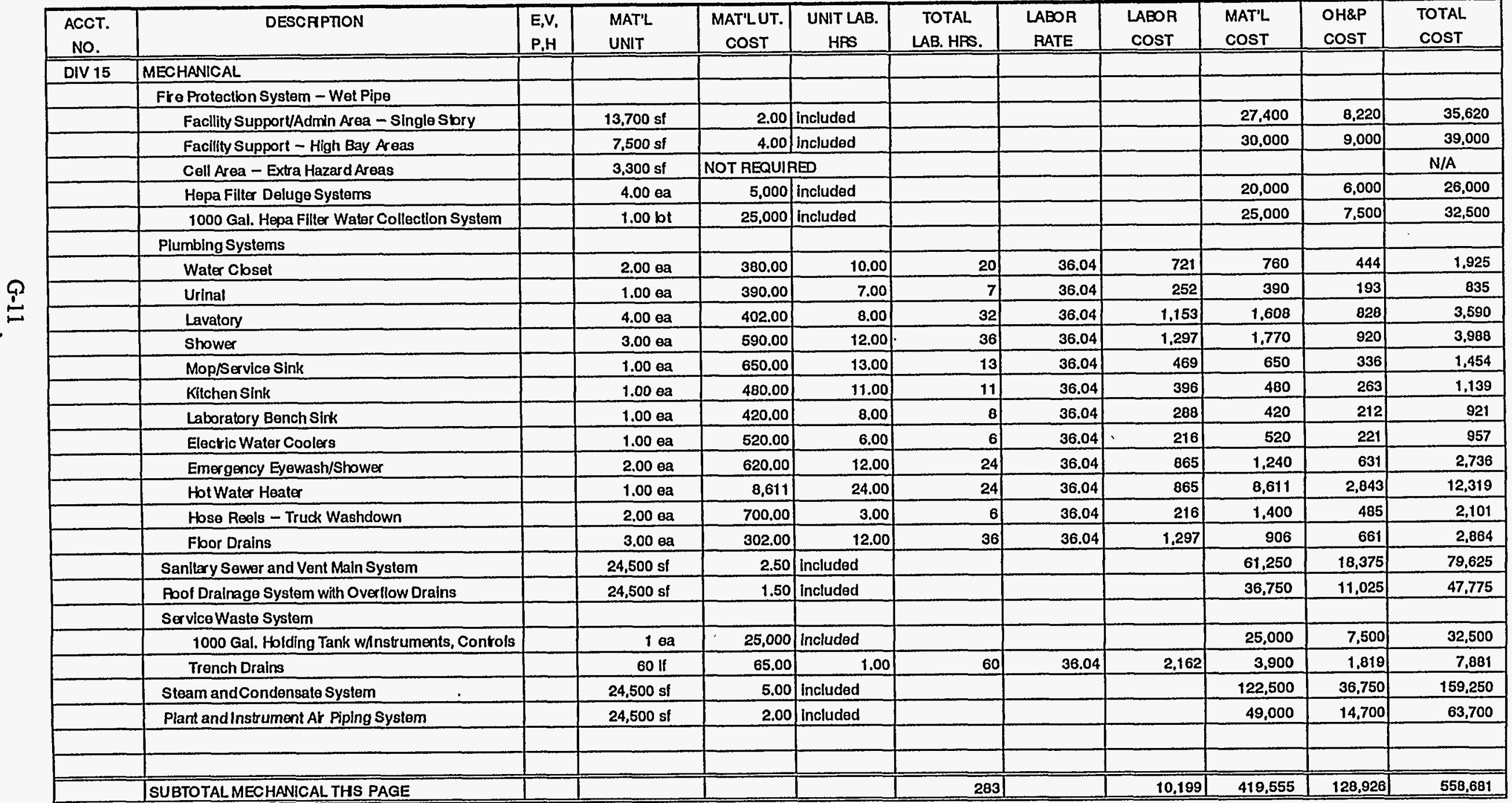


Rev 10-94

Page 9 of 17

Projoct

SNF DAY STORAGEPROJECT DAY TRANSFERCELL

\begin{tabular}{|c|c|c|c|c|c|c|c|c|c|c|c|}
\hline $\begin{array}{l}\text { ACCT. } \\
\text { NO. }\end{array}$ & DESCRPTION & $\begin{array}{l}\text { E.V, } \\
P, H \\
\end{array}$ & $\begin{array}{l}\text { MAT'L } \\
\text { UNIT } \\
\end{array}$ & $\begin{array}{c}\text { MAT'LUT. } \\
\text { COST }\end{array}$ & $\begin{array}{c}\text { UNIT LAB. } \\
\text { HRS }\end{array}$ & $\begin{array}{c}\text { TOTAL } \\
\text { LAB. HRS. }\end{array}$ & $\begin{array}{c}\text { LABOR } \\
\text { RATE } \\
\end{array}$ & $\begin{array}{l}\text { LABOR } \\
\text { COST }\end{array}$ & $\begin{array}{l}\text { MAT'L } \\
\text { COST }\end{array}$ & $\begin{array}{l}\text { OH\&P } \\
\text { COST } \\
\end{array}$ & $\begin{array}{l}\text { TOTAL } \\
\text { COST }\end{array}$ \\
\hline & EQUIPMENT & & & & & & & & & & \\
\hline & AIR HANDUNG UNITS & & & & & & & & & & \\
\hline & AHU - 1, Bay Area Loading/Unloading $16,000 \mathrm{cfm}$ & & $1 \mathrm{ea}$ & 36,000 & 36 & 36 & 34.58 & 1,245 & 36,000 & 11,173 & 48,418 \\
\hline & AHN-2 Anti-C,Prep Booth, Hot Cell 22,830 c/m & & $1 \mathrm{ea}$ & 45,000 & 40 & 40 & 34.58 & 1,383 & 45,000 & 13,915 & 60,298 \\
\hline & AHN-3, Hepa Filter Foom $3,000 \mathrm{clm}$ & & 1 ea & 10,000 & 24 & 24 & 34.58 & 830 & 10,000 & 3,249 & 14,079 \\
\hline & AHU-4, Fan Room 7,000 cfm & & 1 ea & 8,000 & 24 & 24 & 34.58 & 830 & 8,000 & 2,649 & 11,479 \\
\hline & AHN -5, Offlce, \& Support Areas $2,515 \mathrm{cfm}$ & & $1 \mathrm{ea}$ & 10,000 & 24 & 24 & 34.58 & 830 & 10,000 & 3,249 & $\cdot 14,079$ \\
\hline & & & & & & & & & & & \\
\hline & EXHAUST FANS & & & & & & & & & & \\
\hline & Hot Cell Hepa Filter EF-1 \& EF-2, 20,000 clm & & 2 ea & 16,000 & 16 & 32 & 34.58 & 1.107 & 32,000 & 9,932 & 43,039 \\
\hline & Mech. Pm Hepa Filter EF -3 \& EF-4, 4,800 cim & & 2 ea & 4,500 & 16 & 32. & 34.58 & 1,107 & 9,000 & 3,032 & 13,139 \\
\hline & Toilet Rm's. and Jan. Cbset, EF - 6 \& 7 & & $2 \mathrm{ea}$ & 2,000 & 8 & 16 & 34.58 & 553 & 4,000 & 1,366 & 5,919 \\
\hline & . & & & & & & & & & & \\
\hline & & & & & & & & & & & \\
\hline & HEPAFILTER & & & & & & & & & & \\
\hline ** & Hepa Filters, F-1 \& F-2 & & 2 ea & & 16 & 32 & 125.00 & 4,000 & & 1,200 & 5,200 \\
\hline$\star \star$ & Hepa Filters, F-3\&F-4 & & 2 ea & & 16 & 32 & 125.00 & 4,000 & & 1,200 & 5,200 \\
\hline & & & & & & & & & & & \\
\hline & GLYCOL HEAT RECOVERY SYSTEM & & & & & & & & & & \\
\hline & (2) Coils, Pump, Expansion Tark, Piping, Valves, etc. & & $1 \mathrm{bt}$ & 75,000 & 320 & 320 & 34.58 & 11,066 & 75,000 & 25,820 & 111,885 \\
\hline & & & & & & & & & & & \\
\hline & SUPPLEMENTAL COOUNG SYSTEM & & & & & & & & & & \\
\hline & AC-1. - 2 Air Cooled Cond. Unit, 15 bn, 7.5 bn & & $2 \mathrm{ea}$ & 4,500 & 16 & 32 & 34.58 & 1,107 & 9,000 & 3,032 & 13,139 \\
\hline & WC-1 Water Chiller/Condenser Unit, 40 ton & & $1 \mathrm{ea}$ & 30,300 & 88 & 88 & 34.58 & 3,043 & 30,300 & 10,003 & 43,346 \\
\hline & & & & & & & & & & & \\
\hline & & & & & & & & & & & \\
\hline & & & & & & & & & & & \\
\hline & Crane To Set Equipment & & $1 \mathrm{bt}$ & & 160 & 160 & 85.00 & 13,600 & & 4,080 & 17,680 \\
\hline & & & & & & & & & & & \\
\hline & SUBTOTAL MECHANICAL THS PAGE & & & & & 892 & & 44,699 & 268,300 & 93,900 & 406,899 \\
\hline
\end{tabular}

** HEPA Filter Housing will be purchased as GFE. 
Project

SNF DRY STORAGE PROJECT DRY TRANSFERCELL

\begin{tabular}{|c|c|c|c|c|c|c|c|c|c|c|c|}
\hline $\begin{array}{l}\text { ACCT. } \\
\text { No. }\end{array}$ & DESCAPTION & $\begin{array}{l}E, V, \\
P, H\end{array}$ & $\begin{array}{l}\text { MAT'L } \\
\text { UNIT } \\
\end{array}$ & $\begin{array}{c}\text { MAT'LUT. } \\
\text { COST }\end{array}$ & $\begin{array}{c}\text { UNIT LAB. } \\
\text { HRS } \\
\end{array}$ & $\begin{array}{c}\text { TOTAL } \\
\text { LAB. HRS. }\end{array}$ & $\begin{array}{l}\text { LABOR } \\
\text { RATE } \\
\end{array}$ & $\begin{array}{l}\text { LABOR } \\
\text { COST }\end{array}$ & $\begin{array}{l}\text { MAT'L } \\
\text { COST }\end{array}$ & $\begin{array}{l}\text { OH\&P } \\
\text { COST } \\
\end{array}$ & $\begin{array}{l}\text { TOTAL } \\
\text { COST }\end{array}$ \\
\hline & ARDISTRBUTION SYSTEMS & & & & & & & & & & \\
\hline & TAUCK BAY - LOADING/UNLOADING & & & & & & & & & & \\
\hline & Exhaust Hose Reel Systems & & 2 ea & 5,000 & 40 & 80 & 34.58 & 2,766 & 10,000 & 3,830 & 16,596 \\
\hline & Supply and Return Ar Ductwork & & 2,600 sf & 8 i & included & & & & 20,800 & 6,240 & 27,040 \\
\hline & OA Intake Air Louver andDuctwork & & 1 ea & 3,200 & 16 & 16 & 34.58 & 553 & 3,200 & 1,126 & 4,879 \\
\hline & & & & & & & & & & & \\
\hline & & & & & & & & & & & \\
\hline & OFFICE/SUPPORT AREAS/LABORATORY & & & & & & & & & & \\
\hline & OA Intake Air Louvers and Ductwork & & 30 sf & 20 & 8 & 240 & 34.58 & 8,299 & 600 & 2,670 & 11.569 \\
\hline & Supply and Roturn Ar Ductwork & & 12,900 sf & 41 & included & & & & 51,600 & 15,480 & 67,080 \\
\hline & & & & & & & & & & & \\
\hline & HOT CELLUTRANSFER CASKUHEPA FILTER AREAS & & & & & & & & & & \\
\hline & Supply Ductwork (Galv./SST) & & $9.000 \mathrm{sf}$ & 6 i & included & & & & 54,000 & 16,200 & 70,200 \\
\hline & Supplemental Cooling Ductwork & & $2,000 \mathrm{lbs}$ & 0.6 & 0.12 & 240 & 34.58 & 8,299 & 1,200 & 2,850 & 12,349 \\
\hline & SST Exhaust Ductwork b Hepa Filters (12Ga) & & $10,000 \mathrm{lbs}$ & 2 & 0.15 & 1,500 & 34.58 & 51,870 & 20,000 & 21.561 & 93,431 \\
\hline & SST Isolation Dampers & & 4 ea & 4,500 & 4 & 16 & 34.58 & 553 & 18,000 & 5,566 & 24,119 \\
\hline & Galv. Exhaust Ductwork (10 Ga.) b stack & & $5,000 \mathrm{lbs}$ & 0.6 & 0.12 & 600 & 34.58 & 20,748 & 3,000 & 7.124 & 30,872 \\
\hline & Isolation Dampers & & 10 ea & 2500 & 6 & 60 & 34.58 & 2,075 & 25,000 & 8,122 & 35,197 \\
\hline & 30" Dia. Stack & & $1 \mathrm{ea}$ & 32,000 & included & & & & 32,000 & 9,600 & 41,600 \\
\hline & $18^{\prime \prime}$ Dia. Stadk & & 1 ea & 30,000 & included & & & & 30,000 & 9,000 & 39,000 \\
\hline - & & & & & & & & & & & \\
\hline & & & & & & & & & & & \\
\hline & & & & & & & & & & & \\
\hline & & & & & & & & & & & \\
\hline & MISC. REFRIGERATION PIFING \&INSULATION & & & & & & & & & & \\
\hline & Piping \& Accessorles to Air Cooled Condensors & & 1 bt & 30,000 & Included & & & & 30,000 & 9,000 & 39,000 \\
\hline & & & & & & & & & & & \\
\hline & & & & & & & & & & & \\
\hline & SUBTOTAL MECHANICALTHS PAGE & & & & & 2,752 & & 95,164 & 299,400 & 118,369 & 512,933 \\
\hline
\end{tabular}




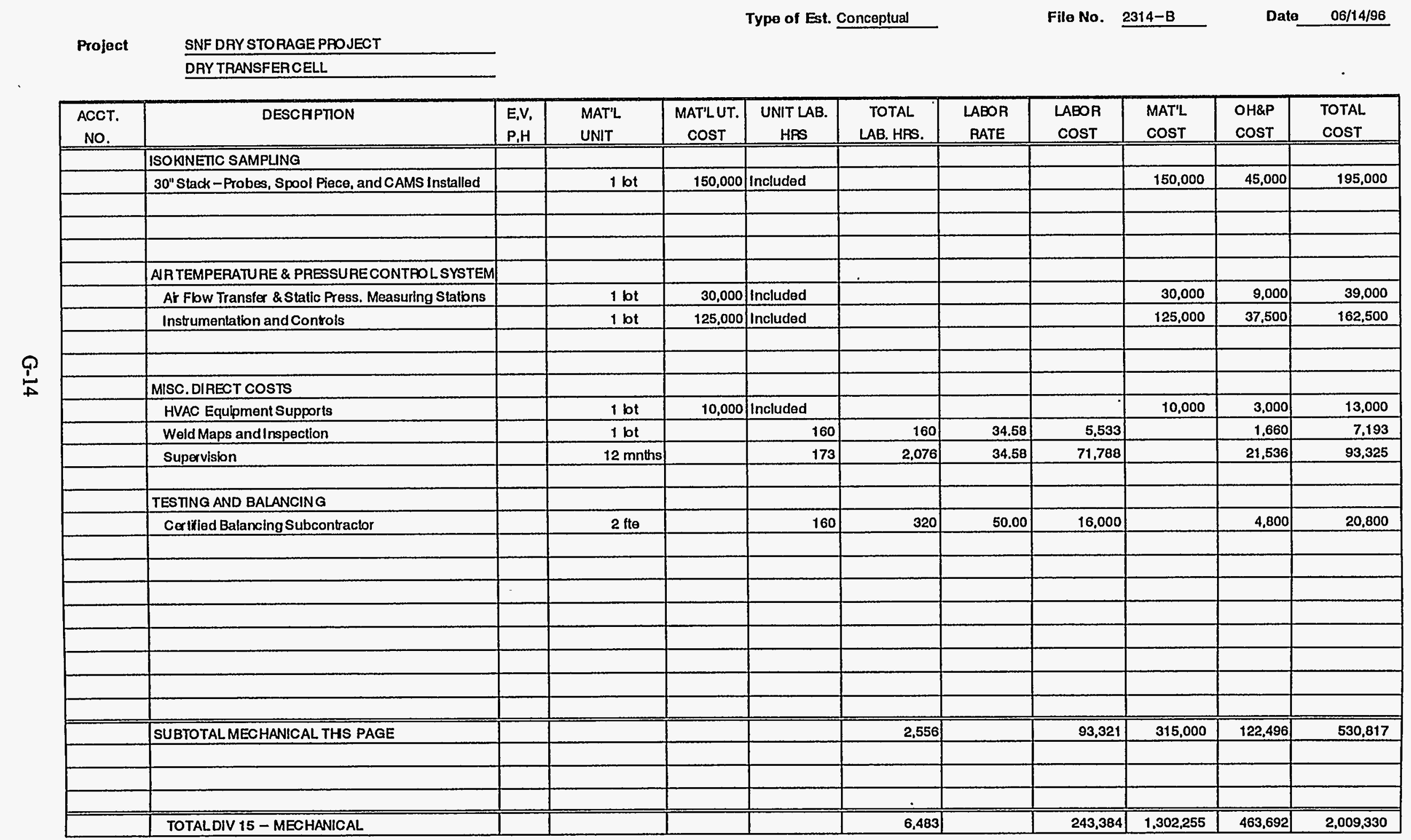


Project SNF DRY STORAGEPROJECT DRY TRANSFERCELL

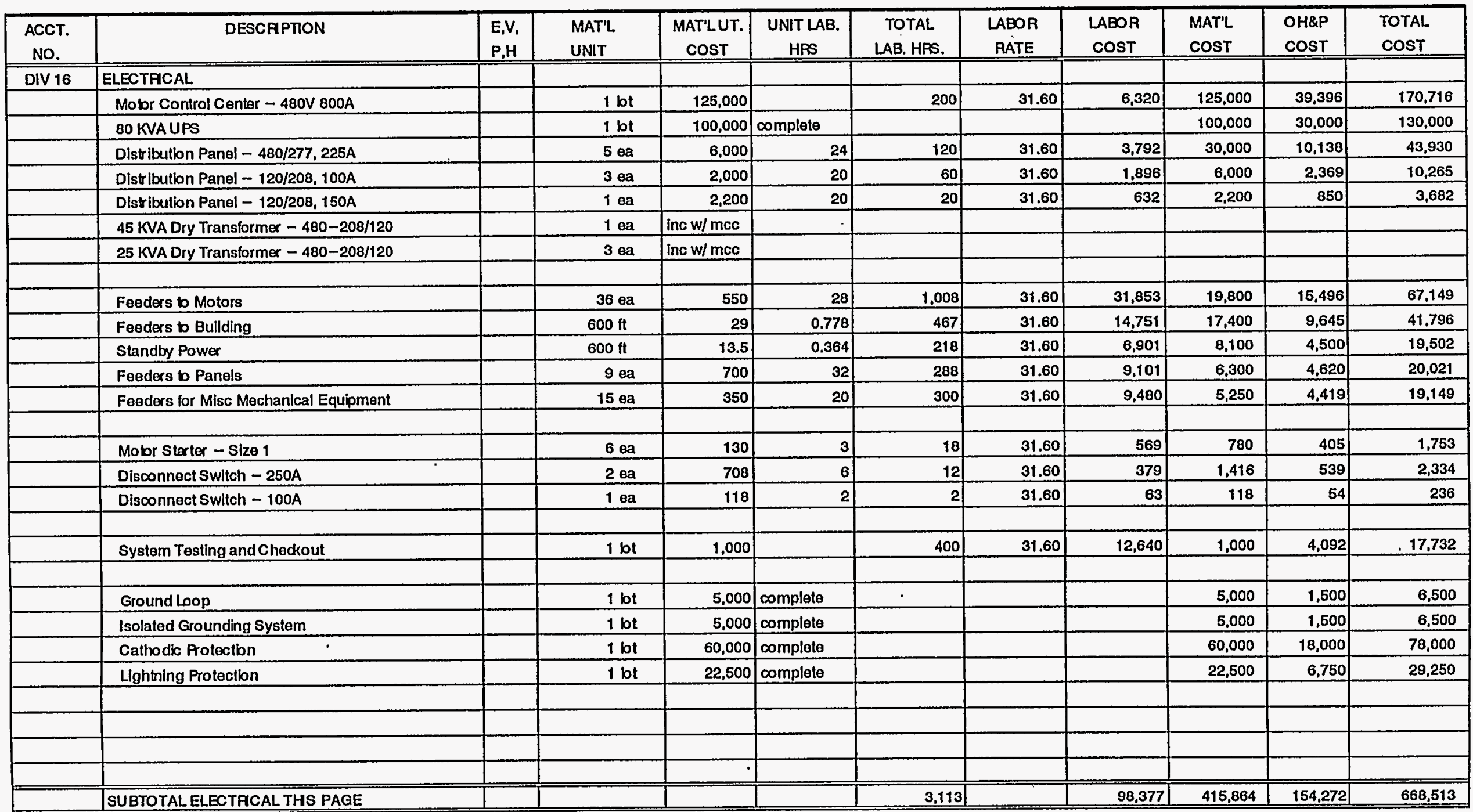


Project

SNF DRY STORAGE PROJECT DRY TRANSFERCELL

\begin{tabular}{|c|c|c|c|c|c|c|c|c|c|c|c|}
\hline $\begin{array}{l}\text { ACCT. } \\
\text { NO. }\end{array}$ & DESCAPTION & $\begin{array}{l}\text { E.V, } \\
\text { P.H }\end{array}$ & $\begin{array}{l}\text { MAT'L } \\
\text { UNIT }\end{array}$ & $\begin{array}{c}\text { MATLUT. } \\
\text { COST }\end{array}$ & $\begin{array}{c}\text { UNIT LAB. } \\
\text { HPS } \\
\end{array}$ & $\begin{array}{c}\text { TOTAL } \\
\text { LAB. HAS. } \\
\end{array}$ & $\begin{array}{l}\text { LABOR } \\
\text { RATE }\end{array}$ & $\begin{array}{l}\text { LABOR } \\
\text { COST }\end{array}$ & $\begin{array}{l}\text { MAT'L } \\
\text { COST }\end{array}$ & $\begin{array}{l}\text { OH\&P } \\
\text { COST }\end{array}$ & $\begin{array}{l}\text { TOTAL } \\
\text { COST }\end{array}$ \\
\hline & Lighting - includes Feoders & & & & & & & & & & \\
\hline & Admin Areas / Utitity Support Aooms & & 13,500 sf & 3 & Complete & & & & 40,500 & 12,150 & 52,650 \\
\hline & Progammable Lighting Contols & & $1 \mathrm{bt}$ & 20,000 & complete & & & & 20,000 & 6,000 & 26,000 \\
\hline & Receptacles / Switches & & $20,000 \mathrm{sf}$ & 0.75 & 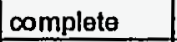 & & & & 15,000 & 4,500 & 19.500 \\
\hline & Welding Receptacle & & $1 \mathrm{ea}$ & 350 & 6 & 6 & 31.60 & 190 & 350 & 162 & 701 \\
\hline & High Bay Lighting - includes Feeders & & $6,500 \mathrm{sf}$ & 6 & complete & & & & 39,000 & 11,700 & 50,700 \\
\hline & Exit Lighting & & 8 ea & 178 & 5 & 40 & 31.60 & 1,264 & 1,424 & 806 & 3,494 \\
\hline & Exterior Lighting & & 6 еа & 725 & 10 & 60 & 31.60 & 1,696 & 4,350 & 1,874 & 8,120 \\
\hline & Hot Cell Lighting and Receptacles & & & & & & & & & & \\
\hline & Coilling $-1000 \mathrm{~W}$ & & $20 \mathrm{ea}$ & 2,500 & 12 & 240 & 31.60 & 7,584 & 50,000 & 17,275 & 74,859 \\
\hline & Walls $-400 W$ & & $8 \mathrm{ea}$ & 1,075 & 10 & 80 & 31.60 & 2,528 & 8,600 & 3,338 & 14,466 \\
\hline & Emergency Lights & & 4 ea & 750 & 4 & 16 & 31.60 & 506 & 3,000 & 1,052 & 4,557 \\
\hline & Gulton Receptacles & & $7 \mathrm{ea}$ & 12,000 & 4 & 28 & 31.60 & 885 & 84,000 & 25,465 & 110,350 \\
\hline & Feeders & & $39 \mathrm{ea}$ & 250 & 6 & 234 & 31.60 & 7,394 & 9,750 & 5,143 & 22,288 \\
\hline & & & & & & & & & & & \\
\hline & & & & & & & & & & & \\
\hline & CCTV - Cameras & & 1102 & 3,000 & 40 & 440 & 31.60 & 13,904 & 33,000 & 14,071 & 60,975 \\
\hline & CCTV - Monitors & & 4 ea & 1,250 & 2 & 8 & 31.60 & 253 & 5,000 & 1.576 & 6,829 \\
\hline & CCTV - Recorders & & $2 \mathrm{ea}$ & 1,000 & 2 & 4 & 31.60 & 126 & 2,000 & 638 & 2,764 \\
\hline & CCTV - QuadSwitches & & 3 ea & 2,000 & 2 & 6 & 31.60 & 190 & 6,000 & 1,857 & 8.046 \\
\hline & CCTV - Camera Controls & & 3 ea & 600 & 2 & 6 & 31.60 & 190 & 1,800 & 597 & 2,586 \\
\hline & CCTV - PTZ Controls & & 2 ea & 900 & 2 & 4 & 31.60 & 126 & 1,800 & 578 & 2,504 \\
\hline & CCTV - 8 Channel Switch & & $2 \mathrm{ea}$ & 1,000 & 2 & 4 & 31.60 & 126 & 2,000 & 638 & 2,764 \\
\hline & ccTV - Cabling & & $5,400 \mathrm{ft}$ & 3.04 & 0.196 & 1,058 & 31.60 & 33,445 & 16.416 & 14,958 & 64,820 \\
\hline & & & & & & & & & & & \\
\hline & Data Acquisition and Recording - See GFE & & - & & & & & & & & \\
\hline & Cabling & & $4,200 \mathrm{ft}$ & 3.04 & 0.196 & 823 & 31.60 & 26,013 & 12,768 & 11,634 & 50,415 \\
\hline & Radiation Moniloring System - Se日 GFE & & & & & & & & & & \\
\hline & Cabling & & $5,800 \mathrm{ft}$ & 1.52 & 0.098 & 568 & 31.60 & 17.961 & 8,816 & 8,033 & 34,811 \\
\hline & SUBTOTAL ELECTRCAL THS PAGE & & & & & 3,626 & & 114.582 & 365.574 & 144,047 & 624,202 \\
\hline
\end{tabular}




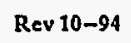

Page 14 of 17

Project

SNF DRY STORAGE PROJECT DRY TRANSFERCELLL

\begin{tabular}{|c|c|c|c|c|c|c|c|c|c|c|c|}
\hline $\begin{array}{c}\text { ACCT. } \\
\text { NO. }\end{array}$ & DESCAPTION & $\begin{array}{l}E, V, \\
P, H \\
\end{array}$ & $\begin{array}{l}\text { MAT'L } \\
\text { UNIT } \\
\end{array}$ & $\begin{array}{c}\text { MAT'LUT. } \\
\text { COST }\end{array}$ & $\begin{array}{c}\text { UNIT LAB. } \\
\text { HAS } \\
\end{array}$ & $\begin{array}{c}\text { TOTAL } \\
\text { LAB. HRS. }\end{array}$ & $\begin{array}{c}\text { LABOR } \\
\text { RATE } \\
\end{array}$ & $\begin{array}{l}\text { LABOR } \\
\text { COST } \\
\end{array}$ & $\begin{array}{l}\text { MAT'L } \\
\text { COST } \\
\end{array}$ & $\begin{array}{l}\text { OH\&P } \\
\text { cost }\end{array}$ & $\begin{array}{l}\text { TOTAL } \\
\text { COST } \\
\end{array}$ \\
\hline & Selsmic Detection System & & 1 bt & 10,000 & albwance & & & & 10,000 & 3,000 & $13,000^{\prime}$ \\
\hline & & & & & & & & & & & \\
\hline & Security System & & & & & & & & & & \\
\hline * & Argus Field Panel & & $10 a$ & 1,500 & 120 & 120 & 31.60 & 3,792 & 1,500 & 1,588 & 6,880 \\
\hline * & Remote Access Panel & & $12 \mathrm{ea}$ & 300 & .40 & 480 & 31.60 & 15,168 & 3,600 & 5,630 & 24,398 \\
\hline \multirow[t]{5}{*}{$\star$} & Remote Distribution Module & & $1 \mathrm{bt}$ & 7,500 & 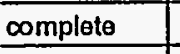 & & & & $7,500^{\circ}$ & 2,250 & 9,750 \\
\hline & Cabling & & $2,800 \mathrm{ft}$ & 3.04 & 0.098 & 274 & 31.60 & 8,671 & 8,512 & 5,155 & 22,338 \\
\hline & Interface to Host Computer - CPP 1674 & & $600 \mathrm{ft}$ & 12.8 & Complete & & & & 7.680 & 2,304 & 9,984 \\
\hline & ConfinedSpace Enty at Man-holes & & 1 ea & & 4 & 4 & 31.60 & 126 & & 38 & 164 \\
\hline & & & & & & & & & & & \\
\hline . & Fiber Optic / Telephone / Wre to Bullding & & $600 \mathrm{ft}$ & 11.5 & 0.214 & 128 & 31.60 & 4,057 & 6,900 & 3,287 & 14,245 \\
\hline & Confined Space Enty at Man-holes & & $8 \mathrm{ea}$ & & 4 & 32 & 31.60 & 1.011 & & 303 & 1,315 \\
\hline & Volce Paging, Fire Alarm and Evac System & & 1 bt & 62,000 & complete & & & & 62,000 & 18,600 & 80,600 \\
\hline & Voice / Data System & & $1 \mathrm{bt}$ & 6,000 & Complete & & & & 6,000 & 1,800 & 7,800 \\
\hline & LAN & & $1 \mathrm{bt}$ & 6,000 & complete & & & & 6,000 & 1.800 & 7,800 \\
\hline & Intercom System & & $1 \mathrm{bt}$ & 15.000 & complete. & & & & 15,000 & 4,500 & 19,500 \\
\hline & & & & & & & & & & & \\
\hline & Supervision & & 27 mnths & & 86.5 & 2,336 & 31.60 & 73,802 & & 22,141 & 95,942 \\
\hline & & & & & & & & & & & \\
\hline & & & & & & & & & & & \\
\hline & & & & & & & & & & & \\
\hline & & & & & & & & & & & \\
\hline & SUBTOTAL ELECTRCAL.THS PAGE & & & & & 3,374 & & 106,628 & 134,692 & 72,396 & 313,716 \\
\hline & & & & & & & & & & & \\
\hline & TOTALDIV 16 - ELECTRCAL & & & & & 10,114 & & 319,587 & 916,130 & 370,715 & $1,606,432$ \\
\hline & & & & & & & & & & & \\
\hline & & & & & & & & & & & \\
\hline & & & & & & & & & & & \\
\hline & & & & & & & & & & & \\
\hline
\end{tabular}

* Denotes Government Furnished Equipment (GFE) - Materlal cost shown is Subcontractor handling foe. 
Project

SNF DRY STORAGE PROJECT DRY TRANSFERCELL

\begin{tabular}{|c|c|c|c|c|c|c|c|c|c|c|c|}
\hline $\begin{array}{l}\text { ACCT. } \\
\text { No. }\end{array}$ & DESCAPTION & $\begin{array}{l}E, V, \\
P, H\end{array}$ & $\begin{array}{l}\text { MAT'L } \\
\text { UNIT } \\
\end{array}$ & $\begin{array}{c}\text { MAT'LUT. } \\
\text { COST }\end{array}$ & $\begin{array}{c}\text { UNIT LAB. } \\
\text { HRS }\end{array}$ & $\begin{array}{l}\text { TOTAL } \\
\text { LAB. HRS. }\end{array}$ & $\begin{array}{l}\text { LABOR } \\
\text { RATE } \\
\end{array}$ & $\begin{array}{l}\text { LABOR } \\
\text { COST } \\
\end{array}$ & $\begin{array}{l}\text { MAT'L } \\
\text { COST } \\
\end{array}$ & $\begin{array}{c}\text { G\&A } \\
\text { CosT }\end{array}$ & $\begin{array}{l}\text { TOTAL } \\
\text { COST }\end{array}$ \\
\hline \multirow[t]{10}{*}{ GFE } & GOVERNMENT FURNISHED EQUIPMENT & & & & & & & & & & \\
\hline & Hot Cell Vlewing Window & & $4 \mathrm{ea}$ & 245,000 & & & & & 980,000 & 150,000 & 980,000 \\
\hline & $150 / 15$ Ton Bildge Crane & & $1 \mathrm{ea}$ & $1,310,000$ & & & & & $1,310,000$ & 150,000 & $1,310,000$ \\
\hline & 7.5 Ton Bridge Crane & & 1 ea & 50,200 & & & & & 50,200 & 15,060 & 50,200 \\
\hline & Fuel Handling Crane - Includes 3 Trolleys, & & & & & & & & & & \\
\hline & Z-Masts, Manipulators, Controls, olc & & 1 ea & $2,920,000$ & & & & & $2,920,000$ & 150,000 & $2,920,000$ \\
\hline & & & & & & & & & & & \\
\hline & Hepa Filters, F-1 \& F-2 Housing & & 2 ea & 120,000 & & & & & 240,000 & 72,000 & 240,000 \\
\hline & Hepa Filter $8, F-3 \& F-4$ Housing & & 2 ea & 55,000 & & & & & 110,000 & 33,000 & 110,000 \\
\hline & & & & & & & & & & & \\
\hline & Welding Machine & & 2 ea & 150,000 & Complete & & & & 300,000 & & 300,000 \\
\hline & Leak, Purge, and Gas Sampling Equipment & & 2 ea & 300,000 & 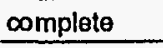 & & & & 600,000 & & 600,000 \\
\hline & Pneumatlc Can Piercing Tool & & $1 \mathrm{ea}$ & 160,000 & Complete & & & & 160,000 & & 160,000 \\
\hline & Can Drying System & & $1 \mathrm{ea}$ & 45,000 & complete & & & & 45,000 & & 45,000 \\
\hline & Helium Leak Detector & & 1 ea & 120,000 & Complete & & & & 120,000 & & 120.000 \\
\hline & G\&A - assume one vendor & & & & & & & & & 150,000 & \\
\hline & & & & & & & & & & & \\
\hline & Argus Field Pand & & 1 ea & 30,000 & & & & & 30.000 & 9,000 & 30,000 \\
\hline & Remote Access Panel & & 12 ea & 3,000 & & & & & 36,000 & 10,800 & 36,000 \\
\hline & Remote Distribution Module & & 1 ea & 75,000 & & 2,000 & 40.00 & 80,000 & 75,000 & 46,500 & 155,000 \\
\hline & . & & & & & & & & & & \\
\hline & $\cdot$ & & & & & & & & & & \\
\hline & & & & & & & & & & & \\
\hline & & & & & & & & & & & \\
\hline & & & & & & & & & & & \\
\hline & & & & & & & & & & & \\
\hline & & & & & & & & & & & \\
\hline & SUBTOTAL GOVERNMENT FURNISHED EQUIPMEN & THS F & & & & & & & & & $7.056,200$ \\
\hline & SUBTOTAL G\&A THS PAGE - NOTIN GFESUBTOI & & & & & & & & & 786,360 & \\
\hline
\end{tabular}




\begin{tabular}{|c|c|c|c|c|c|c|c|c|c|c|c|}
\hline & & & & & & & & & & & \\
\hline & & & & & & & & & & ' & \\
\hline & & & & & & & & & & & \\
\hline & & & & & & & & & & & \\
\hline & & & & & & & & & & & \\
\hline & & . & & & & & & & & & \\
\hline & SEg'616 & & & & & & & & & $7 \forall 1 O 1339 \mathrm{NI} \perp O N-\forall 897 \forall 1 O 1$ & \\
\hline $096^{\prime} \operatorname{Eog}^{\prime} L$ & & & & & & & & & & 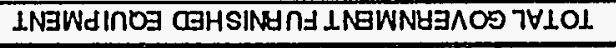 & \\
\hline & & & & & & & & & & & \\
\hline & & & & & & & & & & & \\
\hline & SLZ'EEI & & & & & & & & & 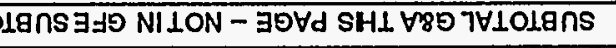 & \\
\hline $09 \angle \angle 60$ & & & & & & & & & SHId & 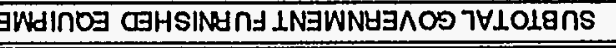 & \\
\hline & & & & & & & & & & & \\
\hline & & & & & & & & & & & \\
\hline & & & & & & & & & & & \\
\hline & & & & & & & & & & & \\
\hline & & & & & & & & & & & \\
\hline $008^{\prime}+\varepsilon$ & $066^{\prime} 01$ & $000^{\prime} 0 \varepsilon$ & $008^{\prime} \mathrm{t}$ & 0000 & 021 & 021 & $000^{\prime} 0 \varepsilon$ & EQ I & & DNOSุ HOMYON & \\
\hline $000^{\prime} 62$ & $00 L^{\prime} B$ & $000^{\prime} 92$ & $000^{\prime} b$ & $00^{\circ} 06$ & 001 & 02 & $000^{\prime} \mathrm{g}$ & Eo $\mathrm{S}$ & & stelnduoj leutosed & \\
\hline & & & & & & & & & & 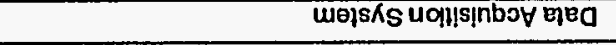 & \\
\hline & & & & & & & & & & & \\
\hline $000^{\circ} 0$ St & $000^{\prime} \mathrm{st}$ & $000^{\circ} 091$ & & & & 비비누 & $000^{\prime} 0 \mathrm{St}$ & E2 1 & & Jọ!uOW sursen / uolı!pey & \\
\hline 000101 & $000^{\circ} \varepsilon$ & $000 \% 01$ & & & & 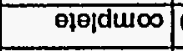 & $000^{\prime} 01$ & EQI & & 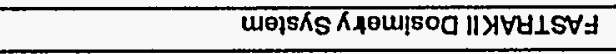 & \\
\hline 000 01 & $000^{\prime} \varepsilon$ & 000101 & & & & 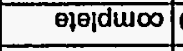 & $00 s^{\prime} z$ & e日t & & OSFIIJPIOH PUEH & \\
\hline $09 \varepsilon^{\prime} Z 1$ & $009^{\prime} \varepsilon$ & $000^{\prime} \mathrm{Zl}$ & $09 \varepsilon$ & $00^{\circ} \mathrm{sb}$ & 8 & $b$ & $000^{\prime} 9$ & EQ Z & & 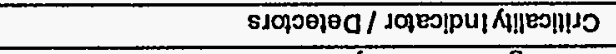 & \\
\hline $09 \varepsilon^{\prime} 01$ & $000^{\prime} \varepsilon$ & $0000^{\prime} 01$ & $09 \varepsilon$ & $00^{\prime} \mathrm{st}$ & 8 & $t$ & $000^{\prime} \mathrm{s}$ & Ea & & Jo!!uOW h!!n!) & \\
\hline $060^{\circ} 28$ & $009^{\prime}+z$ & $000^{\prime} 28$ & 06 & $00 . \mathrm{Sb}$ & 2 & 1 & $000^{\circ} 15$ & Eo Z & $\bar{T}$ & $z-W O d$ & \\
\hline $056^{\prime} 9$ & LEO'Z & $0 \angle L^{\prime} 9$ & 081 & $00 ' s b$ & $b$ & $b$ & $0 \angle L^{\prime} 9$ & 801 & & Budj $\forall-W \forall O$ & \\
\hline $006 ' 99$ & tot'61 & $089^{\prime}+9$ & $09 Z^{\prime} !$ & $00^{\circ} \mathrm{Sp}$ & 82 & $b$ & $002^{\prime} 6$ & $80 \angle$ & & euureg/घieg - WVO & \\
\hline $09 z^{\prime} 9 \varepsilon$ & $00 s^{\prime} 01$ & $000^{\prime} \mathrm{S} \varepsilon$ & 092'เ & $00^{\circ} \mathrm{sb}$ & 82 & 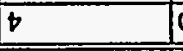 & $000^{\circ} \mathrm{s}$ & $80 \mathrm{~L}$ & & WVy & \\
\hline 1500 & 1500 & ISO0 & 1500 & JIV8 & . 24.64 & \$UH & 1500 & LINก & $H^{\prime} d$ & & ON \\
\hline \multirow[t]{3}{*}{$7 \forall 101$} & $\forall 89$ & $7.1 \forall W$ & 400ष7 & yCaV7 & $7 \forall \perp O \perp$ & 'gVILINก & 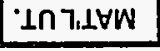 & $7, \perp \forall W$ & $\wedge ' \exists$ & NOLdHOS $\exists a$ & 1008 \\
\hline & & & & & & & & & & 77ヨอष & \\
\hline & & & & & & & & & & 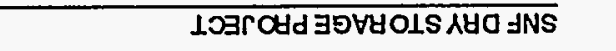 & poolord \\
\hline
\end{tabular}

LI jo 91 eBed

เ6-0I AวY

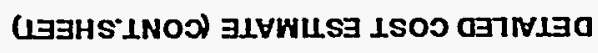

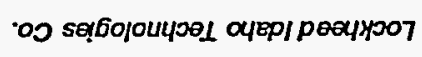


Project

SNF DRY STORAGE PROJECT DAY TRANSFERCELL

\begin{tabular}{|c|c|c|c|c|c|c|c|c|c|c|c|}
\hline $\begin{array}{l}\text { ACCT. } \\
\text { No. }\end{array}$ & DESCRPTION & $\begin{array}{l}E, V \text {, } \\
P, H\end{array}$ & $\begin{array}{l}\text { MAT'L } \\
\text { UNIT }\end{array}$ & $\begin{array}{c}\text { MAT'LUT. } \\
\text { COST }\end{array}$ & $\begin{array}{c}\text { UNIT LAB. } \\
\text { HRS }\end{array}$ & $\begin{array}{c}\text { TOTAL } \\
\text { LAB. HRS. }\end{array}$ & $\begin{array}{l}\text { LABOR } \\
\text { RATE }\end{array}$ & $\begin{array}{l}\text { LABOR } \\
\text { COST }\end{array}$ & $\begin{array}{l}\text { MAT'L } \\
\text { COST }\end{array}$ & $\begin{array}{l}\text { OH\&P } \\
\text { COST }\end{array}$ & $\begin{array}{l}\text { TOTAL } \\
\text { COST }\end{array}$ \\
\hline & ENGINEERNG / DESIGN & & & & & & & & & & \\
\hline & Civil / Structural / Architactural & & 250 dwgs & 5,000 & complete & & & $1,250,000$ & & & $1,250,000$ \\
\hline & Mechanical / Fire Protection & & 80 dwgs & 5,000 & complete & & & 400,000 & & & 400,000 \\
\hline & Electrical / Life Salety & & 80 dwgs & 5,000 & 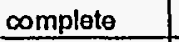 & & & 400,000 & & & 400,000 \\
\hline & Equipment & & 80 dwgs & 5,000 & Complote & & & 400,000 & & & 400,000 \\
\hline & Misc Studies & & $1 \mathrm{bt}$ & & 7,500 & 7,500 & 74.00 & 555,000 & & & 555,000 \\
\hline & Design Revlews & & $2 \mathrm{ea}$ & & 200 & 400 & 74.00 & 29,600 & & & 29,600 \\
\hline & Peformance Specilications - Equipment & & $8 \mathrm{ea}$ & & 200 & 1,600 & 74.00 & 118,400 & & & 118,400 \\
\hline & & & & & & & & & & & \\
\hline & INSPECTION & & & & & & & & & & \\
\hline & Title Ill Inspection & & 27 mnths & & 260 & 7,007 & 62.00 & 434,403 & & & 434,403 \\
\hline & Support - Testing, Compaction & & 12 mnths & & 87 & 1,044 & 62.00 & 64,728 & & & 64,728 \\
\hline & Source Inspection & & 3 trips & 2,000 & 24 & 72 & 62.00 & 4,464 & 6,000 & & 10,464 \\
\hline & & & & & & & & & & & \\
\hline & PROJECT MANAGEMENT & & & & & & & & & & \\
\hline & Project Management & & 57 mnths & & 375 & 21,375 & 74.00 & $1,581,750$ & & & $1,581,750$ \\
\hline & Project Suppt - Cost Estimating, Quality, Safety, ESD & & 57 mnths & & 225 & 12,825 & 74.00 & $\cdot 949,050$ & & & 949,050 \\
\hline & SAR & & $1 \mathrm{bt}$ & 600,000 & & & & 600,000 & & & 600,000 \\
\hline & NRC Application & & $1 \mathrm{bt}$ & 500,000 & & & & 500,000 & & & 500,000 \\
\hline & NRC Feo & & 1 bt & 850,000 & & & & & 850,000 & & 850,000 \\
\hline & & & & & & & & & & & \\
\hline & CONSTRUCTION MANAGEMENT & & & & & & & & & & \\
\hline & Construction Coor dination & & 27 mnth & & 75 & 2,025 & 61.00 & 123,525 & & & 123,525 \\
\hline & Field Engineer & & 27 mnth & & 375 & 10,125 & 56.00 & 567,000 & & & 567.000 \\
\hline & Construction Support & & 27 mnth & & 150 & 4,050 & 56.00 & 226,800 & & & 226,800 \\
\hline & CM Pool Acoount & & $1 \mathrm{bt}$ & & & 16,200 & 26.00 & 421,200 & & & 421,200 \\
\hline & 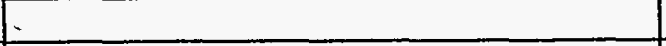 & & & & & & & & & & \\
\hline & & & & & & & & & & & \\
\hline & & & & & & & & & & & \\
\hline & & & & & & & & & & & \\
\hline & & & & & & & & & & & \\
\hline
\end{tabular}


Project

Location

SNF DRY STORAGE PROJECT DRY TRANSFER CELL

\begin{tabular}{|c|c|c|c|c|c|c|c|}
\hline \multirow{3}{*}{ Cost Estimate Element } & \multicolumn{6}{|c|}{ PROBAELE \% VARIATION } & \multirow{3}{*}{ Contingency } \\
\hline & \multirow[t]{2}{*}{$\begin{array}{l}\text { Unescalated } \\
\text { Cost }\end{array}$} & \multirow{2}{*}{$\begin{array}{c}\% \\
\text { Total } \\
\text { Cost } \\
\end{array}$} & \multicolumn{2}{|c|}{$\begin{array}{l}\text { Prob \% Var } \\
\text { From Est }\end{array}$} & \multicolumn{2}{|c|}{ WT \% of Prob } & \\
\hline & & & -1 & + & $=$ & \pm & \\
\hline Tite I and II Design & $3,153,000$ & 9 & 5.00 & 1500 & 0.46 & 1.38 & $1.20 \%$ \\
\hline TIYe III Inspection & 510,000 & 1 & 5.00 & 1500 & 0.07 & 0.22 & $0.19 \%$ \\
\hline Project Management & $4,481,000$ & 13 & 5.00 & 1500 & 0.65 & 1.96 & $1.70 \%$ \\
\hline Construction Management & $1,339,000$ & 4 & 5.00 & 1500 & 0.20 & 0.59 & $0.51 \%$ \\
\hline General Requrements & 449,000 & 1 & 5.00 & 2500 & 0.07 & 0.33 & $0.29 \%$ \\
\hline Sibwak & 674,000 & 2 & 5.00 & 3000 & 0.10 & 0.59 & $0.52 \%$ \\
\hline Concrete & $3,080,000$ & 9 & 5.00 & 2500 & 0.45 & 2.25 & $1.98 \%$ \\
\hline Masonry & 322.000 & 1 & 5.00 & 2500 & 0.05 & 0.23 & $0.21 \%$ \\
\hline Motals & 891,000 & 3) & 5.00 & 2500 & 0.13 & 0.65 & $0.57 \%$ \\
\hline \multicolumn{8}{|l|}{ Wood and Plestles } \\
\hline Moisture Prolection & 117,000 & of & 5.00 & 2500 & 0.02 & 0.09 & $0.08 \%$ \\
\hline Doors and Windows & 388,000 & 1 & 5.00 & 2500 & 0.06 & 0.28 & $0.25 \%$ \\
\hline Finishes & 310,000 & 1 & 5.00 & 2500 & 0.05 & 0.23 & $0.20 \%$ \\
\hline Specialties & 30000 & 0 & 5.00 & 2500 & 0.00 & 0.02 & $0.02 \%$ \\
\hline Equipment & $1,486,000$ & 4 & 5.00 & 2500 & 0.22 & 1.08 & $0.95 \%$ \\
\hline Furnishings & 11000 & of & 5.00 & 2000 & 0.00 & 0.01 & $0.01 \%$ \\
\hline \multicolumn{8}{|l|}{ Special Construction } \\
\hline Conveying Systems & 522,000 & 2 & 5.00 & 2000 & 0.09 & 0.36 & $0.32 \%$ \\
\hline Mechanical & $2,009,000$ & 6 & 5.00 & 2500 & 0.29 & 1.47 & $1.29 \%$ \\
\hline Electrical. & $1,606,000$ & 5) & 5.00 & 2500 & 0.23 & 1.17 & $1.03 \%$ \\
\hline GFE & $7,504,000$ & 22 & 5.00 & 2500 & 1.09 & 5.47 & $4.82 \%$ \\
\hline Procurement Fees & 292,000 & 1) & 5.00 & 2000 & 0.04 & 0.17 & $0.15 \%$ \\
\hline GEA & $1,220,000$ & 4 & 5.00 & 2000 & 0.18 & 0.71 & $0.62 \%$ \\
\hline Escalation & $3,773,000$ & 11 & 5.00 & 2500 & 0.55 & 2.75 & $2.42 \%$ \\
\hline Sublotal & 34267000 & 100 & की & का & 5 & 22 & था \\
\hline
\end{tabular}

Calculated Conthgency

Resultant TEC
Type of Est. Conceptual

File No. 2314-8
Date

Prep'd By
06/17/56

S.M. Bradford

\begin{tabular}{|c|c|}
\hline \multicolumn{2}{|c|}{$\begin{array}{c}\text { PROJECT } \\
\text { CONTINGENCY }\end{array}$} \\
\hline$\%$ & Cost \\
\hline $6.19 \%$ & 417,000 \\
\hline $1.00 \%$ & 67000 \\
\hline $8.80 \%$ & 593,000 \\
\hline $2.63 \%$ & 177,000 \\
\hline $1.49 \%$ & 100,000 \\
\hline $2.70 \%$ & 182,000 \\
\hline $1024 \%$ & 589,000 \\
\hline $1.07 \%$ & 72,000 \\
\hline $2.96 \%$ & 199,000 \\
\hline $0.39 \%$ & 26.000 \\
\hline $1.29 \%$ & 87,000 \\
\hline $1.03 \%$ & $\infty 000$ \\
\hline $0.10 \%$ & 7,000 \\
\hline $4.94 \%$ & 333,000 \\
\hline $0.03 \%$ & 2,000 \\
\hline $1.64 \%$ & 111,000 \\
\hline $6.68 \%$ & 450,000 \\
\hline $5.34 \%$ & 359,000 \\
\hline $2494 \%$ & $1,679,000$ \\
\hline $0.77 \%$ & 52,000 \\
\hline $3.23 \%$ & 217,000 \\
\hline $12.54 \%$ & 845,000 \\
\hline hी & मा \\
\hline
\end{tabular}
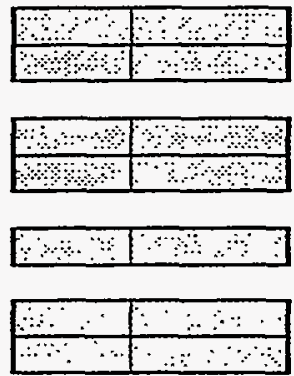

$6,733,000$
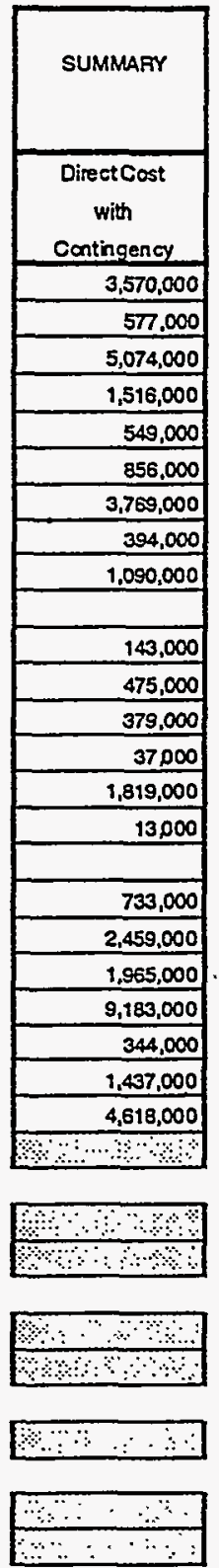

41,000000

Total

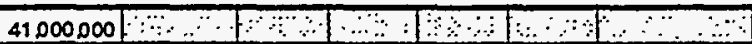

CONTINGENCY ANALYSIS GUIDE BY TYPE OF ESTIMATE:

Guidelines established by DOE/FM-50, Cost Estimating Guide, Vol. 6.

Cost Guide, arid as presented in the INE Cost Estimating Guide. PLANNING

Experimental/Special Conditions CONCEPTUAL

Experimental/Special Conditions TITLEI

TITLE॥

TITLE I/ / AFC
$20 \%-30 \%$ Up to 50\% $15 \%-25 \%$ Up to $40 \%$ $10 \%-20 \%$ $5 \%-15 \%$ Market Conditions 


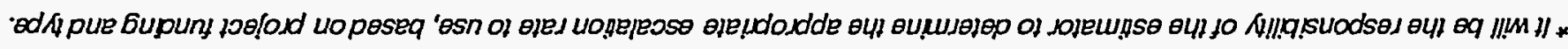

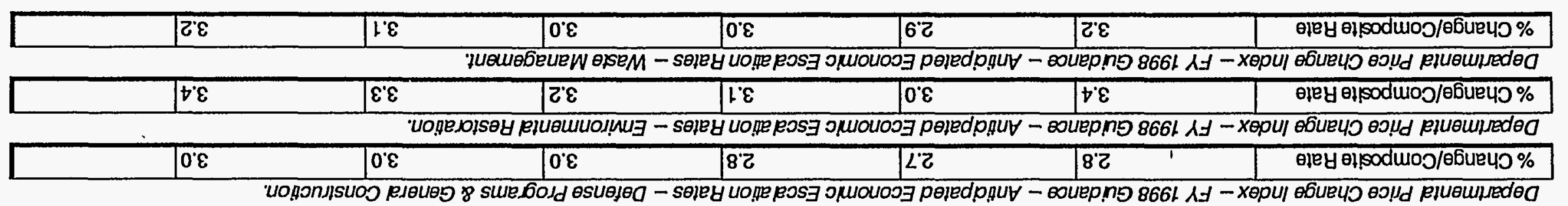

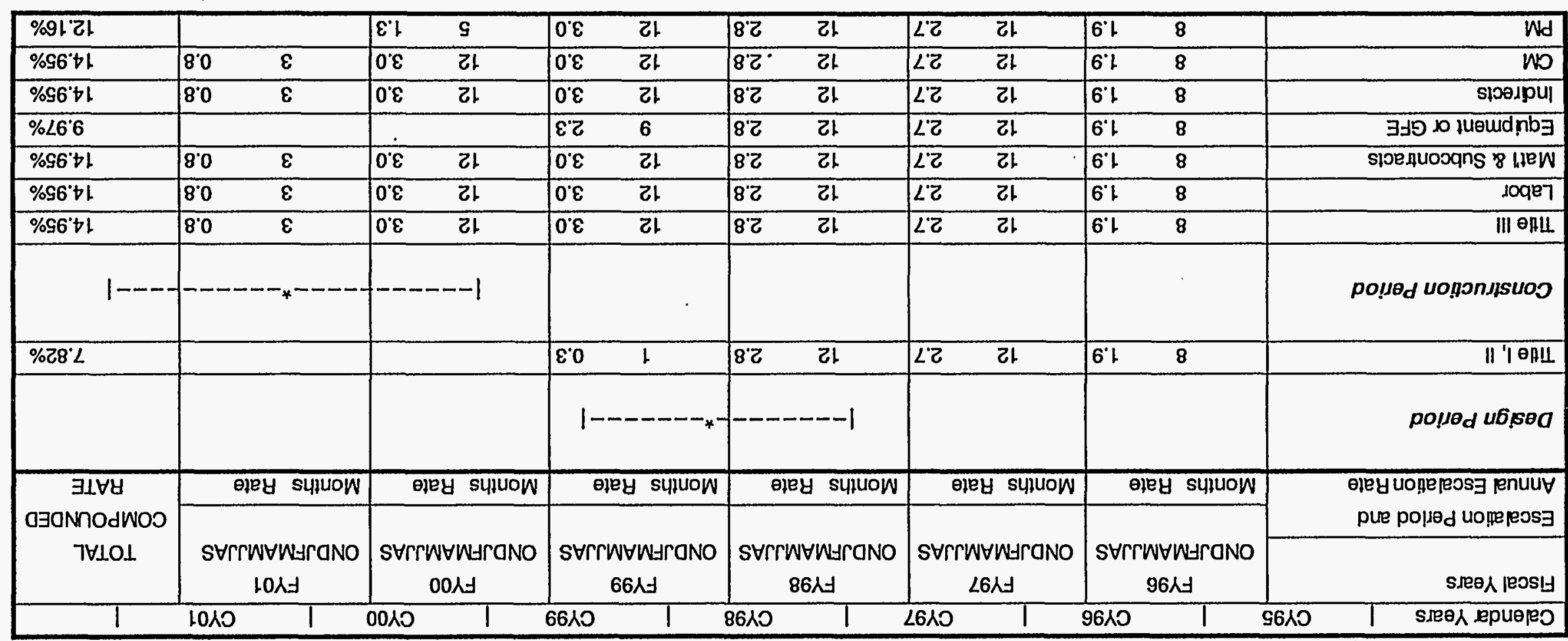

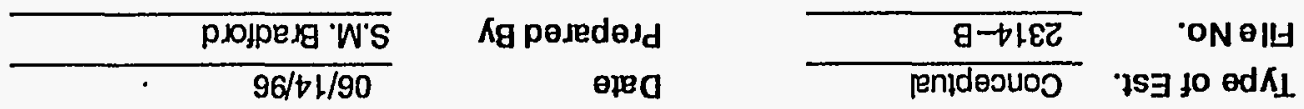

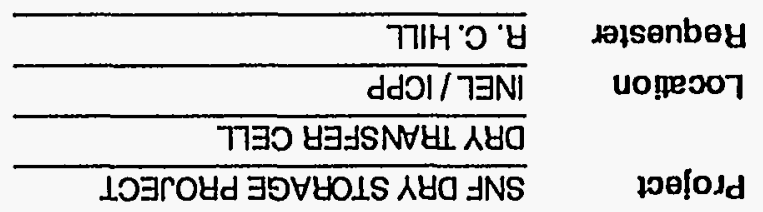


Rev01-96

Project

SNF DFY STORAGE PROJECT DRY STORAGE SYSTEM

Requester R. C. HILL

Unescalated

ENGINEERING, DESIGN AND INSPECTION

Title I and II Design

Title III Inspection

\section{MANAGEMENT}

Project Management

Construction Management

150,000

CONSTRUCTION

Div 1 General Requirements

Div 2 Sitework

Div 3 Concrete

Div 4 Masonry

Div 5 Metals

Div 6 Wood and Plastics

Div 7 Moisture Protection

Div 8 Doors and Windows

Div 9 Finishes

Div 10 Specialties

Div 11 Equipment

Div 12 Furnishings

Div 13 Special Construction

Div 14 Conveying Systems

Div 15 Mechanical

Div 16 Eectrical

GOV'T FURNISHED EQUIPMENT

PROCUREMENT FEES

G\&A

$\begin{array}{r}100,000 \\ \hline 112,000 \\ \hline\end{array}$

8\% of Costruction Coss and GFE

Escalation

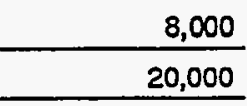

$1,067,000$

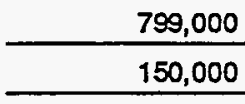

176,000

908,000

$1,235,000$

Type of Est Conceptual

File No 2314-B

Prep'd By S.M. Bradford

Date

Chk'd By

Appr'd By

Totals

240,000

0,000

$\begin{array}{r}97,000 \\ \hline 21,000 \\ \hline\end{array}$
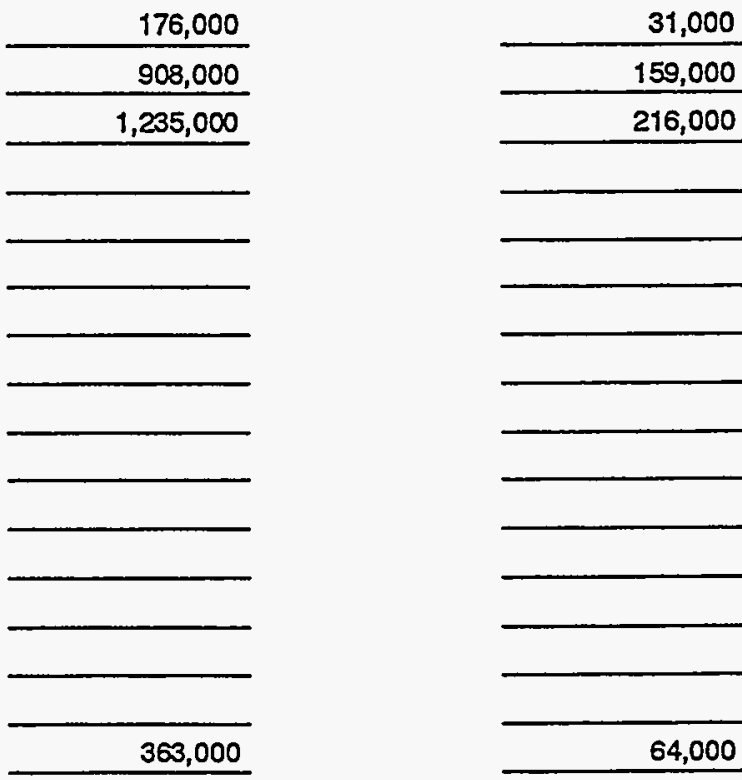

216,000
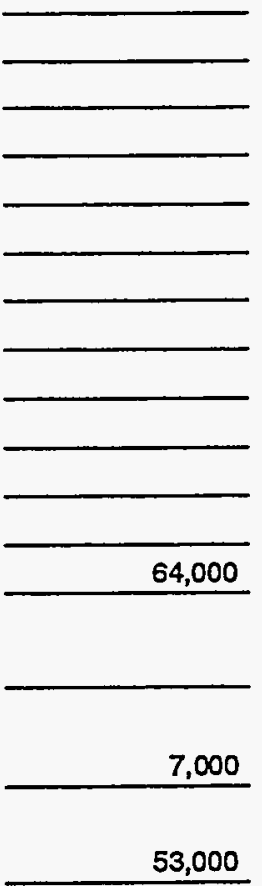

300,000

SUBTOTAL

$7 \%$ of Subwota

PROJECT CONTINGENCY

Management Reserve

Contingency 
Lockhood ldato Technologles Co.

Rev 10-94

Project

SNF DRY STORAGE PROJECT DRYSTORAGESYSTEM

Location

INEL/ICPP

Requester

R.C. HLL
DETAILED COST ESTIMATE SHEET

Type of Est. Conceptual Source (E) Eng. Est.

File No. 2314-B

Date

Prep'd By S.M. Bradford

(M) Vendar

(P) Pur. Order

(H) Handbook Ref.

9
+
+

\begin{tabular}{|c|c|c|c|c|c|c|c|c|c|c|c|}
\hline $\begin{array}{l}\text { ACCT. } \\
\text { NO. }\end{array}$ & DESCAPTION & $\begin{array}{l}E, V_{1} \\
P, H \\
\end{array}$ & $\begin{array}{l}\text { MAT'L } \\
\text { UNIT } \\
\end{array}$ & $\begin{array}{c}\text { MAT'LUT. } \\
\text { COST }\end{array}$ & $\begin{array}{c}\text { UNIT LAB. } \\
\text { HPS }\end{array}$ & $\begin{array}{c}\text { TOTAL } \\
\text { LAB. HAS. }\end{array}$ & $\begin{array}{l}\text { LABOR } \\
\text { PATE } \\
\end{array}$ & $\begin{array}{l}\text { LABOR } \\
\text { COST }\end{array}$ & $\begin{array}{l}\text { MAT'L } \\
\text { COST } \\
\end{array}$ & $\begin{array}{l}\text { OH\&P } \\
\text { COST } \\
\end{array}$ & $\begin{array}{l}\text { TOTAL } \\
\text { COST }\end{array}$ \\
\hline \multirow[t]{6}{*}{ DIV 1} & GENERAL REQUIREMENTS & & & & & & & & & & \\
\hline & Supervision & & 12 mnths & & 173 & 2,076 & 40.00 & 83,040 & & 24,912 & 107,952 \\
\hline & Training & & $10 \mathrm{ea}$ & & 80 & 800 & 40.00 & 32,000 & & 9,600 & 41,600 \\
\hline & Construction Fence & & $2,000 \mathrm{ft}$ & 10 & 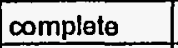 & & & & 20,000 & 6,000 & 26,000 \\
\hline & & & & & & & & & & & \\
\hline & TOTALDIVISION 1 - GENERAL REQUIREMENTS & & & & & & & 115,040 & 20,000 & 40,512 & 175,552 \\
\hline & & & & & & & & & & & \\
\hline \multirow[t]{23}{*}{ DIV 2} & SITEWORK & & & & & & & & & & \\
\hline & Surveying and Layout & & $1 \mathrm{bt}$ & 500 & 160 & 160 & 75.00 & 12,000 & 500 & 3,800 & 16,300 \\
\hline & & & & & & & & & & & \\
\hline & Clear and Grub - Total Area & & $196,926 \mathrm{sf}$ & 0.08 & $\infty$ mplete & & & & 15,754 & 4,700 & 20,454 \\
\hline & Compacted Pit Run Base - Total Pad & & $29,443 \mathrm{cy}$ & 8 & 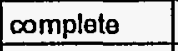 & & & & 235,544 & 70,700 & 306,244 \\
\hline & Excavation & & $3,958 \mathrm{cy}$ & 4 & complete & & & & 15,832 & 4,700 & 20,532 \\
\hline & Compacted Gravel Base - Below Asphall & & $724 \mathrm{cy}$ & 55 & complele & & & & 39,820 & 11,900 & 51,720 \\
\hline & Asphalt & & 724 bns & 60 & Complete & & & & 43,440 & 13,000 & 56,440 \\
\hline & Demolition / Removal of Existing Buildings & & $256,500 \mathrm{cf}$ & 0.45 & complete & & & & 115,425 & 34,600 & 150,025 \\
\hline & Chain Lirk Fence - 8 & & $1,587 \mathrm{ft}$ & 20 & Complete & & & & 31,740 & 9,500 & 41,240 \\
\hline & Remove Existing Fence & & $752 \mathrm{ft}$ & 17 & Complete & & & & 12,784 & 3,800 & 16,584 \\
\hline & & & & & & & & & & & \\
\hline & & & & & & & & & & & \\
\hline & Existlng FW Line - Abandon In Place & & $1 \mathrm{bt}$ & 2,600 & complete & & & & 2,600 & 800 & 3,400 \\
\hline & Trench Excavation / Backfill & & $1,600 \mathrm{cy}$ & 18 & complete & & & & 28,800 & 8,600 & 37,400 \\
\hline & Re-routed FW Line - 10" w/Fittings, Hydant & & $500 \mathrm{ft}$ & 38 & complete & & & & 19,000 & 5,700 & 24,700 \\
\hline & YardFire Potection w/ Hydants & & $600 \mathrm{ft}$ & 42 & complete & & & & 25,200 & 7,600 & 32,800 \\
\hline & Trench Excavation / Backfill & & $1.950 \mathrm{cy}$ & 18 & Complete & & & & 35,100 & 10,500 & 45,600 \\
\hline & & & & & & & & & & & \\
\hline & Mob and Demob & & $1 \mathrm{bt}$ & & & & & & & 82,344 & 82,344 \\
\hline & Sbrm Water Pollution Prevenlion Plan & & $1 \mathrm{bt}$ & 500 & 40 & 40 & 35.00 & 1,400 & 500 & 600 & 2,500 \\
\hline & 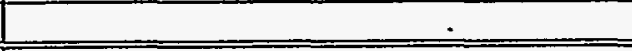 & & & & & & & & & & \\
\hline & TOTALDIV 2 - SITEWORK & & & & & 200 & & 13,400 & 622,039 & 272,844 & 908,283 \\
\hline
\end{tabular}


Project

SNF DRY STORAGE PROJECT DRY STORAGESYSTEM

\begin{tabular}{|c|c|c|c|c|c|c|c|c|c|c|c|}
\hline $\begin{array}{l}\text { ACCT. } \\
\text { No. }\end{array}$ & DESCRPTION & $\begin{array}{l}\text { E,V, } \\
\text { P.H }\end{array}$ & $\begin{array}{l}\text { MAT'L } \\
\text { UNIT } \\
\end{array}$ & $\begin{array}{c}\text { MAT'LUT. } \\
\text { COST }\end{array}$ & $\begin{array}{c}\text { UNIT LAB. } \\
\text { HPS }\end{array}$ & $\begin{array}{c}\text { TOTAL } \\
\text { LAB. HRS. }\end{array}$ & $\begin{array}{l}\text { LABOR } \\
\text { RATE }\end{array}$ & $\begin{array}{l}\text { LABOR } \\
\text { COST }\end{array}$ & $\begin{array}{l}\text { MAT'L } \\
\text { COST }\end{array}$ & $\begin{array}{c}\text { OH\&P } \\
\text { COST }\end{array}$ & $\begin{array}{l}\text { TOTAL } \\
\text { COST }\end{array}$ \\
\hline \multirow[t]{14}{*}{ DIV 3} & CONCRETE & & & & & & & & & & \\
\hline & Concrete Basemat and Approach Slabs & & $3,477 \mathrm{cy}$ & 65 & & & & & 226,005 & 67,802 & 293,807 \\
\hline & Roinbrcing & & $335,000 \mathrm{lb}$ & 0.2 & 0.006 & 2,010 & 32.67 & 65,667 & 67,000 & 39,800 & 172,467 \\
\hline & Formwork & & $4.700 \mathrm{sf}$ & 0.45 & 0.08 & 376 & 32.67 & 12,284 & 2,115 & 4,320 & 18,719 \\
\hline & Mechanically Place & & $3,477 \mathrm{cy}$ & 51 & $\infty$ mplete & & & & 177,327 & 53.198 & 230,525 \\
\hline & & & & & & & & & & & \\
\hline & ShleldWalls & & $1,504 \mathrm{cy}$ & 65 & 0.505 & 760 & 32.67 & 24,814 & 97,760 & 36,772 & 159,346 \\
\hline & Snap Tles and Grout Holes & & $18,800 \mathrm{sf}$ & 1.5 & & & & & 28,200 & 8.460 & 36,660 \\
\hline & Relnforcing & & $169,000 \mathrm{lb}$ & 0.2 & 0.008 & 1,352 & 32.67 & 44,170 & 33,800 & 23,391 & 101,361 \\
\hline & Formwork & & 37.600 sf & 0.66 & 0.087 & 3,271 & 32.67 & 106,870 & 24,816 & 39,506 & 171,192 \\
\hline & Mechanically Place & & $1,504 \mathrm{cy}$ & 25 & 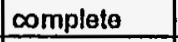 & & & & 37,600 & 11,280 & 48,880 \\
\hline & Engineering - Forms / Shoring & & $1 \mathrm{bt}$ & 1,500 & & & & & 1,500 & 500 & 2,000 \\
\hline & & & & & & & & & & & \\
\hline & TOTALDIV 3 - CONCRETE & & & & & 7,769 & & 253,804 & 696,123 & 285,028 & $1,234,955$ \\
\hline & & & & & & & & & & & \\
\hline & & & & & & & & & & & \\
\hline \multirow[t]{14}{*}{ DIV 16} & ELECTRCAL & & & & & & & & & & \\
\hline & Power b Perimeler Lighting - b DTC & & $500 \mathrm{ft}$ & 30 & complete & & & & 15,000 & 4,500 & 19,500 \\
\hline & Perimeter Lighting & & $1,902 \mathrm{It}$ & 100 & complete & & & & 190,200 & 57,100 & 247,300 \\
\hline & Intusion Delection System - Re-Us TMl-2 Trans & ver Mo & les / Enclosures & & & & & & & & \\
\hline & Cable Set and Accessorles - $276 \mathrm{ft}$ & & 2 ea & 3,482 & & & & & 6,964 & 1,800 & 8,764 \\
\hline & Cable Set and Accossories - $675 \mathrm{ft}$ & & $2 \mathrm{ea}$ & 6,964 & & & & & 13.928 & 3.700 & 17,628 \\
\hline & Contol Module - Located in DTC & & $1 \mathrm{ea}$ & 29,420 & & & & & 29,420 & 7,800 & 37,220 \\
\hline & Interlace Hardware, Misc, Installation of System & & $1 \mathrm{bt}$ & 11,808 & 64 & 64 & 31.60 & 2,022 & 11,808 & 3,700 & 17,530 \\
\hline & Tie- $\ln$ b DTC & & $500 \mathrm{ft}$ & 24 & complete & & & & 12,000 & 3,200 & 15,200 \\
\hline & & & & & & & & & & & \\
\hline & & & & & & & & & & & \\
\hline & & & & & & & & & & & \\
\hline & & & & & & & & & & & \\
\hline & TOTALDIV 16 - ELECTACAL & & & & & 64 & & & 279.320 & 81,800 & 363,142 \\
\hline
\end{tabular}


Project SNF DRY STORAGEPROJECT DRY STORAGESYSTEM

\begin{tabular}{|c|c|c|c|c|c|c|c|c|c|c|c|}
\hline $\begin{array}{l}\text { ACCT. } \\
\text { No. }\end{array}$ & DESCAPTION & $\begin{array}{l}E, V, \\
P, H\end{array}$ & $\begin{array}{l}\text { MAT'L } \\
\text { UNIT }\end{array}$ & $\begin{array}{c}\text { MAT'LUT. } \\
\text { COST }\end{array}$ & $\begin{array}{c}\text { UNIT LAB. } \\
\text { HRS }\end{array}$ & $\begin{array}{c}\text { TOTAL } \\
\text { LAB. HRS. }\end{array}$ & $\begin{array}{l}\text { LABOR } \\
\text { RATE }\end{array}$ & $\begin{array}{l}\text { LABOR } \\
\text { COST }\end{array}$ & $\begin{array}{l}\text { MAT'L } \\
\text { COST }\end{array}$ & $\begin{array}{l}\mathrm{OH} \& \mathrm{P} \\
\text { COST }\end{array}$ & $\begin{array}{l}\text { TOTAL } \\
\text { COST }\end{array}$ \\
\hline & \multicolumn{11}{|c|}{ ADMINISTRATIVECOSTS ASSOCIATED WITH STORAGE YAFD - ONLY - DOES NOTINCWUDE HSMS ORDPCS } \\
\hline & & & & & & & & & & & \\
\hline & ENGINEEANG/DESIGN & & & & & & & & & & \\
\hline & Civil/sructural & & 4 dwgs & 3,500 & complete & & & 14,000 & & & 14,000 \\
\hline & Mechanical & & $3 \mathrm{dwgs}$ & 3,500 & complete & & & 10,500 & & & 10,500 \\
\hline & Electical / Security & & 15 dwgs & 5,000 & complete & & & 75,000 & & & 75,000 \\
\hline & & & & & & & & & & & \\
\hline & & & & & & & & & & & \\
\hline & INSPECTION & & & & & & & & & & \\
\hline & Titls III Inspection - IFTE & & 12 mnths & & 113 & 1,350 & 62.00 & 83,700 & & & 83,700 \\
\hline & Compaction / Testing - .25 FTE & & $12 \mathrm{mnths}$ & & 38 & 450 & 62.00 & 27,900 & & & 27.900 \\
\hline & & & & & & & & & & & \\
\hline & & & & & & & & & & & \\
\hline & PROJECT MANAGEMENT & & & & & & & & & & $\cdot \dot{+}$ \\
\hline & Project Management & & $24 \mathrm{mnths}$ & & 300 & 7,200 & 74.00 & 532,800 & & & 532,800 \\
\hline & Prolect Suppt - Cost Estimating, Quality, Safety, ESD & & 24 mnths & & 150 & 3,600 & 74.00 & 266,400 & & & 286,400 \\
\hline & SAR - Covered under other portions of this $U$ & & & & & & & & & & \\
\hline & NAC Application - Covered under other portions of th & is 4 & & & & & & & & & \\
\hline & NAC Fee - Covered under other portions of this $L$ & & & & & & & & & & \\
\hline & & & & & & & & & & & \\
\hline & CONSTAUCTON MANAGEMENT & & & & & & & & & & \\
\hline & Construction Coordination & & $12 \mathrm{mnth}$ & & 38 & 450 & 61.00 & 27,450 & & & 27,450 \\
\hline & Field Enginea & & $12 \mathrm{mnth}$ & & 38 & 450 & 56.00 & 25,200 & & & 25,200 \\
\hline & Construction Support & & $12 \mathrm{mnth}$ & & 75 & 900 & 56.00 & 50,400 & & & 50,400 \\
\hline & CM Pool Account & & $1 \mathrm{bt}$ & & & 1.800 & 26.00 & 46,800 & & & 46,800 \\
\hline & & & & & & & & & & & \\
\hline & & & & & & & & & & & \\
\hline & & & & & & & & & & & \\
\hline
\end{tabular}


Project

SNF DRY STORAGE PROJECT DRY STORAGE SYSTEM

Location INEL/ICPP

Requestor R. C. HILL
Type \& Est. Conceptual

File No. 2314-B
Date

Prep'd By S.M. Bradford

\begin{tabular}{|c|c|c|c|c|c|c|c|c|c|c|}
\hline \multicolumn{8}{|c|}{ PROBABLE \% VARIATION } & \multicolumn{2}{|c|}{$\begin{array}{c}\text { PROJECT } \\
\text { CONTINGENCY }\end{array}$} & SUMMARY \\
\hline \multirow[t]{2}{*}{ Cost Estimate Element } & \multirow[t]{2}{*}{$\begin{array}{l}\text { Unescalated } \\
\text { Cost }\end{array}$} & \multirow{2}{*}{$\begin{array}{c}\% \\
\text { Total } \\
\text { Cost }\end{array}$} & \multicolumn{2}{|c|}{$\begin{array}{l}\text { Prob\% Var } \\
\text { From Est }\end{array}$} & \multicolumn{2}{|c|}{ WT $\%$ of Prob } & \multirow[t]{2}{*}{ Contingency } & \multirow[t]{2}{*}{$\%$} & \multirow[t]{2}{*}{ Cost } & \multirow{2}{*}{$\begin{array}{l}\text { DirectCost } \\
\text { with } \\
\text { Contingency }\end{array}$} \\
\hline & & & - & + & - & + & & & & \\
\hline The I and II Design & 100,000 & 2 & 5.00 & 1000 & 0.10 & 0.21 & $0.17 \%$ & $0.99 \%$ & 8,000 & 108,000 \\
\hline Tite III Inspection & 112,000 & 2 & 5.00 & 1000 & 0.12 & 0.23 & $0.20 \%$ & $1.11 \%$ & 9,000 & 121,000 \\
\hline Project Management & 799,000 & 16 & 5.00 & 7.00 & 0.82 & 1.15 & $0.95 \%$ & $5.40 \%$ & 45000 & 844,000 \\
\hline Construetion Masagement & 150,000 & 3 & 5.00 & 8.00 & 0.15 & 0.25 & $0.21 \%$ & $1.17 \%$ & 10000 & 160,000 \\
\hline General Requirements & 176,000 & 4 & 5.00 & 2500 & 0.18 & 0.91 & $0.80 \%$ & $4.51 \%$ & 38000 & 214,000 \\
\hline Slbwak & 908,000 & 19 & 5.00 & 3000 & 0.93 & 5.51 & $4.95 \%$ & $2805 \%$ & 235,000 & $1,144,000$ \\
\hline Conerete & $1,235,000$ & 25 & 5.00 & 20.00 & 1.27 & 5.08 & $4.45 \%$ & $25.19 \%$ & 212,000 & $1,447,000$ \\
\hline \multicolumn{11}{|l|}{ Masonry } \\
\hline \multicolumn{11}{|l|}{ Metals } \\
\hline \multicolumn{11}{|l|}{ Wood and Plastles } \\
\hline \multicolumn{11}{|l|}{ Molsture Protection } \\
\hline \multicolumn{11}{|l|}{ Doors and Wndows } \\
\hline \multicolumn{11}{|l|}{ Finishes } \\
\hline \multicolumn{11}{|l|}{ Specialties } \\
\hline \multicolumn{11}{|l|}{ Equlpment } \\
\hline \multicolumn{11}{|l|}{ Furnlshings } \\
\hline \multicolumn{11}{|l|}{ Special Construction } \\
\hline \multicolumn{11}{|l|}{ Convoying Systems } \\
\hline \multicolumn{11}{|l|}{ Mecthanical } \\
\hline Electrical & 363,000 & 7 & 5.00 & 2500 & 0.37 & 1.87 & $1.64 \%$ & $9.31 \%$ & 78000 & 441,000 \\
\hline \multicolumn{11}{|l|}{ GFE } \\
\hline Procurement Fees & 40,000 & 1 & 5.00 & 20.00 & 0.04 & 0.16 & $0.14 \%$ & $0.82 \%$ & 7,000 & 47000 \\
\hline G\&A & 300,000 & 6 & 5.00 & 2000 & 0.31 & 1.23 & $1.08 \%$ & $6.12 \%$ & 51,000 & 351,000 \\
\hline Escalation & 676,000 & 14 & 5.00 & 2500 & 0.70 & 3.48 & $3.05 \%$ & $1733 \%$ & 147,000 & 823,000 \\
\hline Subtotal & $4,859,000$ & 100 & .9 & 3 & 5 & 20 & का & m & $\mathrm{AP}$ & A \\
\hline Calculated Conthgency & 857,857 & m. & $\therefore$ & आ & $\because \%$ & ओ & $1766 \%$ & $\therefore \because \because \because \quad \because$ & मn। & 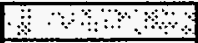 \\
\hline Resultant TEC & $5,716,957$ & $\because \ldots: \because \cdots$ & $\%$ & $\because \therefore$ & m & iसा & \%म & $\therefore$ & सम & 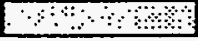 \\
\hline Rounded TEC & $5,700,000$ & ओ & $\therefore+$ & $\because \cdots$ & औ. & $\because \mathrm{min}$ & \%? & $\because \cdots \cdots$ & 3 & and \\
\hline Project Contingency & 841,000 & @ि & $\therefore$ & $\because \div 8$ & $\Leftrightarrow$ & $\because \%$ & $1731 \%$ & $\because \mathrm{O}$ & an & BA \\
\hline Risk to Project & $\because \div: \because: \because 1$ & $\therefore$ & $\therefore \quad \therefore$ & $\because \because$ & $\because: 1$ & $\because \div$ & $18.35 \%$ & $\because \because$ & $\because \because \cdots$ & 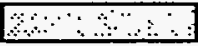 \\
\hline Management Reserve - & 355,000 & $\because \therefore \dot{\square}$ & $\because$ & $\therefore \ldots$ & $\because \because$ & $\because 3$ & $1000 \%$ & 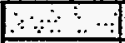 & म्य & an: \\
\hline Contingeney * & 486,000 & $\because \because \because$ & $\because$ & 1 & $\because \cdots$ & मी & की & $\because \because \because \because \because$ & ara & an \\
\hline Total & $5,700,000$ & $3 \because$ & $\therefore \quad \therefore$ & $\because \cdots:$ & $\because$ & 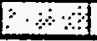 & आ & ओ & 841,000 & 5.700 .000 \\
\hline
\end{tabular}

CONFDENCE LEVEL AND ASSUMED RISKS:

The Lockheed Idaho Technologies Co. Cost Estimate Contingency Analysis Model is based on the applied contingency and the assumptions upon which the estimate was predicated. The model is applied with a suggested risk level of $18 \%$ and a bevel of confidence of $90 \%$ the estimate will kall within the bid range. The Contingency Analysis is based on a weighted average to provide a $90 \%$ probablilty of underrun and $10 \%$ probablity of overrun.

- The calculated Management Reserve and Contingency amounts include Escalation.
CONTINGENCY ANALYSIS GUIDE BY TYPE OF ESTIMATE: Guidelines established by DOE/FM-50, Cost Estimating Guide, Vol. 6 . Cost Guide, and as presented in the INE Cost Estimating Guide. PLANNING Experimental/Special Conditions Up to $50 \%$ CONCEPTUAL

Experimental /Special Conditions TITLEI

$15 \%-25 \%$

Up to $40 \%$

$10 \%-20 \%$

$5 \%-15 \%$

TITLE II

TILEII/AFC 
Lockheedidaho Techndogies Co.

Rev01-96
ESCALATION SHEET

Type of Est.

Fle No. 2314-B
Date

Prepared By S.M. Bradford
Location DAY STORAGE SYSTEM

Requester

\section{INEL/ICPP}

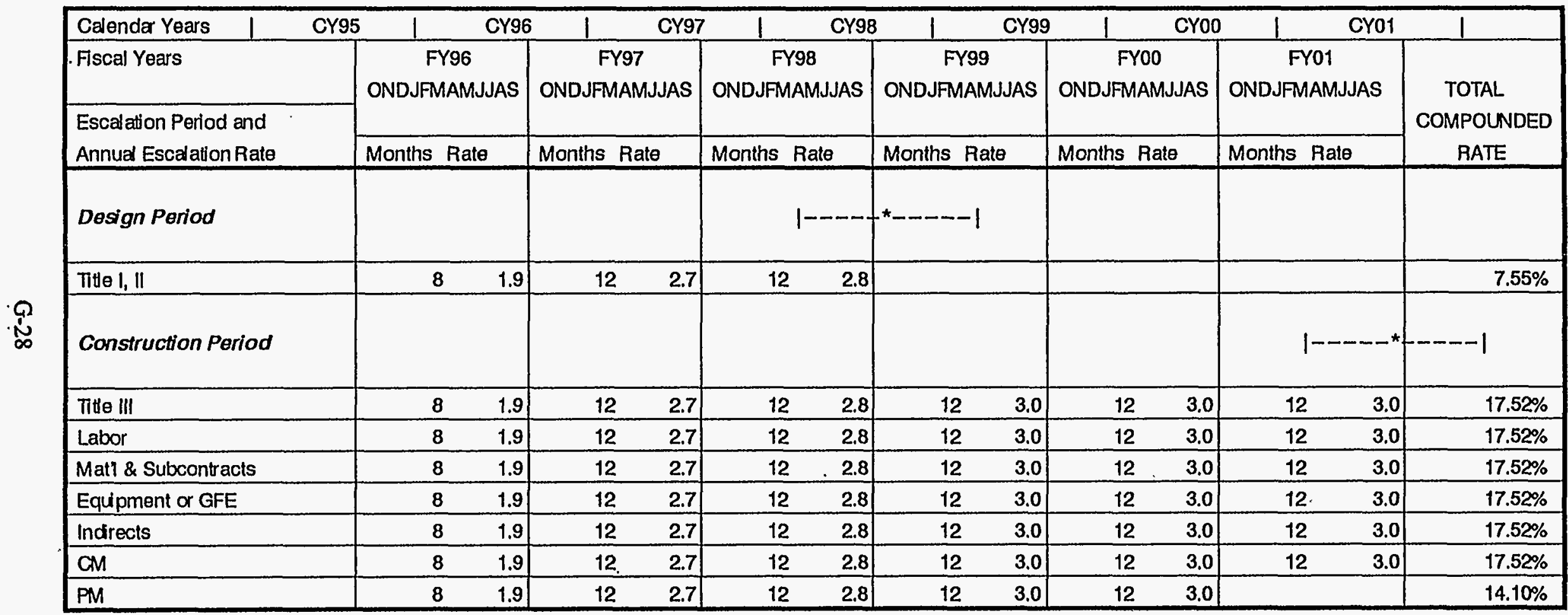

Departmenta Price Change Index - FY 1998 Guidance - Antidpated Economic Escalation Rates - Defense Programs \& Genera Construction.

\begin{tabular}{|c|c|c|c|c|c|c|}
\hline$\%$ Change/Composite Rate & 2.8 & 2.7 & 2.8 & 3.0 & 3.0 & 3.0 \\
\hline
\end{tabular}

Departmenta Price Change Index - FY 1998 Guidance - Antidpated Economic Escalation Rates - Emironmental Restoration.

\begin{tabular}{|c|c|c|c|c|c|c|}
\hline \% Change/Composite Rate & 3.4 & 3.0. & 3.1 & 3.2 & 3.3 & 3.4 \\
\hline \multicolumn{7}{|c|}{ Departmenta Price Change Index - FY 1998 Guidance - Anticipated Economic Escd ation Rates - Waste Management. } \\
\hline \% Change/Composite Rate & 3.2 & 2.9 & 3.0 & 3.0 & 3.1 & 3.2 \\
\hline
\end{tabular}

*It will be the responsibility of the estimator to determine the appropriate escalation rate to use, based on project funding and type. 
Rev 01-96

Project

SNF DRY STORAGE PROJECT DRY STORAGE SYSTEM

Requester INEL / ICPP
Type of Est Conceptual File No 2314-B Prep'd By S.M. Bradford

Escalation $1 \%$ of Comstruetion Cost and GFE

$\begin{array}{r}22,000 \\ \hline 18,000 \\ \hline\end{array}$

Unescalated ENGINEERING, DESIGN AND INSPECTION

$$
\begin{aligned}
& \text { Title I and II Design } \\
& \text { Title III Inspection }
\end{aligned}
$$

MANAGEMENT

Project Management

Construction Management

\section{CONSTRUCTION}

Div 1. General Requirements

Div 2 Sitework

Div 3 Concrete

Div 4 Masonry

Div 5 Metals

Div 6 Wood and Plastics

Div 7 Moisture Protection

Div 8 Doors and Windows

Div 9 Finishes

Div 10 Specialties

Div 11 Equipment

Div 12 Furnishings

Div 13 Special Construction

Div 14 Conveying Systems

Div 15 Mechanical

Div 16 Electrical

GOV'T FURNISHED EQUIPMENT

PROCUREMENT FEES

G\&A

SUBTOTAL

PROJECT CONTINGENCY

Management Reserve

Contingency

TOTAL ESCALATION

$\begin{array}{r}104,000 \\ \hline 62,000 \\ \hline\end{array}$

$5,931,000$

$1,689,000$

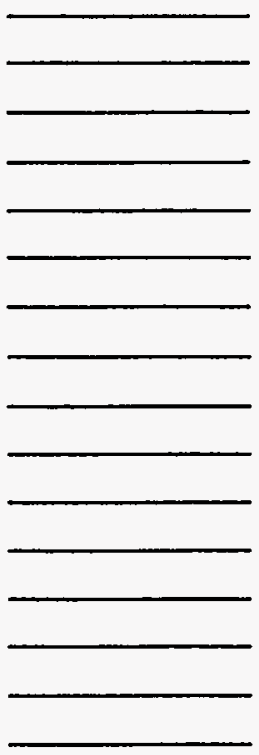

$26,645,000$

400,000

$1,600,000$

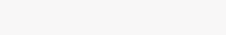

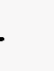

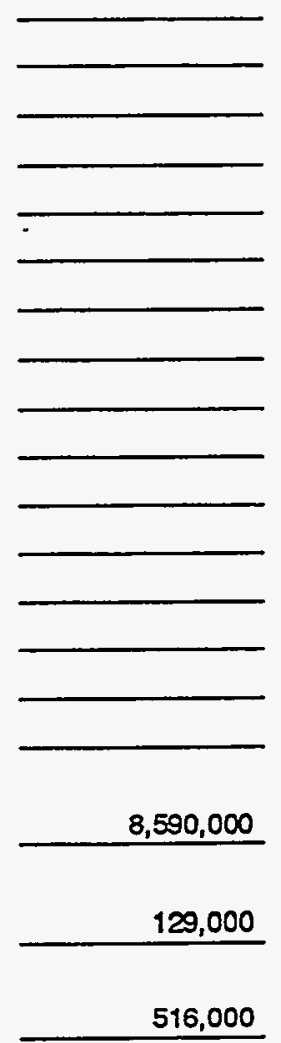

$17 \%$ ofSubcotal

923,000

$3,806,000$
Date Chk'd By

Appr'd By

Totals 206,000

$7,020,000$

$06 / 14 / 96$

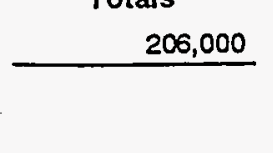

$35,235,000$

529,000

$2,116,000$

$45,706,000$

$7,594,000$ 
Rev 10-94

Page 4 of 18

Project

SNF DRY STORAGE PROJECT DRY STORAGESYSTEM

\begin{tabular}{|c|c|c|c|c|c|c|c|c|c|c|c|}
\hline $\begin{array}{l}\text { ACCT. } \\
\text { No. }\end{array}$ & DESCAIPTION & $\begin{array}{l}E, V, \\
P, H \\
\end{array}$ & $\begin{array}{l}\text { MAT'L } \\
\text { UNIT }\end{array}$ & $\begin{array}{c}\text { MAT'LUT. } \\
\text { COST }\end{array}$ & $\begin{array}{c}\text { UNIT LAB. } \\
\text { HAS }\end{array}$ & $\begin{array}{c}\text { TOTAL } \\
\text { LAB. HRS. }\end{array}$ & $\begin{array}{l}\text { LABOR } \\
\text { RATE }\end{array}$ & $\begin{array}{l}\text { LABOR } \\
\text { COST }\end{array}$ & $\begin{array}{l}\text { MAT'L } \\
\text { COST }\end{array}$ & $\begin{array}{l}\text { OH \& P } \\
\text { COST } \\
\end{array}$ & $\begin{array}{l}\text { TOTAL } \\
\text { COST }\end{array}$ \\
\hline & \multicolumn{11}{|c|}{ ADMINISTRATIVECOSTS ASSOCIATED WITH HSMS Or DPCS - ONLY - DOES NOT INCLUDE ANY YARD WORK } \\
\hline & & & & & & & & & & & \\
\hline & ENGINEERNG / DESIGN & & & & & & & & & & \\
\hline & Performance Speclfication - Storage Modules & & 1 ea & & 200 & 200 & 74.00 & 14,800 & & & 14,800 \\
\hline & \multicolumn{3}{|c|}{ Performance Specification - Canister Assembly - by Fuel Type } & & & & & & & & \\
\hline & Shipping Port PWR - C2 & & 1 ea & & 200 & 200 & 74.00 & 14,800 & & & 14,800 \\
\hline & FSVA & & 1 ea & & 200 & 200 & 74.00 & 14,800 & & & 14,800 \\
\hline & Pathlinder & & 1 ea & & 200 & 200 & 74.00 & 14,800 & & & 14,800 \\
\hline & Shipping Port LWBR & & 1 ea & & 200 & 200 & 74.00 & 14,800 & & & 14,800 \\
\hline & PBF Driver - 5t/62 Rod & & ফ, , & $\%$ & \% \% & \%ै। & & & & & \\
\hline & PBF Driver - $34 / 46 / 49$ Pod & & 1०० & २ै२? & $13 \%$ & का: & & & & & \\
\hline & PBF Drive -28 Fod & & १ै। & \%. & ॥ం। & m! & & & & & \\
\hline & Peachbottom - Core 1 & & $1 \mathrm{ea}$ & & 200 & 200 & 74.00 & 14,800 & & & 14,800 \\
\hline & Peachbottom - Core 2 & & 1 ea & & 200 & 200 & 74.00 & 14,800 & & & 14.800 \\
\hline & Treat & & ४४\%\% & ४। & ४४ & आसे & & & & & \\
\hline & Triga - BERII - Germany & & १७? & ২४। & १ै। & ४४खा & & & & & \\
\hline & Triga - Standard - $20 \%$ Enr. & & ४४४४, & $2+3$ & ॥४ः & ४ै: & & & & & \\
\hline & Triga $-70 \%$ Enr. & & $1 \%, \%$ & ४४४। & ४०, & Pै। & & & & & \\
\hline & Triga - Fllp - 70\% Enr. & & \%४४४४ & $1 \% 1$ & 1ै\% & $1 \% 13$ & & & & & \\
\hline & FRR Triga $-93 \%$ Enr. & & $1 \% 1 \%$ & $\%$ & $\% \%$ & \% & & & & & \\
\hline & ACRR & & 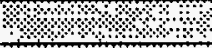 & 3n! & $8 \%$ & 1\%? & & & & & \\
\hline & & & $\%, \%$ & मे। & १९। & २७० & & & & & \\
\hline & Candu - 168" bng & & +W, & \%० & 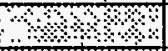 & $10+\%$ & & & & & \\
\hline & Dresden & & १४७? & $3+4$ & की & \%?+: & & & & & \\
\hline & Pulstar - Buffalo & & खा & का & - & २ै। & & & & & \\
\hline & Pulstar - N.C. Stato Univ & & 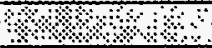 & +13 & ও২ & अू & & & & & \\
\hline & Pulsta - Suny - Bulfab & & ४४४: & 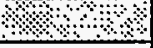 & अै? & \$ै। & & : & & & \\
\hline & & & & & & & & & & & \\
\hline & & & & & & & & & & & \\
\hline & SUBTOTALENGINEERING /DESIGN & & & & & & & & & & 103.600 \\
\hline
\end{tabular}


Rev 10-94

Page 5 of 18

Type of Est. Conceptual

Project

SNF DRY STORAGE PROJECT DAYSTORAGESYSTEM

\begin{tabular}{|c|c|c|c|c|c|c|c|c|c|c|c|}
\hline $\begin{array}{l}\text { ACCT. } \\
\text { NO. }\end{array}$ & DESCAPTION & $\begin{array}{l}\text { E.V, } \\
\text { P.H }\end{array}$ & $\begin{array}{l}\text { MAT'L } \\
\text { UNIT }\end{array}$ & $\begin{array}{c}\text { MAT'LUT. } \\
\text { COST }\end{array}$ & $\begin{array}{c}\text { UNIT LAB. } \\
\text { HRS }\end{array}$ & $\begin{array}{c}\text { TOTAL } \\
\text { LAB. HRS. } \\
\end{array}$ & $\begin{array}{l}\text { LABOR } \\
\text { RATE }\end{array}$ & $\begin{array}{l}\text { LABOR } \\
\text { COST }\end{array}$ & $\begin{array}{l}\text { MAT'L } \\
\text { COST }\end{array}$ & $\begin{array}{l}\text { OH\& P } \\
\text { COST }\end{array}$ & $\begin{array}{l}\text { TOTAL } \\
\text { COST }\end{array}$ \\
\hline & INSPECTION & & & & & & & & & & \\
\hline & Installation of Modules - by Fuel Type & & & & & & & & & & \\
\hline & Shipping Port PWR - C1/C2 & & 3 ea & & 20 & 60 & 62.00 & 3,720 & & - & 3,720 \\
\hline & FSVR & & 22 ea & & 20 & 440 & 62.00 & 27,280 & & & 27.280 \\
\hline & Pathlinder - included w/FSVR & & m & खि & औा & ओ खा & & & & & \\
\hline & Shipping Port LWBR & & $16 \mathrm{ea}$ & & 20 & 320 & 62.00 & 19,840 & & & 19,840 \\
\hline & PBF Driver $-51 / 62$ Pod & & 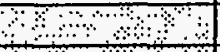 & 3 & अ. & $4 \quad+\infty$ & & & & & \\
\hline & PBF Drivar - $34 / 46 / 49$ Rod & & 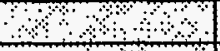 & m: & 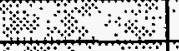 & - & & & & & \\
\hline & PBF Driver - 28 Rod & & आn & \$ి & $3+2$ & an & & & & & \\
\hline & Peachbottom - Core 1 & & 1 ea & & 20 & 20 & 62.00 & 1,240 & & & 1.240 \\
\hline & Peachbottom - Core 2 & & $8 \mathrm{ea}$ & & 20 & 160 & 62.00 & 9.920 & & & 9,920 \\
\hline & Treat & & 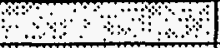 & 4 & - & : & & & & & \\
\hline & Triga - BERII - Germany & & खिए & \% & +1 & 3 & & & & & \\
\hline & Triga - Standard - 20\% Enr. & & H. $: 3$ & ४४ & ४० & की & & & & & \\
\hline & Triga - 70\% Enr. & & आ। & । & ४४ $\cdot$ & (3) & & & & & \\
\hline & Triga - Flip - $70 \%$ Enr. & & आम & 23 & ४ि। & $\because 3$ & & & & & \\
\hline & FRR Triga $-93 \%$ Enr. & & ४ आ & 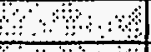 & अ & $\because \quad \therefore$ & & & & & \\
\hline & ACRR & & आ। & ब & अा & n & & & & & \\
\hline & & & +2 & ४४ & अ, & $\because \mathrm{bu}$ & & & & & \\
\hline & Candu - 168" bng & & अ, & मा & १ै: & a $\div \cdot$ & & & & & \\
\hline & Dresden & & ? & आम & का & $\therefore$ & & & & & \\
\hline & Pulstar - Buffalo & & का & 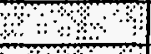 & ! & $\because \cdots$ & & & & & \\
\hline & Pulstar - N.C. State Univ & & 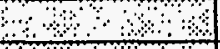 & मा: & $\because 4$ & $\therefore \because \because$ & & & & & \\
\hline & Pulstar - Suny - Bullab & & Ha & खा & $3 \square$ & $\because \quad \cdots$ & & & & & \\
\hline & $T$ & & & & & & & & & & \\
\hline & & & & & & & & & & & \\
\hline & & & & & & & & & & & \\
\hline & - & & & & & & & - & & & \\
\hline & & & & & & & & & & & \\
\hline & SUBTOTALINSPECTION & & & & & & & & & & 62,000 \\
\hline
\end{tabular}


Page 6 of 18

Type of Est. Conceptual

SNF DRY STORAGE PROJECT DRYSTORAGESYSTEM

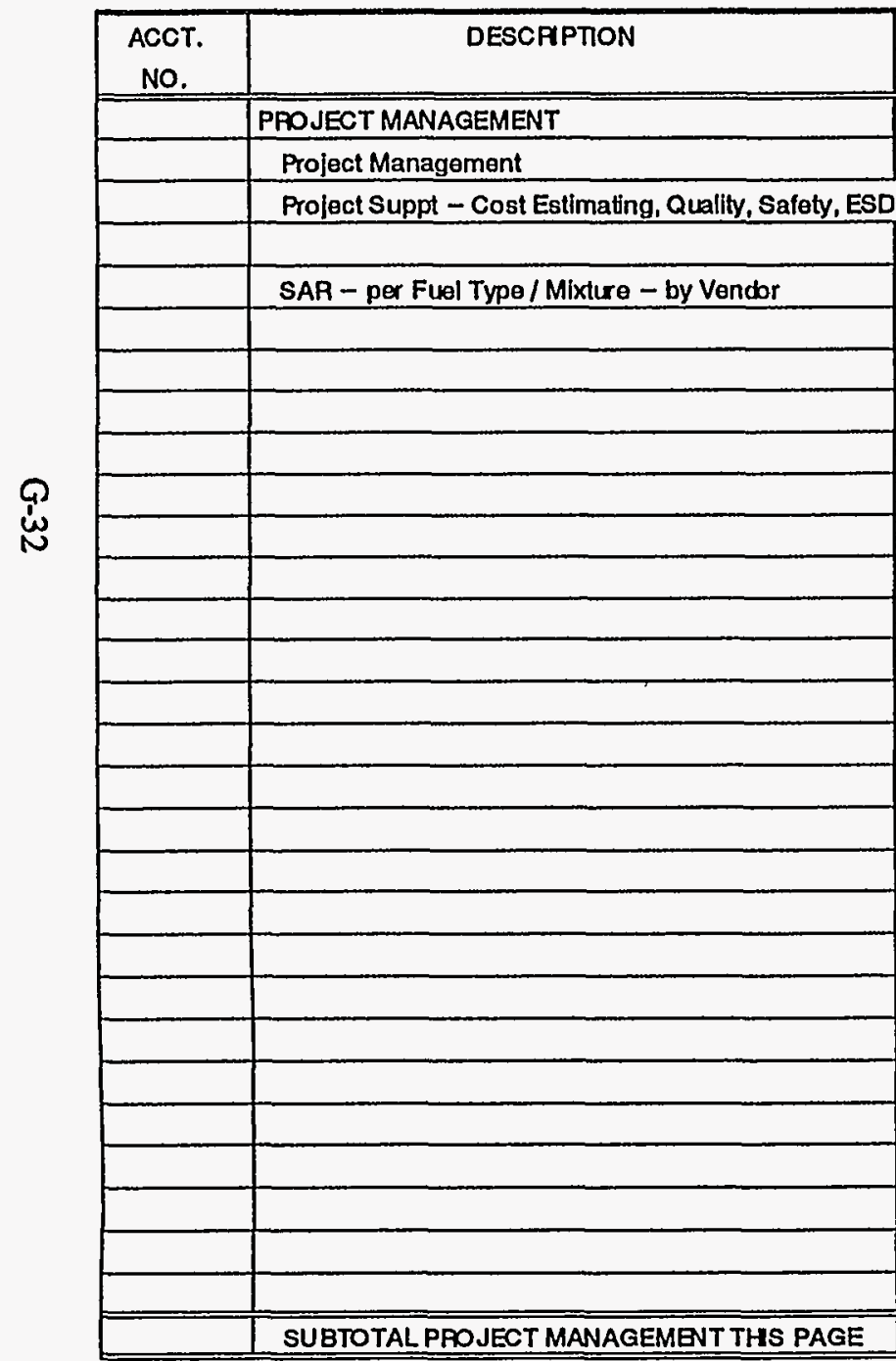

\begin{tabular}{|c|c|c|c|c|c|c|c|c|c|}
\hline $\begin{array}{l}E, V, \\
P, H\end{array}$ & $\begin{array}{l}\text { MAT'L } \\
\text { UNIT }\end{array}$ & $\begin{array}{c}\text { MAT'LUT. } \\
\text { COST }\end{array}$ & $\begin{array}{c}\text { UNIT LAB. } \\
\text { HAS }\end{array}$ & $\begin{array}{c}\text { TOTAL } \\
\text { LAB. HRS. }\end{array}$ & $\begin{array}{l}\text { LABOR } \\
\text { RATE }\end{array}$ & $\begin{array}{l}\text { LABOR } \\
\text { COST }\end{array}$ & $\begin{array}{l}\text { MAT'L } \\
\text { COST } \\
\end{array}$ & $\begin{array}{r}\text { OH\&P } \\
\text { COST }\end{array}$ & $\begin{array}{l}\text { TOTAL } \\
\text { COST }\end{array}$ \\
\hline & & & & & & & & & \\
\hline & 96 mnths & & 225 & 21,600 & 74.00 & $1,598,400$ & & & $1,598,400$ \\
\hline c & 96 mnths & & 75 & 7,200 & 74.00 & 532,800 & & & 532,800 \\
\hline & & & . & & & & & & \\
\hline & & & & & & & & & \\
\hline & & & & & & & & & \\
\hline & & & & & & & & & \\
\hline & & & & & & & & & \\
\hline & & & & & & & & & \\
\hline & & & & & & & & & \\
\hline & & & & & & & & & \\
\hline & & & & & & & & & \\
\hline & & & & & & & & & \\
\hline & & & & & & & & & \\
\hline & & & & & & & & & \\
\hline & & & & & & & & & \\
\hline & & & & & & & & & \\
\hline & & & & & & & & & \\
\hline & & & & & & & & & \\
\hline & & & & & & & & & \\
\hline & & & & & & & & & \\
\hline & & & & & & & & & \\
\hline & & & & & & & & & \\
\hline & & & & & & & & & \\
\hline & & & & & & & & & \\
\hline & & & & & & & & & \\
\hline & & & & & & & & & \\
\hline & & & & & & & & & \\
\hline & & & & & & & & & \\
\hline & & & & & & $2,131,200$ & & & $2,131,200$ \\
\hline
\end{tabular}


Project

SNF DRY STORAGE PROJECT DAY STORAGESYSTEM

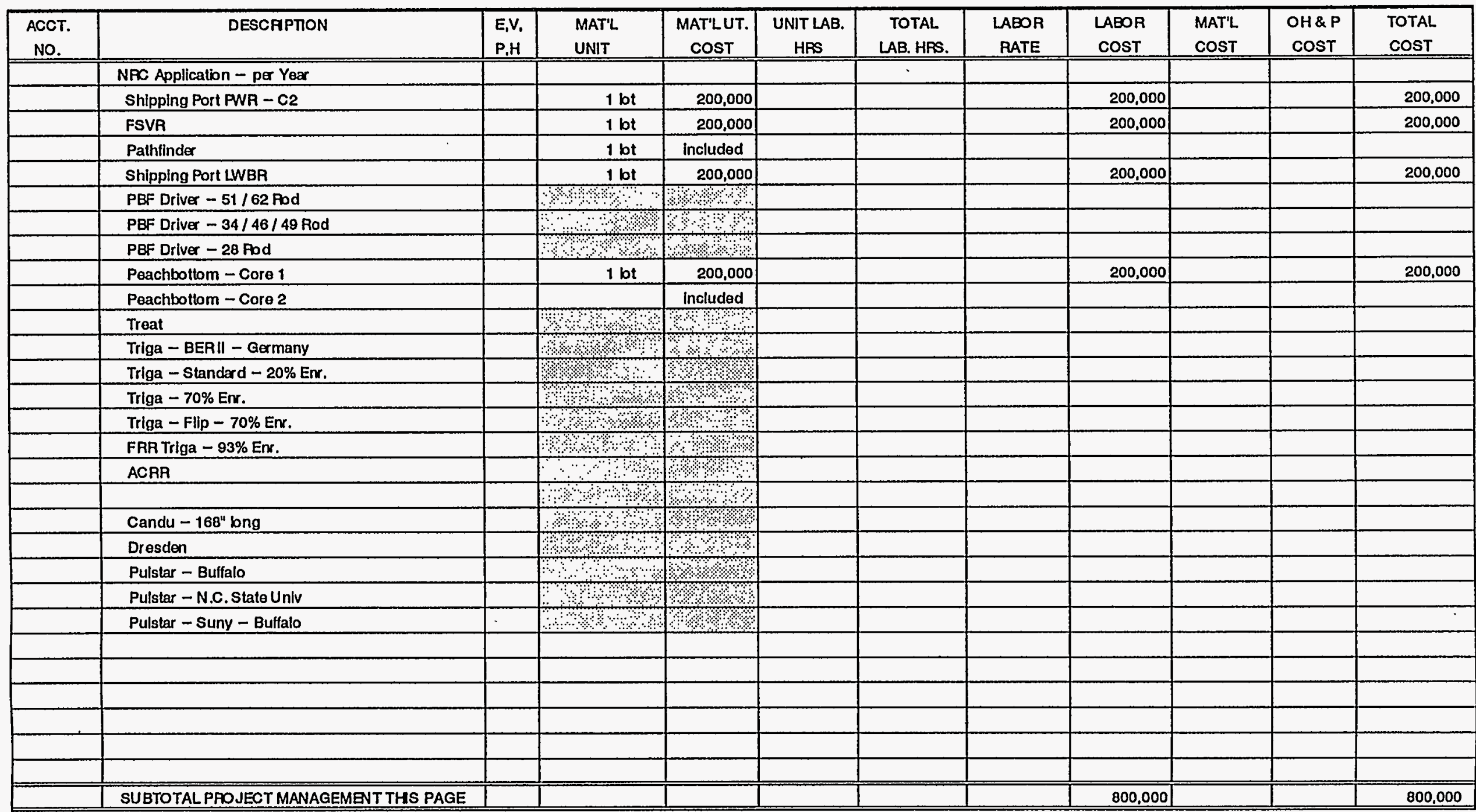




\begin{tabular}{|c|c|c|c|c|c|c|c|c|c|c|c|}
\hline \multirow{2}{*}{$000^{\prime} 000^{\prime} \varepsilon$} & & $000^{\prime} 000^{\prime} \varepsilon$ & 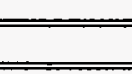 & 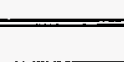 & +2 & 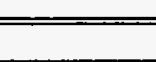 & 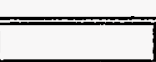 & \begin{tabular}{|l|l|}
-2 \\
\end{tabular} & \multicolumn{2}{|r|}{ 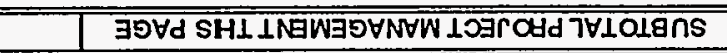 } & 2 \\
\hline & & & & & & & & & & & \\
\hline & & & & & & & & & & & \\
\hline & & & & & & & & & & & \\
\hline & & & & & & & & & & & \\
\hline & & & & & & & & & & 1 & \\
\hline & & & & & & & & & & & \\
\hline & & & & & & & अ) & ४⿻ & & olej!ng - Kuns - reis|nd & \\
\hline & & & & & & & +1 & 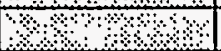 & & 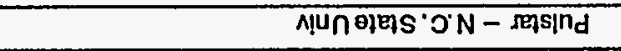 & \\
\hline & & & & & & & \$2., & \%४७ & & 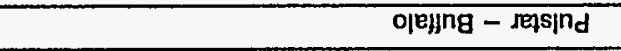 & \\
\hline & & & & & & & 1., & \% \%,। & & Lopseja & \\
\hline & & & & & & & ४\$ & \%४०४४ & & 6uq „891 - npues & \\
\hline & & & & & & & 1 & ४ै७४ & & & \\
\hline & & & & & & & ए४४\% & ४४। & & पषष्प० & \\
\hline & & & & & & & अ। & २४०४ & & 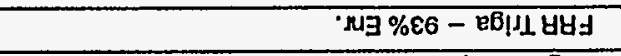 & \\
\hline & & & & & & & ४४ & ४४४४ & & 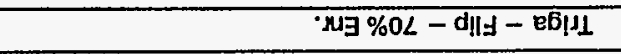 & \\
\hline & & & & & & & \%\%, & ४४২\% & & ' ${ }^{\prime} \exists \% 0 L-\mathrm{eb} \mu \perp$ & \\
\hline & & & & & & & 12ख & 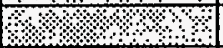 & & 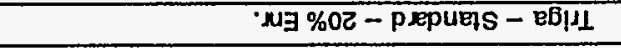 & \\
\hline & & & & & & & 3+3 & ४४०+? & & 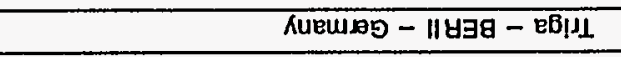 & \\
\hline & & & & & & & ४खि & ४४४४४७ & & 180गI & \\
\hline & & & & & & & pepnjou! & & & 20100- molloqujeed & \\
\hline \multirow[t]{4}{*}{$000^{\prime} 0$ SL } & & OOO'OSL & & & & & $000^{\circ} 09 \mathrm{~S}$ & 191 & & 1. & \\
\hline & & & & & & & 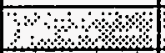 & \%४, & & pqu $8 z-\operatorname{sell10~}=19 d$ & \\
\hline & & & & & & & ४०1 & \%॰ \% \% & & 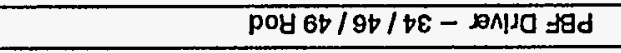 & \\
\hline & $\overline{9}$ & & & & & & \%२ & ڤ & & pq $29 / 15$ - & \\
\hline \multirow[t]{2}{*}{$000^{\prime} 09 L$} & & $000^{\circ} 09 L$ & & & & & $000^{\circ} 0 S L$ & 191 & & HQMT IJOd Buldd!̣us & \\
\hline & & & & & & & Sul & 191 & & sopululted & \\
\hline $000^{\prime} 0 \mathrm{~s} L$ & & $000^{\prime} 09 L$ & & & & & $000^{\prime} 0 \mathrm{SL}$ & 191 & & $\begin{array}{l}\wedge S\rfloor \\
\end{array}$ & \\
\hline \multirow[t]{2}{*}{$000^{\prime} 09 L$} & & $000^{\prime} 09 L$ & & & & & $000^{\prime} 09 L$ & 791 & & 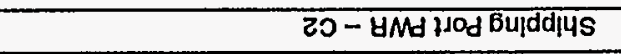 & \\
\hline & & & & & & & & & & $\operatorname{se\theta } \lambda \operatorname{sed}-\theta \theta \mathrm{g} O \mathrm{OUN}$ & \\
\hline 1500 & 1500 & 1500 & 1500 & GIVU & खH $9 \forall$ & SHH & 1500 & IINn & $H^{\prime} d$ & & ON \\
\hline \multirow[t]{3}{*}{$7 \forall 101$} & d8HO & 7.LVW & YOQV7 & y०बष7 & $7 \forall 101$ & gVILINn & $\ln 7.1 \forall W$ & 7.lVW & ' $\wedge$ 'ヨ & NOUdHOS30 & IOOV \\
\hline & & & & & & & & & & 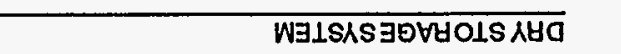 & \\
\hline & & & & & & & & & & LOتCOAd $\exists 9 \forall Y O L S \wedge \forall O J N S$ & 100!osd \\
\hline $96 / 21 / 90$ & $\mathbf{e q}$ & g-t18 & -ON ㅂ‼ & & enjder & 19910 od & & & & & \\
\hline
\end{tabular}


Project SNF DRYSTORAGEPROJECT DRY STORAGESYSTEM

\begin{tabular}{|c|c|c|c|c|c|c|c|c|c|c|c|}
\hline \multirow[t]{28}{*}{$\begin{array}{l}\text { ACCT. } \\
\text { No. }\end{array}$} & DESCAPTION & $\begin{array}{l}\text { E.V. } \\
\text { P.H }\end{array}$ & $\begin{array}{l}\text { MAT'L } \\
\text { UNIT }\end{array}$ & $\begin{array}{c}\text { MAT'LUT. } \\
\text { CosT } \\
\end{array}$ & $\begin{array}{c}\text { UNIT LAB. } \\
\text { HARS } \\
\end{array}$ & $\begin{array}{c}\text { TOTAL } \\
\text { LAB. HAS. }\end{array}$ & $\begin{array}{l}\text { LABOR } \\
\text { RATE } \\
\end{array}$ & $\begin{array}{c}\text { ENGR/LC } \\
\text { COST } \\
\end{array}$ & $\begin{array}{c}\text { PAOCURE } \\
\text { FEE } \\
\end{array}$ & $\begin{array}{c}\text { G\&A } \\
\text { COST }\end{array}$ & $\begin{array}{l}\text { TOTAL } \\
\text { COST }\end{array}$ \\
\hline & PROCUREMENTFEES AND G\&A - by Fuel Type & & & & & & & & & & \\
\hline & NUHOMS Storage Modules & & 1 bt & $7,500,000$ & & & & & 112,500 & w/ canister & 112,500 \\
\hline & Canister Assembly - Includes Canisler w/ Plug, Ba & at, Buck & et - by Fuel Type & & & & & & & & \\
\hline & Shlpping Port PWR - C2 & & 1 bt & $1,910,568$ & & & & & 28,659 & 150.000 & 178,659 \\
\hline & FSVR & & 1 bt & $4,993,560$ & & & & & 74,903 & 450,000 & 524,903 \\
\hline & Pathfindex & & $1 \mathrm{lot}$ & 652,354 & & & & & 9,785 & 150,000 & 159,785 \\
\hline & PBF Driver $-51 / 62$ Aod & & \% \% & \%० & & & & & & i : & \\
\hline & PBF Driver $-34 / 46 / 49$ Rod & & $1 \%+\%$ & \% & & & & & & $\therefore \therefore \therefore$ & \\
\hline & PBF Driver -28 Pod & & \%४\% & \%४\% & & & & & & $\because \because \because$ & \\
\hline & Peachbottom - Core 1 & & $1 \mathrm{bt}$ & $1,024,456$ & & & & & 15,367 & Included & 15,367 \\
\hline & Peachbottom - Core 2 & & 1 bt & $4,328,484$ & & & & & 64,927 & 150,000 & 214,927 \\
\hline & Treat & & \% \% & 12\% & & & & & & $\because \because$ & \\
\hline & Triga - BERII - Germany & & १४४\% & ९४४। & & & & & & a & \\
\hline & Triga - Fllp - 70\% Enr. & & $13 \%$ \% & ڤ४ & & & & & & ध⿰冫: & \\
\hline & FRA Triga - 93\% Enr. & & 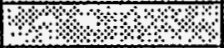 & -13 & & & & & & $\because \vdots \quad \vdots$ & \\
\hline & ACRR & & ४४২\% & সै। & & & & & & 10 & \\
\hline & & & \%४४\% & $1 \%+$ & & & & & & m & \\
\hline & Candu - 168" bng & & \%०४४ & & & & & & & $\because \because \because$ & \\
\hline & Dresden & & 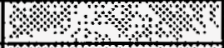 & W० & & & & & & $\because \quad: \quad$ & \\
\hline & Pulstar - Bulfalo & & ४०० & 13+ & & & & & & $\because \because 3$ & \\
\hline & Pulstar - N.C. State Unlv & & $13 \% 1$ & +12 & & & & & & $\therefore$ & \\
\hline & Pulstar - Suny - Buffalo & & २ै\%? & 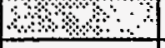 & & & & & & $\because \therefore \therefore \quad \therefore$ & \\
\hline & & & & & & & & & & & \\
\hline & 100 Ton Crane & & $1 \mathrm{ea}$ & $1,250,000$ & & & & & 18,750 & 150,000 & 168,750 \\
\hline & & & & & & & & & & & \\
\hline & & & & & & & & & & & \\
\hline & TOTAL PROCUREMENT FEES AND G\&A & & & & & & & & 399,681 & $1,200,000$ & $1,599,681$ \\
\hline
\end{tabular}


SNF ORY STORAGE PROJECT DRY STORAGE SYSTEM

Location INEL/ICPP

Requestor R.C. HKL
Type of Est. Conceptral

File No. 2314-B
Date

Prep'd By

S.M.Bradford
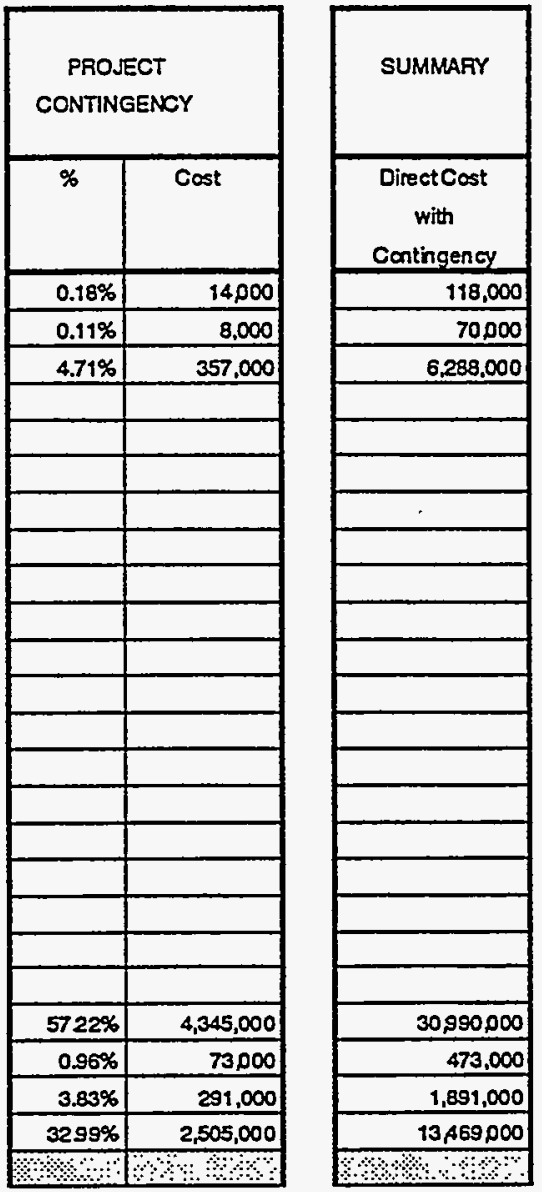

\begin{tabular}{|c|c|c|c|c|c|c|c|}
\hline \multirow{2}{*}{ Cost Estimate Element } & \multirow[t]{2}{*}{$\begin{array}{l}\text { Unescalated } \\
\text { Cost }\end{array}$} & \multirow{2}{*}{$\begin{array}{c}\% \\
\text { Total } \\
\text { Cost }\end{array}$} & \multicolumn{2}{|c|}{$\begin{array}{l}\text { Prob \% Var } \\
\text { From Est }\end{array}$} & \multicolumn{2}{|c|}{ WT \% of Prob } & \multirow[t]{2}{*}{ Contingency } \\
\hline & & & -1 & + & - & + & \\
\hline Tite I and II Design & 104,000 & 0 & 5.00 & 1500 & 0.01 & 0.03 & $0.03 \%$ \\
\hline Tide III Inspection & 62000 & of & 5.00 & 1500 & 0.01 & 0.02 & $0.02 \%$ \\
\hline Frojeet Management & $5,931,000$ & 13 & 5.00 & 7.00 & 0.65 & 0.91 & $0.75 \%$ \\
\hline \multicolumn{8}{|l|}{ Construetion Management } \\
\hline \multicolumn{8}{|l|}{ General Requirements } \\
\hline \multicolumn{8}{|l|}{ Sibwokk } \\
\hline \multicolumn{8}{|l|}{ Concrete } \\
\hline \multicolumn{8}{|l|}{ Mesonry } \\
\hline \multicolumn{8}{|l|}{ Metals } \\
\hline \multicolumn{8}{|l|}{ Wood and Plastios } \\
\hline \multicolumn{8}{|l|}{ Molsture Protection } \\
\hline \multicolumn{8}{|l|}{ Doors and Wndows } \\
\hline \multicolumn{8}{|l|}{ Finshes } \\
\hline \multicolumn{8}{|l|}{ Speclalties } \\
\hline \multicolumn{8}{|l|}{ Eqipment } \\
\hline \multicolumn{8}{|l|}{ Furnishings } \\
\hline \multicolumn{8}{|l|}{ Spocial Construction } \\
\hline \multicolumn{8}{|l|}{ Conveying Systems } \\
\hline \multicolumn{8}{|l|}{ Mechanical } \\
\hline \multicolumn{8}{|l|}{ Electioal } \\
\hline GFE & 26,545000 & 58 & 5.00 & 1800 & 2.91 & 1049 & $9.15 \%$ \\
\hline Procurement Foes & 400,000 & 1 & 5.00 & 20.00 & 0.04 & 0.18 & $0.15 \%$ \\
\hline G\&A & $1,600,000$ & 4 & 5.00 & 2000 & 0.18 & 0.70 & $0.81 \%$ \\
\hline Escalation & 10964000 & 24 & 5.00 & 2500 & 1.20 & 6.00 & $5.28 \%$ \\
\hline Subtotal & 45,708000 & 100 & : : : & था & 5 & 18 & $8+6$ \\
\hline
\end{tabular}
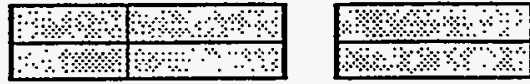

Calculated Contingency

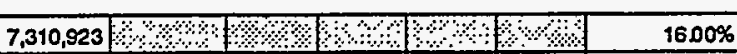

Resultant TEC 53016,923 में
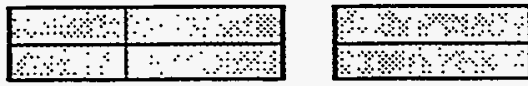

\%?

Project Contingency 7,504,000 40 की

Risk to Project E : :

Management Reserve :

\begin{tabular}{l|l|l|l|l|l|l|l|l|l|l|l|}
$3,788,000$ & $\because \cdots$ & $000 \%$ \\
\hline
\end{tabular} Contingency * $3,805,000$
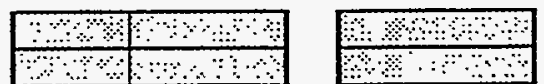

Total

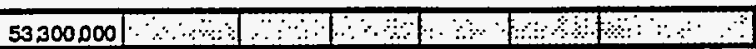

CONFDENCE LEVEL AND ASSUMED RISKS:

The Lockheed I cha Technologies Co. Cost Estimat Contingency Analysis Model is based on the applied contingency and the assumptions upon which the estimate wes predieated. The model is applied with a suggested risk level of $18 \%$ and a bvel of conficence of $90 \%$ the estimate will fall within the bid range. The Contingency Analysis is based on a weighted avera ge to provide a $90 \%$ probability of underrun and $10 \%$ probability of overrun.

- The calculated Management Reserve and Contingency amounts include Escalation.

CONTINGENCY ANALYSIS QUIDE BY TYPE OF ESTIMATE: Guicelines established by DOEIFM-50, Cost Estimating Quide, Vol. 6, Cost Guide, and as presented in the INE Cost Estimating Guide.

PLANNING

CONCEPTUAL

Experimental / Special Conditions TITLEI

TITLEII

TITLE II / AFC
$20 \%-30 \%$ Up to $50 \%$ $15 \%-25 \%$ Up to $40 \%$ $10 \%-20 \%$

$5 \%-15 \%$ Market Conditions 
Lockheed ldaho Techndogles Co.

Rev 01-96

\section{ESCALATION SHEET}

Type of Est. Conceptual

Filo No.
Date

Prepared By
06/14/96

S.M. Bradford

Location INEL/ICPP

Requester R. C. HILL

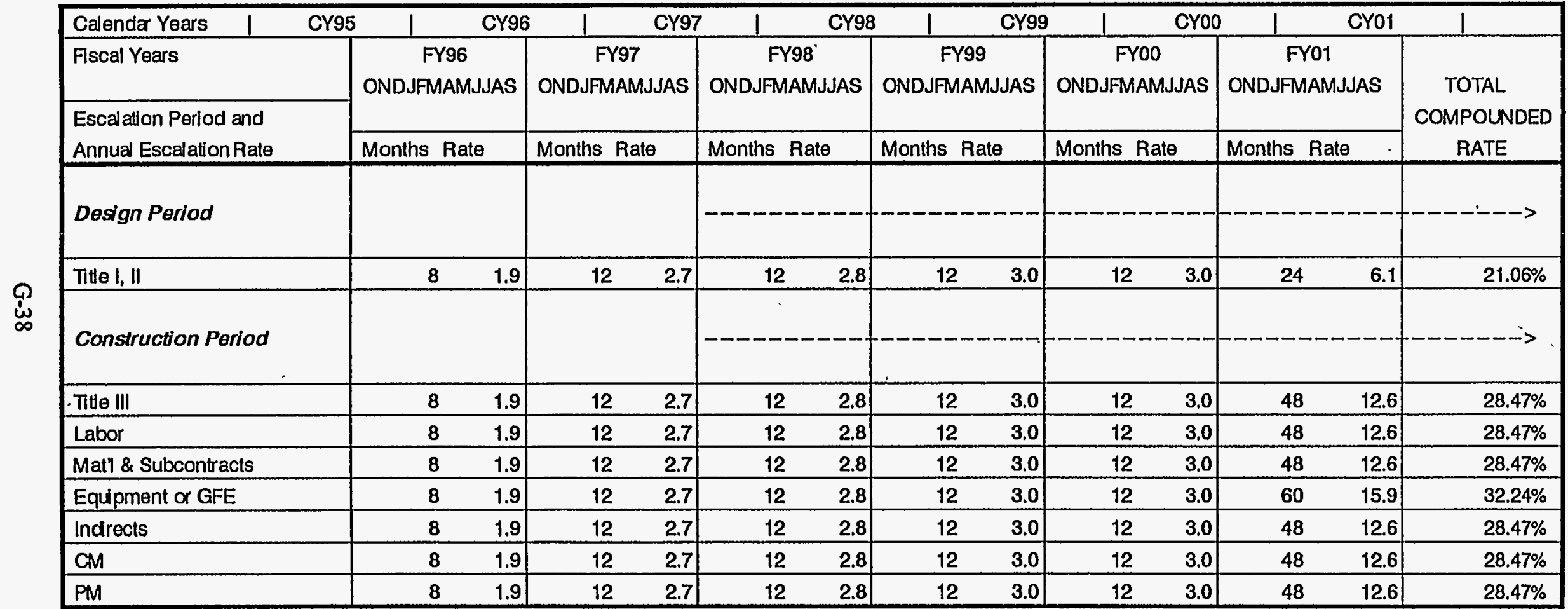

Departmenta Price Change Index - FY 1998 Guldanoe - Antiapated Economic Escalation Rates - Defense Programs \& Genera Construction.

\begin{tabular}{|c|c|c|c|c|c|c|}
\hline \% Change/Composite Rate & 2.8 & 2.7 & 2.8 & 3.0 & 3.0 & 3.0 \\
\hline \multicolumn{7}{|c|}{ Departmenta Price Change Index - FY 1998 Guidance - Antidpated Economic Escalation Rates - Emironmental Restoration. } \\
\hline$\%$ Change/Composite Rate & 3.4 & 3.0 & 3.1 & 3.2 & 3.3 & 3.4 \\
\hline \multicolumn{7}{|c|}{ Departmenta Price Change Index - FY 1998 Guidance - Antidipated Economic Escd ation Rates - Waste Management. } \\
\hline$\%$ Change/Composite Rate & 3.2 & 2.9 & 3.0 & 3.0 & 3.1 & 3.2 \\
\hline
\end{tabular}

* It will be the responsibility of the estimator to determine the appropriate escalation rate to use, based on project funding and type. 


\section{Appendix H \\ Equipment List Spent Nuclear Fuel Dry Storage Project}




\section{Appendix $\mathrm{H}$ \\ Equipment List \\ Spent Nuclear Fuel Dry Storage Project}

\section{Mechanical Equipment}

- Fire extinguisher cabinets

- Projection screen

- Dry marker board

- Furniture

- Cask transfer trolleys (2)

- Cask Handling Bay work platform

- Preparation Booth Area work platform

- Welding machines (2)

- Leak, purge, and gas sampling equipment (2)

- Pneumatic can piercing tool

- Can drying system

- Helium leak detector

- 14-in. Baskets (3)

- $\quad$ Storage stands (2)

- Lifting yokes (3)

- Misc. tooling (2)

- Fuel handling grapples (2)

- Can handling tool (for Peach Bottom fuel)

- Fuel handling tool (for Peach Bottom fuel)

- Fuel handling tool grapple (for Peach Bottom fuel)

- Cask access rollaway stairways (2)

- 150/15-ton bridge crane

- 7.5-ton bridge crane

- Fuel-handling crane with 3 trolleys, z-masts, manipulators, controls, etc.

- 500-gal HEPA filter water collection system

- HEPA filter deluge systems (4)

- Electric water cooler

- Emergency eyewash/shower (2)

- Hot water heater

- Hose reels (2)

- 5,000-gal holding tank with instruments and controls (2)

- Hot Cell, Anti-C Room, and Cask Preparation Area supply air unit

- Utility Support Area supply air unit

- Exhaust Fan Room cooling unit and air cooled condenser

- Administrative Area HVAC unit and air cooled condenser

- Hot Cell exhaust HEPA filters (2)

- Utility Support Area HEPA filters (2)

- Hot Cell exhaust fans (2)

- Utility Support Area exhaust fans (2) 
- Glycol heat recovery system

- Lab fume hood exhaust fan

- Toilet rooms and janitor closet exhaust fans (2)

- Exhaust hose reel systems (2)

- $\quad$ SST isolation dampers (4)

- Isolation dampers (10)

- $\quad$ Probes, spool piece, and CAMS - isokinetic sampling (for 30-in. stack and for 18-in. stack)

- Air flow transfer and static pressure measuring station and associated instrumentation and controls

\section{Electrical Equipment}

- 80 kVA Uninterruptible Power Supply

- 'Distribution panels (5-480/277, 225A; 3-120/208, 100A; 1-120/208, 150A)

- Dry transformer - 480-208/120 (1-45 kVA, 3-25 kVA)

- Feeders

- Motor starter - Size 1(6)

- Disconnect switches (2-250A, 1-100A)

- Lighting (interior, exterior, and exit)

- Receptacles and switches

- Welding receptacle

- CCTV cameras (15)

- $\quad$ CCTV monitors (5)

- CCTV quadswitches (15)

- PCs (5)

- Network server

- VCRs (15)

- Microprocessor based alarm collection system

- Seismic detection device

- $\quad$ RAMs (6)

- CAMs - beta/gamma (6)

- CAM - alpha

- Hand and foot counters (3)

- Holding tank activity monitor

- Criticality indicator/detector (2)

- Alarms monitor

- Hand-held radiation monitoring frisker (4)

- FASTRAK II dosimetry system

- Beta/gamma spectrometer

- Alpha spectrometer

- Argus field panel

- Remote security access panel (12)

- Voice paging, fire alarm, and evacuation system

- Remote distribution module

- Voice/data system

- Local area network

- Intercom system 


\section{Appendix 1}

\section{Drawings}




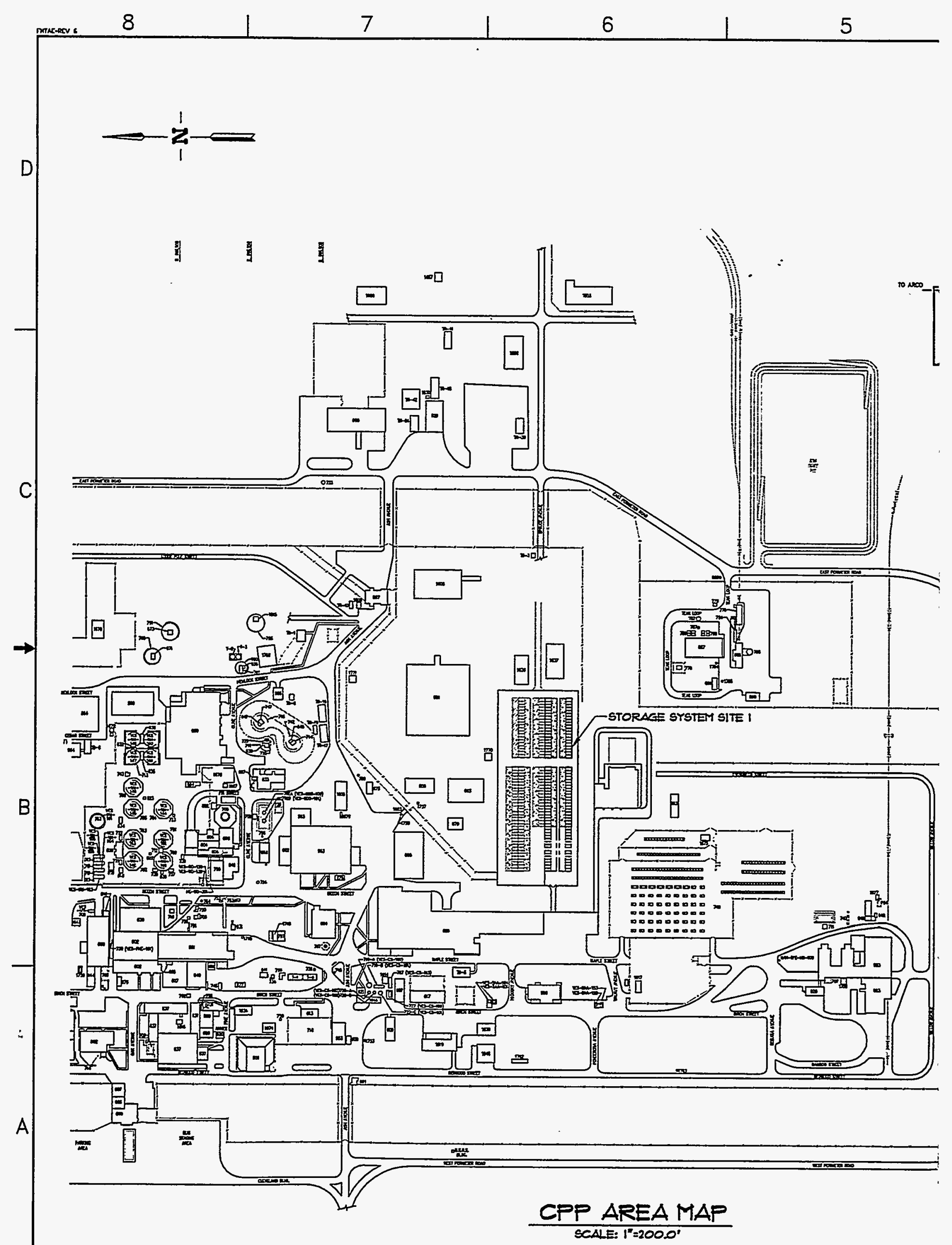




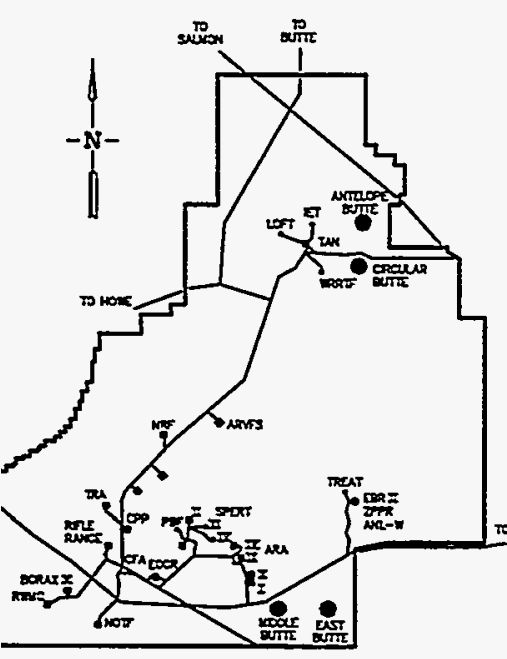

\section{DRAWING INDEX}

\begin{tabular}{|c|c|c|c|c|}
\hline $\begin{array}{l}\text { PAEA } \\
\text { NO. }\end{array}$ & DHK NO. & 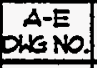 & REY & DRAWING TITLE \\
\hline 1 & & $T-1$ & & AREA MAP AND DRAWING INDEX \\
\hline 2 & & $c-1$ & & SITE MAP \\
\hline 3 & & $C-2$ & & UTILITI PLAN \\
\hline 4 & & $c-3$ & & ENLARSED SITE PLAN \\
\hline 5 & & $c-4$ & & DEMOLITION/INSTALLATION PLAN \\
\hline 6 & & $c-5$ & & STORAGE SECTION AND DETAILS \\
\hline 7 & & A-1 & & MAIN LEVEL FLOOR PLAN \\
\hline 8 & & $A-2$ & & LEVEL THO FLOOR PLAN \\
\hline 9 & & A-3 & & LEVEL THREE FLOOR FLAN \\
\hline 10 & & $\Delta-4$ & & LEVEL FOUR FLOOR PLAN \\
\hline 11 & & A-5 & & ROOF PLAN \\
\hline 12 & & A-6 & & EAST ELEVATION \\
\hline 13 & & $A-7$ & & LEST ELEVATTON \\
\hline 14 & & A-8 & & NORTH ELEYATION \\
\hline 15 & & $A-9$ & & SOUTH ELEVATION \\
\hline 16 & & $A-10$ & & 8ECTION \\
\hline 17 & & $A-11$ & & BECTION \\
\hline IB & & $\Delta-12$ & & SECTION \\
\hline is & & $M-1$ & & PARTIAL MAIN FLOOR EQUIPMENT ARRANKEMTENT \\
\hline 20 & & $M-2$ & & PARTIAL LEYEL THREE AND AEOVE EQUIPTENT ARRANEEMENT \\
\hline 21 & & $M-3$ & & PARTIAL ELEYATION EQUIPMENT ARRANGEMENT \\
\hline 22 & & $M-4$ & & PARTIAL ELEVATION EQUIPMENT ARRANGEMENT \\
\hline 23 & & M.5 & & PARTIAL ELEYATION EQUIPMENT ARRANGEMENT \\
\hline 24 & & M-G & & DELETED \\
\hline 25 & & $M-7$ & & CANINE AND DRY HANDLING BUCKET RACKS \\
\hline 26 & & $M-B$ & & CASK PREPARATION AREA WORK PLATFORM AND DETAILS \\
\hline 27 & & $M-9$ & & CANVINE PLATFORM AND EQUIPTENT ARRANKEMENT \\
\hline 28 & & $M-10$ & & CASK LIFTING YOKES AND CASKS \\
\hline 29 & & $M-11$ & & CASK LIFTING YOKE DETAILS \\
\hline 30 & & $M-12$ & & SHIPPING AND TRANSFER CASKS AND TROLLEY ARRANEIENT \\
\hline 31 & & $M-13$ & & SHIPPING AND TRANSFER CASKS AND TROLLEY ARRANEEMENT \\
\hline 32 & & M-14 & & CAEK TRANGFER TROLLEY AND RAILS \\
\hline 33 & & $M-15$ & & TUBE BASKET, EUCKETS AND CANS \\
\hline 34 & & $M-16$ & & TUBE CONFICURATION CROSS BECTION \\
\hline 33 & & $M-1 T$ & & DPC BASKETS \\
\hline 36 & & $M-18$ & & DPC DUAL PURPOSE CANISTER ASSEMTELIES \\
\hline 37 & & $H Y-1$ & & CONTAMINATION CONTROL PLAN \\
\hline 38 & & $H Y-2$ & & HYAC SCHEMATIC \\
\hline 39 & & $H y-3$ & & HYAC SCHEMATIC \\
\hline 40 & & $H Y-4$ & & HYAC STSTEM-MAIN FLOOR \\
\hline 41 & & $H y-5$ & & HYAC SYSTEM-LEVEL TWO \\
\hline 42 & & $H Y-6$ & & HYAC SYBTEM-LEYEL THREE \\
\hline 43 & & $E-1$ & & ONE-LINE DIALRAM \\
\hline 44 & & $E-2$ & & BECURIT ALARTS \& RADIATION INBTRIMENTATION \\
\hline 45 & & $E-3$ & & SECRRIT ALARMS \& RADIATION INSTRIMENTATION \\
\hline 46 & & $E-4$ & & SECURITI ALARMS \& RADIATION INSTRIMENTATION \\
\hline
\end{tabular}

\section{SITE MAP}

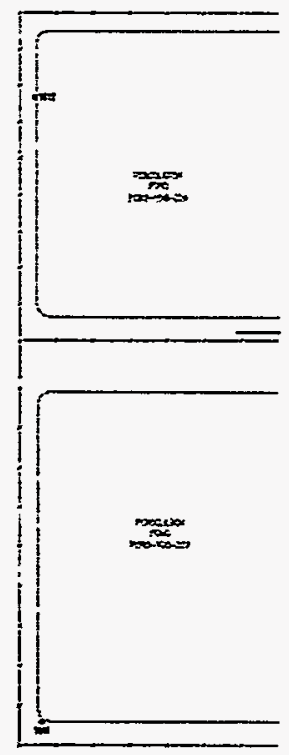

\begin{tabular}{|c|c|c|}
\hline FRR DRAAMG RIDEX SIE DRALAG NO. & & \\
\hline $1^{-} \quad 2^{-}$ & PROECT & \\
\hline SCALE $T^{\circ}=1^{\circ}$ N $1 / 10^{\circ}$ & & \\
\hline 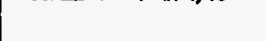 & DESIGN P & HASE \\
\hline 0 & CONCEP & TUAL \\
\hline SCNEE $1^{\circ}=1^{-} \mathbb{N} 1 / 15^{\circ}$ & APPROVED & DATE \\
\hline QUAUTY LIEVEL & & \\
\hline
\end{tabular}

APPROVALS

CONST RE

CONST

OES MG

ESTEN

\begin{tabular}{|l|l|}
\hline CHECKED & \\
\hline
\end{tabular}

DRAWN B RH

REIEASD

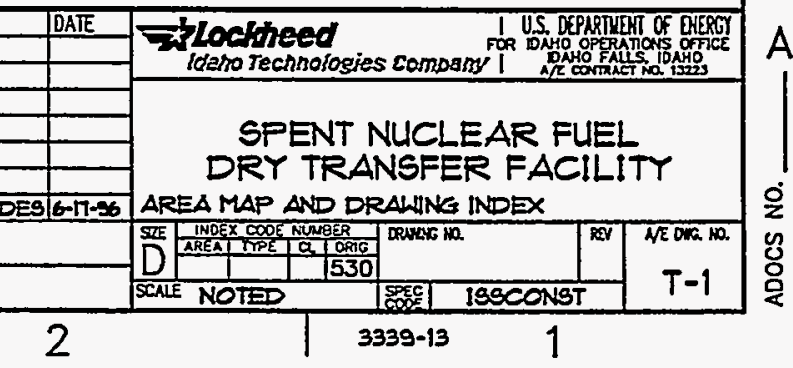




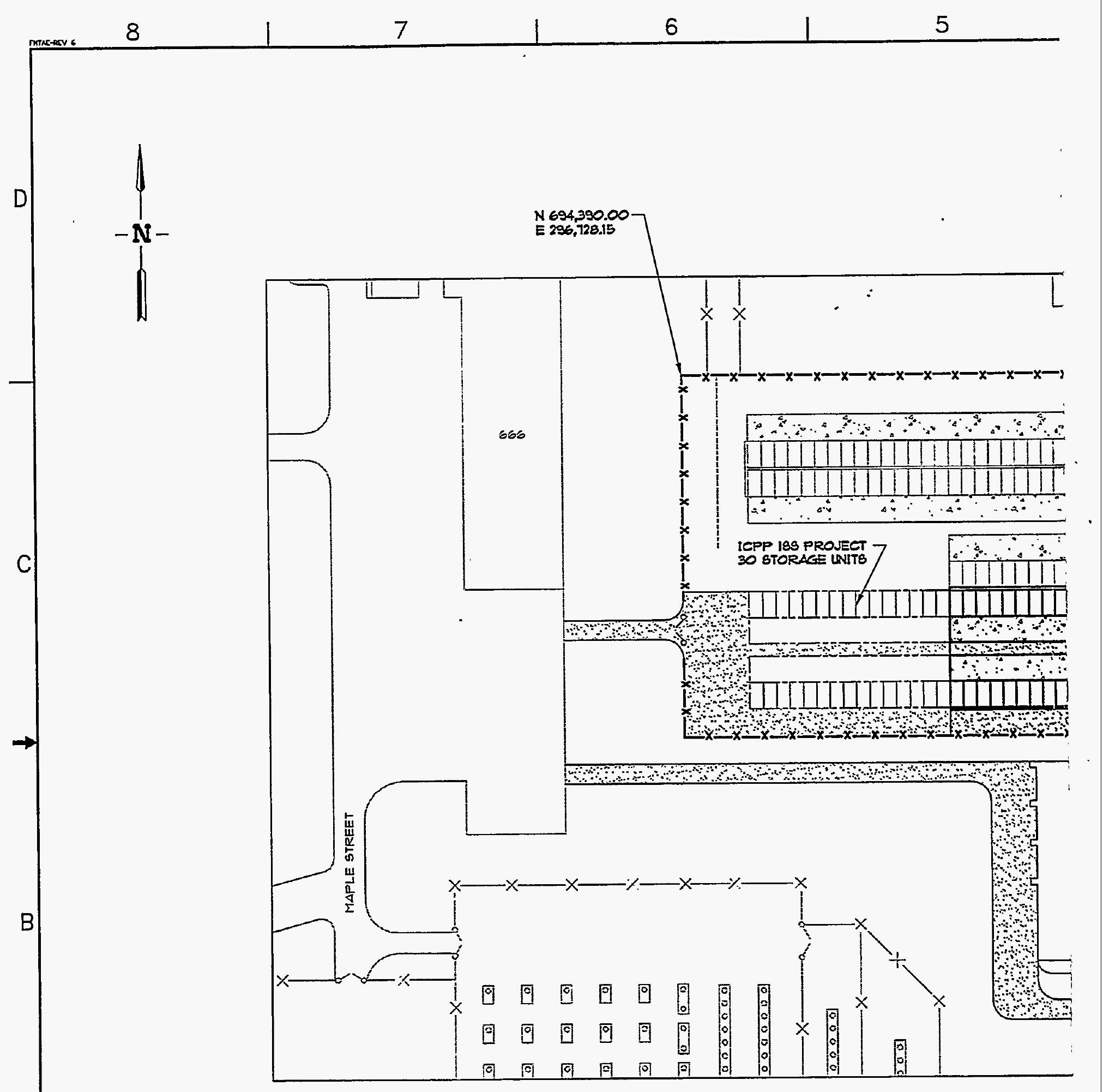

A 


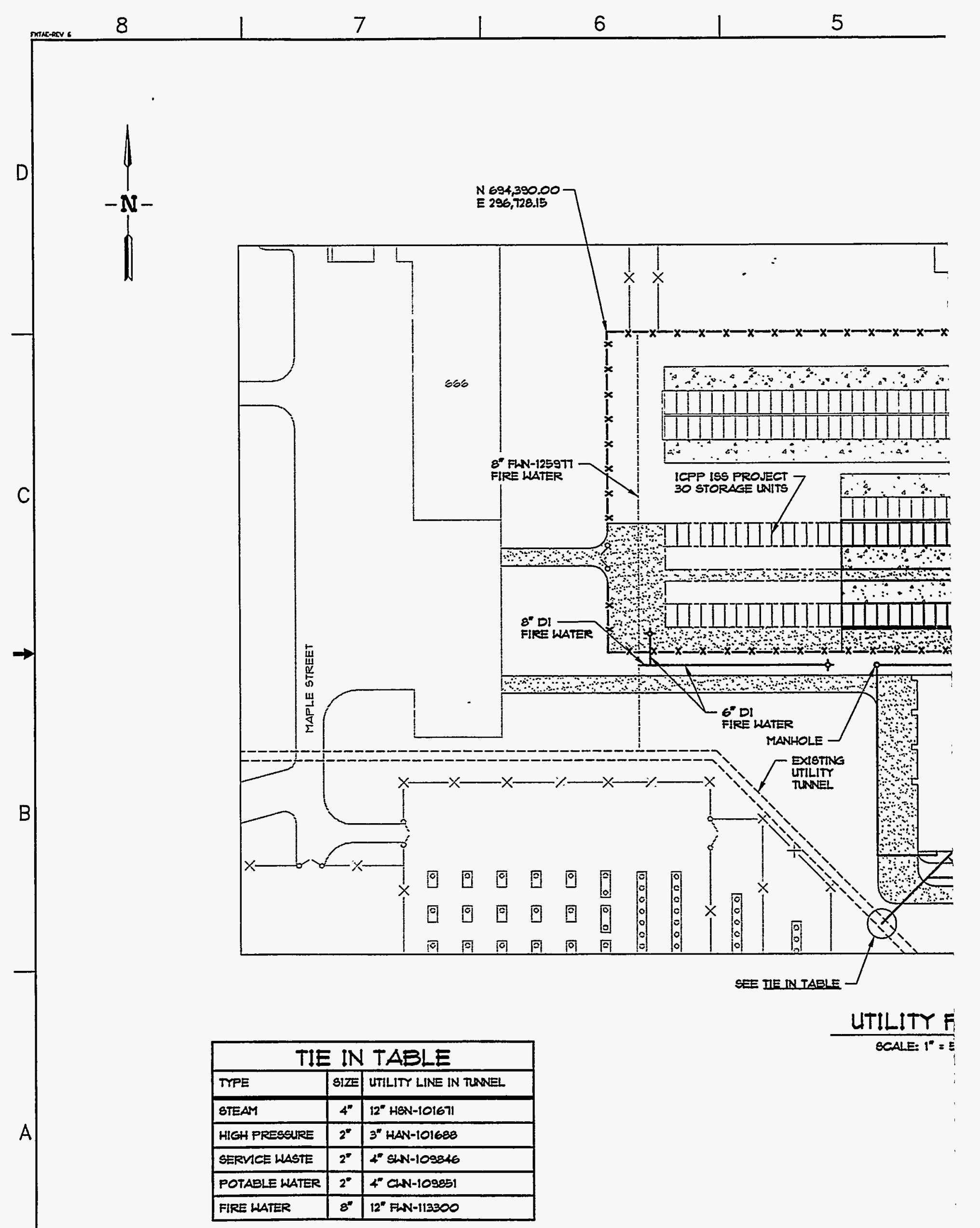




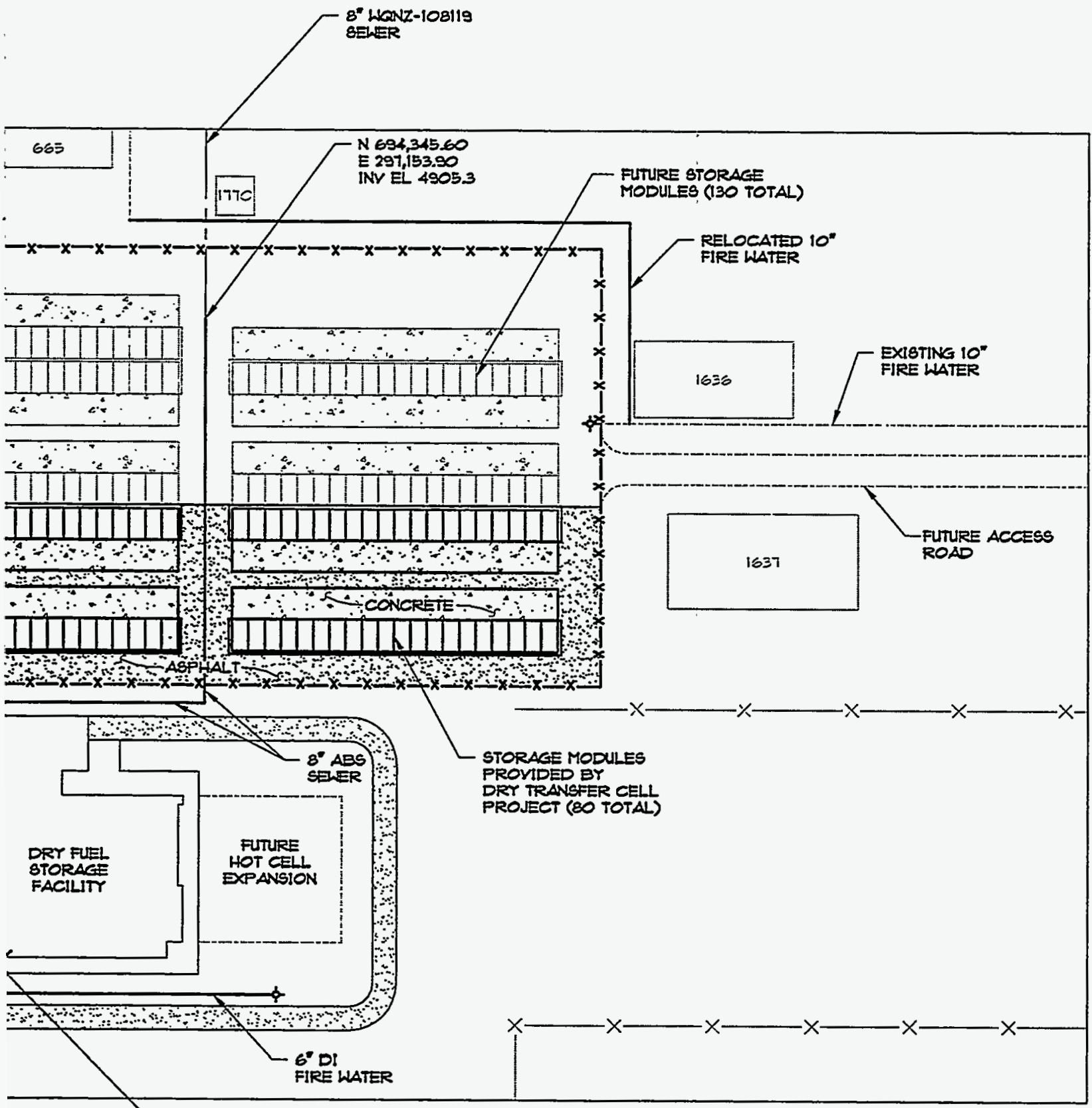

ROUTE TO

MECHANICAL ROOM

'LAN

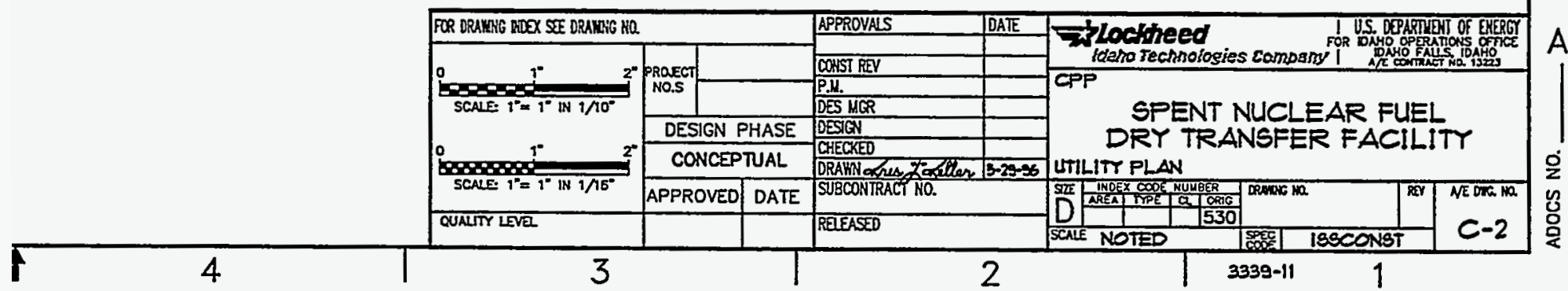




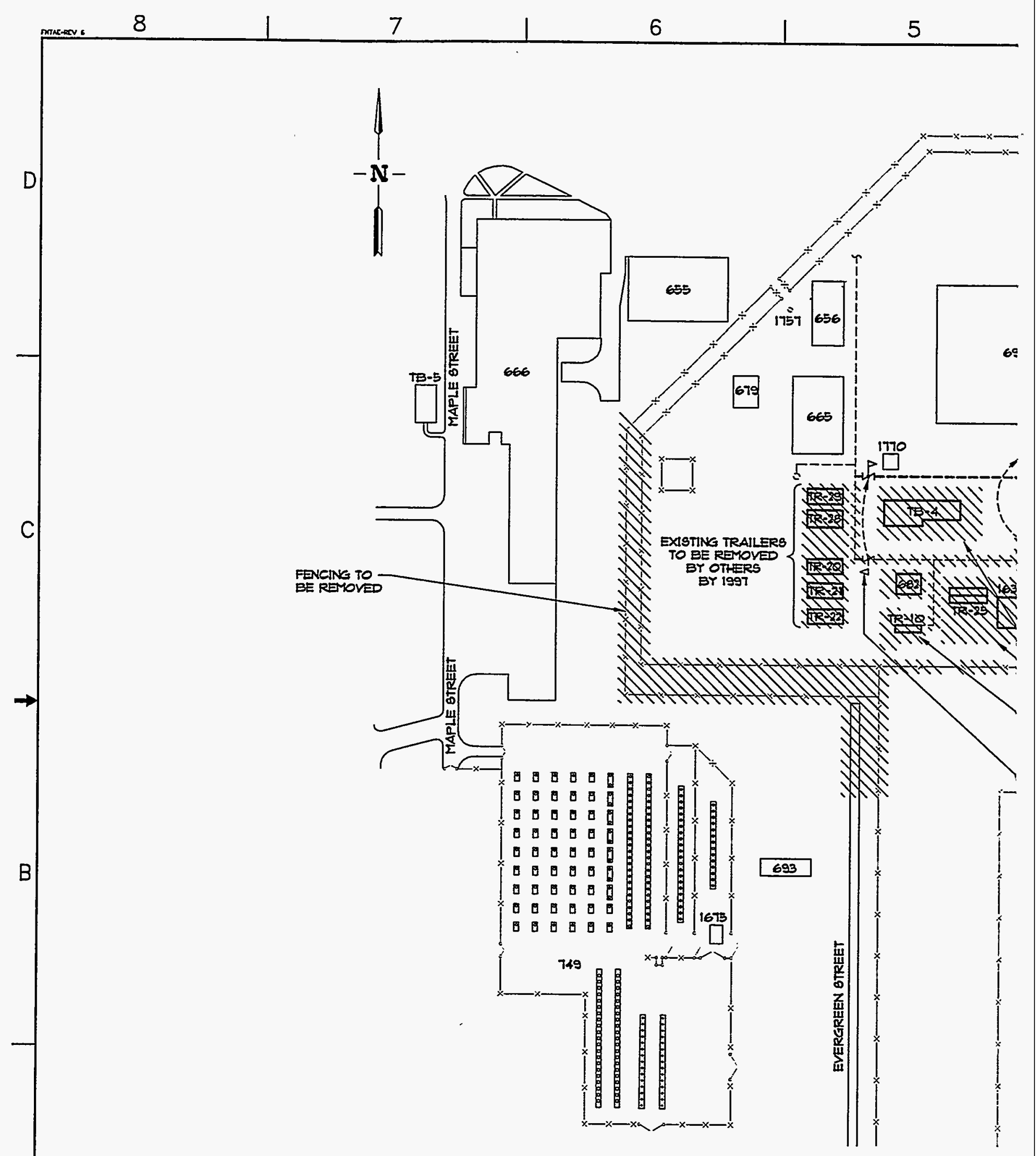



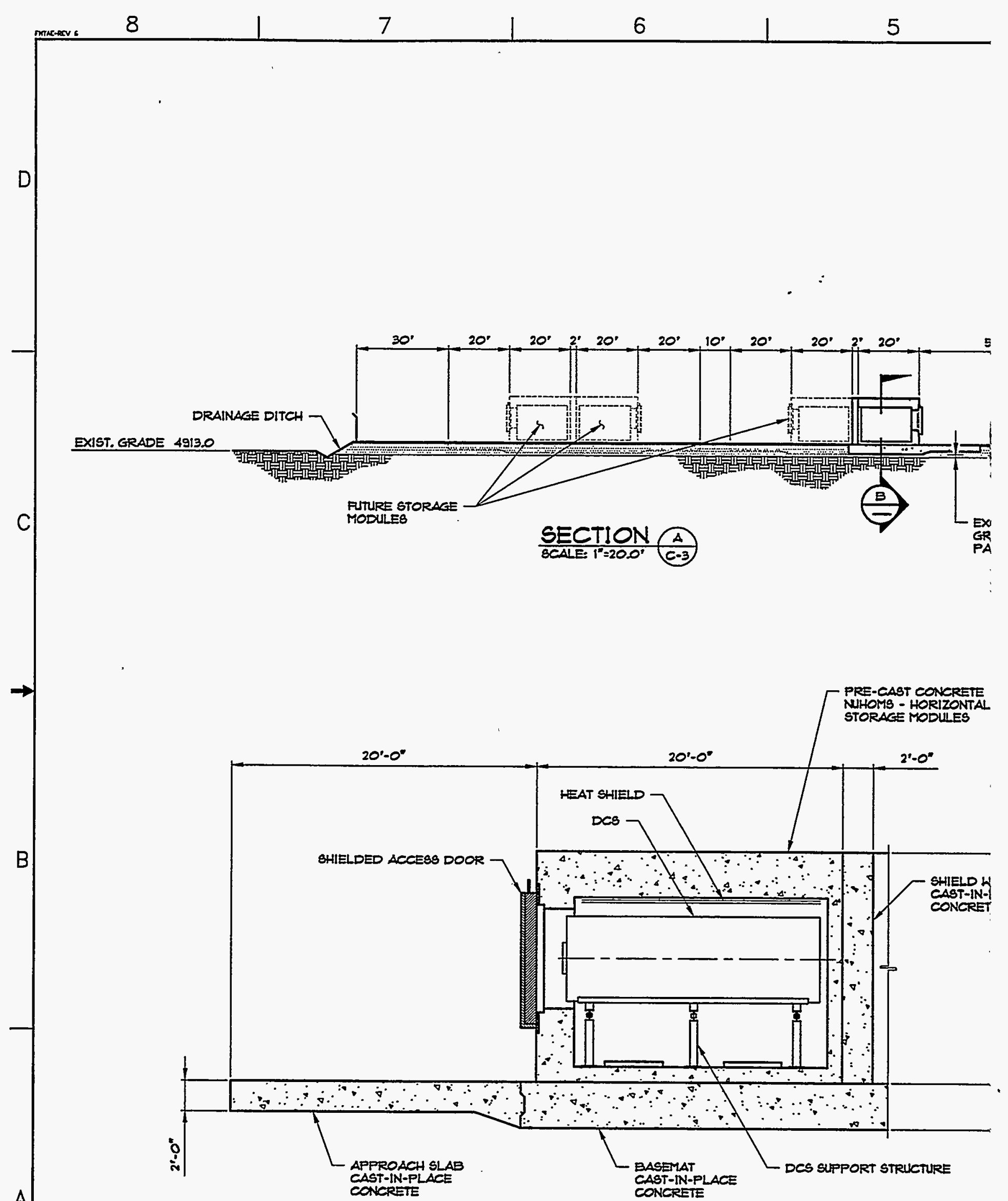

A

DETAL 


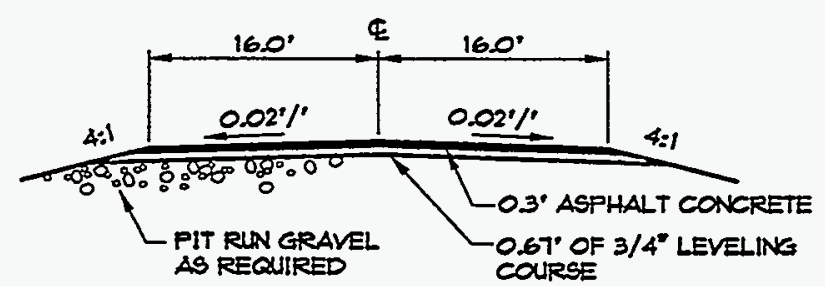

AASHTO HS-2O LOAD RATING TYPICAL ROAD SECTION

FINISH GRADE PAD 4916.0

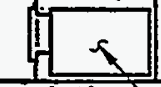

- FaneE

NTS

1

4" ASPHALT ON

6" CRLISHED GRAYEL

AYATE 1'-O" BELOW

DE AND BUILD UP

WPIT RIN GRAVEL
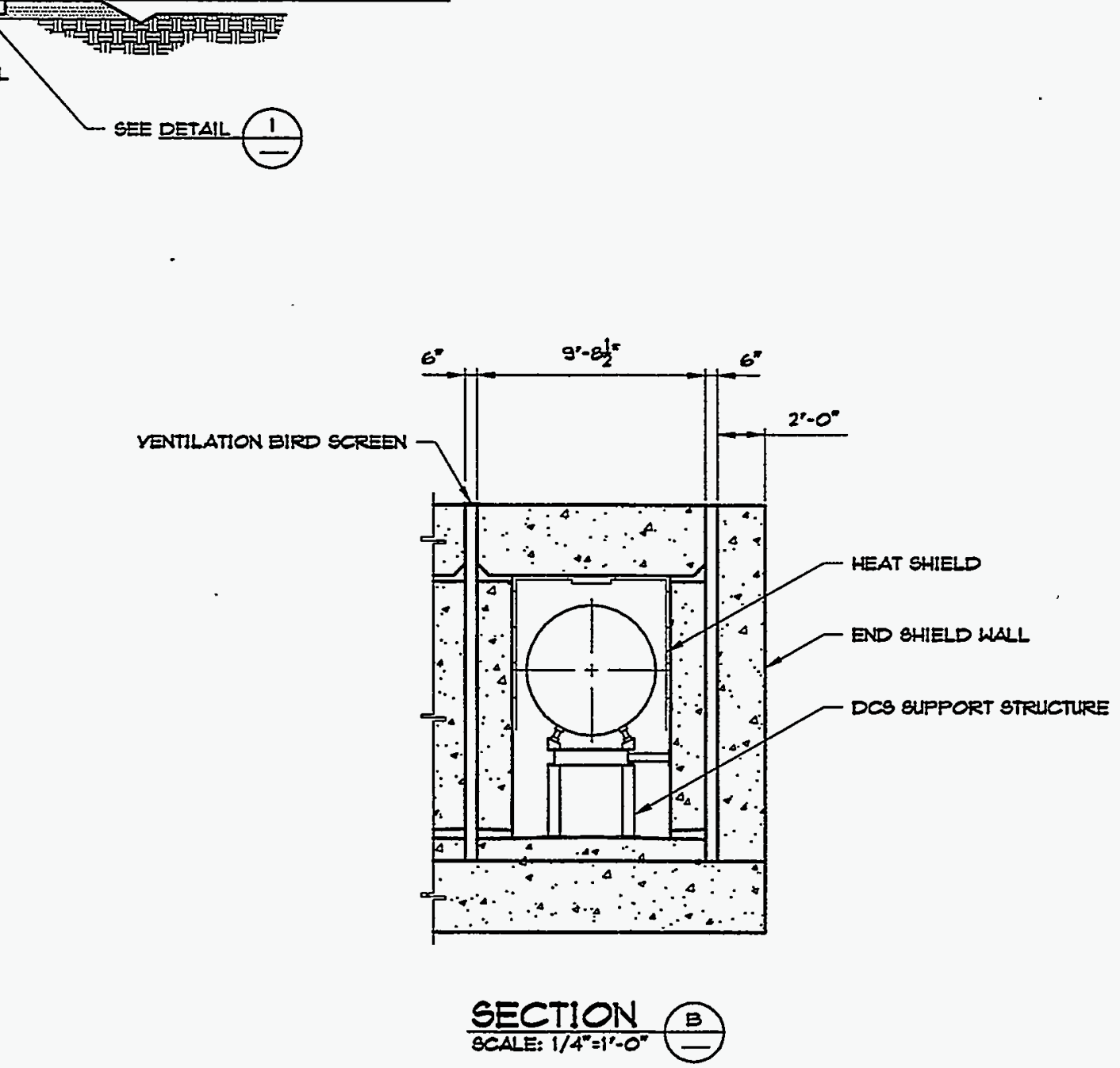

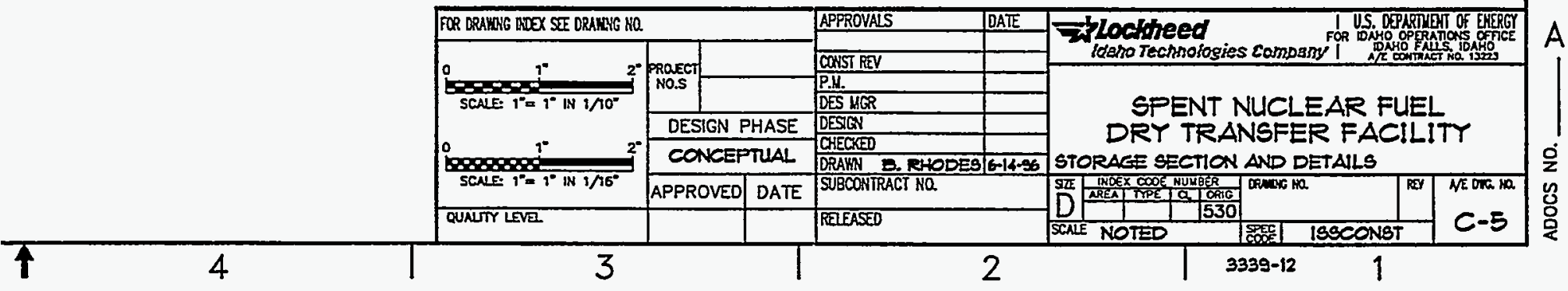




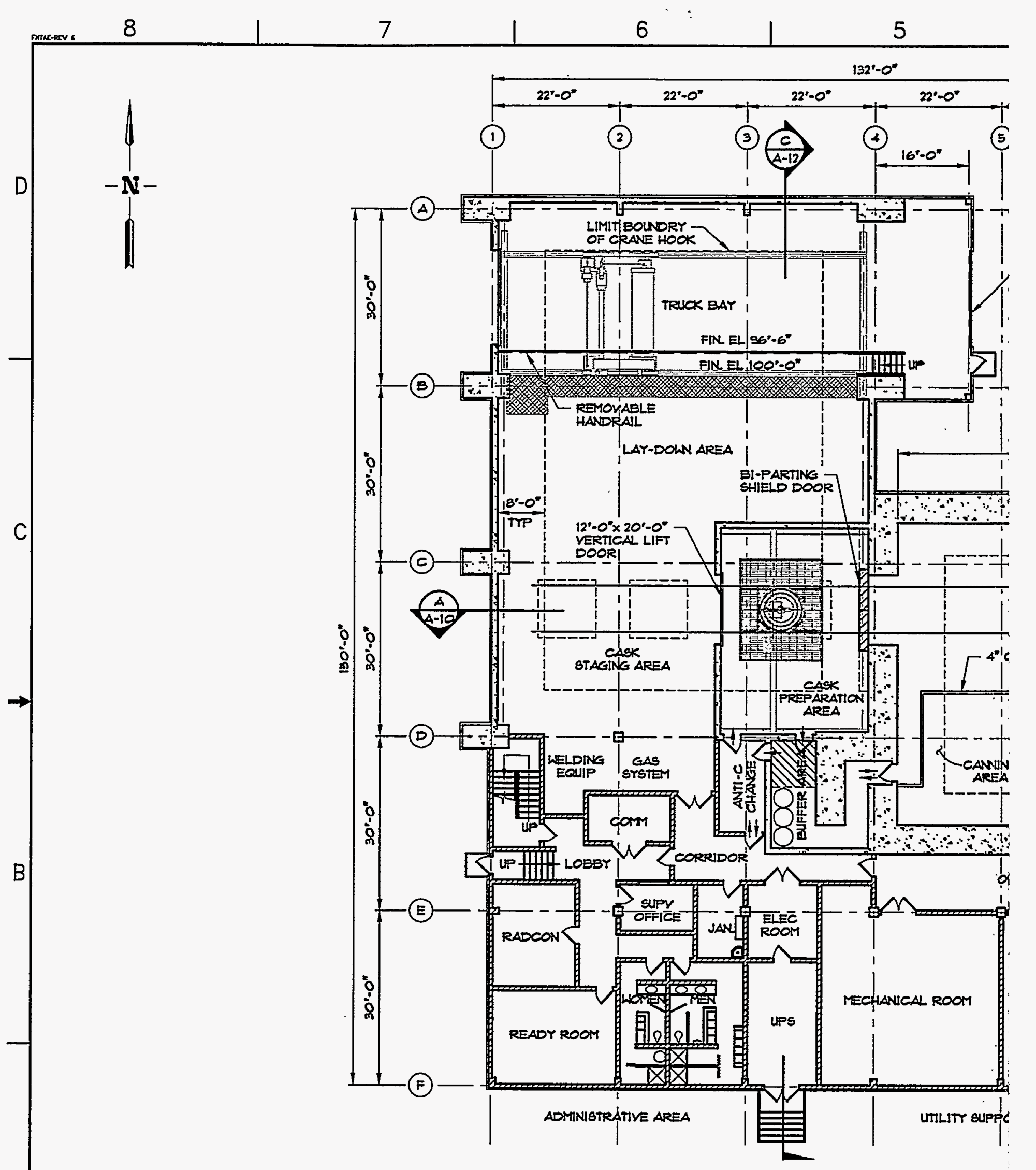

A

MAIN LEYEL FLOOR PL SCALE: 3/32" $21^{\prime}-0^{\circ}$ 


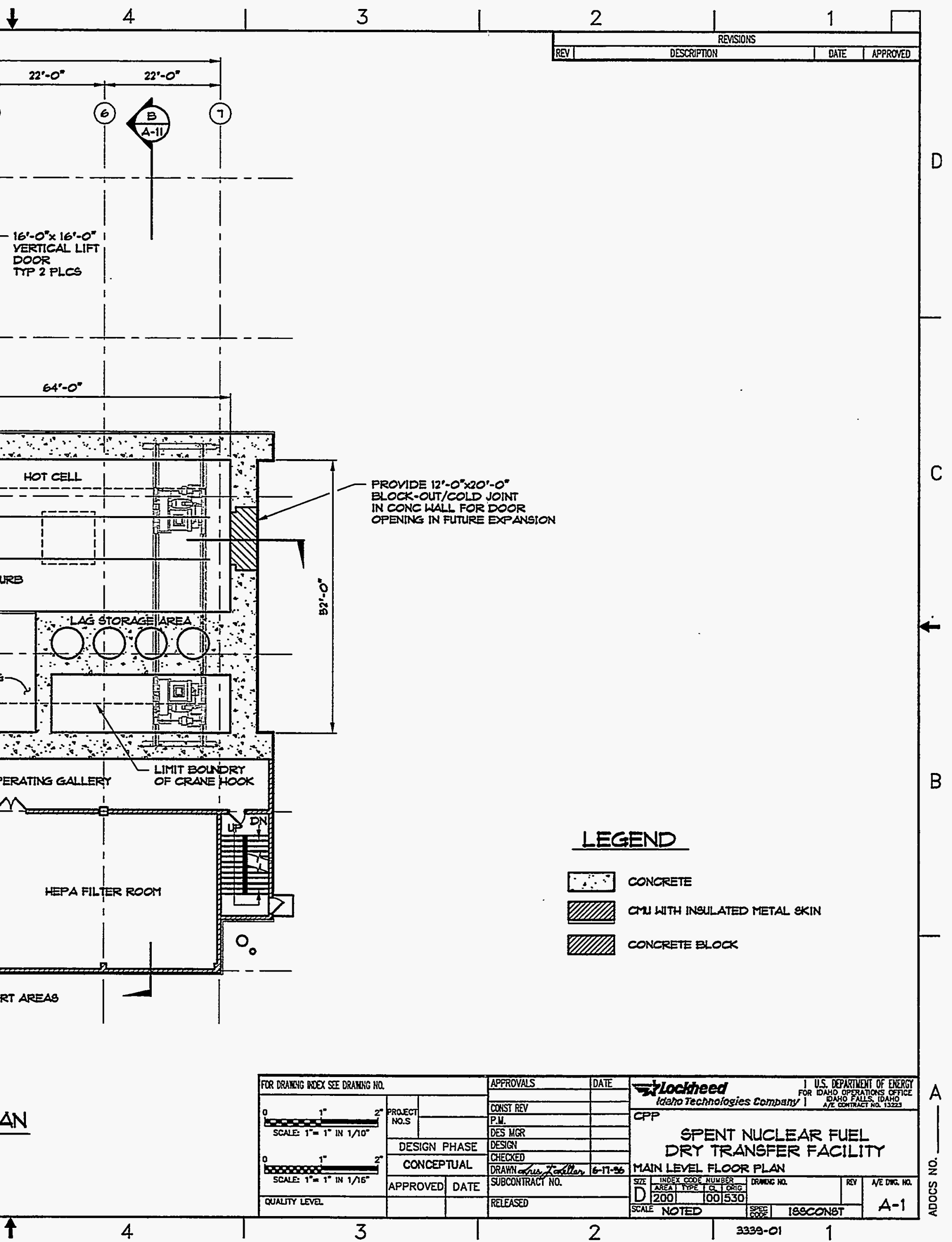




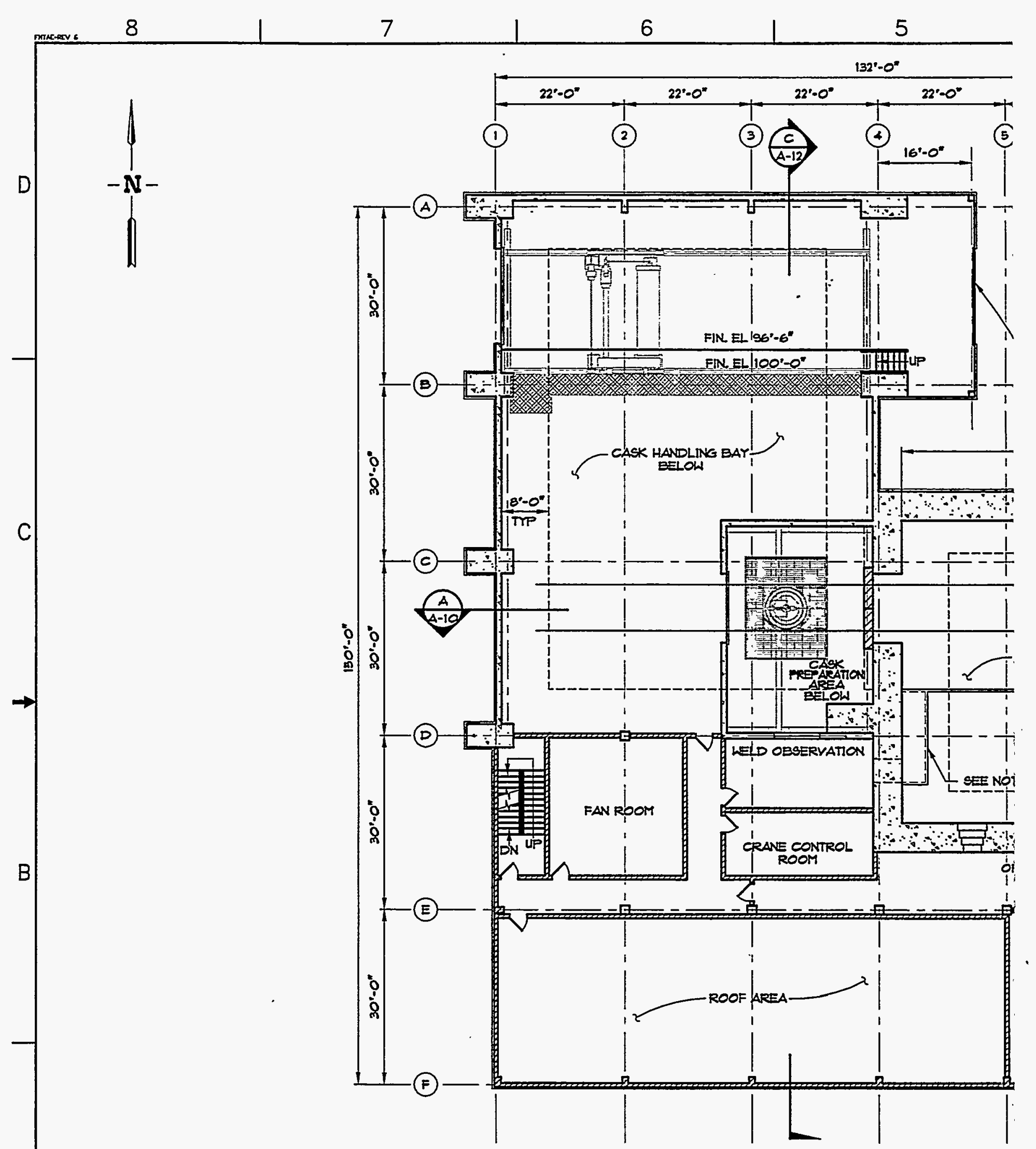




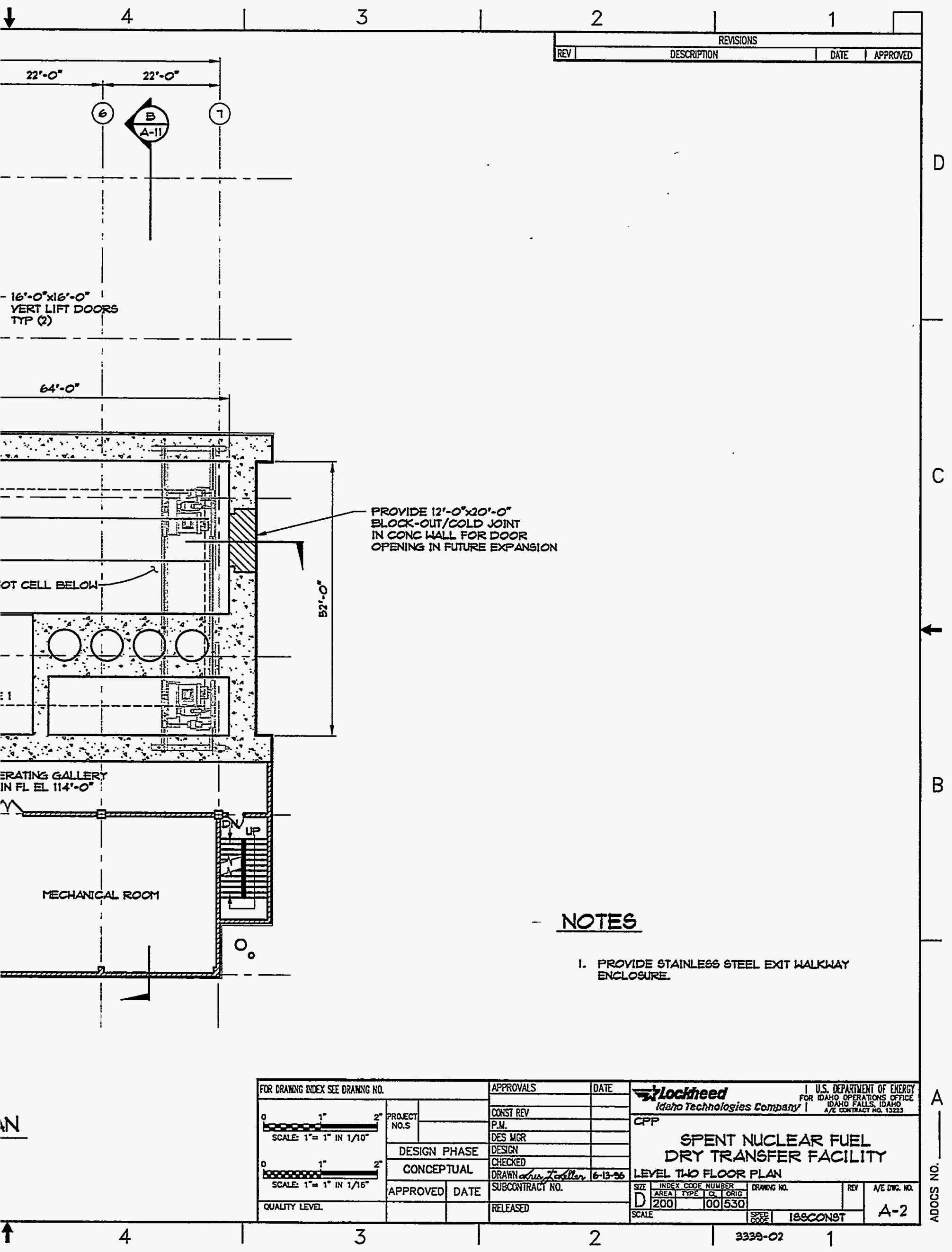




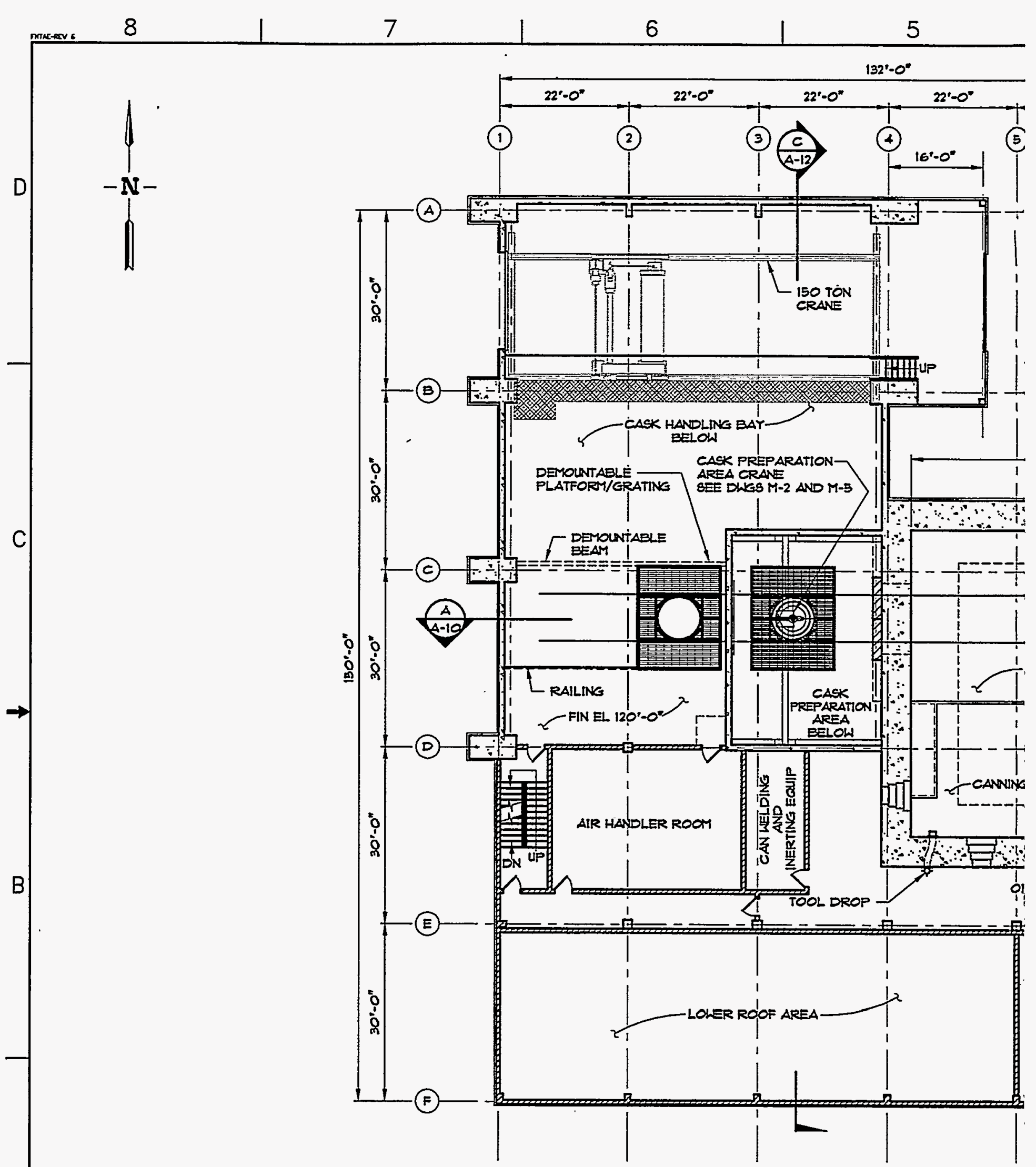

A

LEYEL THREE FLOOR PI SCALE: $3 / 32^{\prime \prime} \times 11^{\circ}-0^{\prime \prime}$ 


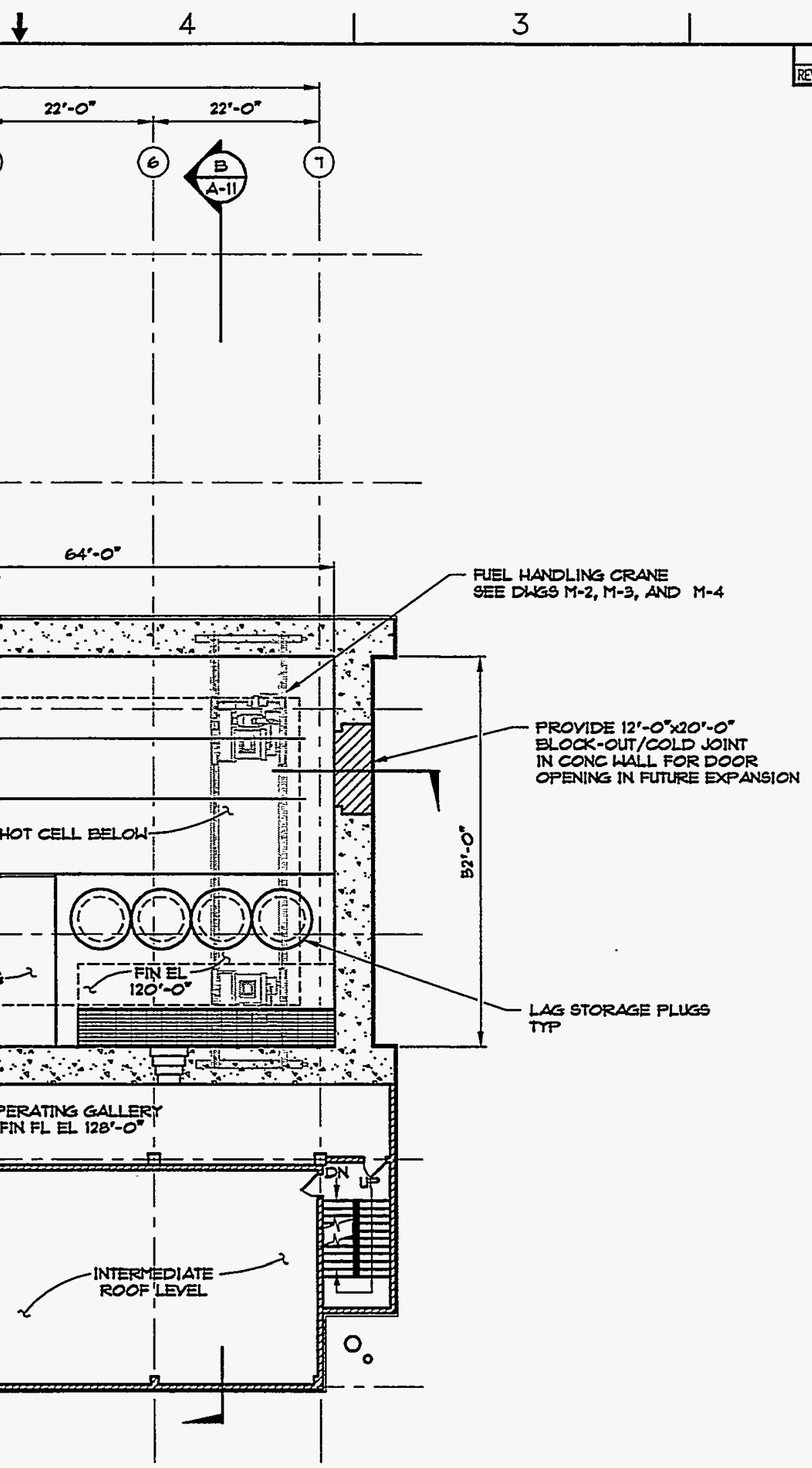

PPNING IN FUTURE EXPANSION

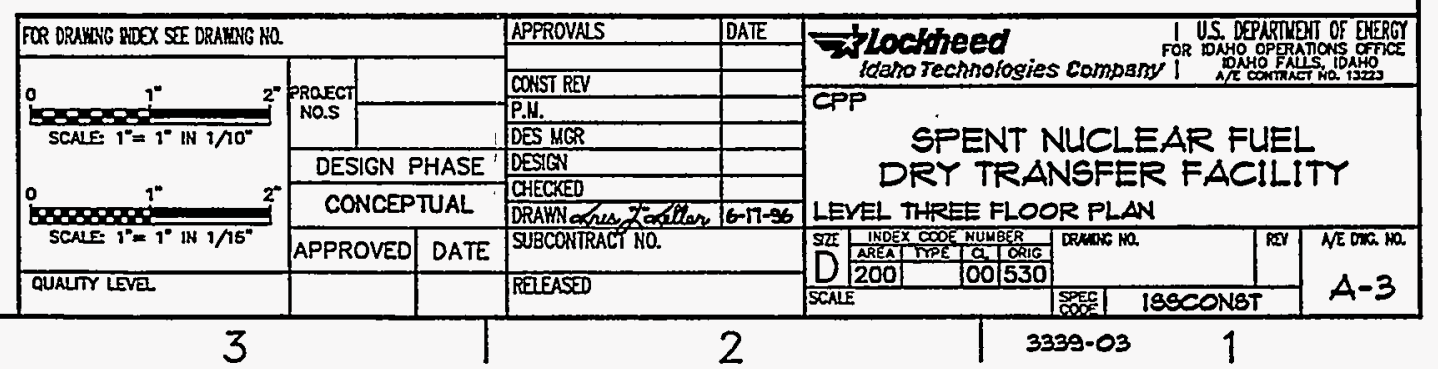

$A$ 


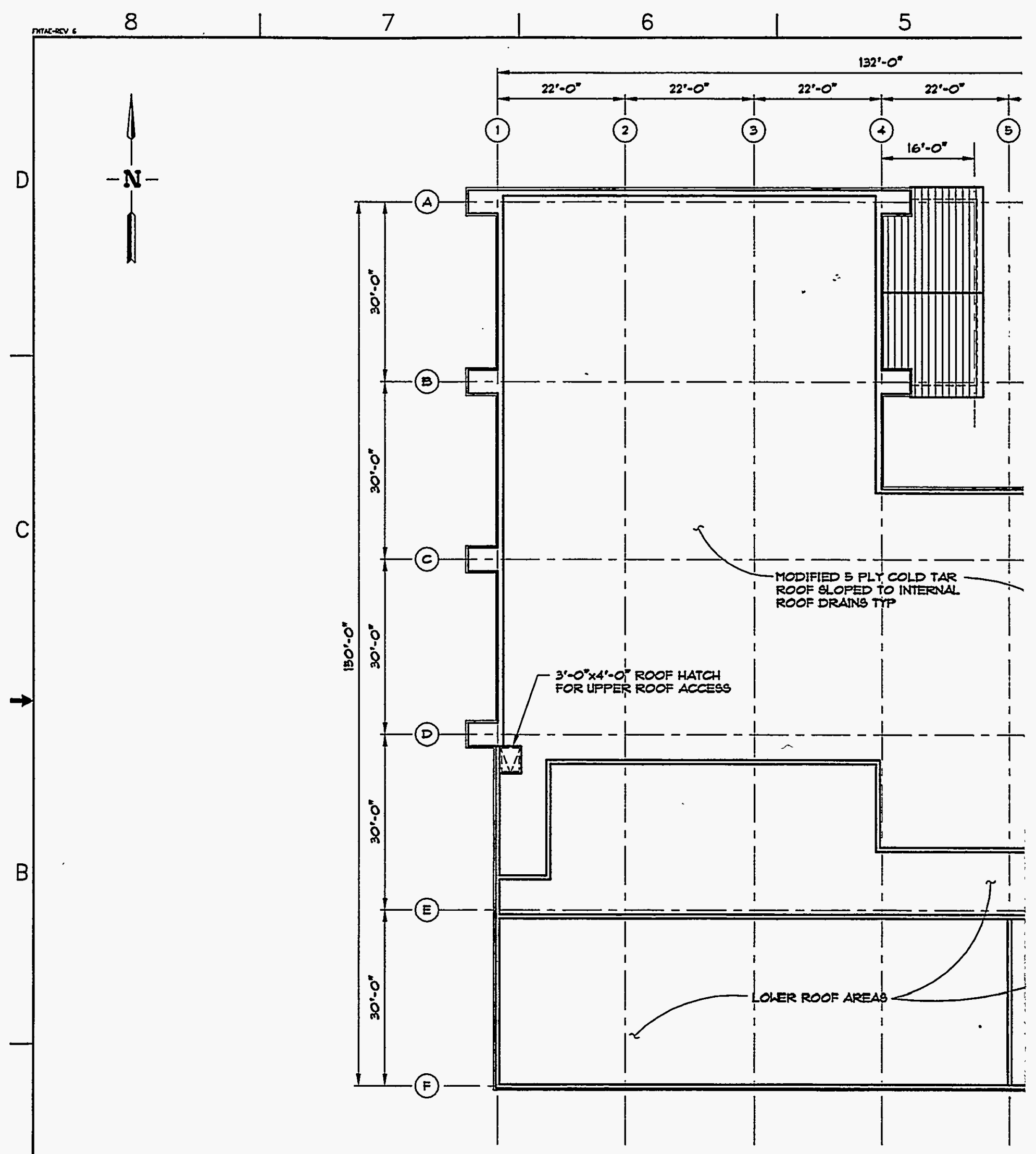




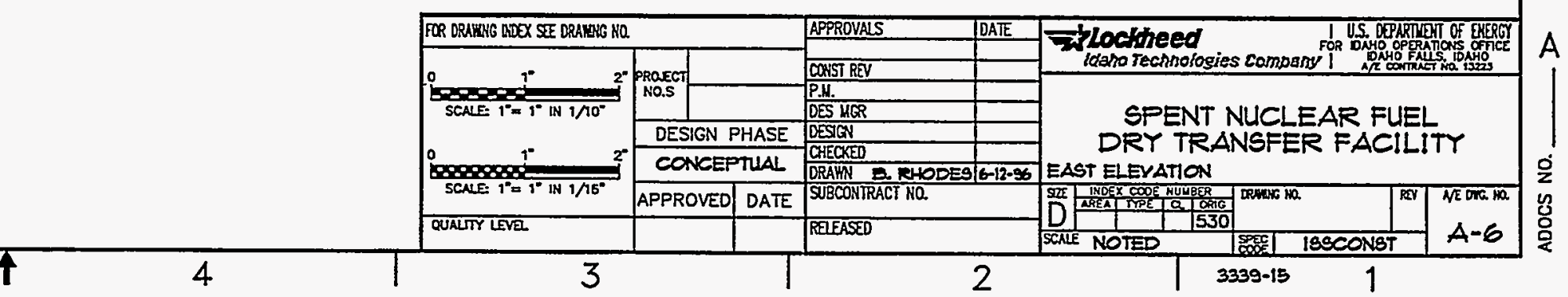




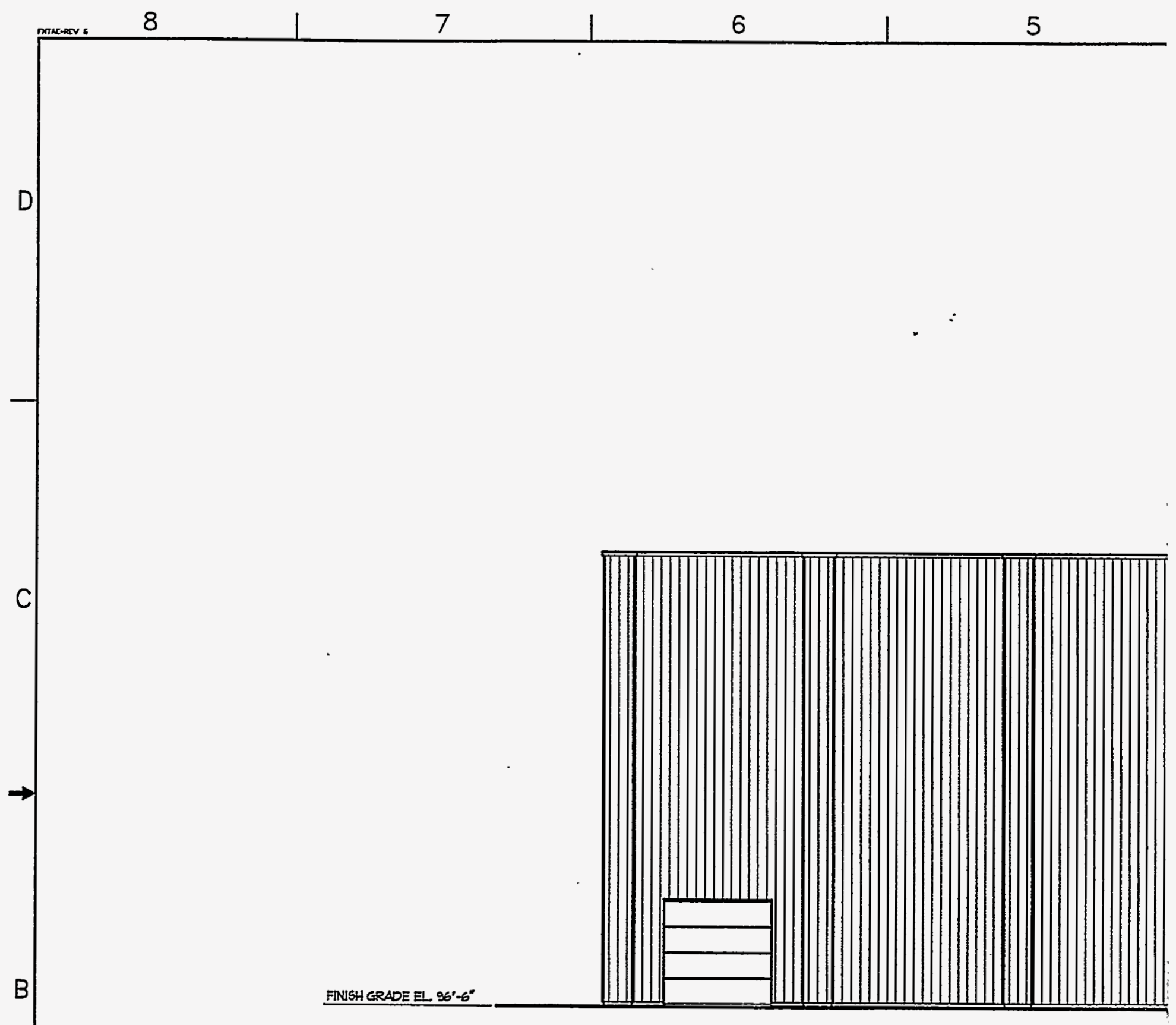
$\frac{\text { WEST ELEYAT| }}{\operatorname{SCALE:~} 3 / 32^{\circ}=1^{\circ} \cdot 0^{\circ}}$ 


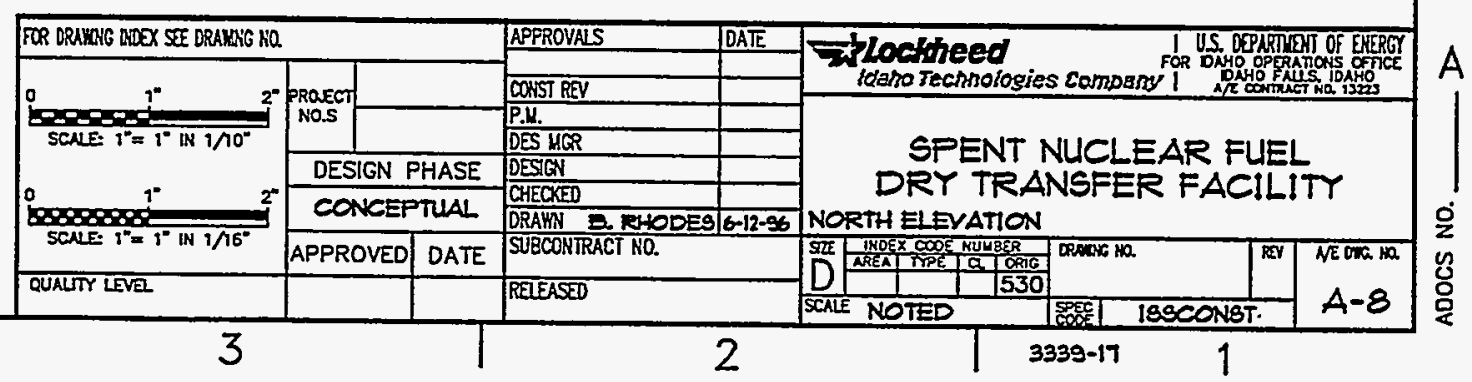


TOP OF PARAPET EL 164'-O"

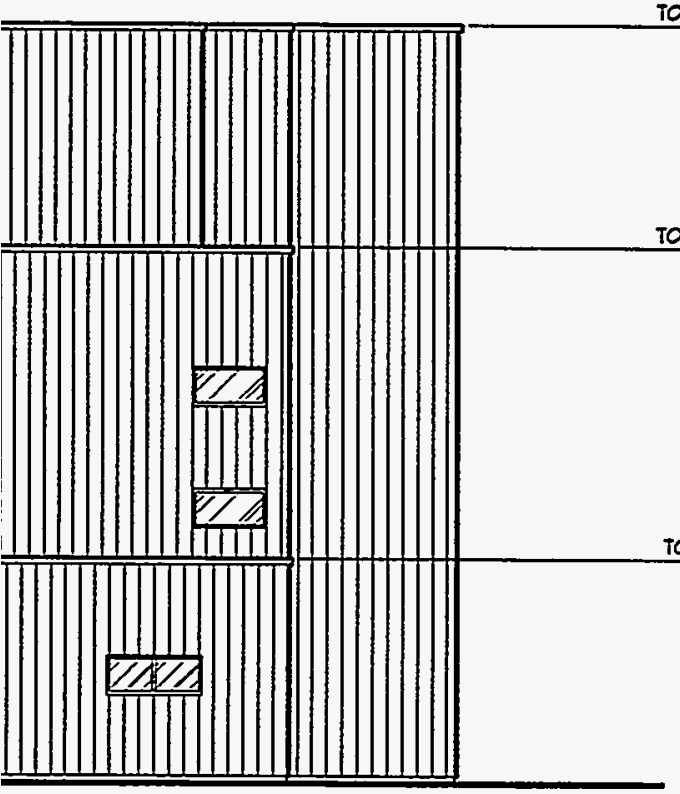

TOP OF PARAPET EL 144'-0"

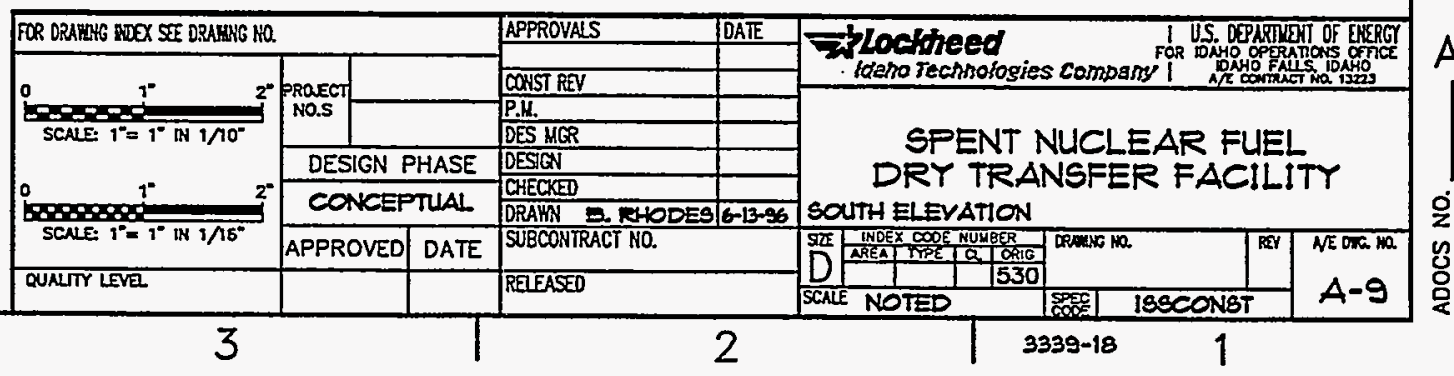




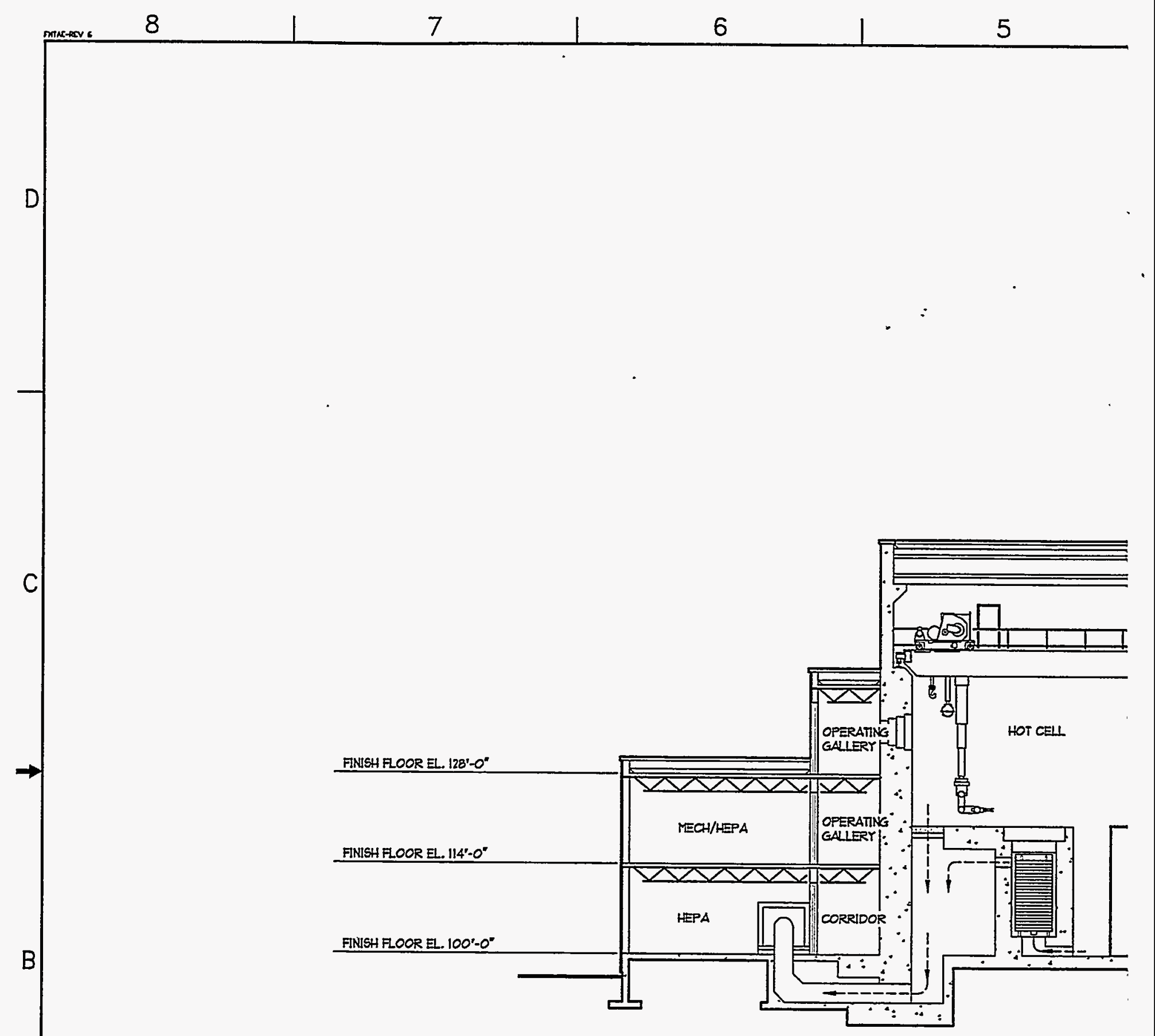

SECTION SCALE: $3 / 32^{\prime \prime}=1^{\prime}-0^{\prime \prime}$

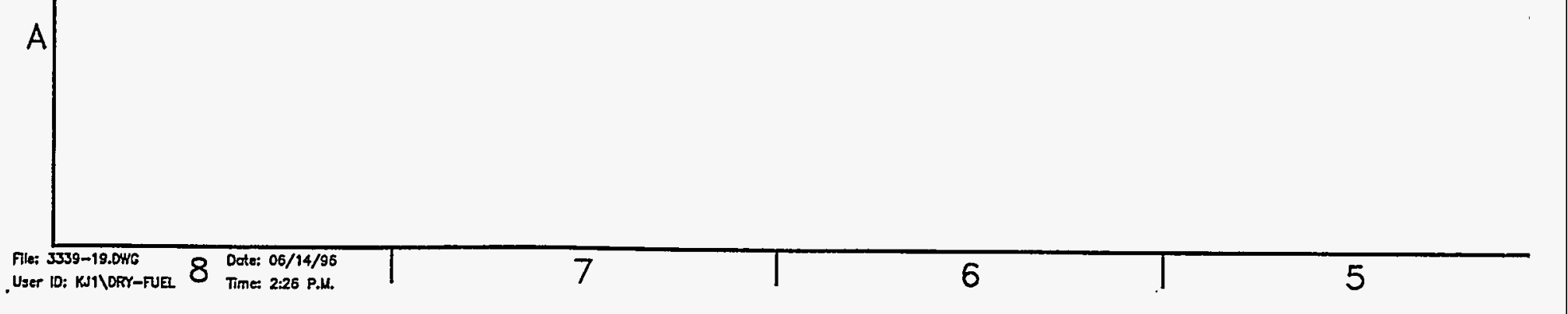




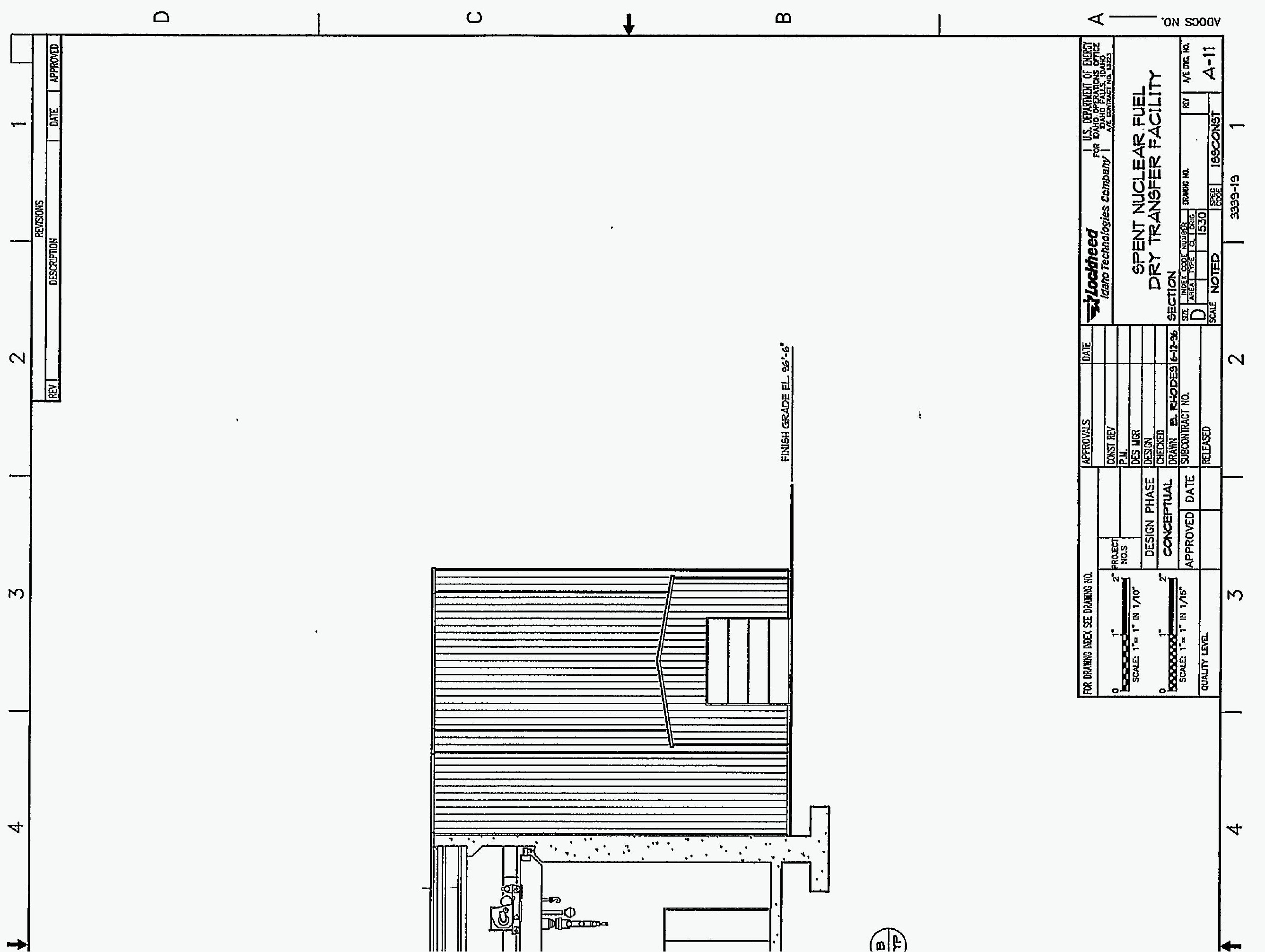




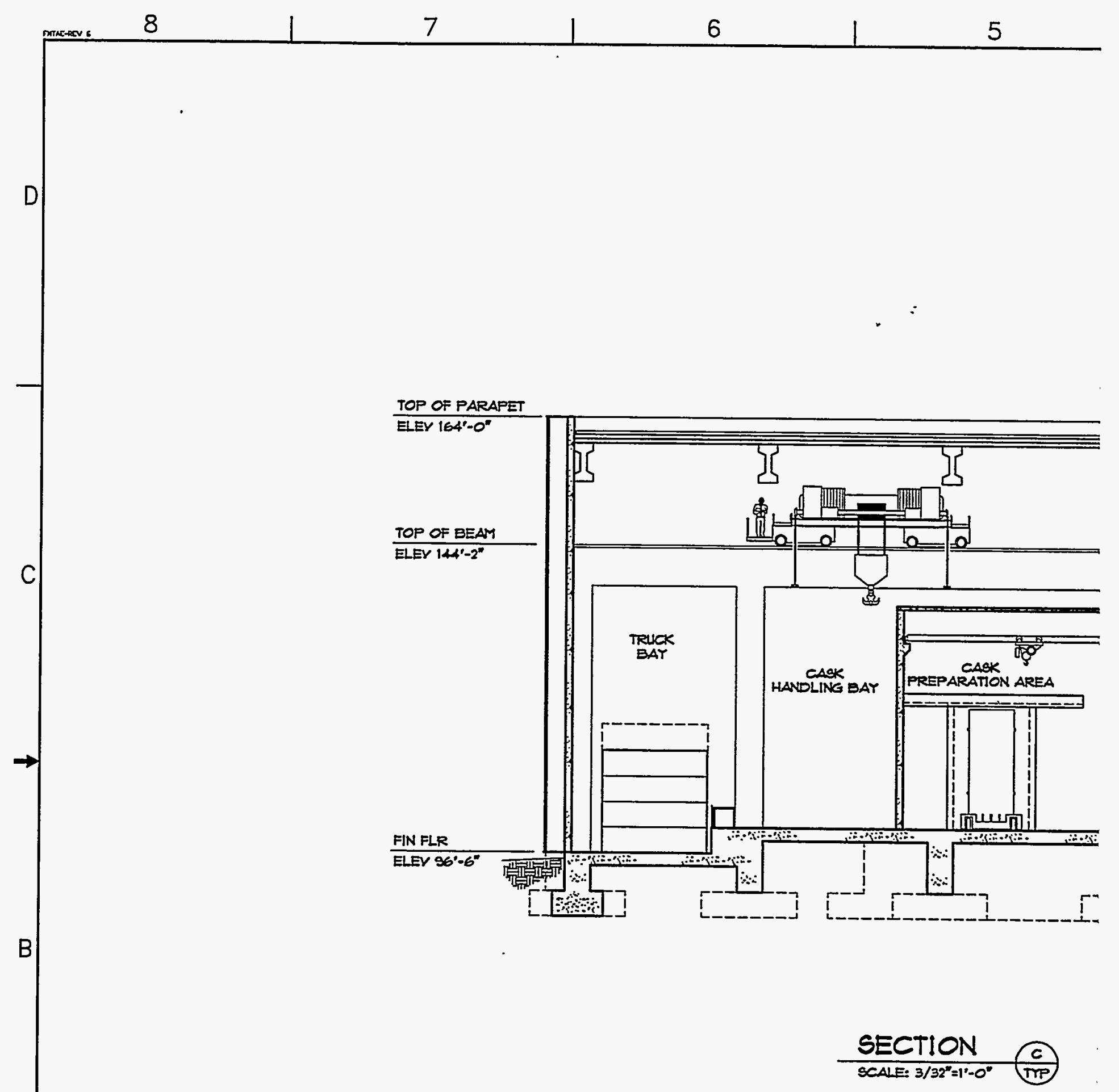

A 


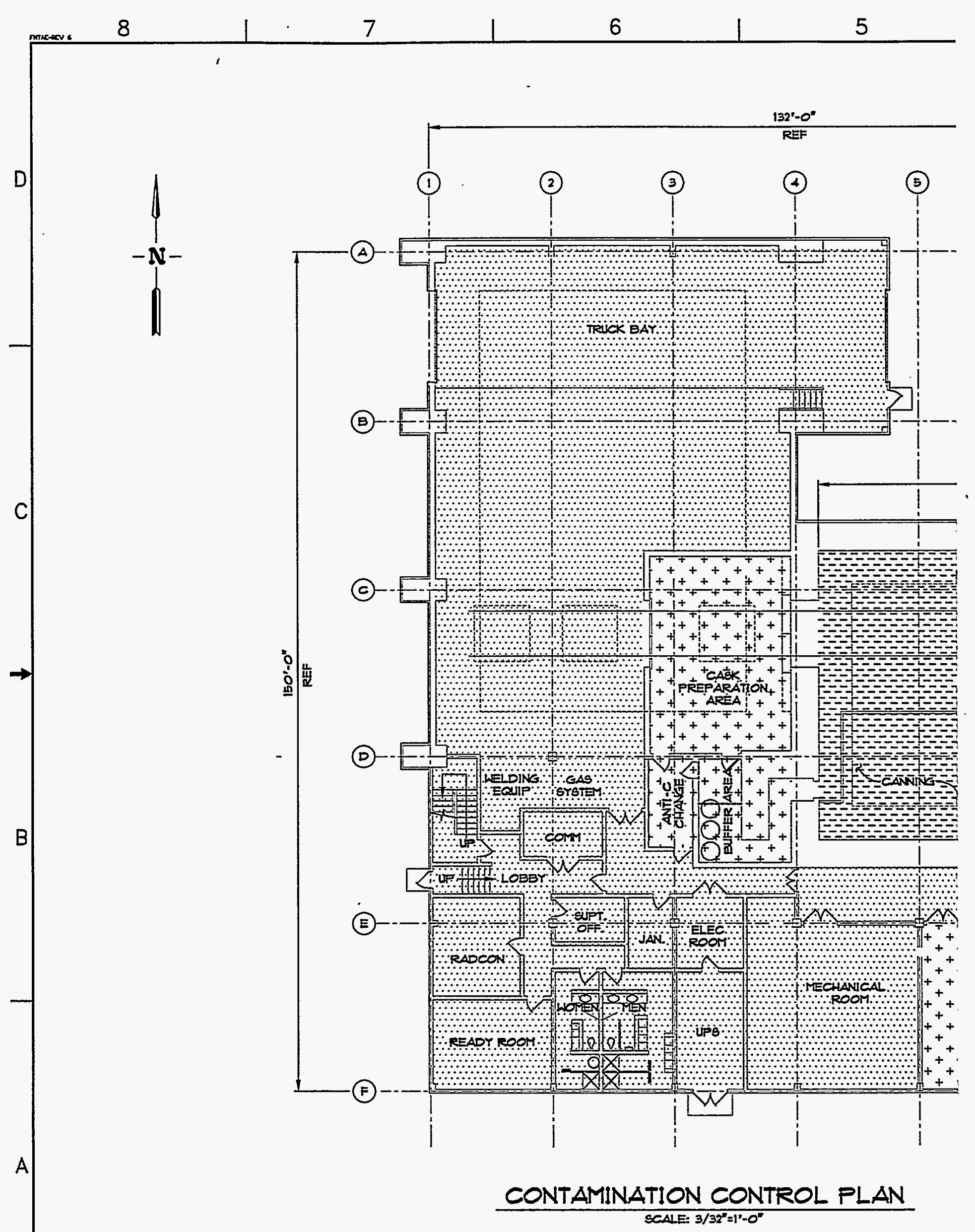




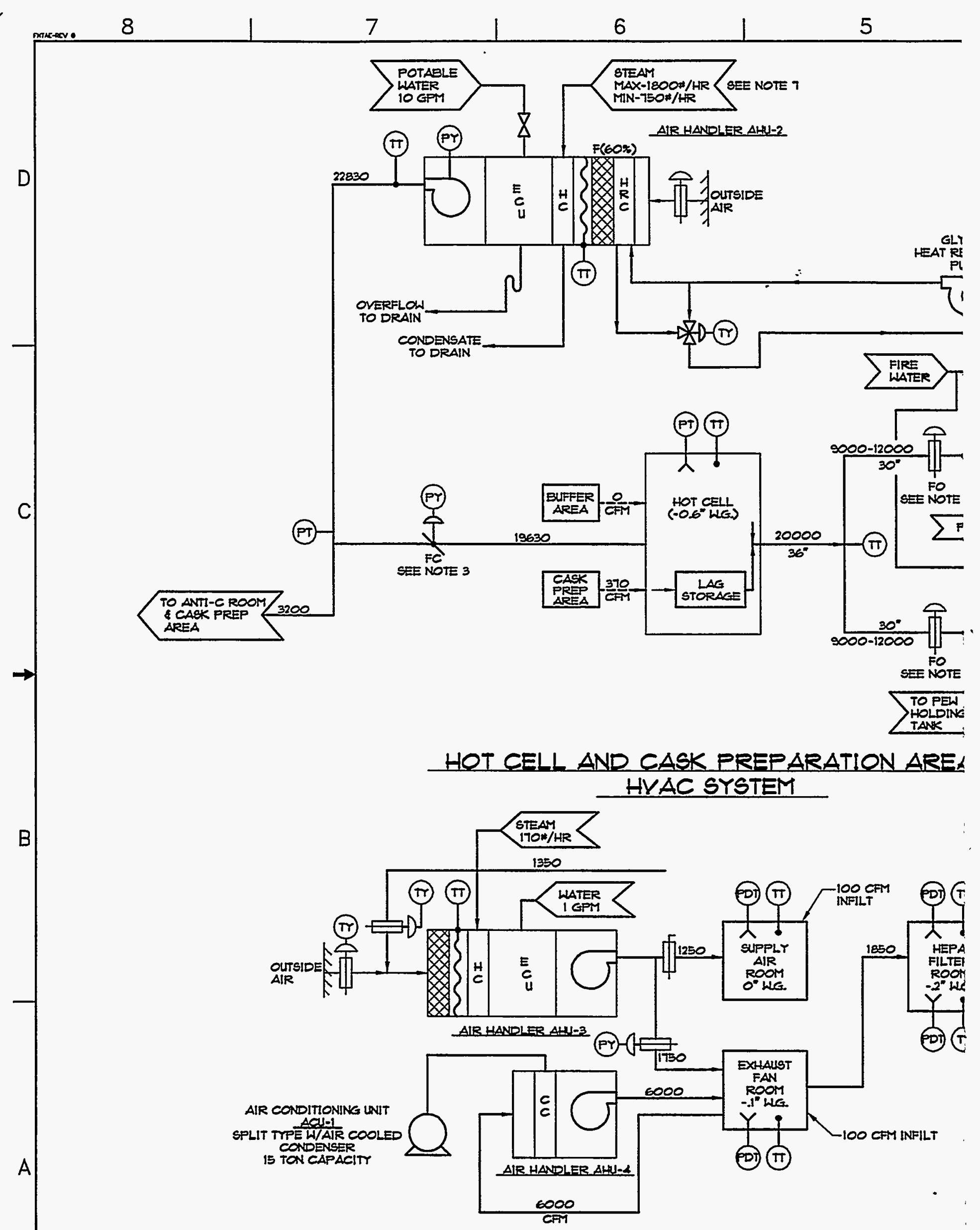

UTILITY SUPPORT AREA HYAC SYSTEM 


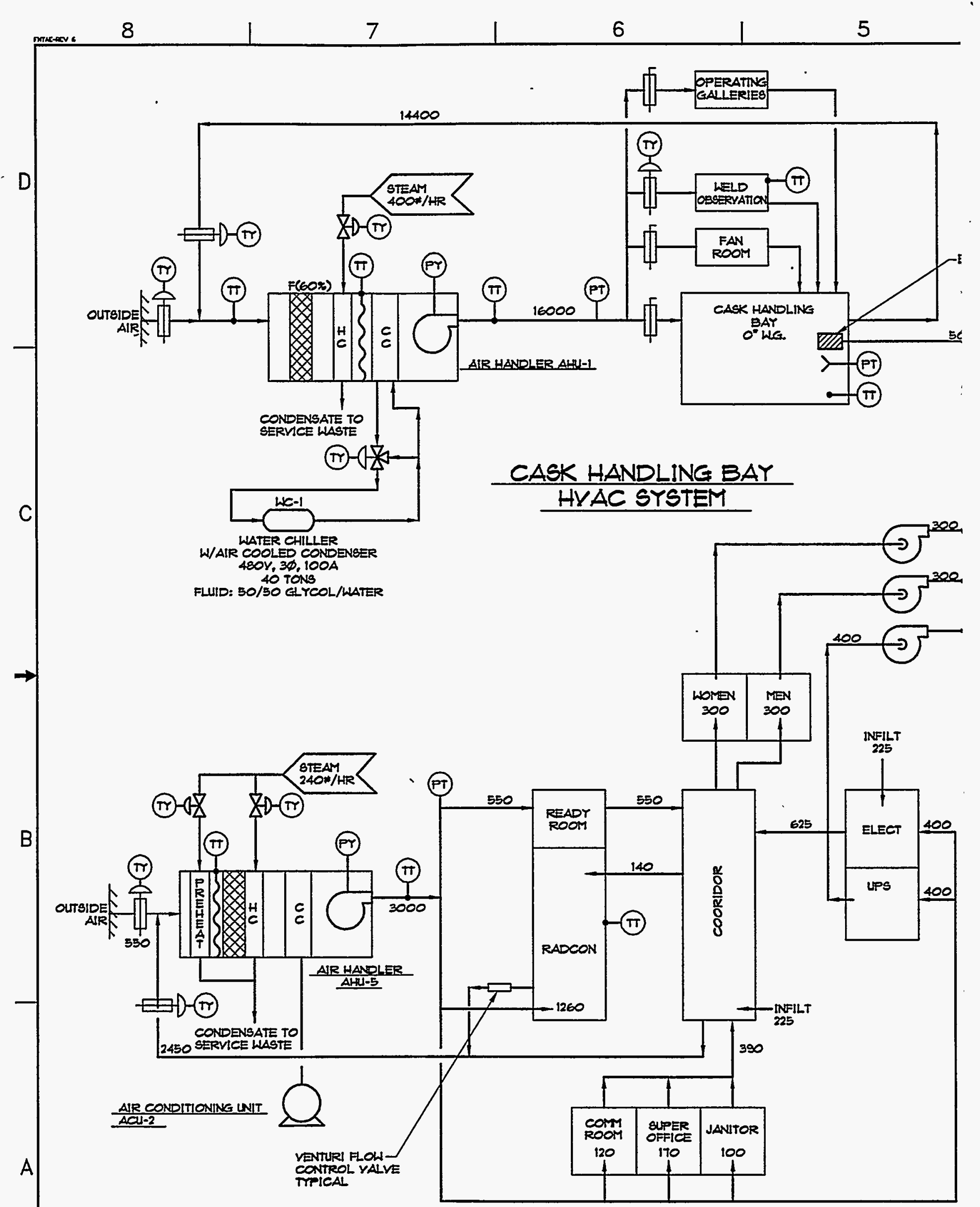

ADMINISTRATIYE AREA HYAC SYSTEM 
HAUST HOSE

$\rightarrow T_{\text {EXHAUSTER }}^{\text {TRUCK }}$
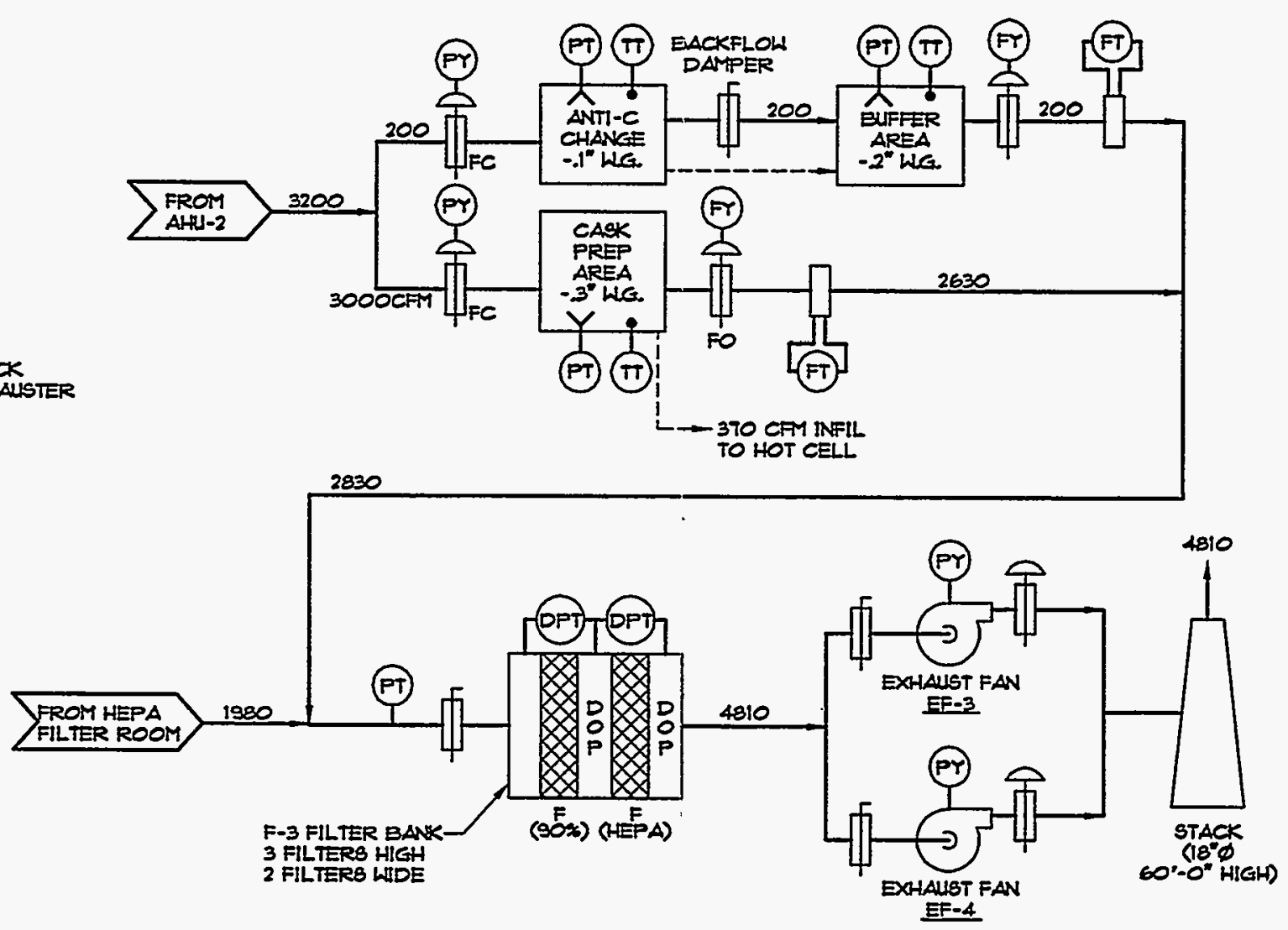

\begin{tabular}{|c|c|c|c|c|c|c|c|c|c|}
\hline \multicolumn{3}{|l|}{ FRR DRANAG HDOX SE DRANAG MQ } & \multirow{3}{*}{$\begin{array}{l}\text { APPROVALS } \\
\text { COISTREV } \\
\end{array}$} & \multirow[t]{2}{*}{ DATE } & \multirow{2}{*}{\multicolumn{5}{|c|}{ 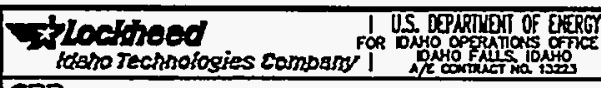 }} \\
\hline \multirow{5}{*}{ 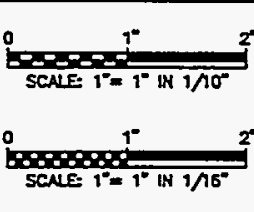 } & & & & & & & & & \\
\hline & No.s & & & & \multirow{3}{*}{\multicolumn{5}{|c|}{$\begin{array}{l}\text { SPP } \\
\text { DRNT NUCLEAR FUEL } \\
\text { DRY STORAGE FACILITY } \\
\text { HYAC SCHEMATIC }\end{array}$}} \\
\hline & DESIGN F & & $\begin{array}{l}\text { DES UGR } \\
\text { DESGN }\end{array}$ & & & & & & \\
\hline & \multicolumn{2}{|c|}{ CONCEPTUAL } & & $5 / 96$ & & & & & \\
\hline & APPROVED & DATE & SUBCONTRACT NO & & 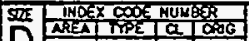 & Dadse ka & & लD & Aहnána \\
\hline QUNUT LEVE & & & REEASED & & \begin{tabular}{|l|l|l|}
$\mathrm{D}$ & 200 \\
SCALE NONE
\end{tabular} & & ISSCONBT & & $H V-3$ \\
\hline
\end{tabular}




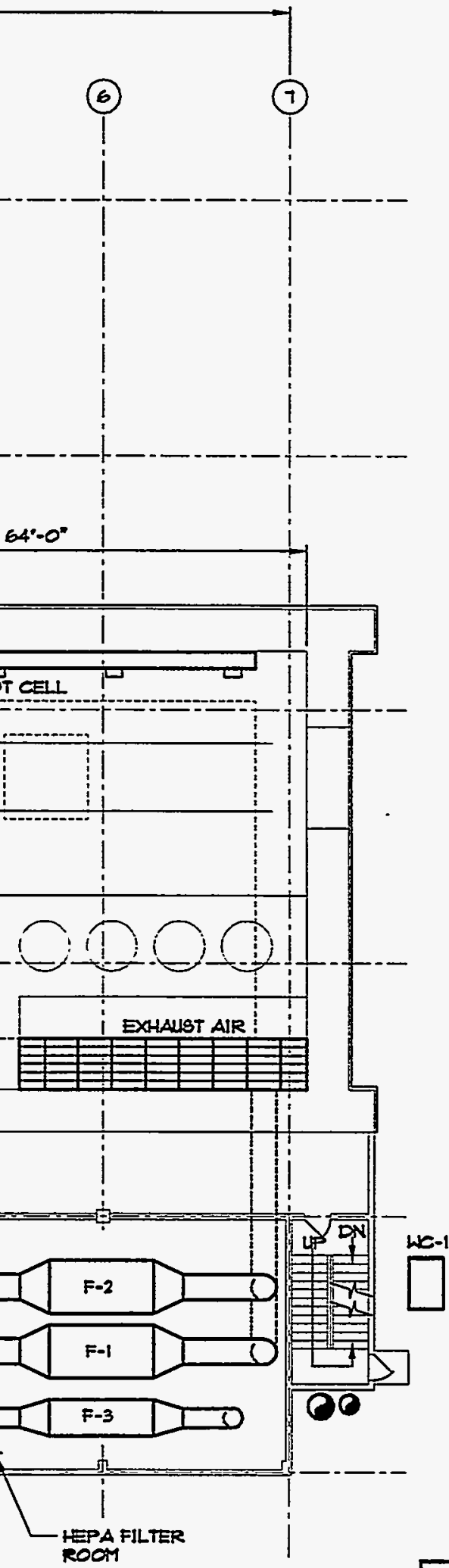

WE-1 NOTES

1. DUCTING IS SHOWN FOR LAYOUT AND IS NOT TO SCALE.

2. DUCTING FOR ADMINISTRATIVE AREA TO BE ROUTED FROM AHI-5 TO ALL AREAS AS SHOWN ON DRALINE HY-3.

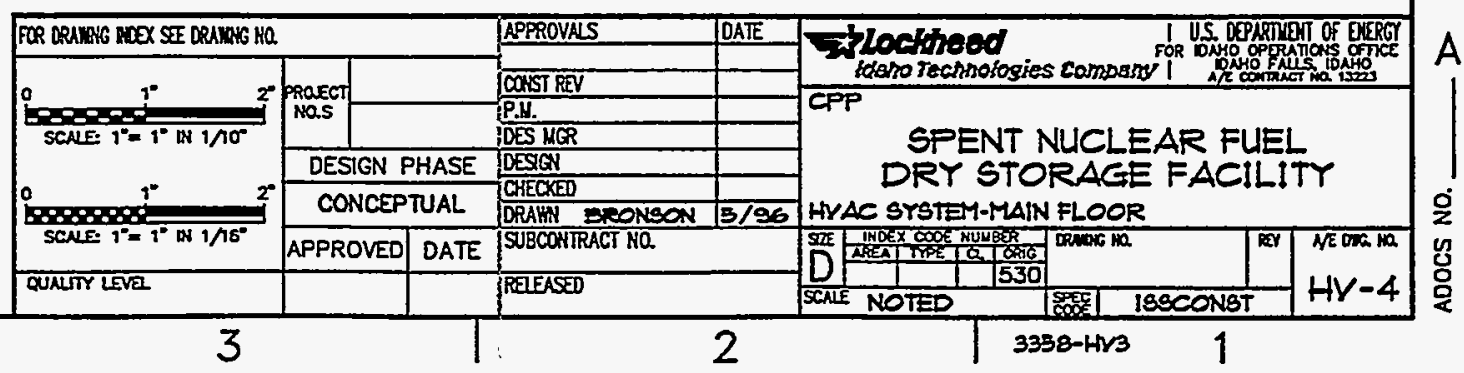




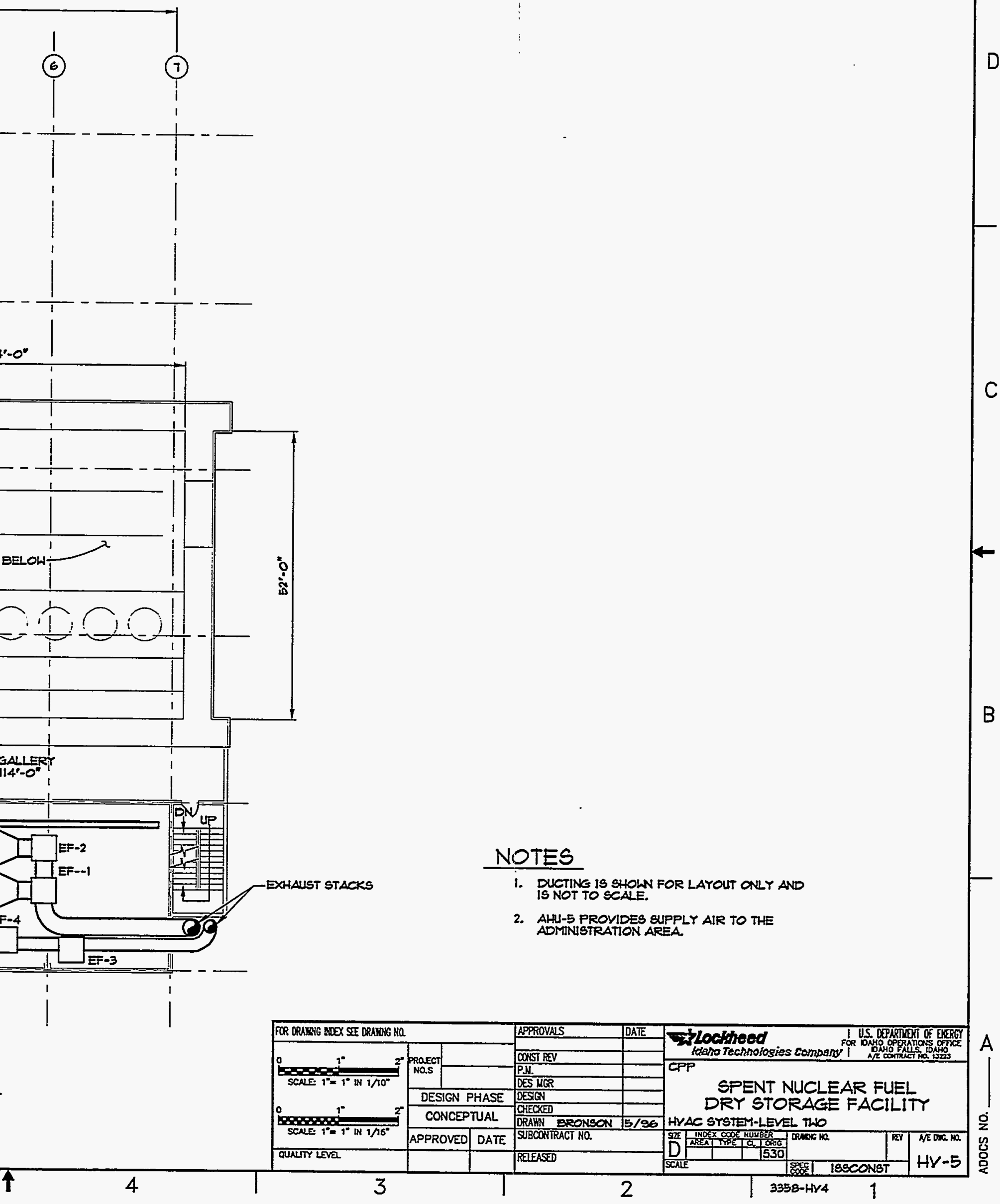




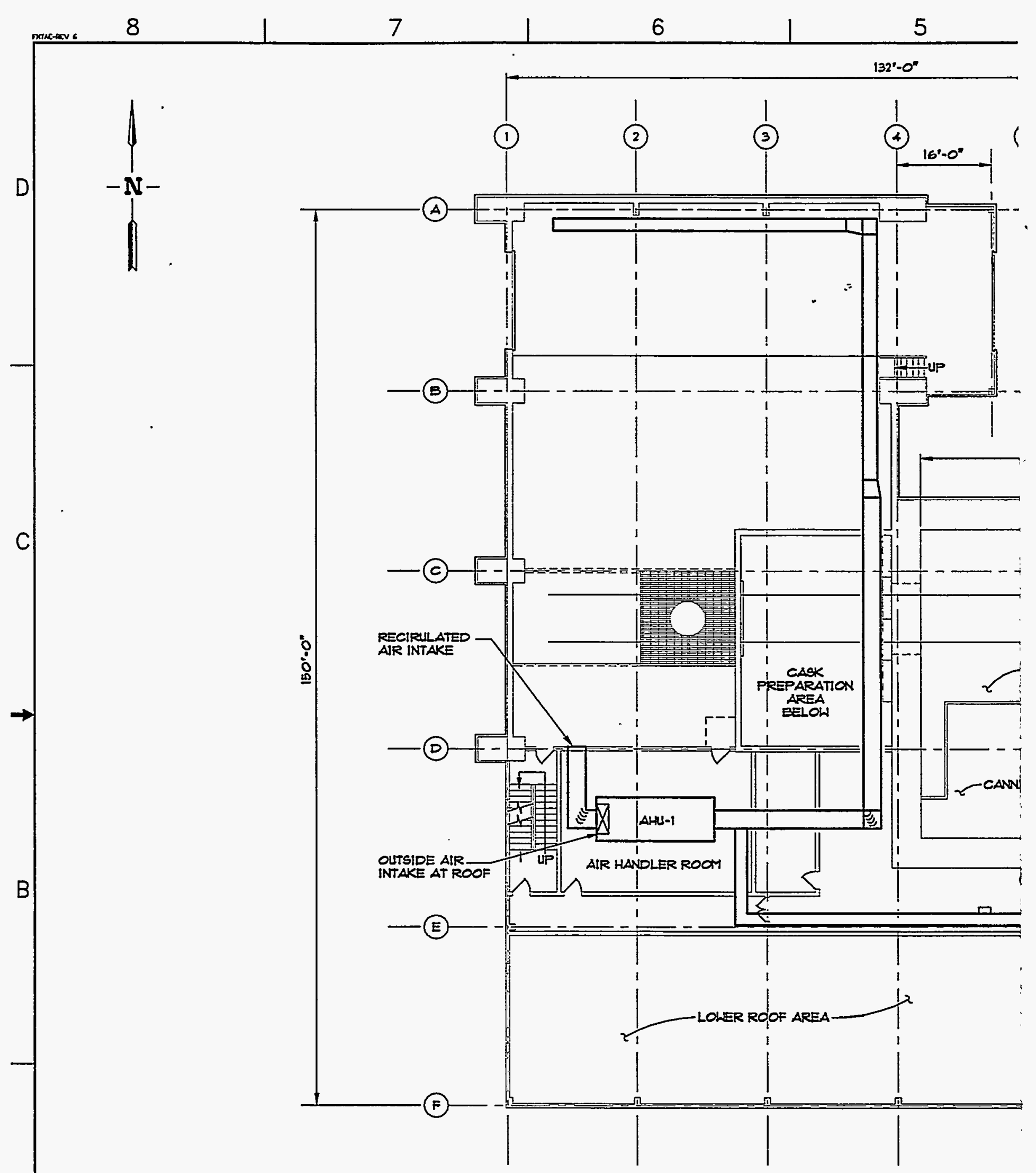




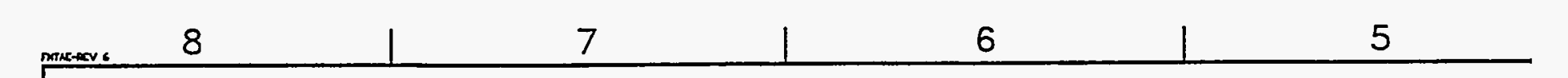

\section{LOAD CENTER 3480 YAC, 3 PH, COMM/STAND-BY}

$\mathrm{D}$

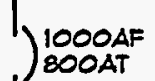

C

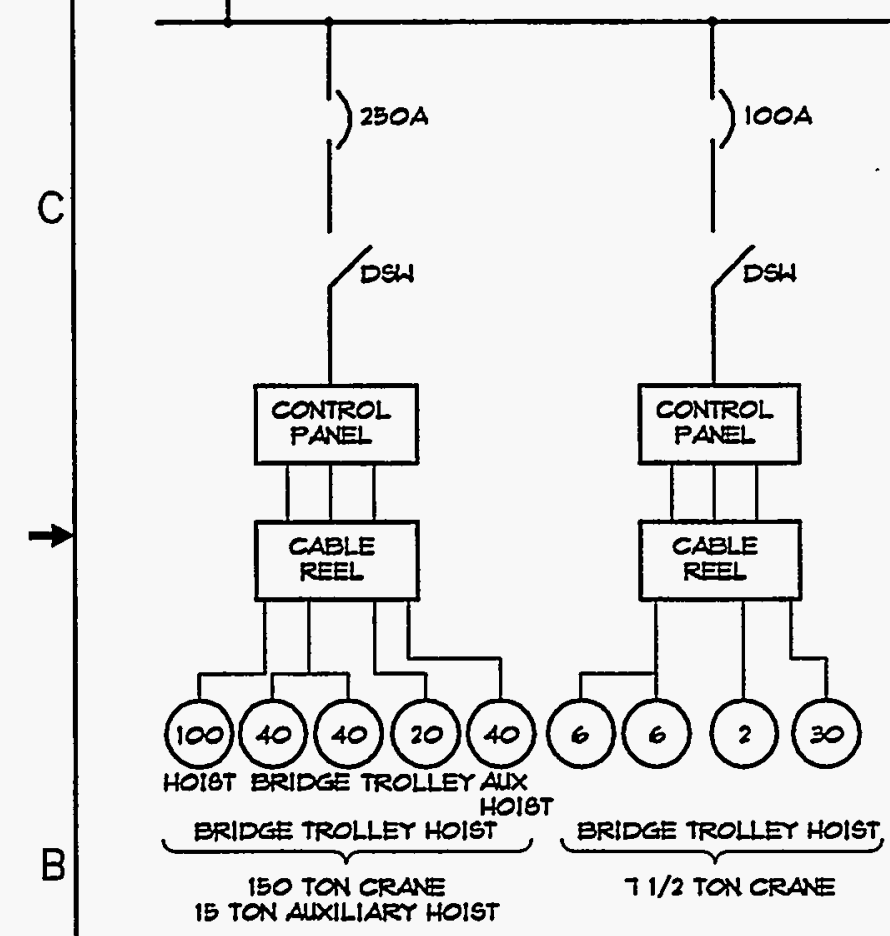

$\int_{G=1}^{800 A T}$

(A)

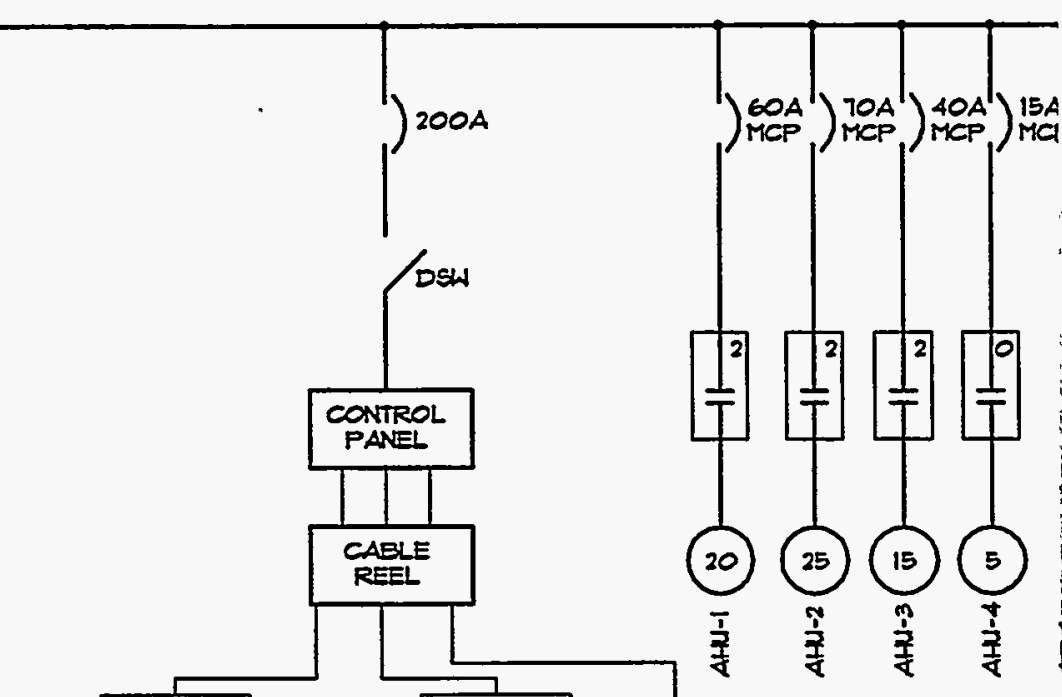

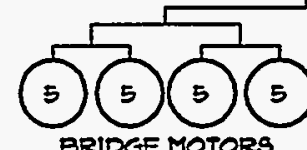

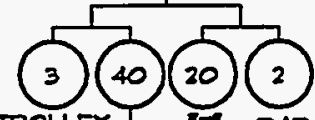

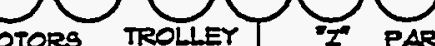
HOIST MOTIONARM

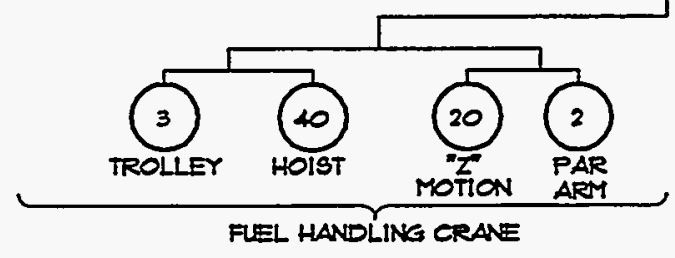

480/27TY CASK DISTRIEUTI

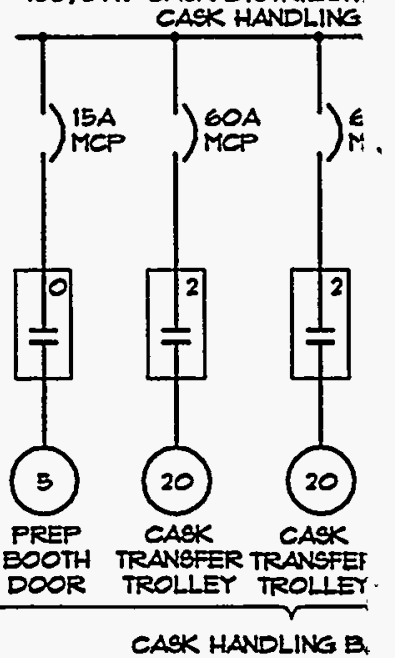

A

ONE-LINE DIAGRAM 


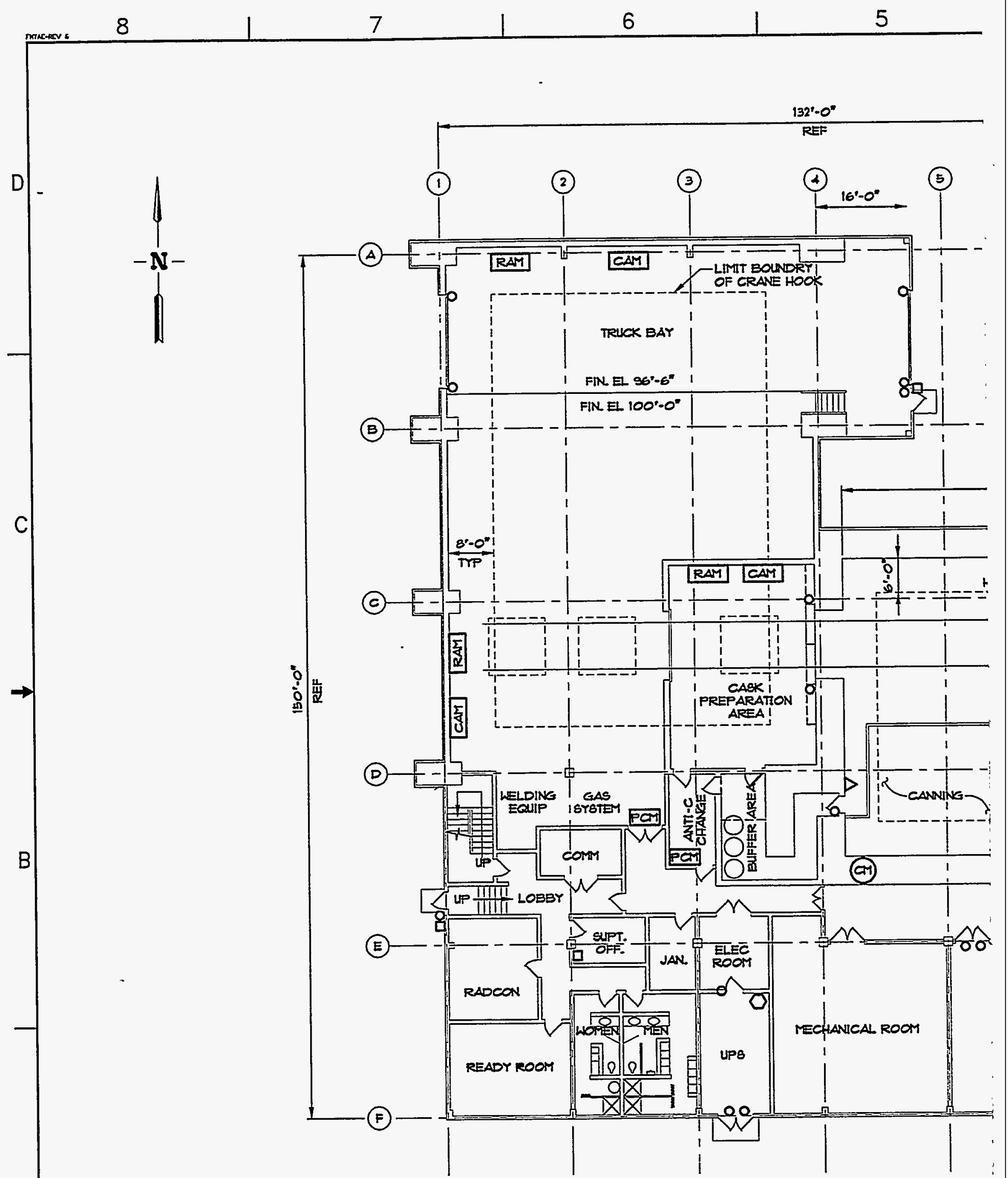

A

MAIN LEYEL FLOOR PLAN

SCALE: $3 / 32^{\circ}=1^{\prime}-0^{\prime \prime}$ 
(6)

(9)

\section{LEGEND}

(9ii) CRITICALITI MONITOR

ECM PERSONEL CONTAMINATION MONITOR

CAT BETAVGAMMA CONGTANT AIR MONITOR

RAM RADIATION AIR MONITOR

ACANA ALPHA CONSTANT AIR MONITOR
$\triangle$ PASSIVE INFRARED DETECTORS
口 REMOTE ACCESS PANEL (CARD READER)
c DoOr alarems
C) AREUS FIELD PANEL

HEPA FIL TER ROOT

$\Delta M$

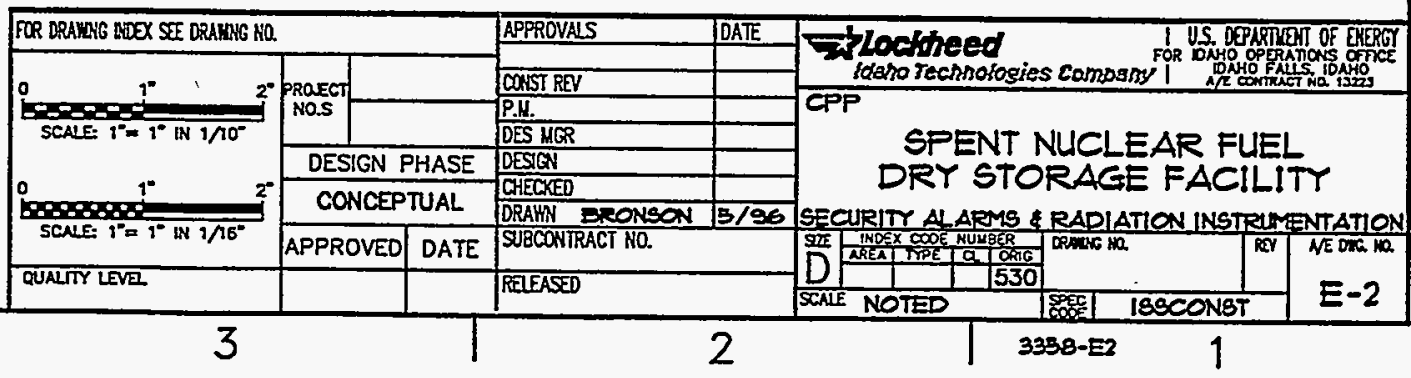




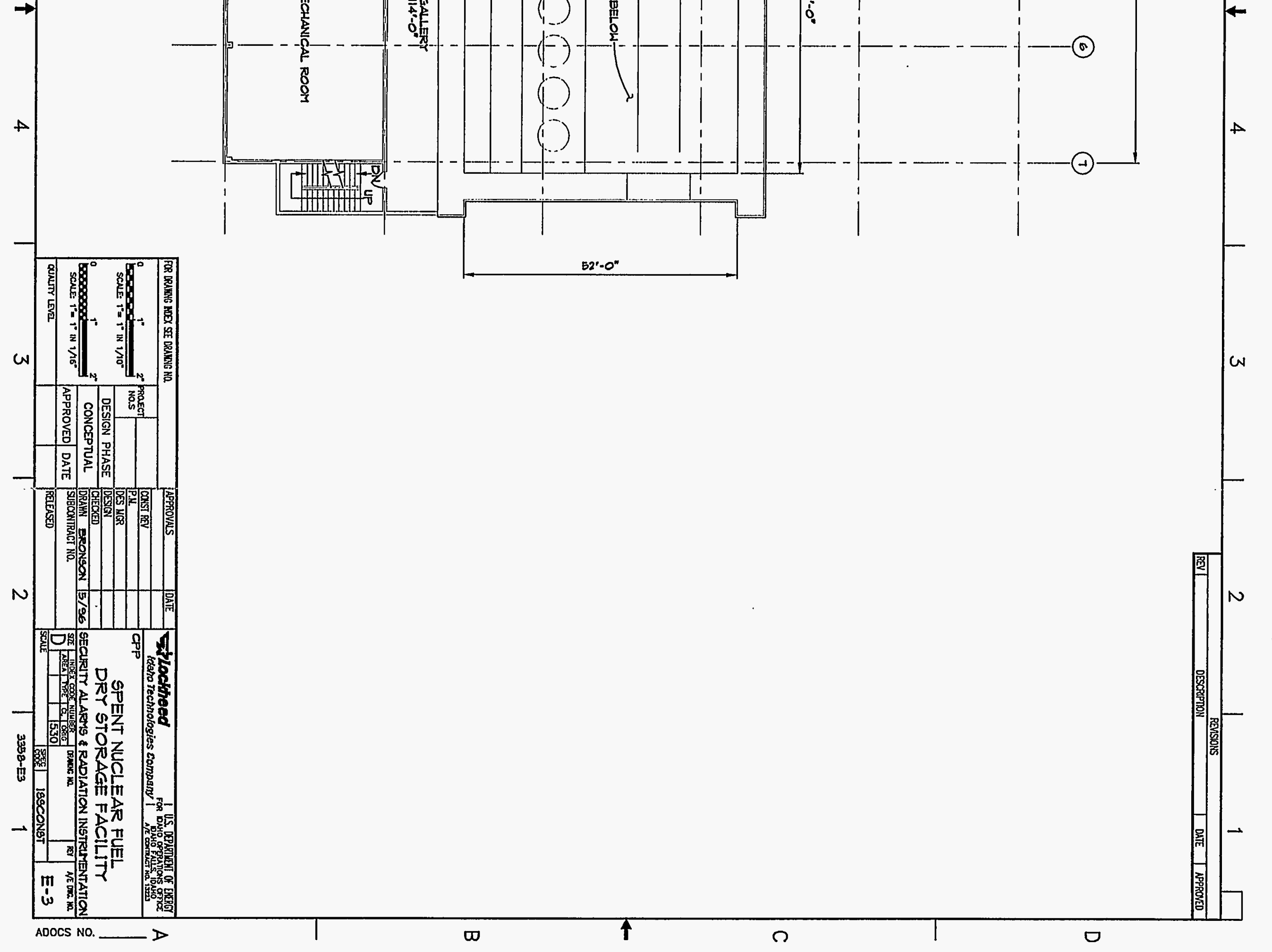




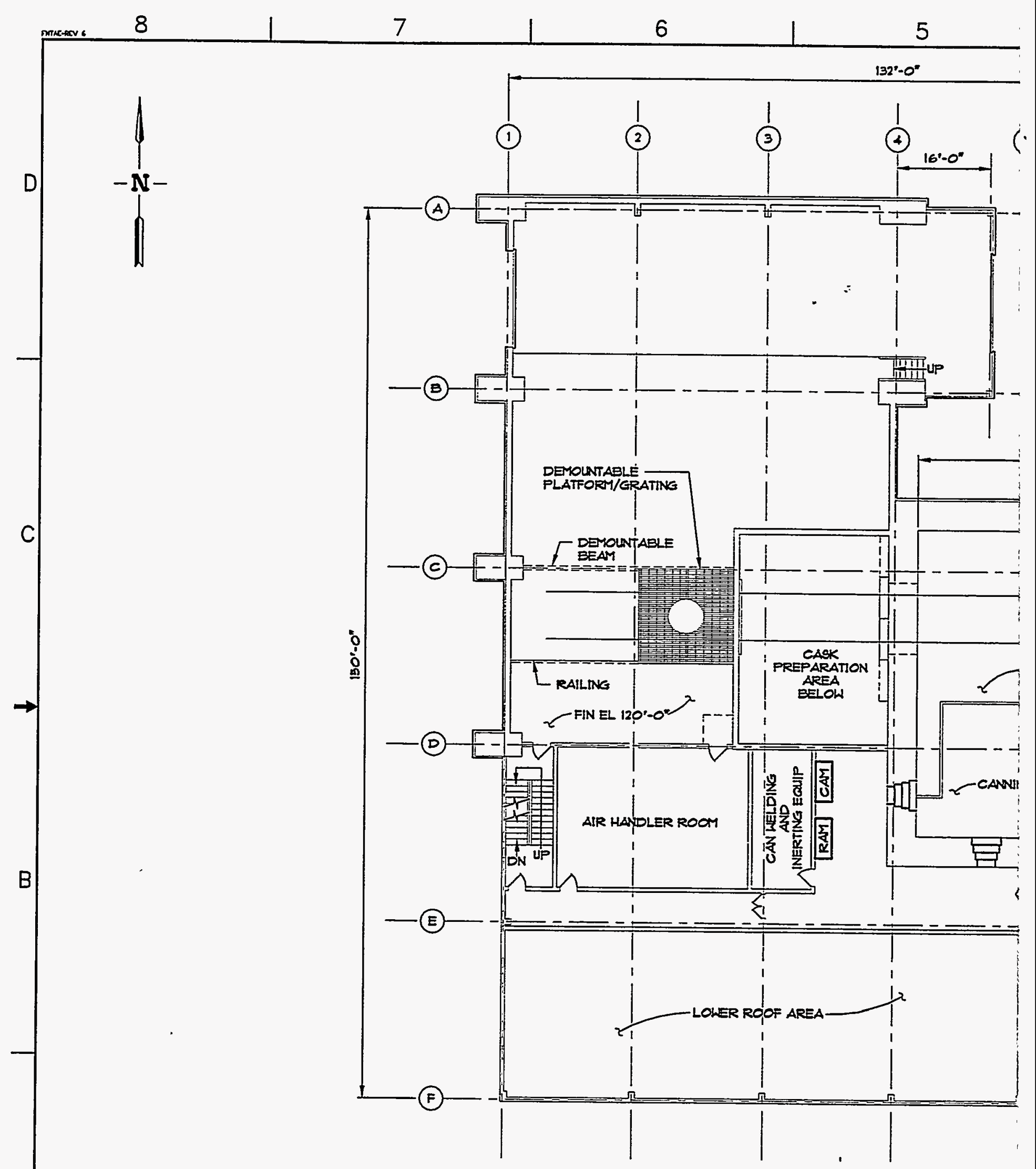

LEYEL THREE FLOOR F SCALE: 3/32"x1"-0 


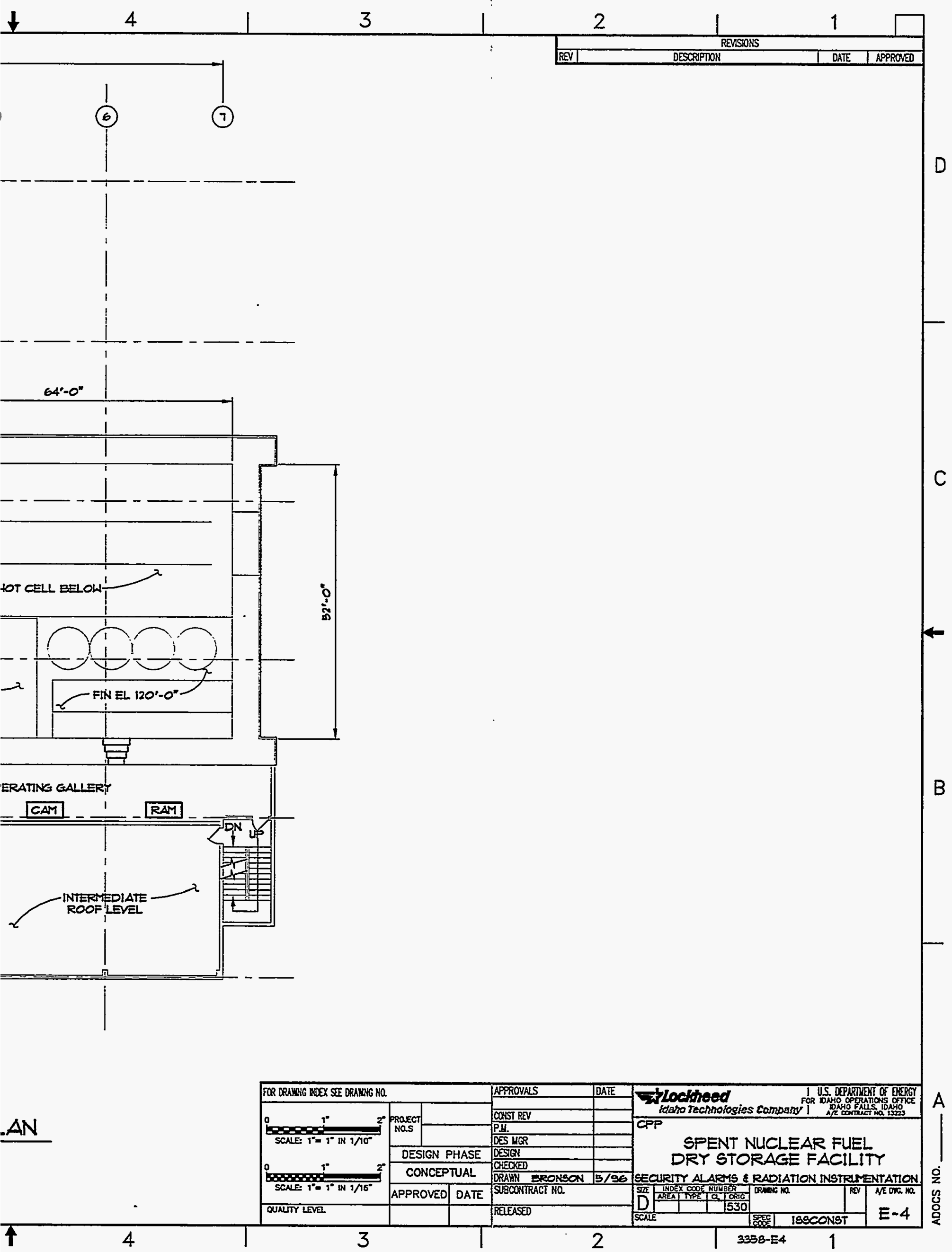




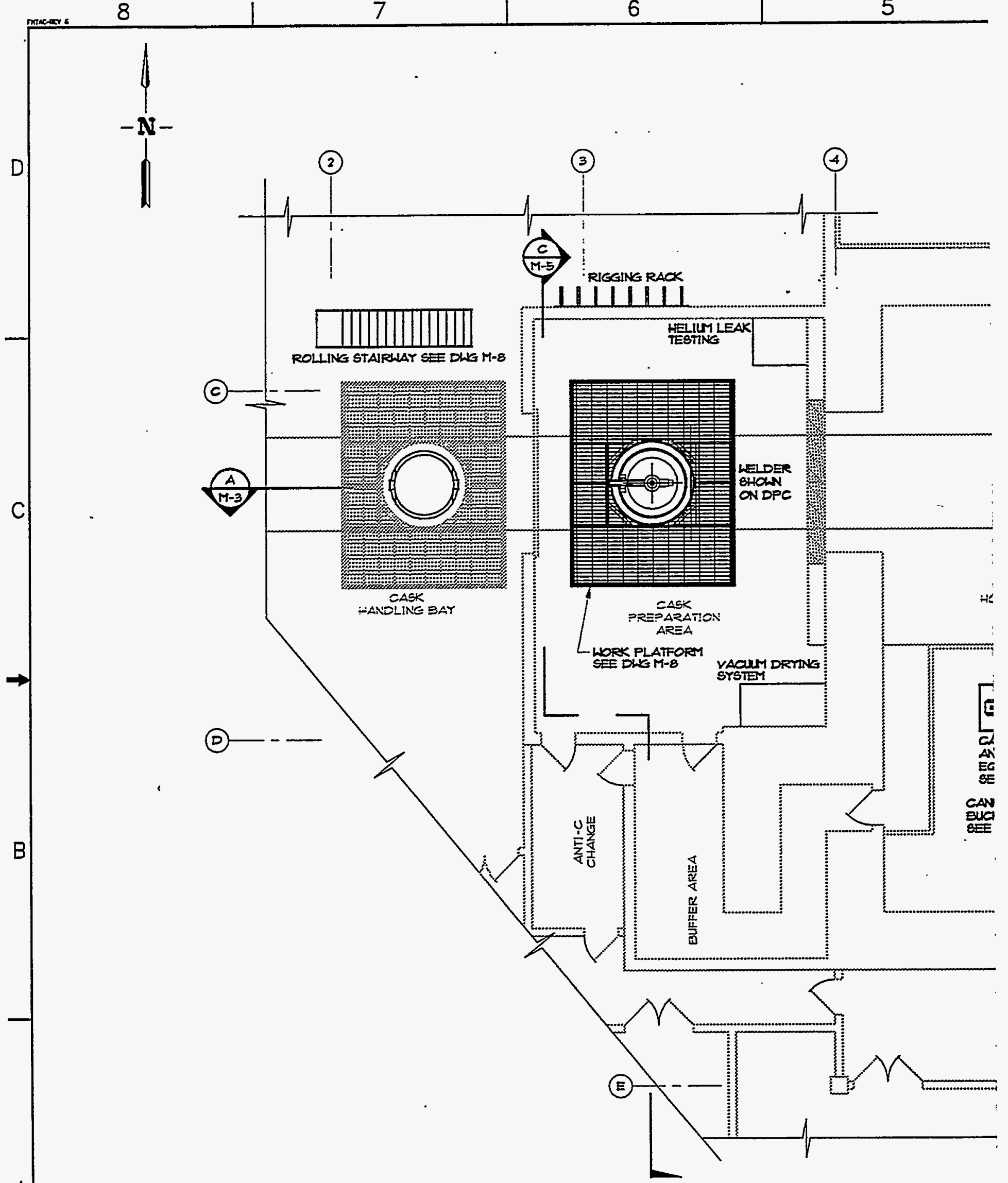

PARTIAL MAIN FLOOR EQUIPMENT ARRANGEN SCALE $3 / 16^{\circ}=1^{\prime}-0^{\circ}$ 
(5)

(6)
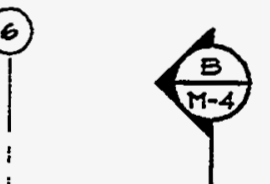

(T)
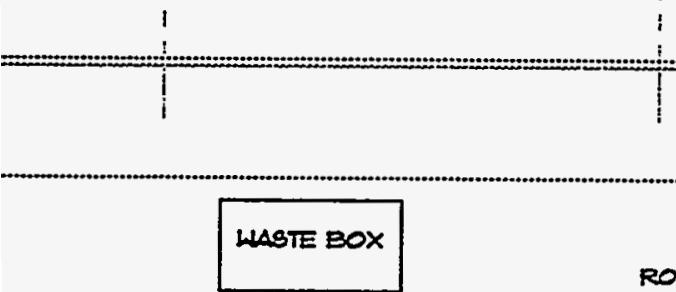

i

|
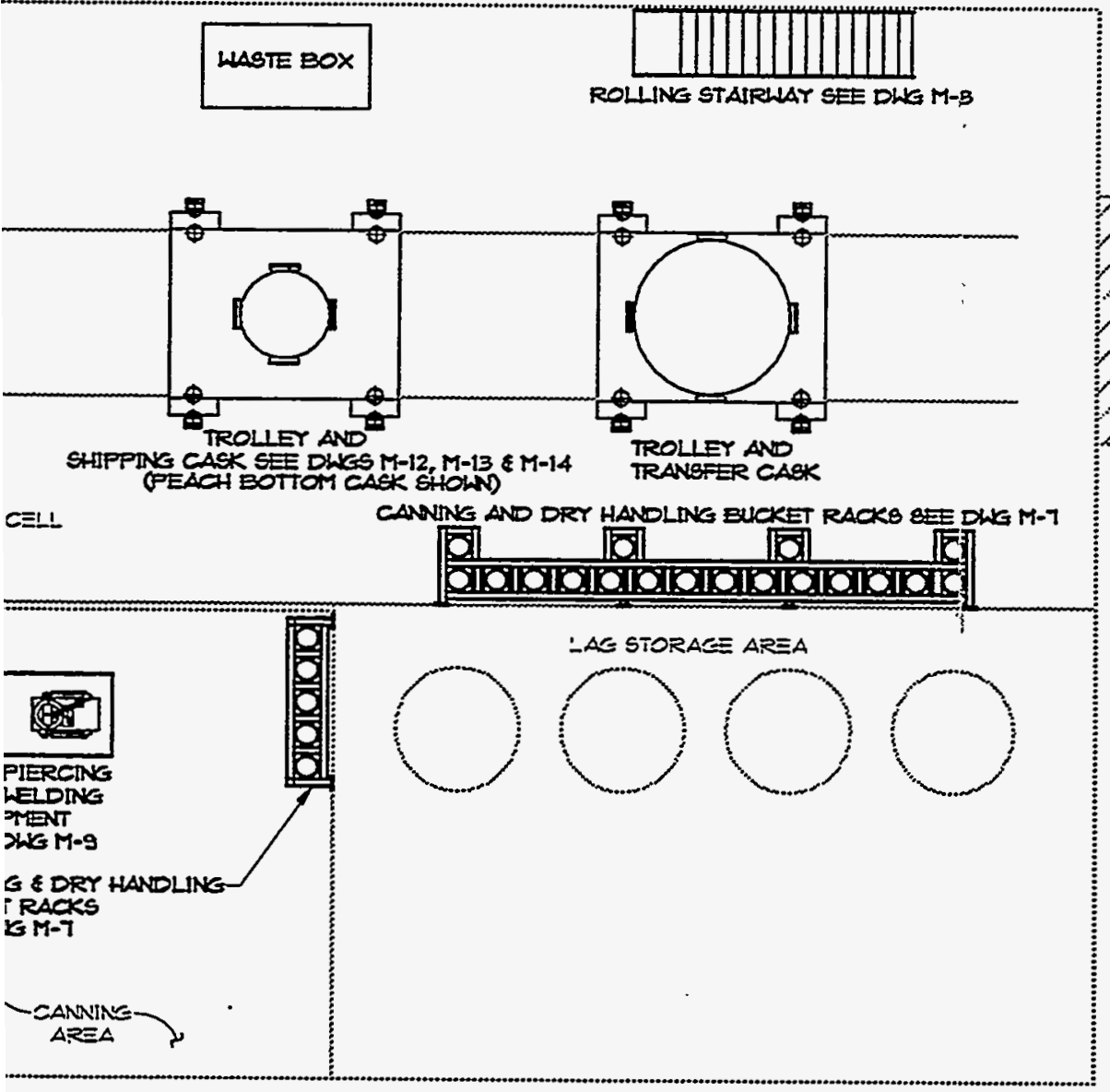

SHIPPIN CASK SEE DHKS M-12, M-13 \& M-14

(PEACH EOTTOM CAEK SHOWN

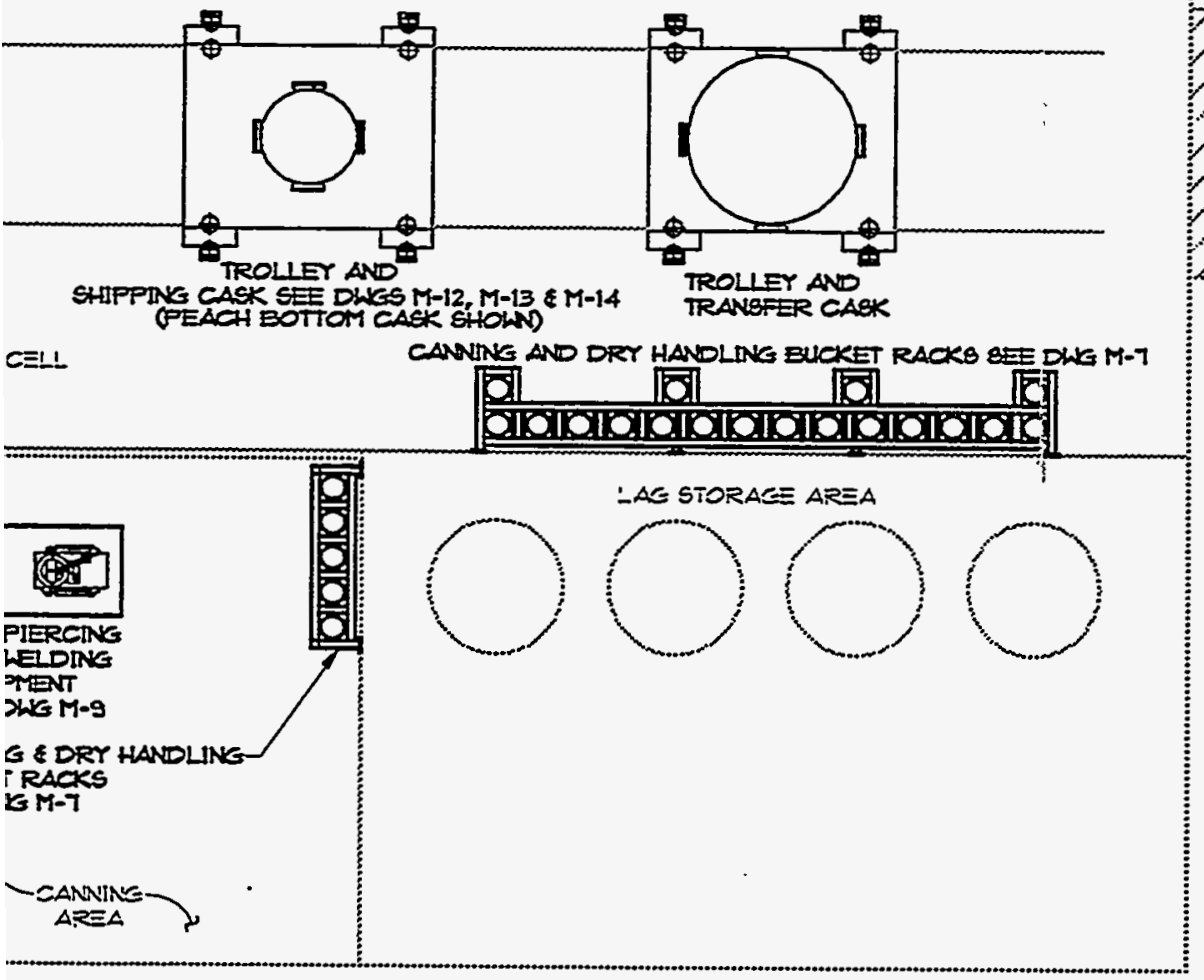

TROLLEY ANO

CANNTE AND DRT HANDLNG BUCKET RACKS BE DWG M-T [1 [D]

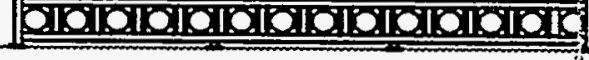
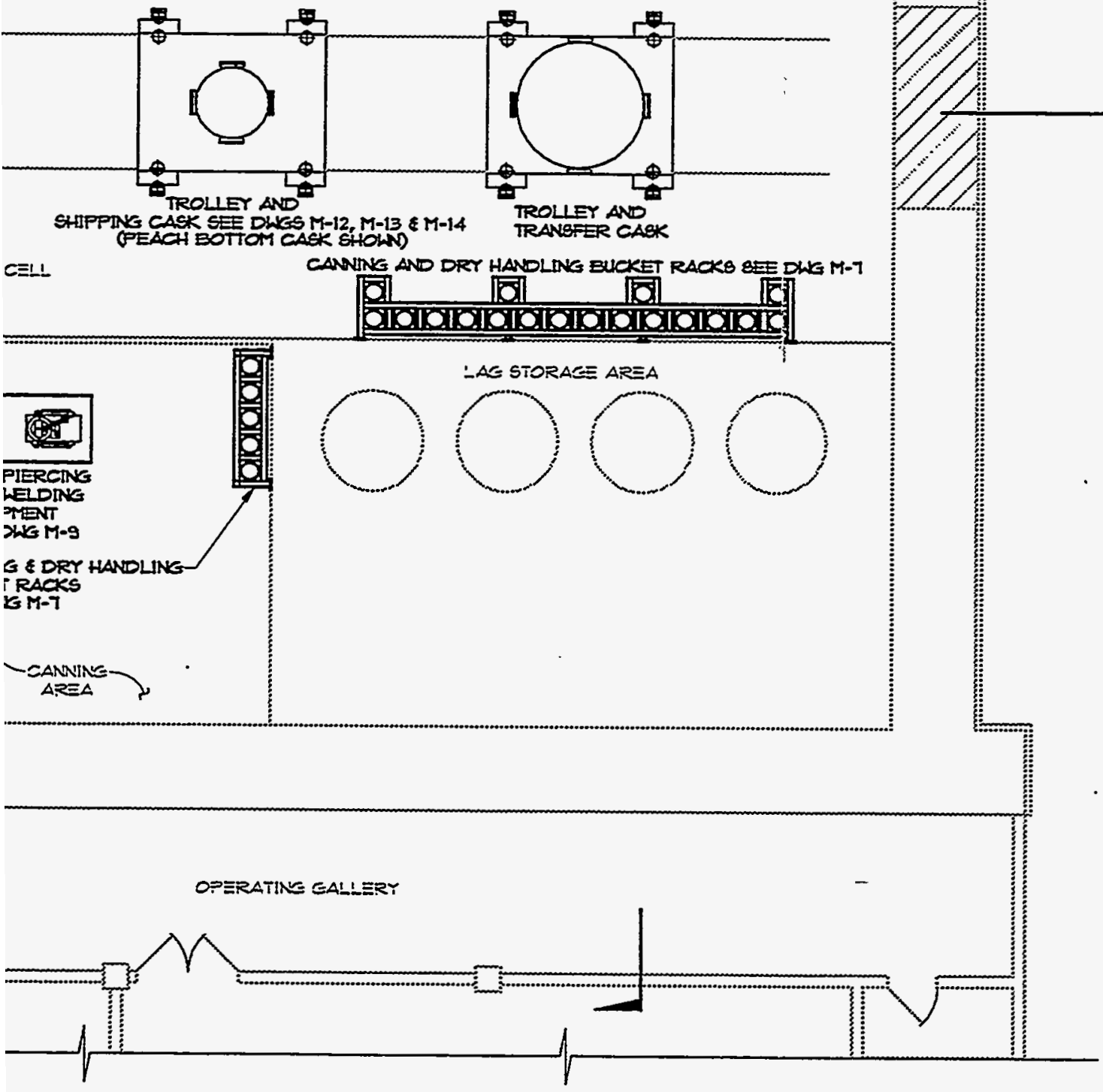

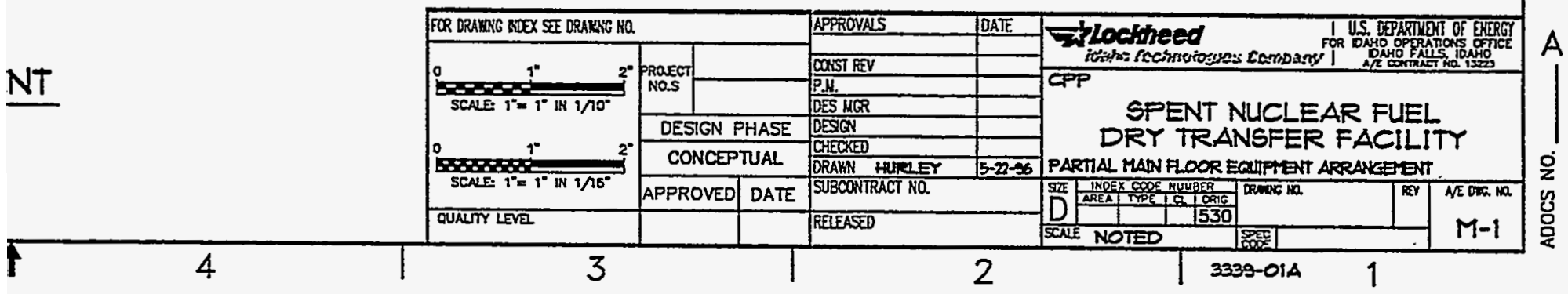




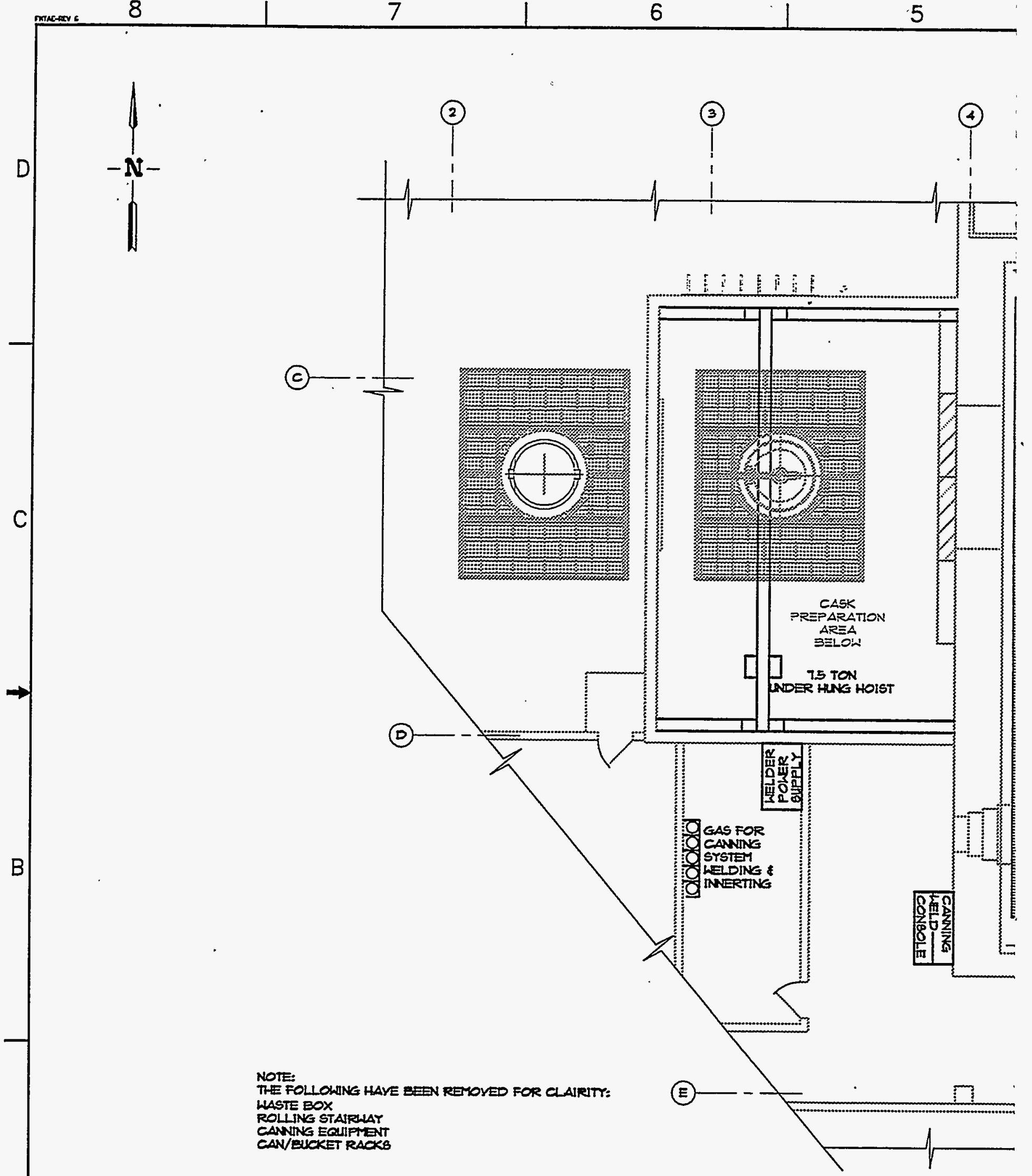

A)

PARTIAL LEYEL THREE AND ABOVE EQUIPN 



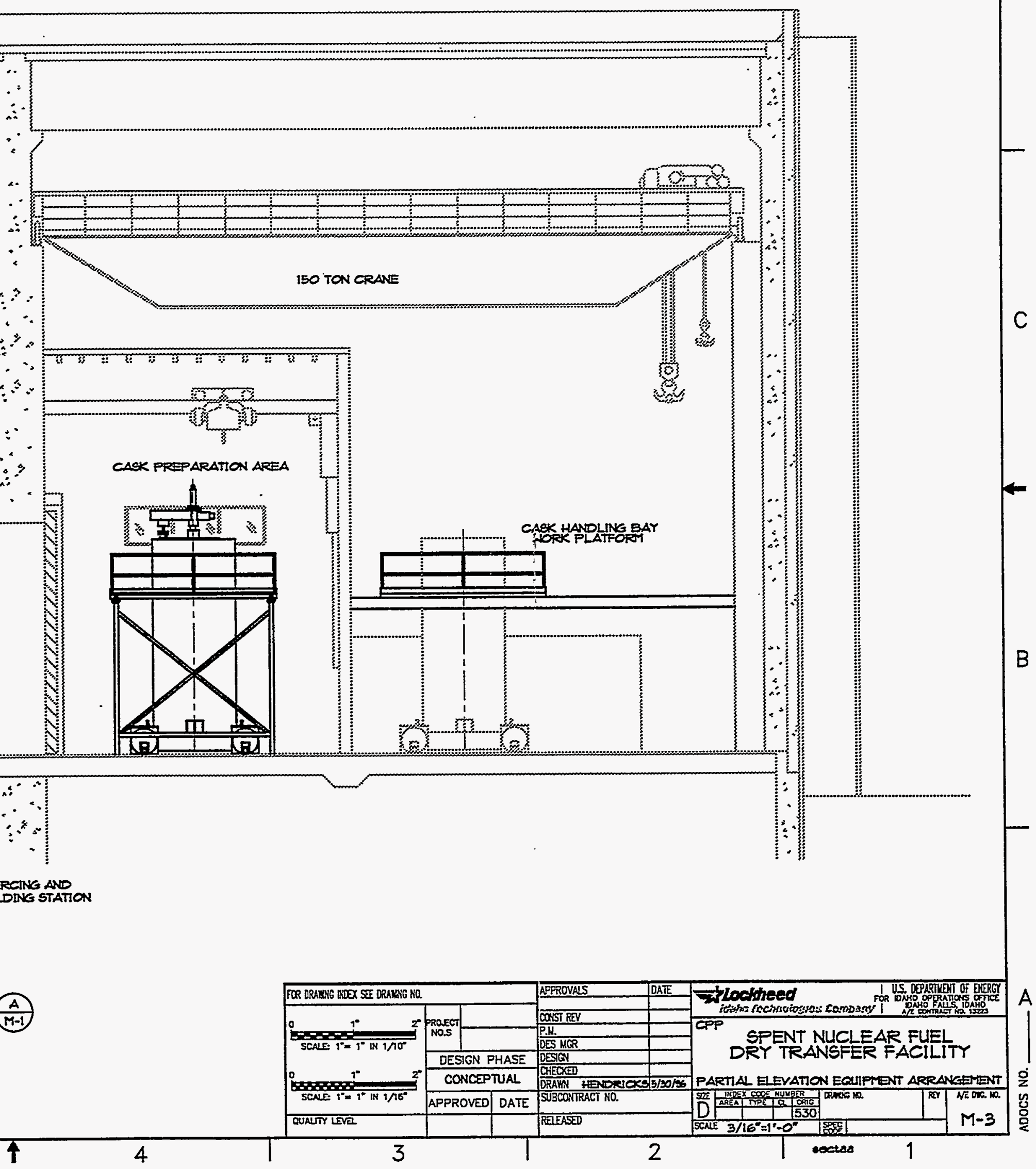




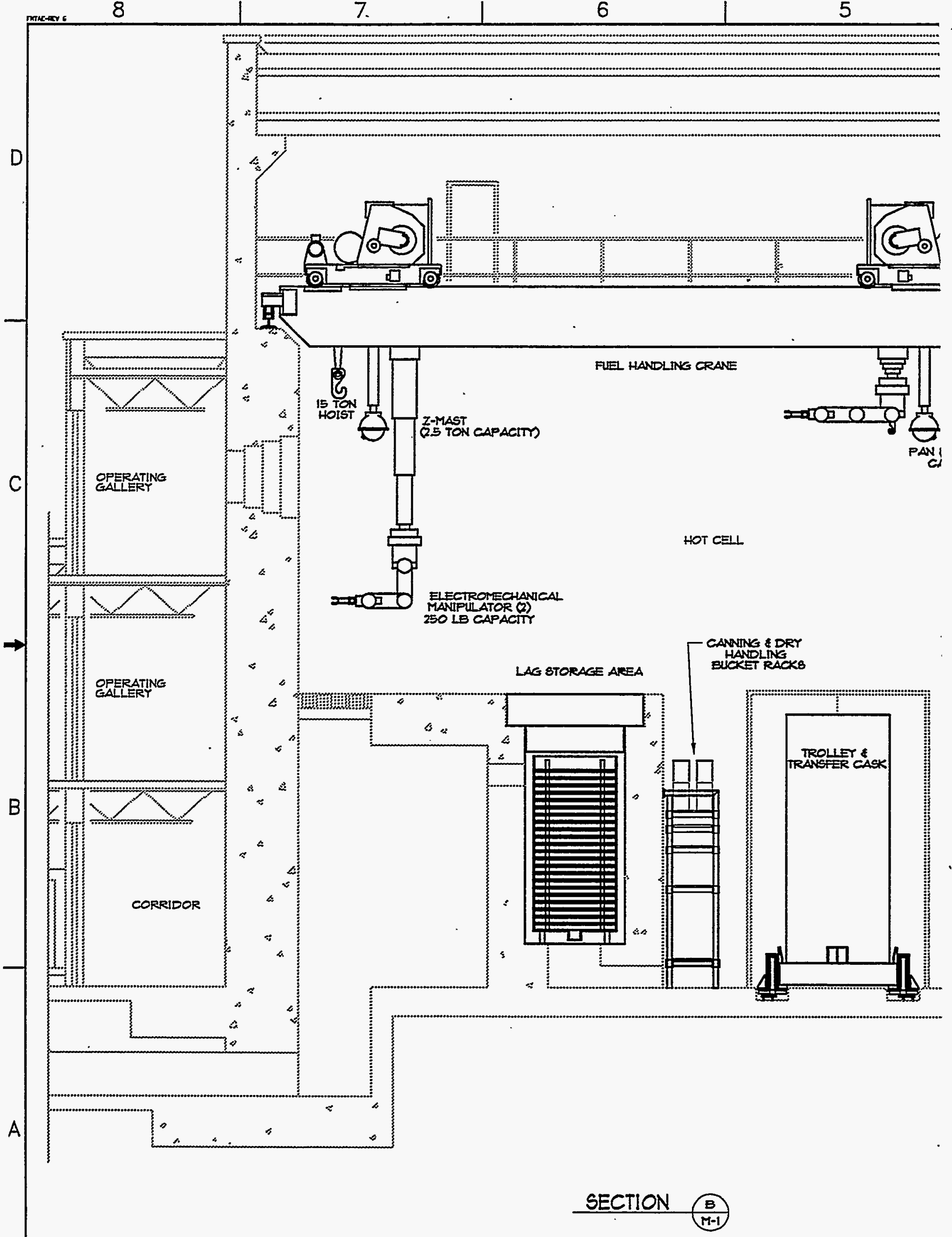




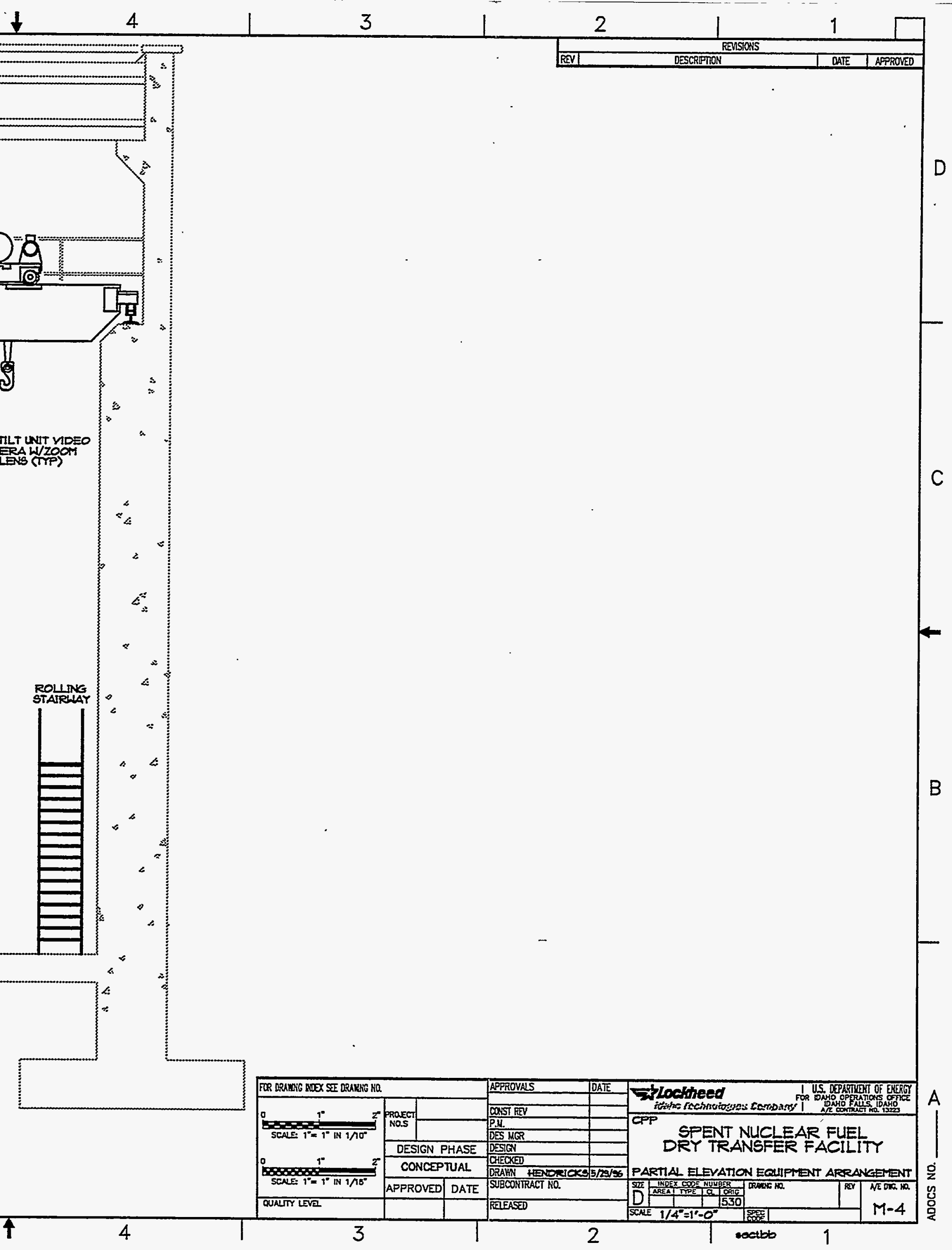




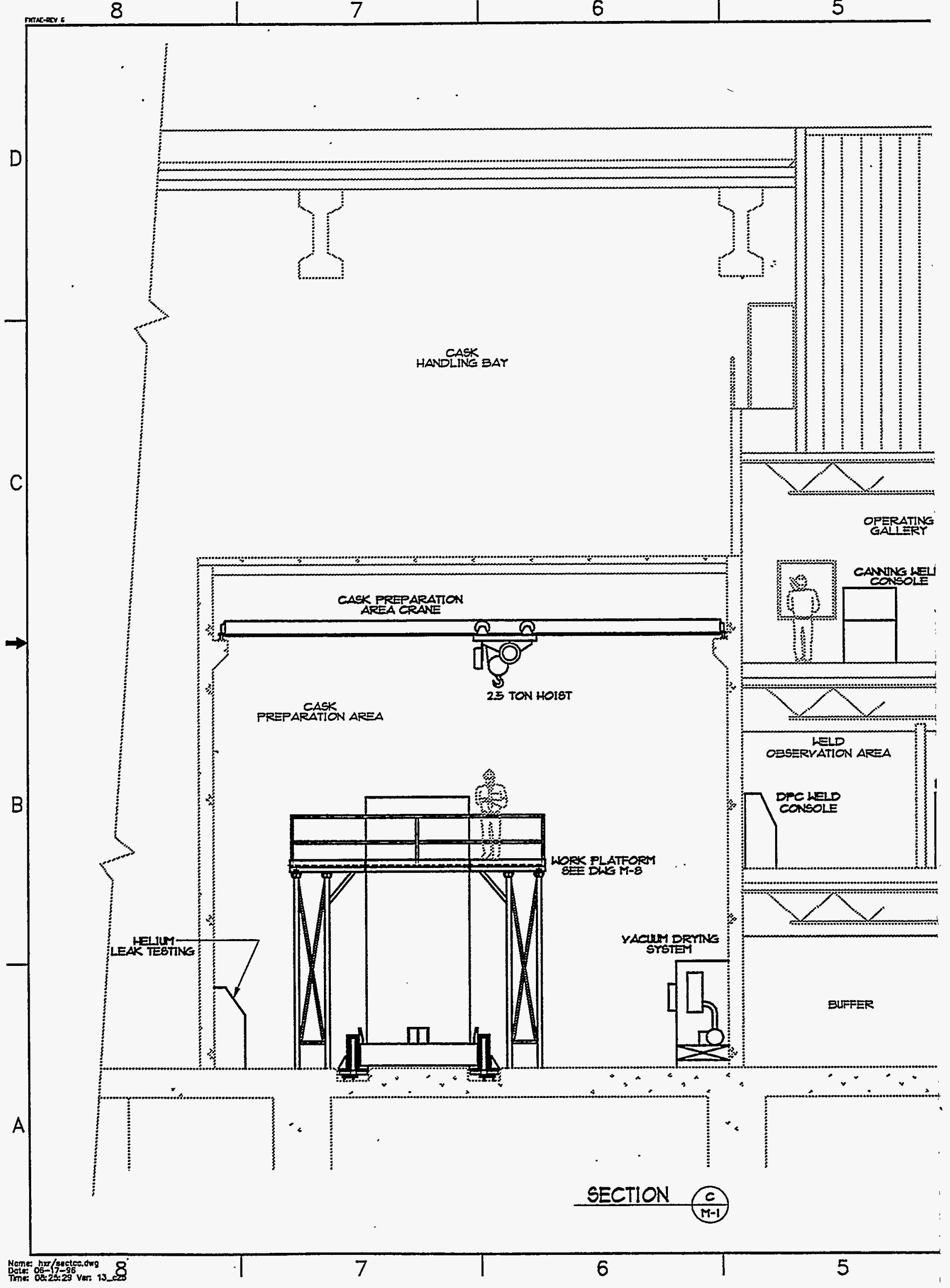



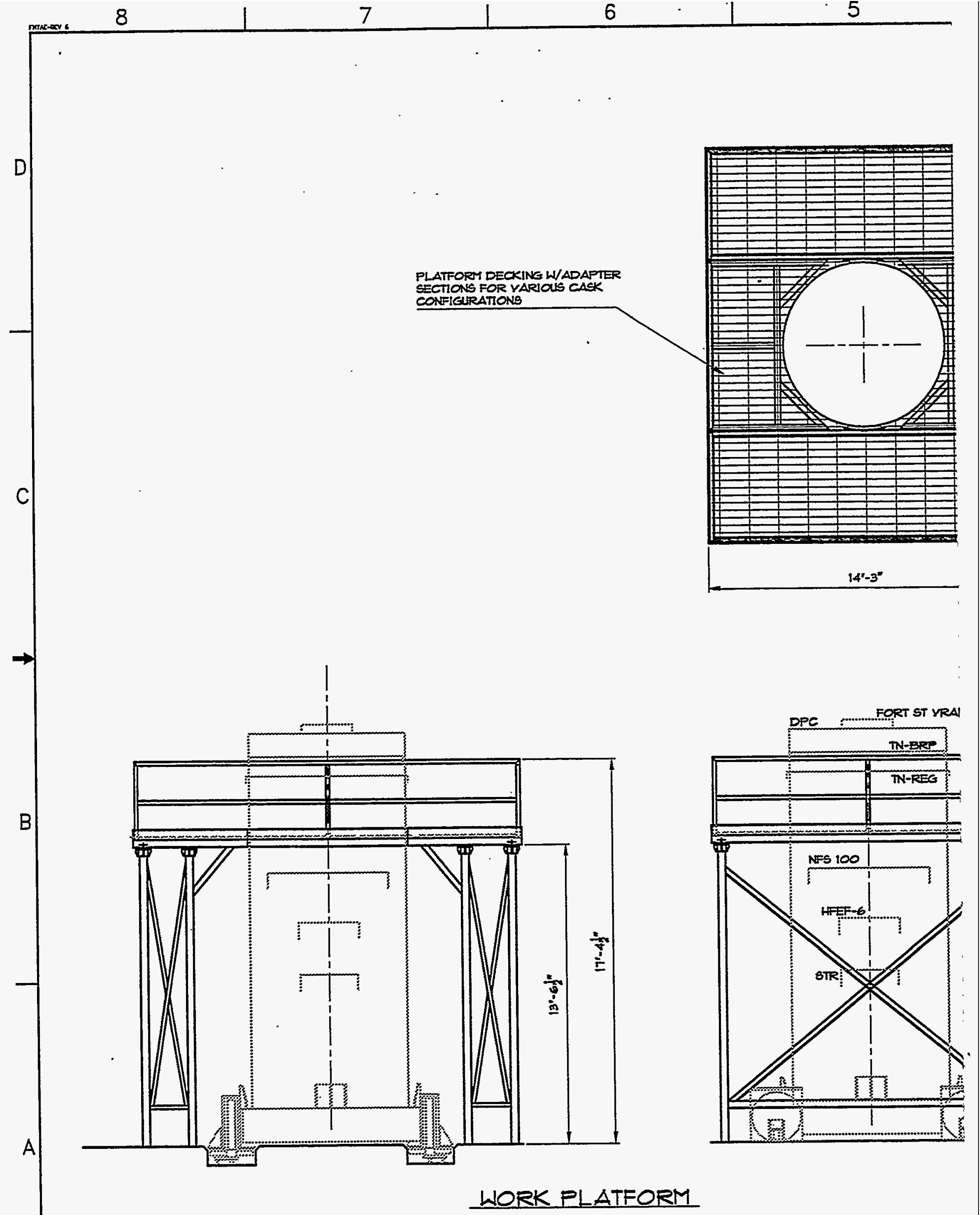

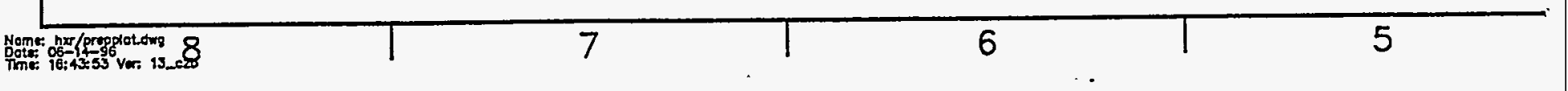




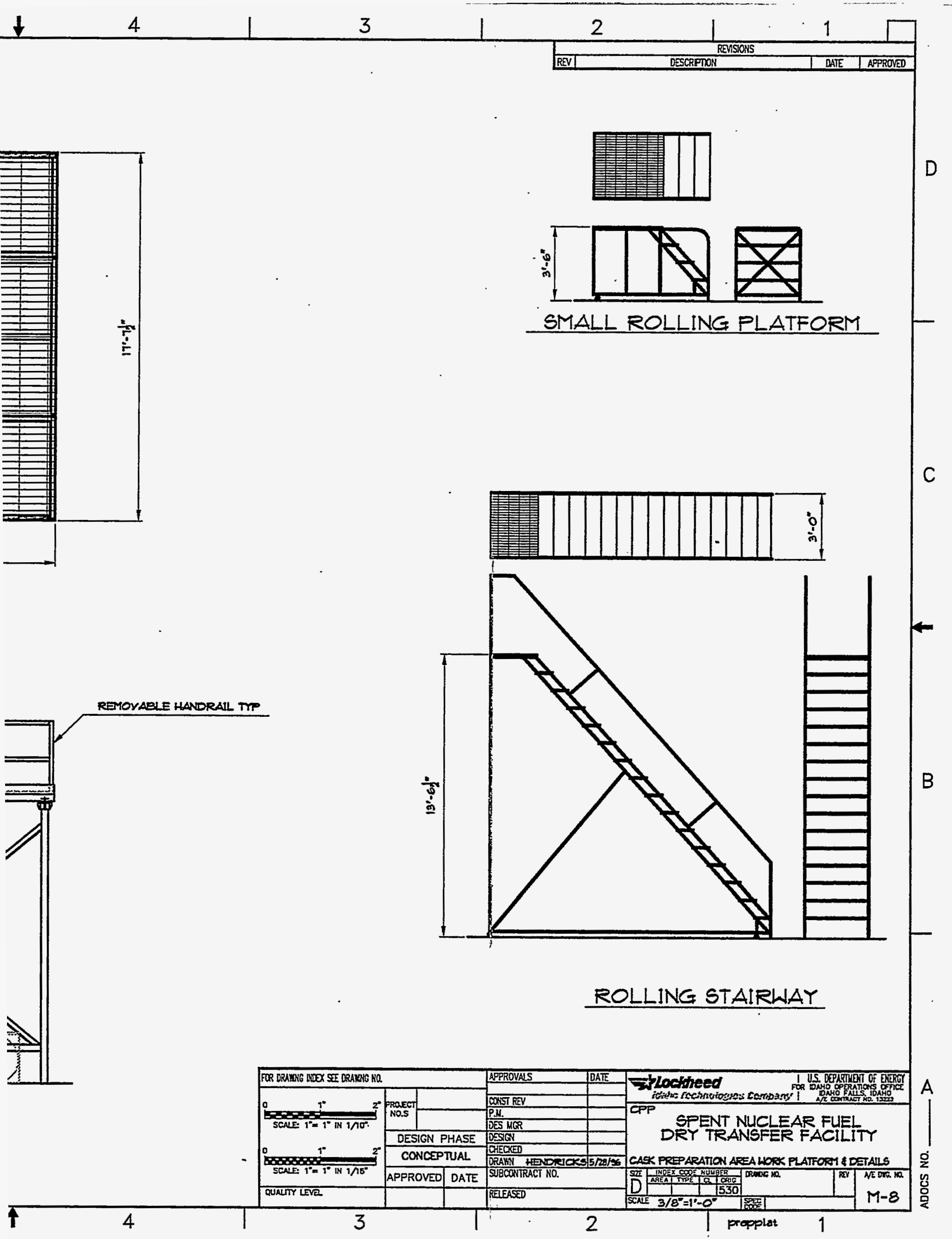



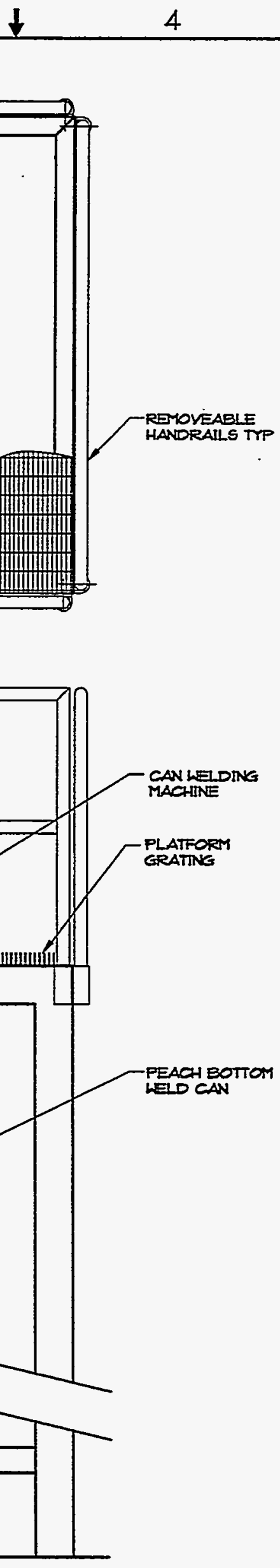

$\mathbf{T}$

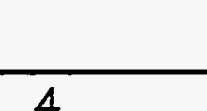

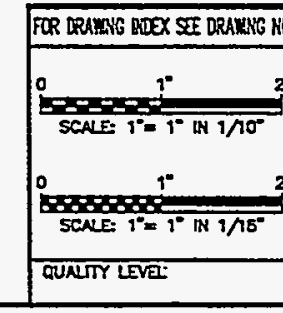

3

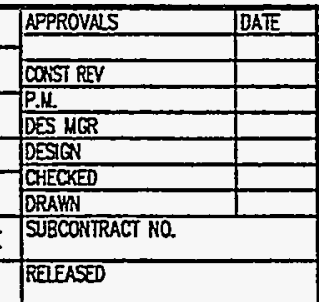

2

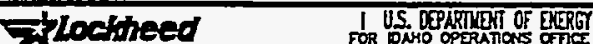

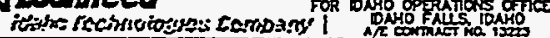

SPENT NUCLEAR FUEL

DRY TRANSFER FACILITY

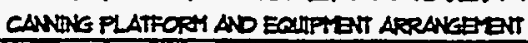

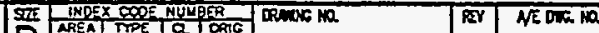
ISA

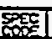
M-9 



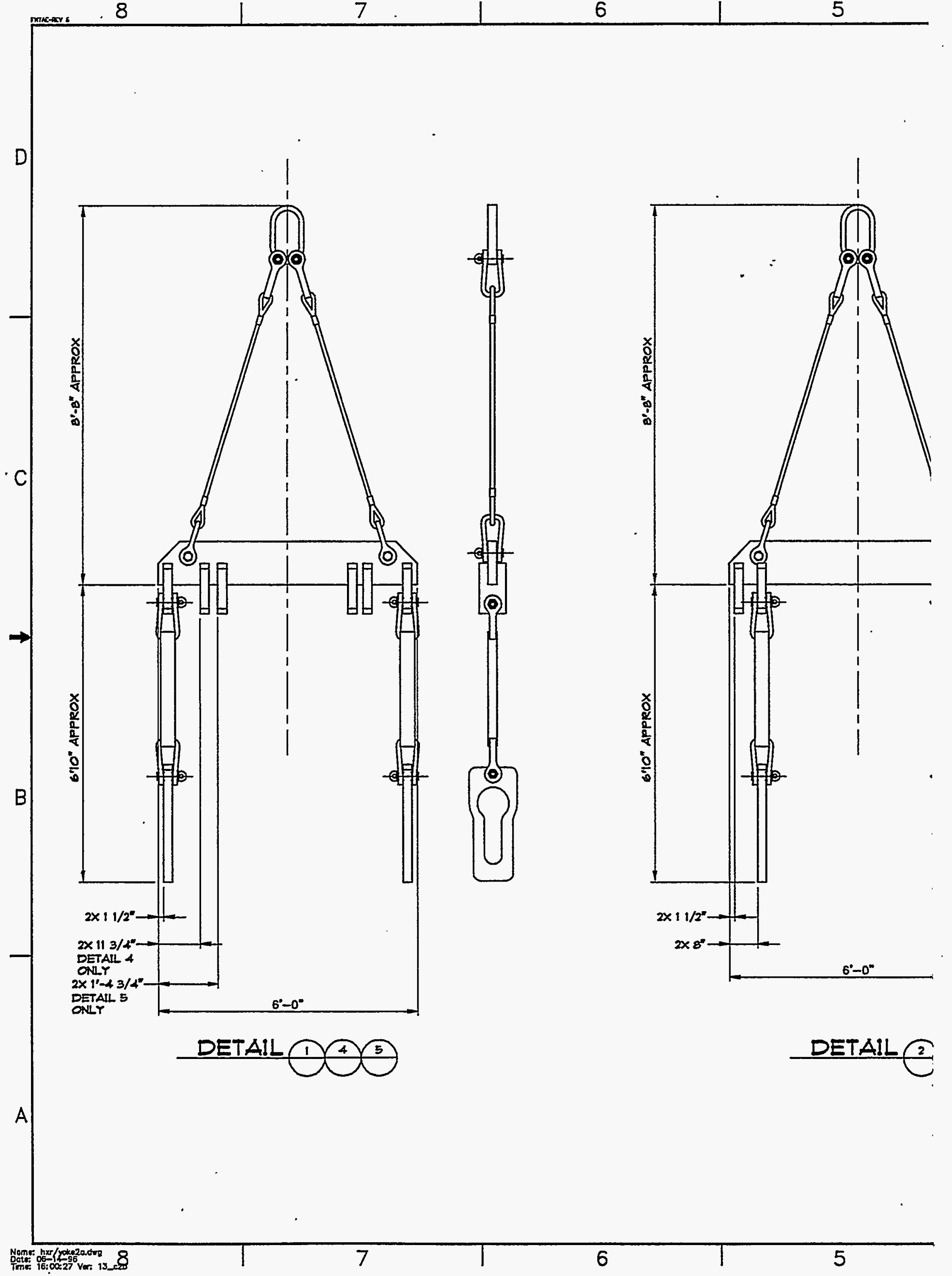




\section{$t$}

4

3
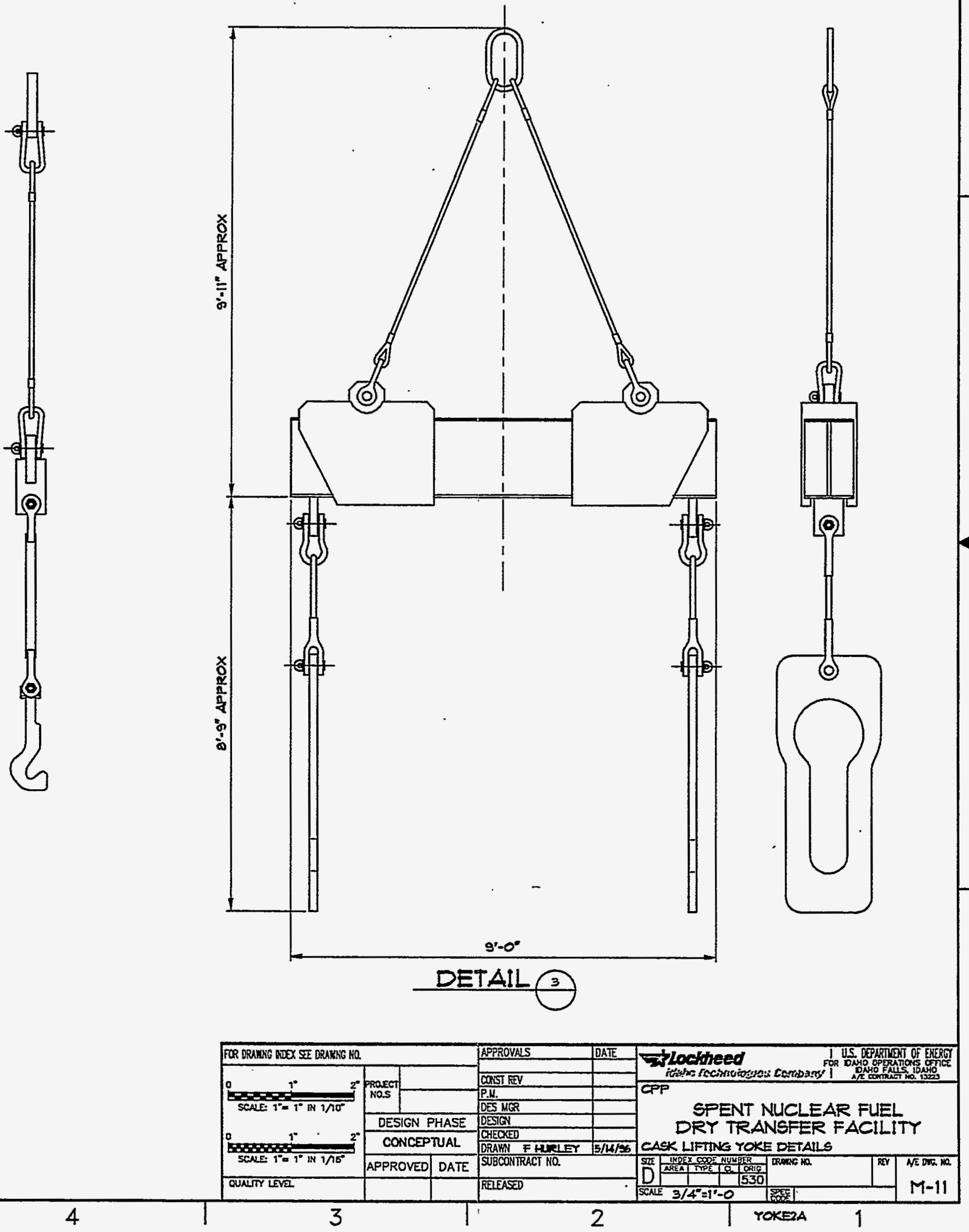

$A$ 



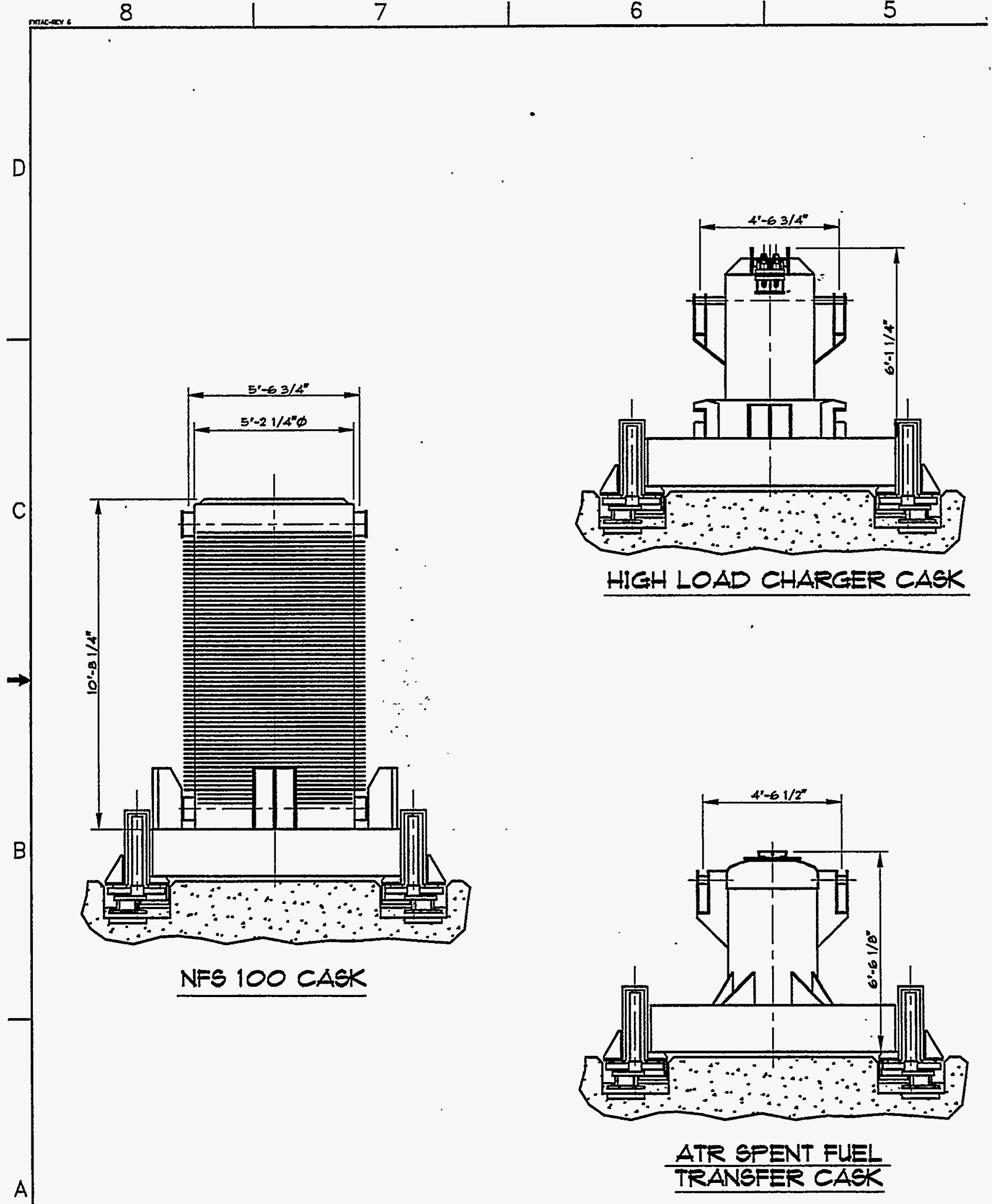




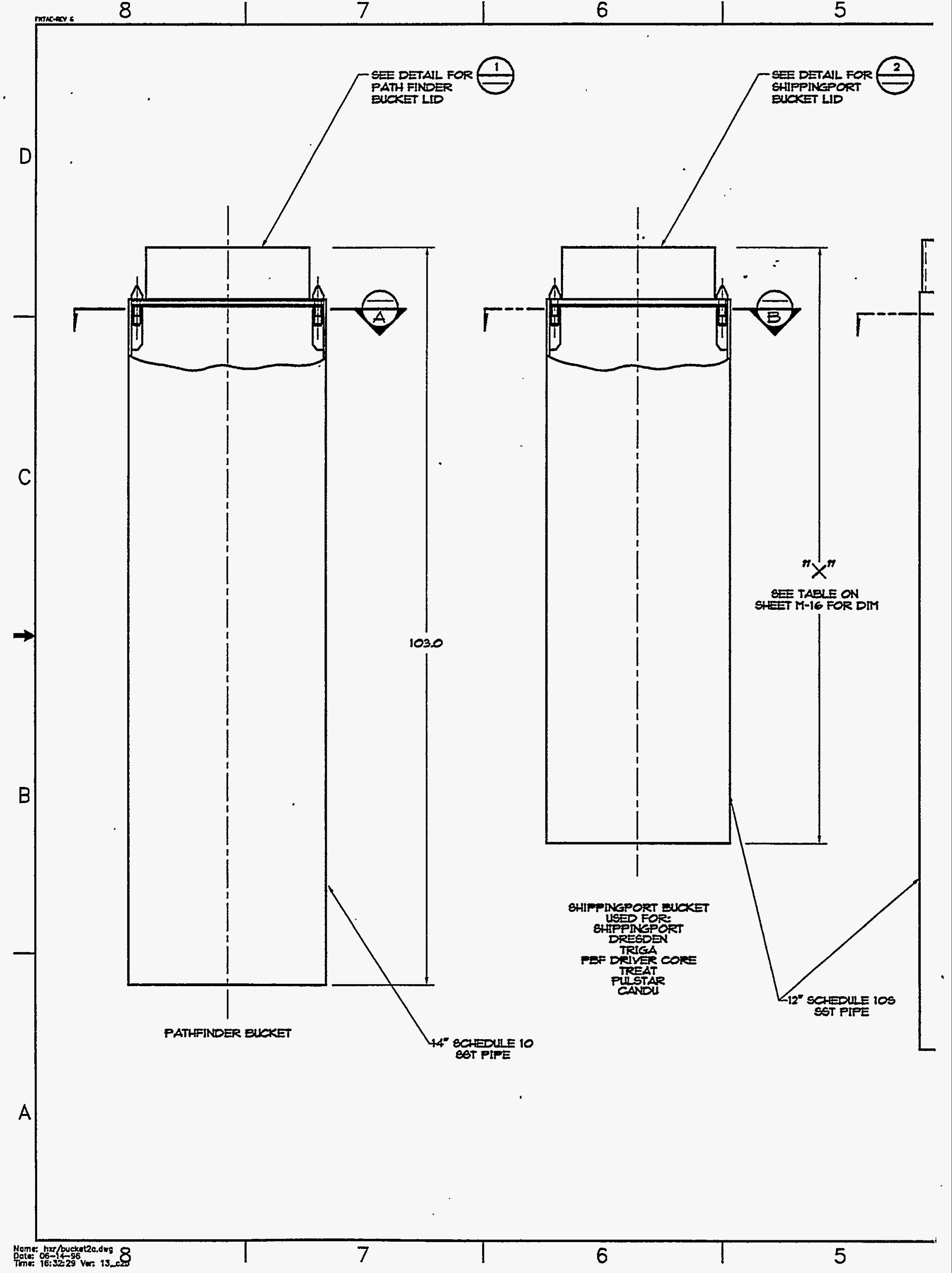



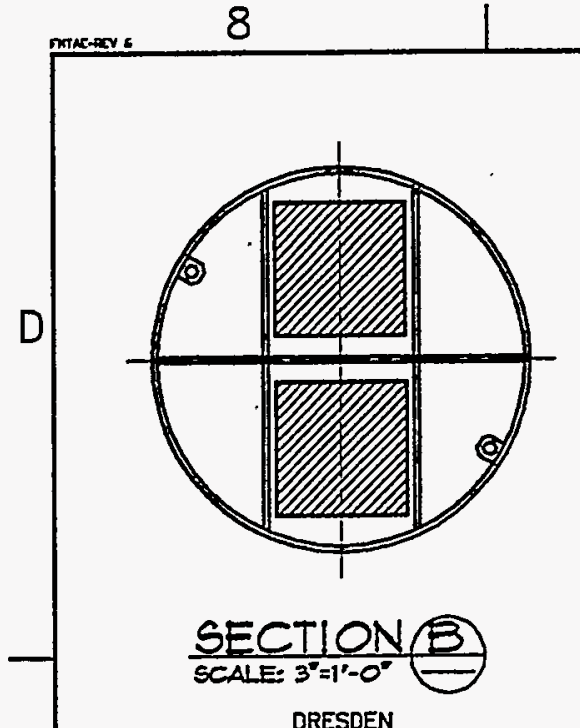

$(4.4 \times 4.4 \times 135$ LONG $)$
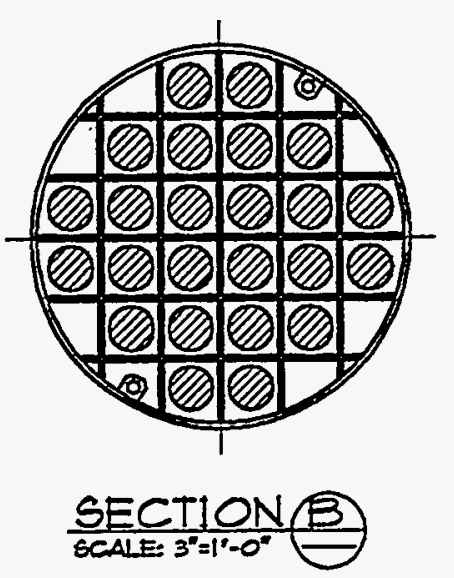

TRIGA
(1.48" DIA $\times 368^{\circ}$ LONG)
ACRR ELENENTS

(1.47 DIA X 2B8 $8^{\circ}$ LONG)

(1. $47^{\circ}$ DIA EX $28.8^{\circ}$ LONG)

B
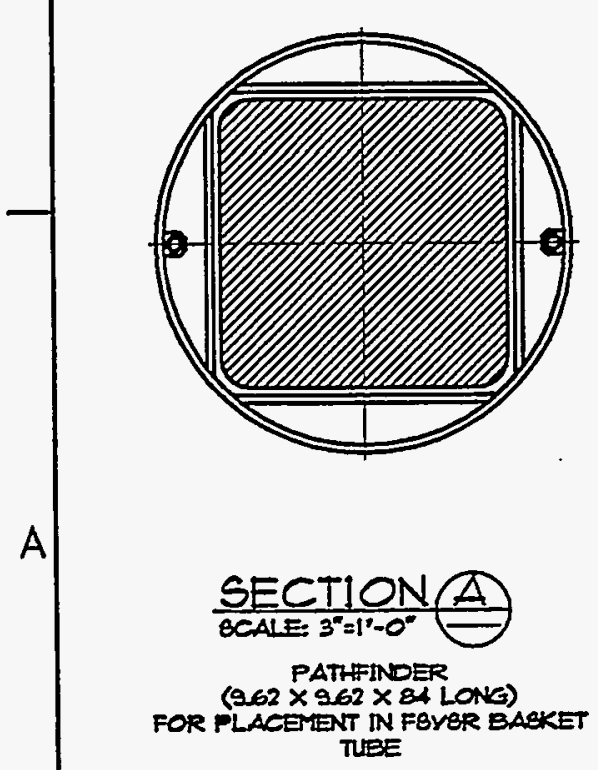

IT IN FBVER BASKET
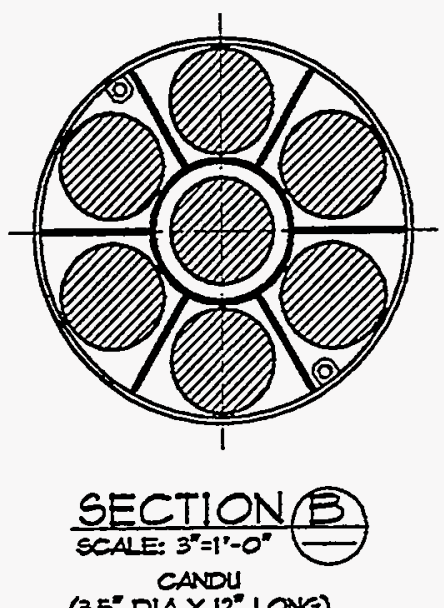

(35" DIA X 12" LONG)

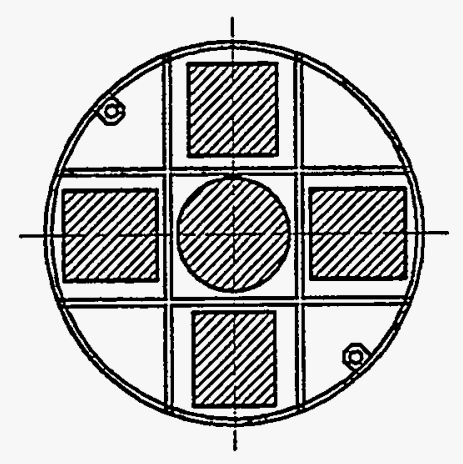

\section{SECTION}

PULSTAR-BUFFALO

(3.0" $3.0^{\circ} \times 28^{\circ}$ LONG)

O $74^{\circ} 35^{\circ} \times 370^{\circ}$.

PUISTAR-SUNT-BUFFALO

$\left(2.74^{\prime \prime} \times 315^{\prime \prime} \times 38^{\prime \prime}\right.$ LONG)

TRITA BER-11 GERMANY

TFIGA BER-II GERMANY
(3.15" $2.99^{\circ} \times 36 B^{\circ}$ LONE)

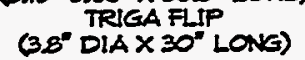

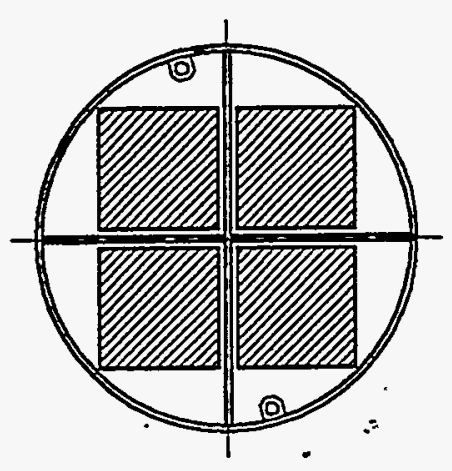

- SECTION $B$

TFEAT
$\left(3.96^{\prime \prime} \times 3.96^{\circ} \times 96^{\prime \prime}\right.$ LONG $)$

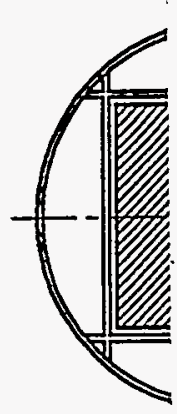

SEC

SHIPF
(733" $\times 7$

8HIPPI

$738^{\circ} \times 7$

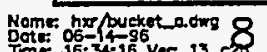

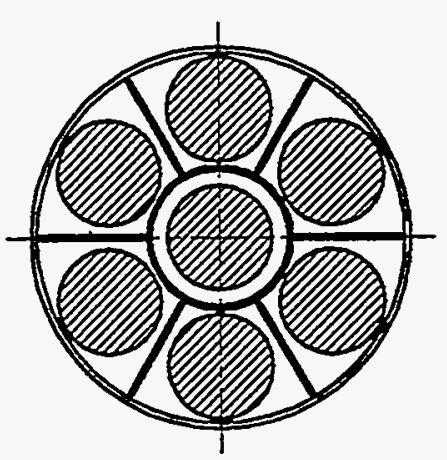

SECTIONC

PEACH BOTTOM CORE 2 (35' DIA X 126 LONG)

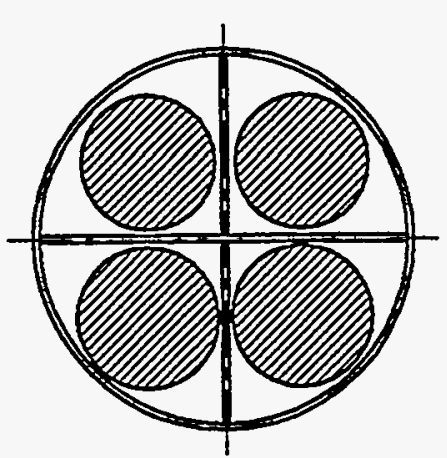

SECTION C PESCH BOTTOM CORE 1 ( $4.75^{\circ}$ DIA X 153" LONG) 


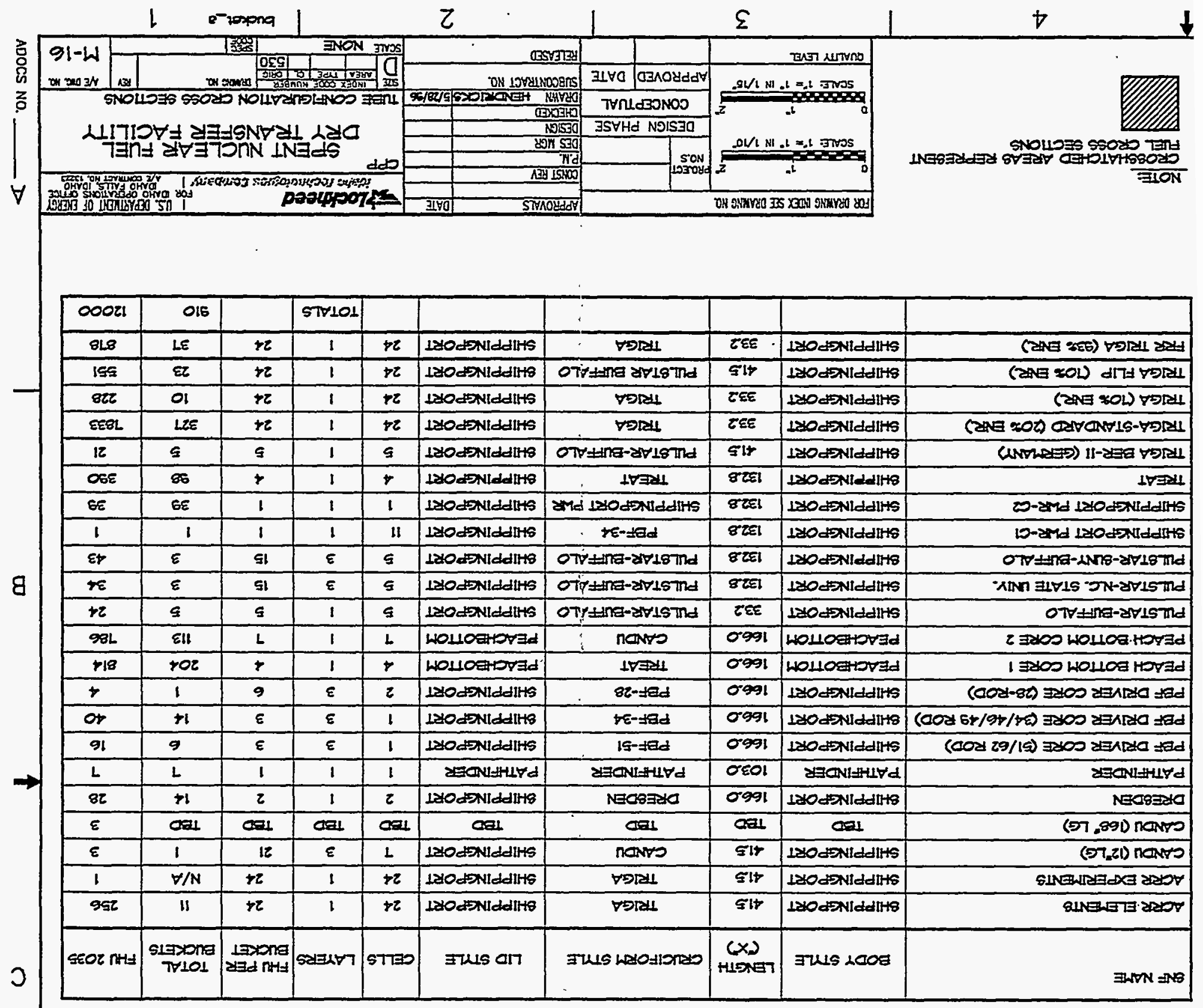

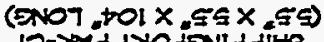

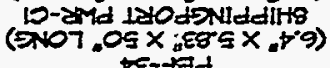

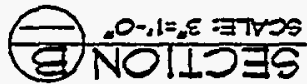

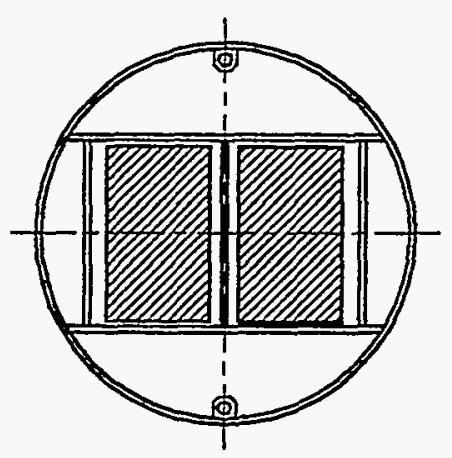
te-sed

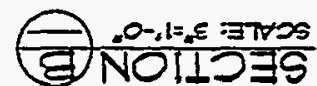

(FN07, 05 X.885 $\times .81-8)$ IS-jed

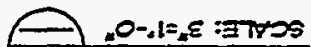
हNOI1D35
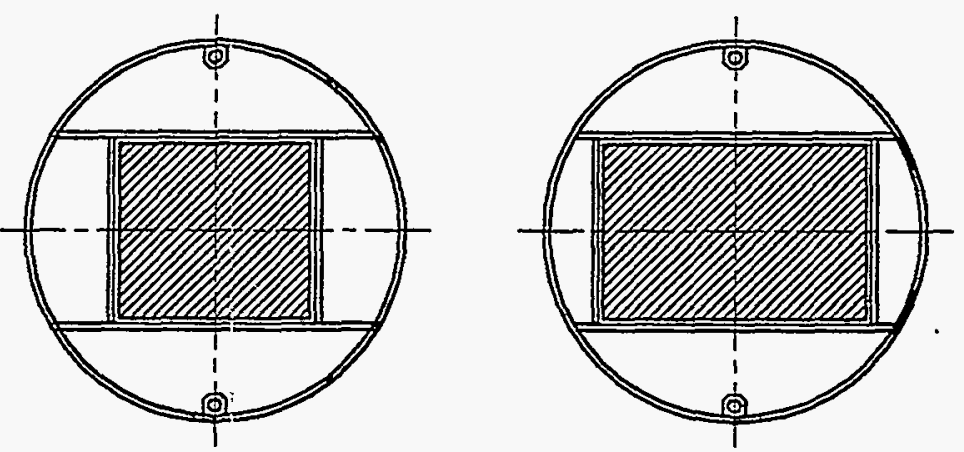

(\$N07,001 $\times$ \& 200-27d 180.

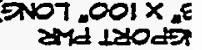

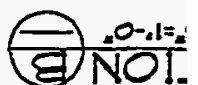

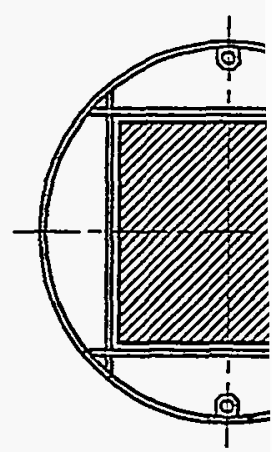




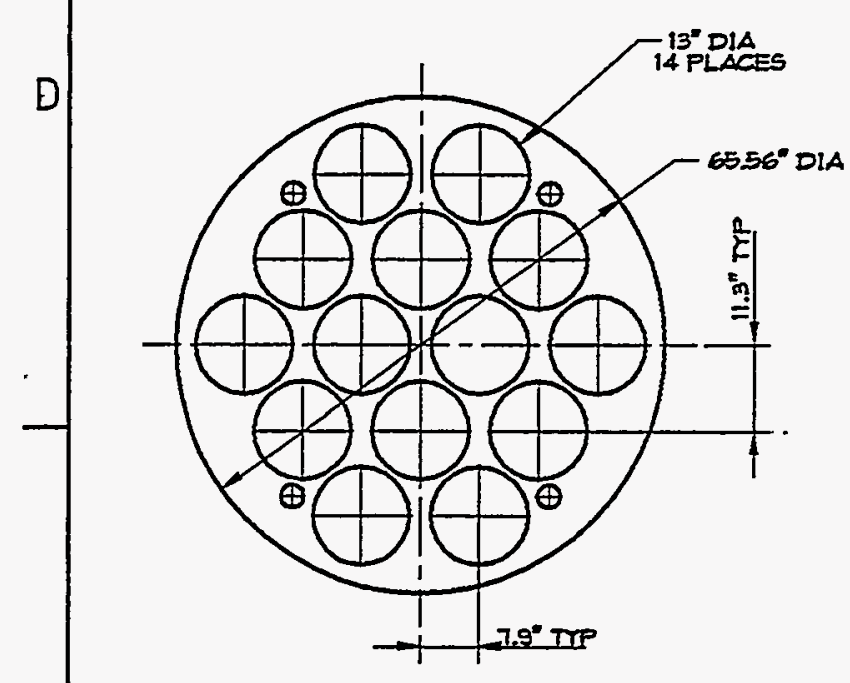

C

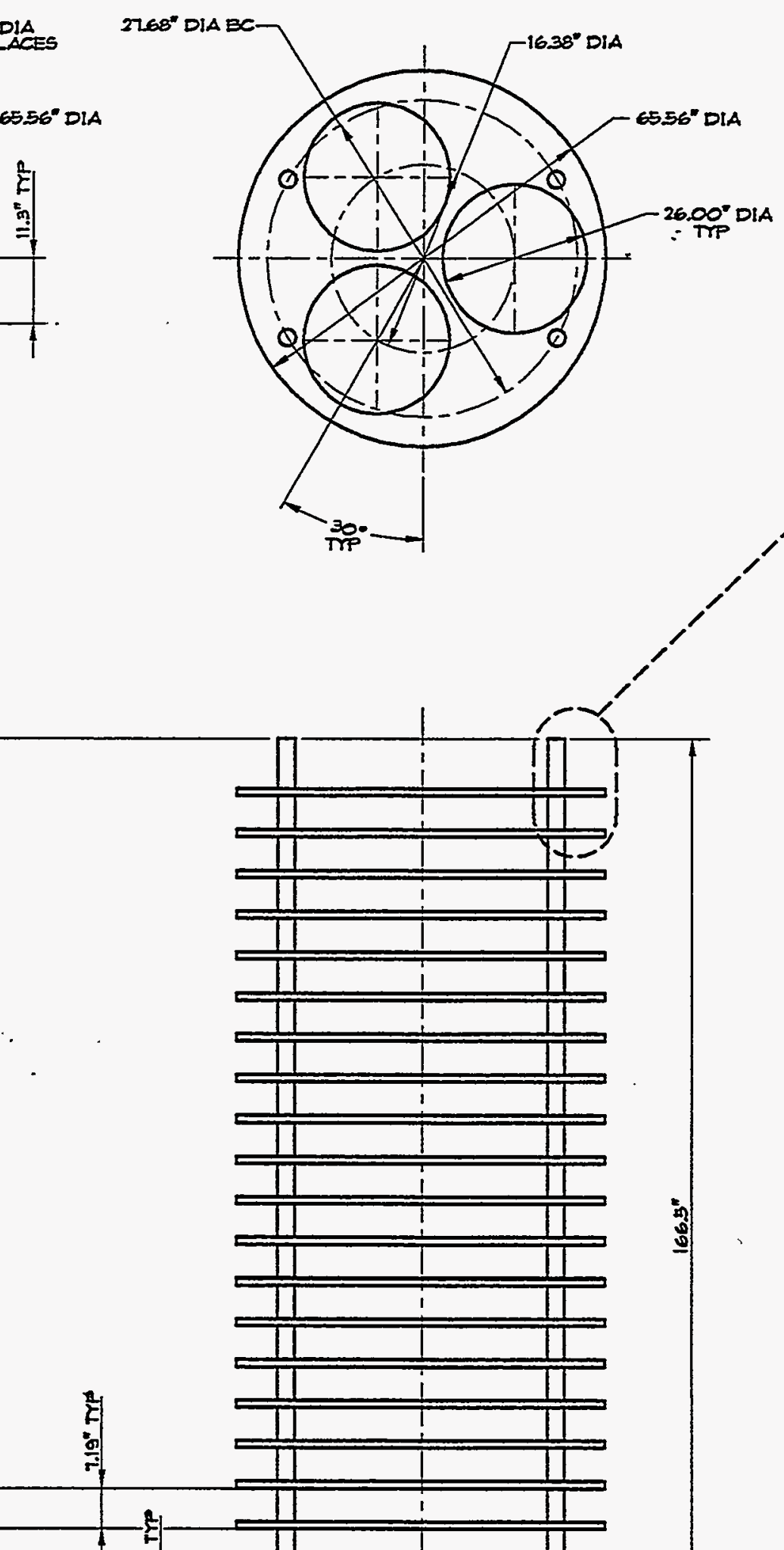

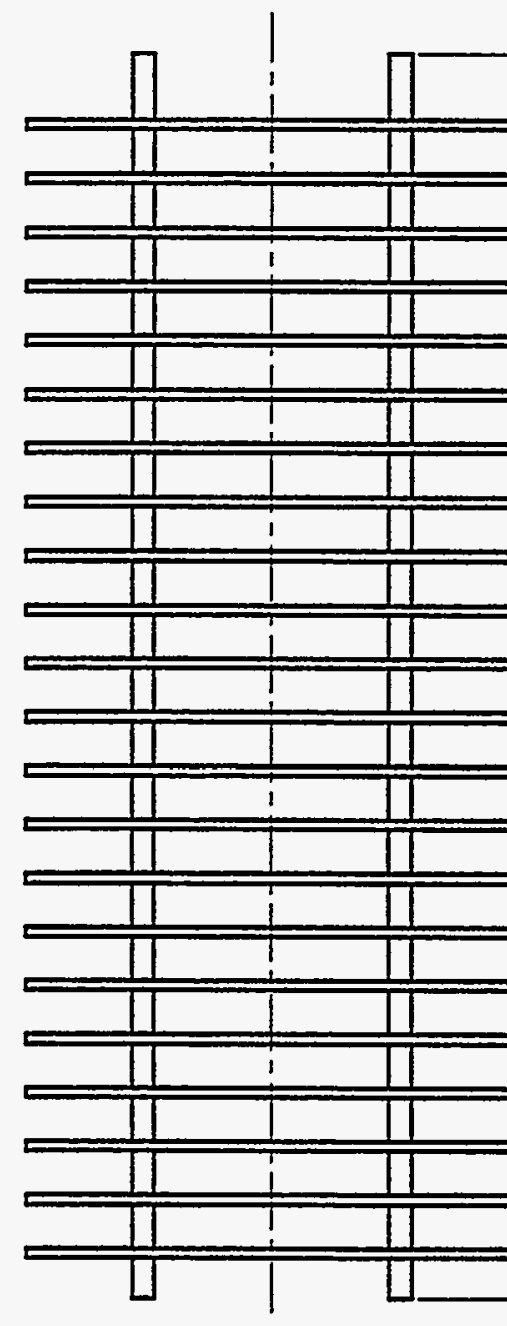

14-TUBE BASKET

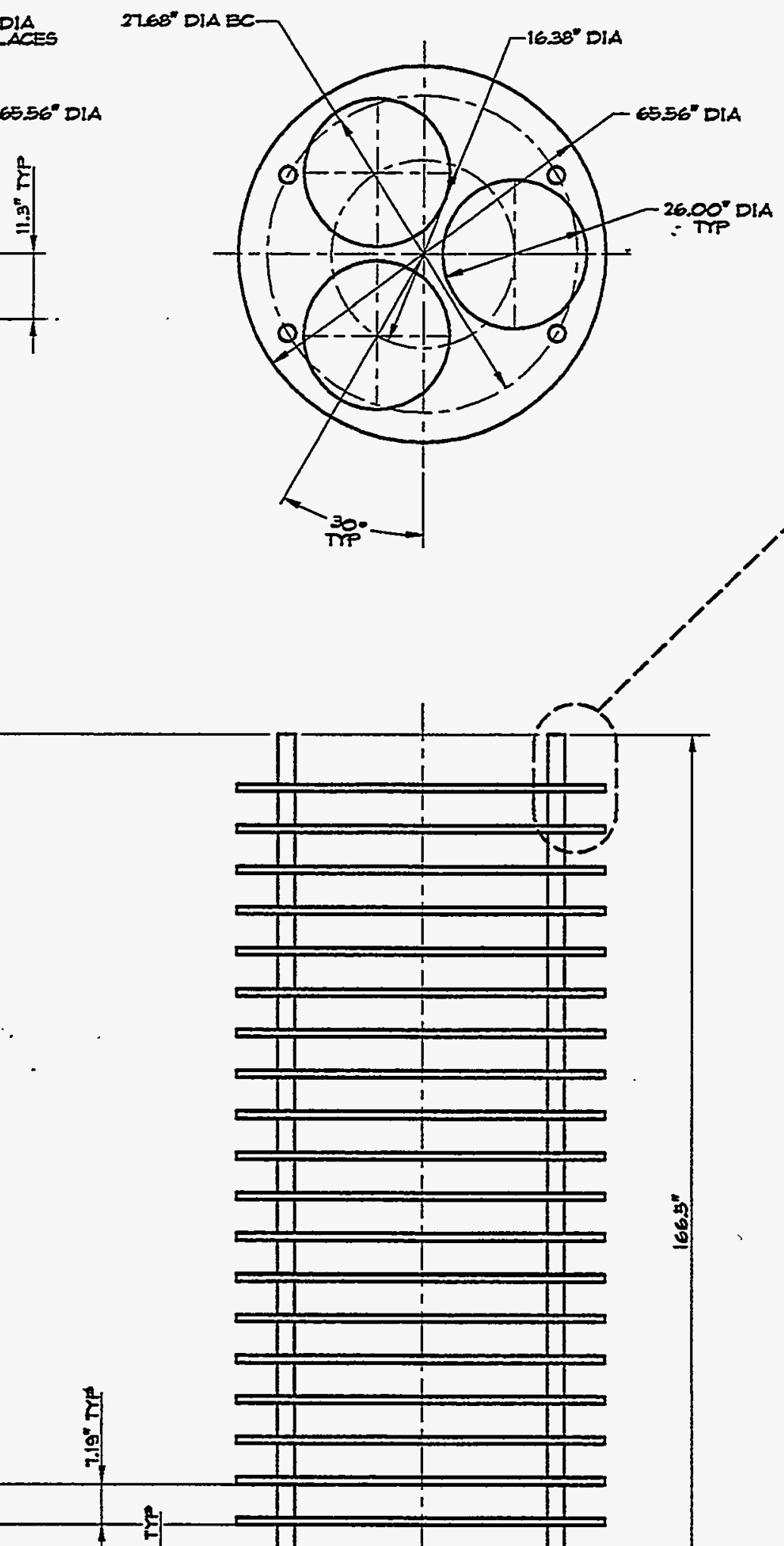

\section{ist}

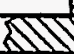

is

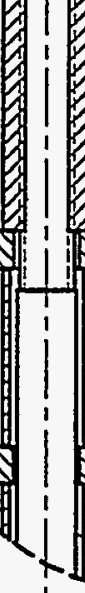

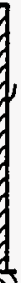
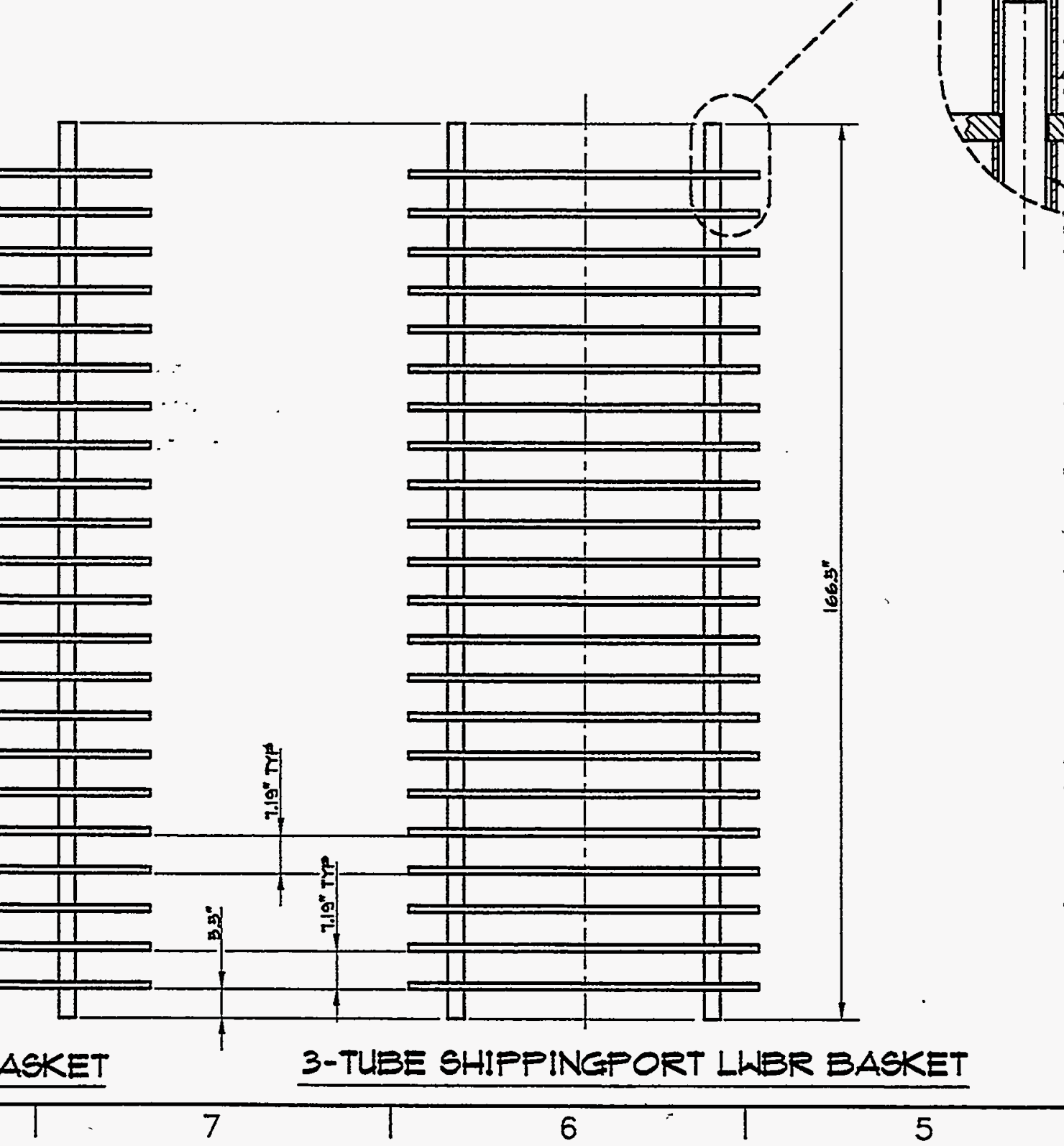

3-TUBE SHIPPINEPORT LWBR BASKET 


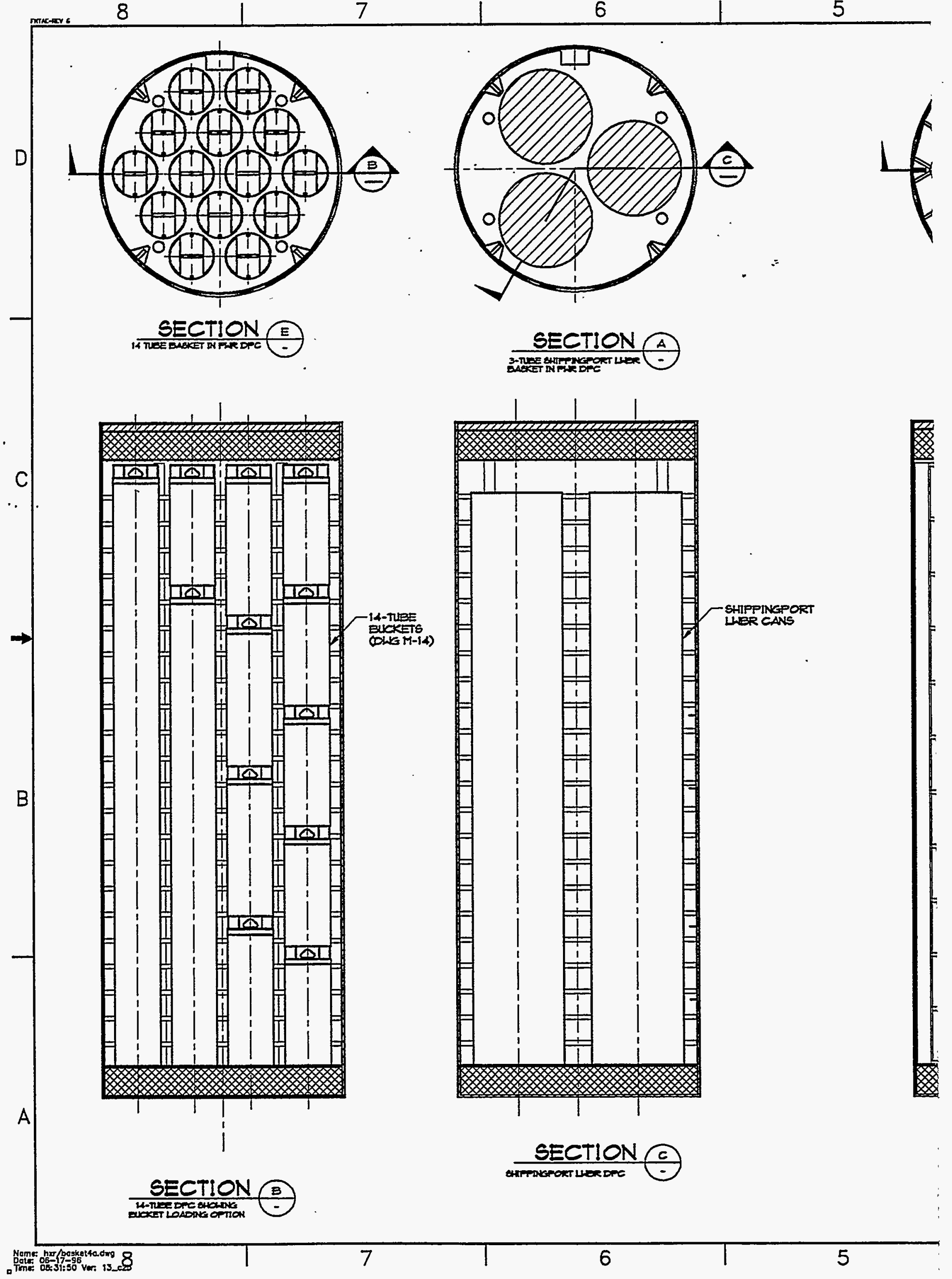



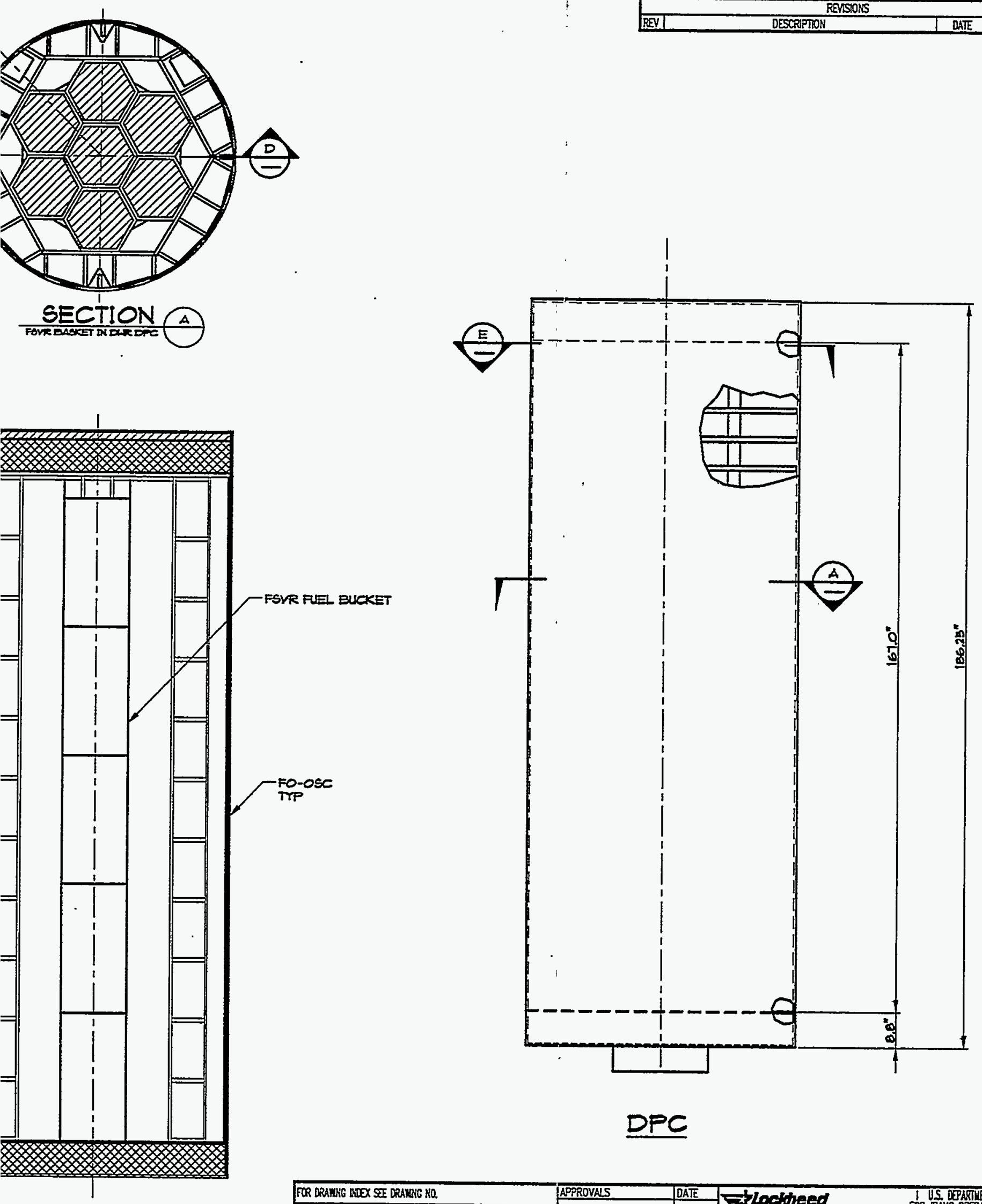

C

$\underset{\text { SECTION }}{\mathrm{O}}$

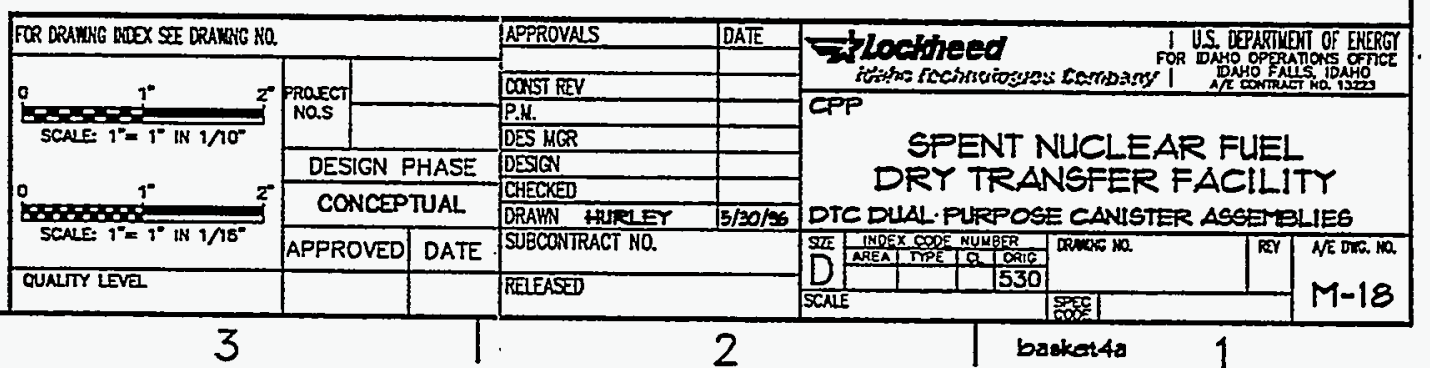

